STEFANIA GOMES RELVA

\title{
MÉTODO DE CARACTERIZAÇÃO DA IRRADIAÇÃO PARA GERAÇÃO FOTOVOLTAICA: UMA ANÁLISE SISTÊMICA DA MODELAGEM DA ENERGIA PRIMÁRIA
}

São Paulo 
STEFANIA GOMES RELVA

Método de caracterização da irradiação para geração fotovoltaica: uma análise sistêmica da modelagem da energia primária

São Paulo 


\section{STEFANIA GOMES RELVA}

Método de caracterização da irradiação para geração fotovoltaica: uma análise sistêmica da modelagem da energia primária

Dissertação apresentada à Escola

Politécnica da Universidade de São

Paulo para obtenção do título de Mestre em Ciências.

São Paulo

2017 


\section{STEFANIA GOMES RELVA}

Método de caracterização da irradiação para geração fotovoltaica: uma análise sistêmica da modelagem da energia primária

Dissertação apresentada à Escola

Politécnica da Universidade de São

Paulo para obtenção do título de Mestre em Ciências.

Área de Concentração:

Sistemas de Potência

Orientador: Prof. Dr. Miguel Edgar Morales Udaeta

São Paulo 
Este exemplar foi revisado e corrigido em relação à versão original, sob responsabilidade única do autor e com a anuência de seu orientador.

São Paulo, de de

Assinatura do autor:

Assinatura do orientador:

Catalogação-na-publicação

\section{Relva, Stefania Gomes}

Método de Caracterização da irradiação para geração fotovoltaica: uma análise sistêmica da modelagem da energia primária / S. G. Relva -- versão corr. -- São Paulo, 2017.

$$
267 \mathrm{p} \text {. }
$$

Dissertação (Mestrado) - Escola Politécnica da Universidade de São Paulo. Departamento de Engenharia de Energia e Automação Elétricas.

1.Energia solar fotovoltaica 2. Energia primária solar 3.Caracterização da irradiação solar I.Universidade de São Paulo. Escola Politécnica. Departamento de Engenharia de Energia e Automação Elétricas Il.t. 
AO SLASH, AOS QUE JÁ FORAM, AOS QUE AINDA VIRÃO. 


\section{AGRADECIMENTOS}

Ao Professor Miguel Edgar Morales Udaeta, por me abrir as portas da Pós-Graduação em Engenharia Elétrica da Escola Politécnica da USP, pela incrível paciência que lidou com todas as minhas resistências e indagações ao longo desse trabalho, pela constante e irrestrita disponibilidade e atenção, não só com as questões acadêmicas, mas com o bem-estar de todos os seus orientandos.

Ao Professor José Aquiles Baesso Grimoni, pela confiança e suporte nos quesitos burocráticos da minha estada na USP e pelas contribuições na minha qualificação.

Ao Professor Luiz Claudio Ribeiro Galvão, agradeço aos incentivos e discussões nas conversas de corredor e atenção com a qualificação desse trabalho.

Ao Professor André Luiz Veiga Gimenes, pelo apoio constante nas questões de desenvolvimento da pesquisa e da infraestrutura necessária para a evolução desse trabalho.

Aos Professor José Gilberto Dalfré Filho do Departamento de Recursos Hídricos da Faculdade de Engenharia Civil da Unicamp, por me despertar o encanto pela engenharia e pela pesquisa e pela orientação nas minhas pesquisas de iniciação científica e trabalho de conclusão de curso.

À Professora Rozely Ferreira dos Santos do Departamento de Recursos Hídricos da Faculdade de Engenharia Civil da Unicamp, por me intrigar com as questões ambientais e sociais, representando o ponto de partida no meu caminho acadêmico e interesse em desenvolver os aspectos mais humanos da engenharia.

Aos meus amigos e colegas de trabalho do GEPEA, em especial ao Vinícius, Jonathas, Martim e Angélica, por todas as conversas acadêmicas e pelos momentos de descontração. Com vocês esse trabalho se tornou mais rico e mais feliz.

A todos os meus queridos da Workster, que me aturam diariamente, acompanhando os meus dramas acadêmicos e reclamações. Agradeço todo o suporte e a alegria diária que é estar com vocês.

À Norma, que talvez não tenha a ciência do quanto me ajudou na realização desse trabalho, agradeço por ter me possibilitado inúmeras horas de paz que foram destinadas a esse estudo. 
Às minhas queridas amigas irmãs, Bella, Carla, Isa Maia, Isa Meucci, Rani, Rafa, Talita e Thais que me viram amadurecer e que amadureceram comigo, que vibram com todas as alegrias e se angustiam com as tristezas. A atenção e presença de vocês me enche de amor.

À Lila, em especial, por colocar a minha cabeça no lugar tantas vezes, por me nortear nos caminhos acadêmicos, por me apresentar visões de mundo que me ajudaram a ser o que sou hoje.

À Mariana e ao Kayo, agradeço por me receberem de portas abertas há tantos anos na casa de vocês, local aonde esse trabalho foi em grande parte produzido, e por serem tão amorosos e preocupados comigo.

À minha tia Clarice, pela compreensão infinita com as minhas ausências, pelo apoio e amor.

Ao Ramon Kayo, dono das minhas maiores admirações, obrigada por acreditar tanto e ser o meu maior incentivo para tudo nessa vida.

Aos meus pais, por todo apoio que recebo hoje e sempre. À minha mãe Doraci, por me mostrar diariamente que paciência e amor não têm limites, por facilitar todas as questões práticas do meu dia-a-dia. Ao meu pai Agostinho, pela preocupação constante em prover o que há de melhor e em garantir a minha segurança em todos os sentidos. 


\section{RESUMO}

O objetivo desse estudo é analisar e sistematizar os elementos necessários à modelagem da energia primária solar para geração fotovoltaica em escala. Metodologicamente, investigamse os assuntos inerentes à solarimetria e a caracterização da radiação solar, desde a formação das equações que definem a incidência da radiação no topo da atmosfera, o desenvolvimento tecnológico de radiômetros, até as normas e critérios de classificação desses equipamentos. Também são elementos metodológicos a caracterização do irradiância solar, incluindo algoritmos de tratamento de dados de irradiância, os processos de estimativa de irradiação para a agricultura e análises probabilísticas de índices de transmitância atmosférica. Busca-se a aplicação das etapas de caracterização e a análise do recurso, definidas neste estudo, por meio da utilização dos dados fornecidos por duas estações solarimétricas: ESUPP e ESPEL. Como resultados são definidos a média diária parcial anual de disponibilidade do recurso para uma região no interior do estado de São Paulo (localização da ESUPP) em $5,29 \mathrm{kWh} / \mathrm{m}^{2}$ e a média diária anual de disponibilidade do recurso para a região metropolitana da cidade de São Paulo (localização da ESPEL) em $4,41 \mathrm{kWh} / \mathrm{m}^{2}$, além disso verifica-se que a relação entre as componentes global horizontal, difusa horizontal e direta vertical varia para os dados das duas estações solarimétricas, de modo que, parte significativa dos dados da ESPEL apresenta medições de irradiância global horizontal $(I G H)$ entre $12 \%$ e $13 \%$ superiores à respectiva componente difusa horizontal $(I D H)$ somada a parcela vertical da respectiva componente direta normal $\left(I D N \cos \theta_{z}\right)$, enquanto que, essa mesma relação para os dados da ESUPP atendem à relação $I G H=I D H+I D N \cos \theta_{z}$ dentro do intervalo aceitável de mais ou menos $10 \%$. Verifica-se também caráter trimodal das curvas de densidade de probabilidade do índice de transmitância da irradiância global para os dados da ESPEL, enquanto os dados da ESUPP refletem em curva de caráter bimodal. Assim é possível constatar a necessidade de definição de um modelo universal de previsibilidade do recurso e verifica-se que os insumos mais relevantes para o modelo podem variar de região para região dada a caracterização geográfica e de microclima. Conclui-se, portanto, a indiscutível necessidade de dados radiométricos confiáveis medidos em solo para avanços científicos, tecnológicos e comerciais do aproveitamento do recurso solar como fonte energética diante do atual contexto da busca por fontes alternativas de energia limpa e evidencia-se o grande caminho a ser percorrido para a consolidação de uma rede confiável, monitorada e amplificada de medições solarimétricas no Brasil e no mundo. 


\begin{abstract}
The purpose of this study is to analyze and to systematize the elements required for modeling primary solar energy for photovoltaic generation in large scale. Solarimetric subjects and subjects related to solar irradiance flux characterization, from the formation of the equations that define the incidence of radiation at the top of the atmosphere, the technologic development of radiometers and the rules and criteria for the classification of these measurement instruments, are methodologically investigated. The characterization of the irradiance flux, including irradiance data treatment algorithms, the irradiance estimate processes for agriculture, and the probability analyses of atmosphere transmittance indexes are also methodological elements. The steps of characterization and resource analysis defined in this study are applied, using data provided for two solarimetric stations: ESUPP and ESPEL. Results showed that the partial annual daily average for resource availability in the countryside of São Paulo State (ESUPP location), is $5.9 \mathrm{kWh} / \mathrm{m}^{2}$, and the annual daily average for resource availability in the metropolitan area of São Paulo City (ESPEL location) is $4.41 \mathrm{kWh} / \mathrm{m}^{2}$. Moreover, it was observed that the relation between the global horizontal, diffuse horizontal and direct vertical components varies between both solarimetric stations, such that a significant part of the ESPEL data shows global horizontal irradiance (GHI) between $12 \%$ and $13 \%$ above the respective diffuse horizontal irradiance $(D H I)$ plus the vertical portion of the respective direct normal component $\left(D N I \cos \theta_{z}\right)$, while the same relation for the ESUPP data attend the $G H I=D H I+D N I \cos \theta_{z}$ relation within the acceptable range of $10 \%$, give or take. ESPEL data presented trimodal characteristics for the probability density curves of the transmittance index for global irradiation, while ESUPP data reflect on the same curve, with bimodal characteristics. Therefore, it is possible to verify the need of the determination of a universal predictability model of the resource and it is possible to affirm that the more relevant inputs to the model can vary from region to region, depending on the geographic character and microclimate. In conclusion, there is an unquestionable need for reliable radiometric data, measured in ground, for scientific, technologic and commercial advances to improve the use of solar resource as energy source, considering the current scenario, which demands alternative sources for clean energy. It is also evident that there is still a long path to be tracked in order to consolidate a reliable, monitored and amplified network for solarimetric measurements in Brazil and in the world.
\end{abstract}




\section{SUMÁRIO}

1 INTRODUÇÃO

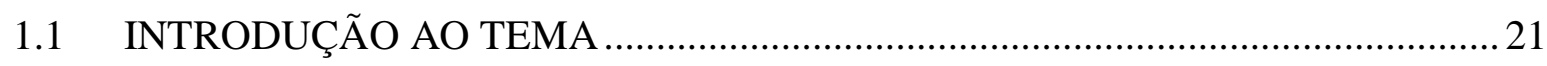

1.1.1 Inserção da Energia Fotovoltaica na Matriz Elétrica Brasileira ...........................22

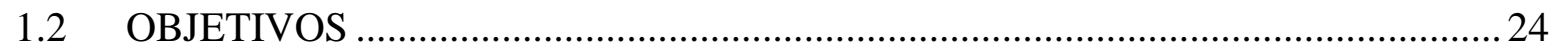

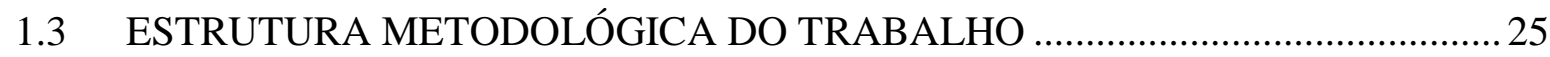

2 RECURSOS RENOVÁVEIS: A MODELAGEM DA ENERGIA PRIMÁRIA

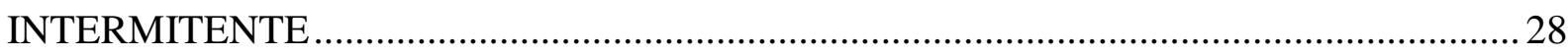

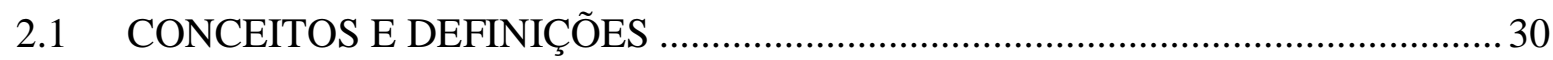

3 ASPECTOS FUNDAMENTAIS DA ANÁLISE DAS GRANDEZAS

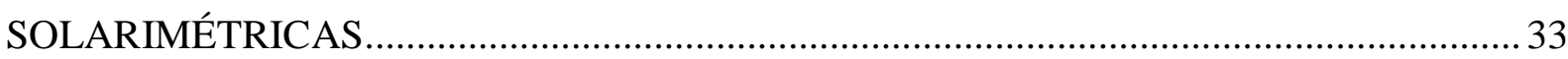

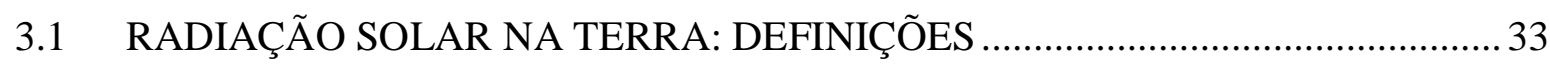

3.1.1 Radiação Global, Direta e Difusa .........................................................................

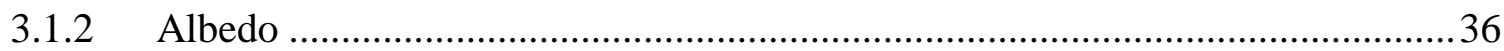

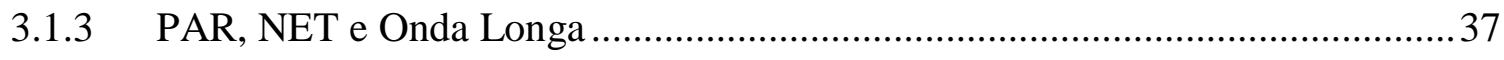

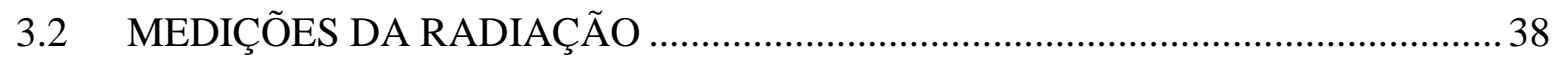

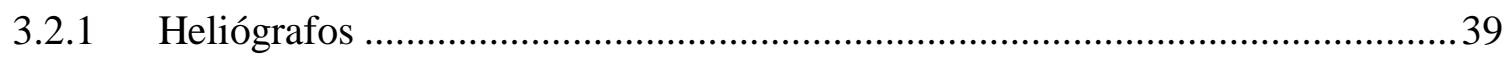

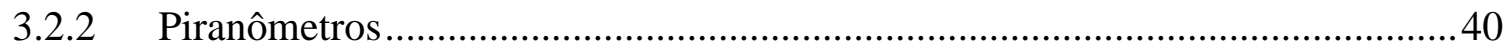

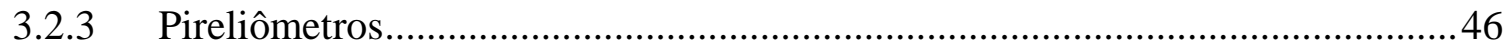

3.3 MEDIÇÕES DE VARIÁVEIS CLIMATOLÓGICAS .............................................. 48

3.4 CLASSIFICAÇÃO E PADRONIZAÇÃO DE ESTAÇÕES SOLARIMÉTRICAS . 50

3.5 REDES DE MEDIÇÕES E DISPONIBILIDADE DE DADOS ...............................55

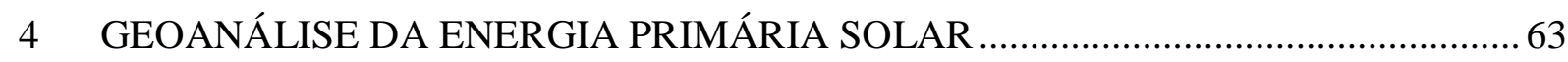

4.1 DISPONIBILIDADE DA IRRADIAÇÃO EXTRATERRESTRE …………….........63

4.2 TRANSMITÂNCIA ATMOSFÉRICA …………………………………….......... 74

4.3 MODELOS DE ESTIMATIVA DA IRRADIAÇÃO.............................................. 79

4.3.1 Modelos Empíricos para Estimativa da Irradiação Direta e Difusa …………......80

4.3.2 Modelos Empíricos para Estimativa da Irradiação Global ..................................81

4.4 ANÁLISE DE CORRELAÇÕES CLIMÁTICAS EM HIDRELÉTRICAS ..............89

5 CARACTERIZAÇÃO DA MÉTRICA SOLAR E SEUS ASPECTOS TEMPORAIS ... 99

5.1 PADRONIZAÇÃO DO REGISTRO DE DADOS................................................... 100

5.1.1 BSRN e o Padrão de Registro de Dados............................................................ 101 
5.1.2 NREL e o Padrão de Registro de Dados........................................................... 104

5.2 PROCEDIMENTOS DE ANÁLISE DE DADOS RADIOMÉTRICOS................. 106

5.2.1 Análise de Qualidade de Dados pela BSRN................................................ 109

5.2.2 Análise de Qualidade de Dados pelo NREL ................................................. 112

5.2.3 Análise de Qualidade de Dados pelo RMIB .................................................. 121

5.3 ANÁLISE DE QUALIDADE: UM REFERENCIAL PARA MODELAGEM ...... 125

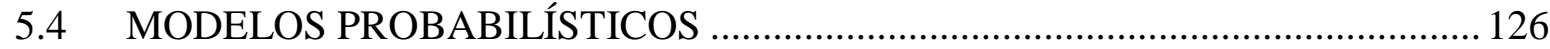

6 SISTEMATIZAÇÃO DOS ELEMENTOS NECESSÁRIOS À MODELAGEM .......... 145

7 CARACTERIZAÇÃO DO RECURSO: UTILIZAÇÃO DE MEDIÇÕES EM SOLO . 152

7.1 CARACTERIZAÇÃO DA ES DA UHE PORTO PRIMAVERA .......................... 152

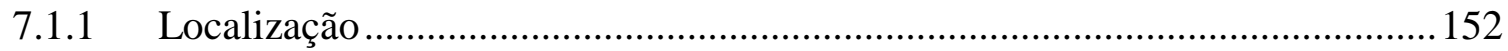

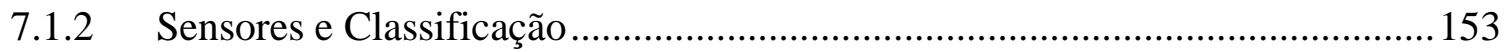

7.2 ANÁLISE E TRATAMENTO DE DADOS DA ESUPP.......................................... 154

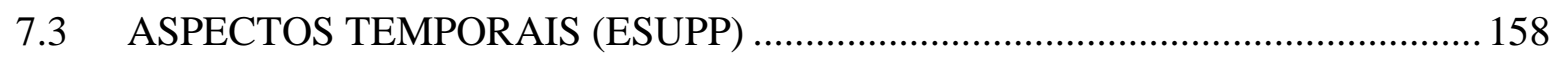

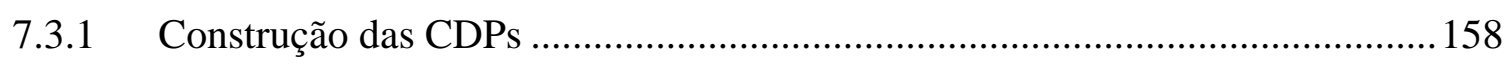

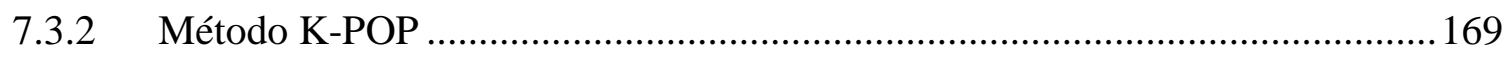

7.3.3 Variação de Medições Subsequentes................................................................ 171

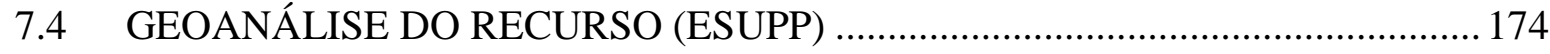

7.4.1 Variável Climática Balizadora e Modelos Empíricos ...................................... 174

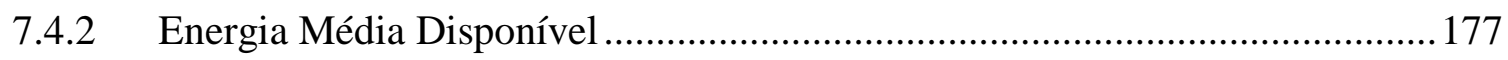

7.5 CARACTERIZAÇÃO DA ES POLI ELÉTRICA ….......................................... 179

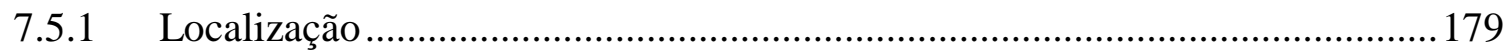

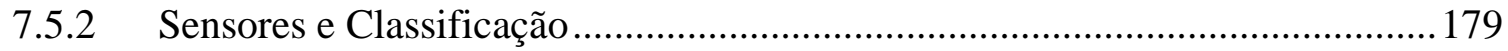

7.6 ANÁLISE E TRATAMENTO DOS DADOS DA ESPEL …................................ 181

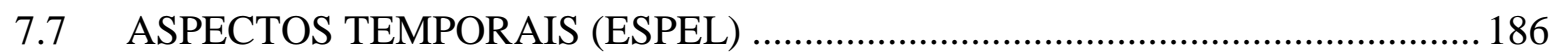

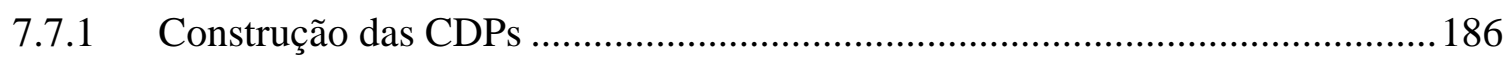

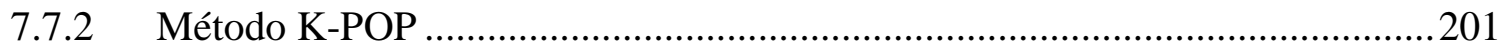

7.7.3 Variação de Medições Subsequentes.................................................................203

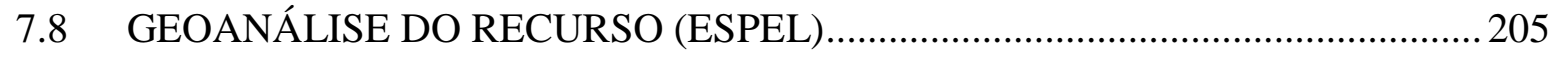

7.8.1 Variável Climática Balizadora e Modelos Empíricos ......................................205

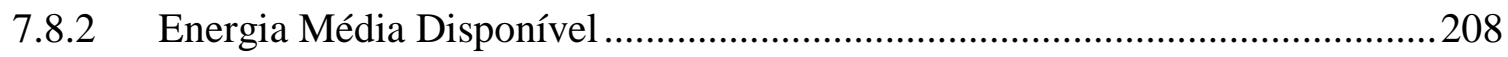

7.9 CONSOLIDAÇÃO DOS RESULTADOS E DISCUSSÕES................................ 210

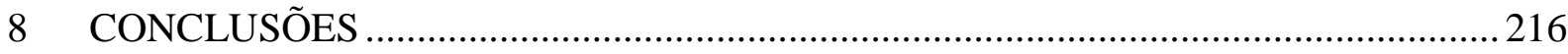




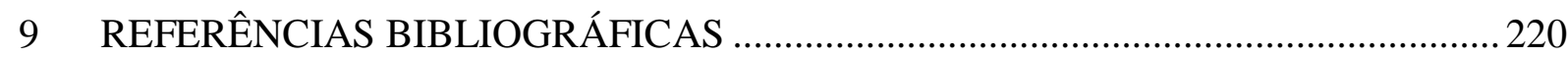

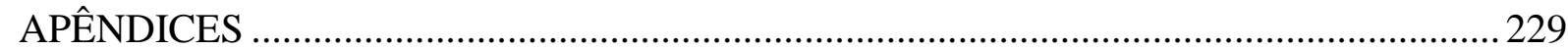




\section{LISTA DE TABELAS}

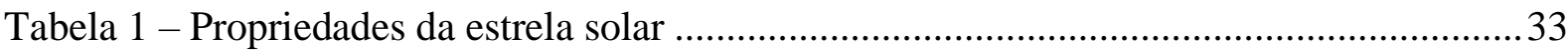

Tabela 2 - Classificação First Class para pireliômetros e piranômetros pela ISO 9060 ..........52

Tabela 3 - Critérios para as medições climatológicas pela WMO …......................................54

Tabela 4 - Critérios para as medições climatológicas pela BSRN ............................................55

Tabela 5 - Distribuição de estações de medição e dimensão territorial....................................61

Tabela 6 - Relação entre o tempo solar e o ângulo horário solar .............................................66

Tabela 7 - Datas de eventos característicos da dinâmica Terra-Sol ....................................... 70

Tabela 8 - Absorção e dispersão da radiação solar em função da massa de ar e da altura solar

Tabela 9 - Hidrelétricas e estações de medição analisadas......................................................90

Tabela 10 - Coeficiente de correlação linear de Pearson........................................................91

Tabela 11 - Coeficiente de correlação linear de Pearson para insolação..................................92

Tabela 12 - Formatos de registro de grandezas definidos pela BSRN ................................... 103

Tabela 13 - Definição dos Intervalos de Massa de Ar .............................................................113

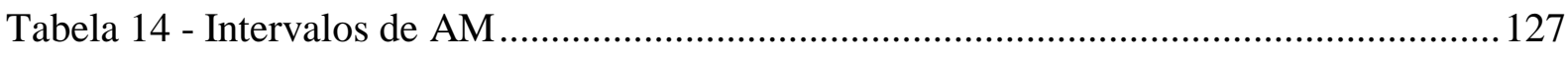

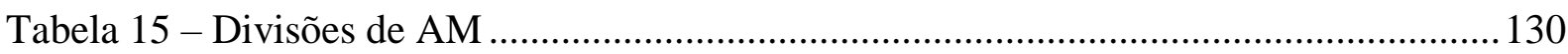

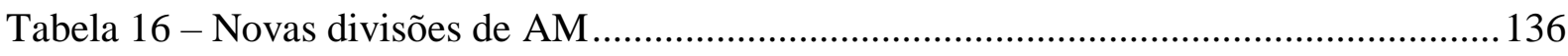

Tabela 17 - Nova determinação dos intervalos de AM...................................................... 158

Tabela 18 - Determinação tradicional dos intervalos de AM .............................................. 159

Tabela 19 - Consolidação do montante de energia disponível .............................................. 178

Tabela 20 - Resultados da análise de qualidade de dados ................................................... 184

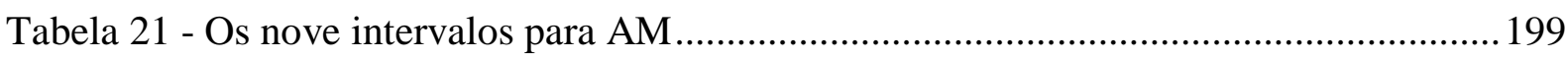

Tabela 22 - Consolidação do montante de energia disponível ...............................................208 


\section{LISTA DE QUADROS}

Quadro 1 - Classificação de estações solarimétricas no Brasil ............................................51

Quadro 2 - Precisão mínima dos radiômetros para estação de alta precisão .............................52

Quadro 3 - Critérios para as medições climatológicas pela ANEEL .......................................54

Quadro 4 - Grupos, organizações e trabalhos internacionais relevantes para a solarimetria ...57

Quadro 5 - Grupos, organizações e trabalhos nacionais relevantes para a solarimetria............58

Quadro 6 - Critérios para extrapolação e interpolação de dados de estações solarimétricas ...60

Quadro 7 - Quadro de esquematização de análise de qualidade de dados pela Rede Sonda.. 111

Quadro 8 - Definição e descrição das classes do método K-POP .......................................... 141

Quadro 9 - Localização da ES UHE Porto Primavera ............................................................ 153

Quadro 10 - Caracterização dos equipamentos da ES UHE Porto Primavera......................... 153

Quadro 11 - Análise de qualidade e tratamento de dados da ES UHE Porto Primavera........ 156

Quadro 12 - Estações climáticas......................................................................................... 164

Quadro 13 - Resultado do métdo K-POP para ES Usina Porto Primavera ............................ 170

Quadro 14 - Localização da ES Poli Elétrica .......................................................................... 179

Quadro 15 - Caracterização dos equipamentos da ES Poli Elétrica ....................................... 179

Quadro 16 - Análise de qualidade e tratamento de dados da ES Poli Elétrica ........................183

Quadro 17 - Resultado do métdo K-POP para ES Poli Elétrica ..........................................202

Quadro 18 - Caracterização do recurso solar na região da ES Poli Elétrica ..........................209 


\section{LISTA DE FIGURAS}

Figura 1 - Definição conceitual da modelagem da energia primária solar ...............................32

Figura 2 - Correlação entre irradiância global, direta e difusa ............................................ 35

Figura 3 - Alteração do albedo em diferentes comprimentos de onda e dias do ano ................36

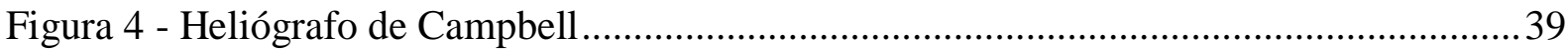

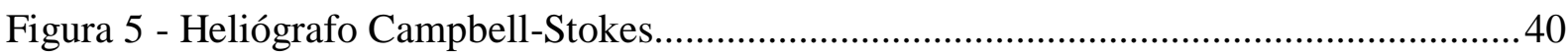

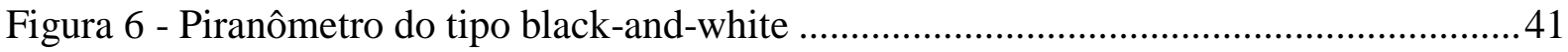

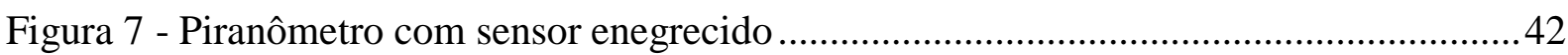

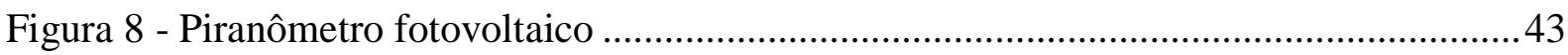

Figura 9 - Esquema de um piranômetro com banda de sombreamento....................................44

Figura 10 - Piranômetro com banda de sombreamento fixa..................................................44

Figura 11 - Piranômetro com sistema de sombreamento rotativo .........................................45

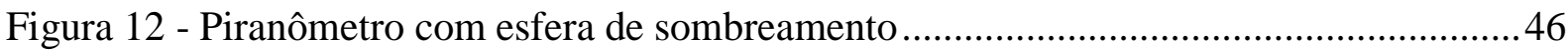

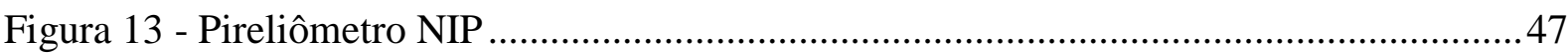

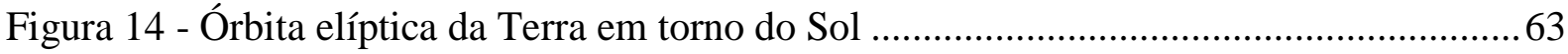

Figura 15 - Composição espectral da radiação solar ..............................................................64

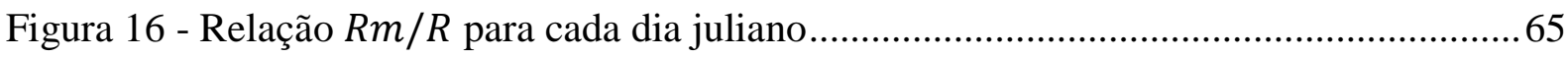

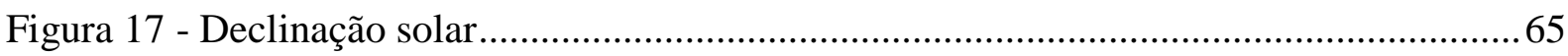

Figura 18 - Irradiação extraterrestre ao meio dia para cada dia juliano- Hemisfério Norte ....68

Figura 19 - Irradiação extraterrestre ao meio dia para cada dia juliano- Hemisfério Sul ........68

Figura 20 - Irradiação média ao meio dia para faixas de $15^{\circ}$ de latitude ...............................69

Figura 21 - Declinação da Terra e distância Terra-Sol para cada dia juliano .......................... 70

Figura 22 - Fotoperíodo nos equinócios para faixas de latitude de $30^{\circ}$..................................71

Figura 23 - Fotoperíodo nos Solstícios para faixas de latitude de $30^{\circ}$.....................................72

Figura 24 - Irradiação extraterrestre na linha do Equador ..................................................73

Figura 25 - Alteração do espectro solar em função da transmitância atmosférica ...................75

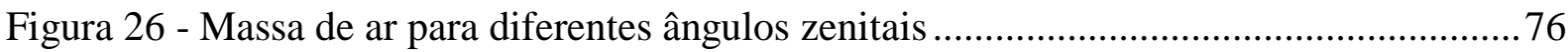

Figura 27 - Normais de insolação em Sobradinho e Tucuruí ..................................................93

Figura 28 - Médias de insolação - UHE Sobradinho............................................................95

Figura 29 - Médias de umidade relativa - UHE Sobradinho .................................................96

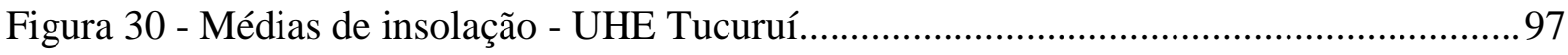

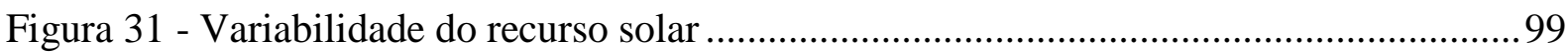

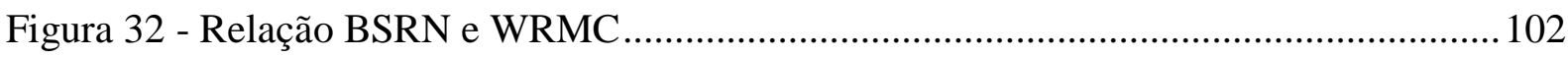

Figura 33 - Incidência da radiação e ângulo zenital ............................................................. 106

Figura 34 - Espaço $k n-k t$ com a plotagem de limites teóricos ........................................... 114

Figura 35 - Limites de $k n-k t$ para diferentes massas de ar ............................................. 116

Figura 36 - Determinação do conjunto $k n-k t$ em condições atmosféricas específicas ..... 117

Figura 37 - Plotagens das relações de $k n-k t$ para avaliação irradiância difusa................... 119

Figura 38 - Limites de $k n-k t$ para períodos de integração diferentes ................................. 120

Figura 39 - Série de irradiância com registro de sombreamento ........................................... 124

Figura 40 - Densidade de distribuição de $k t$ para diferentes massas de ar ............................127

Figura 41 - Distribuição de $k t$ para diferentes períodos de integração ................................... 129 
Figura 42 - Caráter bimodal da densidade de probabilidade de $k t$

Figura 43 - Curvas de densidade de probabilidade para $k t$ em função da massa de ar......... 132

Figura 44 - Curvas de densidade de probabilidade para $k b$ e $k d$ em função da massa de ar. 134

Figura 45 - Distribuição de $k t$ para diferentes massas de ar ................................................. 137

Figura 46 - Distribuição de $k b h$ para diferentes massas de ar .............................................. 138

Figura 47 - Distribuição de $k d$ para diferentes massas de ar ............................................... 139

Figura 48 - As 10 classes definidas para caracterização do recurso solar ...............................141

Figura 49 - Histograma da taxa de alteração de medidas subsequentes ................................. 143

Figura 50 - Função empírica de densidade cumulativa de probabilidade de IDN ................. 144

Figura 51 - Fluxograma das atividades visando à modelagem........................................... 150

Figura 52 - Frequência dos valores de Ktc ................................................................... 157

Figura 53 - Curvas de densidade de probabilidade de $k t$ para o período restrito em função da

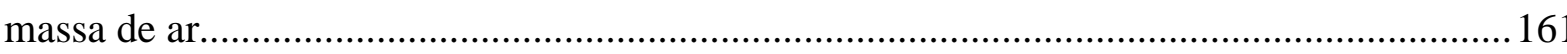

Figura 54 - Curvas de densidade de probabilidade de $k d$ para o período restrito em função da massa de ar.

Figura 55 - Curvas de densidade de probabilidade de $k b$ para o período restrito em função da massa de ar.

Figura 56 - Curvas de densidade de probabilidade de $k t$ para os meses de Out/2015 a $\mathrm{Jan} / 2016$

Figura 57 - Curvas de densidade de probabilidade de $k t$ para os meses de Fev/2016 a

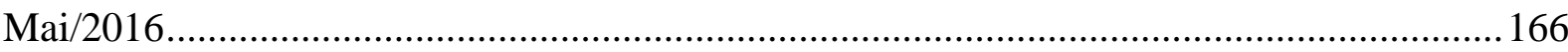

Figura 58 - Curvas de densidade de probabilidade de $k t$ para a Primavera.......................... 167

Figura 59 - Curvas de densidade de probabilidade de $k t$ para o Verão ................................. 168

Figura 60 - Aplicação da metodologia K-POP ................................................................ 170

Figura 61 - Variabilidade do recurso: taxas menores ...................................................... 172

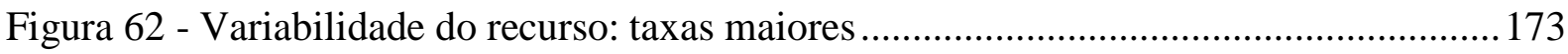

Figura 63 - Correlação IGH x Umidade Relativa e IGH x Temperatura .............................. 175

Figura 64 - Correlação IGH x Pressão Atmosférica e IGH x Precipitação ............................ 176

Figura 65 - Quantidade média de energia disponível por mês- dia característico de cada mês

Figura 66 - Registro fotográfico da esfera de sombreamento desalinhada............................ 181

Figura 67 - Frequência dos valores de $k t c$...................................................................... 185

Figura 68 - Curvas de densidade de probabilidade de $k t$ para a série anual em função da massa de ar.

Figura 69 - Curvas de densidade de probabilidade de $k t$ para a série anual incompleta em função da massa de ar................................................................................................. 188

Figura 70 - Curvas de frequência relativa de ktc para a série completa para diferentes massas

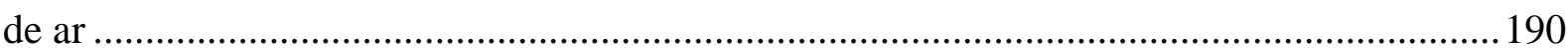

Figura 71 - Curvas de densidade de probabilidade de $k d$ para a série anual em função da

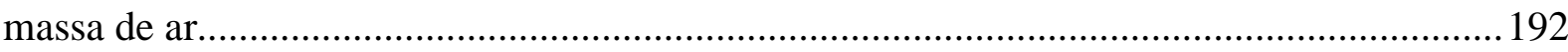

Figura 72 - Curvas de densidade de probabilidade de $k b$ para a série anual em função da massa de ar. 
Figura 73 - Curvas de densidade de probabilidade de $k t$ para os meses de Abr/2015 a $\mathrm{Jul} / 2015$

Figura 74 - Curvas de densidade de probabilidade de $k t$ para os meses de Ago/2015 a Nov2015

Figura 75 - Curvas de densidade de probabilidade de $k t$ para os meses de Dez/2015 a Mar/2016

Figura 76 - Curvas de densidade de probabilidade de $k t$ para a série anual incompleta total

Figura 77 - Curvas de densidade de probabilidade de $k t$ para a série auxiliar....................... 198

Figura 78 - Aplicação da metodologia K-POP para $k t$.........................................................201

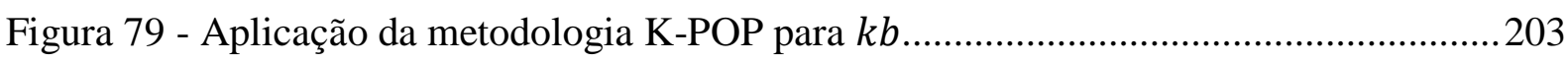

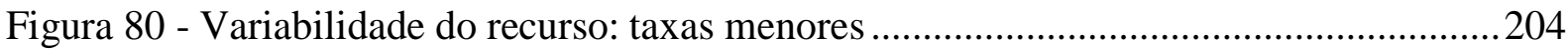

Figura 81 - Variabilidade do recurso: taxas maiores ........................................................205

Figura 82 - Correlação IGH x Umidade Relativa e IGH x Temperatura ...............................206

Figura 83 - Correlação IGH x Pressão Atmosférica e IGH x Precipitação ............................ 207

Figura 84 - Fluxograma validado das atividades visando à modelagem ..............................215 


\section{LISTA DE SIGLAS, ABREVIAÇÕES E SÍMBOLOS}

AM Massa de Ar

ANEEL Agencia Nacional de Energia Elétrica

ARM Atmospheric Radiation Measurement Program

BSRN Baseline Surface Radiation Network

CDP Curva de Densidade de Probabilidade

CESP Companhia Energética de São Paulo

CFR Curva de Distribuição de Frequência Relativa

CPTEC Centro de Previsão de Tempo e Estudos Climáticos

DNI Direct Normal Irradiance.

DHI Difuse Horizontal Irradiance

EPE $\quad$ Empresa de Pesquisa Energética

ES Estação Solarimétrica

ESPEL Estação Solarimétrica POLI Elétrica

ESUPP Estação Solarimétrica Usina Porto Primavera

EUA Estados Unidos da América

GEBA Global Energy Balance Archive

GEPEA Grupo de Energia do Departamento de Engenharia de Energia e Automação Elétricas

GEWEX Global Energy and Water Cycle Experiment

GHI Global Horizontal Irradiance,

GPS Global Position System

IDH Irradiância ou Irradiação Difusa Horizontal

IDN Irradiância ou Irradiação Direta Normal

IGH Irradiância ou Irradiação Global Horizontal

INMET Instituto Nacional de Meteorologia

INPE Instituto Nacional de Pesquisas Espaciais 
ISO International Organization for Standardization

LER Leilão de Reserva

MME Ministério de Minas e Energia

NASA National Aeronautics and Space Administration

NET Saldo de Radiação

NREL National Renewable Energy Laboratory

ONS Operador Nacional do Sistema

PAR Photosynthetically Active Radiation

PCD Plataformas de Coleta de Dados

$\mathrm{PCH} \quad$ Pequena Central Hidrelétrica

PDE Plano Decenal de Expansão de Energia

PIRnaUSP Planejamento Integrado de Recursos Energéticos para o Desenvolvimento Sustentável

RMIB Royal Meteorological Institute of Belgium

SIN Sistema Interligado Nacional

SONDA Sistema de Organização Nacional de Dados Ambientais

SWERA Solar and Wind Resource Assessment

TOA Top of Atmosphere

TUSD Tarifa de Uso do Sistema de Distribuição

TUST Tarifa de Uso do Sistema de Transmissão

UNEP United Nations Environment Programme

UHE Usina Hidrelétrica

UTC Universal Coordinated Time

WMO World Meteorological Organization

WRC World Radiation Center

WRDC Word Radiation Data Center

WRMC World Radiation Monitoring Center

WRR World Radiometric Reference 


\begin{tabular}{|c|c|}
\hline WSG & World Standard Group \\
\hline$\alpha$ & Altura Solar \\
\hline$\delta$ & Declinação Solar \\
\hline$\Delta T$ & Amplitude Térmica Diária \\
\hline$\Delta T_{m}$ & Amplitude Térmica Média Mensal \\
\hline$\theta_{Z}$ & Ângulo Zenital \\
\hline$\mu$ & Média Diária da Série Histórica \\
\hline$\sigma$ & Desvio Padrão \\
\hline$\phi$ & Latitude \\
\hline$\omega$ & Velocidade Angular \\
\hline C & Coeficiente de Nebulosidade \\
\hline$D$ & Coeficiente Adimensional de Poeiras \\
\hline$h$ & Ângulo Horário Solar \\
\hline$H$ & Duração Astronômica do Período Diurno (radianos) \\
\hline$h_{s}$ & Horas do Dia \\
\hline$I_{0}$ & Constante de Potência da Irradiância Extraterrestre \\
\hline$I D H_{c c}$ & Irradiância Difusa Horizontal Calculada para Condições de Céu Claro \\
\hline$I D N_{0}$ & Irradiância ou Irradiação Direta Normal Extraterrestre \\
\hline$I D N_{c c}$ & Irradiância Direta Normal Calculada para Condições de Céu Claro \\
\hline$I D N_{W}$ & Irradiação Direta Normal Atenuada pelo Vapor d'Água \\
\hline$I G H^{\text {Diário }}$ & Média Diária da Irradiação Global Horizontal \\
\hline$I G H_{0}$ & Irradiância ou Irradiação Global Horizontal Extraterrestre \\
\hline$I G H_{C}$ & Irradiância Global Horizontal Calculada \\
\hline$I G H_{c c}$ & Irradiância Global Horizontal Calculada para Condições de Céu Claro \\
\hline K-POP & Método de Análise da Probabilidade de Persistência de Índice de Transmitância \\
\hline$n$ & Insolação \\
\hline$N$ & Duração do Período Diurno (horas) \\
\hline
\end{tabular}


$P \quad$ Pressão Atmosférica

$P_{0} \quad$ Pressão Atmosférica ao Nível do Mar

$P O P_{D} \quad$ Probabilidade de Persistência

$T_{\text {máx }} \quad$ Temperatura Ambiente Máxima Diária

$T_{\text {média }} \quad$ Temperatura Ambiente Média Diária

$T_{\text {min }} \quad$ Temperatura Ambiente Mínima Diária

$k_{b}$ e $k_{n} \quad$ Coeficiente de Transmitância da Radiação Direta Normal

$k_{n}^{\prime} \quad$ Fração da Componente Direta da Radiação

$k_{b h} \quad$ Coeficiente de Transmitância da Radiação Direta Horizontal

$k_{d} \quad$ Coeficiente de Transmitância da Radiação Difusa Horizontal

$k_{d}^{\prime} \quad$ Fração da Componente Difusa da Radiação

$k_{t} \quad$ Coeficiente de Transmitância da Radiação Global Horizontal

$k_{t c} \quad$ Coeficiente da Radiação Global Horizontal em Relação a Radiação Global Horizontal Calculada

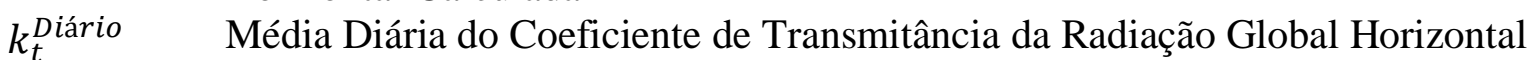

$k_{\text {tmax }} \quad$ Coeficiente Máximo de Transmitância da Radiação Global Horizontal

NDA Dia Juliano

$r \quad$ Coeficiente de Pearson

$R_{m} \quad$ Distância Média entre o Sol e a Terra

$R \quad$ Distância Real entre o Sol e a Terra para um Determinado Dia

$S^{2} \quad$ Variância da Série Histórica

$t \quad$ Coeficiente de Transmitância Atmosférica

$t_{n} \quad$ Hora do Nascer do Sol

$t_{p} \quad$ Hora do Pôr do Sol

UR Umidade Relativa

w Precipitação Diária

$W_{n} \quad$ Quantidade de Água Precipitável na Direção Zenital na Atmosfera 
Média da Série Histórica

Z

Altitude 


\section{INTRODUÇÃO}

\subsection{INTRODUÇÃO AO TEMA}

O acesso à energia elétrica é essencial para a manutenção de serviços de saúde e saneamento e tem uma relação direta com a qualidade de vida. A segurança e garantia do abastecimento de energia promove a confiabilidade dos setores industriais e dos demais setores de infraestrutura. Isso mostra o quão necessário é a operação e constituição eficiente das matrizes elétricas dos países.

O planejamento da matriz elétrica envolve uma série de fatores técnicos, ambientais, sociais, econômicos e políticos. A escolha dos recursos utilizados para produção de energia depende dos tipos de recursos disponíveis em cada região, das tecnologias disponíveis para geração, transmissão e distribuição, e de análises econômicas de viabilidade das opções existentes. Além disso, a produção de energia é uma das atividades que mais gera poluição e mais necessita de recursos naturais, gerando inúmeros impactos sociais e ambientais. Assim, políticas públicas são indispensáveis no equacionamento dessas variáveis, visando promover o maior e melhor retorno à sociedade como um todo.

A logística do transmissão da energia elétrica é extremamente dinâmica, visto a grande limitação do armazenamento da energia. A transmissão deve garantir que grandes quantidades de energia possam ser transferidas dos centros de geração aos centros de carga, assegurando o abastecimento contínuo e imediato em resposta ao aumento ou diminuição da carga, promovendo sempre os menores custos econômicos, ambientais e sociais à operação.

A atual atenção mundial com o desenvolvimento sustentável tem promovido preocupações acerca dos impactos ambientais causados pelo uso de combustíveis fósseis. Neste contexto, nota-se uma tendência mundial de utilização de fontes energéticas limpas e renováveis. Como destaque, a utilização das fontes eólica, solar e biomassa tem ganhado espaço no mercado de geração e comercialização de energia no Brasil e no mundo (TOLMASQUIM, 2016).

A matriz elétrica brasileira tradicionalmente possui um perfil hidrotérmico. Contudo, os aproveitamentos com grandes reservatórios representam uma etapa do desenvolvimento energético brasileiro já finalizada. Os potenciais hidrelétricos ainda não aproveitados no Brasil localizam-se basicamente na região Norte. Esse potencial, que está sendo atualmente explorado, representa a atual expansão hidrelétrica nacional. Essas novas hidrelétricas possuem, em sua maioria, um perfil a fio d'água que reduz a possibilidade de armazenamento 
e a garantia da energia gerada por essa fonte (TOLMASQUIM, 2016). O crescimento da carga sem a construção de novos reservatórios diminui a capacidade de regularização da energia disponível nos próximos anos.

Os grandes centros de carga brasileiros estão localizados nas regiões Sul e Sudeste. Devido à grande extensão territorial brasileira e à infraestrutura de transmissão disponibilizada pelo Sistema Interligado Nacional (SIN), o aproveitamento de potenciais remotos, como as hidrelétricas na Amazônia e os potenciais eólicos e solares no Nordeste é de extremo interesse ao sistema elétrico como um todo. Contudo, a opção da geração de energia próxima ao centro de carga é sempre mais benéfica do ponto de vista da redução de perdas na transmissão e distribuição da energia. Nessa perspectiva, as grandes hidrelétricas da região sudeste têm um potencial de área física e de infraestrutura de transmissão que pode beneficiar a formação de parques geradores híbridos, ou seja, que alocam mais de uma fonte energética na mesma instalação.

O plano de fundo que motiva esse trabalho é justamente este: da perspectiva de instalação de usinas fotovoltaicas em usinas hidrelétricas existentes, otimizando o espaço físico destinado à geração de energia, aproveitando a infraestrutura já instalada de transmissão (considerando a capacidade instalada desse sistema), contribuindo para a reserva de água, limitando as perdas de energia ocasionadas pela transmissão em longas distâncias e otimizando a geração próxima aos principais centros de carga do país.

\subsubsection{Inserção da Energia Fotovoltaica na Matriz Elétrica Brasileira}

Em 2014 os primeiros projetos de energia fotovoltaica foram contratados em leilões de energia de reserva. O Leilão de Energia de Reserva de 2014 (LER/2014) teve 331 projetos habilitados, destes, 31 foram viabilizados, totalizando a contratação de $890 \mathrm{MW}$ de energia fotovoltaica. A nota técnica ${ }^{1}$ lançada pela Empresa de Pesquisa Energética (BRASIL, 2016) sobre a participação dos projetos solares nesse leilão indica que ao todo foram cadastrados 400 projetos que totalizariam uma oferta de 10.790 MW. Sobre as informações exigidas quanto ao recurso solar, a mesma nota técnica explica que

O art. $6^{\circ}$-B10, inciso II, da Portaria MME n ${ }^{\circ}$ 21/2008, estabelece que, para empreendimentos fotovoltaicos, apenas a partir de 2016 será obrigatória a apresentação de histórico de medições contínuas de irradiação global horizontal, por período não inferior a doze

\footnotetext{
${ }^{1}$ Nota Técnica No EPE-DEE-NT-150/2014-r0
} 
meses consecutivos, realizadas no local do empreendimento. Dessa forma, para habilitação técnica no LER/2014, admitiu-se que a Certificação de Produção Anual de Energia fosse elaborada a partir de dados solarimétricos secundários, obtidos, principalmente, a partir de modelos numéricos, com uso de parâmetros derivados de dados de satélites, interpolação de dados terrestres de terceiros, entre outros. Por esse motivo, no LER/2014 ainda foram minoria os projetos que já dispunham de dados solarimétricos medidos em estação instalada no sítio do empreendimento, constatação essa que se aplica inclusive aos 31 projetos vencedores. (BRASIL, 2016)

O primeiro Leilão de Energia de Reserva de 2015 (1 LER/2015), assim como o LER/2014, foi exclusivo aos projetos fotovoltaicos. Neste leilão 382 projetos foram cadastrados, e destes, 341 projetos foram habilitados, totalizando uma oferta habilitada de 11.261 MW. O resultado deste leilão apresentou a contratação de 30 empreendimentos que totalizam 833,8 MW de potência. Dos 30 empreendimentos contratados, apenas um possui Estação Solarimétrica (ES) própria no local do empreendimento, porém com menos de 12 meses de mediçãó2.

O segundo Leilão de Energia de Reserva de 2015 (2 $2^{\circ}$ LER/2015) foi a primeira ocasião em que se verificou a contratação de projetos de energia solar fotovoltaica em um leilão não exclusivo à fonte. Neste leilão participaram projetos eólicos e fotovoltaicos, sendo que 649 projetos de energia fotovoltaica foram cadastrados, e destes, foram habilitados 493, totalizando uma oferta de 13.159 MW de potência. Foram contratados 929,3 MW de capacidade instalada distribuída em 33 projetos. Novamente, dos 33 empreendimentos, apenas 1 possui ES instalada no local ${ }^{3}$.

No Plano Decenal de Expansão de Energia 2023 (PDE 2023) publicado pela EPE em 2014 (BRASIL, 2014a) foi apresentado - pela primeira vez em um plano decenal - as perspectivas de crescimento da participação da fonte fotovoltaica de despacho centralizado na matriz elétrica nacional. A partir de 2017 - ano de entrada das plantas contratadas no LER/2014 - se prevê um aumento anual de 500MW de potência instalada fotovoltaica na matriz, totalizando, em 2023 um potencial instalado de 3,5 GW.

INÁCIO (2015) observa que das 31 usinas contratadas no LER/2014, 29 possuem capacidade instalada entre 29,8 e 30 MW. Segundo o autor isso representa a consolidação de

\footnotetext{
${ }^{2}$ Informações contidas na Nota Técnica Nº EPE-DEE-127/2015-r0

${ }^{3}$ Informações contidas na Nota Técnica No EPE-DEE-NT-023/2016-r0
} 
uma tendência já verificada na geração eólica de limitar a capacidade das usinas a 30 MW com o intuito de se beneficiar dos benefícios tarifários vigentes.

Dentre esses benefícios, destacam-se os descontos nas Tarifa de Uso do Sistema de Transmissão - TUST e Tarifa de Uso do Sistema de Distribuição - TUSD de no mínimo 50\% para empreendimentos com no máximo $30 \mathrm{MW}$ de potência instalada, definido pela Lei $\mathrm{n}^{\mathrm{o}} 10.762$ de $11 / 11 / 2003$.

O desenvolvimento do aproveitamento solar fotovoltaico no Brasil ainda se apresenta em fase bastante inicial, contudo, com perspectivas de crescimento constante. A isenção da necessidade de medições para o cadastro dos projetos nos leilões é temporária. Com o aumento da participação da fonte na matriz espera-se que haja o aumento da disponibilidade de dados medidos em solo em virtude da necessidade latente de melhor conhecimento do comportamento do recurso para fins de operação e comercialização da energia gerada.

Quanto ao período de medição requerida (mínima de 12 meses consecutivos) a princípio requerido pela EPE, é importante observar que tal exigência é visando a participação dos projetos em leilão de energia e não visando o conhecimento aprofundado do recurso energético e da sua disponibilidade e variabilidade. Considerando que o ciclo solar dura cerca de 11 anos (VIGNOLA et al., 2012) é importante o estabelecimento de décadas de série histórica para a validação dos modelos de previsibilidade do recurso.

Percebe-se também que, embora a tecnologia fotovoltaica seja bastante promissora para a geração descentralizada no contexto internacional, no Brasil, a fonte ganha notoriedade por meio de projetos de geração centralizada com porte de $30 \mathrm{MW}$ de potência.

Nesse contexto, realiza-se o estudo dos aspectos da modelagem da fonte solar a partir de dados obtidos por estações solarimétricas, visando o aprimoramento do conhecimento nacional a cerca desse assunto.

\subsection{OBJETIVOS}

O objetivo geral deste trabalho é analisar e sistematizar os elementos necessários à modelagem da energia primária solar para geração fotovoltaica em escala a partir de dados medidos em solo por uma estação solarimétrica. Assim, definem-se os objetivos específicos:

- Estudar o comportamento da radiação solar enquanto recurso energético para geração fotovoltaica;

- Estudar o processo de medição da radiação e a caracterização de uma estação solarimétrica; 
- Determinar o processo de medição da radiação solar e formação de séries históricas;

- Estabelecer e discutir os elementos conceituais para a modelagem da energia primária;

- Mapear os elementos físicos e estatísticos que dão suporte ao desenvolvimento de modelos de previsão de energia de curto e longo prazo;

- Caracterizar a energia primária a partir de dados reais obtidos por estações solarimétricas.

\subsection{ESTRUTURA METODOLÓGICA DO TRABALHO}

Como elementos metodológicos, inicialmente foram estudados os fundamentos da dinâmica Sol - Terra, buscando a compreensão dos fatores que definem a incidência da radiação solar, tanto no topo da atmosfera, como na superfície terrestre. Sequencialmente, por meio de revisão bibliográfica, consulta de livros, relatórios técnicos e normas foi estudado o processo de desenvolvimento dos principais equipamentos solarimétricos (piranômetros, actinógrafos e pireliômetros) identificando a tecnologia utilizada e o processo de funcionamento dos mesmos. Por meio desse estudo e consultas a artigos, teses e dissertações foram mapeados os grupos mais relevantes de estudos solarimétricos no Brasil e no mundo e a partir disso, os websites, documentos e relatórios oficiais desses grupos foram analisados, buscando o entendimento dos procedimentos de manutenção, coleta e tratamento de dados realizados.

Finalizada a compreensão dos principais aspectos vinculados a solarimetria, recorreuse novamente a revisão bibliográfica, objetivando a compreensão dos aspectos climáticos, geográficos e temporais do recurso solar e identificação de modelos existentes de estimativa da irradiação. Inicialmente, a busca na revisão bibliográfica se deu por modelos empíricos que estimam os montantes diários de irradiação no hemisfério sul ou para fins energéticos e as suas respectivas fundamentações físicas e estatísticas. Essa delimitação do escopo de pesquisa se deu em função da observação de dois elementos ao longo da revisão bibliográfica sobre os aspectos solarimétricos: poucas referências a estudos com dados no hemisfério sul e referências reduzidas ao tratamento de dados e estudo da solarimetria para fins energéticos, já que grande parte dos estudos objetiva a utilização dos dados para agricultura. O estudo desses modelos objetivou principalmente a compreensão dos processos de interação da irradiância 
com as demais variáveis climatológicas medidas pelas estações solarimétricas, buscando a identificação de padrões de correlação entre as variáveis.

A partir da identificação dos aspectos climáticos e geográficos que podem interferir na disponibilidade da irradiância em uma determinada região, buscou-se a compreensão dos elementos que interferem na variabilidade de disponibilidade do recurso ao longo do tempo, considerando principalmente o curto prazo, já que, por meio da revisão bibliográfica anterior, verificou-se que a variabilidade do recurso em termos anuais é bastante reduzida. Em contraposição, a variabilidade ao longo do dia pode ser bastante alta. Assim, foi realizada a revisão bibliográfica por meio da consulta principalmente de artigos técnicos visando o mapeamento dos modelos probabilísticos existentes para a caracterização do comportamento da irradiação.

Definidos os elementos teóricos das principais etapas de caracterização da irradiância e da irradiação para fins energéticos, as informações foram sistematizadas e os aspectos e etapas de cálculos necessários à modelagem do recurso, foram esquematizados.

Essas etapas foram aplicadas em dados reais obtidos por estações solarimétricas, os resultados obtidos são discutidos, objetivando a validação do esquema produzido por meio das informações sistematizadas nas revisões bibliográficas.

Assim, essas informações são apresentadas nos próximos capítulos de modo que o primeiro capítulo trata da contextualização técnica na qual esse estudo se desenvolveu e apresenta os objetivos e a estrutura metodológica do desenvolvimento da pesquisa.

O segundo capítulo apresenta a justificativa do objetivo desse estudo além de promover a definição de importantes conceitos dos elementos em estudo, como a definição do que é entendido, nesse contexto de pesquisa, como recurso energético e fonte energética, energia primária e modelagem de energia. As definições mostradas nesse capítulo apresentam e justificam a metodologia adotada.

O capítulo três apresenta fundamentos de análise das grandezas solarimétricas, define a estação solarimétrica e seus equipamentos e as demais referências institucionais e bibliográficas referentes a essa área de conhecimento, como: grupos de estudos internacionais, normas e redes de medições que realizam trabalhos relevantes no desenvolvimento dos estudos solarimétricos. Nesse capítulo discute-se também a escassez de dados no Brasil e no Mundo.

O capítulo quatro trata dos aspectos climáticos e geográficos da energia primária solar. Discutem-se os aspectos que definem o montante de energia primária disponível em função da 
variação no espaço geográfico, identificando os elementos que definem determinadas regiões disporem, ao longo do ano, de uma quantia maior de energia solar do que outras.

O capítulo cinco define os aspectos da métrica solar em função dos elementos temporais. Neste capítulo discute-se a alteração do perfil de uma série histórica de irradiância em função da análise de diferentes escalas de tempo e os processos de análise de qualidade de dados, que por definição, são parametrizados em função do período de coleta e integralização dos dados.

O capítulo seis apresenta a consolidação dos elementos e processos necessários à modelagem, definidos a partir dos elementos discutidos nos capítulos anteriores.

No capítulo sete são utilizados os dados de estações solarimétricas para aplicação das etapas que visam a caracterização do recurso e dos elementos necessários à modelagem e são apresentados os resultados consolidados obtidos.

O capítulo oito apresenta as conclusões e sugestões para trabalhos futuros.

E finalmente, o capítulo nove apresenta as referências bibliográficas. 


\section{RECURSOS RENOVÁVEIS: A MODELAGEM DA ENERGIA PRIMÁRIA INTERMITENTE}

Segundo a definição apresentada por FUJII (2006) no contexto de desenvolvimento da metodologia de Planejamento Integrado de Recursos (PIRnaUSP ${ }^{4}$ ), um recurso energético é composto por uma fonte (radiação solar, água, vento, petróleo, dentre outros) associada a uma tecnologia de aproveitamento. E ainda dentro dessa definição, pode-se considerar que o aproveitamento de uma determinada fonte energética, por uma determinada tecnologia em diferentes faixas de potência configuram diferentes recursos.

Essa definição se justifica devido às especificidades que usinas de geração de uma mesma tecnologia podem possuir em função do seu porte e capacidade de geração. Tomando como exemplo a geração hidrelétrica: a concepção e operação de uma Pequena Central Hidrelétrica (PCH) e de uma Usina Hidrelétrica de grande porte (UHE) são completamente diferentes em diversos aspectos, tais como: área física necessária para instalação, tempo de construção, tempo de retorno de investimento, impactos sociais e ambientais e o impacto da energia gerada no SIN. Esse perfil tão discrepante entre duas usinas que partilham do mesmo princípio tecnológico e da mesma fonte ilustra como a diferenciação de recursos por faixas de potência se faz coerente.

Esse conceito é adotado nesse trabalho visto que a modelagem aqui tratada é visando o aproveitamento fotovoltaico com despacho centralizado.

Os recursos renováveis intermitentes com despacho centralizado, no contexto de conexão ao SIN, demandam uma operação mais dinâmica do sistema em função do perfil não despachável dessas fontes. Justamente em virtude desse perfil e do grande impacto que a inserção em escala desses recursos gera nos sistemas elétricos é importante o conhecimento do comportamento da fonte energética.

O aumento do uso de recursos renováveis é indiscutível e com perspectivas de amplo crescimento na matriz elétrica brasileira. $\mathrm{O}$ armazenamento da energia gerada por fontes intermitentes ainda se apresenta economicamente inviável para geração em escala, principalmente quando tratamos da conjuntura energética nacional.

Dentro das perspectivas da eficiência energética, do desenvolvimento sustentável, da segurança de abastecimento energético, da otimização da operação do sistema elétrico, tanto de geração, quanto de transmissão, é de extrema importância que o aproveitamento de um recurso energético - a partir do momento da instalação do mesmo - seja na sua totalidade. De

\footnotetext{
${ }^{4}$ A definição e explicação completa desse mecanismo de planejamento está disponível em UDAETA (2012)
} 
modo que o coeficiente da relação "energia gerada / disponibilidade do recurso" seja o maior possível.

Em qualquer enfoque dado à discussão do setor elétrico, tal premissa é benéfica e indiscutível. Nesse sentido, para que haja a otimização desse coeficiente, é imprescindível o conhecimento do comportamento da fonte de energia primária ao longo do espaço geográfico e do tempo. É nesse contexto que se define a importância da modelagem da energia primária dos recursos renováveis intermitentes.

A transmitância atmosférica é o principal fator na determinação da quantidade de radiação na superfície terrestre em um determinado momento. Contudo, a caracterização desta vai muito além da cobertura de nuvens no céu. A atmosfera é heterogênea e de difícil definição. Este perfil heterogêneo muda ao longo do tempo e do espaço, dificultando ainda mais a definição de um padrão de transmitância.

Adotando a perspectiva da necessidade de aprimorar o conhecimento nacional acerca de dados solarimétricos para fins energéticos, esse estudo percorreu um longo caminho de compreensão do estado de evolução do estudo solarimétrico, principalmente no contexto internacional. Nesse sentido, buscou-se, ao longo do processo de pesquisa, investigar, ao menos superficialmente - em função das limitações de tempo e necessidade de objetividade todos os assuntos inerentes à solarimetria, desde a formação das relações matemáticas que definem a incidência da radiação no topo da atmosfera, a história de desenvolvimento de radiômetros, normas e critérios de classificação desses equipamentos, os algoritmos de tratamento de dados de irradiância, até os processos de estimativa de irradiação. Esse trabalho busca reunir os elementos mais relevantes deste complexo conjunto de informações tão variadas, promovendo a análise sistêmica, de modo a oferecer uma visão completa dos elementos necessários à modelagem a partir de dados medidos em solo.

Ao longo de todo esse processo de investigação científica e de troca de informações, conceitos e reflexões com demais pesquisadores empenhados nesta ciência, a questão sobre a definição conceitual da modelagem da energia primária solar foi recorrente. Em diversos momentos desse processo perguntou-se: o que é modelagem de energia? O que é modelagem de energia primária? O que é modelagem da energia primária para geração fotovoltaica? $\mathrm{O}$ que é modelagem da energia primária para geração fotovoltaica em escala? Essas perguntas foram respondidas inúmeras vezes e, em algumas delas as respostas definidas foram alteradas, fazendo parte do processo da pesquisa, do amadurecimento do conhecimento científico, cuja contestação é inerente e obrigatória. 
Deste modo, definem-se os conceitos concebidos e/ou aprimorados e definidos nesse trabalho, que nada mais são do que as respostas às questões supracitadas. Não cabendo o conceito de 'definitivo', contudo essas são as melhores definições para esses conceitos que essa pesquisa poderia ter encontrado.

\subsection{CONCEITOS E DEFINIÇÕES}

'Modelagem da energia primária solar para geração fotovoltaica em escala por meio de medições em solo’.

Assumem-se por medições em solo, neste trabalho, os dados obtidos por medições de estações solarimétricas completas devidamente instaladas e operadas em posição determinada (latitude, longitude, altitude) da superfície terrestre. Isso significa que este estudo parte do princípio que esta modelagem só pode ser realizada a partir de dados medidos com qualidade e confiabilidade. O termo 'medição em solo' é uma adaptação do termo em inglês 'ground meassurements' comumente encontrada na bibliografia internacional acerca da solarimetria.

Estações solarimétricas completas correspondem ao conjunto de medidores de: (i) irradiância global horizontal, (ii) irradiância direta normal, (iii) irradiância difusa horizontal, (iv) precipitação, (v) umidade relativa, (vi) pressão atmosférica, (vii) temperatura ambiente e (viii) direção e velocidade do vento.

O estudo dessas medições - principalmente das irradiâncias- tem foco, nesta pesquisa, na geração fotovoltaica em escala. Ou seja, na geração centralizada, por meio de usinas no contexto de fornecimento de energia ao SIN.

Retomando o conceito adotado nesse trabalho de que o 'recurso' é o conjunto de uma 'fonte' energética associada a uma 'tecnologia' de geração de energia elétrica. Define-se que o 'recurso' escolhido são as usinas fotovoltaicas de despacho centralizado, de modo que a fonte definida é a energia primária solar, ou seja, a energia disponibilizada para a geração.

O estudo da energia primária é o processo de construção de conhecimento que antecede o entendimento do funcionamento dos fatores de eficiência dos painéis geradores e do efeito fotovoltaico.

Embora a 'fonte' possa ser tratada independente da 'tecnologia', nesse trabalho a abordagem adotada é a modelagem da 'fonte' para utilização de um determinado 'recurso'. Essa definição se faz necessária visto que a modelagem da energia solar para 'recursos' diferentes permite diferentes abordagens. Como exemplos, pode-se citar a geração fotovoltaica descentralizada ou a utilização de plantas heliotérmicas. 
A geração por placas fotovoltaicas para abastecimento residencial descentralizado não carece de uma modelagem detalhada do recurso, mas sim da estimativa de geração mensal ou, no máximo semanal. Já a operação centralizada, por grandes plantas, pode afetar a segurança do abastecimento energético a ser garantido pelo Operador Nacional do Sistema (ONS), sendo necessárias perspectivas do despacho de curto e curtíssimo prazo do recurso para a otimização da operação do SIN como um todo.

As usinas heliotérmicas, por outro lado, embora possuam perspectivas mais reais de despacho centralizado - e mais controlável por se tratar de outra tecnologia- implicam em outras necessidades específicas quanto à modelagem da 'fonte', já que, para esse recurso, o principal interesse de conhecimento é na parcela de irradiância direta, enquanto que, para a geração fotovoltaica, é de conhecimento técnico consolidado que a parcela de irradiância difusa também contribui para geração.

Feitas tais definições, é necessário explicitar a definição conceitual e metodológica de modelagem que está sendo utilizada nesse estudo. O longo caminho percorrido para o entendimento da solarimetria permitiu a compreensão da modelagem a partir de dados em solo, como o processo de construção de séries históricas somado ao conhecimento de eventos específicos do comportamento do recurso - originados por especificidades climatológicas, geográficas e atmosféricas. O domínio científico desses elementos permite a identificação da probabilidade de ocorrência de eventos específicos, permitindo, a previsão da disponibilidade futura de energia. O quadro da Figura 1 apresenta um fluxograma simplificado dessa definição conceitual de modelagem que norteia a metodologia adotada neste trabalho. 
Figura 1 - Definição conceitual da modelagem da energia primária solar

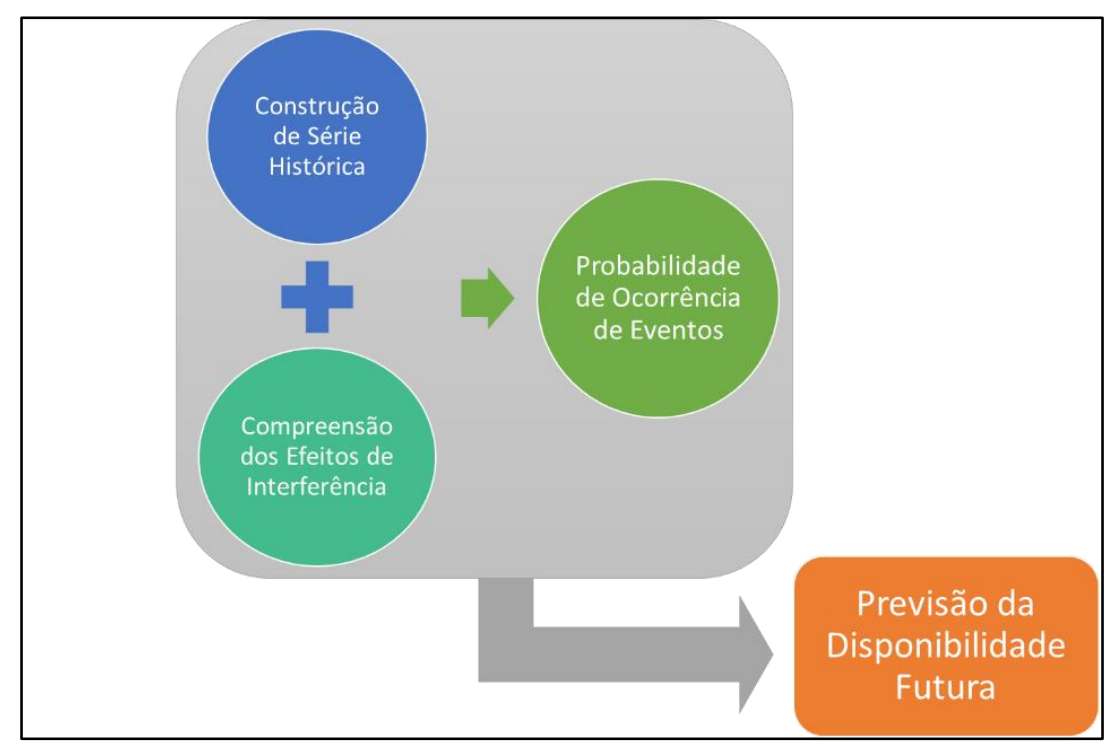

Fonte: Elaboração própria

A modelagem da energia primária é a construção do perfil de distribuição da fonte no tempo e no espaço geográfico. Os modelos de previsão de disponibilidade do recurso são categorizados em três principais vertentes: modelos físicos, modelos estatísticos e empíricos (WEBER, 2011). Os modelos físicos e empíricos são aqueles parametrizados por outras variáveis ou condições climáticas e atmosféricas, como temperatura ambiente, umidade relativa, nebulosidade, dentre outras, que possam nortear a previsão futura de disponibilidade de energia. Na seção 4.3 são detalhadas as diferenças entre os modelos físicos e empíricos. Os modelos estatísticos são aqueles que se utilizam do cômputo de eventos probabilísticos a partir da série histórica para a definição da probabilidade de energia futura. Os dois métodos podem ser utilizados para a previsão de disponibilidade do recurso para curto, médio e longo prazo.

Este estudo é guiado pelo entendimento da modelagem nessas duas vertentes que, embora tenham sido metodologicamente separadas, se misturam e se somam ao longo de todo o processo de entendimento da fonte. Assim, tomando ainda como base a Figura 1, o principal resultado esperado neste trabalho é o mapeamento e sistematização de todas as variáveis e aspectos que tornam viáveis a criação de modelos estatísticos ou físicos para previsão da disponibilidade do recurso, promovendo a criação do sistema de informações necessários ao desenvolvimento de modelos, ou seja, a caracterização e detalhamento dos elementos contornados pelo quadro cinza na Figura 1. Portanto é nos elementos presentes nesse quadro que se restringe os elementos de pesquisa determinados. 


\section{ASPECTOS FUNDAMENTAIS DA ANÁLISE DAS GRANDEZAS SOLARIMÉTRICAS}

Neste capítulo são abordados os principais elementos de estudo para a compreensão do funcionamento de uma estação solarimétrica, incluindo a classificação das mesmas e o mapeamento de grupos de trabalhos de relevância nacional e mundial envolvidos no tema, para tal, inicialmente são apontadas as definições referentes à radiação incidente na superfície terrestre.

\subsection{RADIAÇÃO SOLAR NA TERRA: DEFINIÇÕES}

O Sol é classificado como uma estrela de tamanho médio, cuja temperatura efetiva ${ }^{5}$ é de $5.505{ }^{\circ} \mathrm{C}$. Isso significa que o Sol possui uma radiação similar a um corpo negro aquecido a esta temperatura.

"O corpo negro é um corpo hipotético, que emite e absorve radiação em todos os comprimentos de onda de maneira isotrópica. (...) Toda a radiação incidente é absorvida e, em todos comprimentos de onda, é emitida a máxima radiação possível para a temperatura do corpo" (ROSA, 2003).

A Tabela 1 mostra as principais propriedades da estrela.

Tabela 1 - Propriedades da estrela solar

\begin{tabular}{ll}
\hline Propriedade & Valor \\
\hline Massa & $1,98 \times 10^{33} \mathrm{~g}(332.830$ vezes a da Terra $)$ \\
\hline Raio Equatorial & $6,96 \times 10^{10} \mathrm{~cm}(109$ vezes o da Terra $)$ \\
\hline Densidade Média & $1,41 \mathrm{~g} / \mathrm{cm}^{3}$ \\
\hline Densidade Central & $160 \mathrm{~g} / \mathrm{cm}^{3}$ \\
\hline Idade Aproximada & $4,5 \times 10^{9}$ anos \\
\hline Distância Média da Terra & $1,495 \times 10^{11} \mathrm{~m}( \pm 1,7 \%)$ \\
\hline Temperatura Central & $1,5 \times 10^{7} \mathrm{~K}$ \\
\hline Temperatura Efetiva (fotosfera) & $5.777 \mathrm{~K}$ \\
\hline Luminosidade & $3,827 \times 10^{33}$ ergs/seg \\
\hline Composição Química & Hidrogênio- $92,1 \%$ Hélio- $7,8 \%$. \\
& Oxigênio- $0,061 \%$. Carbono- $0,030 \%$. \\
& Nitrogênio- $0,0084 \%$. Néon- $0,0076 \%$. \\
& Ferro- $0,0037 \% . \quad$ Silício- $0,0031 \%$. \\
Magnésio- $0,0024 \%$. Enxofre- $0,0015 \%$. \\
Todos os restantes- $0,0015 \%$ \\
\hline
\end{tabular}

Fonte: ROSA, 2003

\footnotetext{
5 Temperatura calculada em função da temperatura de bulbo seco, temperatura de bulbo úmido (umidade relativa do ar) e velocidade do ar, ou seja, Temperatura de Sensação Térmica.
} 
A radiação solar é uma radiação eletromagnética que se propaga no vácuo, em todas as direções, composta por um conjunto de ondas com frequências e comprimentos diferentes que são resultantes da liberação de energia das reações químicas que ocorrem no Sol. Essa radiação corresponde a um fluxo de energia, medido em potência (normalmente em watts) por unidade de área (normalmente metro quadrado) que incide sobre um determinado corpo. A atividade solar é determinada pelos ciclos solares, que duram em média 11 anos. A definição dos ciclos é dada pela análise das manchas solares. As manchas solares são regiões nas quais o campo magnético é bastante forte. Nessas regiões a temperatura pode chegar até $4.000{ }^{\circ} \mathrm{C}$ (EUA, 2016). O ciclo solar é o período no qual se verifica o aumento da incidência das manchas solares e o posterior declínio da quantidade e intensidade das manchas. A irradiância extraterrestre varia em torno de $0,1 \%$ a $0,5 \%$ em função do aumento ou redução das atividades solares, ou seja, da quantidade e intensidade de fusões no Sol. (VIGNOLA et al., 2012).

Para que não haja problemas de interpretação dos conceitos tratados neste trabalho, é importante esclarecer as nomenclaturas utilizadas para a referência dos efeitos discutidos, assim, define-se, com base nos conceitos definidos em NBR 10899: Energia FotovoltaicaTerminologia (ABNT, 2013).

I. Radiação Solar: forma de transferência de energia advinda do Sol, através da propagação de ondas eletromagnéticas (ou fótons).

II. Irradiância Solar: taxa na qual a radiação solar incide em uma superfície, por unidade de área dessa superfície, normalmente medida em watt por metro quadrado $\left(\mathrm{W} / \mathrm{m}^{2}\right)$.

III. Irradiação Solar: irradiância solar integrada durante um intervalo de tempo especificado, normalmente uma hora ou um dia, medida em watt hora por metro quadrado $\left(\mathrm{Wh} / \mathrm{m}^{2}\right)$ ou Joule por metro quadrado $\left(\mathrm{J} / \mathrm{m}^{2}\right)$.

Contudo, diversos assuntos referência no assunto tratam de valores da radiação (em W $/ \mathrm{m}^{2}$ ), como valores de "irradiação". O termo também é utilizado na bibliografia pesquisada para referenciar o comportamento geral da disponibilidade de energia, mesmo quando não há especificação da unidade de medida utilizada, ou seja quando não está especificado se há integralização da energia ao longo do tempo ou não. Assim, esse trabalho buscou respeitar a nomenclatura utilizada pelas referências bibliográficas nas citações e, no conteúdo próprio, buscou adotar o padrão NBR supracitado. 


\subsubsection{Radiação Global, Direta e Difusa}

Ao passar pela atmosfera, a radiação é em parte absorvida e/ou espalhada em várias direções até a superfície terrestre. A parte da radiação que alcança a superfície terrestre sem sofrer interferências é chamada de radiação direta (ou radiação direta normal), o montante de radiação afetado pelos efeitos supracitados corresponde à radiação difusa (ou radiação difusa horizontal). A irradiância global horizontal que alcança a superfície (em $\left.\mathrm{W} / \mathrm{m}^{2}\right)$ é definida como a soma do fluxo de radiação dessas duas parcelas. A relação entre as irradiâncias pode ser definida como:

$$
I G H=I D N \times \cos \theta_{z}+I D H
$$

Onde IGH corresponde à irradiância global horizontal, IDN à irradiância direta normal e IDH à irradiância difusa horizontal, o fator $\cos \theta_{z}$ ao $\operatorname{cosseno~do~ângulo~zenital.~O~ângulo~}$ zenital é o formado entre a normal da superfície terrestre (zênite) e a posição do Sol no céu em um determinado momento de um determinado dia.

A correlação entre as parcelas de irradiância direta, difusa e global não é linear, baixos valores de irradiância difusa ocorrem quando a irradiância global está baixa, em dias de céu muito nublado, ou quando a irradiância global está alta, em dias de céu limpo. O gráfico da Figura 2 mostra a relação entre as variáveis.

Figura 2 - Correlação entre irradiância global, direta e difusa

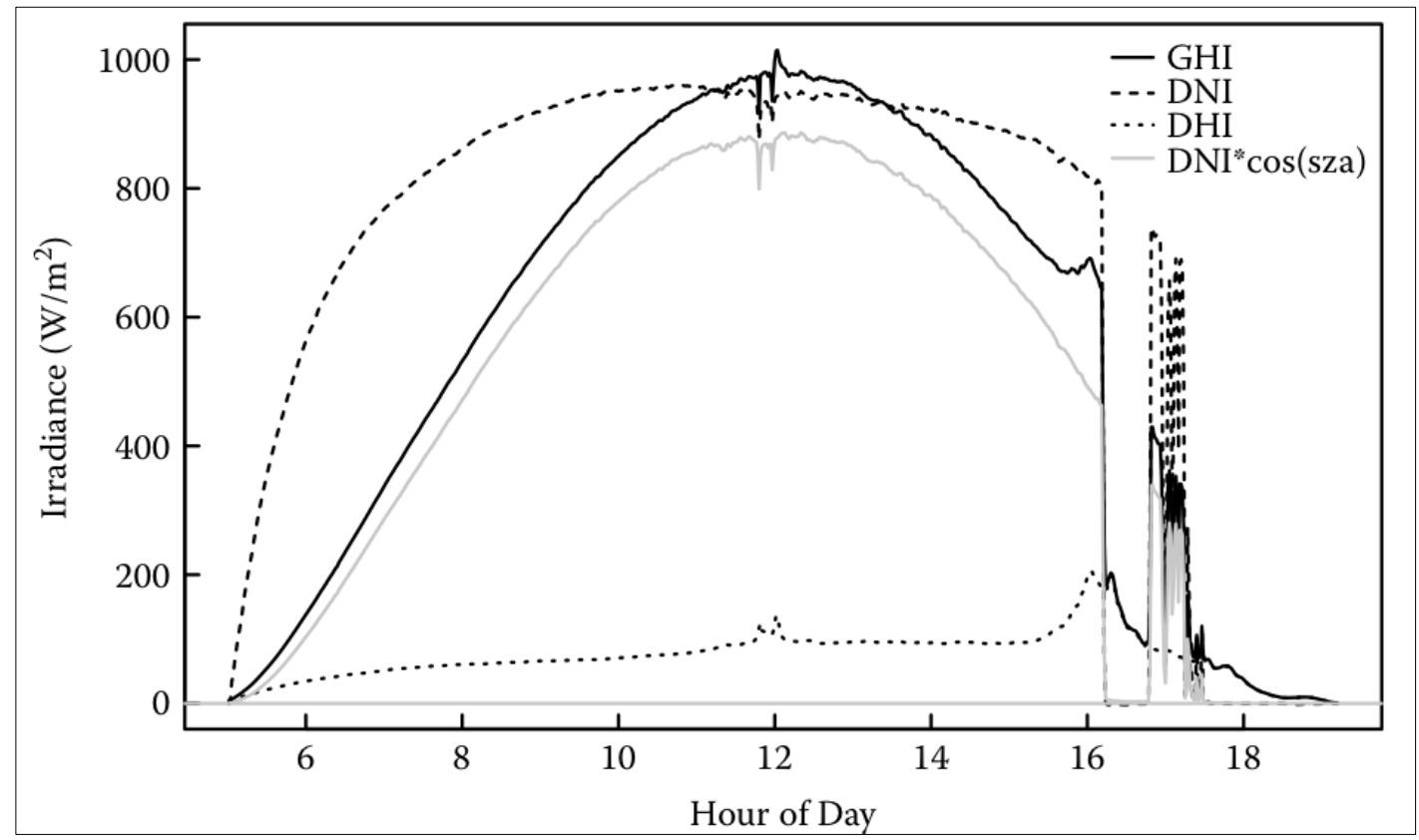

Fonte: VIGNOLA et. al., 2012 
A linha em cinza do gráfico representa a irradiância direta horizontal (DNI*cos(sza)), enquanto que a linha em pontilhado grosso representa a irradiância direta normal (IDN). No período entre 16:00 e 17:00 horas, nota-se que a irradiância global (GHI) é igual à irradiância difusa (DHI), momento no qual o Sol estava encoberto por nuvens, aumentando a fração de irradiância difusa ${ }^{6}$.

\subsubsection{Albedo}

Toda superfície reflete parte da radiação que incide sobre ela. No geral, o albedo é definido como o total da irradiância refletida dividido pelo total da irradiância incidida. Em teoria, o ângulo de reflexão do fluxo de radiação de uma superfície é igual ao ângulo de incidência. Como as superfícies não são perfeitamente lisas, essa relação não ocorre na prática. As superfícies refletem de maneira diferente diferentes comprimentos de onda. Cada material se comporta de uma maneira em relação às porções de radiação absorvidas e refletidas em função do perfil espectral da radiação incidente. Enquanto algumas superfícies refletem altos índices da radiação visível, como a neve, outras refletem principalmente a radiação infravermelha ou ultravioleta. A Figura 3 mostra como o albedo se altera em função do tempo e em função do comprimento de onda.

Figura 3 - Alteração do albedo em diferentes comprimentos de onda e dias do ano

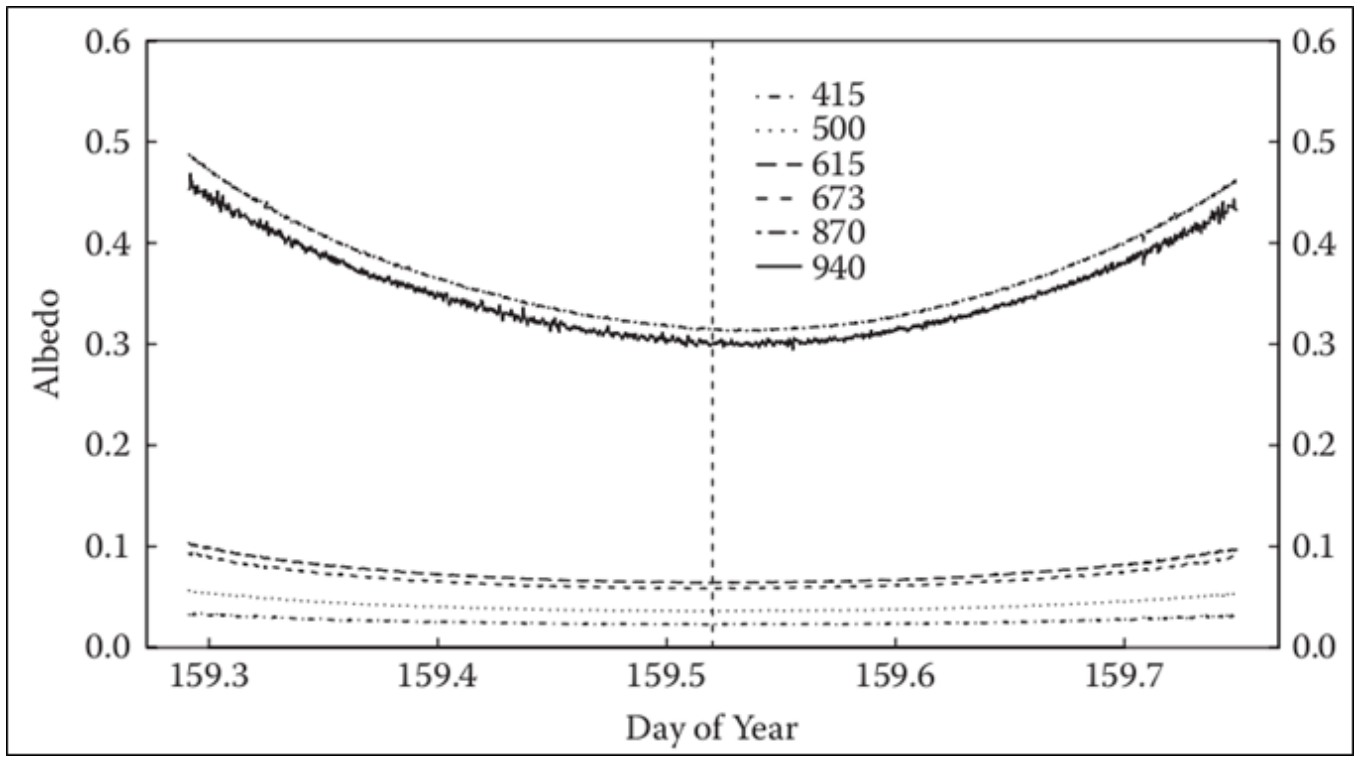

Fonte: VIGNOLA et. al., 2012

\footnotetext{
${ }^{6}$ No gráfico da Figura 2 a legenda está definida com as siglas, do inglês: GHI- global horizontal irradiance, DNI- direct normal irradiance e DHI- difuse horizontal irradiance.
} 
As medições do gráfico da Figura 3 foram realizadas no hemisfério norte. Os menores valores medidos para o albedo foram no dia 8 de junho, data na qual o Sol encontra-se com maior altura para o meio-dia, logo a radiação incide diretamente sobre as superfícies, diminuindo o efeito do albedo. Nota-se também a grande variação do albedo em função do comprimento de onda mostrado em $\mathrm{nm}$ na legenda no centro do gráfico. A superfície do local de medição compreende vegetação rasteira.

A maior parte dos aproveitamentos energéticos solares ocorre em superfícies inclinadas. Nestas, parte da radiação refletida pelo solo incide nas placas solares, de modo que o conhecimento dessa radiação permite o melhor entendimento da eficiência das tecnologias de geração de energia. Também é importante ressaltar que o albedo das superfícies próximas a equipamentos solares de medição ou geração de energia afeta a componente de radiação difusa e esta é a componente da radiação com maior grau de incertezas nas medições realizadas.

\subsubsection{PAR, NET e Onda Longa}

Além das definições já apresentadas para a radiação solar, existem outras classificações em função do objetivo de estudo. Para estudos acerca da agricultura é extremamente importante o conhecimento da radiação PAR (photosynthetically active radiation), essa nomenclatura refere-se à radiação entre 400 e $700 \mathrm{~nm}$ e indica a radiação fotossinteticamente ativa, ou seja, aquela usada pelas plantas para a realização da fotossíntese. O conhecimento da radiação PAR é de grande importância para pesquisas nas áreas biológicas, agronômicas e agrometeorológicas principalmente no que tange a relação entre a radiação e a taxa de crescimento vegetal e fotossintética, contudo, poucos sensores da radiação fotossinteticamente ativa estão disponíveis nos institutos de pesquisa ou mesmo em universidades. (FRISINA, et al., 2003).

Para o estudo das mudanças climáticas, é de grande importância o conhecimento da radiação NET ou o saldo de radiação, que corresponde à diferença entre a radiação que incide sobre um determinado espaço e a radiação emitida por ele. Esse saldo da radiação em $\mathrm{W} / \mathrm{m}^{2}$, ou seja, a irradiância correspondente, é a soma vetorial das irradiâncias global e atmosférica e da irradiância terrestre. Durante o dia, a irradiância NET costuma possuir valores positivos, enquanto que, durante a noite ela assume valores negativos visto que nesse período a radiação emitida é maior do que a atmosférica incidente. A radiação terrestre, também denominada como radiação de onda longa, ou radiação noturna, é a radiação emitida pela terra de volta à atmosfera. Da mesma maneira que a terra absorve a radiação proveniente do Sol, ela também 
absorve parte da radiação na faixa do infravermelho proveniente da atmosfera e das nuvens, denominada de radiação atmosférica. O conhecimento do saldo da radiação indica o conhecimento da energia disponível na superfície do planeta. Portanto, essas medições possuem relevância tanto nos estudos climatológicos, quanto nos estudos de agricultura e energia.

São pouquíssimos os sensores para medição de irradiâncias NET e PAR instalados ao redor do mundo, os valores de irradiância NET possuem nível de incerteza maior em virtude do alto número de fatores que influenciam na quantidade da radiação tanto incidida quanto refletida, como o albedo, a altura solar, o índice de nebulosidade, dentre outros. Embora esses fatores influenciem na medição de qualquer radiação, no caso da irradiância NET, por constituir uma somatória de irradiâncias, esses erros precisam ser contabilizados diversas vezes, elevando ao quadrado o nível de incerteza.

\subsection{MEDIÇÕES DA RADIAÇÃO}

Tecnologias para medições solarimétricas têm sido desenvolvidas ao longo dos últimos séculos. Tradicionalmente, a coleta de dados se restringia à medição da insolação. A insolação corresponde a quantidade, em horas por dia, que a irradiância permanece igual ou superior a um determinado valor. A recomendação da Organização Mundial de Meteorologia (WMO) é de que esse valor mínimo seja de $120 \mathrm{~W} / \mathrm{m}^{2}$.

Para o desenvolvimento de projetos energéticos, o conhecimento detalhado do comportamento da radiação é de extrema importância, assim como a formulação das séries históricas do recurso disponível. Contudo, o desenvolvimento das tecnologias de medições é relativamente recente, implicando na dificuldade de obtenção de séries históricas para a radiação solar.

O conhecimento sobre a radiação solar avançou rapidamente durante a segunda metade do século XIX, através do avanço científico em três diferentes frentes de trabalho: instrumentação, observação e teoria. Os maiores avanços acerca das tecnologias de medição ocorreram no século XX. (COULSON, 1975)

A seguir apresenta-se uma breve caracterização das tecnologias dos heliógrafos (medidores de insolação), piranógrafos (ou actinógrafos) e piranômetros (medidores da irradiância global ou difusa) e dos pireliômetros (medidores da irradiância direta). Os equipamentos solarimétricos são definidos como de alta/boa/moderada qualidade pela WMO (2012) ou como de padrão primário/secundário e primeira/segunda classe pela ISO 9060. 
Essas definições estão detalhadas ao longo deste capítulo e inevitavelmente foram atribuídas às descrições de alguns equipamentos citados nas próximas seções.

\subsubsection{Heliógrafos}

As medições de insolação são as mais encontradas no mundo no que tange as medições solarimétricas. Dentre as tecnologias desenvolvidas, a mais utilizada atualmente corresponde ao heliógrafo Campbell - Stokes.

O primeiro projeto deste equipamento, desenvolvido em 1853 por Campbell, utilizava uma esfera de vidro cheia de água como lente esférica para a concentração dos raios solares na superfície branca de uma cavidade de pedra. A parte interna da cavidade era gravada com linhas para representar as horas do dia e pintada com verniz ou tinta óleo. O calor dos raios concentrados derretia a pintura durante os períodos de incidência direta da radiação. Os períodos de radiação direta eram coletados diariamente, por meio do registro das marcas verificadas em função do derretimento da tinta. Posteriormente, a cavidade em pedra foi substituída por uma peça no mesmo formato em madeira e a esfera cheia de água foi trocada por uma esfera sólida de vidro.

A Figura 4 mostra cavidade em madeira com os registros resultantes da concentração dos raios no heliógrafo desenvolvido por Campbell.

Figura 4 - Heliógrafo de Campbell

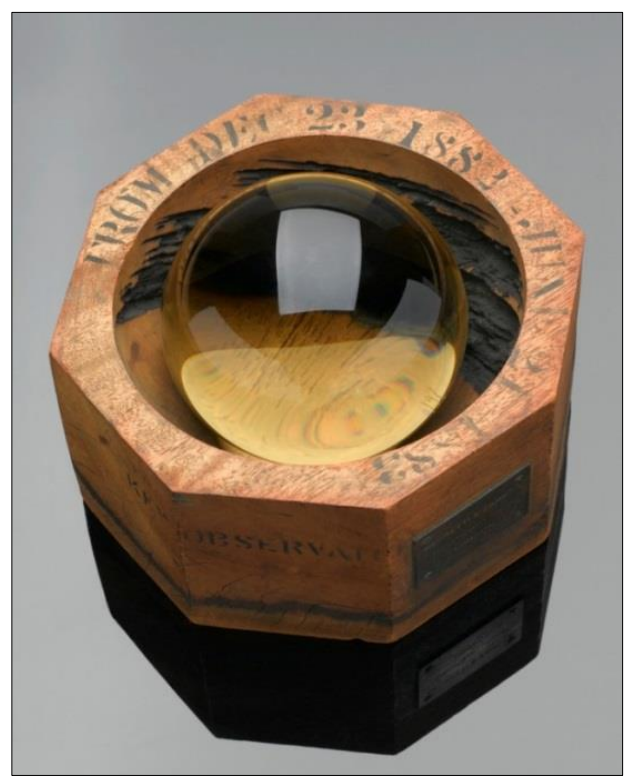

Fonte: SCIENCE MUSEUM GROUP, 2014 
As modificações significativas deste sistema foram aplicadas por Stokes em 1879, resultando basicamente no modelo utilizado atualmente. A esfera utilizada atualmente é de vidro ou quartzo e, no lugar da peça de pedra ou madeira, são utilizadas faixas de papel com precisas marcações das horas e minutos. As faixas são fixadas em estrutura metálica como mostra a Figura 5. As faixas são queimadas conforme a radiação direta incide sobre a esfera com intensidade igual ou maior que $120 \mathrm{~W} / \mathrm{m}^{2}$. O registro obtido (heliograma) é uma medida do tempo durante o qual houve incidência de raios solares diretos. A aparente simplicidade do método resultou na realização de numerosos trabalhos que tentam avaliar a irradiação solar por meio dos heliogramas (CEBALLOS et al., 1992), parte desses trabalhos é apresentada no Capítulo 4.

Figura 5 - Heliógrafo Campbell-Stokes

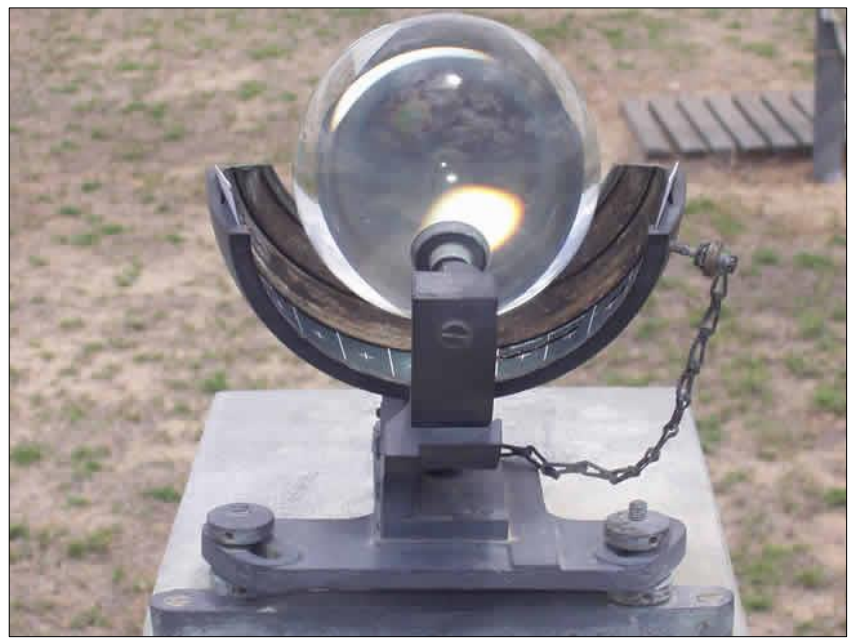

Fonte: AUSTRÁLIA, 2014

\subsubsection{Piranômetros}

A irradiância global é medida por radiômetros denominados piranômetros que possuem sensores termoelétricos, termomecânicos ou fotovoltaicos. Os piranômetros com sensores termomecânicos são denominados actinógrafos ou piranógrafos.

Atualmente os piranômetros mais utilizados possuem sensores baseados no princípio da termopilha ou do efeito fotovoltaico.

Os piranômetros termoelétricos utilizam basicamente dois tipos de detectores: (i) black-and-white: o receptor possui superfícies brancas e pretas dispostas alternativamente em formato anelar ou quadriculado, nestes instrumentos, as juntas quentes das termopilhas estão em contato com as superfícies negras e as frias em contato com as superfícies brancas; e (ii) 
receptores com a superfície totalmente enegrecida: a superfície fica em contato com as juntas quentes e frias em associação a um bloco de metal com grande condutividade térmica, protegidas da radiação, com aproximadamente a temperatura ambiente.

A resposta desses equipamentos é altamente dependente da inclinação dos mesmos ou da posição zenital, isso ocorre porque a incidência dos raios diretos do Sol na superfície branca ou preta altera o nível de aquecimento das superfícies, alterando o valor medido. Essa dependência pode ser reduzida utilizando disposições dos sensores brancos e pretos alternadas com superfícies de cada cor menores, ou acoplando o equipamento a um rastreador de modo que a mesma superfície esteja constantemente recebendo a irradiância direta. Por esses fatores, não é recomendada a utilização deste equipamento para medições em superfícies inclinadas visto que, conforme a inclinação aumenta, a responsividade do equipamento diminui. A Figura 6 mostra o piranômetro Eppley 8-48.

Figura 6 - Piranômetro do tipo black-and-white

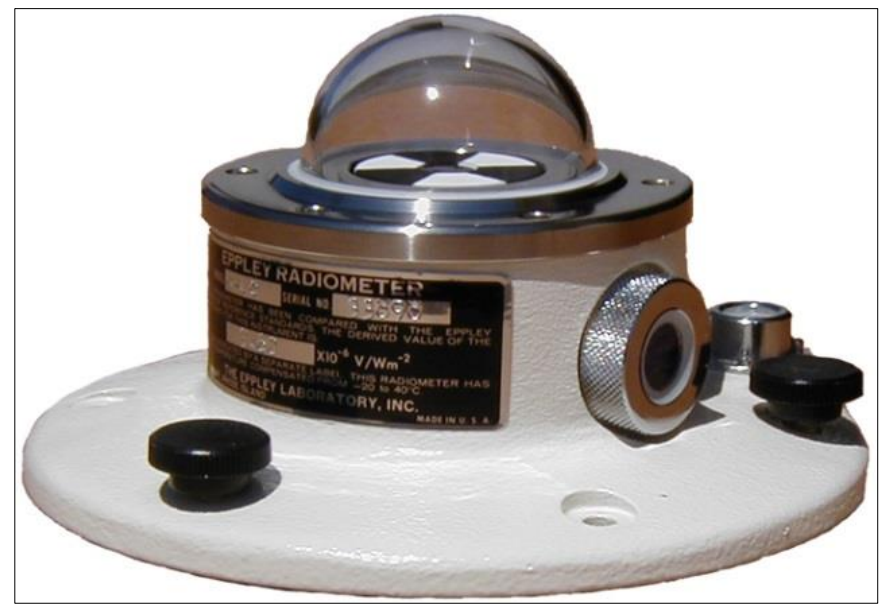

Fonte: EPPLEY, 2014

Os piranômetros de receptor totalmente enegrecido produzem uma tensão em função da diferença de temperatura entre as juntas quentes e frias, portanto, para medições ideais, a única troca de calor deve acontecer entre o disco enegrecido e o corpo do equipamento. Para evitar a perda de calor por outros processos, muitos piranômetros utilizam duas cúpulas de vidro e possuem a junta quente isolada para evitar a passagem de calor aos demais componentes e estruturas do aparelho. Esses equipamentos também possuem problemas com a não linearidade de respostas conforme a intensidade da irradiância, possuindo melhores respostas para irradiâncias mais altas. Isso ocorre em função das perdas térmicas, quando estas ocorrem com uma irradiância alta, a percentagem de perda é pequena, já com 
irradiâncias mais baixas, a mesma perda térmica representa uma percentagem muito maior do montante de irradiância incidente. A Figura 7 mostra o piranômetro de modelo CM 4 da Kipp \& Zonen.

Figura 7 - Piranômetro com sensor enegrecido

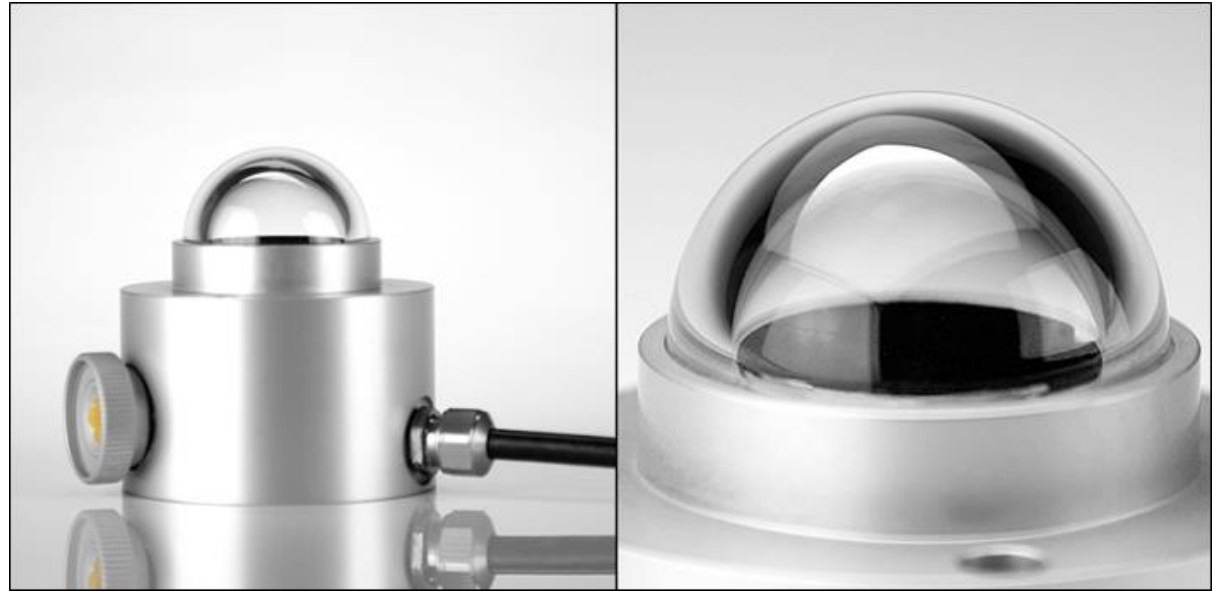

Fonte: KIPP \& ZONEN, 2014

Os piranômetros termoelétricos, no geral têm boa precisão, na faixa de 2 a $5 \%$ nas medições totais diárias considerando a instalação, manutenção e calibração corretas. (WMO, 2012).

O piranômetros fotovoltaicos utilizam o princípio das células fotovoltaicas para a construção de fotodiodos de modo a medir o fluxo de radiação incidente. Esses equipamentos possuem uma resposta rápida às alterações de irradiância, contudo a sua resposta espectral é seletiva, e as medições possuem forte dependência da temperatura, o que os coloca como equipamentos de segunda classe. O piranômetros fotovoltaicos possuem um custo mais baixo do que os demais equipamentos, esse fator tem sido o principal incentivo para o desenvolvimento destes equipamentos. A Figura 8 mostra o piranômetro fotovoltaico LICOR, modelo LI-200. 
Figura 8 - Piranômetro fotovoltaico

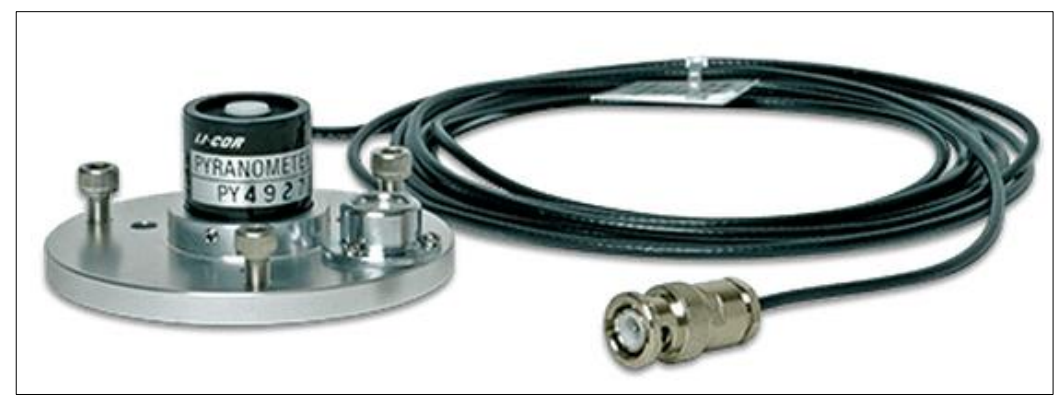

Fonte: LI-COR, 2014

O principal problema de medições desse tipo de piranômetro se relaciona à seletividade espectral, isso ocorre em função das características do efeito fotovoltaico que constitui o principal elemento do sensor desses piranômetros, e que, portanto, é incorrigível. A energia de um fóton só é utilizada para a movimentação de um elétron, quebrando a camada de valência. Se o fóton possuir mais energia do que a necessária para a movimentação do elétron, o restante da energia transforma-se em calor. Quanto menor o comprimento da onda da luz, mais energia o fóton possui. A corrente produzida pelo efeito fotovoltaico não aumenta proporcionalmente conforme a energia dos fótons incidentes é maior. Estas características definem uma boa resposta ao piranômetros fotovoltaicos para ondas de comprimento entre 450 e $900 \mathrm{~nm}$ (VIGNOLA et. al., 2012).

Os piranômetros também são utilizados para a medição da irradiância difusa. O principal desafio para esta medição consiste em conseguir adaptar um mecanismo no qual, o sensor receba apenas a radiação refletida sem estar exposto à radiação direta. Para isso, utiliza-se um piranômetro convencional com uma estrutura de sombreamento que normalmente são: banda de sombreamento em forma de aro ou semiaro, esfera de sombreamento ou disco de sombreamento. As bandas de sombreamento tradicionalmente são posicionadas fixamente ao piranômetro o que gera altas incertezas nas medições obtidas. Outro sistema mais eficiente da medição da irradiância difusa consiste no acoplamento de um disco de sombreamento a um mecanismo de rotação ou a utilização de uma esfera de sombreamento. A Figura 9 mostra o esquema do posicionamento de banda fixa de sombreamento. 
Figura 9 - Esquema de um piranômetro com banda de sombreamento

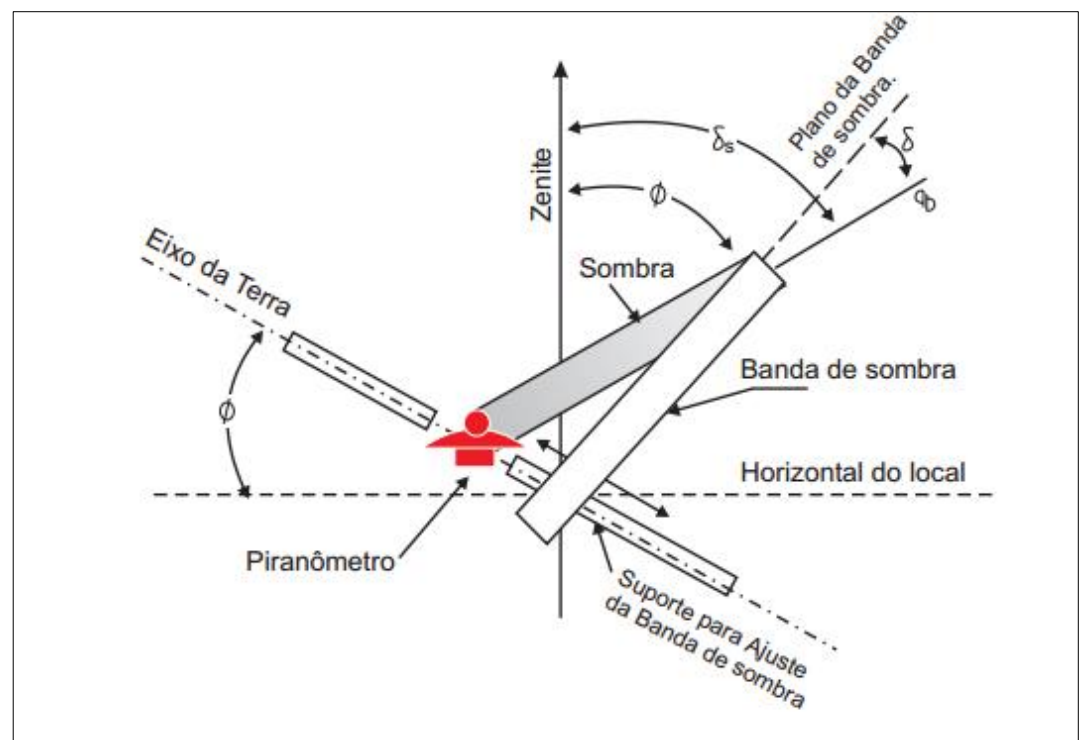

Fonte: TIBA et al., 2000

A utilização da banda de sombreamento evita que a radiação direta incida sobre o sensor do piranômetro, contudo, ela também bloqueia parte da radiação difusa que deveria incidir no equipamento. Esse mecanismo precisa ser ajustado conforme a mudança da declinação solar, esse ajuste deve ser mais frequente nos equinócios, quando a declinação do Sol muda mais rapidamente. A banda de sombreamento deve ficar ajustada de modo que o detector do piranômetro fique dentre de um ângulo de $1,5^{\circ}$ do centro da sombra projetada pela radiação direta, como mostrado na Figura 10.

Figura 10 - Piranômetro com banda de sombreamento fixa

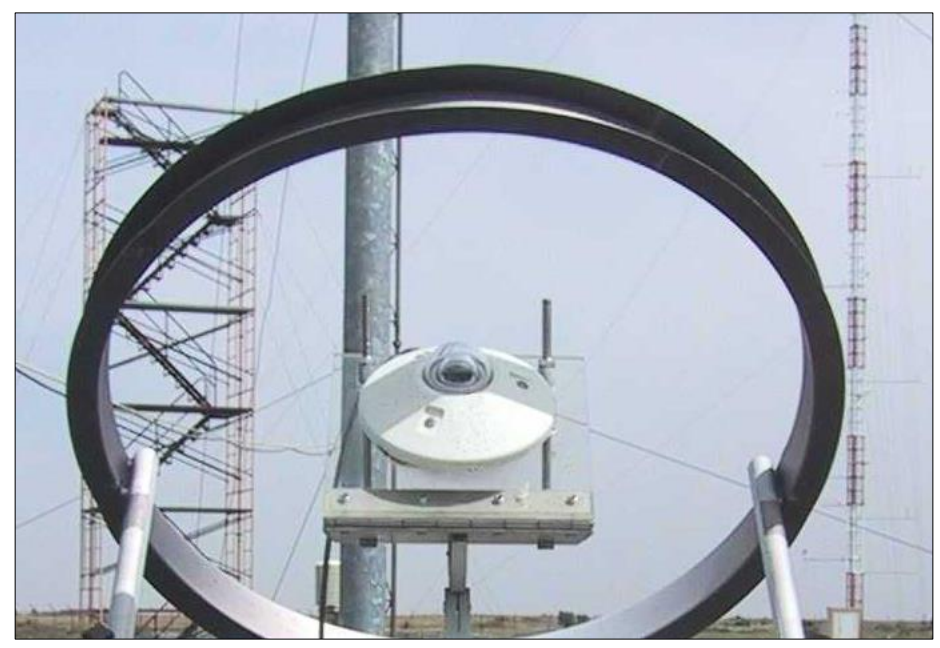

Fonte: CIBA, 2014 
A banda de sombreamento fixa pode bloquear até $20 \%$ da radiação difusa, por esse motivo é necessária a aplicação de fatores de correção nas medições obtidas (VIGNOLA et. al., 2012). O grande problema dos fatores de correção consiste nos seus baixos níveis de confiabilidade visto que a radiação difusa não se mantém uniforme, a sua quantidade varia em função das condições atmosféricas e da altura solar. O principal método para a obtenção de fatores de correção consiste em equacionar as medições obtidas das irradiâncias direta e global, contudo, a relação entre essas componentes não é linear. Um fator de correção obtido para determinadas condições não poderá ser aproveitado em configurações climáticas e geográficas diferentes com um nível aceitável de confiabilidade.

O sistema de sombreamento rotativo (ou disco de sombra) permite que medidas sejam feitas em intervalos muito pequenos alternando momentos em que o receptor está coberto e em momentos que ele está exposto, essas medições, através de uma metodologia de cálculo, fornece o fator de correção que deve ser utilizado para a obtenção das medições de irradiância difusa, irradiância global e, por aproximação, estimativas da irradiância direta. Uma configuração típica desse mecanismo é apresentada na Figura 11.

Figura 11 - Piranômetro com sistema de sombreamento rotativo

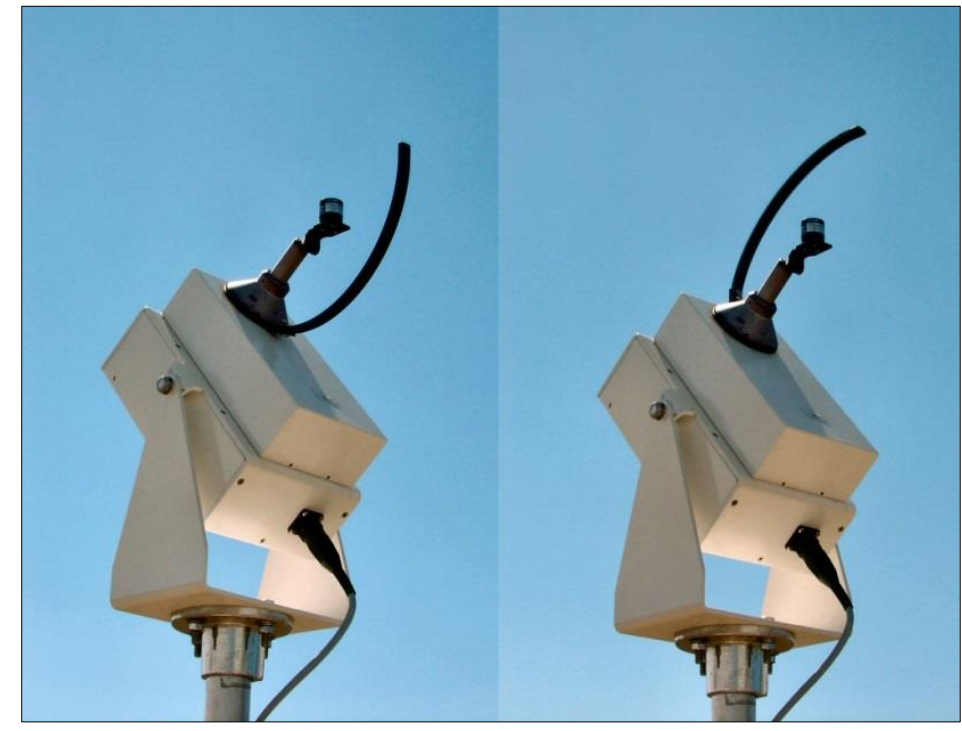

Fonte: VOLKER-QUASCHNIN, 2014

Muitos dos equipamentos utilizados com o sistema de sombreamento rotativo possuem sensores fotovoltaicos, o principal problema desses sensores é a sua seletividade espectral, dentre os piranômetros termoelétricos, os que possuem sensores do tipo black-and-white são 
mais indicados para a medição da irradiância difusa visto que as suas perdas térmicas são menores em comparação aos piranômetros com sensores totalmente enegrecidos.

O mecanismo que tem sido amplamente utilizado nos novos equipamentos consiste em um piranômetro acoplado à um rastreador solar no qual é fixada uma esfera de sombreamento como mostrado na Figura 12.

Figura 12 - Piranômetro com esfera de sombreamento

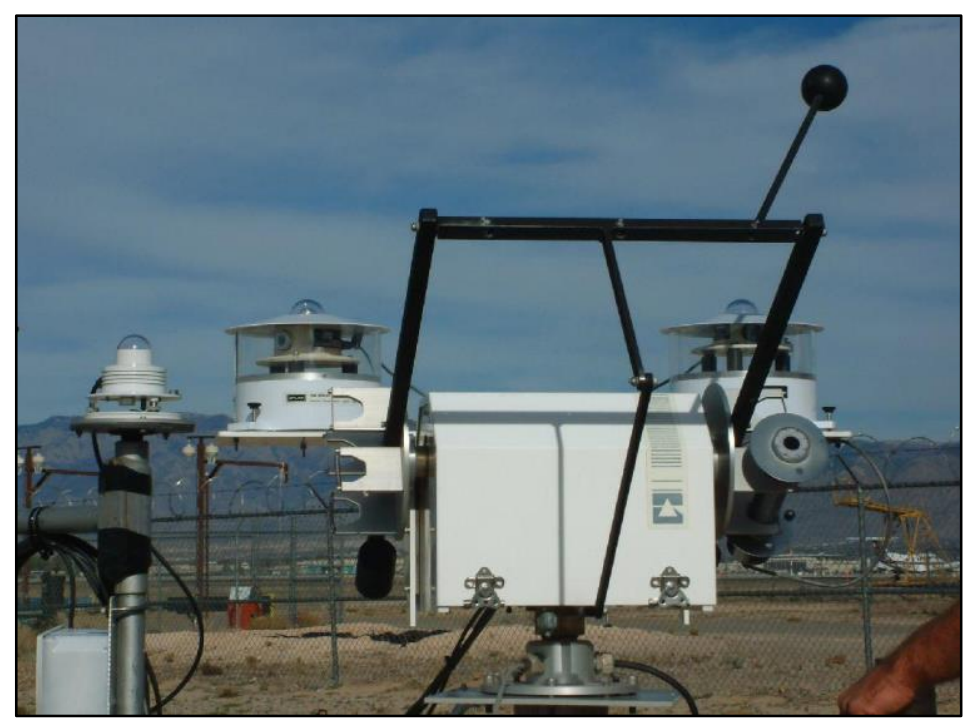

Fonte: EUA, 2015

Por meio de um dispositivo de GPS o rastreador solar move-se conforme a trajetória do sol no céu, de modo que a esfera permaneça sombreando o sensor ao longo do dia. A vantagem desse sistema é que a esfera de sombreamento, por possuir área menor do que o disco fixo, permite menores erros no processo de medição. A desvantagem é operacional visto que há necessidade de monitoramento constante da calibração do rastreador solar para que não haja imprecisão no sombreamento.

\subsubsection{Pireliômetros}

Pireliômetros são os equipamentos utilizados para a medição da irradiância direta. O mecanismo básico de funcionamento de um pireliômetro corresponde à capacidade de receber apenas a radiação direta provinda do Sol. Para tal, o equipamento possui um pequeno orifício para a incidência dos raios solares e deve ser acoplado a um dispositivo de rastreamento, de modo que este orifício permaneça disposto perpendicularmente à incidência da radiação direta. 
O princípio operacional desses equipamentos é baseado na termopilha, operando de forma basicamente igual aos piranômetros termoelétricos. O principal erro de medições origina-se na dificuldade de adequação do rastreamento do Sol e da abertura angular do receptor. Se operados de maneira satisfatória, os pireliômetros possuem erros de medição em torno de $0,5 \%$, sendo considerados equipamentos de alta precisão.

O desenvolvimento dos pireliômetros iniciou-se no século XIX, a grande motivação para o desenvolvimento deste tipo de equipamento foi a definição da constante de irradiância solar e as suas variações em função do tempo. (COULSON, 1975). O primeiro equipamento a alcançar medidas satisfatórias foi o pireliômetro de Poulliet, desenvolvido em 1837. O equipamento determinou a constante em $1227 \mathrm{Wm}^{-2}$ (VIGNOLA et. al., 2012), hoje definida em $1367 \mathrm{Wm}^{-2}$ pela NASA.

Os dois equipamentos mais utilizados atualmente, o pireliômetro NIP da Eppley e o pireliômetro Kipp \& Zonen (atualmente disponível nos modelos SHP1 e CHP1) funcionam a base de termopares. O NIP possui uma termopilha com oito juntas de Cobre-Constantan com compensador de temperatura e está apresentado na Figura 13.

Figura 13 - Pireliômetro NIP

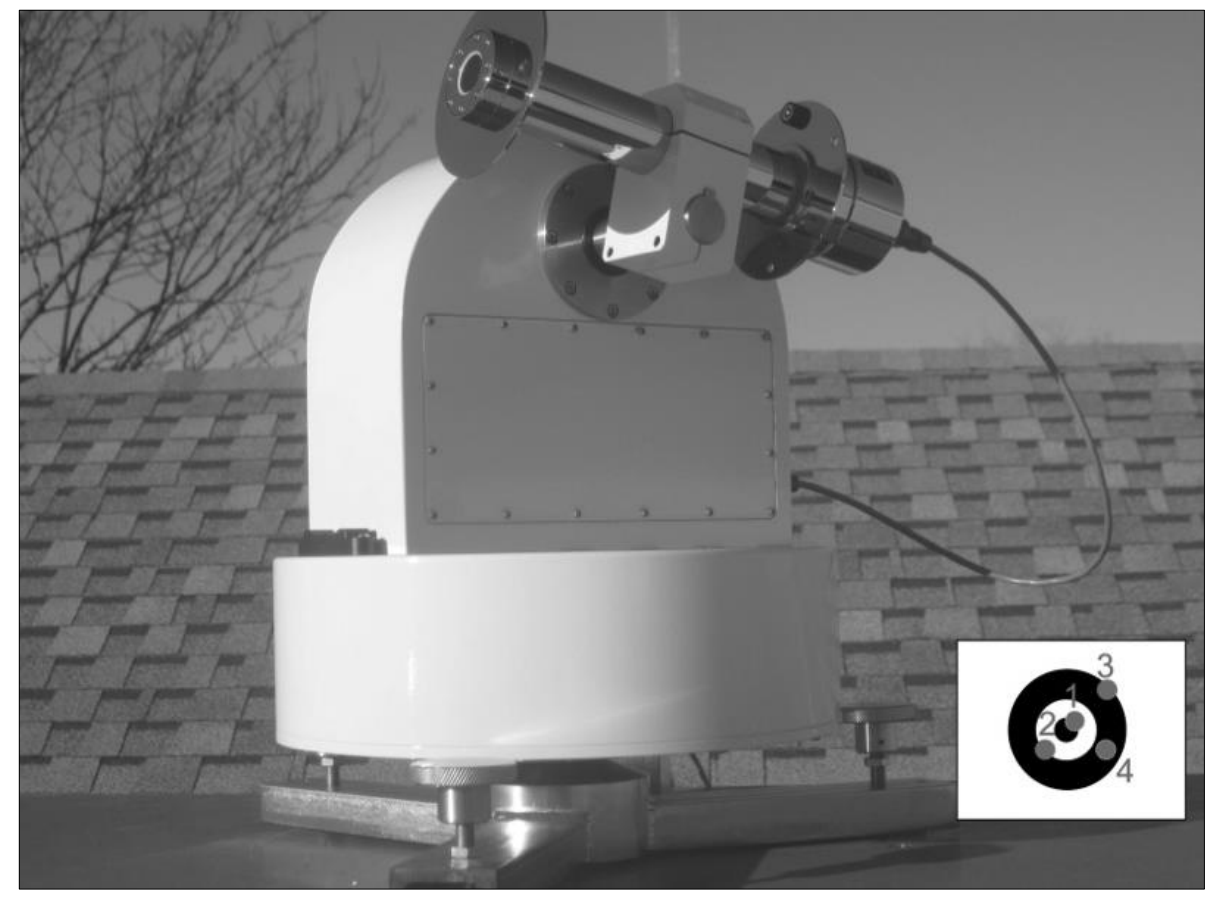

Fonte: VIGNOLA et. al., 2012

Nota:

Os pontos 1,2 e 4 mostrados no detalhe indicam as posições admissíveis para a focalização do Sol no equipamento. 
Os pireliômetros SHP1 e CHP2 possuem uma termopilha com quarenta juntas de Manganina-Constanta distribuídas em dois grupos com 20 juntas cada um, nos quais um fica protegido da radiação. Como estes equipamentos não possuem um compensador de temperatura, eles possuem um termômetro. Sabendo-se as variações de temperatura é possível aplicar um fator de correção nos valores medidos. Esses equipamentos são considerados de primeira classe, enquanto o modelo Eppley é classificado como de segunda classe.

Nas estações solarimétricas com medidores de irradiância difusa com esfera de sombreamento, a estrutura de rastreador solar é utilizada tanto para a fixação da esfera, quanto para a fixação do pireliômetro, utilizando uma mesma estrutura e o mesmo sistema de GPS para a movimentação dos dois instrumentos.

\subsection{MEDIÇÕES DE VARIÁVEIS CLIMATOLÓGICAS}

A medição das variáveis climatológicas é essencial para diversos fins como: estudos de mudanças climáticas, agricultura, aproveitamentos energéticos, dentre outros. No caso específico dos aproveitamentos energéticos, essas variáveis são de interesse em três frentes de estudos primordiais ao desenvolvimento de plantas solares:

I. Estudo do comportamento da irradiância incidente: compreendendo-se as alterações do comportamento da radiação em função das características climáticas é possível definir a previsibilidade da irradiância incidente, aprimorando as previsões de energia disponível.

II. Estudo das incertezas de equipamentos solarimétricos: as variações climáticas alteram o padrão de resposta de equipamentos radiométricos. Para que o primeiro item possa ser viabilizado é necessário que o fluxo de radiação solar seja medido por equipamentos bem calibrados, confiáveis e com um padrão de incerteza bem definido.

III. Estudo da eficiência de plantas solares: para garantir a confiabilidade e atratividade de plantas solares também é necessário a identificação dos fatores externos que influenciam na eficiência das mesmas.

Nesse sentido, nota-se que o comportamento da radiação e os aproveitamentos energéticos solares estão totalmente relacionados com as variáveis climatológicas, o que as tornam elementos de estudo tão importantes quanto à própria radiação.

Assim, os equipamentos que compõe uma ES completa de alta precisão, além dos radiômetros para medição da radiação são: um sensor de umidade; um barômetro; um 
termômetro; um pluviômetro; um anemômetro e um anemoscópio. Dentre esses equipamentos, nenhum deles faz qualquer tipo de registro sobre a nebulosidade.

A nebulosidade é a variável atmosférica com o maior nível de incerteza e subjetividade na obtenção de dados. Não existem metodologias definidas para a mensuração da altura do topo da nebulosidade e a principal metodologia para a definição da quantidade de nuvens consiste no processo de observação do céu por profissionais treinados. Esses profissionais analisam imagens fotográficas do céu ou fazem a observação direta, ECHER, et al. (2006) apresentam em detalhes as metodologias de definição de nebulosidade, enquanto DIAS e DUARTE (2002) apresentam uma metodologia de definições do índice de nebulosidade a partir de modelos matemáticos que relacionam dados de irradiância medidos com a porcentagem do céu coberta.

Quanto à necessidade de medições de ventos em uma ES, ela se justifica pelo fato de que a incerteza das medições é afetada pelo vento, se as devidas precauções não são tomadas. A compensação de temperatura inadequada do transdutor pode afetar a incerteza das medições. $\mathrm{O}$ vento afeta as medições de precipitação, tanto a quantidade média diária, quanto a intensidade de precipitação. As rajadas de vento afetam a incidência da precipitação nos coletores (VIGNOLA et al., 2012)

Além disso, o registro de velocidade e direção de ventos oferece uma perspectiva completa de análise das condições climatológicas do local, favorecendo o entendimento das condições climáticas totais em casos de eventos raros, por exemplo. Assim, a análise de dados de vento favorece a segurança na análise da coerência dos demais dados climatológicos. Essas medições contribuem para a caracterização do perfil climático e podem ser utilizadas como indicativo de eventos futuros, em curto prazo, por exemplo, o aumento de ventos em conjunto com queda de pressão atmosférica pode indicar perspectivas de precipitação e consequentemente queda da disponibilidade do recurso solar nas próximas horas.

A medição das variáveis meteorológicas possui um histórico de desenvolvimento tecnológico mais antigo e consolidado do que as medições radiométricas. A quantidade de estações meteorológicas encontradas ao redor do mundo é muito maior do que os medidores de radiação, isso permite que tais variáveis possuam históricos de medição mais definidos, permitindo uma melhor parametrização de incertezas e relações de influências entre as variáveis. Essas determinações ainda se encontram aquém quando se trata de medições radiométricas. 


\subsection{CLASSIFICAÇÃO $\quad$ E PADRONIZAÇÃO DE ESTAÇÕES SOLARIMÉTRICAS}

Atualmente quatro principais entidades possuem papéis relevantes no que tange os estudos de radiação e equipamentos radiométricos e climatológicos: ISO, WMO, BSRN e NREL. Os dois primeiros destacam-se pela contribuição acerca da padronização e classificação de equipamentos - constituindo os critérios técnicos e a fundamentação teórica necessária para tal, enquanto os dois últimos se destacam pela publicação de estudos acerca da radiação e métodos para tratamento e análise de dados.

A Organização Internacional de Padronização (ISO) é responsável por importantes publicações quanto à padronização de instrumentos e medições radiométricas, dentre os documentos já publicados, destaca-se a ISO 9060, publicada em 1990 que trata da especificação e classificação de equipamentos para a radiação direta e global para fins de projetos energéticos.

A Organização Mundial de Meteorologia (WMO) é o principal órgão de referência internacional em dados climatológicos. Em 2012, a WMO publicou a edição atualizada em 2010 do Guia de Referência de Equipamentos Meteorológicos e Métodos de Observação (WMO, 2012), sendo este, o principal e mais completo documento sobre padronização de medições radiométricas e meteorológicas.

A Rede BSRN (Baseline Surface Radiation Network) é um projeto do Painel de Radiação do Experimento de Energia Global e Ciclo da Água (GEWEX), vinculado ao Centro Mundial de Monitoramento de Radiação (WRMC). O projeto é destinado a identificar importantes alterações no campo de radiação da Terra a partir da superfície de modo a relacioná-las às alterações climáticas.

O NREL (Laboratório Nacional de Energias Renováveis) é uma instituição governamental norte-americana que desenvolve pesquisas em relação às fontes alternativas de energia, oferecendo uma série de ferramentas de estimativa de radiação, registros de estações solarimétricas e de dados solarimétricos dos Estados Unidos e de outras regiões do mundo.

O NREL também oferece uma série de publicações de estudos acerca de dados radiométricos.

Já em relação à calibração dos instrumentos radiométricos, a responsabilidade é dos centros regionais, nacionais e mundiais de calibração. O Centro de Radiação Mundial (WRC) é responsável por manter a referência básica e o Grupo de Padronização Mundial (WSG) de instrumentos é responsável por estabelecer a Referência Mundial Radiométrica (WRR). 
Durante as comparações internacionais, organizadas a cada cinco anos, os padrões dos centros regionais são comparados com o WSG, e seus fatores de calibração são ajustados para a WRR. (WMO, 2012). O Centro de Radiação Mundial mantém os pireliômetros de padrão primário. A partir desses, os modelos de radiômetros são comparados e enquadrados nas classificações de padrão secundário, primeira classe e segunda classe, definidas pela ISO, e nas classificações de alta, boa e moderada qualidade definidas pela WMO.

No Brasil, o único documento oficial encontrado que fornece as diretrizes de obtenção e classificação de uma ES é o Documento que acompanha o Ofício Circular n 0004/2012SPE/ANEEL, de 16/08/2012. Assunto: Estação solarimétrica e equipamento de medição associados à Chamada de Projeto de P\&D Estratégico No 013/2011 (BRASIL, 2012). Este documento define a ES em duas categorias, conforme mostrado no Quadro 1.

Quadro 1 - Classificação de estações solarimétricas no Brasil

\begin{tabular}{|c|c|c|}
\hline Medição & $\begin{array}{l}\text { Configuração A } \\
\text { Alta Precisão }\end{array}$ & $\begin{array}{l}\text { Configuração B } \\
\text { Geral }\end{array}$ \\
\hline \multirow[t]{2}{*}{ Solar } & $\begin{array}{l}\text { Uma estrutura provida com o } \\
\text { sistema de rastreamento de dois } \\
\text { eixos, controlado por sensores } \\
\text { solares; } \\
\text { Um piranômetro livre para } \\
\text { medição de irradiação global; }\end{array}$ & Estrutura firme fixa; \\
\hline & $\begin{array}{l}\text { Um piranômetro sombreado para } \\
\text { medição de irradiação difusa; } \\
\text { Um pireliômetro posicionado ao } \\
\text { sol pelo sistema de } \\
\text { sombreamento. }\end{array}$ & $\begin{array}{l}\text { Dois medidores tipo "Piranômetro } \\
\text { com Banda de Sombra", ou: } \\
\text { Um piranômetro livre para medição de } \\
\text { irradiação global e; } \\
\text { Um piranômetro sombreado para } \\
\text { medição de irradiação difusa; }\end{array}$ \\
\hline \multirow[t]{5}{*}{ Climática } & \multicolumn{2}{|l|}{ Um medidor de umidade do ar; } \\
\hline & \multicolumn{2}{|l|}{ Um medidor de pressão barométrica; } \\
\hline & \multicolumn{2}{|l|}{ Um termômetro; } \\
\hline & \multicolumn{2}{|l|}{ Um pluviômetro; } \\
\hline & \multicolumn{2}{|c|}{$\begin{array}{l}\text { Um anemômetro de concha a } 10 \mathrm{~m} \text { do solo e; } \\
\text { Um medidor de direção dos ventos (Anemoscópio) a } 8,5 \mathrm{~m} \text { do solo; } \\
\text { Ou } \\
\text { Um anemômetro ultrassônico a } 10 \mathrm{~m} \text { acima do solo, com características } \\
\text { iguais ou melhores ao conjunto anemômetro de concha e Anemoscópio. }\end{array}$} \\
\hline $\begin{array}{l}\text { Comunicação } \\
\text { e registro de } \\
\text { dados }\end{array}$ & \multicolumn{2}{|c|}{$\begin{array}{l}\text { Um sistema de comunicação } \\
\text { Um registrador de medições (Datalogger), com um mês de autonomia de } \\
\text { armazenamento de dados. }\end{array}$} \\
\hline
\end{tabular}

Fonte: adaptado de BRASIL, 2012 
O documento também especifica o nível de precisão dos radiômetros, conforme os critérios da ISO 9060. O Quadro 2 mostra as especificações do documento da ANEEL para as estações de configuração A, que são as consideradas nesse estudo.

Quadro 2 - Precisão mínima dos radiômetros para estação de alta precisão

\begin{tabular}{|l|l|l|l|l|}
\hline Instrumentos & Grandeza Medida & $\begin{array}{l}\text { Precisão } \\
\text { Mínima }\end{array}$ & $\begin{array}{l}\text { Intervalo } \\
\text { de Limpeza }\end{array}$ & $\begin{array}{l}\text { Intervalo } \\
\text { Máximo de } \\
\text { Calibração }\end{array}$ \\
\hline Piranômetro & Irradiação global & First Class & Diário & Anual \\
\hline $\begin{array}{l}\text { Piranômetro com } \\
\text { Sombreamento }\end{array}$ & Irradiação difusa & First Class & Diário & Anual \\
\hline $\begin{array}{l}\text { Pireliômetro } \\
\text { Piranômetro com } \\
\text { Banda de Sombra }\end{array}$ & Irradiação normal direta & First Class & Diário & Anual \\
\hline & Irradiação global & First Class & Semanal & Anual \\
\hline & Irradiação normal direta & First Class & & \\
\hline
\end{tabular}

Fonte: adaptado de BRASIL, 2012

O documento indica radiômetros classificados como de primeira classe pela ISO 9060. Segundo a norma, essa classificação deve obedecer aos critérios mostrados na Tabela 2.

Tabela 2 - Classificação First Class para pireliômetros e piranômetros pela ISO 9060

\begin{tabular}{|c|c|c|}
\hline Especificação & Piranômetro & Pireliômetro \\
\hline $\begin{array}{l}\text { Tempo de resposta } \\
\text { Tempo para } 95 \% \text { das respostas }\end{array}$ & $<30 \mathrm{~s}$ & $<20 s$ \\
\hline $\begin{array}{l}\text { Compensador de temperatura: } \\
\text { Resposta a } 200 \mathrm{Wm}^{-2} \text { de radiação térmica (ventilado) }\end{array}$ & $+15 \mathrm{~W} / \mathrm{m}^{2}$ & n.a. ${ }^{7}$ \\
\hline $\begin{array}{l}\text { Reposta em relação a alteração de } 5 \mathrm{~K} \text { em } 1 \text { hora na } \\
\text { temperatura ambiente }\end{array}$ & $\pm 4 \mathrm{~W} / \mathrm{m}^{2}$ & $\pm 3 \mathrm{~W} / \mathrm{m}^{2}$ \\
\hline $\begin{array}{l}\text { Estabilidade } \\
\text { Porcentagem de alteração da resposta do equipamento em } \\
\text { um ano }\end{array}$ & $\pm 1,5 \%$ & $\pm 1 \%$ \\
\hline $\begin{array}{l}\text { Linearidade } \\
\text { Porcentagem de desvio da medição em relação à } 500 \mathrm{Wm}^{-} \\
2 \text {, em um intervalo de } 100 \mathrm{Wm}^{-2} \text { a } 1000 \mathrm{Wm}^{-2}\end{array}$ & $\pm 1 \%$ & $\pm 0,5 \%$ \\
\hline $\begin{array}{l}\text { Resposta em relação às alterações da direção A taxa de } \\
\text { erros causada por assumir que a resposta do equipamento à } \\
\text { radiação normal é válida para todas as direções de } \\
\text { incidência, quando se está medindo, em qualquer direção, } \\
\text { uma porção de radiação cuja a irradiância de incidência } \\
\text { normal é equivalente à } 1000 \mathrm{Wm}^{-2}\end{array}$ & $\pm 20 \mathrm{~W} / \mathrm{m}^{2}$ & n.a. \\
\hline
\end{tabular}




\begin{tabular}{|c|c|c|}
\hline Especificação & Piranômetro & Pireliômetro \\
\hline $\begin{array}{l}\text { Sensibilidade Espectral } \\
\text { Porcentagem de desvio do produto da absorção pela } \\
\text { transmitância espectral da média correspondente dentro do } \\
\text { intervalo de } 0,35 \text { a } 1,5 \mu \mathrm{m} \text { de comprimento de onda }\end{array}$ & $\pm 5 \%$ & $\pm 1 \%$ \\
\hline $\begin{array}{l}\text { Reposta em relação à alteração de temperatura } \\
\text { Porcentagem de erro devido a mudança de temperatura em } \\
\text { um intervalo de } 50 \mathrm{~K}\end{array}$ & $\pm 4 \%$ & $\pm 2 \%$ \\
\hline $\begin{array}{l}\text { Resposta à inclinação } \\
\text { Porcentagem de desvio da resposta do aparelho quando } \\
\text { inclinado no intervalo entre } 0^{\circ} \text { à } 90^{\circ} \text {, considerando a sua } \\
\text { resposta quando disposto na horizontal para } 1.000 \mathrm{Wm}^{-2} \text { de } \\
\text { irradiância }\end{array}$ & $\pm 2 \%$ & $\pm 0,5 \%$ \\
\hline
\end{tabular}

Fonte: adaptado de ISO (1990)

A ISO 9060 define os piranômetros e pireliômetros em três categorias: secondary standard, first class e second class. A classificação como secondary class só pode ser atribuída a um equipamento específico e não a um conjunto de equipamentos. Esta categoria é aplicada no caso da calibração de um equipamento diretamente a um pireliômetro absoluto (primary class) mantido pelos centros mundiais ou nacionais de radiação.

A classificação first class é, portanto, a mais criteriosa da ISO 9060 que pode ser aplicada a um grupo de radiômetros fornecido no mercado. Já em relação à classificação da WMO, os pireliômetros são classificados em duas categorias: high quality e good quality e os piranômetros em três categorias: high quality, good quality e moderate quality. Os critérios first class para piranômetros da ISO são bastante semelhantes aos critérios good quality da WMO, enquanto que, para pireliômetros, a classe first class da ISO se apresenta como um meio termo entre as classes high quality e good quality da WMO. As classificações de high quality da WMO são bastante semelhantes às classificações de secondary standard da ISO. A WMO indica que as classificações de high quality são próximas ao estado da arte e só podem ser alcançadas em estações com instalações e equipes especializadas.

A Tabela 2 também permite a identificação dos principais fatores que interferem nas medições de radiação. Estes fatores precisam ser levados em consideração no momento de tratamento dos dados obtidos por esses equipamentos. Os níveis de incerteza discriminados na Tabela 2 só são obtidos com medições em campo através da devida calibração, instalação e manutenção desses equipamentos. É importante que os equipamentos sejam instalados nivelados para que não haja alterações nos níveis de incerteza quanto à resposta à inclinação e resposta em relação às alterações de direção quando a radiação direta for medida por piranômetros. A instalação também deve ocorrer em local mais livre possível de obstáculos 
que causem alteração nos albedos para que a resposta espectral não se altere. A estabilidade, linearidade e o tempo de resposta só serão mantidos se a limpeza e a manutenção dos equipamentos ocorrerem de maneira periódica e correta. Por esses motivos o Quadro 2 indica os intervalos de limpeza e manutenção.

Além dos critérios de medição da radiação, a Configuração A definida pela ANEEL também define os critérios para a medição das demais variáveis climatológicas, como mostrado no Quadro 3.

Quadro 3 - Critérios para as medições climatológicas pela ANEEL

\begin{tabular}{|c|c|c|c|c|}
\hline Instrumentos & $\begin{array}{c}\text { Grandeza } \\
\text { Medida }\end{array}$ & $\begin{array}{l}\text { Precisão } \\
\text { Mínima }\end{array}$ & $\begin{array}{c}\text { Intervalo } \\
\text { de } \\
\text { Limpeza }\end{array}$ & $\begin{array}{c}\text { Intervalo } \\
\text { Máximo de } \\
\text { Calibração }\end{array}$ \\
\hline Barômetro & $\begin{array}{l}\text { Pressão } \\
\text { atmosférica }\end{array}$ & $\pm 5 \mathrm{hPa}\left(\mathrm{a} 25^{\circ} \mathrm{C}\right)$ & Semanal & Anual \\
\hline $\begin{array}{l}\text { Termosistência de } \\
\text { Platina }\end{array}$ & $\begin{array}{l}\text { Temperatura } \\
\text { ambiente }\end{array}$ & $\pm 0,2^{\circ} \mathrm{C}$ & Semanal & Anual \\
\hline $\begin{array}{l}\text { Sensor de Umidade } \\
\text { Capacitivo }\end{array}$ & $\begin{array}{l}\text { Umidade relativa } \\
\text { do ambiente }\end{array}$ & $\pm 0,1 \%$ & Semanal & Anual \\
\hline Pluviômetro & Precipitação & $1 \%$ a $50 \mathrm{~mm} / \mathrm{h}$ & Semanal & Anual \\
\hline $\begin{array}{l}\text { Anemômetro de copo } \\
\text { ou anemômetro } \\
\text { ultrassônico }\end{array}$ & $\begin{array}{l}\text { Velocidades do } \\
\text { vento }\end{array}$ & $\pm 0,005 \mathrm{~m} / \mathrm{s}$ & Semanal & Anual \\
\hline $\begin{array}{l}\text { Anemoscópio ou } \\
\text { anemômetro } \\
\text { ultrassônico }\end{array}$ & Direção do vento & $\pm 1^{\circ}$ & Semanal & Anual \\
\hline
\end{tabular}

Fonte: BRASIL, 2012

O documento da ANEEL não define uma classificação para os demais equipamentos climatológicos, mas sim, uma especificação de precisão mínima. A WMO (2012) fornece critérios das condições e características ideais para estes equipamentos que são apresentadas na Tabela 3.

Tabela 3 - Critérios para as medições climatológicas pela WMO

\begin{tabular}{llc}
\hline \multirow{2}{*}{ Grandeza Medida } & \multicolumn{2}{c}{ Incerteza de medição } \\
\cline { 2 - 3 } & \multicolumn{1}{c}{ Ideal } & Operacional \\
\hline Pressão & $\pm 0,1 \mathrm{hPa}$ & $\pm 0,15 \mathrm{hPa}$ \\
Atmosférica & & $\pm 0,2 \mathrm{~K}$ \\
\hline Temperatura & $\pm 0,3 \mathrm{~K}$ para $\mathrm{T} \leq-40^{\circ} \mathrm{C}$ & \\
ambiente & $\pm 0,1 \mathrm{~K}$ para $-40^{\circ} \mathrm{C}<\mathrm{T} \leq+40^{\circ} \mathrm{C}$ & \\
& $\pm 0,3 \mathrm{~K}$ para $\mathrm{T}>+40^{\circ} \mathrm{C}$ & \\
\hline
\end{tabular}




\begin{tabular}{llll}
\hline \multirow{2}{*}{ Grandeza Medida } & \multicolumn{2}{c}{ Incerteza de medição } \\
\cline { 2 - 4 } & & \multicolumn{2}{c}{ Operacional } \\
\hline Umidade relativa & $1 \%$ & Psicômetros & $\begin{array}{l}\text { Sensores no } \\
\text { estado sólido }\end{array}$ \\
\cline { 2 - 4 } do ambiente & & $\pm 0,2 \mathrm{k}$ & $\pm 0,3 \%$ \\
\hline Precipitação & $\pm 0,1 \mathrm{~nm}$ para quantidades $\leq 5,0 \mathrm{~nm}$ & A maior entre $\pm 5 \%$ ou $\pm 0,1 \mathrm{~nm}$ \\
& $\pm 2 \%$ para quantidades $>5,0 \mathrm{~nm}$ & \\
\hline Velocidade do & $\pm 0,5 \mathrm{~m} / \mathrm{s}$ para velocidades $\leq 5,0 \mathrm{~m} / \mathrm{s}$ & $\pm 0,5 \mathrm{~m} / \mathrm{s}$ para velocidades $\leq 5,0$ \\
vento & $\pm 10 \%$ para velocidades $>5,0 \mathrm{~m} / \mathrm{s}$ & $\mathrm{m} / \mathrm{s}$ \\
& & $\pm 10 \%$ para velocidades $>5,0 \mathrm{~m} / \mathrm{s}$ \\
\hline Direção do vento & $5^{\circ}$ & $5^{\mathbf{0}}$ \\
\hline
\end{tabular}

Fonte: WMO, 2012

A BRSN (MCARTHUR, 2005) também apresenta uma tabela com as incertezas e resoluções típicas de equipamentos medidores de dados climatológicos em campo. As determinações apresentadas pela BSRN são apresentadas na Tabela 4.

Tabela 4 - Critérios para as medições climatológicas pela BSRN

\begin{tabular}{lll}
\hline Variável Medida & Resolução & Incerteza \\
\hline Temperatura do Ar & $0.1^{\circ} \mathrm{C}$ & $\pm 0.3^{\circ} \mathrm{C}$ \\
\hline Temperatura de Ponto de Orvalho & $0.1^{\circ} \mathrm{C}$ & $\pm 0.5^{\circ} \mathrm{C}$ \\
\hline Temperatura do Solo & $0.1^{\circ} \mathrm{C}$ & $\pm 0.3{ }^{\circ} \mathrm{C}$ \\
\hline Umidade Relativa & $1 \%$ & $\pm 7 \%$ \\
\hline Velocidade do Vento & $0.5 \mathrm{~m} / \mathrm{s}$ & $\pm 5 \%$ ou $\pm 2 \mathrm{~m} / \mathrm{s}$ \\
\hline Direção do Vento & $5^{\circ}$ & $\pm 10^{\circ}$ \\
\hline Precipitação Acumulada & $0.2 \mathrm{~mm}$ & $\begin{array}{l}\text { Melhor entre: } \pm 0.2 \mathrm{~mm} \mathrm{ou} \pm 2 \% \text { do } \\
\text { total }\end{array}$ \\
\hline Intensidade da Precipitação & $0.2 \mathrm{~mm} / \mathrm{h}$ & $\begin{array}{l}\text { Melhor entre: } \pm 0.2 \mathrm{~mm} / \mathrm{h} \text { ou } \pm 2 \% \\
\text { do total }\end{array}$ \\
\hline Profundidade da Neve & $1 \mathrm{~mm}$ & $\begin{array}{l}\text { Melhor entre: } \pm 10 \mathrm{~mm} \mathrm{ou} \pm 2 \% \text { do } \\
\text { valor }\end{array}$ \\
\hline Pressão Atmosférica & $0.1 \mathrm{hPa}$ & \begin{tabular}{l} 
$\pm 0.5 \mathrm{hPa}$ \\
\hline
\end{tabular} \\
\hline
\end{tabular}

Fonte: MCARTHUR, 2005

A comparação do Quadro 3 com as Tabelas 3 e 4 permite a conclusão de que os critérios de medição dos documentos da ANEEL estão, em geral, mais restritos do que aqueles definidos pela WMO e BSRN.

\subsection{REDES DE MEDIÇÕES E DISPONIBILIDADE DE DADOS}

Ao longo do desenvolvimento tecnológico solarimétrico, uma série de estações foi descontinuada e, escalas, equipamentos e tecnologias - consideradas como padrão de 
referência - foram alterados. Essas modificações são naturais em qualquer processo de desenvolvimento de tecnologias. Atualmente, embora se tenha alcançado melhoras significativas nos níveis de incertezas dos equipamentos radiométricos, verificam-se baixos índices de instalação, registro e manutenção desses equipamentos. Nesse sentido, a ciência e o mercado de energia solar evoluíram na elaboração de métodos de aproximação e extrapolação de medições radiométricas obtidas em regiões próximas.

O relatório técnico da $\operatorname{IRSOLAV}^{8}$ (2010), indica duas principais metodologias - a partir de dados medidos em solo - para a determinação da irradiação (em Wh/m²) solar em um determinado local, que não possui uma ES: (i) utilização de dados de medição de estações próximas ao local: esse método se torna viável apenas para terrenos relativamente planos e quando a distância da estação de medição não supera $10 \mathrm{~km}$, no caso de terrenos muito acidentados ou estações mais distantes o uso dos dados se torna totalmente inapropriado; (ii) interpolação de medições disponíveis próximas ao local: esse método pode ser utilizado apenas em áreas com uma grande quantidade de estações e desde que a distância entre as estações esteja em torno de 10 à $50 \mathrm{~km}$.

CROSS e WALD (2004) citam uma série de estudos para indicar que médias diárias de irradiação global podem ser consideradas válidas para uma área de $30 \mathrm{~km}$ da localização da estação de medição. TIBA et al. (2000), baseando-se no estudo de GALLEGOS e LOPARDO (1988) afirmam que em regiões fito geográficas homogêneas, a média mensal da irradiação global diária média pode ser extrapolada até $200 \mathrm{~km}$ de distância com erros da ordem de $15 \%$.

PAULESCU et al. (2013) afirmam que muitos países têm desenvolvido redes de trabalho para medições radiométricas, contudo os investimentos e custos de manutenção dessas redes de medição são bastante significativos. Portanto, atualmente ainda são encontradas poucas estações instaladas ao redor do mundo, mesmo em países desenvolvidos. Além disso, os autores explicam que os tipos de medições e a qualidade dos dados obtidos variam de região para região. Normalmente dados de irradiação global e de insolação são encontrados mais facilmente em valores totais diários ou médias mensais. As irradiações direta e difusa, bem como os índices de cobertura de nuvens no céu e registros horários de irradiação são mais difíceis de serem encontrados e apenas poucas estações possuem medições de albedo e de irradiação em planos inclinados.

Essa questão é ainda mais especificada por CROSS e WALD (2004) que indicam que o acesso à informação relevante é dificultado em função de uma série de razões, dentre elas os

\footnotetext{
${ }^{8}$ Empresa incubada pelo Centro de Pesquisa de Energia, Meio Ambiente e Tecnologia do Ministério de Ciência e Tecnologia da Espanha e pelo Parque Científico de Madri
} 
autores destacam: (i) o baixo número de estações instaladas, (ii) o acesso dificultado em função dos diferentes tipos de formatos de dados, padrões de armazenamento, períodos e intervalos de medições diferentes e (iii) as regiões providas de medições e os intervalos de medições muitas vezes não atendem às necessidades atuais dos interessados pela informação. PAULESCU et al. (2013) e CROSS e WALD (2004) concordam que não se pode determinar a quantidade de equipamentos medidores de radiação instalados ao redor do mundo. Tampouco é possível quantificar os tipos de equipamentos e as respectivas variáveis medidas e muito menos se consegue garantir a qualidade da informação disponibilizada por todos os equipamentos.

Verifica-se ainda nesse contexto que a maior parte dos grupos nacionais, regionais e internacionais engajados no armazenamento e controle de dados radiométricos não o fazem objetivando o uso específico para aproveitamentos energéticos, visto que esses dados são de interesse de diversas frentes de estudos, como a agricultura e a meteorologia. Com o intuito de se obter uma estimativa da quantidade de estações medidoras de radiação instaladas ao redor do mundo e analisar os grupos e estudos vinculados ao avanço dos estudos solarimétricos, realizou-se um levantamento dos grupos, organizações e trabalhos relevantes para a solarimetria. Os Quadros 4 e $5^{9}$ apresentam uma síntese dos elementos mais relevantes encontrados nesse levantamento em âmbito internacional e nacional, respectivamente.

Quadro 4 - Grupos, organizações e trabalhos internacionais relevantes para a solarimetria

\begin{tabular}{|c|c|c|c|}
\hline \multicolumn{4}{|c|}{ Word Radiation Data Center (WRDC) } \\
\hline $\begin{array}{l}\text { Dados } \\
\text { Disponibilizados }\end{array}$ & \multicolumn{3}{|c|}{$\begin{array}{l}\text { Irradiâncias Global: somas diárias e mensais e médias mensais } \\
\text { Irradiâncias Difusa: somas diárias e mensais e médias mensais } \\
\text { Insolação: somas e médias mensais }\end{array}$} \\
\hline $\begin{array}{l}\text { Estações } \\
\text { Vinculadas }\end{array}$ & $\begin{array}{l}\text { Aproximadamente } \\
1.440 .{ }^{10}\end{array}$ & $\begin{array}{l}\text { Regiões de } \\
\text { Captação }\end{array}$ & $\begin{array}{l}130 \text { países distribuídos na } \\
\text { América, Ásia, África, Europa e } \\
\text { Oceania e estações na Antártida. }\end{array}$ \\
\hline $\begin{array}{l}\text { Descrição } \\
\text { Observações }\end{array}$ & \multicolumn{3}{|c|}{$\begin{array}{l}\text { O WRDC é o centro de coleta de dados da maior rede de medições } \\
\text { radiométricas do mundo, desenvolvido e mantido pela Organização } \\
\text { Mundial de Meteorologia (WMO). A WMO é o principal grupo de } \\
\text { estudos e manutenção de dados climatológicos do mundo, e embora o } \\
\text { órgão seja de extrema relevância para os estudos radiométricos é } \\
\text { importante enfatizar que o foco das medições mantidas pelo grupo é } \\
\text { meteorológico e não energético. }\end{array}$} \\
\hline
\end{tabular}

\footnotetext{
${ }^{9}$ Embora as informações de dados disponibilizados dispostas nos Quadros 4 e 5 configuram períodos de medições e integrações diversos, optou-se, no geral, pela utilização do termo "irradiâncias" já que essas medições são mais comumente apresentadas em W/m².

${ }^{10}$ Estimativa elaborada através das informações dispostas em WRDC (2014)
} 


\begin{tabular}{|c|c|c|c|}
\hline \multicolumn{4}{|c|}{ Baseline Surface Radiation Network (BSRN) } \\
\hline $\begin{array}{l}\text { Dados } \\
\text { Disponibilizados }\end{array}$ & \multicolumn{3}{|c|}{$\begin{array}{l}\text { Médias de } 1 \text { minuto de: irradiância global (calculada pela soma das } \\
\text { irradiâncias difusa e direta), irradiância global (medida por } \\
\text { piranômetros), irradiância difusa, irradiância direta e irradiância } \\
\text { atmosférica }^{11} \text {. }\end{array}$} \\
\hline & $\begin{array}{l}\text { Aproximadamente } \\
52^{12}\end{array}$ & $\begin{array}{l}\text { Regiões de } \\
\text { Captação }\end{array}$ & $\begin{array}{l}\text { América, Ásia, África, Europa, } \\
\text { Oceania e Antártida. }\end{array}$ \\
\hline $\begin{array}{l}\text { Descrição } \\
\text { Observações }\end{array}$ & \multicolumn{3}{|c|}{$\begin{array}{l}\text { O projeto é destinado a identificar importantes alterações no campo da } \\
\text { radiação da Terra a partir da superfície de modo a relacioná-las às } \\
\text { alterações climáticas. Diferente do WRDC e do GEBA que arquivam } \\
\text { médias de irradiância de longa data de mais de mil estações associadas } \\
\text { com os serviços meteorológicos nacionais, o BSRN consiste apenas em } \\
\text { um pequeno número de estações de pesquisa selecionadas, que } \\
\text { proporcionam tipicamente médias de } 1 \text { minuto de fluxos de radiação da } \\
\text { melhor qualidade possível atualmente disponível. }\end{array}$} \\
\hline \multicolumn{4}{|c|}{ Global Energy Balance Archive (GEBA) } \\
\hline $\begin{array}{l}\text { Dados } \\
\text { Disponibilizados }\end{array}$ & \multicolumn{3}{|c|}{$\begin{array}{l}\text { Médias mensais de: irradiância global, direta, difusa, terrestre }{ }^{13} \text {, } \\
\text { atmosférica, albedo, saldo de radiação de onda longa e saldo global de } \\
\text { irradiação, dentre outras variáveis específicas discriminadas em ETH } \\
\text { (2014). }\end{array}$} \\
\hline $\begin{array}{l}\text { Estações } \\
\text { Vinculadas }\end{array}$ & & $\begin{array}{l}\text { Regiões de } \\
\text { Captação }\end{array}$ & $\begin{array}{l}\text { América, Ásia, África, Europa, } \\
\text { Oceania e Antártida. }\end{array}$ \\
\hline $\begin{array}{l}\text { Descrição } \\
\text { Observações }\end{array}$ & \multicolumn{3}{|c|}{$\begin{array}{l}\text { O GEBA é um banco de dados central dos fluxos de energia em todo o } \\
\text { mundo instrumentalmente medidos na superfície terrestre, localizado no } \\
\text { Instituto do Clima e Ciências Atmosféricas ETH de Zurique, Suíça. A } \\
\text { maioria dos dados publicados no GEBA já foi informada por alguma } \\
\text { outra publicação o valor agregado pelo GEBA a essas medições } \\
\text { relaciona-se a: (i) uma certa padronização das medições, (ii) integração } \\
\text { de dados de irradiância com dados históricos da estação centralizados } \\
\text { em apenas um banco de dados, (iii) procedimentos de controle de } \\
\text { qualidade aplicado às médias mensais, (iv) a redistribuição dos dados. }\end{array}$} \\
\hline
\end{tabular}

Fonte: Elaboração própria

Quadro 5 - Grupos, organizações e trabalhos nacionais relevantes para a solarimetria

\section{Atlas Solarimétrico do Brasil: banco de dados terrestres}

Dados Obtidos Irradiância Global: períodos de medição variados

Insolação: períodos de medição variados

\begin{tabular}{l|l|l|l} 
Estações & $\begin{array}{l}\text { Aproximadamente } 140^{15} \\
\text { piranômetros e actinógrafos }\end{array}$ & Regiões de Captação & Brasil \\
Vinculadas & &
\end{tabular}

(continua)

\footnotetext{
${ }^{11}$ A radiação atmosférica, ou de onda longa descendente, representa a radiação de onda longa proveniente dos processos de refração e difração sofridos pela radiação na atmosfera, a irradiância atmosférica representa a medição dessa radiação $\mathrm{em} \mathrm{W} / \mathrm{m}^{2}$.

12 Estimativa elaborada através das informações dispostas em MCARTHUR (2005)

${ }^{13}$ A radiação terrestre representa a radiação de onda longa emitida pela Terra de volta à atmosfera.

${ }^{14}$ GILGEN E OHMURA (1999).

${ }^{15}$ Estimativa elaborada através das informações do mapa da pg. 33 da publicação de TIBA et al. (2000)
} 


\begin{tabular}{|c|c|c|c|}
\hline \multicolumn{4}{|c|}{ Atlas Solarimétrico do Brasil: banco de dados $t$} \\
\hline $\begin{array}{l}\text { Descrição e } \\
\text { Observações }\end{array}$ & \multicolumn{3}{|c|}{$\begin{array}{l}\text { O atlas, publicado em 2000, representa um dos principais esforços } \\
\text { brasileiros em identificar os instrumentos e medições solarimétricas } \\
\text { disponíveis no Brasil. O trabalho para a formulação do documento } \\
\text { contou com um trabalho de pesquisa e análise das publicações dos } \\
\text { últimos } 40 \text { anos que contém dados de irradiação e irradiância, além } \\
\text { disso, o grupo de trabalho também elaborou um levantamento dos } \\
\text { equipamentos radiométricos instalados ao longo do país. A publicação } \\
\text { não oferece os dados obtidos pelos equipamentos utilizados. }\end{array}$} \\
\hline \multicolumn{4}{|c|}{ Modelo GL 1.2/INPE-CPTEC } \\
\hline $\begin{array}{l}\text { Dados } \\
\text { Disponibilizados }\end{array}$ & \multicolumn{3}{|c|}{ Irradiância Global: médias m } \\
\hline $\begin{array}{l}\text { Estações } \\
\text { Vinculadas }\end{array}$ & Aproximadamente $99^{16}$ & Regiões de Capta & Brasil \\
\hline $\begin{array}{l}\text { Descrição e } \\
\text { Observações }\end{array}$ & \multicolumn{3}{|c|}{$\begin{array}{l}\text { O modelo GL foi desenhado para avaliar campos de radiação solar à } \\
\text { superfície a partir de informações de satélites geoestacionários. } \\
\text { O INPE }{ }^{17} \text { mantém o Centro de Previsão de Tempo e Estudos Climáticos } \\
\text { (CPTEC) que é responsável pela operação de uma série de estações } \\
\text { ambientais automáticas (ou plataformas de coleta de dados- PCD). } \\
\text { A metodologia utilizada no modelo GL é validade através da } \\
\text { comparação com dados medidos em superfície pelas PCDs. Por meio da } \\
\text { análise de um dos relatórios de avaliação de rendimento do modelo GL } \\
1.2 \text { foi possível obter uma estimativa da quantidade de PCDs que } \\
\text { mantem a medição de dados radiométricos. }\end{array}$} \\
\hline \multicolumn{4}{|c|}{ Rede SONDA/ Projeto SWERA } \\
\hline $\begin{array}{l}\text { Dados } \\
\text { Disponibilizados }\end{array}$ & \multicolumn{3}{|c|}{$\begin{array}{l}\text { Médias de } 1 \text { minuto de: irradiância global, irradiância difusa, } \\
\text { irradiância direta, irradiância atmosférica e irradiância } \\
\text { fotossinteticamente ativa. }\end{array}$} \\
\hline Estações & Aproximadamente $16^{18}$ & Regiões de Captação & Brasil \\
\hline $\begin{array}{l}\text { Descrição e } \\
\text { Observaçõ̃es }\end{array}$ & \multicolumn{3}{|c|}{$\begin{array}{l}\text { A rede SONDA surgiu como um projeto do INPE com o objetivo de } \\
\text { desenvolver os estudos acerca da medição da radiação solar em } \\
\text { superfície no Brasil e apoiar o projeto SWERA }{ }^{19} \text { da } \text { UNEP }^{20} \text {. }\end{array}$} \\
\hline
\end{tabular}

Fonte: Elaboração própria

Para a elaboração dos Quadros 4 e 5, verificou-se apenas os dados disponíveis de irradiâncias. Portanto, nesses quadros não se pode considerar a quantidade de estações de medição como estações solarimétricas completas, pois essa não foi a verificação efetuada. A obtenção de dados climatológicos é muito mais comum do que a de dados radiométricos.

Com o intuito de realizar um exercício de verificação da quantidade de medições de radiação em solo disponíveis atualmente, buscou-se realizar o cálculo estimado da quantidade

\footnotetext{
${ }^{16}$ Estimativa elaborada através das informações do mapa da pg. 14 da publicação do CPTEC (BRASIL, 2005)

${ }^{17}$ Instituto Nacional de Pesquisas Espaciais

${ }^{18}$ Estimativa elaborada através das informações sobre a caracterização do Projeto SONDA (BRASIL, 2014b)

${ }^{19}$ Projeto de Avaliação dos Recursos Solar e Eólico

${ }^{20}$ Programa Ambiental das Nações Unidas
} 
de estações necessárias para que houvesse o mapeamento do recurso solar a partir de medições em solo. Para tal, utilizou-se os critérios observados por alguns autores supracitados. Esses critérios foram sistematizados no Quadro 6.

Quadro 6 - Critérios para extrapolação e interpolação de dados de estações solarimétricas

\begin{tabular}{|l|l|l|}
\hline \multicolumn{1}{|c|}{ Autores } & $\begin{array}{c}\text { Critério (Distância } \\
\text { Radial) }\end{array}$ & \multicolumn{1}{c|}{ Restrição/Metodologia } \\
\hline $\begin{array}{l}\text { CROS e WALD } \\
(2004)\end{array}$ & $30 \mathrm{~km}$ & Utilização dos mesmos dados. \\
\hline TIBA et al. (2000) & $200 \mathrm{~km}$ & $\begin{array}{l}\text { Extrapolação da média mensal, com erros da } \\
\text { ordem de 15\%. }\end{array}$ \\
\hline IRSOLAV (2010) & $10 \mathrm{~km}$ & $\begin{array}{l}\text { Utilização dos mesmos dados de média } \\
\text { mensal e em terrenos relativamente planos }\end{array}$ \\
\hline 10 a $50 \mathrm{~km}$ & $\begin{array}{l}\text { Interpolação dos valores de média mensal de } \\
\text { estações próximas desde que elas estejam } \\
\text { desse intervalo de distância entre elas. }\end{array}$ \\
\hline
\end{tabular}

Fonte: Elaboração própria

Admite-se que todos os autores definiram os critérios e restrições para valores médios mensais de irradiância global. Como o intuito desse estudo é mostrar a distribuição ideal - ou ao menos uma estimativa - das estações de medição, considera-se a instalação de muitas estações, nesse sentido a metodologia de interpolação da IRSOLAV entre dados de estações próximas se faz coerente.

Neste critério, a distância definida não é entre o ponto que se objetifica a obtenção dos valores de irradiância e as estações, mas sim, entre as estações. Como este exercício sugere uma situação ideal e homogenia de distribuição de estações solarimétricas adotou-se o critério de distância entre estações de $50 \mathrm{~km}$ de modo que um ponto localizado na média da distância entre duas estações se distanciará em $25 \mathrm{~km}$ de cada estação obedecendo também o critério mostrado por CROSS e WALD (2004). Portanto adota-se como parâmetro ideal uma ES instalada a cada $25 \mathrm{~km}$ radiais, ou seja, 1 estação a cada aproximadamente $2.000 \mathrm{~km}^{2}$.

Em vista dos dados mostrados nos Quadros 4 e 5, fica evidente que esse critério se mostra bastante otimista. Com o intuito de mostrar a escassez de medições em solo de irradiância em termos numéricos, optou-se por adotar como exemplo, a análise dos dados fornecidos pela WRDC, em virtude do maior detalhamento e amplitude do trabalho do grupo.

As estações vinculadas ao WRDC se distribuem de maneira completamente heterogênea ao longo dos países vinculados ao grupo. A Tabela 5 evidencia a quantidade de 
estações em alguns países e aponta a média de distribuição das estações e a quantidade de estações ideal adotando o critério de uma estação a cada $2.000 \mathrm{~km}^{2}$.

Tabela 5 - Distribuição de estações de medição e dimensão territorial

\begin{tabular}{lllll}
\hline País & Estações $^{\mathbf{2 1}}$ & Ideal $^{\mathbf{2 2}}$ & Território $^{\mathbf{2 3}}$ & Média $^{\mathbf{2 4}}$ \\
\hline China & 12 & 4.798 & $9.596 .960,0$ & 800,0 \\
\hline Rússia & 30 & 8.549 & $17.098 .242,0$ & 570,0 \\
\hline França & 153 & 322 & $643.801,0$ & 4,2 \\
\hline EUA & 79 & 4.913 & $9.826 .675,0$ & 124,4 \\
\hline Canadá & 185 & 4.992 & $9.984 .670,0$ & 54,0 \\
\hline Chile & 28 & 378 & $756.102,0$ & 27,0 \\
\hline Japão & 18 & 189 & $377.915,0$ & 21,0 \\
\hline Alemanha & 43 & 178 & $357.022,0$ & 8,3 \\
\hline Espanha & 63 & 253 & $505.370,0$ & 8,0 \\
\hline
\end{tabular}

Fonte: Elaboração própria

Dentre os países selecionados para esse exercício acadêmico, a França se encontra com a melhor quantidade relativa de estações solarimétricas e ainda assim o valor de estações é menor que a metade da quantidade ideal. É importante enfatizar que essa análise quantitativa se constrói sobre um modelo simplificado que sugere uma representação holística da situação.

O Brasil não possui estações de medição de radiação vinculadas à WRDC. Através da análise do Modelo GL 1.2/INPE-CPTEC determinou-se a existência de 99 estações. Considerando que o Brasil possui uma extensão territorial de 8,514,877 km² (EUA, 2014), define-se que o país deveria registrar a instalação de 4.257 estações solarimétricas. Isso significa que atualmente o Brasil possui, em média 1 estação a cada 8,6 x $10^{3} \mathrm{~km}^{2}$. Em termos percentuais, o país possui apenas $2 \%$ da quantidade de estações ideal. Enquanto a França, Alemanha e Espanha possuem $48 \%, 24 \%$ e $25 \%$ respectivamente.

Este exercício de verificação da quantidade ideal de estações com medições de radiação objetivou uma demonstração numérica da disponibilidade de dados, e para tal, adotaram-se uma série de simplificações, tais como: não foram consideradas as limitações geográficas e as áreas de interesse real de instalação de estações, bem como a real heterogeneidade espacial do posicionamento das estações medidoras de radiação existentes e considerou-se, apenas a existência de medidores de irradiância global, sem considerar a

\footnotetext{
${ }^{21}$ Quantidade de estações vinculadas à WRCD em 2015

${ }^{22}$ Quantidade de estações ideal

${ }^{23}$ Extensão Territorial em Km² (EUA, 2014)

${ }^{24}$ Média de distribuição das estações solarimétricas $\left(10^{3} \mathrm{Km}^{2}\right.$ por estação)
} 
medição das demais variáveis necessárias para a composição de uma estação solarimétrica completa.

Contudo, a observação mais relevante deste exercício foi a dificuldade em conseguir efetuar um levantamento, ao menos estimado, da quantidade de medidores de irradiância instalados no Brasil.

Para uma aproximação da quantidade de radiômetros instalados foi necessária a estimativa através da análise de um mapa de validação de um modelo fundamentado em informações de satélites geoestacionários, em função dos poucos dados disponíveis em relação às PCDs controladas pela CPTEC. 


\section{GEOANÁLISE DA ENERGIA PRIMÁRIA SOLAR}

A geoanálise da energia primária solar diz respeito à identificação dos fatores que interferem na disponibilidade dessa energia ao longo da superfície terrestre. A radiação que alcança o topo da atmosfera terrestre é praticamente constante ao longo do tempo, contudo, como a Terra está em movimento em torno do Sol, essa radiação extraterrestre atinge o topo da atmosfera de diferentes regiões terrestres ao longo do dia e dos meses. Por isso, os fatores iniciais que devem ser analisados para o entendimento do recurso é a dinâmica de movimento Terra - Sol que define a contabilização da radiação extraterrestre em dada região.

\subsection{DISPONIBILIDADE DA IRRADIAÇÃO EXTRATERRESTRE}

A definição da radiação extraterrestre que chega ao topo da atmosfera em um determinado espaço do planeta Terra depende basicamente da atividade solar, e da distância da Terra em relação ao Sol. A órbita elíptica da Terra em torno do Sol possui um raio médio de 149.598.106 km. Essa distância varia em $\pm 1,67 \%$ ao longo do ano, como mostrado na Figura 14.

Figura 14 - Órbita elíptica da Terra em torno do Sol

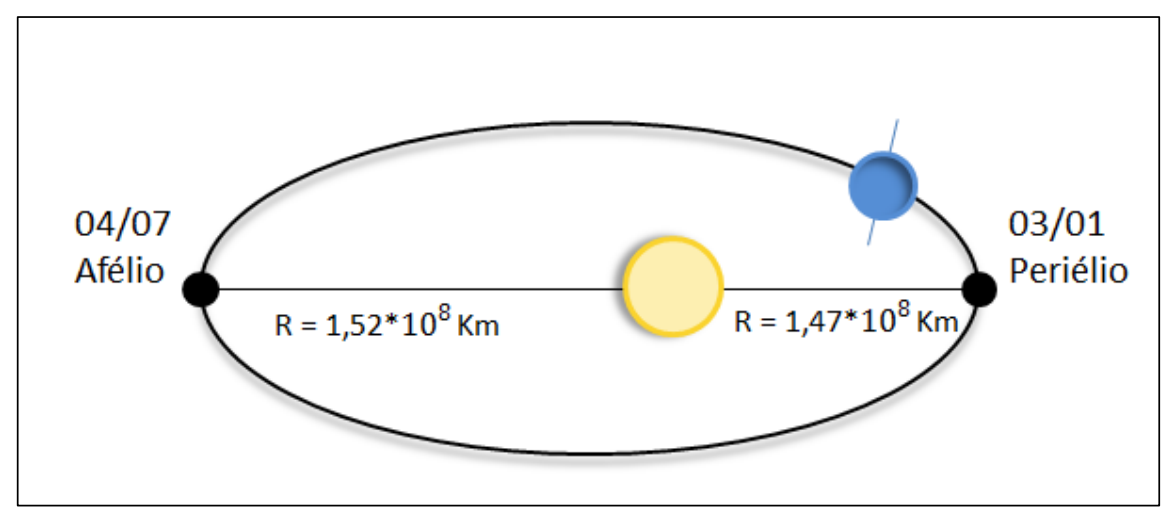

Fonte: Elaboração própria

Portanto, a irradiância extraterreste, que também pode ser denominada como irradiância direta normal extraterrestre $\left(\mathrm{IDN}_{0}\right)$, em determinado dia do ano, pode ser definida como:

$$
I D N_{0}=I_{0}\left(\frac{R_{m}}{R}\right)^{2} \quad\left[W / m^{2}\right]
$$

Onde, $R_{m}$ corresponde ao raio médio da elipse, $R$ à distância real da Terra no determinado dia do ano, e $I_{0}$ à constante de potência da irradiância solar extraterrestre. A 
radiação alcança o topo da atmosfera terrestre percorrendo o espaço extraterrestre de maneira praticamente uniforme, a absorção da radiação solar por alguns íons presentes na cromosfera resulta na alteração da radiação extraterrestre, cuja composição espectral é mostrada no gráfico da Figura 15. O fluxo de energia emitido resultante dessa radiação - ou constante de potência da irradiância solar extraterrestre $\left(I_{0}\right)$ - foi definida pela NASA como uma constante de potência equivalente à 1367 Watts por metro quadrado.

Figura 15 - Composição espectral da radiação solar

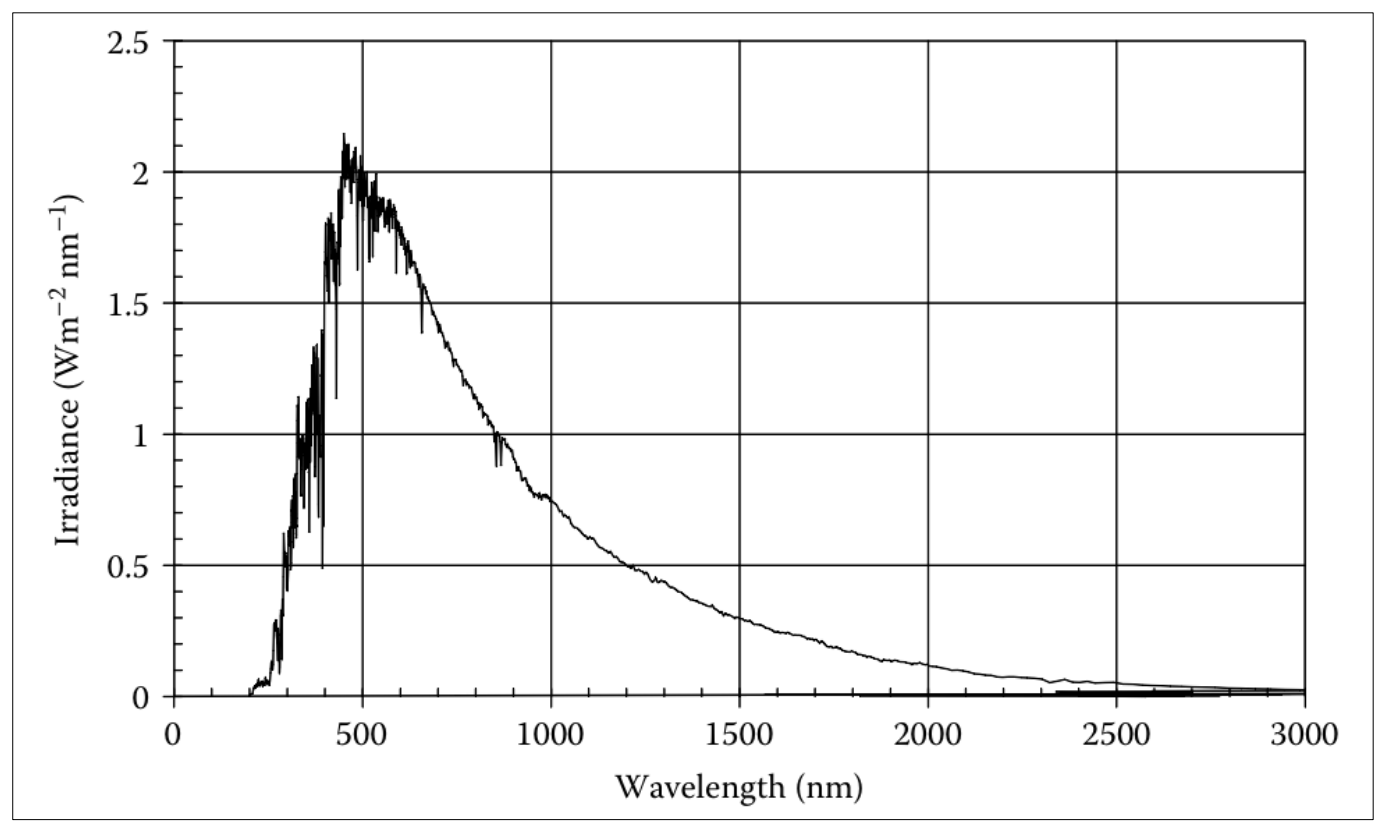

Fonte: VIGNOLA et. al., 2012

A relação $\left(\frac{R_{m}}{R}\right)^{2}$ para cada dia do ano, por meio da equação (3) (SENTELHAS e ANGELOCCI, 2009):

$$
\left(\frac{R_{m}}{R}\right)^{2}=1+0,033 \cos (360 N D A / 365)
$$

Aonde NDA corresponde ao dia juliano, ou seja, o dia do ano, que varia de 1 a 365, de modo que 1 de janeiro corresponde ao dia juliano 1 e 31 de dezembro corresponde ao dia juliano 365. O gráfico da Figura 16 apresenta a relação $R_{m} / R$ para cada dia Juliano. 
Figura 16 - Relação $R_{m} / R$ para cada dia juliano

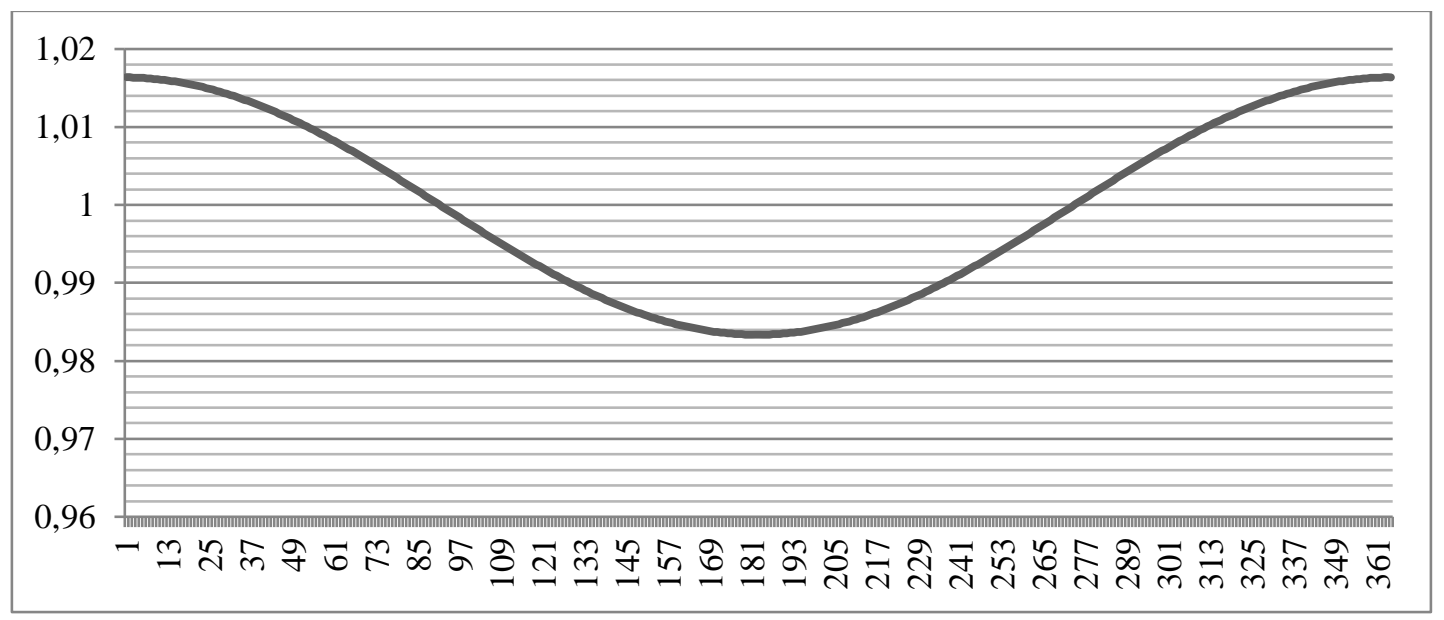

Fonte: Elaboração própria

A irradiância $\left(I_{0}\right)$ - foi calculada com base no raio médio $\left(R_{m}\right)$ da elipse do movimento de translação da Terra. Ao longo do ano, a Terra percorre a trajetória elíptica com uma inclinação de cerca de $23,45^{\circ}$ em relação ao plano equatorial, como mostrado na Figura 17. Portanto, para a definição da energia solar incidente em um determinado espaço da superfície terrestre, deve ser analisada a posição do Sol em relação ao espaço em análise. Essa configuração varia conforme o posicionamento na terra, o dia do ano e o horário do dia.

Figura 17 - Declinação solar

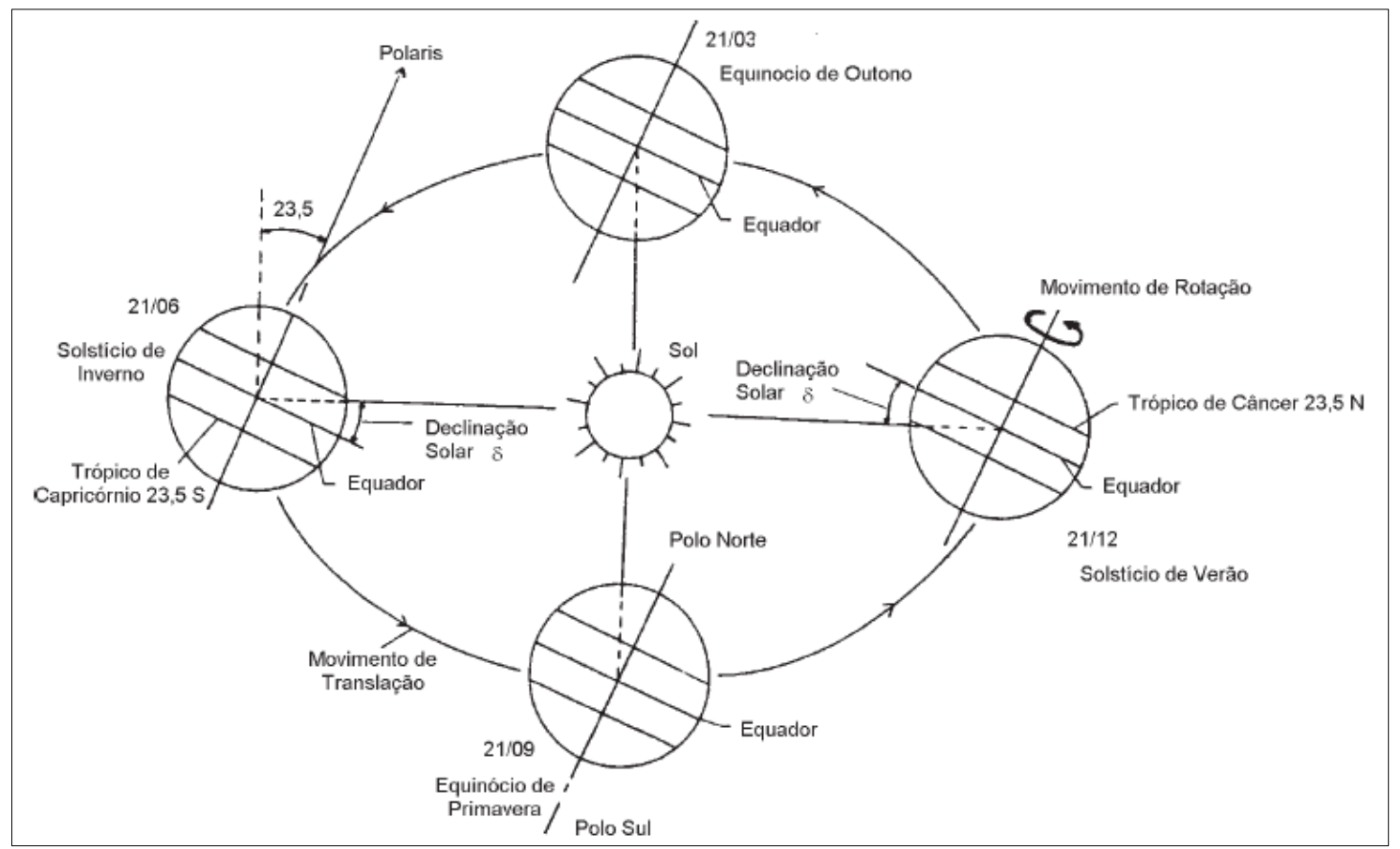


Na Figura 17, o ângulo representado por $\delta$ corresponde à Declinação Solar, esse ângulo é responsável pela alteração da altura do Sol no horizonte no mesmo horário em diferentes dias do ano. A declinação solar varia conforme o dia do ano no seguinte intervalo:

$$
-23,45^{\circ} \leq \delta \leq 23,45^{\circ}
$$

Do ponto de vista de um observador na Terra, posicionado em determinada latitude, a posição do Sol, em relação ao ponto de observação, varia ao longo do eixo Leste-Oeste, ao longo do dia, em função do movimento de rotação e sofre certa variação no eixo Norte-Sul ao longo do ano em função do movimento de translação da Terra inclinada.

Durante os equinócios (21/03 e 21/09), momentos em que o Sol está sobre o plano do equador, o período de incidência da radiação solar é de 12 horas para todos os locais da Terra e o ângulo de incidência dos raios do Sol ao meio dia é de $90^{\circ}$ na Linha do Equador. Já nas demais latitudes, o ângulo de incidência dos raios solares ao meio dia é menor do que $90^{\circ} \mathrm{em}$ função da declinação solar.

O que define o ângulo de incidência dos raios solares é o ângulo zenital. O ângulo zenital $\left(\theta_{z}\right)$ é definido como a angulação entre a posição do Sol no céu e a vertical (Zênite). Este ângulo é complementar ao ângulo de incidência dos raios solares (ou altura solar). O ângulo zenital é definido em função da declinação solar $(\delta)$, latitude $(\phi)$ e o ângulo horário solar $(h)$.

O ângulo horário solar é definido em função do movimento de rotação da Terra que rotacionando $360^{\circ} \mathrm{em}$ aproximadamente 24 horas define uma velocidade angular $(\omega)$ de $15^{\circ}$ por hora. A relação entre esse ângulo e as horas do dia $\left(h_{s}\right)$ é apresentada na Tabela 6.

Tabela 6 - Relação entre o tempo solar e o ângulo horário solar

\begin{tabular}{llllllllllllllll}
\hline hs & $\ldots$ & 6 & 7 & 8 & 9 & 10 & 11 & 12 & 13 & 14 & 15 & 16 & 17 & 18 & $\ldots$ \\
\hline h & $\ldots$ & -90 & -75 & -60 & -45 & -30 & -15 & 0 & 15 & 30 & 45 & 60 & 75 & 90 & $\ldots$ \\
\hline
\end{tabular}

Fonte: SHAYANY, 2006

Deste modo, pode-se definir matematicamente a velocidade angular da terra como:

$$
\omega=d h / d t
$$

A relação que define o ângulo zenital pode ser obtida pela construção de um triângulo esférico (SHAYANY, 2006), de modo que: 


$$
\cos \theta_{z}=\sin \phi \sin \delta+\cos \phi \cos \delta \cos h
$$

A demonstração da expressão pode ser encontrada em VIANELLO e ALVES (2002).

Quando o Sol está na altura máxima (no zênite, $\theta_{z}=0$ ), a área sobre a qual a energia da radiação se distribui é mínima e o fluxo de energia é máximo. Quanto menor a altura do Sol, maior a área na superfície da Terra alcançada pelos raios solares e consequentemente menor a insolação.

Para Porto Alegre, por exemplo, cuja latitude é $30^{\circ}$, a altura máxima do Sol no Solstício de Verão é $83,55^{\circ}$, já que o Sol está a $\left(30^{\circ}\right.$ lat. - $23,45^{\circ}$ decl.) $6,55^{\circ}$ do zênite ao meio-dia local. Ao meio-dia, no Solstício de Inverno a altura máxima do Sol é $36,55^{\circ}\left(30^{\circ}\right.$ lat $+23,45^{\circ}$ decl. $=53,55^{\circ}$ do zênite $)$.

Para o meio dia, admite-se $h=0$, desse modo:

$$
\cos \theta_{z}=\sin \phi \sin \delta+\cos \phi \cos \delta
$$

Aplicando-se a relação trigonométrica, tem-se que:

$$
\cos \theta_{z}=\cos (\phi-\delta)
$$

Portanto, para o meio dia, $\theta_{z}=|\phi-\delta|$.

O montante de radiação que constitui a energia primária disponível é aquele que incide normal à superfície de captação, considerando uma superfície de captação sem ângulo de inclinação, a maior disponibilidade se dá quando $\Theta_{z}$ tende à zero. Utilizando-se desse raciocínio SHAYANI (2006) define que a menor componente horizontal da radiação ocorre quando $\phi=\delta$. Essa situação só pode ser verificada ao longo do ano na região compreendida aproximadamente entre os trópicos de câncer e capricórnio. Portanto, analisando-se apenas a dinâmica de movimento Terra-Sol, esta é a região aonde a incidência da radiação pode ser melhor aproveitada.

Pela relação da equação (7) pode-se calcular o ângulo zenital ao meio dia de cada dia do ano, para cada latitude. A declinação solar para cada dia do ano pode ser encontrada por meio da relação (SENTELHAS e ANGELOCCI, 2009):

$$
\delta=23,45 \sin [(360 / 365)(N D A-80)]
$$

A parcela da radiação aproveitada por uma superfície horizontal corresponde à componente vertical da radiação incidente, também denominada de irradiância global horizontal extraterrestre $\left(I G H_{0}\right)$ em W/m² ou a irradiação global horizontal extraterrestre em 
$\left(\mathrm{Wh} / \mathrm{m}^{2}\right)$. Portanto a parcela aproveitável da energia extraterrestre para o meio dia, em cada dia do ano, para diferentes latitudes é definido por:

$$
I G H_{0}=I D N_{0} \cos \theta_{z}
$$

Utilizando-se das equações (2), (3), (7), (8) e (9) é possível calcular a irradiância extraterrestre ao meio dia para cada latitude. Os gráficos das Figuras 18 e 19 mostram o valor da componente vertical da irradiação extraterrestre incidente, em $\mathrm{Wh} / \mathrm{m}^{2}$, para as diferentes latitudes, ao meio dia, para cada dia juliano.

Figura 18 - Irradiação extraterrestre ao meio dia para cada dia juliano- Hemisfério Norte

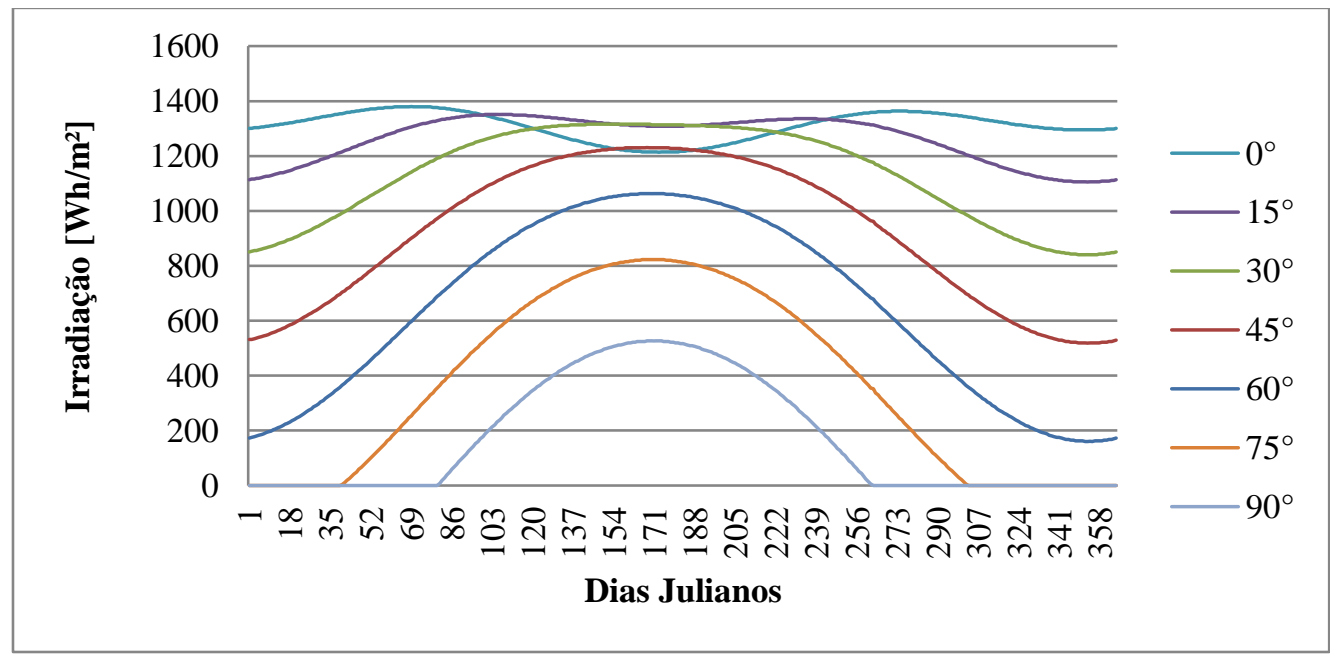

Fonte: Elaboração própria

Figura 19 - Irradiação extraterrestre ao meio dia para cada dia juliano- Hemisfério Sul

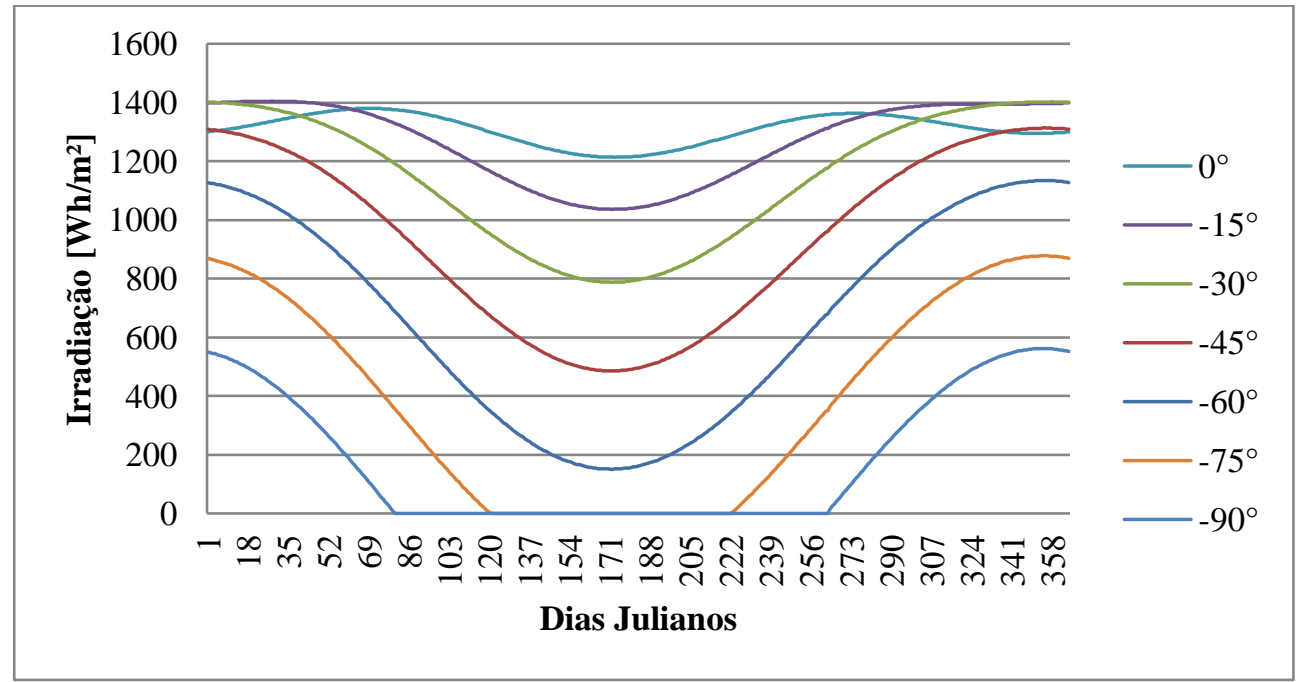

Fonte: Elaboração própria, 2015 
As curvas para as latitudes opostas apresentam comportamentos praticamente opostos para a irradiação ao meio dia. A curva da irradiação na linha do equador é a que apresenta a maior média. Para as curvas das latitudes $90^{\circ}, 75^{\circ},-75^{\circ}$ e $-90^{\circ}$, verificam-se períodos de valores nulos. A declinação da Terra também define os fotoperíodos. Regiões de latitudes extremas possuem períodos do ano de pleno Sol e outros de plena escuridão. A diferença entre os fotoperíodos ao longo dos dias do ano reduz na medida em que se aproxima de latitudes próximas à nula. Contudo, para todas as regiões, a média anual do fotoperíodo é de 12 horas diárias. Calculando-se a média de cada curva, observa-se o gráfico da Figura 20.

Figura 20 - Irradiação média ao meio dia para faixas de $15^{\circ}$ de latitude

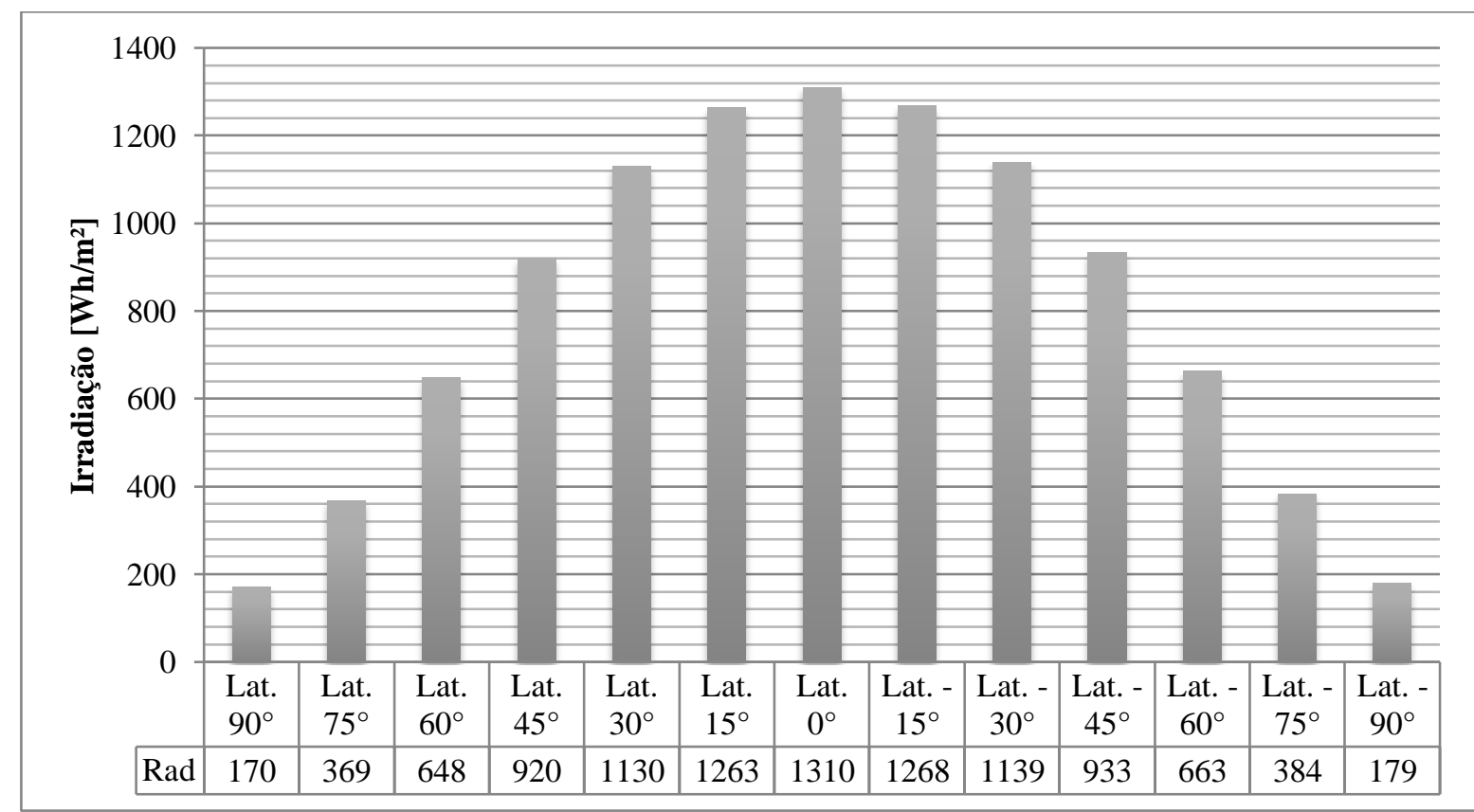

Fonte: Elaboração própria

As médias da irradiação ao meio dia para as latitudes do hemisfério Norte são ligeiramente menores do que as médias do hemisfério Sul. Isso ocorre em função do Afélio e Periélio, apresentados na Figura 14.

O gráfico da Figura 21 apresenta as curvas da declinação solar e da relação entre a distância média e a distância real da Terra em relação ao Sol para cada dia do ano. Quando os valores de $R_{m} / R$ são maiores do que 1 , a Terra se encontra à menores distâncias do Sol ao longo dos dias. Nesse período verificam-se declinações negativas, ou seja, é o período do ano no qual a incidência de raios solares no Hemisfério Sul é maior e mais intensa, como apresentado na Figura 17. 
Figura 21 - Declinação da Terra e distância Terra-Sol para cada dia juliano

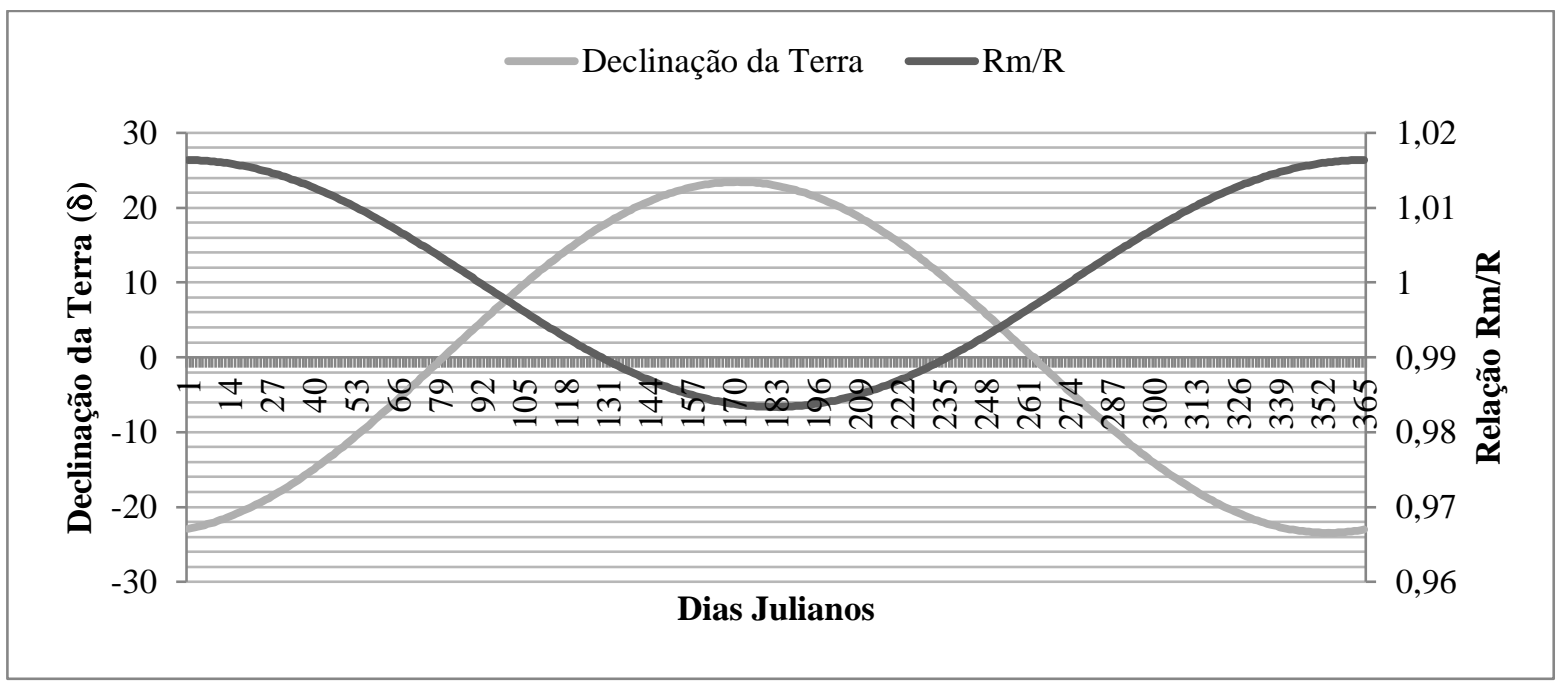

Fonte: Elaboração própria

A Tabela 7 define as datas específicas de ocorrência desses eventos que alteram o comportamento da incidência da irradiância extraterrestre para as diferentes faixas de latitude.

Tabela 7 - Datas de eventos característicos da dinâmica Terra-Sol

\begin{tabular}{llllll}
\hline Data & $\begin{array}{c}\text { Dia } \\
\text { Juliano }\end{array}$ & Evento & $\begin{array}{c}\text { Distância Sol- } \\
\text { Terra }(\mathbf{R m} / \mathbf{R})\end{array}$ & $\begin{array}{c}\text { Irradiância } \\
\text { Extraterrestre } \\
\left(\mathbf{I D N}_{\mathbf{0}}\right)\left[\mathbf{W} / \mathbf{m}^{2}\right]\end{array}$ & $\begin{array}{c}\text { Declinação } \\
\text { da Terra }\left(^{\circ}\right)\end{array}$ \\
\hline $03 / 01$ & 3 & Periélio & 1,016 & 1412 & $-22,75$ \\
\hline $21 / 03$ & 80 & Equinócio & 1,003 & 1375,7 & 0 \\
\hline $21 / 06$ & 172 & Solstício & 0,984 & 1322,6 & 23,45 \\
\hline $04 / 07$ & 185 & Afélio & 0,983 & 1321,9 & 22,8 \\
\hline $21 / 09$ & 264 & Equinócio & 0,997 & 1359,5 & 0 \\
\hline $21 / 12$ & 355 & Solstício & 1,016 & 1411,4 & $-23,45$ \\
\hline
\end{tabular}

Fonte: Elaboração própria

Os gráficos das Figuras 22 e 23 foram elaborados com base nas equações (2), (3), (5), (8) e (9) para os dias da Tabela 7, para faixas de $30^{\circ}$ de latitude. 
Figura 22 - Fotoperíodo nos equinócios para faixas de latitude de $30^{\circ}$

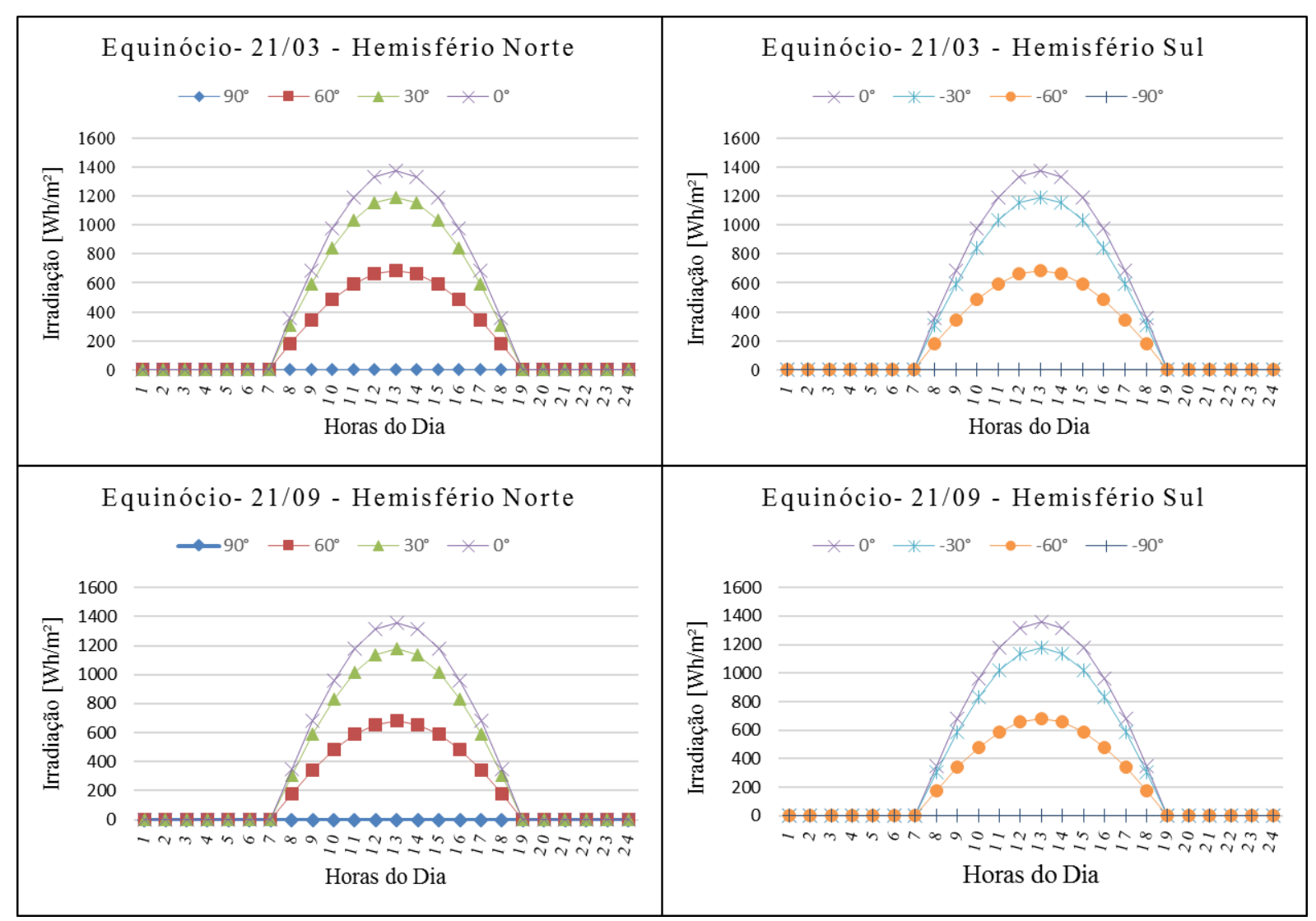

Fonte: Elaboração própria

Durante os equinócios o fotoperíodo é de 12 horas para todas as latitudes nas quais incide a luz solar. Contudo, as faixas de latitudes menos extremas recebem mais radiação durante o fotoperíodo em função da maior componente vertical do ângulo de incidência da radiação.

Já para as datas de solstício, é possível verificar como o fotoperíodo se altera em cada faixa de latitude. Latitudes próximas à linha do equador sofrem menos o efeito dessa alteração. 
Figura 23 - Fotoperíodo nos Solstícios para faixas de latitude de $30^{\circ}$

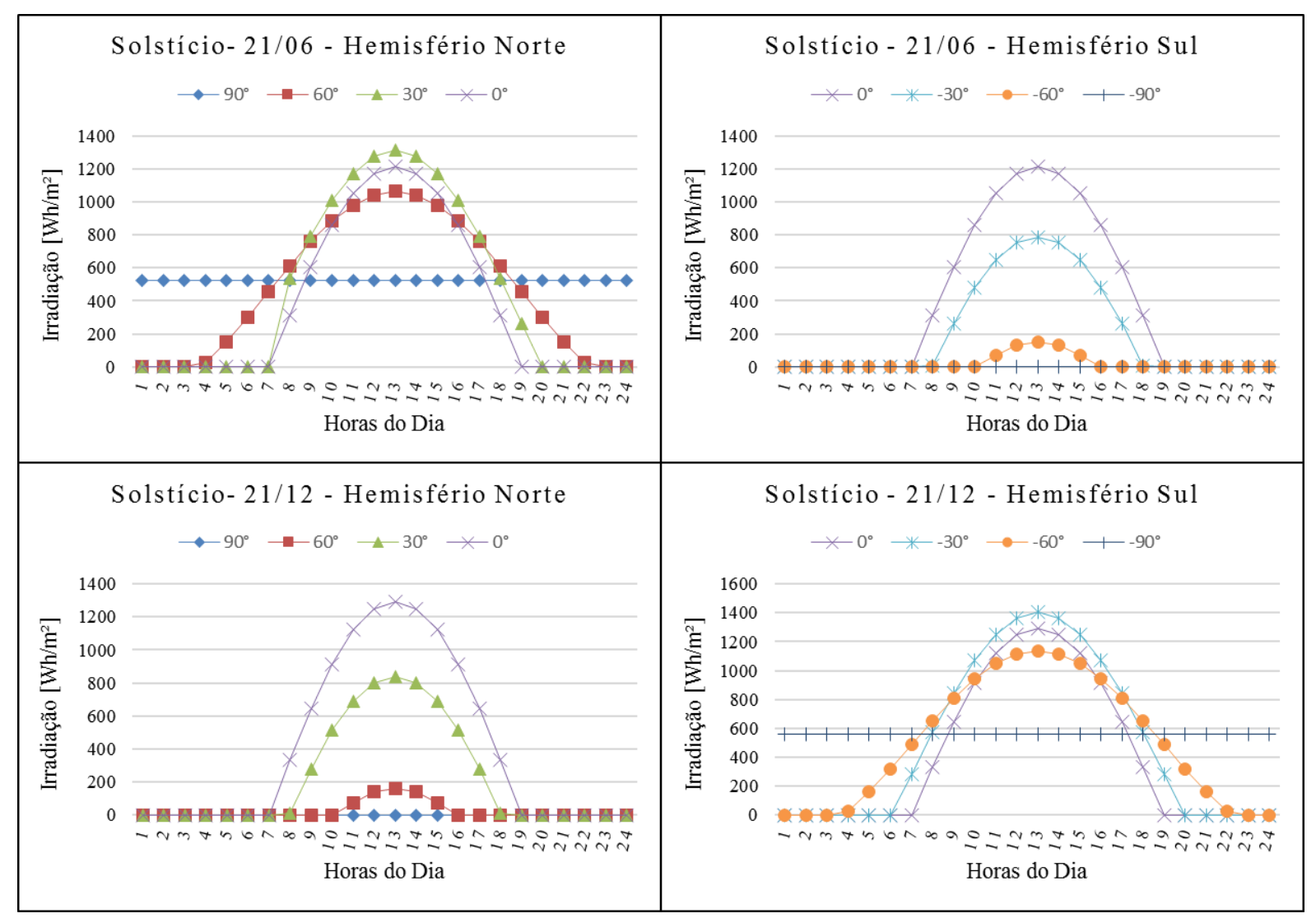

Fonte: Elaboração própria, 2015

$I G H_{0}$, para um dado momento, pode ser calculado por meio da equação (10). Como pode ser observado pela análise dos gráficos das Figuras 22 e 23, é possível verificar que o valor diário de $\mathrm{IGH}_{0}$ é obtido por meio do cálculo da área correspondente à curva da irradiância horizontal extraterrestre e o eixo $x$, ou seja:

$$
I G H_{0}^{\text {Diário }}=\int_{t_{p}}^{t_{n}} I D N_{0} \cos \theta_{z} d t
$$

Aonde $t_{n}$ e $t_{p}$ indicam o momento de nascer e pôr do sol respectivamente. Deste modo, substituindo-se IDN $_{0}$ pela equação (2) e considerando $I_{0}=1367 \mathrm{~W} / \mathrm{m}^{2}$, substituindo $\cos \theta_{z}$ pela equação (5) e $d t$ por $(d h / d \omega)$ como indica a equação (4), e sabendo-se que $t_{n}$ e $t_{p}$ correspondem aos ângulos horários $-H$ e $+H$, como mostrado na Tabela 6 , a resolução da integral é: 


$$
I G H_{0}^{\text {Diário }}=37,6\left(\frac{R_{m}}{R}\right)^{2}(H \sin \phi \sin \delta+\cos \phi \cos \delta \operatorname{sen} H)
$$

Com $H$ representando a duração astronômica do período diurno, em unidade de

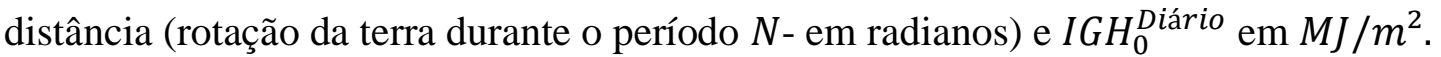

Os ângulos $-h$ e $+h$, que correspondem ao nascer e pôr do sol respectivamente $\mathrm{e}$ ocorrem quando o ângulo zenital se encontra na posição de $90^{\circ}$, portanto, zerando o termo $\cos \theta_{z}$ na equação (5), temos que:

$$
\begin{aligned}
& 0=\sin \phi \sin \delta+\cos \phi \cos \delta \cos h \\
& \cos h=-\frac{\sin \phi \sin \delta}{\cos \phi \cos \delta}: \\
& \cos h=-\operatorname{tg} \phi \operatorname{tg} \delta
\end{aligned}
$$

A duração $N$ pode ser calculada por meio da expressão:

$$
\mathrm{N}=2 \mathrm{H} / 15
$$

A alteração causada pela distância Sol-Terra na radiação extraterrestre é da ordem de 3\%. O gráfico da Figura 24 apresenta a irradiação global horária na linha do equador para os dias de Afélio e Periélio.

Figura 24 - Irradiação extraterrestre na linha do Equador

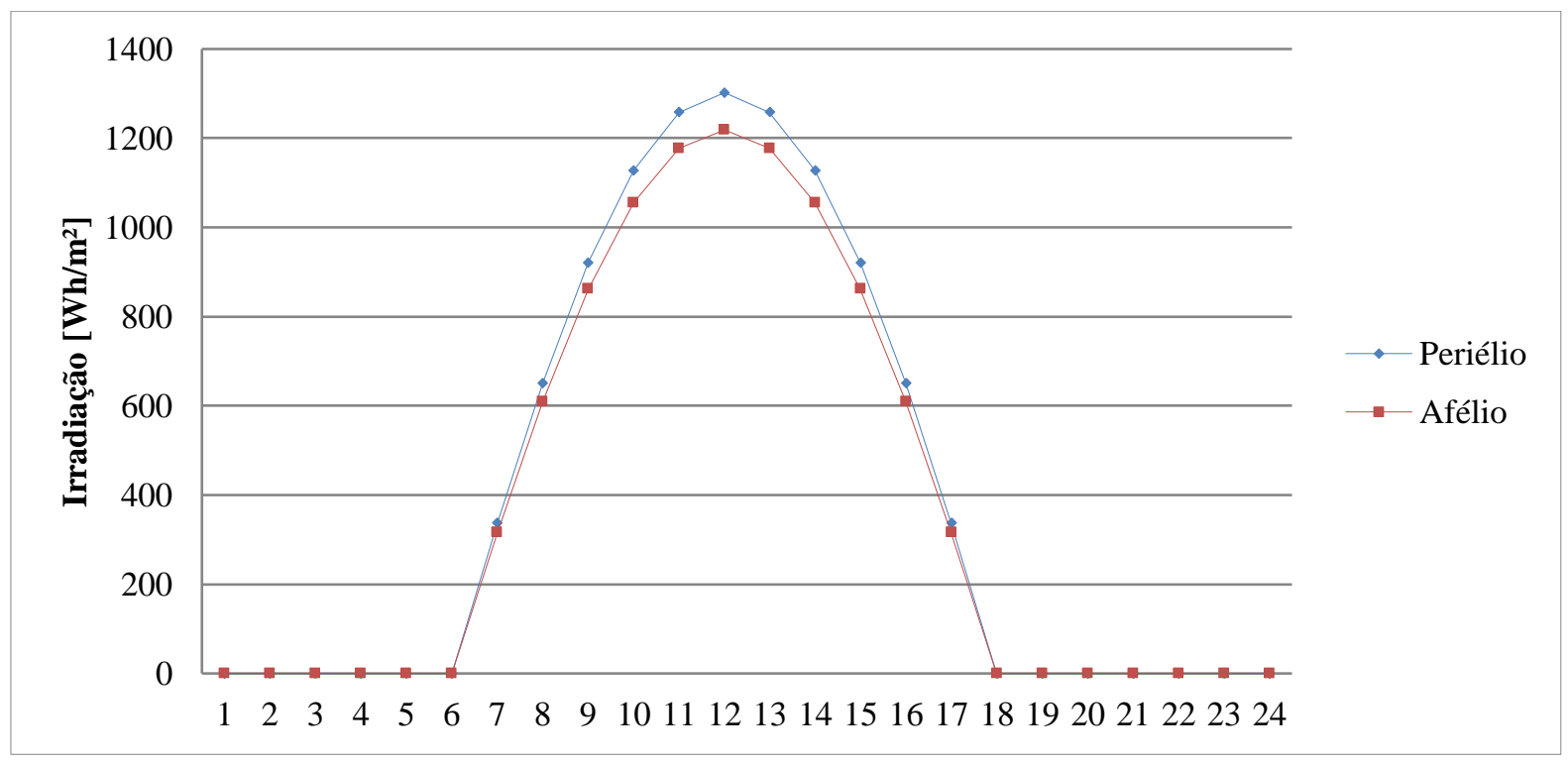

Fonte: Elaboração Própria, 2015 
Essa diferença, quando considerado o efeito que a atmosfera exerce sobre a radiação, se torna praticamente desprezível. A radiação eletromagnética proveniente do Sol, quando em contato com algum meio físico, interage com o mesmo, gerando fenômenos como a refração e a absorção. A densidade do fluxo de energia solar e o espectro da radiação que chega ao topo da atmosfera são diferentes daqueles que alcançam a superfície terrestre. A razão entre a irradiância solar na superfície terrestre e no topo da atmosfera é definida como transmitância atmosférica.

\subsection{TRANSMITÂNCIA ATMOSFÉRICA}

A radiação solar é atenuada pelos processos de absorção e espalhamento causados pelas partículas aerossóis, de gases atmosféricos e pelo vapor d'água. Os coeficientes de absorção e espalhamento dependem da composição do espectro da luz solar e da composição atmosférica de gazes e aerossóis, como esses fatores são de grande variabilidade, a transmitância atmosférica é variável e de difícil determinação. (MARTINS et al., 2004)

As características físicas da atmosfera são tão complexas que certamente o homem jamais conseguirá simulá-la fielmente em laboratório (...). A enorme variação das escalas espaciais e temporais dos fenômenos meteorológicos - desde segundos até milhares de anos de duração; desde centímetros até dezenas de quilômetros de escala espacial - complica ainda mais os estudos meteorológicos. Outra grande dificuldade da modelagem atmosférica se refere à composição do ar atmosférico: a presença de todos os estados da matéria, as mudanças de fase, as reações químicas e fotoquímicas, as trocas de propriedades, os diferentes regimes de escoamentos (...) tudo isso deve ser considerado nos estudos diagnósticos e prognósticos da atmosfera. (VIANELLO e ALVES, 2002; pg. 23).

O espectro da luz solar, antes de passar pela atmosfera é composto por 53\% de radiação invisível aos olhos humanos, desta parcela, uma pequena parte corresponde à radiação ultravioleta (ondas com comprimento menor que $400 \mathrm{~nm}$ ) e uma grande parte corresponde à radiação infravermelha (ondas com comprimentos maiores que $780 \mathrm{~nm}$ ). $\mathrm{O}$ restante do espectro- 47\%- corresponde à parcela de luz visível com ondas de comprimento entre $380 \mathrm{~nm}$ e $780 \mathrm{~nm}$. O gráfico da Figura 25 mostra como a transmitância atmosférica altera o espectro solar que alcança a superfície terrestre através dos processos de absorção e espalhamento. 
Figura 25 - Alteração do espectro solar em função da transmitância atmosférica

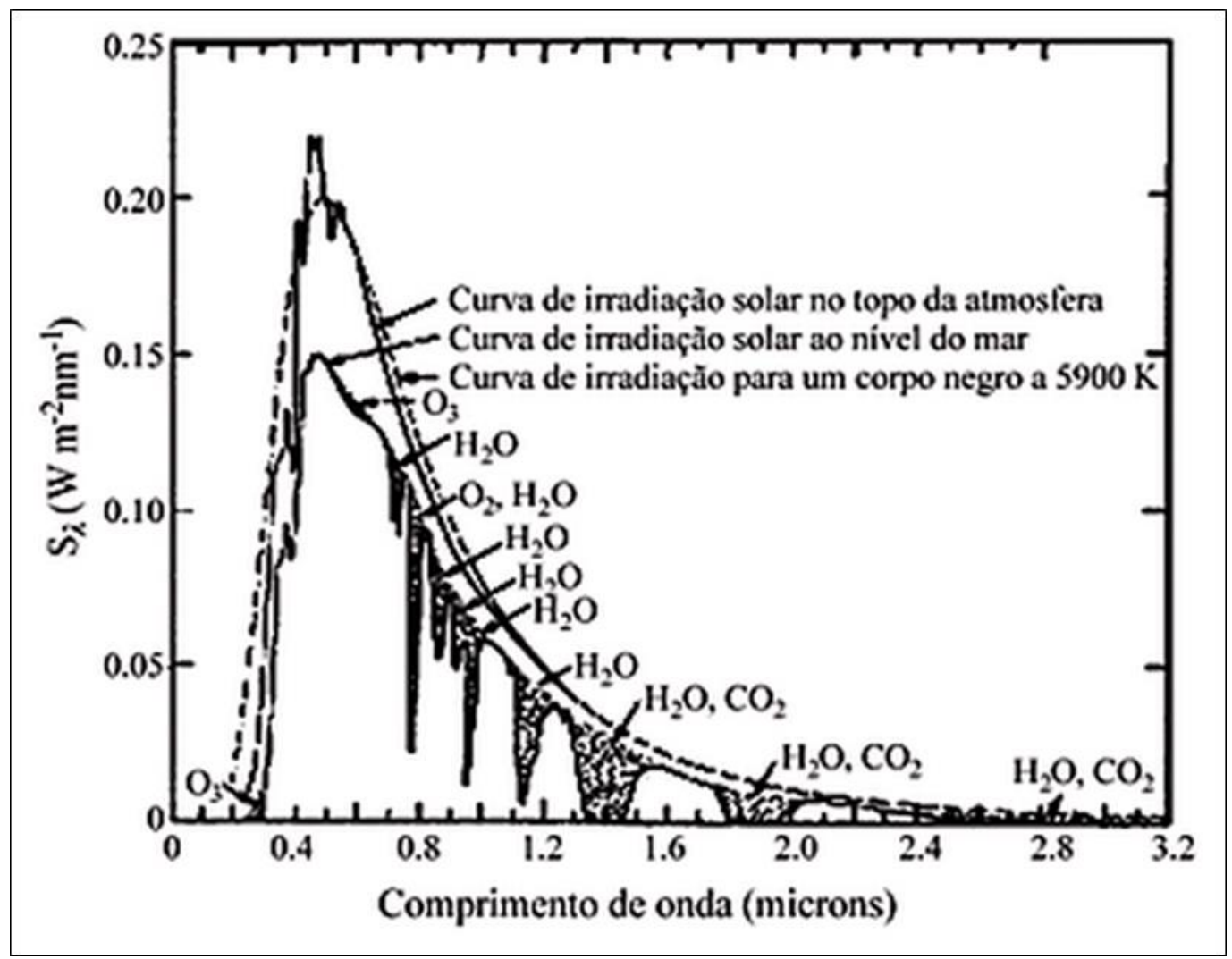

Fonte: MARTINS; et.al., 2004

O processo de espalhamento (puro) ocorre quando toda a energia do feixe luminoso que incidir em uma partícula da atmosfera permanecer no campo de radiação dessa partícula. Nesse caso, toda a energia do feixe luminoso é dispersada pela partícula em todas as direções, como se essa partícula estive se transformado em um corpo emissor de energia. Pela teoria de Rayleigh, o espalhamento da energia de um feixe luminoso, por uma partícula esférica de raio $R$, é inversamente proporcional à quarta potência do comprimento de onda $\lambda$ do feixe, desde que $R<0,1 \lambda$. No caso de $R>0,1 \lambda$, a teoria de Rayleigh não se aplica, tornando-se necessário a utilização de uma teoria mais complexa, como a Teoria de Mie (VIANELLO e ALVES, 2002).

A Teoria de Mie é válida para a refração de ondas de qualquer comprimento, por partículas de qualquer tamanho, contudo, a técnica resulta em uma soma numérica infinita, os valores finais dos coeficientes de refração são obtidos por aproximações matemáticas. O espalhamento proporcionado pela atmosfera terrestre é maior para os comprimentos de onda menores. 
A maior parte da radiação ultravioleta sofre processos de absorção e espalhamento ao passar pela camada de Ozônio. As moléculas de ar interferem mais nas radiações de ondas curtas do que em ondas longas. Mais de 99\% da radiação solar apresenta ondas com comprimento inferior à $5 \mu \mathrm{m}$, com a maior parte compreendendo em 0,4 e $1,2 \mu \mathrm{m}$. Isso indica que praticamente toda a radiação solar encontra-se na região de ondas curtas. Os componentes atmosféricos interferem mais ou menos em determinados comprimentos de onda. A absorção da radiação solar é seletiva, sendo o vapor d'água, o ozônio $\left(\mathrm{O}_{3}\right)$ e o dióxido de carbono $\left(\mathrm{CO}_{2}\right)$ os principais agentes absorvedores, como mostrado no gráfico da Figura 25. A radiação reemitida pelo sistema Terra- Atmosfera compreende a faixa do infravermelho. (MARTINS et al., 2004)

Quanto maior o percurso da radiação ao longo da atmosfera, maior a interação entre a atmosfera e a radiação solar, e quanto maior a interação, maior é a ocorrência de processos de absorção e espalhamento da radiação. Nesse sentido, define-se a Massa de $\operatorname{Ar}(\mathrm{AM})$. O fator AM indica um múltiplo do percurso da radiação solar na atmosfera. A relação entre o ângulo zenital e a Massa de Ar, é definida do seguinte modo:

$$
A M=1 / \cos \theta_{z}
$$

Assim, quando o Sol se encontra na posição Zenital $\left(\Theta_{Z}=0^{\circ}\right), A M=1$. A Figura 26 mostra a relação de AM para algumas configurações de posição solar.

Figura 26 - Massa de ar para diferentes ângulos zenitais

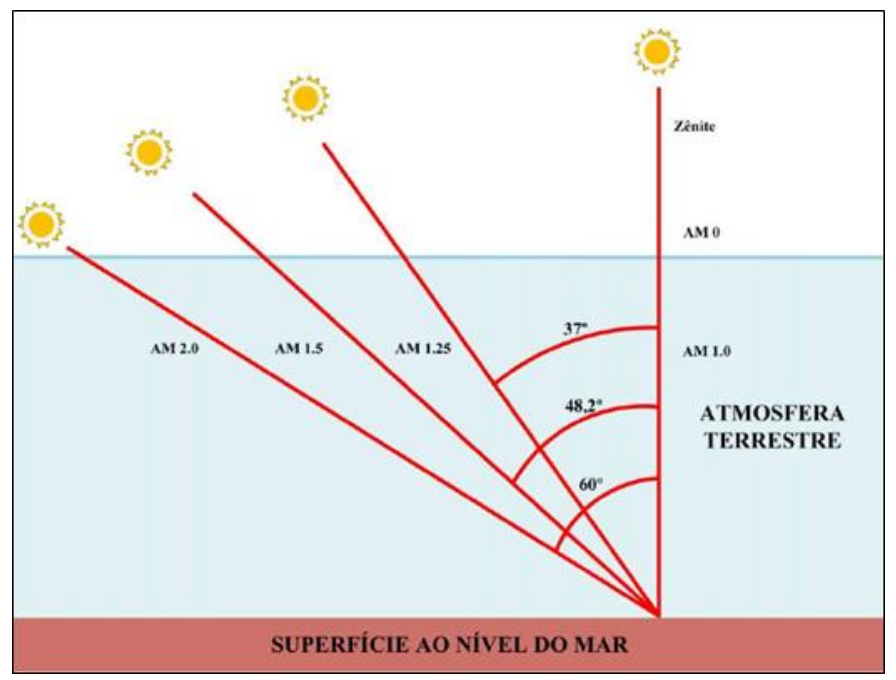

Fonte: VILELA, 2010 
Define-se, portanto, que a transmitância atmosférica é definida basicamente pelos seguintes elementos:

- Dispersão de Rayleigh (dispersão molecular);

- Dispersão de Mie (dispersão por partículas de pó e poluição do ar);

- Absorção pelas moléculas da atmosfera $\left(\mathrm{O}_{3}, \mathrm{H}_{2} \mathrm{O}, \mathrm{O}_{2}, \mathrm{CO}_{2}\right)$.

A Tabela 8 mostra algumas relações entre a parcela de radiação afetada pela transmitância atmosférica em função dos coeficientes de dispersão e absorção e das massas de ar. Os intervalos dos valores estimados possuem uma variação expressiva, isso mostra a dificuldade de definição da influência atmosférica na radiação incidente.

Tabela 8 - Absorção e dispersão da radiação solar em função da massa de ar e da altura solar

\begin{tabular}{cccccc}
\hline $\boldsymbol{\theta}_{\mathbf{z}}$ & AM & Absorção & Dispersão de Rayleigh & Difusão de Mie & Redução Total \\
\hline $\mathbf{0}^{\circ}$ & 1,00 & $8,7 \%$ & $9,4 \%$ & $0-25,6 \%$ & $17,3-38,4 \%$ \\
\hline $\mathbf{3 0}^{\mathbf{0}}$ & 1,15 & $9,2 \%$ & $10,5 \%$ & $0,7-29,5 \%$ & $19,4-42,8 \%$ \\
\hline $\mathbf{6 0}^{\mathbf{0}}$ & 2,00 & $11,2 \%$ & $16,3 \%$ & $4,1-44,9 \%$ & $28,8-59,1 \%$ \\
\hline $\mathbf{8 0}^{\mathbf{0}}$ & 5,76 & $16,2 \%$ & $31,9 \%$ & $15,4-74,3 \%$ & $51,8-85,4 \%$ \\
\hline $\mathbf{8 5}^{\circ}$ & 11,5 & $19,5 \%$ & $42,5 \%$ & $24,6-86,5 \%$ & $65,1-93,8 \%$ \\
\hline
\end{tabular}

Fonte: adaptado de DGS, 2005

Portando, admitindo-se o cálculo da irradiância extraterrestre já apresentado, a irradiância direta que alcança a superfície terrestre $(I D N)$ pode ser calculada com um alto grau de confiabilidade sabendo-se (i) a composição espectral extraterrestre, (ii) a composição e distribuição dos elementos na atmosfera naquele determinado momento (iii) a distância entre o Sol e a Terra no determinado dia do ano e (iv) o tamanho do percurso da radiação através da atmosfera, definido pelo ângulo zenital e altura solar. Dessa maneira, IDN pode ser definido como:

$$
I D N_{\text {instantânea }}=I D N_{0} \cdot t
$$

Onde, $I D N_{0}$ corresponde à irradiância direta normal extraterrestre, já definida na equação (2) e $t$ à transmitância atmosférica. A grande dificuldade é justamente na determinação da transmitância. Para tal, e devido à escassez de medições da radiação em solo, uma série de fórmulas e modelos matemáticos foram gerados para a estimativa das parcelas de irradiância direta normal, global horizontal, difusa horizontal e dos índices de transmitância no geral. 
Segundo VIANELLO e ALVES (2002), $t$ pode ser definido por meio da expressão:

$$
\begin{aligned}
& t=\exp \cdot\left[-0,089(P \cdot A M / 1013)^{0,75}-0,174\left(W_{n} \cdot A M / 20\right)^{0,60}-\right. \\
& \left.0,083(D \cdot A M)^{0,90}\right]
\end{aligned}
$$

Aonde, $P$ corresponde à pressão atmosférica em milibars, $W_{n}$ à quantidade de água precipitável na atmosfera na direção zenital em mm, $A M$ à massa ótica de ar e $D$ corresponde a um padrão adimensional de poeiras.

A massa de ar, como já exposto, possui relação com o percurso que a radiação faz ao longo da atmosfera e possui relação direta com o ângulo zenital. A relação entre a massa de ar e o ângulo zenital pode ser calculada pela equação (13) ou pela expressão dada por VIANELLO e ALVES (2002):

$$
A M=35\left(1224 \cdot \cos ^{2} \theta_{z}+1\right)^{-1 / 2}
$$

Já VIGNOLA et al. (2012) definem a transmitância atmosférica como:

$$
\mathrm{t}=\exp \cdot\left[\left(-\mathrm{AM} \cdot\left(\tau_{\mathrm{a}}+\tau_{\mathrm{r}}+\tau_{\mathrm{g}}+\tau_{\mathrm{NO}_{2}}+\tau_{\mathrm{w}}+\tau_{\mathrm{O}_{3}}\right)\right]\right.
$$

Aonde $\tau_{a}$ corresponde à profundidade ótica devido à absorção e espalhamento por aerossóis, $\tau_{r}$ corresponde à profundidade ótica devido à dispersão de Rayleigh, $\tau_{g}$ corresponde à profundidade ótica em função da absorção por outros gases, que não sejam: dióxido de carbono $\left(\mathrm{CO}_{2}\right)$, oxigênio $\left(\mathrm{O}_{2}\right)$ e dióxido de nitrogênio $\left(\mathrm{NO}_{2}\right), \tau_{\mathrm{NO}_{2}}$ corresponde à profundidade ótica em função da absorção por dióxido de nitrogênio, $\tau_{w}$ corresponde à profundidade ótica em função da absorção pelo vapor d'água e $\tau_{O_{3}}$ corresponde à profundidade ótica em função da absorção pelo ozônio.

Os coeficientes das equações (15) e (17) variam em função do espaço e tempo. VIANELLO e ALVES (2002) indicam que o padrão adimensional de poeiras (D), por exemplo, foi definido por Schulze como um valor que varia entre 0,2 e 3 conforme as condições atmosféricas. Os autores encontram um coeficiente $D=0,41$ para Viçosa-MG, para o mês de junho. Ainda segundo os mesmos autores, $W_{n}$ pode ser obtida pela fórmula de Hann e assume o valor de 2,5. Já as variáveis expostas por VIGNOLA et al. (2012) são colocadas de maneira genérica, indicando uma expressão geral que engloba as variáveis 
consideradas nos modelos matemáticos de estimação da irradiação, portanto, não foram atribuídos valores a elas.

\subsection{MODELOS DE ESTIMATIVA DA IRRADIAÇÃO}

Os métodos para a estimativa de irradiação ${ }^{25}$ podem ser definidos a partir de quatro práticas: (i) utilização de medições de uma ES próxima, (ii) interpolação dos dados de várias estações próximas, (iii) uso de dados estimados via satélite, por meio da análise de imagens que indicam a cobertura de nuvens e (iv) emprego de modelos. Os modelos podem ser definidos principalmente em duas categorias: (a) empíricos ou (b) físicos (WEBER, 2011), ainda que também hajam os modelos estatísticos que são detalhados no Capítulo 5.

Os modelos empíricos são aqueles que partem de uma variável climatológica (como insolação, umidade relativa do ar, gradiente de temperatura) e relacionam tal variável ao montante de irradiação global (médio horário, diário, mensal ou anual) por meio de variáveis empíricas que devem ser determinadas para cada região de estudo, através de dados existentes, normalmente por meio da aplicação de regressão linear. Normalmente esses modelos partem do valor de irradiação extraterrestre, buscando demais parametrizações de atenuação do efeito atmosférico.

Os modelos físicos constituem uma abordagem teórica que busca definir a equação de transferência radiativa para descrever matematicamente os processos físicos que ocorrem na atmosfera (WEBER, 2011). Contudo, tal definição é bastante complexa, visto a dificuldade em identificar a composição atmosférica, como mostrado na Tabela 8.

A quantidade de modelos empíricos encontrados na bibliografia referente ao assunto é bastante significativa. Muitos dos modelos de estimativa de irradiação global são desenvolvidos pelas ciências agrônomas já que a irradiação diária global é um dado de entrada nos modelos de definição da evapotranspiração de referência. Verifica-se também grande quantidade de modelos aplicados em países do hemisfério norte, com poucas aplicações e adaptações para países do hemisfério sul. Também é notável a dificuldade de identificar publicações e estudos científicos que busquem a aplicação desses modelos com o intuito de estimar o montante de energia para fins energéticos.

\footnotetext{
${ }^{25}$ Nessa seção utiliza-se tanto o termo irradiação quanto irradiância. Os modelos de estimativa geralmente partem da perspectiva da identificação do montante de energia diário ou horário, ou seja: "a irradiância solar integrada durante um intervalo de tempo especificado, normalmente uma hora ou um dia (...)", conforme detalhado na pg. 34. Contudo, buscou-se respeitar a terminologia adotada por cada autor.
} 
Como o objetivo deste trabalho visa a geração de energia e o conhecimento do comportamento da irradiação para esse fim no Brasil, buscaram-se analisar modelos testados principalmente no país e em países do hemisfério sul que se utilizam de dados de demais variáveis climatológicas, com o intuito de identificar as correlações entre a radiação e as demais condições climáticas. As seções seguintes tratam de alguns desses modelos ${ }^{26}$.

\subsubsection{Modelos Empíricos para Estimativa da Irradiação Direta e Difusa}

São muito comuns os modelos que definem a irradiação difusa e direta com base em medições da irradiação global. Estes modelos são denominados "modelos de decomposição" (RAICHIJK e TADDEI, 2012). Muitos deles possuem como variável de entrada apenas os dados de irradiação ou irradiância global. O princípio de construção desses modelos parte da formação de séries históricas das frações difusas $\left(k_{d}^{\prime}\right)$, de índices de transmitância $\left(k_{t}\right)$, ou da fração direta $\left(k_{n}^{\prime}\right)$. As equações (18), (19) e (20) definem o cálculo desses coeficientes.

$$
\begin{aligned}
& k_{d}^{\prime}=I D H / I G H \\
& k_{t}=I G H / I G H_{0} \\
& k_{n}^{\prime}=I D N \cdot \cos \theta_{Z} /_{I G H}
\end{aligned}
$$

De posse das medições de irradiação $\left(\mathrm{Wh} / \mathrm{m}^{2}\right)$ ou irradiância $\left(\mathrm{W} / \mathrm{m}^{2}\right)$ global, o $k_{t}$ pode ser facilmente calculado. Muitos dos modelos de decomposição apresentam equações para $k_{d}^{\prime}$ e $k_{n}^{\prime}$ em função dos $\mathrm{k}_{\mathrm{t}}$ encontrados. Ou seja, esses modelos não vinculam a definição das irradiações a nenhuma variável climatológica, mas sim à definição de um histórico padrão do comportamento da transmitância. Essas correlações entre estes índices geralmente são criadas de posse das três medições (irradiância direta, difusa e global), nas quais se aplicam cálculos de correlações, definindo equações empíricas que possam ser aplicadas em outras regiões nas quais só haja a disponibilidade de dados de irradiância ou irradiação global.

Além desse tipo de modelo, a irradiação ou irradiância direta pode ser estimada por meio das equações de transmitância, como as apresentadas nas equações (15) e (17). Já o cálculo da parcela de irradiância difusa normalmente é definido por meio de modelos que relacionam a irradiância global com a irradiância direta normal, definindo um coeficiente de

\footnotetext{
${ }^{26}$ As referências bibliográficas originais dos modelos tratados nas seções seguintes podem ser encontradas em cada um dos autores referenciados que produziram os trabalhos de análises dos respectivos modelos.
} 
relação entre essas duas parcelas. Contudo, como já citado no Capítulo 3, essa relação não é linear, baixos valores de irradiância difusa ocorrem quando a irradiância global está baixa, em dias de céu muito nublado, ou quando a irradiância global está alta, em dias de céu limpo.

VIANELLO e ALVES (2002) apresentam duas expressões para a estimativa da irradiação difusa. Ambas foram desenvolvidas empiricamente. A primeira corresponde a equação de Albrecht, definida como:

$$
I D H=a\left(I D N_{W}-I D N\right) \cos \theta_{Z}
$$

Sendo a o coeficiente empírico, a ser definido para cada região. IDN está definido na equação (14) e $I D N_{W}$ corresponde à irradiação solar direta em uma superfície normal à incidência dos raios solares ao nível do solo atenuada apenas pelo vapor d'água. $I D N_{W}$ pode ser obtida pela expressão:

$$
\begin{array}{r}
I D N_{W}=I D N_{0} \times 0,938^{-0,0154 W \cdot A M}+0,004\left(W_{n} \cdot A M\right)^{2,1}-1,086 \times \\
10^{-5}\left(W_{n} \cdot A M\right)^{3}+\left[121,948(1+W \cdot A M) / 1+\left(W_{n} \cdot A M\right)^{2}\right]
\end{array}
$$

A segunda expressão apresentada por VIANELLO e ALVES (2002) foi desenvolvida para a Austrália e segundo os autores, apresentou bons resultados quando usada em ViçosaMG. A expressão é definida como:

$$
I D H=0,007167+0,1357(1-0,0111)^{0,05 \cdot \theta_{z}}
$$

Com o $\theta_{z}$ em graus e $I D H$ em cal.cm ${ }^{-2} \cdot \mathrm{min}^{-1}$.

De posse dos valores da irradiação difusa e da irradiação direta é possível obter-se valores para a irradiação global por meio da equação (1). Contudo, existe uma infinidade de modelos que relacionam a irradiação global (normalmente a média diária) com outras variáveis climatológicas.

\subsubsection{Modelos Empíricos para Estimativa da Irradiação Global}

Para obter a média diária da irradiação global, é possível estimá-la por meio de dados de insolação. A equação Angströn-Prèscott é uma das de uso mais difundido para estimativa da irradiação global diária (VIANELLO e ALVES, 2002): 


$$
I G H^{\text {Diário }}=I G H_{0}\left(a+b \cdot{ }^{n} / N\right)
$$

Sendo que, $a$ e $b$ correspondem a coeficientes empíricos, obtidos por regressão linear para cada localidade; $n$ corresponde à insolação e $N$ corresponde à duração astronômica do período diurno, em horas.

Para a determinação dos coeficientes $a$ e $b$ é necessário que inicialmente haja uma série histórica de dados de irradiação global e os respectivos dados de insolação, para que seja possível a determinação dos coeficientes. De posse desses coeficientes é possível estimar a irradiação global para os períodos que só possuam dados de insolação. Portanto, os modelos empíricos têm uso regional, e não podem ser replicados para outras regiões sem a adaptação dos coeficientes empíricos.

BORGES et al. (2009) testaram três modelos de estimativa de irradiação global para a cidade de Cruz das Almas (BA). Os autores utilizaram os coeficientes empíricos originais de cada modelo, sem realizar as adaptações regionais. Foram testados os modelos de Thornton \& Running, Weiss e Hargreaves \& Samani. Os dois primeiros correspondem a adaptações do modelo Bristow \& Campbell e o último foi testado utilizando dois coeficientes definidos pelos autores do modelo (um para regiões costeiras e outro para regiões interiores). O melhor resultado foi obtido com o modelo Hargreaves \& Samani com o coeficiente para regiões costeiras, embora a cidade não se localize exatamente numa costa. BORGES et al. (2009) indicam que resultados ainda mais próximos entre o estimado e o observado poderiam ser encontrados se o coeficiente fosse inicialmente adaptado para a região.

GUEDES et al. (2005) procurou relacionar a umidade relativa, nebulosidade e irradiância solar no Observatório Espacial do Sul localizado no estado do Rio Grande do Sul, Brasil. Os dados obtidos indicam pouca relação entre a irradiância e a umidade relativa e alta relação entre a irradiância e nebulosidade, porém com alta dispersão de dados quando os níveis de nebulosidade são altos, o estudo também mostra que há pouca ou nenhuma correlação entre a nebulosidade e a umidade relativa do ar.

CARVALHO et al. (2011) testaram seis modelos em algumas cidades do norte de Minas Gerais. Os autores calcularam os coeficientes empíricos de cada modelo com base em um ano de medição, de cada uma das nove cidades consideradas no estudo. Os coeficientes foram considerados diferentes para cada cidade, contudo, iguais para cada mês do ano. $\mathrm{Ou}$ seja, foi calculado apenas um valor de cada coeficiente para cada cidade, considerando médias anuais e não mensais. Os modelos analisados foram: Annandale, Bristow \& Campbell, 
Hargreaves $^{27}$, Donatelli \& Campbell, Hargreaves \& Samani ${ }^{28}$ e Hunt (a). CARVALHO et al. (2011) concluíram que os melhores resultados foram obtidos com os modelos Bristow \& Campbell e Donatelli \& Campbell. Os piores resultados foram obtidos com o modelo Hunt (a), contudo, as diferenças entre os resultados alcançados com cada modelo são pequenas.

SILVA et al. (2012) realizaram um trabalho semelhante ao de CARVALHO et al (2012) para cidades do Nordeste de Minas Gerais. Os modelos avaliados foram: Annandale, Bristow \& Campbell, Hargreaves, Chen (a), Jong \& Stewart, Donatelli \& Campbell, Hargreaves \& Samani, Hunt (a) e Hunt (b). Os que apresentaram melhores resultados foram: Jong \& Stewart, Donatelli \& Campbell e Bristow \& Campbell. Os piores resultados foram obtidos por: Annandale, Hargreaves \& Samani e Hunt (a).

DANTAS (2013) testou nove modelos para a cidade de Mossoró (RN). Os coeficientes empíricos foram calculados para o mês mais seco (abril) e mais chuvoso (Outubro) e também para o ano todo (como coeficiente único, análogo à metodologia definida por CARVALHO et al., 2012). Os modelos testados foram: Bahel, Hargreaves \& Samani, Hargreaves, Swartman \& Ongulade, Ododo (a) e Ododo (b), Chen (a) e Chen (b), e finalmente um modelo multiplicativo definido por DANTAS (2013). Para o mês de abril, os modelos que obtiveram os melhores resultados foram: Chen (b), Bahel e Swartman \& Ongulade e o pior resultado foi obtido pelo modelo Hargreaves \& Samani. Para o mês de outubro e para o ano todo, os modelos que apresentaram melhores resultados foram: Ododo (b), Chen (b) e Dantas (multiplicativo). O pior resultado obtido para o mês de outubro foi por meio do modelo Swartman \& Ongulade e para o ano todo foi através do modelo Hargreaves. Os modelos foram aplicados para cálculo da irradiação global média diária.

FERNEDA et al (2014) avaliaram quatro modelos para a região de Sinop (MT), todos cuja variável de entrada é a amplitude térmica: Hargreaves \& Samani, Bristow \& Campbell, Thornton \& Running e Weiss. Os coeficientes foram calculados para irradiação global horária média anual. O modelo com as melhores estimativas foi Hargreaves \& Samani, e o modelo Weiss apresentou os piores resultados, sendo esses próximos aos apresentados pelo modelo Bristow \& Campbel.

DE LA CASA et al. (2003) testaram quatro modelos para estimativa da irradiação global diária média para a Província de Córdova na Argentina, em três cidades diferentes. Os

\footnotetext{
${ }^{27}$ Referenciado como CHEN et al (2004) em CARVALHO et al. (2011) e em SILVA et al. (2012), e como HARGREAVES et al (1985) em DANTAS (2013).

${ }^{28}$ Referenciado como HARGREAVES (1981) em CARVALHO et al. (2011) e em SILVA et al. (2012), e como ALLEN (1997) em Dantas (2013).
} 
coeficientes foram calculados para o ano todo, para o semestre de verão e para o semestre de inverno. Os quatro modelos foram escolhidos com base em diferentes variáveis de entrada, sendo assim definidos: Angströn-Prèscott (variável de entrada: nebulosidade), Bristow \& Campbel (variável de entrada: amplitude térmica), Jong \& Stewart (variáveis de entrada: precipitação e amplitude térmica) e Black (variável de entrada: nebulosidade). Os modelos que utilizam a insolação e a nebulosidade possuem melhores resultados do que aqueles que consideram a amplitude térmica, mesmo quando esta está vinculada ao índice de precipitação.

TORRES et al. (2013) compararam os modelos Bristow \& Campbel e Hargreaves \& Samani com base em médias diárias de irradiação global em Patacamaya na Bolívia. O modelo Bristow \& Campbel se apresentou ligeiramente melhor que o modelo Hargreaves \& Samani.

GANA e AKPÓOTU (2013) e OUALI e ALKAMA (2014) utilizaram dados de irradiação global para analisar modelos de estimativa no Norte da África. Embora os estudos tenham sido realizados para localidades no Hemisfério Norte, eles foram os únicos dentre os estudos supracitados que analisam os modelos para estimativa de irradiação sob a perspectiva do aproveitamento energético. Os modelos analisados por GANA e AKPÓOTU (2013) foram: Angströn-Prèscott, Ogelman, El-Metwally, Bakirci, todos baseados na insolação como variável de entrada, para a região de Kebbi na Nigéria. O modelo Ogelman apresentou os melhores resultados enquanto Balinci apresentou os piores.

OUALI e ALKAMA (2014) realizaram um interessante estudo para a formação de modelos empíricos de estimativa de irradiação para cidade de Bajaia na Argélia. Os autores utilizaram dados coletados de oito em oito minutos de 5 variáveis: precipitação, umidade relativa, insolação, pressão e temperatura ambiente. Os dados foram agrupados em médias diárias mensais e utilizados para o cálculo de coeficientes empíricos anuais de modelos prédefinidos na literatura e modelos propostos pelos autores.

Com base nesses dados meteorológicos, e possuindo dados de irradiação global diária, os autores construíram modelos, baseados em regressão linear, com 1, 2, 3, 4 ou 5 variáveis de entrada. Todas as combinações possíveis foram testadas. O modelo com uma variável de entrada que apresentou resultados mais precisos foi aquele baseado na insolação. Considerando duas variáveis de entrada, o modelo que apresentou os melhores resultados foi aquele que utilizou a insolação e a umidade relativa. Considerando três variáveis de entrada, o modelo de maior eficiência foi aquele que considerou a insolação, a umidade relativa e a temperatura. Para quatro variáveis de entrada, o melhor modelo foi o que considerou a 
isolação, a umidade relativa, a temperatura média diária e a pressão atmosférica. Também foi construído o modelo com as 5 variáveis, que foi o que apresentou o melhor resultado dentre os modelos criados. Esse modelo foi comparado com quatro modelos existentes: AngströnPrèscott, Bahel, Newland e Abdalla. Dentre esses, o modelo desenvolvido por OUALI e ALKAMA (2014) continuou apresentando os melhores resultados. Os modelos AngströnPrèscott, Bahel, e Abdalla apresentaram resultados ligeiramente inferiores ao modelo proposto pelos autores e bastantes semelhantes entre si. O modelo Newland apresentou os piores resultados. Os autores concluírem que, na medida em que mais variáveis meteorológica são consideradas, melhores são os resultados obtidos em um modelo simples de regressão linear.

Com base nos estudos supracitados, são listados a seguir os modelos mais relevantes encontrados na literatura para a estimativa da irradiação global diária.

- Equação de Bennett

A equação de Bennett relaciona dados de insolação com coeficientes empíricos para se obter a média da irradiação global diária:

$$
I G H^{\text {Diário }}=I G H_{0}^{\text {Diário }}\left(a+b \cdot \frac{n}{N}+c \cdot z\right)
$$

De modo que, $a, b$, e $c$ são coeficientes empíricos e $z$ corresponde à altitude do local. Os demais termos são os mesmos definidos para a equação de Angströn-Prèscott. Segundo VIANELLO e ALVES (2002), esse modelo foi aplicado com sucesso para o Hemisfério Sul. Este foi o único modelo, dentre os analisados na literatura, que considera a altitude para o cálculo da estimativa de irradiação global.

- Modelos de Bahel e Olgeman

Bahel utilizou dados de 48 estações ao redor do mundo, com diferentes condições meteorológicas, desenvolvendo um modelo com quatro coeficientes empíricos que definem a transmitância atmosférica (DANTAS, 2013; OUALI e ALKAMA, 2014) 


$$
\frac{I G H^{\text {Diário }}}{I G H_{0}^{\text {Diário }}}=a+b\left(\frac{n}{N}\right)+c\left(\frac{n}{N}\right)^{2}+d\left(\frac{n}{N}\right)^{3}
$$

De modo que, $a, b, c$, e $d$ são os coeficientes empíricos. O modelo de Olgeman é bastante semelhante ao de Bahel, a única diferença é que este segundo modelo não considera o termo cúbico apresentado no modelo de Bahel.

- Modelo de Ouali \& Alkama

O modelo desenvolvido por OUALI e ALKAMA (2014) por meio da regressão linear, considerando dados na Argéria. O modelo considera cinco variáveis meteorológicas de entrada.

$$
\frac{I G H^{\text {Diário }}}{I G H_{0}^{\text {Diário }}}=a+b\left(\frac{n}{N}\right)+c\left(T_{\text {média }}\right)+d(U R)+e(P)+f(w)
$$

De modo que, $a, b, c, d$, e e $f$ são os coeficientes empíricos, $T_{\text {média }}$ corresponde à temperatura média diária, $U R$ corresponde à umidade relativa, $\boldsymbol{P}$ corresponde à pressão atmosférica e $w$ corresponde à precipitação diária.

- Modelos Bristow \& Campbel e Donatelli \& Campbell

Um dos modelos mais encontrados na bibliografia é o modelo Bristow \& Campbel. Em alguns estudos é elencado como um dos melhores modelos e, em outros como o que apresentou os piores resultados. Desse modelo sugiram novos modelos adaptados, sendo o principal deles, o modelo de Donatelli \& Campbell - equação (29):

$$
\begin{aligned}
& \frac{I G H^{\text {Diário }}}{I G H_{0}^{\text {Diário }}}=a\left[1-\exp \left(-b \cdot \Delta T^{c}\right)\right] \\
& \frac{I G H^{\text {Diário }}}{I G H_{0}^{\text {Díário }}}=a\left[1-\exp \left(-b \cdot \frac{\Delta T^{c}}{\Delta T_{m}}\right)\right]
\end{aligned}
$$

De modo que, $a, b$, e $c$ são coeficientes empíricos, $\Delta T$ corresponde à amplitude térmica diária, $\Delta T_{m}$ corresponde à média mensal da amplitude térmica. 
- Modelo Hargreaves \& Samani

Outro modelo muito encontrado na bibliografia e assim como os modelos Bristow \& Campbel e Donatelli \& Campbell, se baseia na amplitude térmica para a determinação da irradiação global.

$$
\frac{I G H^{\text {Diário }}}{I G H_{0}^{\text {Diário }}}=a \sqrt{T_{\operatorname{máx}}-T_{\min }}
$$

HARGREAVES e SAMANI (1982) sugeriram que $a$ corresponde ao coeficiente empírico relacionado à transmitância atmosférica e que pode ser aproximado à 0,16 para regiões continentais interiores e 0,19 para zonas costeiras. ALLEN (1995) sugeriu que o coeficiente $a$ deve ser calculado em função da altitude do local, por meio da relação:

$$
a=a_{0} \sqrt{\frac{P}{P_{0}}}
$$

De modo que, $T_{\text {máx }}$ e $T_{\text {min }}$ correspondem às temperaturas máximas e mínimas diárias, respectivamente, $a_{0}$ é uma variável empírica, definida por ALLEN (1995) com o valor de 0,17 para regiões continentais interiores e como 0,20 para regiões costeiras. $P$ corresponde à pressão atmosférica média para o local, definida em função da altitude e $P_{0}$ corresponde a pressão atmosférica ao nível do mar.

- Modelo Jong \& Stewart

O modelo de Jong \& Stewart considera como variáveis de entrada a precipitação e a variação de temperatura. Este modelo apresenta bom desempenho quando comparado ao desempenho de demais modelos que consideram a amplitude térmica como variável de entrada, contudo o seu rendimento se apresentou inferior aos modelos que consideram a insolação como principal variável de entrada.

$$
\frac{I G H^{\text {Diário }}}{I G H_{0}^{\text {Dírio }}}=a\left(T_{\text {máx }}-T_{\min }\right)^{b}\left(1+c w+d w^{2}\right)
$$

$T_{\text {máx }}$ e $T_{\min }$ correspondem às temperaturas máximas e mínimas diárias, respectivamente, $w$ corresponde à precipitação diária (em $\mathrm{mm}$ ) e $a, b, c$, e $d$ são os coeficientes empíricos. 
- Modelo Black

Único modelo encontrado na bibliografia que considera a nebulosidade como variável de entrada. A nebulosidade $(C)$ é mensurada em frações do céu cobertas por nuvens em um determinado momento. DE LA CASA et al. (2003) consideraram os valores de nebulosidade em oitavos. Os valores foram medidos às $2 \mathrm{~h}, 8 \mathrm{~h}, 14 \mathrm{~h}$ e $20 \mathrm{~h}$ de cada dia. A média diária foi obtida considerando o valor médio das medições das $8 \mathrm{~h}, 14 \mathrm{~h}$ e $20 \mathrm{~h}$.

$$
\frac{I G H^{\text {Diário }}}{I G H_{0}^{D i a ́ r i o}}=a+b C+c C^{2}
$$

De modo que, $a, b$, e $c$ são coeficientes empíricos.

Todos os modelos trabalham na perspectiva de equacionar o quanto da irradiação global extraterrestre não alcança a superfície terrestre em função da transmitância atmosférica, de modo semelhante à construção do índice de claridade da equação (14), assim, os modelos de estimativa de irradiação global podem ser genericamente representados por essa equação.

$$
I G H=I G H_{0} \cdot k_{t}
$$

A definição de $k_{t}$ é o que representa todos os modelos analisados. A maior parte deles considera a amplitude térmica diária para tal. Deve-se a isso, o fato de esse ser um dos dados meteorológicos mais comuns de se obter histórico de medições. Contudo, percebe-se que os modelos que utilizam como variável de entrada a insolação, apresentam, no geral, melhores resultados.

A precisão dos modelos aumenta conforme novas variáveis de entrada são consideradas. A relação da irradiação global com a insolação é bastante significativa, como já era de se esperar. Um segundo fator de grande relevância é a umidade relativa do ar para a definição da transmitância atmosférica.

A regressão linear se apresentou como método eficiente e amplamente utilizado para a definição de modelos, embora alguns apresentem métodos mais complexos, contudo, este não é um fator decisivo para o bom desempenho ou não de um modelo. Observa-se também que o desempenho de um determinado modelo pode variar em função das condições climáticas, como observado por DANTAS (2013) que obteve resultados bastante diferentes de desempenho de diferentes modelos para o período chuvoso e o período seco, concluindo que o modelo mais adequado para uma condição climática pode ou não ser o menos adequado para 
a condição climática oposta. Com isso, conclui-se que não há uma relação absoluta com nenhuma das variáveis meteorológicas para a definição da irradiação global diária.

A nebulosidade é outro fator que merece destaque. Esta variável é amplamente discutida nos modelos físicos de estimativa de irradiação e nas estimativas via imagens de satélite (e realiza grande interferência no montante de radiação disponível na superfície terrestre), contudo é muito pouco utilizada em modelos empíricos. Isso ocorre em função da pouca disponibilidade de medições dessa variável. Logicamente e intuitivamente define-se que "quanto há chuva não há sol e quando há sol, não há chuva", contudo, a precipitação se apresenta como uma variável de pouca relevância na definição dos modelos empíricos para a irradiação global diária.

Aproveitando-se do plano de fundo desse estudo que é a instalação de plantas fotovoltaicas em hidrelétricas existentes, e utilizando-se dos conceitos compreendidos e utilizados na formação de modelos empíricos de irradiação, buscou-se promover uma análise das relações entre a incidência da radiação e demais variáveis meteorológicas em hidrelétricas brasileiras, acrescentando também a verificação de uma possível relação com os regimes de vazões dessas hidrelétricas.

\subsection{ANÁLISE DE CORRELAÇÕES CLIMÁTICAS EM HIDRELÉTRICAS}

Os históricos de medições de radiação são extremamente raros no Brasil. Nota-se que a irradiação global média diária possui uma relação bastante forte com a insolação. As normais meteorológicas disponibilizadas pelo INMET (BRASIL, 2014c) englobam séries de insolação, precipitação, nebulosidade, evaporação e umidade relativa. Essas variáveis foram utilizadas para identificar as possíveis correlações entre as mesmas, objetivando a identificação de variáveis balizadoras na estimativa de irradiância e a verificação da falta de padrão dessas relações em microclimas diferentes.

Inicialmente foram identificados, através das séries históricas de vazão disponibilizadas pelo ONS e das normais meteorológicas disponibilizadas pelo INMET, postos de medição instalados em hidrelétricas brasileiras ou próximas a estas. Nesta etapa as coordenadas geográficas das estações disponibilizadas pelos dois órgãos foram consideradas para a identificação de hidrelétricas próximas. Foram identificadas quatro hidrelétricas com respectivas estações meteorológicas de interesse. A Tabela 9 apresenta a localização das hidrelétricas definidas e as estações de medição. 
Tabela 9 - Hidrelétricas e estações de medição analisadas

\begin{tabular}{|c|c|c|c|c|}
\hline & UHE & Localização & $\begin{array}{c}\text { Estação } \\
\text { Meteorológica }\end{array}$ & Localização \\
\hline \multirow{2}{*}{1} & \multirow{2}{*}{ Itaipu } & $25^{\circ} 24^{\prime} \mathrm{S}$ & \multirow{2}{*}{ Foz do Iguaçú } & $25^{\circ} 33^{\prime} \mathrm{S}$ \\
\hline & & $54^{\circ} 35^{\prime} \mathrm{W}$ & & $54^{\circ} 34^{\prime} \mathrm{W}$ \\
\hline \multirow{2}{*}{2} & \multirow{2}{*}{ Sobradinho } & $9^{\circ} 25^{\prime} \mathrm{S}$ & \multirow{2}{*}{ Petrolina } & $09^{\circ} 22^{\prime} \mathrm{S}$ \\
\hline & & $40^{\circ} 49^{\prime} \mathrm{W}$ & & $40^{\circ} 28^{\prime} \mathrm{W}$ \\
\hline \multirow{2}{*}{3} & \multirow{2}{*}{ Tucuruí } & $3^{\circ} 50^{\prime} \mathrm{S}$ & \multirow{2}{*}{ Tucuruí } & $03^{\circ} 46^{\prime} \mathrm{S}$ \\
\hline & & $49^{\circ} 38^{\prime} \mathrm{W}$ & & $49^{\circ} 40^{\prime} \mathrm{W}$ \\
\hline \multirow{2}{*}{4} & \multirow{2}{*}{ Jupiá } & $20^{\circ} 46^{\prime} \mathrm{S}$ & \multirow{2}{*}{ Três Lagoas } & $20^{\circ} 47^{\prime} \mathrm{S}$ \\
\hline & & $51^{\circ} 37^{\prime} \mathrm{W}$ & & $51^{\circ} 42^{\prime} \mathrm{W}$ \\
\hline
\end{tabular}

Fonte: Elaboração própria com dados de BRASIL (2014c) e BRASIL (2014d)

O Brasil é um país de dimensões continentais e que possui uma grande variedade climática e geográfica, por isso buscou-se hidrelétricas em diferentes regiões do país para a validação das correlações a serem empregadas.

O INMET (BRASIL,2014c) calcula, com base nas séries históricas fornecidas por cada estação, as normais climatológicas. Esses valores representam a média de cada mês de uma determinada variável durante um período de 30 anos. As normais disponibilizadas pelo INMET atualmente correspondem ao período de 1961 a 1990.

A seguir apresenta-se uma breve descrição das normais utilizadas.

I. Insolação: as séries históricas e normais climatológicas adotadas neste exercício indicam a quantidade de horas de irradiância acima $120 \mathrm{~W} / \mathrm{m}^{2}$ por mês. A análise apenas de dados de insolação foi definida em função da dificuldade de obtenção de séries históricas de irradiância global, direta e difusa.

II. Nebulosidade: a medição da nebulosidade é fornecida em valores decimais que correspondem a quantidade do céu coberto por nuvens em um determinado momento. Os valores de séries históricas e normais utilizados neste exercício correspondem à média dos fatores de nebulosidade encontrados para cada mês do ano. Esses fatores variam de 0 a 1 e não indicam a espessura ou altura das nuvens, apenas a parcela do céu coberta em um dado momento de verificação.

III. Precipitação: como o elemento central desse estudo é a análise da fonte primária de energia solar, as séries históricas que indicam a quantidade de precipitação não foram consideradas. Para esse estudo foram analisadas séries históricas da quantidade de dias de chuva, ou seja, a quantidade de dias no mês em que a precipitação supera 1 $\mathrm{mm}$. 
IV. Evaporação: os valores de evaporação obtidos estão em porcentagem e representam a média mensal da evaporação diária para as séries históricas.

V. Umidade Relativa: os valores de umidade relativa obtidos estão em porcentagem e representam a média mensal da umidade relativa diária para as séries históricas. As normais são obtidas, para essa e para as demais variáveis, como a média de cada mês no período de 30 anos pré-estabelecido.

VI. Vazão: a série histórica de vazões disponibilizada pela ONS (BRASIL, 2014d) foi utilizada para a análise de correlação com as demais variáveis. Com base nessa série foi obtida a média de cada mês para cada hidrelétrica da Tabela 9 correspondente ao período de 1961 a 1990.

As normais de insolação, nebulosidade, precipitação, evaporação, umidade relativa e vazão foram correlacionadas entre si através do cálculo do coeficiente de Pearson. O Coeficiente de Pearson $(r)$ define a correlação linear entre duas variáveis $(X$ e $Y)$. $\mathrm{O}$ seu cálculo é obtido por meio da equação (34):

$$
r=\frac{\operatorname{cov}(X, Y)}{\sqrt{\operatorname{var}(X) \cdot \operatorname{var}(y)}}
$$

A Tabela 10 mostra as diretrizes de interpretação do coeficiente de Pearson.

Tabela 10 - Coeficiente de correlação linear de Pearson

\begin{tabular}{ll}
\hline Coeficiente & Correlação \\
\hline $\boldsymbol{r}=\mathbf{1} / \boldsymbol{r}=-\mathbf{1}$ & Perfeita (Positiva / Negativa) \\
\hline$(\mathbf{0 . 8} \leq \boldsymbol{r}<\mathbf{1}) /(-\mathbf{1}<\boldsymbol{r} \leq-\mathbf{0 . 8})$ & Forte (Positiva / Negativa) \\
\hline$(\mathbf{0 . 5} \leq \boldsymbol{r}<\mathbf{0 . 8}) /(-\mathbf{0 . 8}<\boldsymbol{r} \leq-\mathbf{0 . 5})$ & Moderada (Positiva / Negativa) \\
\hline$(\mathbf{0 . 1} \leq \boldsymbol{r}<\mathbf{0 . 5}) /(-\mathbf{0 . 5}<\boldsymbol{r} \leq-\mathbf{0 . 1})$ & Fraca (Positiva / Negativa) \\
\hline$(\mathbf{0} \leq \boldsymbol{r}<\mathbf{0 . 1}) /(-\mathbf{0 . 1}<\boldsymbol{r}<\mathbf{0})$ & Muito fraca (Positiva / Negativa) \\
\hline $\boldsymbol{r}=\mathbf{0}$ & Nula \\
\hline
\end{tabular}

Fonte: Elaboração própria

Como o foco deste trabalho está na definição da energia solar, a Tabela 11 mostra apenas as correlações encontradas para as normais de insolação de cada hidrelétrica com as demais variáveis. 
Tabela 11 - Coeficiente de correlação linear de Pearson para insolação

\begin{tabular}{lllll}
\hline & Itaipu & Sobradinho & Tucuruí & Jupiá \\
\hline Nebulosidade & $-0,3$ & $-0,6$ & $-0,9$ & $-0,3$ \\
\hline Precipitação & 0,3 & $-0,6$ & $-0,5$ & $-0,3$ \\
\hline Evaporação & 0,8 & 0,9 & 0,4 & $-0,2$ \\
\hline Umidade Relativa (\%) & $-0,6$ & $-0,9$ & $-0,4$ & 0,0 \\
\hline Vazão & 0,6 & $-0,6$ & $-0,4$ & 0,0 \\
\hline
\end{tabular}

Fonte: Elaboração própria

A análise dos coeficientes obtidos confirma que não há um padrão bem definido entre o comportamento da insolação e das demais variáveis para condições climáticas e geográficas diferentes.

A nebulosidade e precipitação são variáveis que naturalmente interferem negativamente na incidência de radiação solar, já que a formação de nuvens tende a impedir a incidência da radiação direta. Contudo, na hidrelétrica de Itaipu verificou-se uma correlação fraca positiva entre precipitação e insolação, o que tenderia à interpretação de que quanto mais dias de chuva em um mês, maior seria a incidência de radiação. Tal constatação foge do lógico e do esperado, por esse motivo foram verificadas as relações entre a precipitação de Itaipu com as demais variáveis do local. As normais de precipitação tiveram correlações fracas positivas com a vazão e nebulosidade; moderada negativa com a umidade relativa e moderada positiva com a evaporação. As correlações com a evaporação e com a umidade relativa são novamente contrárias à lógica. Tal constatação induz à conclusão de que haja no local alguma outra variável climática que possua uma interferência maior nas normais climatológicas. Uma das possíveis explicações é a localização da hidrelétrica, próxima às Cataratas do Iguaçú (posição geográfica: $25^{\circ} 41^{\prime} \mathrm{S}, 54^{\circ} 26^{\prime} \mathrm{W}$ ). Este estudo supõe que essa formação hidrológica e geográfica possua maior interferência nas variáveis climáticas do que os dias do mês com altas precipitações no local.

A hidrelétrica de Jupiá, que pertence a mesma bacia hidrográfica de Itaipu, localizando-se a montante da mesma, também apresentou valores nulos ou de fraca correlação entre as variáveis analisadas e a normal de insolação. Os valores de correlação mais significantes obtidos foram nas hidrelétricas de Tucuruí e Sobradinho. Na primeira, a insolação possui forte relação negativa com a nebulosidade enquanto que na segunda, as relações mais significativas são encontradas com as normais de umidade relativa e evaporação. 
A hidrelétrica de Tucuruí é localizada em meio à floresta Amazônica, região que possui um período de chuvas bem definido que resulta na melhor definição do comportamento da radiação ao longo do ano. Já a hidrelétrica de Sobradinho localiza-se no semiárido brasileiro, clima caracterizado por alta incidência de radiação e poucas chuvas. O gráfico da Figura 27 mostra o comportamento da normal de insolação para as duas hidrelétricas ao longo do ano.

Figura 27 - Normais de insolação em Sobradinho e Tucuruí

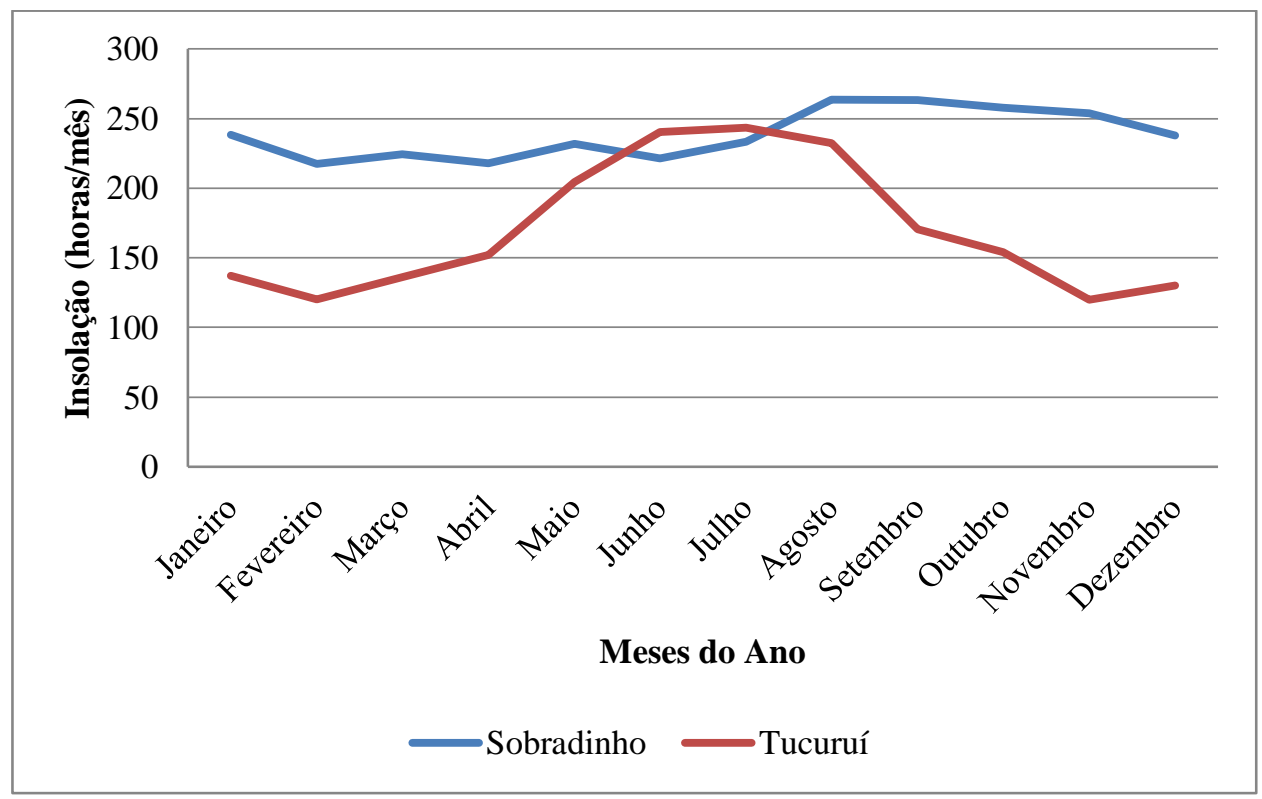

Fonte: Elaboração própria

A insolação em Sobradinho apresenta um perfil mais constante ao longo do ano. Como a quantia de chuva por ano é reduzida, os índices de precipitação e nebulosidade acarretam em menores efeitos na quantia de irradiação disponível e por consequência, essa radiação possui grande efeito na umidade relativa e nos índices de evaporação. Em nenhuma das hidrelétricas analisadas o histórico de vazão pode ser interpretado como elemento balizador das normais de insolação.

Com o intuito de identificar se as fortes correlações encontradas em Tucuruí e Sobradinho permanecem constantes ao longo dos anos, as séries históricas das estações meteorológicas de Tucuruí e Petrolina foram analisadas. A estação de Tucuruí possui registro de dados desde 1970 e a de Petrolina desde 1962. O principal problema da análise das séries históricas foi a grande falta de dados encontrada. Buscaram-se, portanto, as variáveis que satisfizessem o objetivo desse estudo e possuíssem a maior quantidade de dados disponíveis. 
Em Petrolina, dos 53 anos analisados, considerando de janeiro a dezembro, apenas 23 anos possuem dados completos mensais de insolação, 26 anos de umidade relativa e 31 anos de nebulosidade. Em Tucuruí, dos 45 anos analisados, apenas 14 possuem dados completos mensais de insolação, 15 de umidade relativa e 23 de nebulosidade. Foram encontrados 21 anos de medidas mensais completas de precipitação em Petrolina e 9 em Tucuruí.

Em virtude desta falta de dados, foram pesquisados os anos completos de medição de insolação (ou com apenas 1 mês sem dados) em Petrolina que também possuíssem dados completos de umidade relativa. Para essas séries o coeficiente de Pearson foi novamente aplicado. O mesmo processo foi realizado para Tucuruí analisando os dados de insolação e de nebulosidade.

Desta interação, o cálculo foi realizado em 18 séries em Petrolina e em 15 séries em Tucuruí. Os coeficientes de Pearson se mantiveram bastante próximos aos calculados utilizando os valores das normais, mesmo para os anos cujos dados não foram utilizados para a construção das normais, ou seja, anos posteriores à 1990. Isso mostra que as séries são consistentes e obedecem a um padrão previsível de correlação dentro da lógica climática de cada hidrelétrica.

Alguns estudos indicam que a construção de reservatórios de hidrelétricas e o respectivo desmatamento dessas regiões podem alterar consideravelmente o microclima da região (Souza, 2010). Portanto, buscou-se identificar se a construção de hidrelétricas altera o microclima de modo a beneficiar ou não a geração fotovoltaica. Alterações das quais os programas e cálculos de aproximação do potencial solar muitas vezes não consideram.

Essa constatação pode ser verificada no caso das estimativas de irradiância para a floresta Amazônica brasileira pelo modelo GL versão 1.2 (BRASIL, 2005), apresentado na seção 3.5. Na avaliação deste modelo, comparando-o com medições em terra, verifica-se um gradiente sistemático de desvios na direção da Amazônia que sugere que o modelo considera valores excessivamente baixos de água precipitável (portanto, subestima a absorção de radiação pelo vapor).

Foram analisadas as médias mensais de insolação, umidade relativa e nebulosidade para as hidrelétricas de Tucuruí e Sobradinho, antes e depois do enchimento do reservatório das mesmas. A metodologia inicialmente definida buscava comparar as médias mensais dos anos imediatamente anteriores e imediatamente posteriores ao enchimento dos reservatórios. Em virtude da falta de dados completos, essa metodologia teve que ser adaptada. 
O reservatório de Sobradinho foi cheio em 1979, alagando uma área de $4.214 \mathrm{~km}^{2}$. Anterior a esta data a série histórica possui dados completos de insolação de 1973 a 1978. Posterior a esta data verificam-se dados completos apenas em 1984, sendo que de 1980 a 1983 e de 1985 a 1992 não há nenhum dado de insolação disponível. Os dados de insolação são verificados novamente a partir de 1993. O gráfico da Figura 28 apresenta as médias mensais de insolação para os períodos anteriores e posteriores com dados disponíveis.

Figura 28 - Médias de insolação - UHE Sobradinho

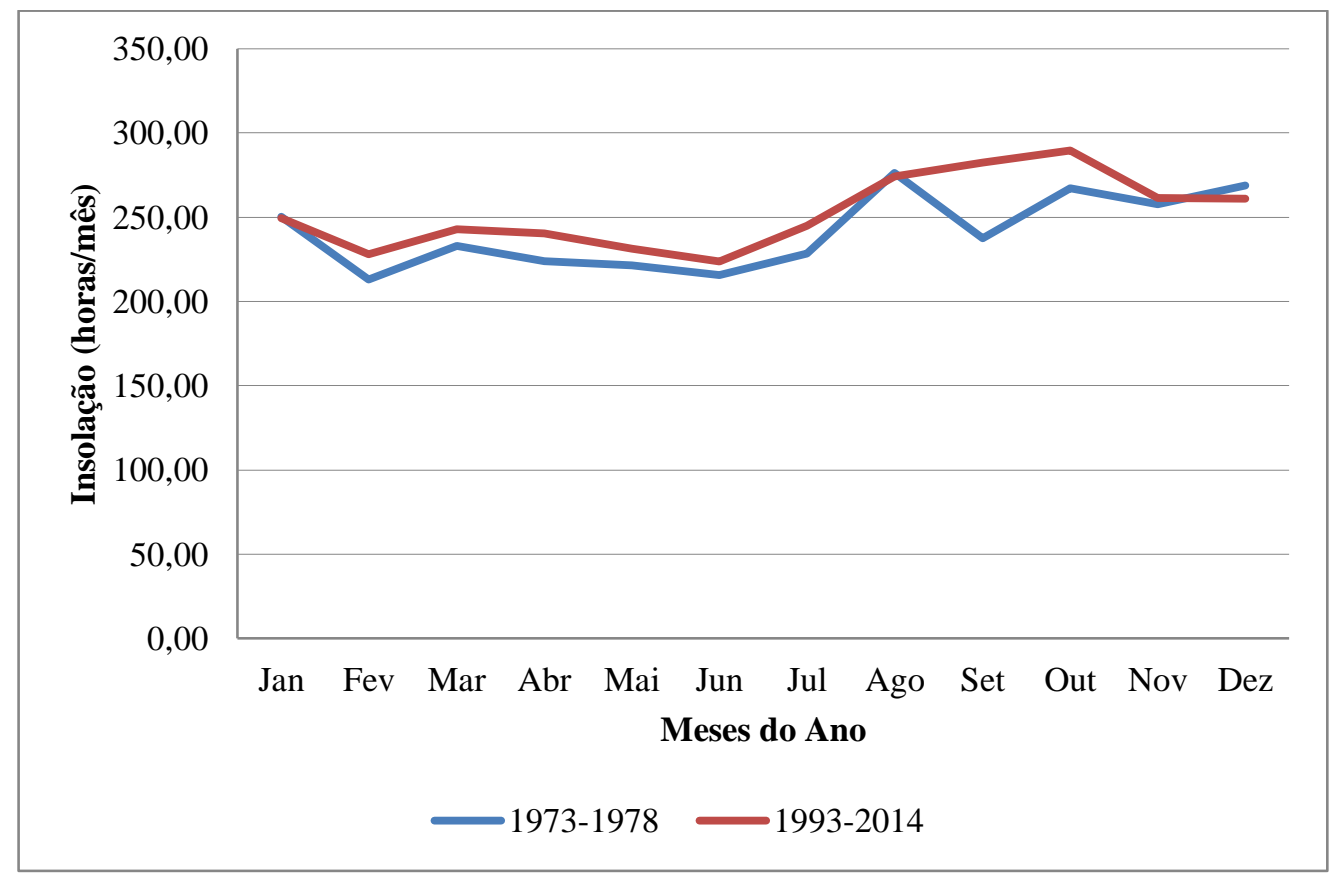

Fonte: Elaboração própria

As médias mensais de insolação apresentaram um pequeno aumento após o enchimento do reservatório, exceto para os meses de janeiro, agosto e dezembro. No mês de setembro o aumento da média de insolação foi de cerca de $19 \%$, correspondendo à maior alteração. A média de insolação antes do enchimento do reservatório foi de 2.893,48 horas de Sol por ano. A média após o enchimento do reservatório foi de aproximadamente 3.016,52 horas de Sol por ano. O que corresponde à cerca de $4 \%$ de aumento. Considerando os desvios padrão de cada média; os longos períodos sem dados e a diferença da quantidade de dados disponíveis antes e depois do enchimento do reservatório, considera-se que a alteração é insignificante. Como os dados de insolação disponíveis após o enchimento datam de mais de uma década após o enchimento, buscou-se repetir a análise com variáveis correlacionadas com uma maior quantidade de dados disponíveis. Portanto esse processo foi repetido para os 
dados de umidade relativa visto que essa variável foi a que apresentou a relação mais forte com a série de insolação em Sobradinho.

A série histórica de umidade relativa apresenta uma quantidade de dados significativa de 1971 a 1978 , de 1980 a 1984 e de 1991 a 2014. Os dois primeiros intervalos representam os anos imediatamente antes e imediatamente depois do enchimento do reservatório. Os resultados da análise das médias mensais desses intervalos são apresentados no gráfico da Figura 29.

Figura 29 - Médias de umidade relativa - UHE Sobradinho

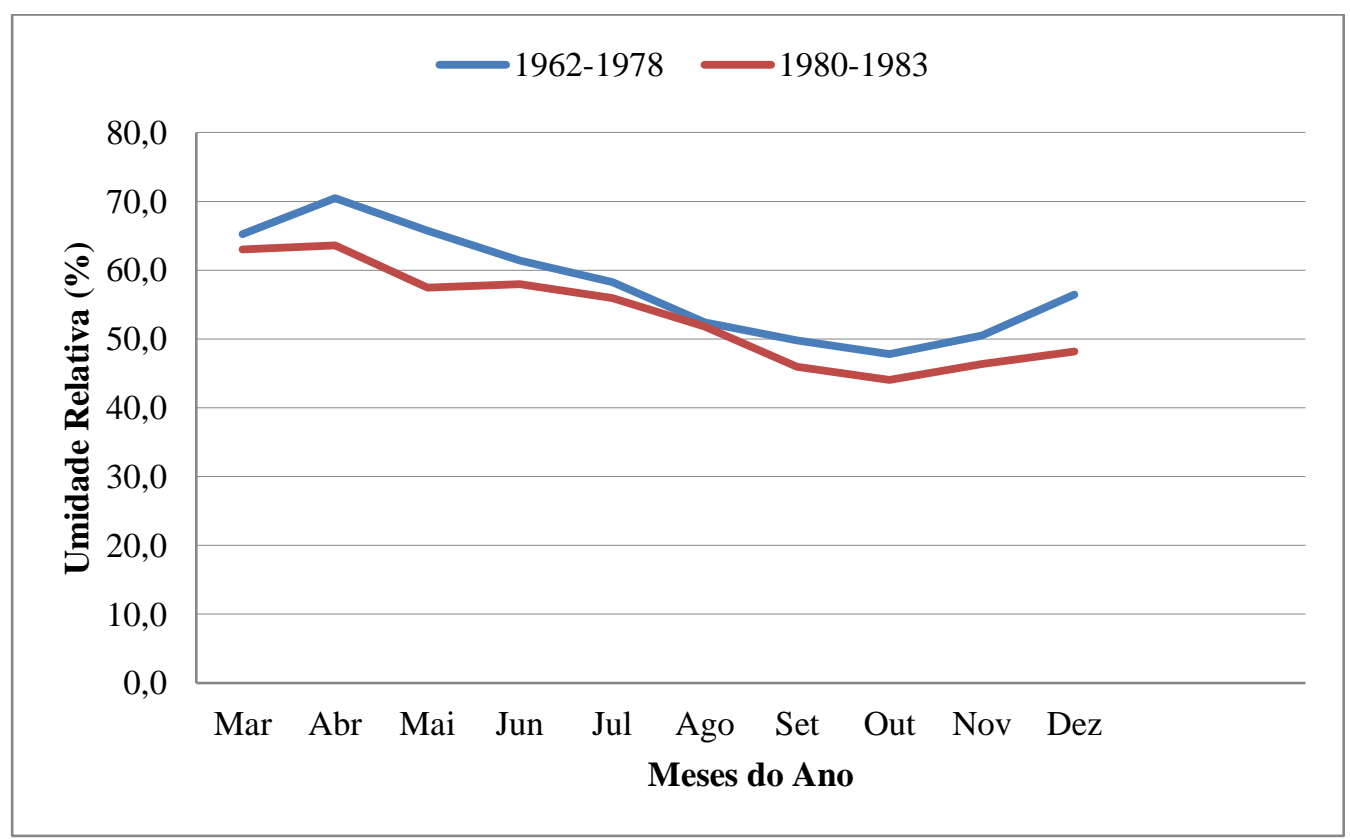

Fonte: Elaboração própria

A média anual da umidade relativa foi 7,5\% menor no segundo período. Considerando o período posterior completo (de 1980 a 2014) a média anual apresentou-se 6,2\% menor do que do período anterior ao enchimento do reservatório.

Esse mesmo processo foi replicado aos dados da hidrelétrica de Tucuruí. O reservatório de Tucuruí foi enchido em 1985, alagando uma área de $2.850 \mathrm{~km}^{2}$. A análise da insolação obedeceu aos mesmos critérios e a mesma construção lógica apresentada para a construção dos resultados de Sobradinho. Os dados das médias de insolação são apresentados no gráfico da Figura 30. 
Figura 30 - Médias de insolação - UHE Tucuruí

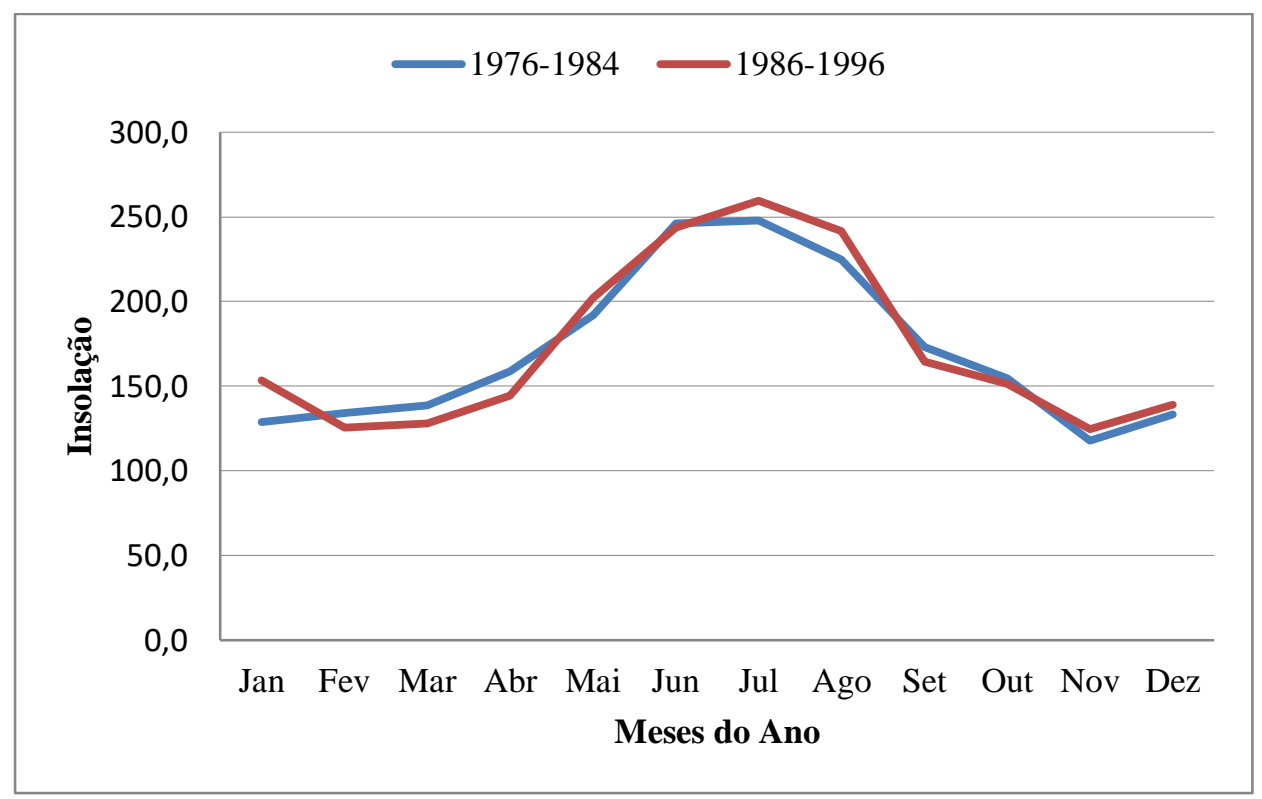

Fonte: Elaboração Própria, 2014

As médias mensais de insolação apresentaram um pequeno aumento após o enchimento do reservatório nos meses de janeiro, maio, julho, agosto, novembro e dezembro. A média de insolação antes do enchimento do reservatório foi de 2,050.3 horas de Sol por ano. A média após o enchimento do reservatório foi de aproximadamente 2,077.0 horas de Sol por ano (considerando os períodos de tempo discriminados no gráfico da Figura 30). O que corresponde à cerca de 1,3\% de aumento. Considerando o desvio padrão das séries analisadas, o aumento é insignificante. Quando considerado o período total posterior ao enchimento do reservatório (1986-2014) o aumento médio apresentado foi de 5,4\%.

Este mesmo processo foi replicado para os índices de nebulosidade das duas hidrelétricas e os resultados obtidos não divergem do padrão de relações encontradas paras as demais variáveis apresentadas.

Como estes resultados foram obtidos através da análise de médias e desvio padrão, modelos estatísticos mais refinados podem ser aplicados para a validação das constatações obtidas. Recorreu-se, portanto à pesquisa bibliográfica para o aprimoramento desta questão. Modelos estatísticos de testes de hipóteses aplicados a dados de Tucuruí concluíram que a formação do represamento pode impactar o clima de regiões próximas (GUIDON, 1991). Outros estudos que buscaram alterações no microclima de Tucuruí não alcançaram resultados muito discrepantes dos apresentados nesse estudo (SOUZA, 2010). Quanto à UHE Sobradinho, um estudo que também utilizou a análise de normais (CAMPOS, 1990) verificou 
que o represamento influenciou em um aumento de $13 \%$ das precipitações médias nas cidades vizinhas à hidrelétrica (GUIDON, 1991). Nenhum dos estudos analisados é destinado à identificação de alteração do perfil de radiação na região das usinas.

A maior dificuldade encontrada neste exercício foi a obtenção de dados. Não são encontradas séries de medição de irradiância de longa data. Muitas das estações meteorológicas brasileiras não estão com a série de dados disponibilizada, e nas que possuem, verificam-se grandes períodos sem medições

O comportamento climático e a correlação entre variáveis climatológicas são específicos de cada região, de modo que a instalação de uma rede consistente de medidores de radiação são de extrema necessidade para a definição do comportamento dessa fonte ao longo dos anos. 


\section{CARACTERIZAÇÃO DA MÉTRICA SOLAR E SEUS ASPECTOS TEMPORAIS}

A quantidade média anual do fluxo de radiação em uma determinada região é muito pouco variável. Uma infinidade de modelos empíricos e computacionais já está validada para a estimativa de médias mensais e diárias de irradiação global. Contudo, quando tratamos da variabilidade em minutos e segundos, esta se apresenta extremamente alta. As alterações podem atingir até $60 \%$ dos seus valores de pico em questão de segundos (MILLS et al, 2009). Essas variações, em função da passagem de nuvens são bastante aleatórias e motivo de grande preocupação por parte dos planejadores e operadores do sistema elétrico (INÁCIO, 2015). O gráfico da Figura 31 apresenta a alteração do perfil do recurso em função do período de integração dos dados.

Figura 31 - Variabilidade do recurso solar

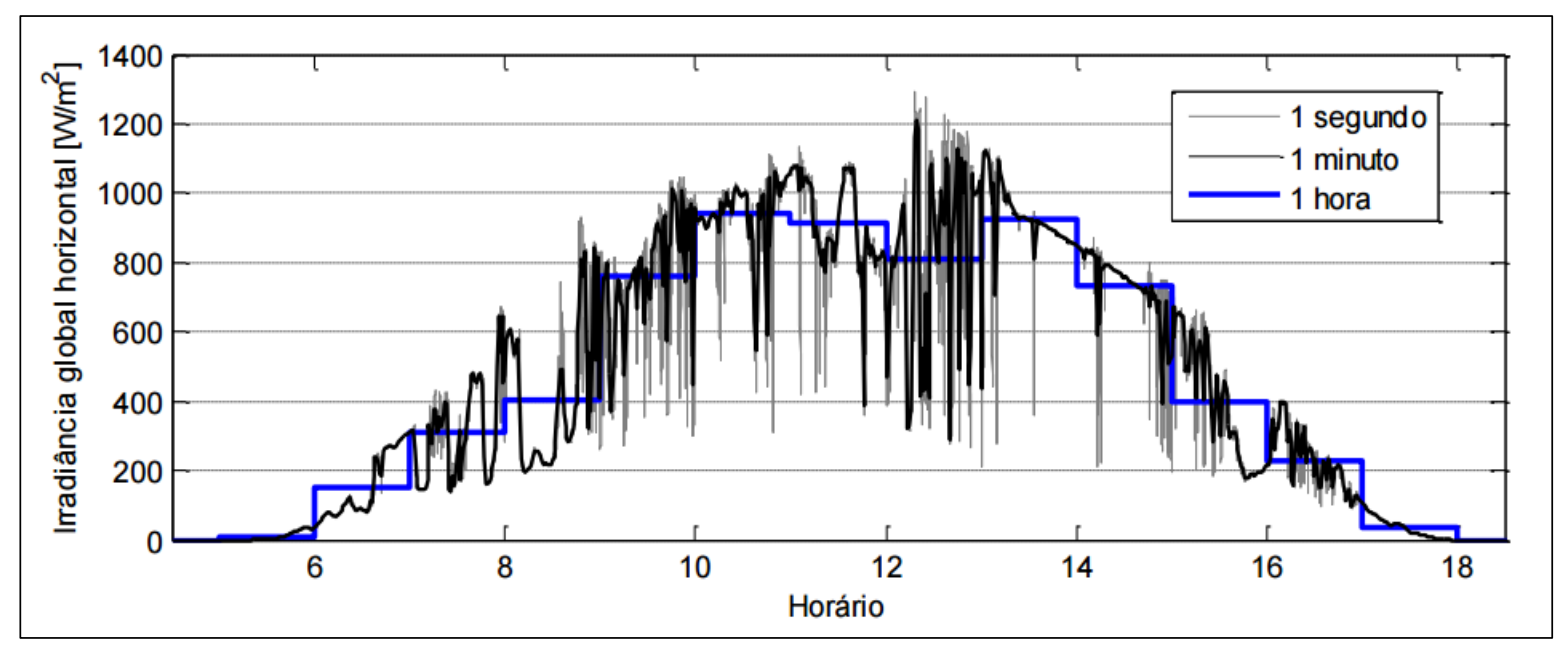

Fonte: Inácio, 2015

Para uma boa caracterização do recurso solar, é importante que as medições sejam realizadas em curtos períodos. Contudo, a sistematização desses dados, muitas vezes coletados em $1 \mathrm{hz}$ e integrados em 1 minuto, necessita de um controle rigoroso de coleta e tratamento de dados. De modo que as séries históricas possam ser construídas com precisão. Quanto melhor o nível de padronização da forma de armazenamento desses dados, mais fácil e confiável será a construção da análise da irradiância registrada. 


\subsection{PADRONIZAÇÃO DO REGISTRO DE DADOS}

A obtenção dos dados de irradiância pode ser organizada sob diversos critérios. Quanto ao registro das medições radiométricas, a ANEEL (BRASIL, 2012) indica que os registros devem conter no mínimo as seguintes informações:

- Dia do início do intervalo (de 1 minuto) de medição - formato [AAAAMMDD]

- Horário do início do intervalo (de 1 minuto) de medição - formato [hhmmss]

- Código de erro do intervalo, com "0" indicando medição sem erro - formato [xxx] As medições de irradiação ${ }^{29}$ direta, difusa e global, devem ser registradas com as seguintes informações:

$\mathrm{Em}\left[\mathrm{W} / \mathrm{m}^{2}\right]$, no formato $[\mathrm{xxxx}, \mathrm{xxx}]$ :

i. Média do intervalo de integração de 1 minuto;

ii. Máxima instantânea (1s) registrada no intervalo de integração;

iii. Mínima instantânea (1s) registrada no intervalo de integração;

iv. Desvio padrão no intervalo de integração.

O documento ainda define uma frequência de medição de $1 \mathrm{hz}$ e um período de integração de 1 minuto.

Segundo a BSRN (MCARTHUR, 2005), o output final de cada variável radiométrica deve consistir na média de medição de 1 minuto, o mínimo, máximo e o desvio padrão. Essa especificação é baseada no tempo típico de resposta de piranômetros e pireliômetros first class, que costuma ser em torno de 1 minuto. A BSRN também indica que os dados de mínimo, máximo e desvio padrão não precisam ser enviados à base de dados centralizada, mas que devem ser registrados e manterem-se arquivados

A padronização do registro de medições é importante para que as interpretações dos dados possam ser corretas em relação: à medida a qual o dado se refere, às suas possíveis incertezas e ao horário de medição. O registo da hora, minuto e segundo de medição é um elemento que, se não for registrado em um padrão previamente acordado, pode gerar erros de interpretação e análise de dados. A primeira definição a ser considerada é a convenção de horários adotados. Deve-se registrar e esclarecer se o horário de registro do histórico de dados consiste no horário regional, no fuso horário oficial do país ou na padronização em UTC. A segunda definição consiste nas incertezas de sincronia dos diferentes relógios e registros de

\footnotetext{
${ }^{29}$ Embora a unidade de medição se dê em W/m² o documento da ANEEL (BRASIL, 2012) utiliza a nomenclatura "irradiação" ou invés de "irradiância", assim optou-se por preservar a nomenclatura utilizada no momento da citação.
} 
medição quando se considera uma rede de estações solarimétricas. Muitos institutos meteorológicos nacionais transmitem sinais de tempo, baseados no horário padrão do país, em frequências de ondas curtas de sinais de rádio. Esses sinais podem ser recebidos a milhares de quilómetros do transmissor, dependendo das condições ionosféricas. Com a decodificação apropriada e a correção de atrasos, a precisão do sinal de tempo pode ser melhor do que $1 \mathrm{~ms}$ (MCARTHUR, 2005).

A padronização do registro de dados, além de ser indispensável para a formação coerente de uma base regional, nacional ou mundial de dados, também é necessária no caso da utilização deste registro em softwares de análises de qualidade de dados.

Em virtude dessas situações, são apresentadas as principais considerações da BSRN e do NREL quanto à padronização dos registros de dados de irradiação.

\subsubsection{BSRN e o Padrão de Registro de Dados}

Para dados de irradiância direta, difusa e global, a BSRN recomenda: média do intervalo de integração de 1 minuto, máxima e mínima instantâneas deste período e desvio padrão. As medições de irradiância devem ser registradas em $\mathrm{W} / \mathrm{m}^{2}$ no formato [xxxx]: quatro casas de inteiros. A BSRN também destina um código para cada radiômetro, assim, o registro dos dados medidos também indica por qual equipamento a variável foi medida, cada modelo de piranômetro, pireliômetro e pirgeômetro ${ }^{30}$ recebe um código próprio que deve ser informado em todas as medidas feitas por esses equipamentos (WMO, 2013).

Os arquivos de dados a serem enviados para a BSRN devem conter o número de identificação da estação, os dados do cientista responsável e a data do período de medição. Os dados devem ser enviados mensalmente. O quadro da Figura 32 apresenta o processo utilizado.

\footnotetext{
${ }^{30}$ Medidores de irradiância terrestre - referente à radiação de onda longa
} 
Figura 32 - Relação BSRN e WRMC

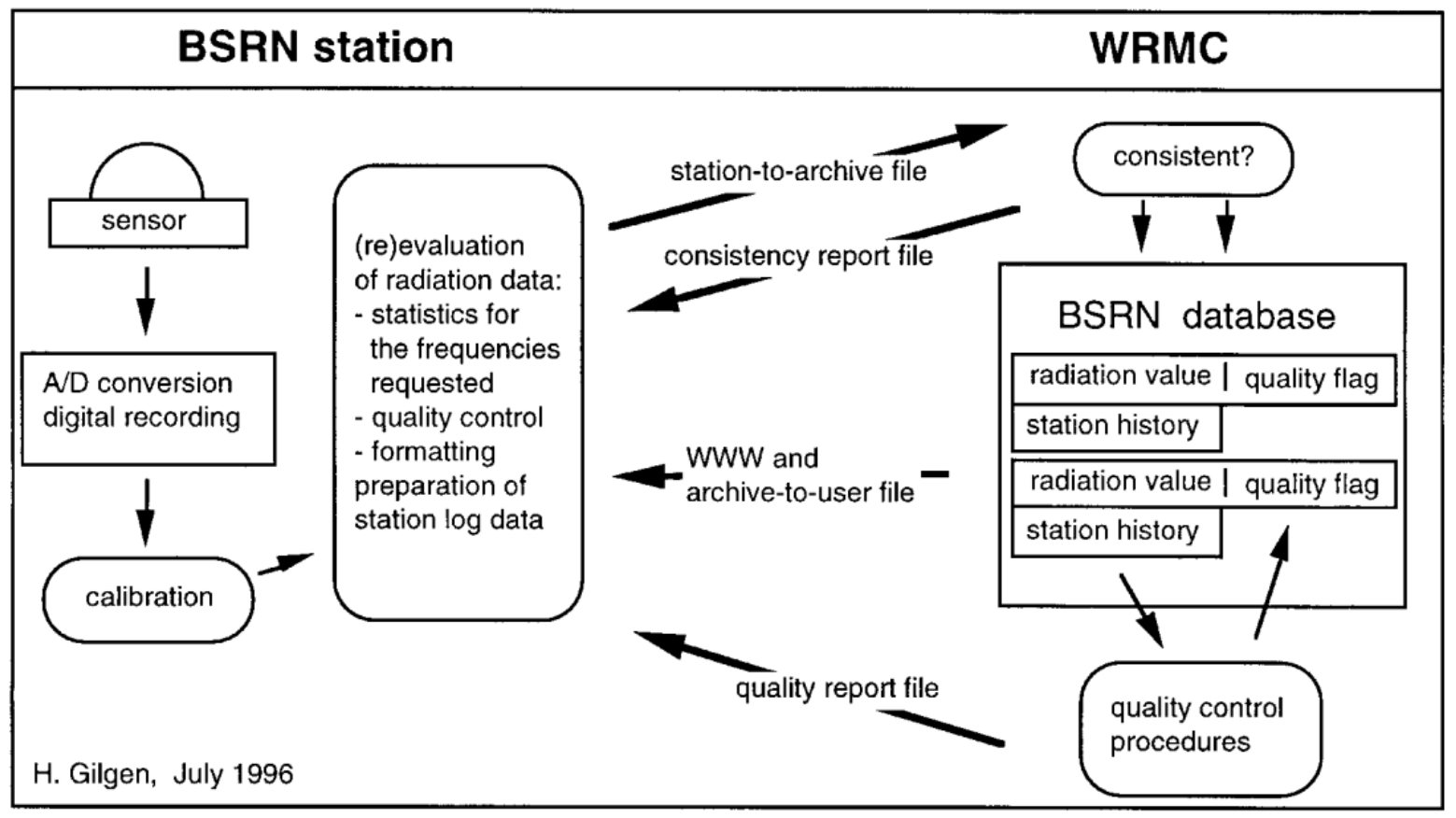

Fonte: MCARTHUR (2005)

As medições são feitas nas estações BSRN. Os dados são acumulados durante um mês e sua qualidade é verificada pelo cientista da estação. Os conjuntos de dados mensais são então encaminhados para o WRMC (Centro Mundial de Monitoramento de Radiação) usando o formato de arquivo BSRN estação-de-arquivo em código ASCII.

A transferência de dados é feita preferencialmente por via eletrônica. As estações BSRN devem manter o registro e as leituras originais para permitir a qualquer momento uma reavaliação. Um conjunto de dados mensal consiste em dados de registro de estação e dados climatológicos (incluindo os dados de radiação). Os dados de registro de estação consistem na descrição da estação, dos instrumentos de medição e das medições. Os dados de registro de estação são escritos na primeira parte do arquivo. A radiação e os outros dados climatológicos são escritos na segunda parte do arquivo.

O gerenciador de dados do WRMC fornece um arquivo de registro padrão e um programa de verificação de formato e recomenda a aplicação do programa de verificação de formato antes de um arquivo ser encaminhado para o WRMC. O programa de verificação de formato, entretanto, não executa verificações de consistência. A consistência dos arquivos é verificada no WRMC. Se um arquivo é definido como consistente, os dados são inseridos na base de dados BSRN. Se um arquivo for considerado incompatível, um relatório de consistência é encaminhado para a estação. 
No WRMC, procedimentos de controle de qualidade automatizados são aplicados aos dados de fluxo radiativo para detectar valores errôneos que, posteriormente, são sinalizados. Os dados de irradiância sinalizados no WRMC como errôneos e o motivo da sinalização são relatados para a estação. Se o cientista da estação julgar que os dados sinalizados são, de fato, questionáveis, ele deve reavaliar a base de dados mensal e enviar uma nova versão para a WRMC.

Todo esse processo requer a padronização do formato dos dados, tanto para que eles possam ser inseridos na base de dados, quanto para que eles possam ser submetidos aos testes de qualidade. A Tabela 12 mostra as principais definições assumidas pela BSRN para o registro dos principais dados climatológicos e radiométricos.

Tabela 12 - Formatos de registro de grandezas definidos pela BSRN

\begin{tabular}{|c|c|c|c|c|c|}
\hline Parâmetro & Abreviação & Unidade & $\begin{array}{l}\text { Limite } \\
\text { inferior }\end{array}$ & $\begin{array}{l}\text { Limite } \\
\text { Superior }\end{array}$ & Formato \\
\hline Data/horário & Date/Time & & -10000 & 1000 & $\begin{array}{l}\text { yyyy-MM- } \\
\text { dd'T'HH:mm }\end{array}$ \\
\hline Azimute & Azim & deg & 0 & 360 & $\# \# 0.0$ \\
\hline Irradiância Difusa & DIF & $\mathrm{W} / \mathrm{m}^{2}$ & -10 & 3000 & \#\#\#0 \\
\hline $\begin{array}{l}\text { Irradiância Difusa, } \\
\text { máximo }\end{array}$ & DIF max & $\mathrm{W} / \mathrm{m}^{2}$ & -10 & 3000 & \#\#\#0 \\
\hline $\begin{array}{l}\text { Irradiância Difusa, } \\
\text { mínimo }\end{array}$ & DIF min & $\mathrm{W} / \mathrm{m}^{2}$ & -10 & 3000 & \#\#\#0 \\
\hline $\begin{array}{l}\text { Irradiância Difusa, } \\
\text { desvio padrão }\end{array}$ & DIF std dev & $\mathrm{W} / \mathrm{m}^{2}$ & 0 & 100 & $\# 0.0$ \\
\hline Irradiância Direta & DIR & $\mathrm{W} / \mathrm{m}^{2}$ & -10 & 3000 & \#\#\#0 \\
\hline $\begin{array}{l}\text { Irradiância Direta, } \\
\text { máximo }\end{array}$ & DIR max & $\mathrm{W} / \mathrm{m}^{2}$ & -10 & 3000 & \#\#\#0 \\
\hline $\begin{array}{l}\text { Irradiância Direta, } \\
\text { mínimo }\end{array}$ & DIR min & $\mathrm{W} / \mathrm{m}^{2}$ & -10 & 3000 & \#\#\#0 \\
\hline $\begin{array}{l}\text { Irradiância Direta, } \\
\text { desvio padrão }\end{array}$ & DIR std dev & $\mathrm{W} / \mathrm{m}^{2}$ & 0 & 100 & $\# 0.0$ \\
\hline $\begin{array}{l}\text { Ângulo de } \\
\text { Elevação }\end{array}$ & alpha & deg & 0 & 90 & $\# 0.0$ \\
\hline Altura do chão & Height & $\mathrm{m}$ & 0 & 99999 & \#\#\#\#0 \\
\hline Umidade Relativa & $\mathrm{RH}$ & $\%$ & 0 & 100 & $\# 0.0$ \\
\hline $\begin{array}{l}\text { Pressão na altitude } \\
\text { determinada }\end{array}$ & PPPP & $\mathrm{hPa}$ & 0 & 1100 & \#\#\#0 \\
\hline $\begin{array}{l}\text { Pressão } \\
\text { Atmosférica }\end{array}$ & PPPP & $\mathrm{hPa}$ & 0 & 2000 & \#\#\#0.0 \\
\hline Irradiância Global & SWD & $\mathrm{W} / \mathrm{m}^{2}$ & -10 & 3000 & $\# \# \# 0$ \\
\hline
\end{tabular}




\begin{tabular}{llllll}
\hline Parâmetro & Abreviação & Unidade & $\begin{array}{l}\text { Limite } \\
\text { inferior }\end{array}$ & $\begin{array}{l}\text { Limite } \\
\text { Superior }\end{array}$ & Formato \\
\hline $\begin{array}{l}\text { Irradiância Global, } \\
\text { Maximo }\end{array}$ & SWD max & $\mathrm{W} / \mathrm{m}^{2}$ & -10 & 3000 & $\# \# 0$ \\
\hline $\begin{array}{l}\text { Irradiância Global, } \\
\text { Mínimo }\end{array}$ & SWD min & $\mathrm{W} / \mathrm{m}^{2}$ & -10 & 3000 & $\# \# 0$ \\
\hline $\begin{array}{l}\text { Irradiância Global, } \\
\text { desvio padrão }\end{array}$ & $\begin{array}{l}\mathrm{SWD} \text { std } \\
\mathrm{dev}\end{array}$ & $\mathrm{W} / \mathrm{m}^{2}$ & 0 & 100 & $\# 0.0$ \\
\hline $\begin{array}{l}\text { Temperatura do } \\
\text { Ar }\end{array}$ & $\mathrm{TTT}$ & ${ }^{\circ} \mathrm{C}$ & 0 & 999 & $\# \# 0.0$ \\
\hline $\begin{array}{l}\text { Temperatura do } \\
\text { Ar, máximo }\end{array}$ & $\mathrm{TxTxTx}$ & ${ }^{\circ} \mathrm{C}$ & -100 & 100 & $\# \# 0.0$ \\
\hline $\begin{array}{l}\text { Temperatura do } \\
\text { Ar, mínimo }\end{array}$ & $\mathrm{TnTnTn}$ & ${ }^{\circ} \mathrm{C}$ & -100 & 100 & $\# \# 0.0$ \\
\hline $\begin{array}{l}\text { Direção do Vento } \\
\text { Velocidade do }\end{array}$ & $\mathrm{dd}$ & $\mathrm{deg}$ & 0 & 360 & $\# \# 0$ \\
\begin{tabular}{l} 
Vento \\
\hline
\end{tabular} & $\mathrm{m} / \mathrm{s}$ & 0 & 120 & $\# \# 0.0$ \\
\hline
\end{tabular}

Fonte: PANGEA, 2014

A Tabela 12 apresenta as principais variáveis medidas, a abreviação utilizada para o registro dos dados, a unidade de medida, o valor mínimo e máximo aceitável para cada variável e o formato requerido. Os limites expressos na tabela são bastante abrangentes e indicam um critério inicial e geral de consistência.

\subsubsection{NREL e o Padrão de Registro de Dados}

Para definir a qualidade de dados de irradiância o NREL desenvolveu um software denominado SERI QC que testa e sinaliza os dados de irradiância que aparentam estar inconsistentes. O software foi desenvolvido para ser usado com dados de 1 minuto até dados de 60 minutos e tem sido utilizado por diferentes grupos ao redor do mundo, como pelo programa de medições de radiação atmosférica (ARM) do departamento norte-americano de energia. O software também tem sido utilizado em redes de medição na Coreia, Arábia Saudita e WMO.

Para a utilização do software os dados devem ser fornecidos em um determinado formato. O software requer informações iniciais de uma nova estação a ser registrada como: breve caracterização incluindo localização (cidade e estado); posição geográfica da estação (longitude e latitude em números decimais), fuso horário onde a estação está (o software aceita fuso horários decimais e define convenções de sinais para definição do fuso), com isso, um número de identificação da estação será gerado e esse número deve ser utilizado antes da 
inserção de novos documentos com registros de medição dessa estação. Para cada medida, o algoritmo do software requer o dado de irradiância solar em W/m² e o horário da medição.

O manual para usuários do software (MAXWELL et al., 1993) exemplifica o formato ideal. O software desconsidera os valores decimais para datas e horários, mas considera duas casas decimais para os dados de irradiância e, para cada medição, deve-se indicar o horário quando a medição foi finalizada. Valores de medição perdidos devem ser indicados utilizando valores de dados acima de $8.000 \mathrm{~W} / \mathrm{m}^{2}$. Por exemplo, uma medição que foi finalizada às 11 horas da manhã, do dia 12 de maio de 1979, deve ser registrada da seguinte maneira:

\section{$\begin{array}{llllllll}79 & 5 & 12 & 11 & 0 & 928.03 & 1102.47 & 9900.00\end{array}$}

Os horários devem variar entre 00:01 a 24:00. E o software demanda dados de irradiância difusa, direta e global para cada linha de dados. Nesse exemplo fornecido pelo manual, a medição foi finalizada no ano de 1979, no mês 5, dia 12 às 11 horas e zero minutos e registrou uma irradiância global de $928,03 \mathrm{~W} / \mathrm{m}^{2}$, a irradiância direta foi medida em $1.102,47 \mathrm{~W} / \mathrm{m}^{2}$ e o valor da componente difusa foi perdido/ não foi medido.

Dados de estações diferentes devem ser registrados em documentos diferentes. E todos os dados de uma mesma estação podem ser registrados em um mesmo documento, embora a eficiência do software melhore com arquivos menores. $\mathrm{O}$ menor intervalo de dados a ser utilizado consiste em 1 mês de medições, o intervalo mínimo de medição é de 1 minuto e o máximo é de 60 minutos. Se dados de mais de 1 ano de medição forem utilizados para a definição das curvas padrão de comportamento, é necessário dividir os dados por meses. Por exemplo, para definir as curvas de dados para o mês de janeiro de três anos consecutivos, os dados de janeiro dos três meses devem estar no mesmo arquivo.

Dados que não estejam registrados nesse formato podem ser submetidos ao software aplicando as devidas alterações no próprio programa. Além dos dados de irradiância global direta e difusa o software aceita a inserção de outras variáveis. O programa lê os arquivos com dados de irradiância e os separa em três regimes diferentes de massa de ar: baixo, médio e alto. O regime de massa de ar baixo é $\leq 1.25$, o médio é $>1.25$ e $\leq 2.5$ e alto é $>2.5$ e $\leq 5.58$. Essas definições são elaboradas após a inserção dos dados a serem analisados pelo programa. Maiores detalhes dessas alterações podem ser verificados em MAXWELL et al. (1993; cap. $8)$.

Dada a padronização dos registros de dados, é importante a verificação da consistência dos mesmos. Contudo, essa verificação varia em função do período de integralização das 
medições. Em função disso, buscou-se o entendimento e verificação de procedimentos de análise de qualidade de dados adotados por instituições vinculadas à solarimetria e redes de medições solarimétricas. Objetiva-se com isso, identificar a variação da caracterização do recurso sob a perspectiva dos períodos de análises.

\subsection{PROCEDIMENTOS DE ANÁLISE DE DADOS RADIOMÉTRICOS}

O processo de controle de qualidade de dados de radiação inicia-se com a preparação para coleta de dados, ainda na definição, instalação e calibração dos equipamentos que realizarão as medições. Cuidados também precisam ser tomados durante o processo de medição, incluindo a escolha e manutenção dos equipamentos e cabeamentos de processamento e transmissão de dados. Depois que os dados são coletados, os processos a serem realizados correspondem a uma avaliação da qualidade dos dados, enquanto que o controle da qualidade é realizado em todas as etapas supracitadas (MAXWELL et al., 1993).

A radiação global e a radiação difusa são medidas por piranômetros de sensores fixos, de modo que a posição aparente do Sol, em relação ao sensor, varie ao longo do dia. A Figura 33 apresenta a incidência da radiação (linha diagonal) em um dado momento do dia.

Figura 33 - Incidência da radiação e ângulo zenital

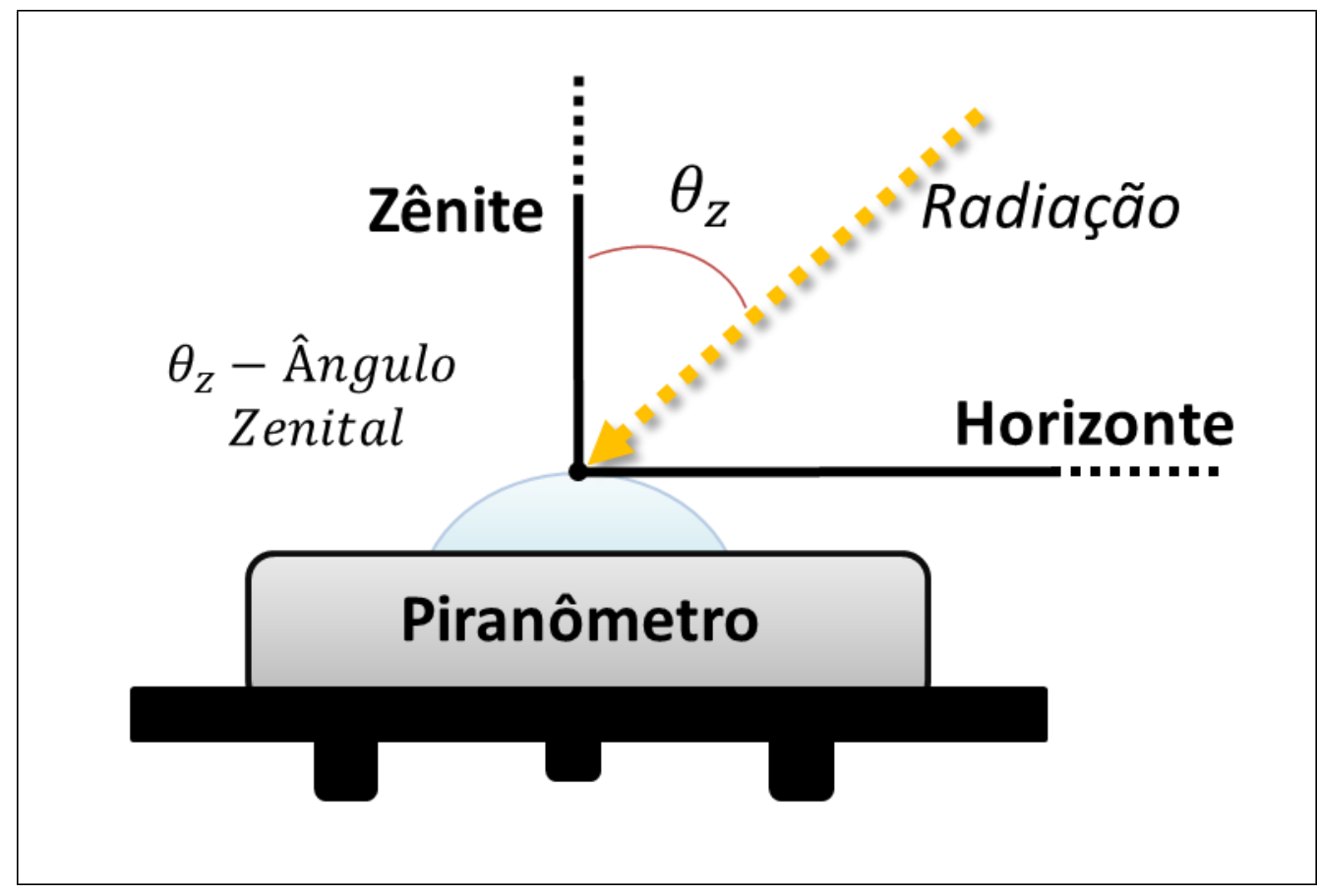

Fonte: Elaboração própria 
Nesse momento, o pireliômetro, recebe exclusivamente a radiação direta normal $(I D N)$ já que o equipamento, embora possua o mesmo princípio funcionamento de um piranômetro, possui um orifício de abertura restrito e acompanha rotacionalmente o movimento aparente do Sol. O piranômetro medidor da radiação global está recebendo apenas a componente vertical dessa radiação, somada à componente difusa também recebida por esse sensor. Desse modo, define-se que, a radiação recebida pelo sensor de irradiância global $(I G H)$ deve ser igual à componente vertical da irradiância medida pelo pireliômetro (IDN $\times$ $\cos \theta_{z}$ ) somada à irradiância difusa $(I D H)$ medida pelo piranômetro com sombreamento. $\mathrm{Ou}$ seja, a Equação (1) apresentada nesse trabalho e relembrada a seguir:

$$
I G H=I D N \times \cos \theta_{z}+I D H
$$

Essa é a principal equação de correlação entre as componentes de radiação e é utilizada em diversos métodos, de diferentes formas, para a verificação da qualidade e coerência de dados de radiação medidos por estações solarimétricas.

Seguindo a mesma linha de raciocínio, é possível afirmar que o limite físico possível para a medição da radiação global em um dado momento $t$ corresponde à componente vertical da irradiância extraterrestre naquele dado momento $(t)$, que possui um angulo zenital $\theta_{z}$. Assim:

$$
I G H(t) \leq I D N_{0}(t) \cdot \cos \theta_{Z}(t)
$$

Aonde $I G H(t)$ corresponde à irradiância global horizontal no momento $t, I D N_{0}(t)$ corresponde da irradiância extraterrestre normal no momento $t$ e $\cos \theta_{Z}(t)$ corresponde ao cosseno do ângulo zenital no dado momento $t$.

Durante todo o período do dia, do momento em o Sol nasce até o momento em que o Sol se põe, é possível verificar claridade natural. Mesmo nos dias em que o sol aparece totalmente coberto por nuvens (momento em que a irradiância direta tende à zero), assim é possível concluir que a irradiância difusa $(I D H)$ nunca obtém valores nulos ao longo do dia. Desse modo, conclui-se que, no limite, a irradiância difusa é no máximo igual à irradiância global. De modo que, a princípio, o limite físico mínimo das três componentes pode ser definido como zero e:

$$
I D H(t) \leq I G H(t) \leq I D N(t) \cdot \cos \theta_{Z}(t)
$$

Aonde $I D H(t)$ corresponde à irradiância difusa horizontal no momento $t, I G H(t)$ corresponde à irradiância global horizontal no momento $t, I D N_{0}(t)$ corresponde da 
irradiância extraterrestre normal no momento $t$ e $\cos \theta_{Z}(t)$ corresponde ao cosseno do ângulo zenital no dado momento $t$.

Estas análises correspondem a definições iniciais de limites físicos possíveis para as três principais componentes da radiação. Valores registrados além desses limites devem ser apontados como, no mínimo duvidosos. Contudo, mesmo os valores verificados dentro desse intervalo podem apresentar erros. Desse modo, outros testes com diferentes metodologias podem ser aplicados com o objetivo de delimitar o intervalo de conjunto de dados considerados válidos de maneira mais restrita e eficiente.

As medições de radiação são mais suscetíveis a erros do que as variáveis meteorológicas (MORADI, 2009 apud JOURNÉE e BERTRAD, 2011). Mesmo sob as melhores circunstâncias de manutenção e instalação de equipamentos existem situações que os dados apresentarão erros. Se a análise de qualidade de dados foi realizada constantemente, com dados atuais, é possível manter a qualidade dos dados obtidos e identificar rapidamente erros de operação dos equipamentos.

Os processos de análise de qualidade de dados normalmente envolvem a definição de limites físicos (que costumam ser limites amplos que não permitem a identificação de erros menos grosseiros de medição), análises estatísticas dos dados (que identificam dados questionáveis ou eventos raros) ou comparações com modelos de estimativa de medidas reais.

As análises estatísticas apresentam-se como uma boa alternativa de metodologia de análise de dados, contudo, é necessário observar que essas análises só se tornam eficientes a partir da existência de um histórico de medições. Por último, poderia se considerar a análise de qualidade de dados por redundância, ou seja, por meio da medição da mesma variável por dois equipamentos diferentes, contudo, essa opção é normalmente inviabilizada em função do aumento de custo que tal medida acarretaria.

São apresentadas a seguir três metodologias de análise de qualidade de dados. Pretende-se, com a análise destas, aprofundar o entendimento das relações entre as componentes de radiação em função da análise de períodos diferentes (medições em minutos, horas e dias) e apresentar modelos criados e aplicados por instituições confiáveis que mantém dados de uma rede de estações. A primeira metodologia apresentada foi desenvolvida pela BSRN e também é utilizada pela rede Sonda no Brasil. A segunda metodologia corresponde à desenvolvida pelo NREL, por meio da análise do Manual para Usuários do Software SERI QC. A terceira metodologia foi desenvolvida pelo Instituto Meteorológico Royal da Bélgica (RMIB) com o objetivo de aplicação nos dados das estações do próprio instituto. 


\subsubsection{Análise de Qualidade de Dados pela BSRN}

A BSRN define uma série de equações para validação dos dados. Os testes definidos pela BSRN (LONG e DUTTON, 2002) indicam análises de limites físicos possíveis, limites extremamente raros e comparações entre as componentes para dados coletados de $1 \mathrm{hz}$ e integrados em 1 minuto.

\section{Limites Físicos Possíveis}

Irradiância Global:

Min: $-4 W / m^{2}$

Máx: $I D N_{0} \times 1,5 \times\left(\cos \theta_{Z}\right)^{1,2}+100 \mathrm{Wm}^{-2}$

Irradiância Difusa:

Min: $-4 W / m^{2}$

Máx: $I D N_{0} \times 0,95 \times\left(\cos \theta_{Z}\right)^{1,2}+50 \mathrm{Wm}^{-2}$

Irradiância Direta Normal:

Min: $-4 W / m^{2}$

Máx: $I D N_{0}$

Para irradiância direta horizontal: Max: $I D N_{0} \cos \theta_{Z}$

\section{Limites Extremamente Raros}

Irradiância Global:

Min: $-2 W / m^{2}$

Máx: $I D N_{0} \times 1,2 \times\left(\cos \theta_{Z}\right)^{1,2}+50 \mathrm{Wm}^{-2}$

Irradiância Difusa:

Min: $-2 W / m^{2}$ 
Máx: $I D N_{0} \times 0,75 \times\left(\cos \theta_{Z}\right)^{1,2}+30 \mathrm{Wm}^{-2}$

Irradiância Direta Normal:

Min: $-2 W / m^{2}$

Máx: $I D N_{0} \times 0,95 \times\left(\cos \theta_{Z}\right)^{0,2}+10 \mathrm{Wm}^{-2}$

Para irradiância direta horizontal: Max: $I D N_{0} \times 0,95 \times\left(\cos \theta_{Z}\right)^{1,2}+10 \mathrm{Wm}^{-2}$

\section{Comparações}

Irradiância Global Medida em Comparação com a Irradiância Global Calculada $\left(I G H_{C}\right)$ :

A irradiância global pode ser calculada somando o valor medido de irradiância difusa com a componente vertical do valor medido de irradiância direta $\left(I G H=I D N \times \cos \theta_{z}+\right.$ $I D H)$. Assim, a BSRN define que:

$I G H / I G H_{C}=+/-8 \%$ de 1.0 para $\theta_{Z}<75^{\circ}$ e $I G H_{C}>50 \mathrm{Wm}^{-2}$

$I G H / I G H_{C}=+/-15 \%$ de 1.0 para $93^{\circ}<\theta_{Z}<75^{\circ}$ e $I G H_{C}>50 \mathrm{Wm}^{-2}$

Se a IGH $<50 \mathrm{Wm}^{-2}-$ teste não é possível

\section{Taxa da Irradiância Difusa}

$I D H / I G H<1.05$ para $\theta_{Z}<75^{\circ}$ e IGH $>50 \mathrm{Wm}^{-2}$

$I D H / I G H<1.10$ para $93^{\circ}<\theta_{Z}<75^{\circ}$ e IGH $>50 \mathrm{Wm}^{-2}$

Se a IGH $<50 \mathrm{Wm}^{-2}$ - teste não é possível

Os valores mínimos negativos (ao invés de nulos, como demonstrado inicialmente) são em decorrência de rápidas variações nos dados de medição, em função do sombreamento repentino do equipamento e em função das taxas de incertezas inerentes a qualquer radiômetro, além de efeitos como o resfriamento repentino da temperatura ambiente, causando uma diferença entre a temperatura das cúpulas dos equipamentos. Estas especificidades são justamente encontradas em dados de um intervalo de medição reduzido. Dados de médias horárias negativas, ou superiores à irradiância extraterrestre certamente apresentam erros de medição.

Nota-se também uma maior flexibilização dos critérios quando assumidos ângulos azimutais maiores, isso ocorre porque, quanto mais próximo da linha do horizonte o Sol estiver, maiores são as possibilidades de erros dos equipamentos em função da grande 
componente horizontal da radiação incidente e em função do aumento da probabilidade de aparecimento de sombras. Ou seja, quanto maiores os ângulos azimutais, maior é a dificuldade de caracterização do recurso. LONG e DUTTON (2002) indicam que os limites estabelecidos têm o objetivo de abranger todas as latitudes e todos os regimes climáticos das estações participantes do programa e que esses limites podem ser refinados para cada quadro climático e localização específica de modo que se obtenham resultados mais precisos.

A Rede Sonda, do INPE-CPTEC, utiliza a mesma metodologia da BSRN, com algumas alterações nos limites definidos. A Rede Sonda (BRASIL, 2015) destaca a necessidade de verificação dos desvios padrão das medições. Isso é relevante porque sensores com problemas de operação podem definir, como registro de dados, uma repetição do último dado medido. Portanto, se o desvio padrão de uma série de dados for igual a zero, significa que o equipamento não está realizando as medições corretamente.

A Rede Sonda aplica estes critérios em sequência semelhante também para dados anemométricos e meteorológicos como mostrado no Quadro 7.

Quadro 7 - Quadro de esquematização de análise de qualidade de dados pela Rede Sonda

\begin{tabular}{|c|c|c|c|}
\hline Etapas & $\begin{array}{l}\text { Variáveis } \\
\text { Anemométricas }\end{array}$ & $\begin{array}{l}\text { Variáveis } \\
\text { Meteorológicas }\end{array}$ & $\begin{array}{l}\text { Variáveis } \\
\text { Radiométricas }\end{array}$ \\
\hline 1 & \multicolumn{3}{|c|}{$\begin{array}{l}\text { Algoritmo } 1 \\
\text { Dado suspeito quando fisicamente impossivel. }\end{array}$} \\
\hline 2 & \multicolumn{3}{|c|}{$\begin{array}{l}\text { Algoritmo } 2 \\
\text { Dado suspeito quando o evento é extremamente raro. }\end{array}$} \\
\hline 3 & \multicolumn{2}{|c|}{$\begin{array}{l}\text { Algoritmo } 3 \\
\text { Dado suspeito quando apresenta uma evolução temporal não } \\
\text { condizente com o esperado para a variável. }\end{array}$} & $\begin{array}{l}\text { Algoritmo } 3 \\
\text { Dado suspeito quando } \\
\text { inconsistente com medidas } \\
\text { apresentadas por outras } \\
\text { variáveis da mesma } \\
\text { estação. }\end{array}$ \\
\hline 4 & $\begin{array}{l}\text { Algoritmo } 4 \\
\text { Dado suspeito quando inconsistente } \\
\text { com medidas apresentadas por outras } \\
\text { variáveis da mesma estação. }\end{array}$ & \multicolumn{2}{|c|}{$\begin{array}{l}\text { Algoritmo } 4 \\
\text { (ainda não aplicado) } \\
\text { Dado suspeito caso a medida esteja } \\
\text { inconsistente quando comparada com } \\
\text { estimativas de modelos computacionais. }\end{array}$} \\
\hline
\end{tabular}

Fonte: BRASIL, 2015

Assim como na metodologia definida pela BSRN, a Rede Sonda não recomenda que os dados não aprovados nos testes de qualidade sejam descartados. Estes dados devem ser sinalizados e mantidos de modo que o histórico real de medição esteja sempre armazenado. A análise desse conjunto de dados pode auxiliar na avaliação da operação da estação ao longo dos anos, além de sinalizar efeitos esporádicos e principais origens de erros. 


\subsubsection{Análise de Qualidade de Dados pelo NREL}

A análise de qualidade de dados utilizada pelo NREL corresponde à metodologia desenvolvida para o software SERI QC. A análise promovida por essa metodologia é basicamente estatística e flexível às diversas unidades de medida, isso porque o software trata da análise de irradiância por meio de grandezas adimensionais que são obtidas em função da normalização dos valores medidos de irradiância direta, global e difusa com a irradiância extraterrestre. Assim, definem-se os índices de transmitância de irradiância direta $\left(k_{n}\right)$, transmitância de irradiância difusa $\left(k_{d}\right)$ e transmitância de irradiância global $\left(k_{t}\right)$. Estas grandezas adimensionais possuem a mesma fundamentação dos cálculos da fração difusa $\left(k_{d}^{\prime}\right)$, de índices de claridade $\left(k_{t}\right)$ e da fração direta $\left(k_{n}^{\prime}\right)$, apresentados para formação de modelos de desconstrução de estimativa das componentes direta e difusa. As equações (35), (36) e (37) definem o cálculo desses coeficientes.

$$
\begin{aligned}
& k_{d}=I D H / I G H_{0} \\
& k_{t}=I G H / I G H_{0} \\
& k_{n}=I D N / I D N_{0}
\end{aligned}
$$

MAXWELL et al. (1993) afirmam que os próprios dados de medição obtidos na estação devem ser utilizados para a análise de qualidade dos dados dessa estação. A princípio isso parece representar um paradoxo, por isso, são necessárias algumas considerações para suportar essa abordagem:

I. Assume-se que a estação é mantida de forma adequada, com equipamentos de boa tecnologia, bem calibrados e limpos constantemente, isso define que a maior parte dos dados será de qualidade e apenas uma pequena parcela apresentará erros.

II. A utilização dos próprios dados para definir o conjunto de dados plausíveis não requer a consideração de dados meteorológicos, apresentando-se como viável para regiões que não possuem o registro das variáveis atmosféricas.

III. O método possui desvantagens quando utilizado para estações novas ou sem registro histórico. Contudo, baseando-se nas experiências de aplicação dessa metodologia em diferentes estações, é possível estabelecer limites matemáticos iniciais que serão refinados conforme a estação aumentar a sua base histórica de dados. 
Essa aparente desvantagem pode-se tornar uma vantagem quando consideradas as alterações climáticas ao longo dos anos que podem caracterizar alterações nos limites de dados de radiação plausíveis para cada região. Desse modo, um modelo de determinação de limites dinâmico pode ajustar as alterações ao longo dos anos, aprimorando a análise de qualidade de dados.

A NREL também recomenda o armazenamento dos dados não aprovados nos testes de qualidade. Estes dados devem ser sinalizados. A sinalização apenas indica se os dados estão ou não dentro dos limites definidos, contudo, isso não define se os dados contêm erros ou não. Indicações que os dados não estão dentro dos limites pré-definidos podem indicar que:

- Os dados estão com erro devido a uma ou mais fontes de erros;

- Os limites aceitáveis podem ter sido erroneamente definidos ou não são apropriados para a as condições específicas em que os dados foram coletados;

- Os dados podem ter sido influenciados por fenômenos de vida curta que não são considerados nos limites esperados.

Por sua vez, os dados sinalizados como dentro de limites pré-definidos podem indicar que:

- Os dados são corretos e de boa qualidade;

- Os limites esperados são amplos demais para detectar dados incorretos;

- Os limites foram erroneamente ajustados e não podem detectar dados incorretos.

Assim, recomenda-se que os limites aceitáveis sejam ajustados de maneira que até 5\% dos dados bons sejam sinalizados como ruins, tendo como consequência a minimização de sinalização de dados ruins como bons. A metodologia definida inicia-se com o cálculo dos índices $k_{t}$ e $k_{n}$ para todos os dados do registro. Os dados podem configurar medições de 1 até 60 min. São definidos limites para $k_{t}$ e $k_{n}$ em função do período de integração dos dados e em função da massa de ar definida para o conjunto de dados. As massas de ar são definidas em três conjuntos como mostrado na Tabela 13.

Tabela 13 - Definição dos Intervalos de Massa de Ar

\begin{tabular}{lll}
\hline Intervalos & Massa de Ar & Ângulo Zenital \\
\hline Baixa & $1.00-1.25$ & $0^{\circ}-36.96^{\circ}$ \\
\hline Média & $1.25-2.50$ & $36.96^{\circ}-66.57^{\circ}$ \\
\hline Alta & $2.50-5.76$ & $66.57^{\circ}-80.00^{\circ}$ \\
\hline
\end{tabular}

Fonte: MAXWELL et al., 1993 
A definição dos limites dos espaços $k_{n}-k_{t}$ é definida em duas etapas, inicialmente definem-se os limites teóricos e posteriormente os limites empíricos.

\section{- Limites Teóricos}

A Figura 34 mostra os valores de $k_{n}-k_{t}$ para todos os dados horários coletados em Tallahassee, (Flórida, EUA), nos anos de 1977 a 1980, com ângulos zenitais inferiores a 80 com a discriminação dos limites teóricos.

Figura 34 - Espaço $k_{n}-k_{t}$ com a plotagem de limites teóricos

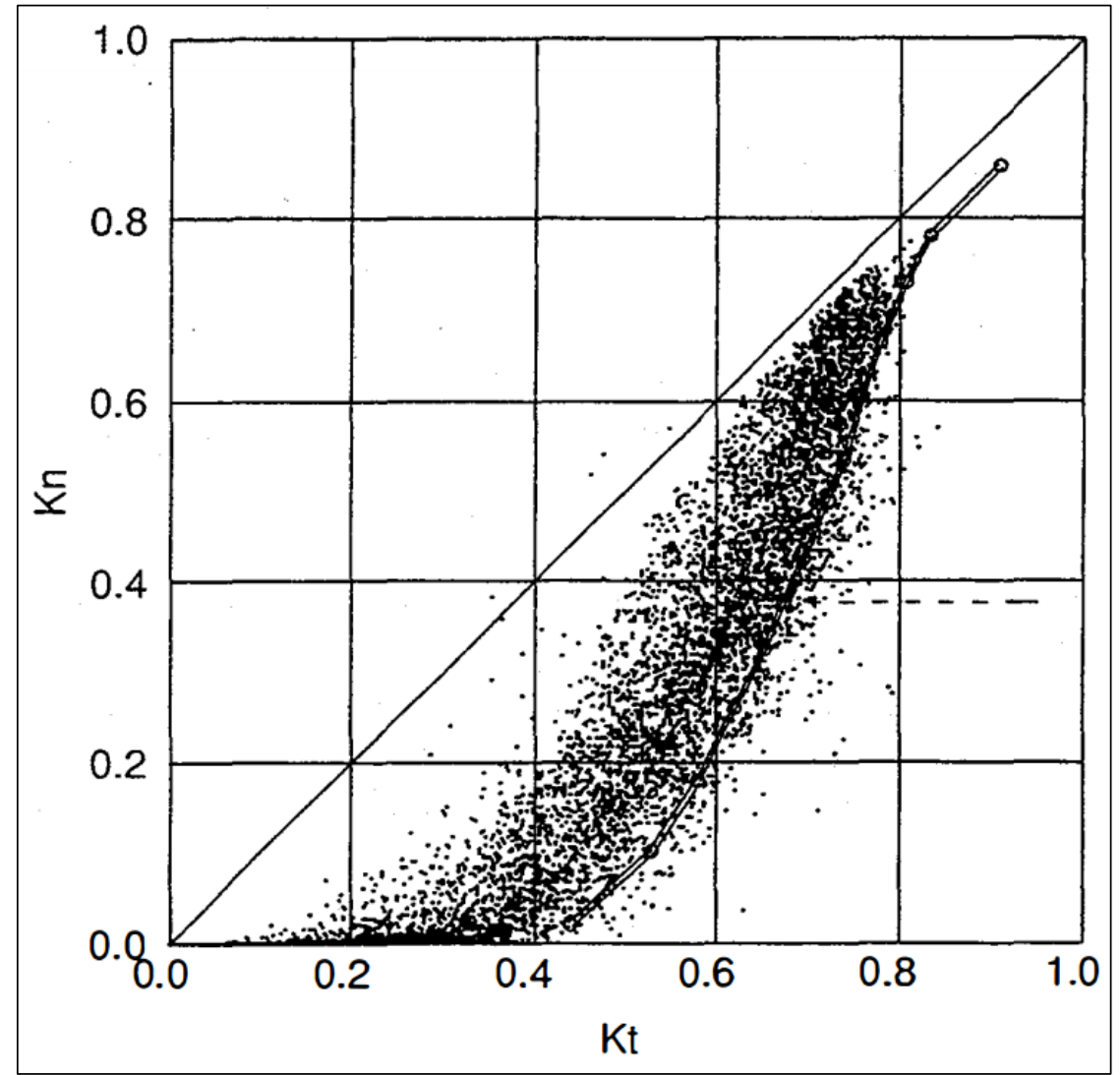

Fonte: MAXWELL et al., 1993

A linha diagonal $(0,0 ; 1,1)$ representa o primeiro limite teórico que indica que, obrigatoriamente $k_{t}>k_{n}$. Esse limite parte da equação (38):

$$
k_{t}=k_{n}+k_{d}
$$

Se substituirmos os índices pelos seus valores de referência, temos: 


$$
\frac{I G H}{I D N_{0} \cos \theta_{Z}}=\frac{I D N}{I D N_{0}}+\frac{I D H}{I D N_{0} \cos \theta_{Z}}
$$

Ao multiplicar a equação pelo fator $\left(I D N_{0} \cos \theta_{Z}\right)$, temos:

$$
I G H=I D N \times \cos \theta_{z}+I D H
$$

Como a parcela da irradiância difusa não assume valores negativos e, a não ser em configurações astrológicas específicas (como eclipse), não alcança valores nulos ao longo do dia, conclui-se que, de fato $k_{t}>k_{n}$.

O segundo limite teórico é representado pela curva em S no lado direito da plotagem. Essa curva é definida pelo modelo Bird Cludless Sky Model. A parte superior da curva (delimitada pela linha pontilhada) é gerada utilizando-se uma massa de ar fixa de 1.0 e variando-se outros dois padrões atmosféricos. O ponto mais alto da curva representa a atmosfera sem nenhum vapor d'água ou concentração de aerossóis. A quantidade desses elementos é gradativamente aumentada até o meio da curva (linha pontilhada). A partir desse ponto, os índices de vapor d'água e turbidez são fixados (em 6.0 e 7.0, respectivamente) e a massa de ar é gradativamente aumentada até 6.0. Finalizando a constituição da parte inferior da curva.

Estes são os limites iniciais definidos pelo software. Essa constituição inicial foi utilizada como modelo de aplicação em dados de diversas estações. Esse processo deu origem aos limites empíricos.

\section{- Limites Empíricos}

O modelo inicial foi utilizado em séries de dados de vários anos, para os 12 meses do ano em mais de 40 estações. Com isso foram observados os efeitos de massa de ar, variações sazonais e de padrões atmosféricos, alguns dos efeitos observados são apresentados.

\section{Efeito de Nuvens}

Com o aumento da cobertura de nuvens, é observado que os valores de medição de irradiância direta caem mais rapidamente do que os da irradiância global. Deste modo, conforme a cobertura de nuvens aumenta, mais os pontos no gráfico $k_{n}-k_{t}$ se afastam do limite teórico da diagonal $(0,0 ; 1,1)$. Os pontos voltam a se aproximar da diagonal quando $k_{n}$ alcança valores próximos a zero. Quando o Sol está na borda de uma nuvem o efeito da dispersão pode aumentar até $30 \%$. 
Altos valores de irradiância difusa também são observados na presença de neve e com o céu coberto por nuvens o efeito de multi-reflexão da radiação entre o solo e as nuvens aumenta potencialmente o valor da irradiância difusa e, nesses casos, a irradiância global pode alcançar valores superiores à irradiância extraterrestre. Essas situações ocorrem em um curto período de tempo, portanto dados extremos são observados quando o período de integração dos dados é reduzido. Valores medidos de irradiância global maiores do que a irradiância extraterrestre em períodos de integração maiores, como 1 hora, provavelmente constituem erros de medição, contudo o mesmo não pode ser afirmado para dados com período de integração de 1 ou 5 minutos.

\section{Efeitos da Massa de Ar}

A Figura 35 mostra a plotagem de dados de uma mesma região para os três intervalos de massa de ar. É possível notar que os limites do espaço de dados aceitáveis se movem para baixo e para a esquerda na medida em que a massa de ar aumenta.

Figura 35 - Limites de $k_{n}-k_{t}$ para diferentes massas de ar

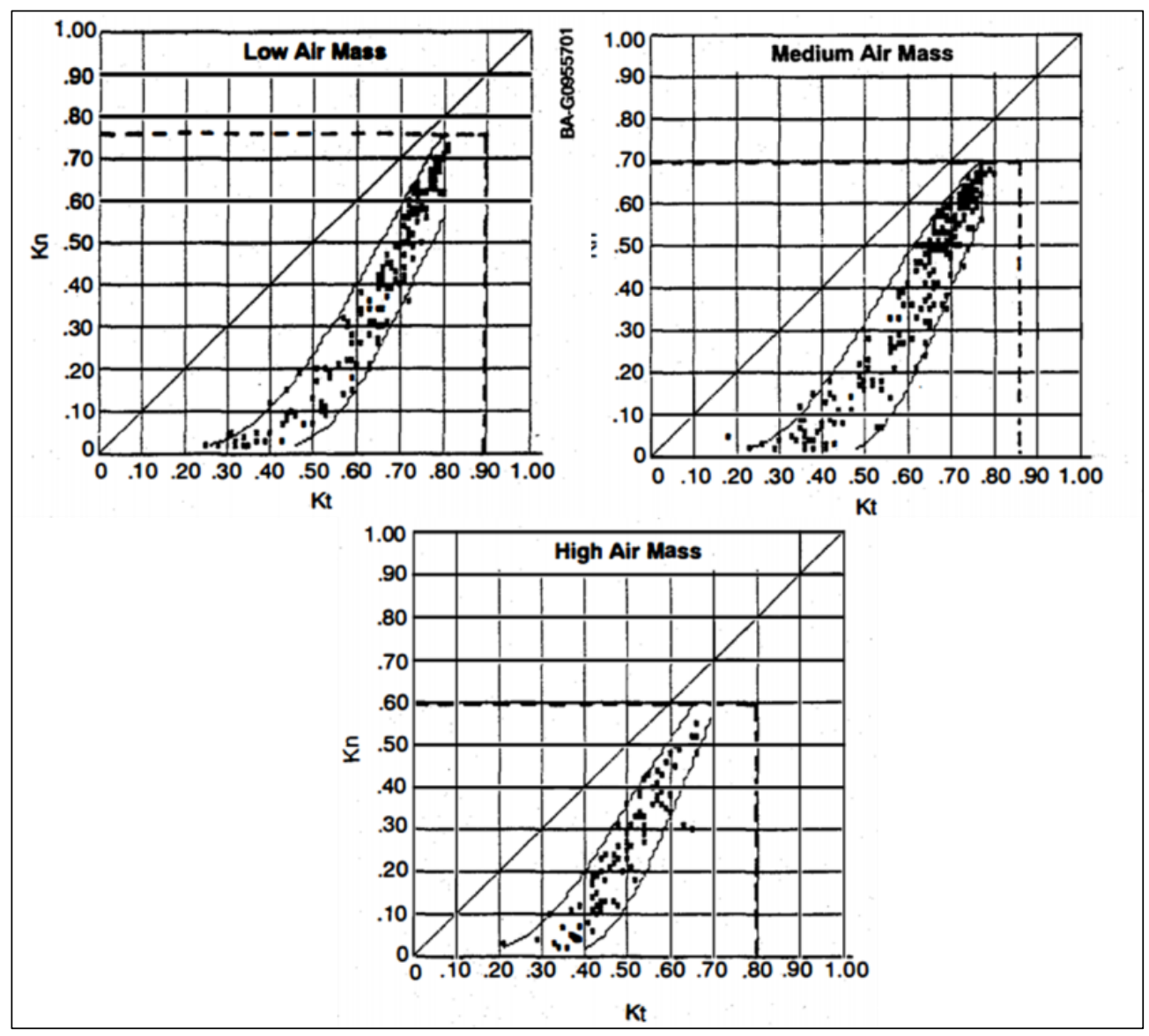

Fonte: MAXWELL et al., 1993 
Esses efeitos, nessa taxa de alteração foram tão consistentes durante a aplicação do modelo em diferentes estações que essa relação foi incorporada ao algoritmo do software. Alterações ainda maiores que estas podem ser verificadas para regiões muito úmidas, porém dificilmente variações menores são verificadas.

\section{Efeitos Atmosféricos}

Movimentos verticais no espaço $k_{n}-k_{t}$ podem ocorrer em função do aumento da turbidez atmosférica. Com o encobrimento do Sol por nuvens, teoricamente a irradiância direta tenderá a zero e a irradiância difusa aumentará, enquanto a irradiância global tenderá a baixas alterações.

Em função das experiências de aplicação da metodologia em diversas regiões sob diversas condições atmosféricas, foi possível a delimitação de espaços característicos dos conjuntos $k_{n}-k_{t}$. Esses espaços são mostrados na Figura 36.

Figura 36 - Determinação do conjunto $k_{n}-k_{t}$ em condições atmosféricas específicas

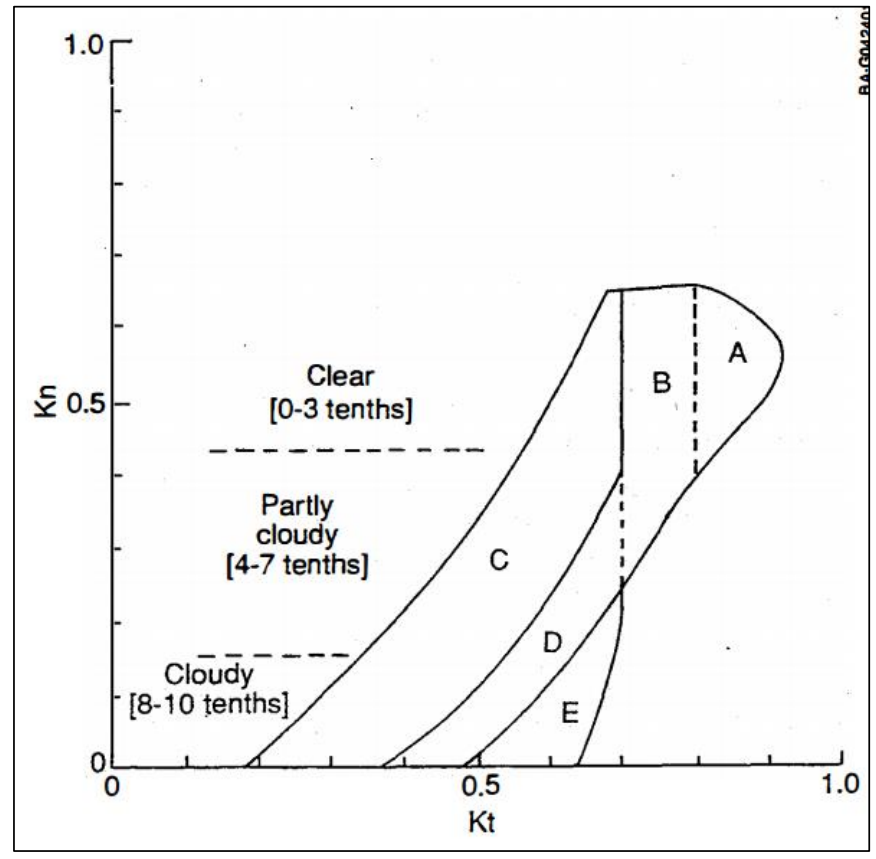

Fonte: MAXWELL et al., 1993

Como esperado, quanto maior é a presença de nuvens, menores são os valores de $K_{n}$ obtidos. Dados na região A são normalmente obtidos para períodos de integração de 15 minutos ou menos e normalmente indicam altos valores de irradiância difusa em função do aumento dos efeitos de reflexão e espalhamento da radiação, principalmente pelo 
posicionamento específico do Sol em relação a um conjunto determinado de nuvens, como a localização do Sol na borda das nuvens.

Dados na região B são observados para períodos de integração entre 1 minuto e 1 hora. A frequência de ocorrência diminui conforme o tempo de integração aumenta. Assim como na região $\mathrm{A}$, dados nesse espaço são verificados na ocorrência de fenômenos específicos de posicionamento do Sol em relação às nuvens.

A observação de centenas de estações mostra que cerca de $90 \%$ dos pontos se situam na região $\mathrm{C}$, sendo que a parte superior corresponde ao céu claro (de 0 à 3 décimos do céu coberto por nuvens: [0-3 tenths]), a parte do meio, ao céu parcialmente encoberto (de 4 à 7 décimos do céu coberto por nuvens: [4-7 tenths]) e a parte inferior ao céu encoberto (de 8 à 10 décimos do céu coberto por nuvens: [8-10 tenths]).

Os dados verificados na região D são obtidos em condições de tempo nublado, de períodos de integração curtos e longos. A frequência de ocorrência diminui conforme o tempo de integração aumenta. Novamente, isso indica que estes são fenômenos de vida relativamente curta. Dados sem erros de medição que caem dentro da região e são provavelmente o resultado de uma combinação de cobertura de nuvens e alto albedo da superfície.

A linha vertical entre a região B e região C é claramente observada para dados de hora em hora, quando os pontos de dados dentro da região B são quase inexistentes. Este limite vertical é aparentemente criado por uma absorção atmosférica mínima e efeito de espalhamento variado. No topo desta linha vertical encontramos dados para as condições atmosféricas muito claras.

Por meio da análise dos limites empíricos e das regiões definidas no gráfico da Figura 36 , fica claro que os limites para os conjuntos $k_{n}-k_{t}$ dependem das condições climáticas e meteorológicas que variam de região para região e ao longo do ano, portanto seria errôneo aplicar o mesmo padrão de limites para todas as estações.

\section{- A Irradiância Difusa e Os Períodos de Integração}

Com o intuito de verificar a consistência de dados de irradiância difusa, foi aplicado, em diversos dados de diversas estações um teste de comparação de duas plotagens do espaço $k_{n}-k_{t}$, como mostrado na Figura 37. 
Figura 37 - Plotagens das relações de $k_{n}-k_{t}$ para avaliação irradiância difusa

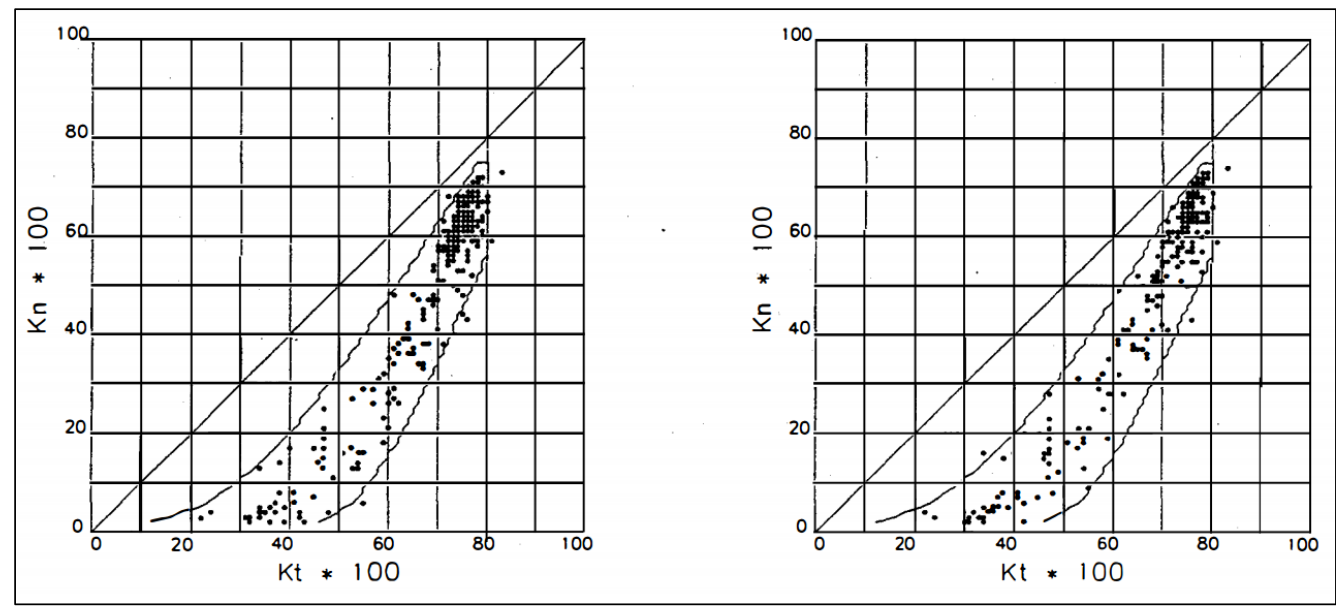

Fonte: adaptado de MAXWELL et al., 1993

O gráfico da esquerda corresponde à plotagem dos valores de $k_{n}-k_{t}$ obtidos pelas medições de irradiância direta e global. O gráfico da direita corresponde à plotagem dos valores de $k_{n}-k_{t}$, sendo que os valores de $k_{n}$ foram calculados, utilizando-se a equação (38) já apresentada.

Para a aplicação da fórmula, os valores de $k_{d}$ foram obtidos através das medições de irradiância difusa. As aplicações desse teste em diversas estações forneceram resultados bastante semelhantes aos mostrados na Figura 37. Contudo, verifica-se que os efeitos de curta duração de reflexão da radiação por nuvens alteram as relações entre as componentes de radiação para dados de curtos períodos de integração. Portanto, os limites precisam ser específicos para períodos de integração diferentes.

Um exemplo do efeito de diferentes tempos de integração é mostrado na Figura 38. Os dados de 1 minuto foram obtidos pela Universidade de Trinity, em San Antonio (Texas, EUA). Eles foram integrados em 5 minutos, 15 minutos, e 1 hora. Portanto, todos os dados apresentados nesta figura vieram da mesma amostra. O gráfico superior direito da Figura 38 corresponde aos dados integrados em 1 minuto, o superior direito corresponde aos dados integrados em 5 minutos, o inferior esquerdo corresponde aos dados integrados em 15 minutos e o inferior direito aos dados integrados em 1 hora. 
Figura 38 - Limites de $k_{n}-k_{t}$ para períodos de integração diferentes

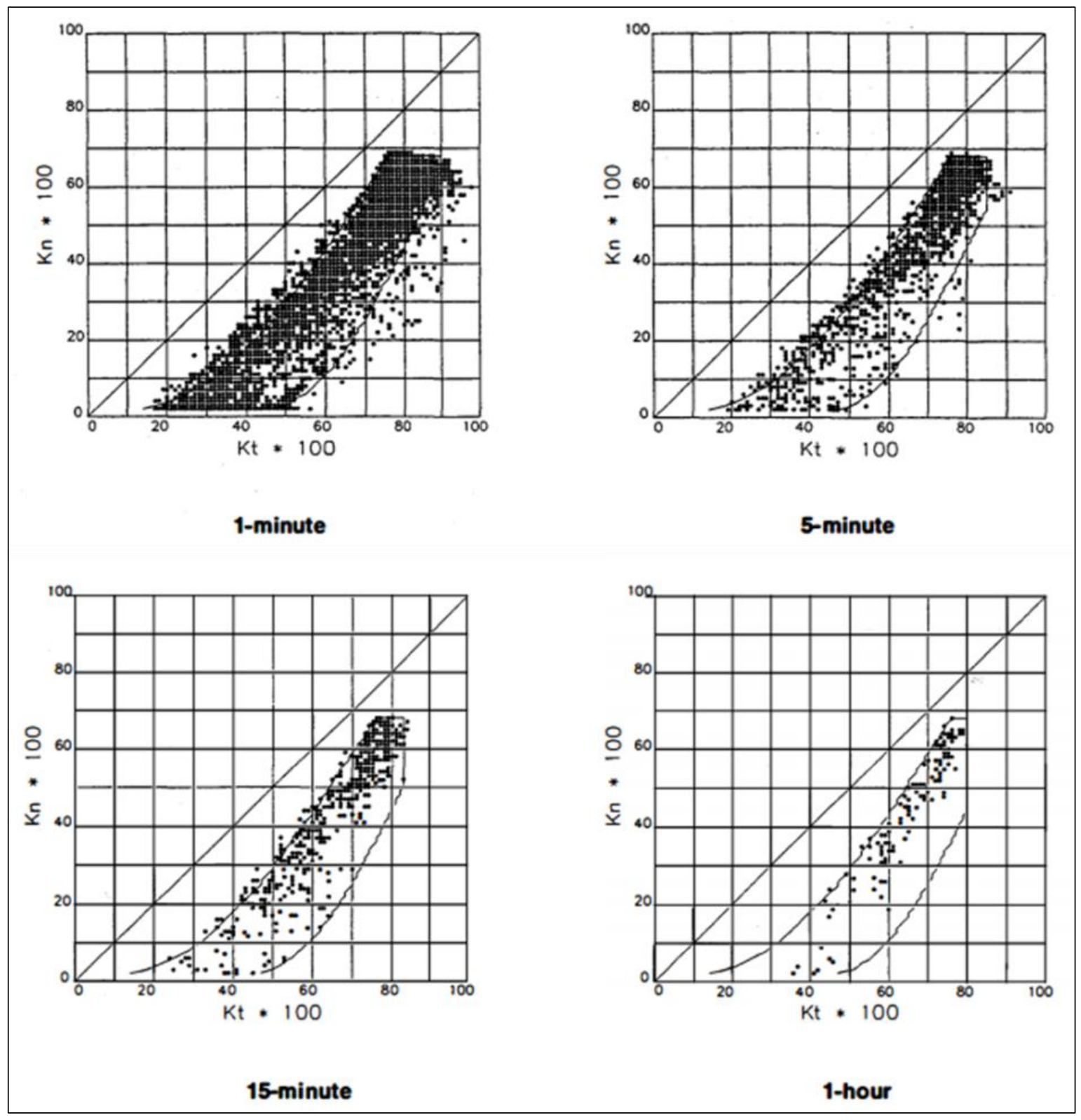

Fonte: adaptado de MAXWELL et al., 1993

A análise dos gráficos possibilita concluir que os efeitos de curto prazo da componente difusa são suavizados quando ocorre a integração dos dados em 1 hora. É também importante notar que um limite $k_{\text {tmax }}$ de cerca de 0,9 para os dados de 1 minuto, diminui para 0,85 para os dados de 5 minutos, para 0,83 para dados de 15 minutos, e de 0,80 para dados de 1 hora (MAXWELL et al., 1993). 


\subsubsection{Análise de Qualidade de Dados pelo RMIB}

O RMIB desenvolveu uma metodologia de definição de testes de qualidade para dados de radiação que envolvem testes quase automáticos e a utilização de um software para a análise dos registros de dados das estações pertencentes ao instituto. Para tal Journée e Bertrand (2011) oferecem uma série de referências de outras metodologias que foram analisadas para o desenvolvimento da metodologia em questão. Os autores indicam que a maior parte das metodologias desenvolvidas até então visavam a análise de dados horários ou diários. O instituto realiza a medição de dados de radiação de 10 minutos e o histórico de medições é registrado com dados de 30 minutos. Portanto, a metodologia desenvolvida visa a análise de qualidade de dados integrados nesses períodos de tempo.

Assim como as demais metodologias, recomenda-se o armazenamento de dados indicados como errôneos e ressalta-se a importância da manutenção do registro de dados original. A metodologia utiliza limites para valores aceitáveis de dados com base em baixas altitudes europeias. Portanto, os critérios precisam ser adaptados para outras faixas de altitudes.

Os testes realizados pelo RMIB dividem-se em testes de limites físicos, testes de continuidade, testes de persistência e testes por envoltória, definidos pelos índices de claridade e transmitância verificados na metodologia do NREL.

\section{- Testes de Limites Físicos}

Primeiramente, a irradiância global, como já discutido, deve ser inferior à irradiância extraterrestre. É possível que, em situações pontuais essa suposição não seja atendida, contudo, isso costuma ocorrer em altas altitudes, no caso de nuvens convectivas (Yang et al.,2010 apud Journée e Bertrand, 2011). Como a metodologia foi desenvolvida visando dados coletados em baixas altitudes, os primeiros critérios adotados são: limitar valores aceitáveis de irradiância direta, difusa e global à irradiância extraterrestre.

A metodologia, assim como a desenvolvida pela NREL, também utiliza um modelo de céu claro para a definição de outros limites iniciais. O modelo utilizado corresponde a uma alteração do modelo inicial utilizado para a realização do Atlas Europeu de Radiação Solar. Neste modelo o usuário deve informar: horário, data, latitude, longitude e altitude referentes à medição, como retorno são fornecidos valores calculados da irradiância difusa para condições de céu claro $\left(I D H_{c c}\right)$, da irradiância global para condições de céu claro $\left(I G H_{c c}\right)$, e da irradiância direta para condições de céu claro $\left(I D N_{c c}\right)$. 
A segunda etapa de testes de limites físicos corresponde à comparação das medições obtidas com os valores fornecidos pelo modelo de céu claro:

$$
\begin{aligned}
& I G H \leq 1,1 I G H_{c c} \\
& I D N \leq I D N_{c c} \\
& I D H \geq I D H_{c c}
\end{aligned}
$$

Como a componente difusa é menor em condições de céu claro, essa etapa de testes promove o valor mínimo da parcela difusa.

Todos os limites dessas duas etapas consideram a altura solar $(\alpha)$ superior a $2 \%$. O ângulo da altura solar é complementar ao ângulo zenital. Para alturas solares inferiores a 2\%, em função dos erros do sensor e do fenômeno de refração, define-se que:

$$
I G H \leq 2 I G H_{c c}
$$

Assim como em condições de céu claro, a irradiância difusa alcança valores mínimos e a irradiância direta e global alcança valores máximos. Em condições atmosféricas de alta turbidez, o contrário deve ser verificado. Enquanto, nessas condições, a irradiância direta pode ser zero, a irradiância difusa nunca alcança valores nulos ao longo do dia. Como o limite inferior da irradiância difusa é definido em dias de céu limpo, pode-se limitar, de maneira mais refinada, o valor máximo da irradiância direta como:

$$
I D N \cos \theta_{z}<I G H-I D H_{c c}
$$

Que é basicamente um valor que atende a expressão:

$$
\begin{aligned}
& I D N \cos \theta_{z}<0,95 I G H, \text { para } \alpha>2^{\circ} e: \\
& I D N=I G H, \text { para } \alpha<2^{o}
\end{aligned}
$$

Define-se que, o valor máximo da irradiância difusa, considerando a relação da equação (1), é:

$$
I D H \leq I G H
$$

Quanto ao valor mínimo da irradiância global, inicialmente definiu-se com base na bibliografia pesquisada, um valor de $3 \%$ da irradiância extraterrestre para dados diários ou 
horários. Portanto, como critério tem-se que a média diária dos dados coletados $(\mu)$ deve ser no mínimo 3\% da irradiância extraterrestre:

$$
\mu I G H \geq 0.03 I G H_{0}
$$

Como esse critério pode excluir uma série de dados válidos quando o período de integração é inferior a 60 minutos, definiu-se que:

$$
\begin{aligned}
& I G H / I G H_{0} \geq 10^{-4}(\alpha-10) \text { se } \alpha>10, e: \\
& I G H \geq 0 \text { se } \alpha<10, e: \\
& I D N \cos \theta_{z} \geq 0 \text { se } \alpha<2
\end{aligned}
$$

\section{- Testes de Continuidade}

Outra maneira de verificar a consistência de dados de irradiância é verificando a taxa de aumento ou diminuição das medições em dois períodos subsequentes. Se as taxas se apresentarem extremamente altas, pode haver erro das medições de algum sensor ou a presença de sombreamento. Portanto, JOURNÉE e BERTRAD (2011) definem que, para medições subsequentes de 30 em 30 minutos:

$$
\begin{aligned}
& \left|\frac{I G H(t)}{I G H_{0}(t)}-\frac{I G H(t-1)}{I G H_{0}(t-1)}\right|<0.75 \\
& \left|\frac{I D N \cos \theta_{Z}(t)}{I G H_{0}(t)}-\frac{I D N \cos \theta_{Z}(t-1)}{I G H_{0}(t-1)}\right|<0.65 \\
& \left|\frac{I D H(t)}{I G H_{0}(t)}-\frac{I D H(t-1)}{I G H_{0}(t-1)}\right|<0.35
\end{aligned}
$$

O teste de continuidade compara as variações entre dois instantes das irradiâncias global, direta e difusa. Para a irradiância global, a variação deve ser inferior a $75 \%$ entre dois instantes. Variações acima de $1000 \mathrm{~W} / \mathrm{m}^{2}$ não devem ser plausíveis. Para a irradiância direta, o limite de variação deve ser inferior a $65 \%$ e para a irradiância difusa, o limite é $35 \%$. Estes testes só podem ser aplicados para ângulos de altura solar superiores a $2^{\circ}$.

Tomando-se como base a equação (1), é interessante notar que as alterações nas medições de irradiância global devem ser acompanhadas por alterações nas medições da parcela difusa e direta da irradiação. A comparação entre a evolução das medições da irradiância direta e global pode ser muito útil para a identificação de momentos de 
sombreamento do sensor de radiação global. Para definir essa situação de sombreamento, quatro condições devem ser atendidas simultaneamente.

$$
\begin{aligned}
& \alpha(t) \geq 2^{\mathrm{o}} \\
& I D N \cos \theta_{z}(t) \geq I G H(t) \quad \text { e IDN } \cos \theta_{z}(t-1)<I G H(t-1) \\
& \left|\frac{I G H(t)}{I G H_{0}(t)}-\frac{I G H(t-1)}{I G H_{0}(t-1)}\right|>0.1 \\
& \frac{I G H(t)-I G H(t-1)}{I G H_{0}(t)-I G H_{0}(t-1)}>3 \text { ou }<-1
\end{aligned}
$$

A Figura 39 apresenta uma demonstração gráfica do comportamento das curvas de irradiância em um momento de sombreamento do sensor de irradiância global.

Figura 39 - Série de irradiância com registro de sombreamento

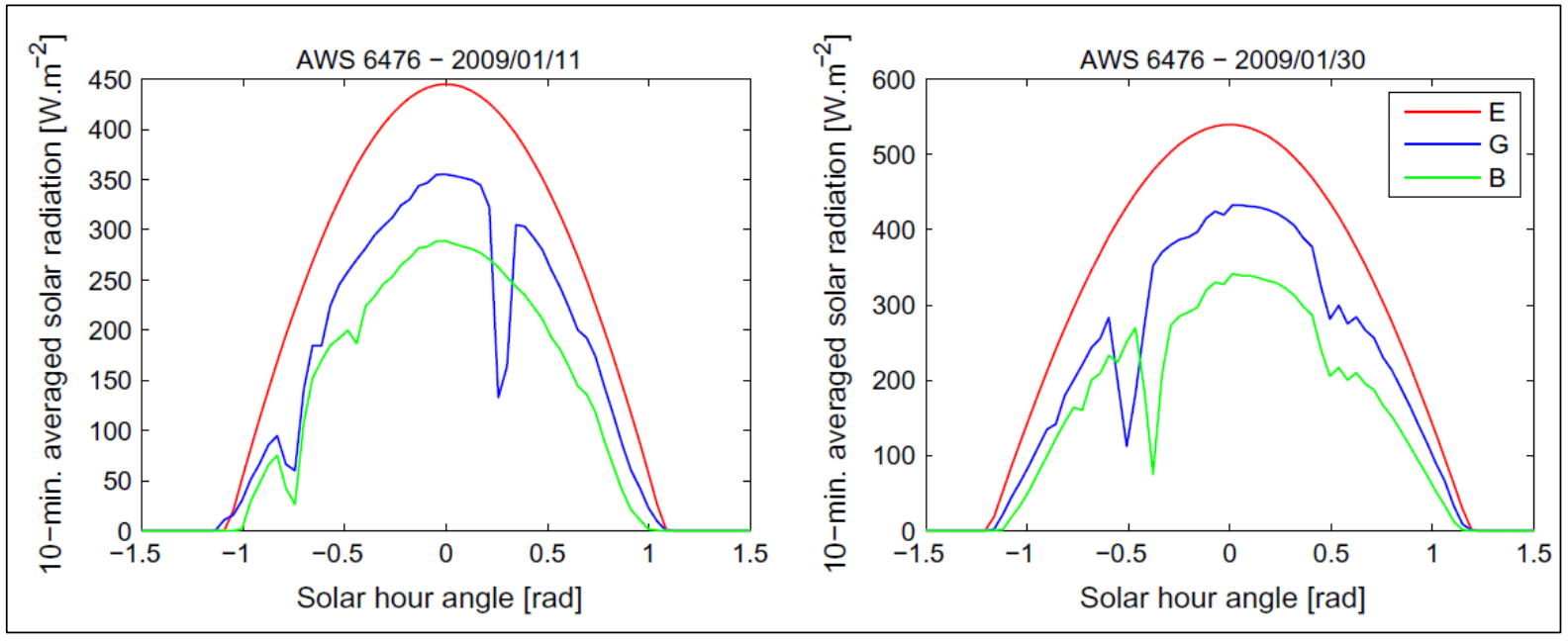

Fonte: JOURNÉE e BERTRAD, 2011

Notas:

O gráfico da esquerda representa apenas o sensor de irradiância global horizontal sombreado e o da direita representa os sensores de irradiância direta normal e global horizontal sombreados.

A curva denominada como E representa a irradiância horizontal extraterrestre $\left(I G H_{0}\right)$. A curva denominada como G representa a irradiância global horizontal (IGH). E a curva denominada como B representa a irradiância direta normal (IDN).

\section{- Testes de Persistência}

Quando os sensores falham pode haver a reprodução de medições anteriores, logo, o desvio padrão $(\sigma)$ nulo ou muito baixo pode significar sensores com falhas, da mesma maneira que desvios padrão muito altos podem ser indício de sensores funcionando de 
maneira intermitente. Em função disso a metodologia definiu um método de avaliar as medições de irradiância difusa, direta e global considerando os desvios padrão e as médias diárias $(\mu)$ das medições realizadas, de modo que:

$$
\begin{aligned}
& \frac{1}{8} \mu\left(\frac{I G H}{I G H_{0}}\right) \leq \sigma\left(\frac{I G H}{I G H_{0}}\right) \leq 0.35 \\
& \frac{1}{6} \mu\left(\frac{I D H}{I G H_{0}}\right) \leq \sigma\left(\frac{I D H}{E I G H_{0}}\right) \leq 0.2 \\
& \varphi \leq \sigma\left(\frac{I D N \cos \theta_{z}}{I G H_{0}}\right) \leq 0.2
\end{aligned}
$$

Sendo que:

$$
\begin{aligned}
& \varphi=0 \text { se } \mu\left(\frac{I D N \cos \theta_{z}}{I G H_{0}}\right) \leq 0.1 \\
& \varphi=\frac{1}{2} \mu\left(\frac{I D N \cos \theta_{z}}{I G H_{0}}\right) \text { se } 0.1<\mu\left(\frac{I D N \cos \theta_{z}}{I G H_{0}}\right) \leq 0.2 \\
& \varphi=0.1+\frac{1}{20}\left(\mu\left(\frac{I D N \cos \theta_{z}}{I G H_{0}}\right)-0.2\right) \text { se } \mu\left(\frac{I D N \cos \theta_{z}}{I G H_{0}}\right) \quad \text { receber valores }
\end{aligned}
$$

diferentes dos estipulados nos intervalos anteriores

\section{- Testes de Envoltória}

Os testes de envoltória definidos pela RMIB consistem na metodologia do software SERI QC (MAXWELL et al., 1993), considerando as alterações sugeridas por YOUNES et al. (2005).

Além destes testes o RMIB também efetua testes espaciais que considera a comparação das medições da estação com as medições obtidas em estações próximas e analisa modelos matemáticos de formação de dados e de limites de dados viáveis. Como tais metodologias requerem esforços que vão além da análise de dados da própria estação, elas não serão detalhadas nesse trabalho. Maiores detalhes das alterações efetuadas nos testes de envoltórias e os demais parâmetros utilizados pelo RMIB podem ser verificados em JOURNÉE e BERTRAD (2011).

\subsection{ANÁLISE DE QUALIDADE: UM REFERENCIAL PARA MODELAGEM}

Os procedimentos de análise de qualidade foram detalhadamente apresentados pois são uma ferramenta importante para a compreensão do comportamento do recurso em 
intervalos de tempo diferentes. Verificam-se como determinadas variáveis climáticas são importantes para a definição do recurso.

Os gráficos apresentados pelo NREL mostram como os efeitos instantâneos são suavizados em períodos de integração maiores. De modo que, os limites de dados aceitáveis para pequenos períodos de integração devem ser superiores àqueles para dados integrados em uma hora ou mais.

A aplicação constante de procedimentos de qualidade em dados coletados por uma ES é o primeiro passo para a caracterização do comportamento do recurso naquela região ao longo das horas do dia, dos dias dos meses e dos meses do ano.

O ângulo azimutal é o principal fator balizador dos aspectos temporais do recurso, ele é uma métrica para a estimativa de incertezas e, através do cálculo das massas de ar, permite a compreensão da interferência atmosférica nos dados analisados. O cálculo de coeficientes de transmitância é amplamente utilizado para a caracterização do recurso. Os testes de continuidade do RMIB, por exemplo, podem ser utilizados como orientador para estimativas de dados perdidos. Nesse sentido, verifica-se como a previsão da variabilidade do recurso é complexa para curto e curtíssimo prazo. As variações em dados integrados na ordem de minutos são originadas de efeitos atmosféricos pontuais, cuja única maneira de prever é por meio de estimativas de probabilidade, para diferentes configurações de massa de ar.

\subsection{MODELOS PROBABILÍSTICOS}

Diversos estudos foram realizados ao longo das últimas décadas com o intuito de definir funções de densidade de probabilidade e funções de densidade de probabilidade cumulativa para a modelagem da irradiância instantânea.

LIU e JORDAN (1960) e BENDT et al (1981) concordaram que, em termos das curvas de densidade cumulativa, valores médios mensais de $k_{t}$ eram suficientes para a caracterização do comportamento da irradiância global. BENDT et al (1981) aplicaram a estatística de Boltzmann para a modelagem de curvas de densidade cumulativa de $k_{t}$.

SUEHRCKE e MCCORMICK (1988) avaliaram o modelo proposto por BENDT et al (1981), realizando um estudo sobre a distribuição de densidade cumulativa de probabilidade para $k_{t}$ calculados por meio de medições instantâneas. Os autores efetuaram um método experimental, no qual medidas de irradiância global de 1 minuto foram utilizadas para o cálculo de $k_{t}$. Os dados foram medidos por uma estação em Perth (Austrália), durante novembro de 1985 e novembro de 1986 . Para o cálculo de $k_{t}$, foi considerada a constante de 
irradiância extraterrestre $\left(I_{0}=1.367 \mathrm{~W} / \mathrm{m}^{2}\right)$. Os índices foram calculados para quatro intervalos diferentes de massa de ar, como mostrado na Tabela 14.

Tabela 14 - Intervalos de AM

\begin{tabular}{cl}
\hline AM nominal & AM real \\
\hline $\mathbf{1 , 0}$ & $1,0 \leq A M \leq 1,1$ \\
\hline $\mathbf{1 , 5}$ & $1,4 \leq A M \leq 1,6$ \\
\hline $\mathbf{2 , 0}$ & $1,8 \leq A M \leq 2,2$ \\
\hline $\mathbf{3 , 0}$ & $2,7 \leq A M \leq 3,3$ \\
\hline
\end{tabular}

Fonte: SUEHRCKE e MCCORMICK, 1988

Foram construídos quatro gráficos, mostrados na Figura 40, da densidade de probabilidade cumulativa de dados de $k_{t}$. Um gráfico para cada intervalo de massa de ar.

Figura 40 - Densidade de distribuição de $k_{t}$ para diferentes massas de ar

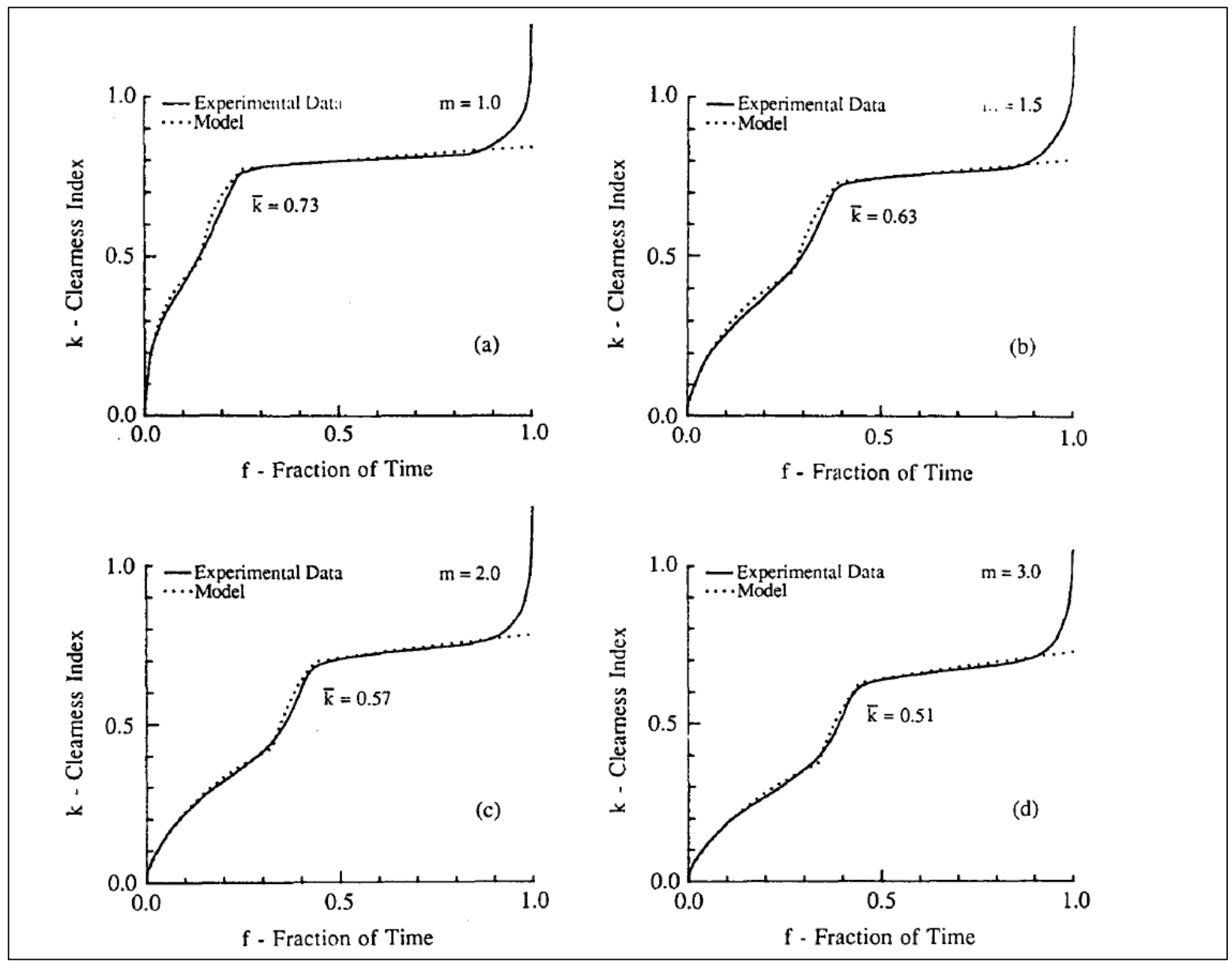

Fonte: SUEHRCKE e MCCORMICK, 1988 
Pelas curvas apresentadas na Figura 40, considerando as medições instantâneas, o período de tempo em que são verificados valores de $k_{t}$ intermediários são mínimos, o que possibilita a primeira interpretação de que existem apenas duas configurações para a previsão da radiação: nublado e céu limpo. De modo que a presença de $k_{t}$ intermediários corresponde em média à $10 \%$ do tempo e são verificados em duas situações: (i) quando o Sol está começando a ser coberto ou descoberto por uma nuvem espessa ou (ii) em dias de muitas nuvens muito finas no céu.

Quando essas curvas são construídas para valores horários ou diários de $k_{t}$, como as realizadas por LIU e JORDAN (1960) e BENDT et al (1981) a quantidade de $k_{t}$ intermediários verificada é expressivamente maior com base nos efeitos de anulação que a média horária causa nos efeitos instantâneos.

Com base nessa constatação, os autores utilizaram apenas dados de $k_{t}$ da massa de ar nominal de 1,5 para construir quatro novos gráficos. O primeiro para os dados de $k_{t}$ de um minuto, o segundo para dados de $k_{t}$ integrados em 5 minutos, o terceiro com dados de $k_{t}$ integrados em 20 minutos e o último, com os dados integrados em 1 hora. Os gráficos são apresentados na Figura 41. 
Figura 41 - Distribuição de $k_{t}$ para diferentes períodos de integração

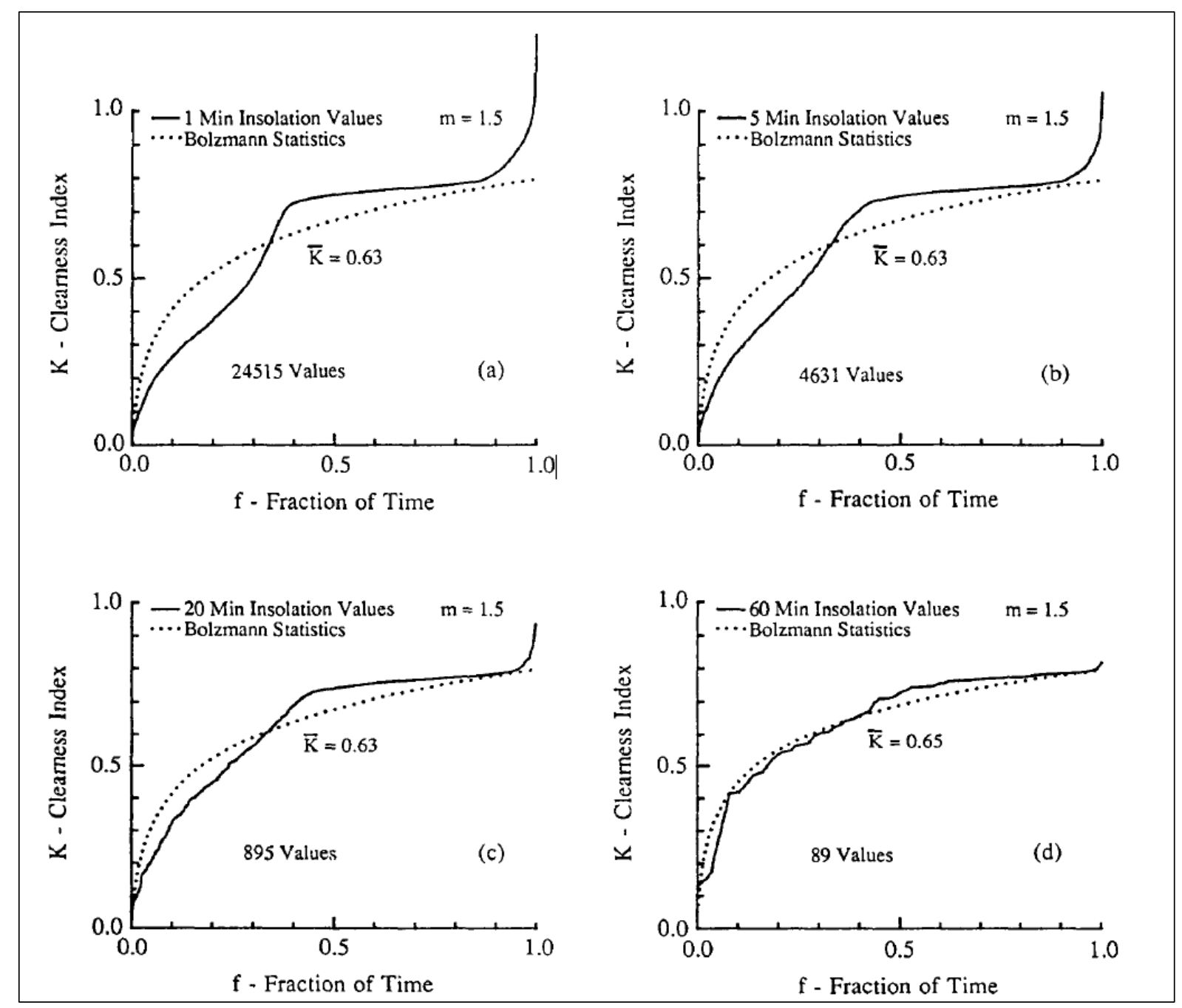

Fonte: SUEHRCKE e MCCORMICK, 1988

A análise desse estudo permite a constatação de que dados integrados a partir de 20 minutos começam a perder o perfil de instantaneidade da caracterização do recurso. Concluise, portanto, que o carácter instantâneo da radiação deve ser caracterizado por intervalos de integração inferiores à média horária.

A publicação de SUEHRCKE e MCCORMICK (1988) foi a primeira na bibliografia pesquisada que divide as curvas de densidade de probabilidade e/ou de densidade cumulativa de probabilidade em função da massa de ar. Os autores fazem interessantes análises sobre o caráter bimodal das curvas de densidade cumulativa de probabilidade de $k_{t}$, afirmando que o caráter bimodal aumenta conforme a diminuição do período de média para valores instantâneos e que fica mais nítido conforme adotam-se valores de massas de ar maiores. 
SKARTVEIT e OLSETH (1992) afirmam que, mesmo durante uma hora de alta variação de $k_{t}$ as curvas de densidade de probabilidade de valores instantâneos $\left(k_{t}\right.$ de 1 minuto) variam muito pouco daquelas com $k_{t}$ calculados com base em médias de 5 minutos. Esses autores definiram modelos para a distribuição de densidade de probabilidade de irradiância global e direta normal utilizando-se 1 ano de medições de irradiância global média em duas estações nos EUA. Os modelos foram validados com dados de uma terceira estação também nos EUA. Os autores utilizaram uma combinação linear de duas funções Beta de probabilidade para o desenvolvimento do modelo e ainda estabeleceram um segundo modelo para estimar a distribuição de densidade de probabilidade em médias de 5 minutos de irradiância direta normal e global, tendo como dados de entrada médias horárias da irradiância global. Os cálculos realizados pelos autores foram em função de $K$ : um coeficiente adimensional obtido pela divisão do valor medido de irradiância global, pelo valor esperado de irradiância global para condições de céu claro. Esses valores de irradiância global esperados foram obtidos por meio de um modelo matemático para condições de céu claro préestabelecido.

TOVAR et al. (1998) estabeleceram um modelo para estimativa de curvas de densidade de probabilidade (CDP) de $k_{t}$, condicionadas a massa de ar, baseando-se na soma de duas funções da estatística de Boltzmann para atender o carácter bimodal dessa distribuição. Os autores utilizaram valores médios de $k_{t}$ de 1 minuto. $k_{t}$ foi obtido pela divisão da irradiância global aferida pela irradiância no topo da atmosfera.

O intervalo de massas de ar utilizado por esses autores difere do utilizado por SUEHRCKE e MCCORMICK (1988), a Tabela 15 apresenta a divisão utilizada nesse estudo.

Tabela 15 - Divisões de AM

\begin{tabular}{cc}
\hline AM nominal & \multicolumn{1}{c}{ AM real } \\
\hline $\mathbf{1 , 0}$ & $1,0<A M<1,2$ \\
$\mathbf{1 , 5}$ & $1,4<A M<1,6$ \\
\hline $\mathbf{2 , 0}$ & $1,8<A M<2,2$ \\
\hline $\mathbf{2 , 5}$ & $2,3<A M<2,7$ \\
\hline $\mathbf{3 , 0}$ & $2,75<A M<3,25$ \\
\hline
\end{tabular}

Fonte: TOVAR et al, 1998

Os autores utilizaram um pouco mais de dois anos de medição de irradiância atmosférica de modo que $2 / 3$ dos dados foi utilizado para a construção do modelo e o $1 / 3$ restante para a sua validação. 
A Figura 42 apresenta a análise do caráter bimodal para dados de $k_{t}$ correspondentes à média por minuto (gráfico da esquerda) e à média horária (gráfico da direita).

Figura 42 - Caráter bimodal da densidade de probabilidade de $k_{t}$

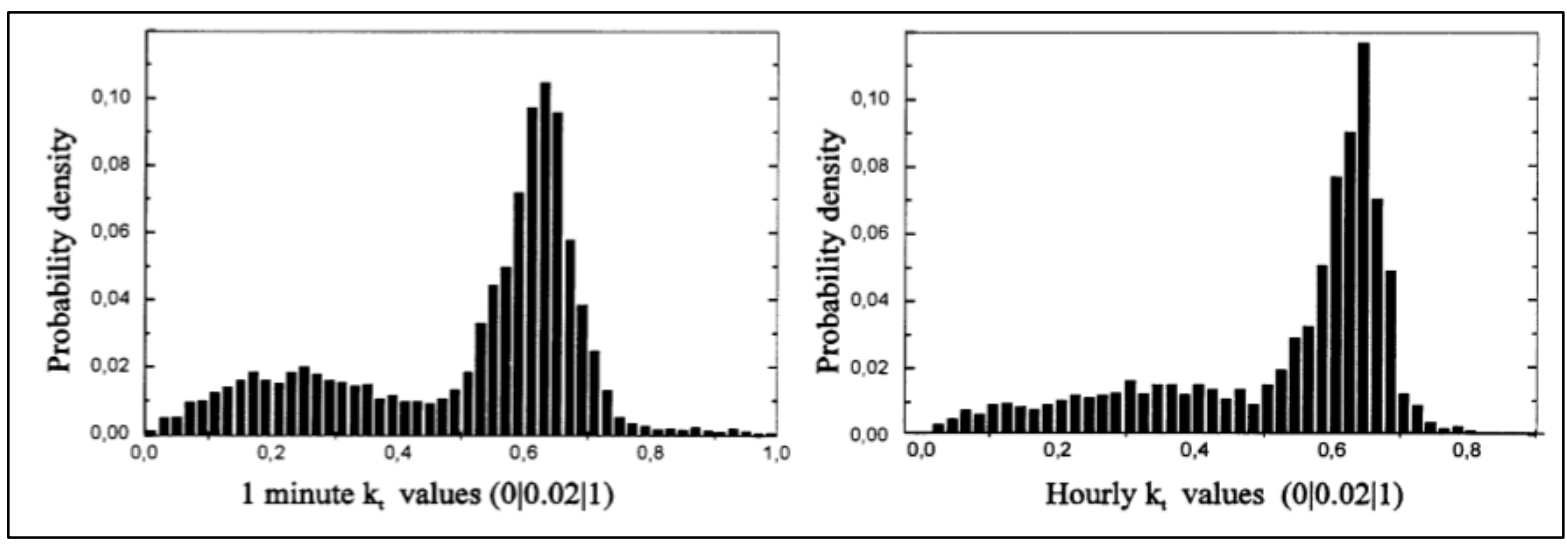

Fonte: TOVAR et al, 1998

Concordando com SUEHRCKE e MCCORMICK (1988), os autores identificaram que o caráter bimodal é acentuado conforme o tempo da média de $k_{t}$ é reduzido e conforme a massa de ar aumenta. SUEHRCKE e MCCORMICK (1988) e TOVAR et al (1998) afirmam que o segundo pico da curva de densidade de probabilidade corresponde aos momentos de céu claro enquanto que o primeiro pico (de menor probabilidade em relação ao segundo) corresponde à períodos de céu coberto por nuvens. Esses autores ainda explicam que, conforme a massa de ar aumenta, há um aumento do primeiro pico da curva de densidade de probabilidade. Esse resultado pode ser associado com o fato de que, para grandes ângulos zenitais, a sombra produzida pelas nuvens é maior. Na Figura 43 é possível identificar o aumento do caráter bimodal conforme o aumento da massa de ar. Todos os gráficos foram produzidos com dados de $K_{t}$ de 1 minuto. $\mathrm{O}$ primeiro gráfico (superior esquerdo) indica a curva de densidade de probabilidade $(\mathrm{CDP})$ parra valores de $k_{t}$ referentes à massa de ar $(A M)$ igual à 1 , conforme apresentado na Tabela 15. O segundo gráfico (superior direito) apresenta a CDP para $A M=1,5$. O terceiro gráfico (inferior esquerdo) apresenta a CDP para $A M=2,5$ e o último, para $A M=3,0$. A notação $(0|0,02| 1)$, indica que os valores de $K_{t}$, que no limite, variam de 0 a 1 , foram divididos em 50 intervalos de tamanho 0,02 para a construção do histograma. 
Figura 43 - Curvas de densidade de probabilidade para $k_{t}$ em função da massa de ar

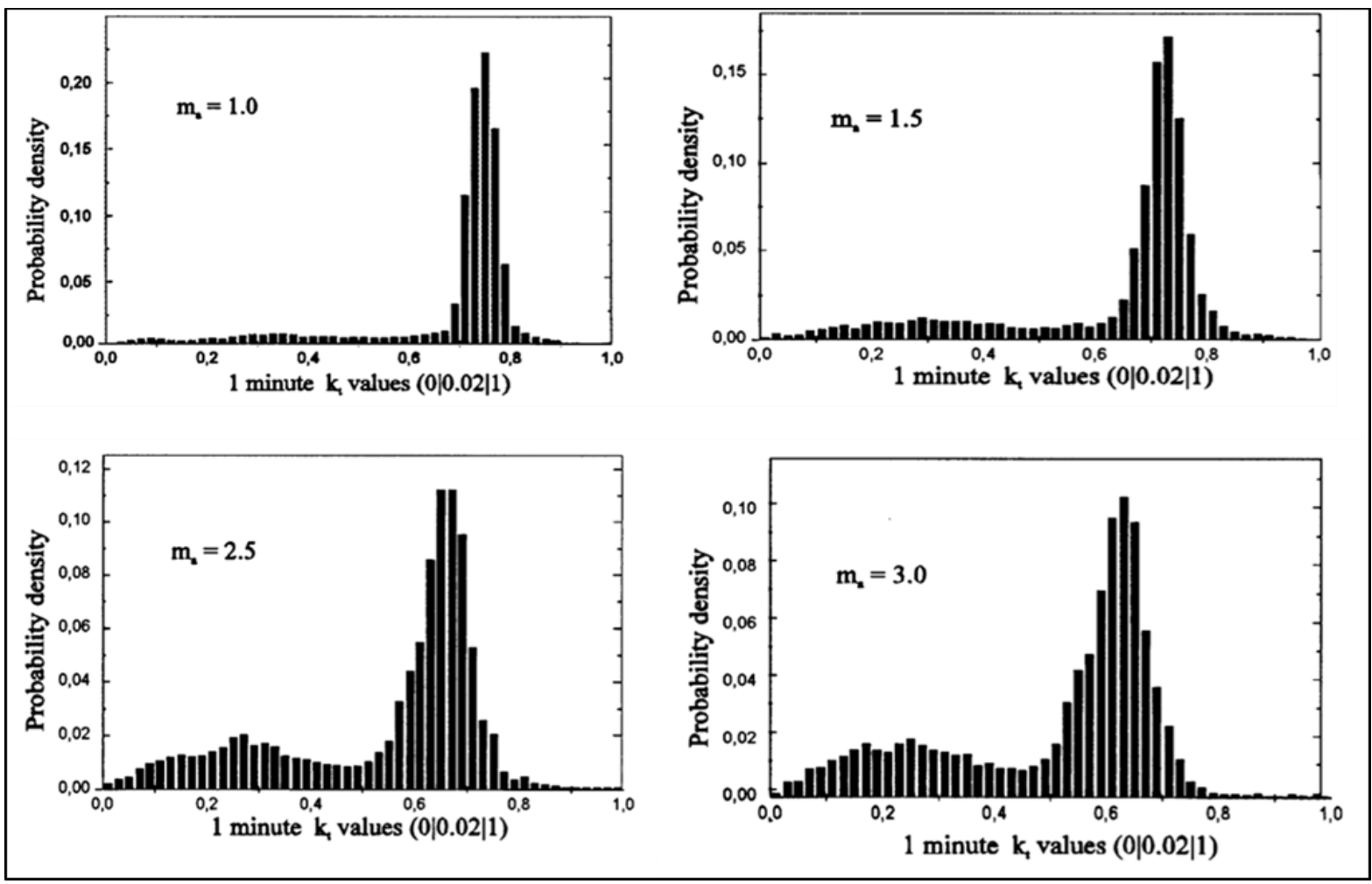

Fonte: TOVAR et al, 1998

O modelo definido por TOVAR et al, 1998, constituído pela soma linear de duas funções da estatística de Boltzmann é, de maneira genérica definido por:

$$
f\left(k_{t} \mid A M\right)=f_{1}\left(k_{t}\right)+f_{2}\left(k_{t}\right)
$$

De modo que $f_{1}\left(k_{t}\right)$ e $f_{2}\left(k_{t}\right)$ correspondem à modelagem referente à cada uma das duas partes características da curva de carácter bimodal, obtidas pela equação:

$$
f_{i}\left(k_{t)}=A_{i} \times \frac{\left.\lambda e^{\left(k_{t}-k_{t}\right)}\right) \lambda_{i}}{\left.\left[1+e^{\left(k_{t}-k_{t}\right.}\right) \lambda_{i}\right]^{2}} \operatorname{com} i=1,2\right.
$$

Os autores, após adequarem as diversas funções empíricas da Figura 43 no modelo da equação (39), obtiveram os valores experimentais de $A_{1}, \lambda_{1}, k_{t_{01}}, \lambda_{2}, k_{t_{02}}$ para cada massa de ar, enquanto que $A_{2}$ deve ser encontrado pela condição de normalização que define a função de densidade cumulativa de probabilidade: 


$$
\int_{0}^{1} f_{1}\left(k_{t}\right)+f_{2}\left(k_{t}\right) d k_{t}=1
$$

Finalizada essa etapa, os autores, por meio de regressão linear, colocaram todas as variáveis em função da massa de ar, definindo-se, portanto, um modelo para a caracterização das curvas de densidade de probabilidade de $K_{t}$, possuindo como único dado de entrada, o valor da massa de ar.

Os mesmos autores replicaram essa metodologia para a modelagem de CDPs da irradiância difusa e da irradiância direta em TOVAR et al (1999). Os modelos foram elaborados para os coeficientes $k_{d}$ e $k_{b} . k_{d}$ foi obtido dividindo-se o valor aferido de irradiância difusa pela irradiância global horizontal extraterrestre, enquanto que $k_{b}$ foi obtido dividindo-se a irradiância direta normal aferida pela irradiância global extraterrestre. Foram utilizados pouco mais de 4 anos medições, calculando-se os coeficientes para valores de medição médios de 1 minuto.

Os autores apresentaram as curvas empíricas de $k_{d}$ e $k_{b}$ e essas podem ser verificadas na Figura 44. Os gráficos da esquerda correspondem às CDPs de $k_{d}$, enquanto que os da direita correspondem às CDPs de $k_{b}$. Os dois primeiros gráficos (superiores) do conjunto são referentes à $A M=1$. Os dois gráficos subsequentes apresentam as CDPs de $k_{b}$ e $k_{d}$ (respectivamente) para $A M=1,5$. A terceira dupla de gráficos apresenta as CDPs para $A M=$ 2,0. A quarta dupla de gráficos apresenta as CDPs para $A M=2,5$. A última dupla, para $A M=3,0$. A notação $(0|0,02| 1)$, indica que os valores de $k_{b}$ e $k_{d}$, que no limite, variam de 0 a 1, foram divididos em 50 intervalos de tamanho 0,02 para a construção do histograma. As divisões de $A M$ foram elaboradas conforme a Tabela 15.

Os gráficos de $k_{b}$ também apresentam um caráter bimodal com perfil exponencial no primeiro intervalo $(0-0,02)$ independente do valor da massa de ar. Esse máximo caracteriza situações de céu completamente nublado e parcialmente coberto por nuvens associado a momentos de transição nos quais nuvens estão bloqueando a passagem da radiação direta. Essas situações são mais frequentes com massas de ar maiores em função da maior grossura das nuvens e da maior sombra que elas produzem. O segundo máximo corresponde a valores de $k_{b}$ que variam entre 0,5 e 0,8 , dependendo da massa de ar. Valores intermediários possuem baixa probabilidade de ocorrência. Conforme ocorre o aumento de $A M$, menor é o valor de $k_{b}$ que corresponde ao segundo máximo. 
Figura 44 - Curvas de densidade de probabilidade para $k_{b}$ e $k_{d}$ em função da massa de ar
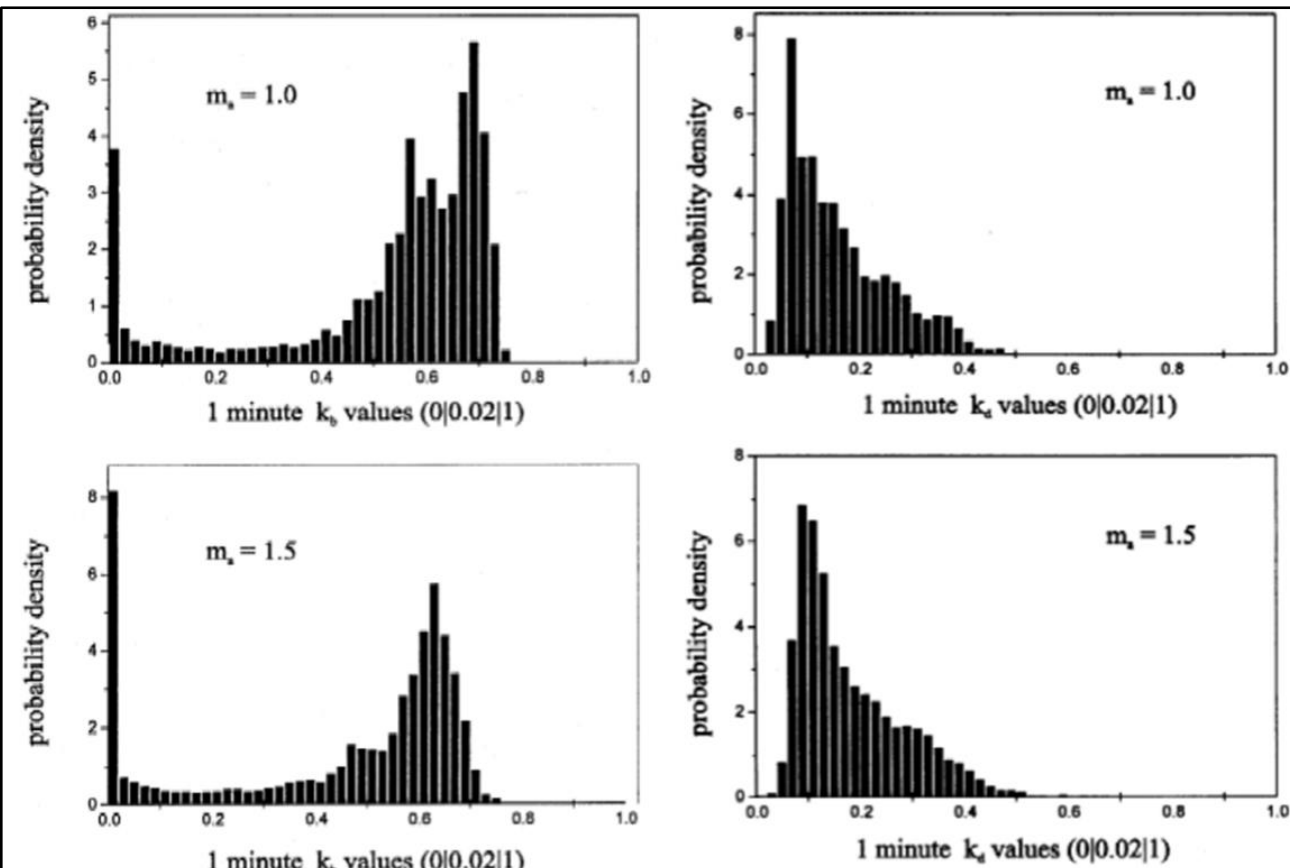

1 minute $k_{\mathrm{b}}$ values $(0|0.02| 1)$
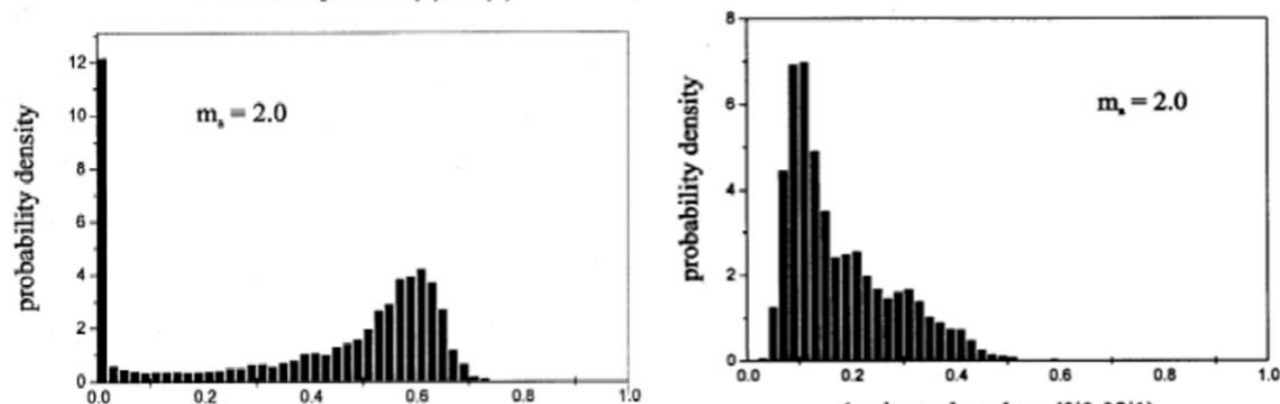

1 minute $\mathrm{k}_{\mathrm{b}}$ values $(0|0.02| 1)$
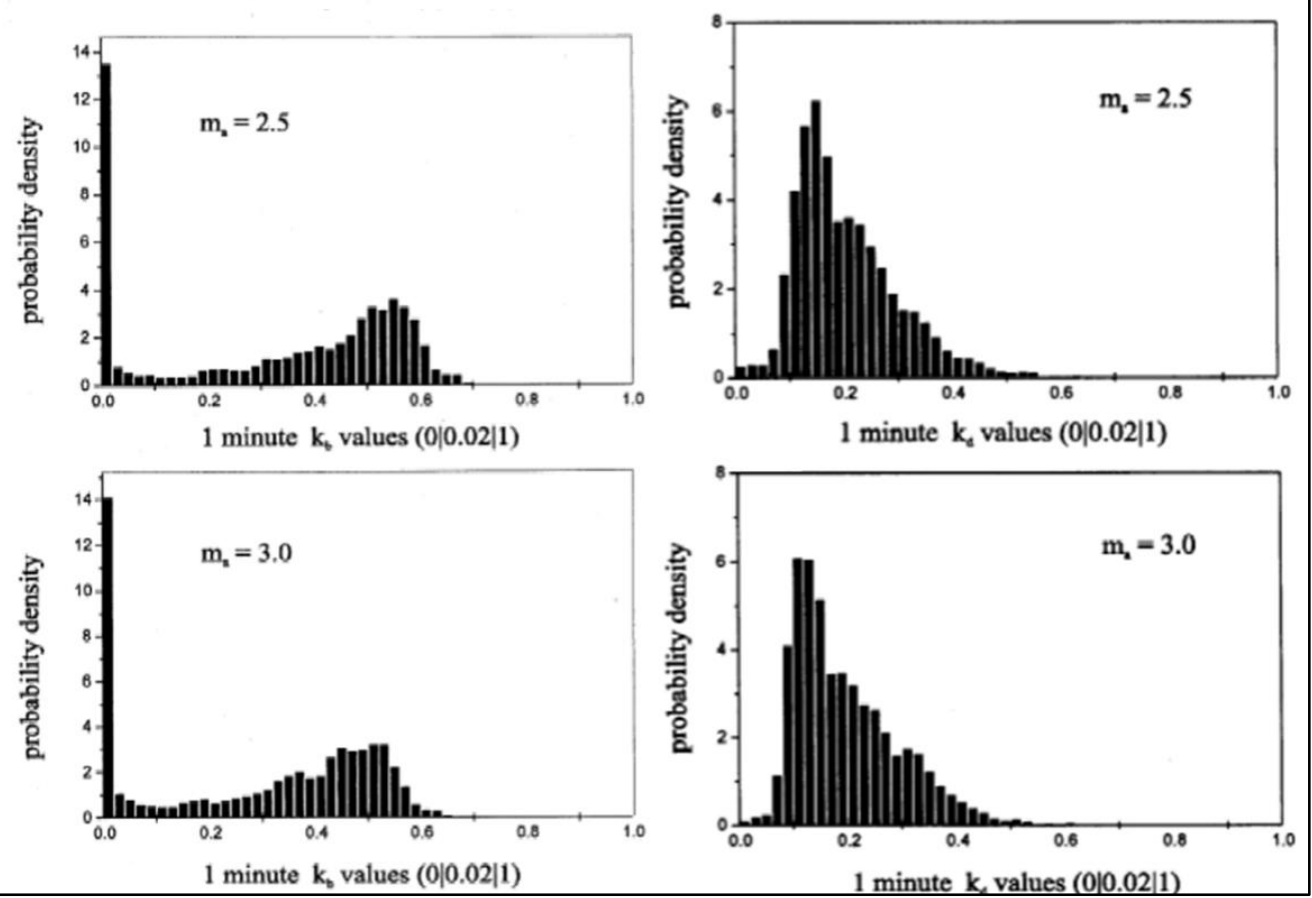

Fonte: TOVAR et al, 1998 
Já as curvas de $k_{d}$ são as que apesentam menor dependência em relação à massa de ar (considerando tanto $k_{b}$ como $k_{t}$ ). Os valores de $k_{d}$, independente da massa de ar, se restringiram ao intervalo entre 0 e 0,5 . A possível explicação para essa baixa dependência da massa de ar é que o processo de espalhamento da radiação aumenta conforme o aumento da massa de ar, levando a um aumento da parcela difusa da radiação. Contudo, o processo de redução da quantia de irradiância total que alcança a superfície terrestre (tanto em função do espalhamento, como da absorção) também aumenta conforme o aumento da massa de ar, de modo que um efeito anula o outro e o perfil de disponibilidade de $k_{d}$ permanece sem grandes alterações.

Os autores definiram um modelo adaptado baseado em Boltzmann para a modelagem de $k_{d}$, inserindo um coeficiente $\beta$ na equação (39). A explicação estatística/matemática da adaptação pode ser encontrada em TOVAR et al (1999). Para a modelagem de $k_{b}$ os autores se utilizaram dessa mesma função adaptada, somada à uma função exponencial. E finalmente colocaram as variáveis em função de $A M$, seguindo o mesmo procedimento definido para $k_{t}$, adotando o mesmo princípio para a condição de normalização.

ASSUNÇÃO et al (2003) realizaram um estudo similar os estudos de TOVAR et al. (1998) e TOVAR et al (1999). Os autores utilizaram dados de irradiâncias global e direta normal de um período de 4 anos de uma estação em Botucatu (Brasil). Os dados foram utilizados para calcular $k_{t}, k_{b h}$ e $k_{d}$. Sendo que $k_{t}$ foi obtido dividindo-se o valor da irradiância global horizontal pela irradiância extraterrestre. Enquanto que $k_{b h}$ corresponde à relação entre a irradiância direta horizontal, ou seja, a componente normal de IDN em uma superfície horizontal com a irradiância extraterrestre e $k_{d}$ foi obtido inicialmente por uma estimativa da parcela de irradiância difusa por meio da equação (38) do capítulo anterior, haja vista que essa medição não foi aferida e dividindo-se essa estimativa pela irradiância extraterrestre.

Os autores definiram a modelagem das CDPs utilizando-se funções beta e suas adaptações de coeficientes do modo a se adequar as formas de todas as distribuições. Os intervalos de massa de ar utilizados pelos autores estão discriminados na Tabela 16 e não coincidem com os intervalos adotados por TOVAR et al. (1998), porém, bastante similares aos adotados por SUEHRCKE e MCCORMICK (1988). Os autores utilizaram, para as três componentes, os mesmos intervalos de massa de ar e valores de coeficientes correspondentes à média de 5 minutos. 
Tabela 16 - Novas divisões de AM

\begin{tabular}{cc}
\hline AM nominal & AM real \\
\hline $\mathbf{1 , 0}$ & $0,9 \leq A M \leq 1,1$ \\
\hline $\mathbf{1 , 5}$ & $1,4 \leq A M \leq 1,6$ \\
\hline $\mathbf{2 , 0}$ & $1,8 \leq A M \leq 2,2$ \\
\hline $\mathbf{3 , 0}$ & $2,7 \leq A M \leq 3,3$ \\
\hline
\end{tabular}

Fonte: ASSUNÇÃO et al, 2003

A Figura 45 apresenta as CDPs experimentais de ASSUNÇÃO et al (2003) para os valores de $k_{t}$. O primeiro gráfico (superior esquerdo) indica a curva de densidade de probabilidade parra valores de $k_{t}$ referentes à massa de ar $(A M)$ igual à 1 , conforme apresentado na Tabela 16. O segundo gráfico (superior direito) apresenta a CDP para $A M=$ 1,5. O terceiro gráfico (inferior esquerdo) apresenta a CDP para $A M=2,0$ e o último, para $A M=3,0$.

Diferentemente do observado nos trabalhos de TOVAR et al. (1998) e SUEHRCKE e MCCORMICK (1988), as CDPs de ASSUNÇÃO et al (2003) apresentam uma redução do carácter bimodal em função do aumento da massa de ar, resultado mais semelhante ao encontrado por Skartveit e Olseth (1992). ASSUNÇÃO et al (2003) não identificaram qualquer fator climático que padronizasse similaridades ou divergências entre os estudos que justificassem essa diferenciação no perfil das CDPs. Contudo afirmam que, diversos fatores podem causar a variação das CDPs de $k_{t}$ e que esses fatores podem estar vinculados ao aumento do espalhamento da radiação direta conforme a massa de ar aumenta, associado ao aumento das sobras produzidas pelas nuvens e do aumento da espessura dessas nuvens verificadas em massas de ar maiores. Deste modo, é visível que o caráter bimodal é reduzido, não pelo aumento exacerbado do primeiro pico da CDP, mas sim pela expressiva redução do segundo pico, promovendo maior uniformidade da distribuição. 
Figura 45 - Distribuição de $k_{t}$ para diferentes massas de ar

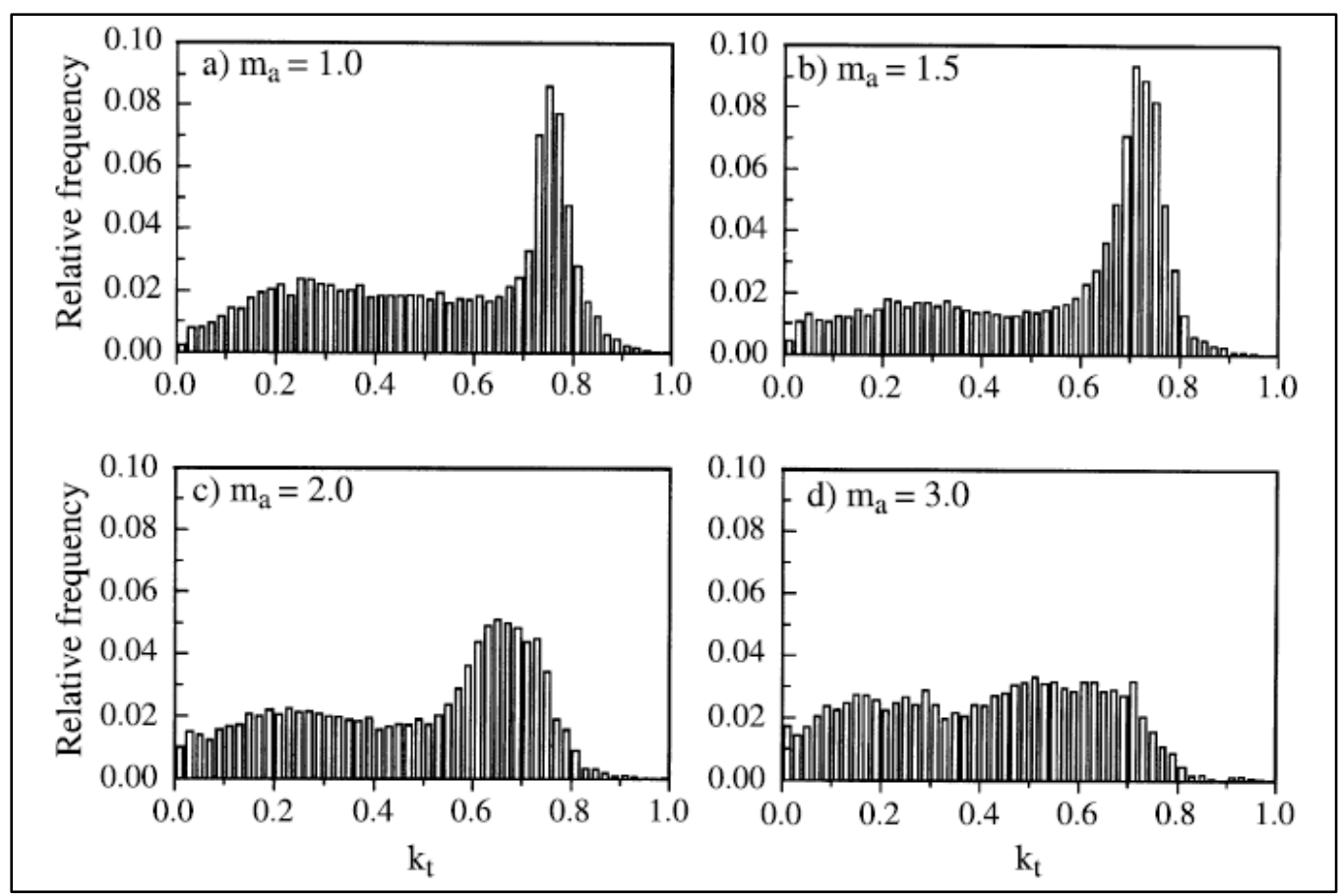

Fonte: ASSUNÇÃO et al, 2003

Quanto à distribuição de $k_{b h}$, ASSUNÇÃO et al (2003) identificaram o mesmo perfil de distribuição encontrado para $k_{b}$ em TOVAR et al (1999), contudo, o intervalo do primeiro pico ficou definido em valores de $k_{b h}$ entre 0 e 0,05 . Como pode ser observado nos gráficos da Figura 46, embora o perfil das CDPs seja semelhante nos dois estudos, os resultados de ASSUNÇÃO et al (2003) divergem dos encontrados por TOVAR et al (1999) e SKARTVEIT e OLSETH (1992) no sentido de que, nesse primeiro estudo, a probabilidade do primeiro pico tende a diminuir com o aumento das massas de ar, enquanto que, nos dois outros estudos a relação verificada é contrária.

O primeiro gráfico da Figura 46 (superior esquerdo) indica a curva de densidade de probabilidade parra valores de $k_{b h}$ referentes à massa de ar $(A M)$ igual à 1 , conforme apresentado na Tabela 16. O segundo gráfico (superior direito) apresenta a CDP para $A M=$ 1,5. O terceiro gráfico (inferior esquerdo) apresenta a CDP para $A M=2,0$ e o último, para $A M=3,0$.

ASSUNÇÃO et al (2003) afirmam que a possível explicação para essa divergência é que a intensificação da convecção de nuvens tipo cumulus em massas de ar menores é mais frequente em climas tropicais, como no caso da região de coleta de dados. Embora verificamse essas alterações do primeiro pico em função de $A M$, os autores ainda afirmam que as CDPs 
de $K_{b h}$ não variam consideravelmente com o aumento de $A M$, embora verifica-se também a redução do segundo pico conforme o aumento da massa de ar.

Figura 46 - Distribuição de $k_{b h}$ para diferentes massas de ar

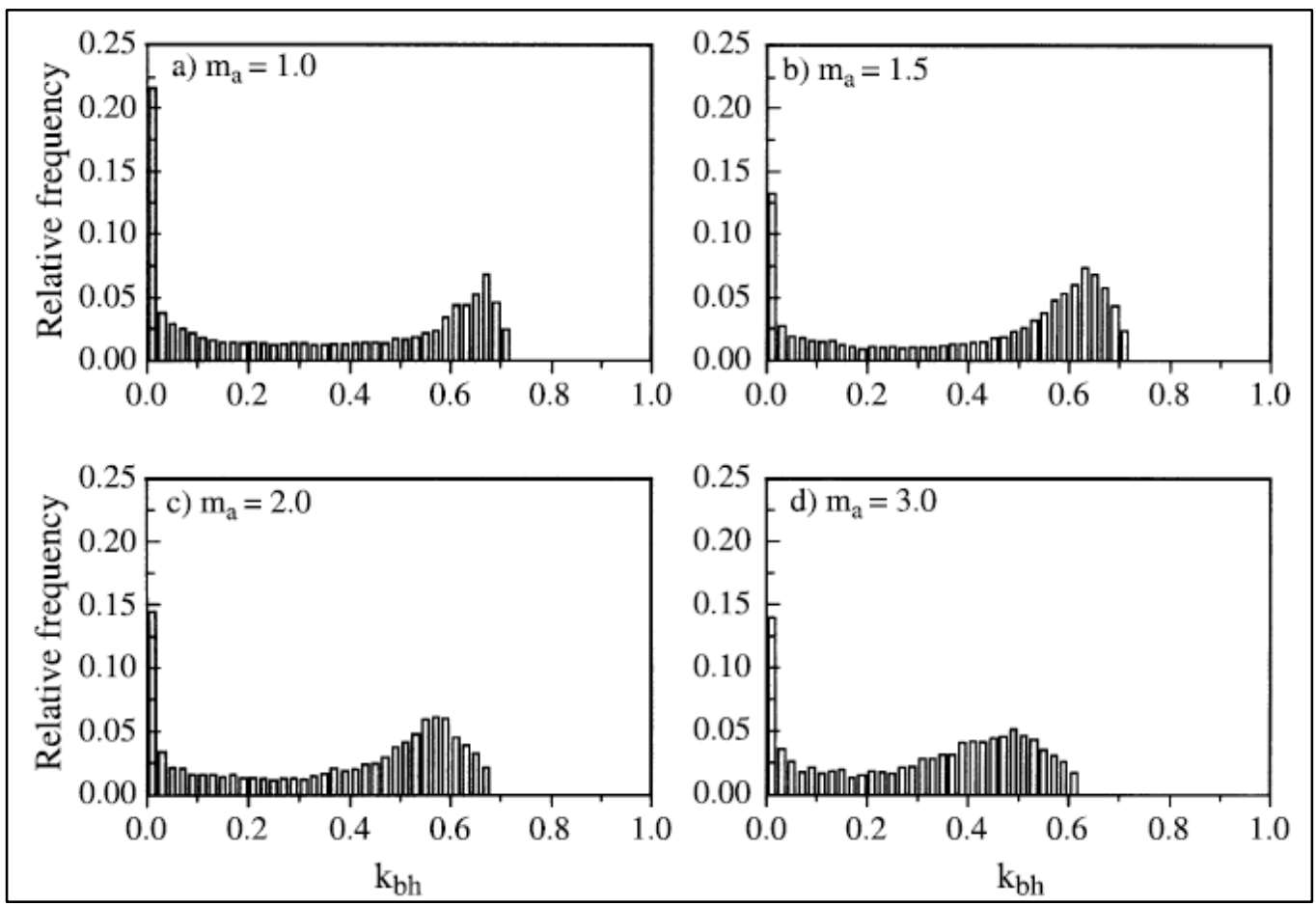

Fonte: ASSUNÇÃO et al, 2003

Com relação às CDPs de $k_{d}$ os autores também verificaram uma distribuição de um único pico, contudo com valores mais dispersos. Enquanto os valores de $k_{d}$ de TOVAR et al (1999) variavam no intervalo de 0 a 0,5, os valores de ASSUNÇÃO et al (2003) obtiveram valores entre 0,01 e 0,81 . Novamente foi verificado que a distribuição de $k_{d}$ não possui forte dependência da massa de ar. Os autores explicam tal fato esclarecendo que a irradiância difusa alcança o seu máximo ao meio dia de períodos totalmente nublados, enquanto que alcança seus mínimos também ao meio dia, porém de períodos totalmente sem nuvens.

A Figura 47 apresenta as CDPs de $k_{d}$ construídas por ASSUNÇÃO et al (2003). O primeiro gráfico (superior esquerdo) indica a curva de densidade de probabilidade parra valores de $k_{t}$ referentes à massa de ar $(A M)$ igual à 1 , conforme apresentado na Tabela 22 . $\mathrm{O}$ segundo gráfico (superior direito) apresenta a CDP para $A M=1,5$. O terceiro gráfico (inferior esquerdo) apresenta a CDP para $A M=2,0$ e o último, para $A M=3,0$.

Comparando-se os gráficos do lado esquerdo da Figura 44 com os gráficos da Figura 47 nota-se que, em ambos os grupos de gráficos, o valor de $k_{d}$ correspondente ao pico tende a 
valores maiores conforme o aumento da massa de ar, contudo, essa tendência apresenta-se mais significativa no estudo de ASSUNÇÃO et al (2003) do que no estudo de TOVAR et al (1999).

Figura 47 - Distribuição de $k_{d}$ para diferentes massas de ar

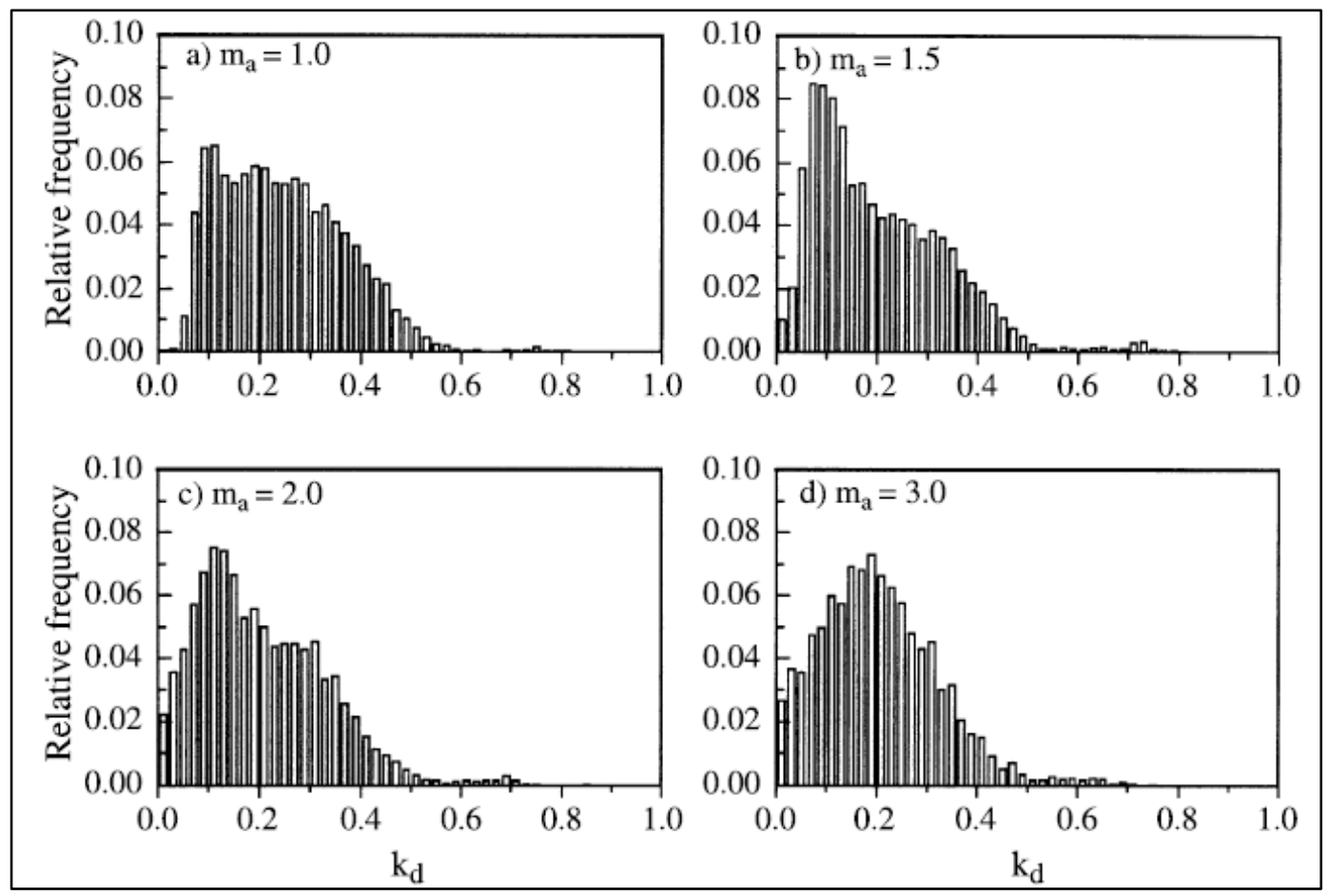

Fonte: ASSUNÇÃO et al, 2003

Os autores utilizaram, para a modelagem dos três coeficientes, diferentes combinações da função Beta de probabilidade, apresentada a seguir:

$$
f(x)=\frac{\Gamma(\alpha+\beta)}{\Gamma(\alpha) \Gamma(\beta)} x^{\alpha-1}(1-x)^{\beta-1}
$$

De modo que $\alpha$ e $\beta$ são parâmetros definidos pelas seguintes equações:

$$
\alpha=\frac{\bar{x}^{2}-\bar{x}^{3}}{S^{2}}-\bar{x} \quad \text { e } \quad \beta=\left(\frac{\bar{x}^{3}-2 \bar{x}^{2}+\bar{x}}{S^{2}}\right)+\bar{x}-1
$$

$\bar{x}$ e $S^{2}$ correspondem, respectivamente à média e à variância da série de dados, de modo que:

$$
\bar{x}=\frac{\sum_{i=1}^{n} f_{i} x_{i}}{\sum_{i=1}^{n} f_{i}} \quad \text { e } \quad S^{2}=\frac{\sum_{i=1}^{n} f_{i} x_{i}{ }^{2}-\bar{x}^{2} \sum_{i=1}^{n} f_{i}}{\sum_{i=1}^{n} f_{i}-1}
$$

$\operatorname{Com} x=k_{d}, k_{b h}, k_{t}$. 
Os autores definiram a soma de duas funções Beta para a modelagem de $k_{t}$, a soma de três funções Beta para a modelagem de $k_{b h}$, e a utilização de uma função Beta para modelagem de $k_{d}$. Os parâmetros das equações foram identificados para cada massa de ar e depois colocados em função de $A M$ e a condição de contorno foi aplicada de maneira análoga à TOVAR et al (1998 e 1999).

KANG e TAM (2013) desenvolveram uma nova metodologia de caracterização do recurso solar baseado em Aguiar et al. (1988), definida como método K-POP. KANG e TAM (2013) definem a caracterização do recurso solar para geração de energia em dois aspectos: quantidade e qualidade.

A análise da quantidade é definida pelos autores através do cálculo do $k_{t},-$ conforme equação (36) do capítulo anterior. Quanto maior o valor do índice, menor é a influência da transmitância no montante de irradiância extraterrestre que passa pela atmosfera.

A análise da qualidade é definida pela identificação do nível de variabilidade do recurso ao longo do dia por meio da análise de medições de irradiância global horizontal de 1 minuto. A metodologia de análise se dá pelo seguinte processo:

A. Utiliza-se no mínimo um ano de medições de IGH de 1 minuto;

B. Calcula-se, para cada minuto, de cada dia, o índice $k_{t}$;

C. Aproxima-se o valor de cada $k_{t}$ calculado para uma casa decimal, definindo-se os valores de $\widetilde{k_{t}}$;

Exemplo: $k_{t}=0,6675 \Rightarrow \widetilde{k_{t}}=0,7$

D. Calcula-se a variação entre $\tilde{k}$ 's subsequentes de cada dia:

$$
\Delta \widetilde{k_{t}}=\left|\tilde{k}_{t}(t)-\tilde{k}_{t}(t-1)\right|
$$

E. Calcula-se a probabilidade para cada dia $\left(P O P_{D}\right)$ de $\Delta \tilde{k}=0-$ denominado de probabilidade de persistência.

F. Calcula-se o $k_{t}^{\text {Diário }}$

$$
k_{t}^{\text {Diário }}=\frac{I G H^{\text {Diário }}}{I G H_{0}^{\text {Diário }}}=\frac{\int_{t_{p}}^{t_{n}} I G H d t}{\int_{t_{p}}^{t_{n}} I D N_{0} \cos \theta_{z} d t}
$$

G. Os valores de $k_{t}^{\text {Diário }}$ e $P O P_{D}$ são plotados em um gráfico divido em 10 quadrantes conforme a Figura 48. A caracterização de cada quadrante está no Quadro 8. 
Figura 48 - As 10 classes definidas para caracterização do recurso solar

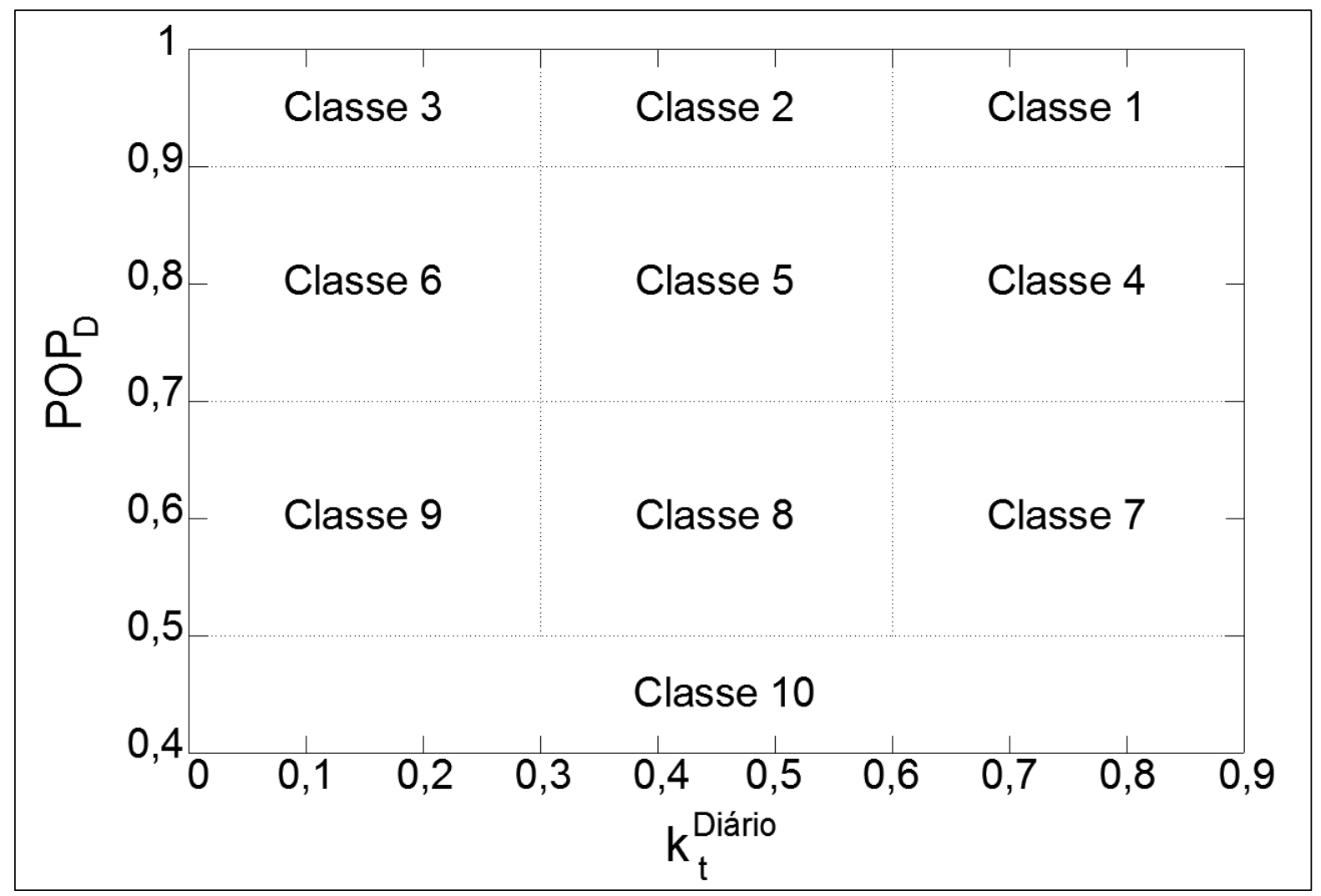

Fonte: adaptado de KANG e TAM, 2013

Quadro 8 - Definição e descrição das classes do método K-POP

\begin{tabular}{|c|c|c|c|}
\hline Classe & $k_{t}^{\text {Diário }}$ & $P O P_{D}$ & Descrição \\
\hline 1 & $k_{t}^{\text {Diário }} \geq 0,6$ & $P O P_{D} \geq 0,9$ & $\begin{array}{l}\text { Grande quantidade e muita } \\
\text { qualidade; condição de céu claro e } \\
\text { estável para quase o dia todo. }\end{array}$ \\
\hline 2 & $0,3 \leq k_{t}^{\text {Diário }}<0,6$ & $P O P_{D} \geq 0,9$ & $\begin{array}{l}\text { Média quantidade e muita } \\
\text { qualidade; parcialmente coberto por } \\
\text { nuvens, condição de céu } \\
\text { relativamente estável para a maior } \\
\text { parte do dia. }\end{array}$ \\
\hline 3 & $k_{t}^{\text {Diário }}<0,3$ & $P O P_{D} \geq 0,9$ & $\begin{array}{l}\text { Pequena quantidade e muita } \\
\text { qualidade; coberto por nuvens, } \\
\text { condição de céu relativamente } \\
\text { estável para a maior parte do dia. }\end{array}$ \\
\hline 4 & $k_{t}^{\text {Diário }} \geq 0,6$ & $0,7 \leq P O P_{D}<0,9$ & $\begin{array}{l}\text { Grande quantidade e média } \\
\text { qualidade; condição de céu claro, } \\
\text { porém variável ao longo do dia. }\end{array}$ \\
\hline
\end{tabular}




\begin{tabular}{|c|c|c|c|}
\hline Classe & $k_{t}^{\text {Diário }}$ & $P O P_{D}$ & Descrição \\
\hline 5 & $0,3 \leq k_{t}^{\text {Diário }}<0,6$ & $0,7 \leq P O P_{D}<0,9$ & $\begin{array}{l}\text { Média quantidade e média } \\
\text { qualidade; parcialmente coberto por } \\
\text { nuvens, condição de céu variável ao } \\
\text { longo do dia. }\end{array}$ \\
\hline 6 & $k_{t}^{\text {Diário }}<0,3$ & $0,7 \leq P O P_{D}<0,9$ & $\begin{array}{l}\text { Pequena quantidade e média } \\
\text { qualidade; nebulosidade e condições } \\
\text { do céu variando ao longo do dia. }\end{array}$ \\
\hline 7 & $k_{t}^{\text {Diário }} \geq 0,6$ & $0,5 \leq P O P_{D}<0,7$ & $\begin{array}{l}\text { Grande quantidade e pouca } \\
\text { qualidade; parcialmente ensolarado, } \\
\text { com condições do céu variando } \\
\text { significativamente na maior parte do } \\
\text { dia. }\end{array}$ \\
\hline 8 & $0,3 \leq k_{t}^{\text {Diário }}<0,6$ & $0,5 \leq P O P_{D}<0,7$ & $\begin{array}{l}\text { Média quantidade e pouca } \\
\text { qualidade; vários graus de } \\
\text { nebulosidade, com condições do céu } \\
\text { variando significativamente na } \\
\text { maior parte do dia. }\end{array}$ \\
\hline 9 & $k_{t}^{\text {Diário }}<0,3$ & $0,5 \leq P O P_{D}<0,7$ & $\begin{array}{l}\text { Pequena quantidade e pouca } \\
\text { qualidade; céu coberto por nuvens } \\
\text { com vários graus de flutuação ao } \\
\text { longo do dia todo. }\end{array}$ \\
\hline 10 & $k_{t}^{\text {Diário }}<0,5$ & $P O P_{D}<0,5$ & $\begin{array}{l}\text { Muita pouca qualidade, vários graus } \\
\text { de nebulosidade e altos níveis de } \\
\text { flutuação ao longo do dia todo. }\end{array}$ \\
\hline
\end{tabular}

Fonte: adaptado de KANG e TAM, 2013

Os autores empregaram a metodologia em três regiões dos EUA, com diferentes condições climáticas. As principais constatações dos autores foram: (i) a qualidade da irradiância é geralmente mais alta e mais acertada em condições de muito altos ou muito baixos índices de irradiância no dia, a qualidade é baixa para todos os valores de quantidade de irradiância intermediários; (ii) verifica-se alta consistência anual, indicando que a medição de 1 ano pode ser considerada suficiente para a caracterização do recurso local na região; (iii) a análise das três diferentes regiões apresenta classes dominantes comuns, sendo elas: 1, 4 e 5; (iv) quando verificada a classificação por meses ou estações do ano, cada região possui classes dominantes características para cada época, (v) o valor médio anual de $k_{t}^{\text {Diário não }}$ varia muito de região para região.

A análise desse estudo permite novamente a constatação de que a caracterização anual do recurso obedece a padrões mais constantes e consequentemente previsíveis do que a análise para curtos períodos de tempo.

KOUMPAROU et al. (2015) aplicaram essa metodologia para a caracterização da radiação na França e em Chipre. Na França, as classes dominantes foram: 1, 3, 4 e 5, 
totalizando 81,1\% da distribuição. Em Chipre, as classes dominantes foram 1, 4 e 5, totalizando $88,4 \%$ da distribuição. Isso mostra que as classes dominantes comuns aos EUA também são verificadas nos dois países europeus. A análise para os dois países foi realizada para quatro anos de medição. Percebe-se novamente que os valores médios anuais de $k_{t}^{\text {Diário }} \mathrm{e}$ $P O P_{D}$ variam muito pouco, mostrando novamente que a caracterização de 1 ano de medições pode caracterizar o comportamento do recurso na região de maneira satisfatória.

Além da classificação diária das condições da quantidade e qualidade KOUMPAROU et al. (2015) também analisaram a taxa de alteração de medições de 1 minuto subsequentes para os quatro anos. Os histogramas da Figura 49 mostram que a maior parte das alterações está entre 1-5 W/m² (75,4\% em Chipre e 64,3\% na França).

Figura 49 - Histograma da taxa de alteração de medidas subsequentes

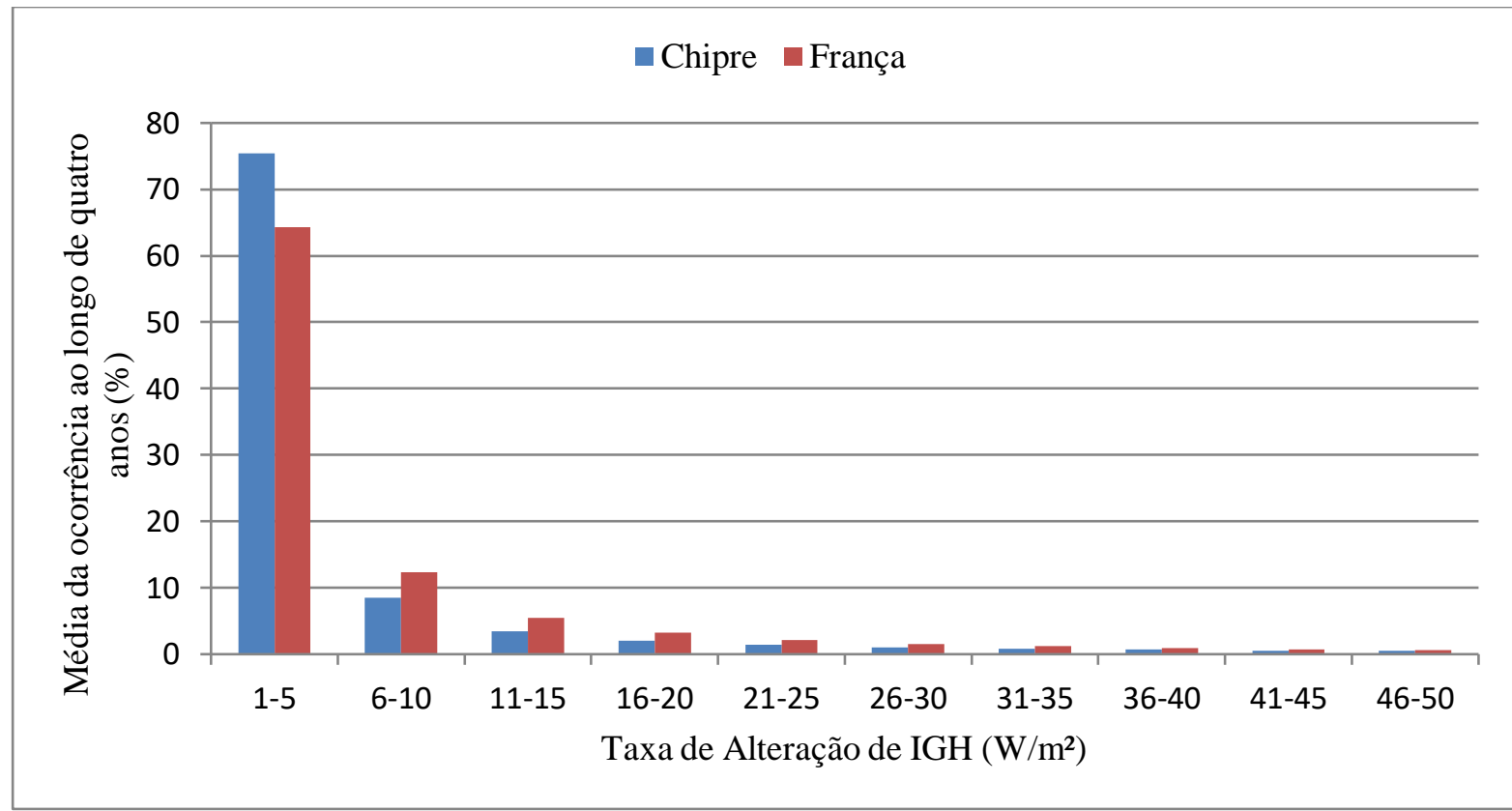

Fonte: adaptado de KOUMPAROU et al.,2015

Por meio da construção de funções de frequência relativa dos dados apresentados nos histogramas, os autores concluíram que a flutuação média da radiação em Chipre é de 12 $\mathrm{W} / \mathrm{m}^{2}$, com $38 \mathrm{~W} / \mathrm{m}^{2}$ de desvio padrão, enquanto que a flutuação média encontrada para a França é de $16 \mathrm{~W} / \mathrm{m}^{2}$ com $50 \mathrm{~W} / \mathrm{m}^{2}$ de desvio padrão. Os altos valores de desvio padrão mostram como a variabilidade da flutuação é alta, sendo necessário o conhecimento mais detalhado, de momento a momento para a caracterização do recurso em uma determinada região. 
NIKOLAIDIS et al. (2016) utilizaram o método K-POP para o dimensionamento do sistema de armazenamento de energia de uma planta de concentrador solar também em Chipre. Os autores, além de utilizar o método para a caracterização do perfil do recurso na região, também construíram uma curva empírica de densidade cumulativa de probabilidade da taxa de variação da irradiância direta normal (IDN) de períodos subsequentes, utilizando diferentes períodos para a média dos dados (1, 3, 16 e 60 minutos). Os resultados são apresentados na Figura 50.

Figura 50 - Função empírica de densidade cumulativa de probabilidade de IDN

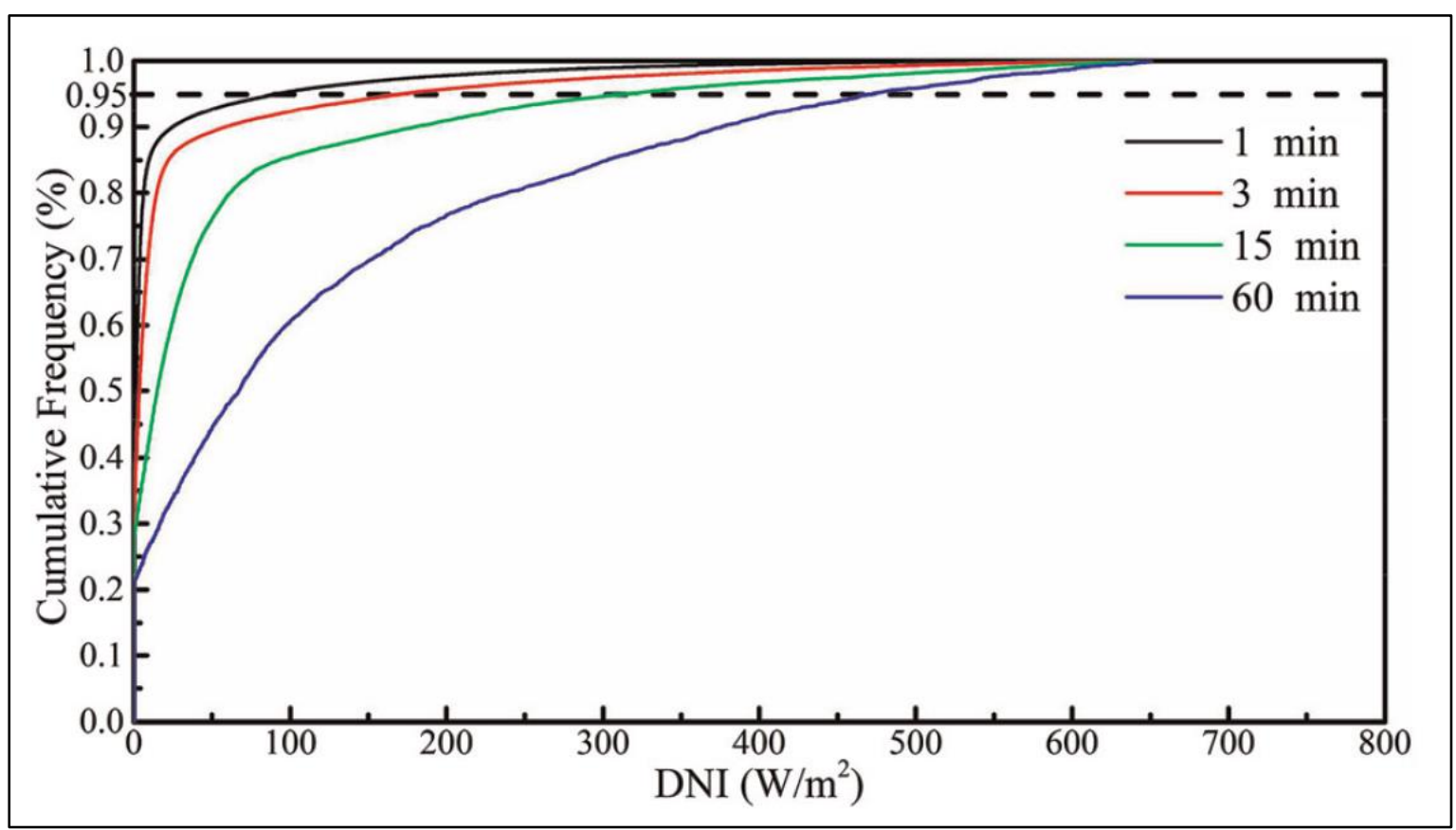

Fonte: NIKOLAIDIS., 2015

Deste modo, define-se que, tratando de medições de 1 minuto, $95 \%$ das variações de medições subsequentes são de até $90 \mathrm{~W} / \mathrm{m}^{2}$, enquanto que, tratando de medições de 1 hora, 95\% das variações da quantidade de IDN de uma hora para outra variam em até $472 \mathrm{~W} / \mathrm{m}^{2}$.

KANG e TAM (2013), citando OLSETH e SKARTVEIT (1984) e AGUIAR et al. (1988), afirmam que o perfil de $k_{t}^{\text {Diário }}$ tem uma correlação significativa com valores precedentes de $k_{t}^{\text {Diário }}$ para uma determinada região e que a sua função de densidade cumulativa para um determinado período apenas se relaciona com os valores médios de $k_{t}^{\text {Diário }}$ para aquele período. 


\section{SISTEMATIZAÇÃO DOS ELEMENTOS NECESSÁRIOS À MODELAGEM}

A geoanálise da energia primária solar define as possibilidades da criação de modelos físicos do recurso. Partindo-se do cálculo da irradiância extraterrestre, sabe-se que esse montante de energia deve ser atenuado pelos efeitos atmosféricos e climatológicos intrínsecos a cada região. Considerando a previsão do recurso em longo prazo, verifica-se uma forte correlação entre a radiação global e a insolação. Os cálculos realizados para as UHEs analisadas mostram que esses modelos de regressão linear devem ser específicos à cada região já que as principais variáveis balizadoras da disponibilidade do recurso se alteram de região para região, mesmo em faixas de latitude relativamente próximas. Assim, para que modelos físicos possam ser desenvolvidos ou para que se possa adotar modelos já existentes para uma determinada região, é importante mapear quais os inputs ideais, esses inputs são definidos a partir da geoanálise da energia primária.

Considerando a implantação de parques híbridos (usinas fotovoltaicas em hidrelétricas existentes), não foi possível comprovar se, a alteração de microclima gerada pela construção do reservatório propicia ou não a geração fotovoltaica, assim, essa verificação, a princípio, pode ser desconsiderada.

A verificação de variáveis climáticas balizadoras é relevante dentro da perspectiva de estimativa de recurso para longos períodos de tempo: médias mensais ou formação de dias característicos de cada mês, ou de cada estação climática do ano, mas não são capazes de estimar o recurso disponível em curto e curtíssimo prazo. A criação de modelos físicos para curto prazo carece de uma outra abordagem de definição de variáveis climáticas balizadoras. Abordagem essa, mais complexa, que requer a análise de correlações das variáveis em tempos diferentes, ou seja, a análise se o comportamento das variáveis climáticas no momento $t$ possui relação com a disponibilidade dos índices de irradiância no tempo $t+1$. Essa análise também requer a parametrização de $t$, isto é, identificar se essa relação é estabelecida entre períodos de horas, minutos, dias ou semanas.

A caracterização da métrica solar e dos seus aspectos temporais define as possibilidades da criação de modelos estatísticos do recurso que se define com base em eventos raros, aleatórios e específicos atmosféricos regionais. Dada essa constatação, é possível obter-se o perfil de comportamento dos dados da irradiância para uma determinada região em períodos distintos através da análise e tratamento dos dados e da construção de curvas de densidade de probabilidade e curvas de densidade cumulativa de probabilidade. A 
partir do comportamento dessas curvas é possível criar padrões de comportamento em função das massas de ar.

Embora o início dos estudos do comportamento instantâneo de radiação date da década de 60, nota-se, por meio dos estudos apresentados sobre os aspectos temporais, que ainda não há uma definição e concordância técnica do modelo estatístico ideal para a modelagem da irradiância. Além disso, também se conclui que o perfil instantâneo das irradiâncias direta difusa e global, embora possuam certos padrões de comportamento, não possuem um padrão bem definido em função das variações da massa de ar, apresentando diferentes perfis de comportamento para diferentes regiões.

O entendimento do comportamento instantâneo da irradiância ainda possui lacunas que devem ser preenchidas, a saber:

I. Definição do padrão de cálculo de $k_{t}, k_{b}$ e $k_{d}$. Não há uma definição acerca do denominador utilizado para o cálculo desses coeficientes, alguns utilizam a irradiância extraterrestre horizontal $\left(I G H_{0}\right)$, outros a irradiância extraterrestre normal $\left(I D N_{0}\right)$, outros utilizam até mesmo a irradiância global horizontal esperada pra condições de céu claro.

II. Definição do critério de divisão das massas de ar nominais: os autores analisados também não utilizaram o mesmo padrão para a definição dos intervalos correspondentes às massas de ar nominais. Além disso, nenhum estudo encontrado verifica a diferença das CDPs considerando os dados do período da manhã e do período da tarde em massas de ar diferentes. As definições das massas de ar apresentam-se confusas, como exemplo cita-se ASSUNÇÃO et al (2003) que utilizaram, para o primeiro intervalo de $A M$, o valor inferior de 0,9 , sendo que o valor mínimo de $A M$, por definição, corresponde a 1 .

III. Período de média dos valores: também não há um consenso acadêmico e técnico sobre qual período de obtenção de dados que satisfaz a condição de estudo de caráter instantâneo, embora a maioria dos autores estejam restringido valores de média de 1 minuto ou 5 minutos para cálculo dos coeficientes.

IV. Função estatística satisfatória para a modelagem do comportamento instantâneo das irradiâncias: diversos autores têm testado diferentes funções para a adequação do caráter instantâneo da radiação como as funções Beta de probabilidade, da estatística de Boltzmann, e funções de Gauss- encontradas no estudo de JURADO et al (1995). Alguns autores debruçam o entendimento sobre funções de densidade de 
probabilidade enquanto outros possuem enfoque nas distribuições de densidade cumulativa de probabilidade, embora saiba-se que a segunda nada mais é do que a integral da primeira.

Verifica-se, portanto, que ainda não há um consenso técnico e acadêmico acerca da caracterização da irradiância instantânea, de modo que, o melhor método para a caracterização do recurso em uma determinada região é por meio da construção das CDPs e aplicação do método K-POP com dados existentes, aferidos e verificados no local em que se pretende a instalação das plantas fotovoltaicas, seguido da análise da distribuição dos valores de flutuação entre medidas subsequentes.

Estações solarimétricas são compostas por equipamentos de alta precisão, mas que exigem cuidados de operação e calibração. É importante considerar que, mesmo assumindo as melhores práticas de operação, limpeza e monitoramento dos equipamentos solarimétricos, inevitavelmente ocorrerão períodos sem a disponibilidade de dados, que podem ocorrer pelos mais variados motivos, como: desligamento do rastreador solar por possíveis erros do sistema GPS, desligamento da estação devido à falta de fornecimento de energia, necessidade de manutenção ou calibração anual dos radiômetros, dentre outros.

A série histórica destes momentos nos quais não há disponibilidade de dados deve ser realizada por outros métodos. No caso da já existência de séries longas de medição daquela estação - mais de um ano de medição - e considerando curtos períodos de falta de dados, pode-se realizar o preenchimento da série histórica através do histórico já existente por meio da interpolação de dados.

No caso de a estação não possuir uma longa série histórica de medições já verificada, pode-se realizar a extrapolação e interpolação de dados de estações próximas - considerando que essas existam, algo pouco provável atualmente no Brasil. Isso pode ser realizado por meio das metodologias apresentadas na seção 3.5 para a estimativa da irradiação global média diária ou mensal. De posse dessa estimativa, as aproximações das componentes direta e difusa podem ser realizadas através dos modelos de desconstrução citados no Capítulo 4.

No caso de um longo período sem medições, a série histórica pode ser preenchida por meio dos métodos supracitados balizados pelas variáveis climatológicas relevantes daquela determinada estação de medição. Além disso, de posse de um histórico de medições de uma ES, é essencial a verificação da qualidade e coerência desses dados.

Com base em toda a fundamentação teórica, define-se a síntese de todos os processos necessários à definição de modelos de energia primária solar para geração fotovoltaica em 
escala a partir de dados medidos em solo, conforme apresentado no Fluxograma da Figura 51. Esses processos englobam desde a obtenção de dados por uma determinada estação até a caracterização do recurso solar para cada período do dia de cada mês, de cada estação do ano.

Deste modo, o primeiro processo é definido pela caracterização da estação solarimétrica em questão. Deve-se documentar o posicionamento da mesma (altitude, latitude longitude), bem como todos os equipamentos instalados (marca, modelo e processo de instalação, manutenção e calibração conforme indicação dos fornecedores e da WMO).

Definindo-se o posicionamento da estação, o primeiro procedimento a ser realizado é o cálculo de $I G H_{0}$ e $I D N_{0}$, minuto a minuto, para um ano completo na latitude determinada, já que esse dado é utilizado em diversas etapas da análise e tratamento dos dados e caracterização do recurso.

Caracterizada a estação e definida a irradiância extraterrestre, é necessário definir um padrão de registro de dados, conforme estabelecido na seção 5.1. A partir disso é necessário definir o processo de análise de qualidade de dados, adotando-se uma rotina já estabelecida como as demonstradas na seção 5.2 ou estabelecer uma rotina própria de análise. Em caso do estabelecimento de uma rotina própria de análise, é necessária a verificação dos limites estabelecidos por testes de envoltória, continuidade, limites físicos e empíricos. Conforme se estabelece uma série histórica, deve-se reavaliar o processo de análise de qualidade de dados, verificando se os limites estabelecidos se fazem coerentes.

Os dados brutos devem ser armazenados e deve-se seguir à definição do processo de preenchimento de dados faltantes. Para o preenchimento de dados faltantes é necessário o estabelecimento de três procedimentos, um para $I G H$, outro para $I D N$ e outro para $I D H$.

Quando estabelecido um ano de histórico de medições, o procedimento para preenchimento de séries históricas de IGH deve incorporar a definição de variáveis climáticas balizadoras e a definição de um modelo empírico que melhor se encaixe na determinada região, como os apresentados na seção 4.3. Podem ser definidos mais de um modelo, considerando diferentes estações do ano. Os procedimentos para preenchimento de séries de $I D H$ e $I D N$ devem preferencialmente tratar de modelos de decomposição. O preenchimento de pequenos períodos de dados ou dados isolados pode ser validado por testes estatísticos, empíricos e de continuidade pertencentes ao processo de análise de qualidade.

Definindo-se o preenchimento de dados faltantes a série histórica deve ser armazenada com dados validados integrados em 1 minuto. 
Com o estabelecimento da estação e do processo de construção de série histórica, definindo-se modelos empíricos e a irradiância extraterrestre, já é possível a obtenção da quantidade média anual de energia disponível para aquela região a partir de 1 ano de medições.

Para a definição do comportamento do recurso em curto e curtíssimo prazo deve-se proceder a análise de $k_{t}$ utilizando-se dados de 1 minuto. Recomenda-se a separação dos dados para diferentes massas de ar, considerando a diferenciação dos dados em ao menos três períodos: início da manhã, ao longo do dia e fim de tarde. Deste modo, deve-se proceder à construção das curvas de densidade de probabilidade (CDP) dos coeficientes de transmitância e das curvas de distribuição de frequência relativa (CFR) da variação de medições subsequentes para as três variáveis (IGH,IDN e $I D H)$, para os diferentes períodos de massa de ar. Os cálculos devem ser realizados para os dias de um mesmo mês com o intuito de formatar um dia característico para cada mês. Os dias característicos dos meses pertencentes à mesma estação do ano devem ser agrupados definindo a possibilidade da formação de um dia característico para cada estação do ano. Utilizando-se desse mesmo procedimento deve ser aplicado o método k-POP. Finalizando a caracterização do comportamento do recurso para diferentes horas do dia, de diferentes dias do mês, de diferentes meses da estação, de diferentes estações do ano.

O fluxograma da Figura 51 apresenta a construção deste método apresentado. 
Figura 51 - Fluxograma das atividades visando à modelagem

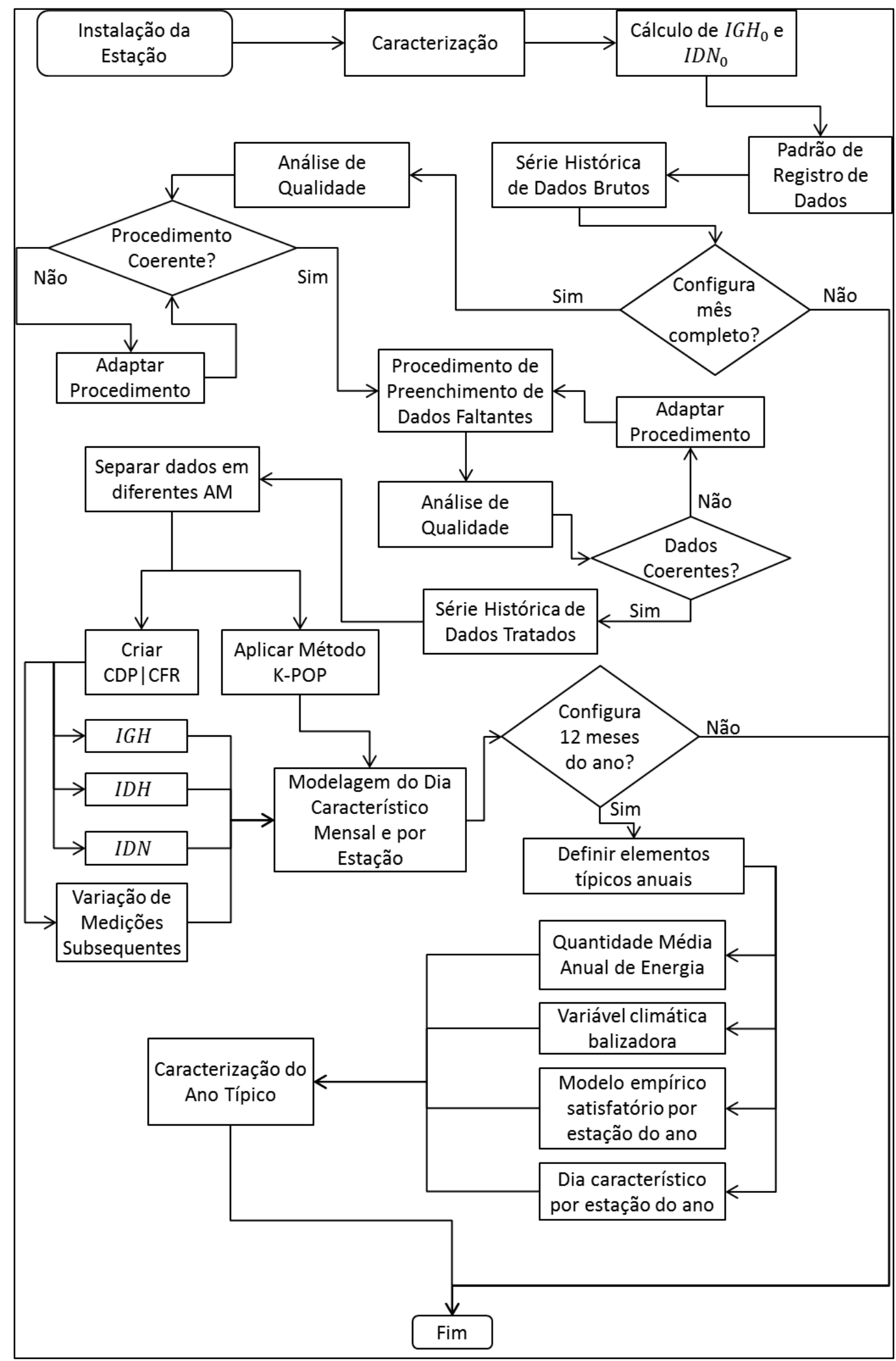

Fonte: Elaboração própria 
Os processos estabelecidos no fluxograma representam etapas que envolvem conhecimentos técnicos vinculados às tecnologias de medição (seção 3.2) e à relação do movimento Sol-Terra e à interação da radiação com a atmosfera (seção 3.1). Portanto, este fluxograma deve ser adotado como uma ferramenta de verificação dos processos estabelecidos para cada ES vinculada a fins energéticos. Ele, por si só, não possui utilização se não acompanhado pelo conhecimento prévio estabelecido ao longo dos capítulos anteriores.

Dada a disponibilidade de dados da estação solarimétrica instalada na UHE Eng. Sérgio Motta (ou UHE Porto Primavera), pretende-se aplicar nestes dados, as etapas apresentadas no fluxograma da Figura 51, objetivando a validação da sistematização da caracterização da energia através dos dados da estação. 


\section{CARACTERIZAÇÃO DO RECURSO: UTILIZAÇÃO DE MEDIÇÕES EM SOLO}

Conforme análise do fluxograma apresentado na Figura 51 do capítulo anterior, a definição da caracterização visando a modelagem é realizada em três macroetapas, sendo elas: (i) a caracterização da estação, (ii) a geoanálise do recurso e a (iii) análise dos aspectos temporais.

A caracterização da estação engloba basicamente as etapas de registro da instalação da estação; a caracterização de equipamentos com os respectivos modelos e classificações de qualidade; e a definição: do padrão de registro de dados, do armazenamento da série histórica de dados brutos, do procedimento de análise de qualidade de dados, do procedimento de preenchimento de dados faltantes e do armazenamento da série histórica de dados tratados.

A análise da métrica solar e dos aspectos temporais é definida pelas etapas de separação dos dados em diferentes massas de ar e definição das CDPs e aplicação do método K-POP, verificando a possibilidade de elaboração de um dia característico probabilístico mensal e de cada estação do ano e ainda analisa as flutuações imediatas dos dados. Essa análise visa caracterização do recurso em curto e curtíssimo prazo.

A geoanálise é definida a partir da completude de no mínimo um ano de medição, de modo que se definam o dia característico de quantidade de energia por estação climática e por mês do ano, um modelo empírico de estimativa da radiação satisfatório por estação climática e/ou por mês do ano, a variável climática balizadora e a quantidade média anual de energia disponível. Essa análise visa a previsibilidade do recurso em longo prazo e o entendimento do seu comportamento na região, em função das demais características climáticas.

As seções seguintes apresentam os detalhes e resultados que foram possíveis de serem obtidos das três macroetapas supra detalhadas.

\subsection{CARACTERIZAÇÃO DA ES DA UHE PORTO PRIMAVERA}

\subsubsection{Localização}

A ES está localizada no Município de Rosana- SP, Brasil. Conforme as especificações do Quadro 9. 
Quadro 9 - Localização da ES UHE Porto Primavera

\begin{tabular}{|c|c|c|c|c|}
\hline Nome & \multicolumn{4}{|c|}{ Estação Solarimétrica UHE Porto Primavera (ESUPP) } \\
\hline Município & \multicolumn{4}{|c|}{ Rosana } \\
\hline Estado & \multicolumn{4}{|l|}{ São Paulo } \\
\hline Coordenadas Geográficas & Latitude & $-22,486^{\circ}$ & Longitude & $-52,955^{\circ}$ \\
\hline Altitude & \multicolumn{4}{|c|}{261 metros } \\
\hline Hora (UTC) & \multicolumn{4}{|c|}{-3} \\
\hline
\end{tabular}

Fonte: Elaboração própria

A ESUPP está localizada em uma área fechada e com vegetação rasteira, sob a influência do albedo deste tipo de vegetação e também do albedo da superfície do reservatório e da grade de proteção do mesmo.

\subsubsection{Sensores e Classificação}

Os equipamentos instalados são descritos no Quadro 10.

Quadro 10 - Caracterização dos equipamentos da ES UHE Porto Primavera

\begin{tabular}{|l|l|}
\hline Equipamento & Marca/Modelo \\
\hline Anemômetro & $\begin{array}{l}\text { Thies First Class Advanced } \\
4.3351 .00 .000\end{array}$ \\
\hline Anemoscópio & $\begin{array}{l}\text { Thies Wind Vane compact } \\
4.3129 .70 .701\end{array}$ \\
\hline Termo - higrômetro & KP S52100 \\
\hline Barômetro & AB60 \\
\hline Pluviômetro & Young/52203 \\
\hline Piranômetro -IGH & Kipp\&Zonen/CMP6 \\
\hline Piranômetro - IDH & Kipp\&Zonen/CMP6 \\
\hline Pireliômetro & EKO MS-56 \\
\hline
\end{tabular}

Fonte: Elaboração própria

A ES começou a registrar dados no início da noite de 19 de setembro de 2015. No dia 14 de novembro de 2015 foi verificado o desligamento do rastreador solar. O equipamento teve de ser enviado ao fabricante no Japão para manutenção, implicando, até o momento de fechamento deste estudo, na falta de medições das irradiâncias normal direta e difusa horizontal. Com a retirada do rastreador solar para manutenção, também foi retirado o pireliômetro e a esfera de sombreamento do piranômetro destinado à medição de irradiância difusa. Assim, as medições de irradiância normal direta e difusa horizontal estão disponíveis 
apenas para o período de 19 de setembro de 2015 à 14 de novembro de 2015, nomeado neste estudo como "período restrito".

A ES também conta com um datalogger Ammonit, de modelo METEO-40M, um conjunto de placas fotovoltaicas e conjunto de baterias para alimentação da estação e o rastreador solar responsável pela manutenção da posição ideal da esfera de sombreamento e do pireliômetro. O termo-higrômetro foi, a princípio instalado embaixo da placa fotovoltaica. Essa localização foi alterada em 12 de março de 2016. Deste modo, os dados de temperatura e umidade deste período estão comprometidos em virtude do aquecimento recorrente da parte de baixo de toda placa fotovoltaica em funcionamento.

Os sensores de radiação (piranômetros e pireliômetro) da estação obedecem a classificação first class da ISO 9060.

\subsection{ANÁLISE E TRATAMENTO DE DADOS DA ESUPP}

O processo de análise e tratamento de dados se inicia com o registro dos elementos de limpeza e manutenção da estação e o processo de registro de dados, tanto brutos como tratados.

A ESUPP não possui rotina de manutenção e limpeza definida, ficando exposta às condições climáticas sem realização de procedimentos que assegurem a qualidade dos dados. Os dados são disponibilizados online a partir do software da empresa responsável pela instalação da estação. Os dados disponíveis são brutos, sendo que não há nenhum procedimento de filtro ou composição/substituição de dados faltantes/errados.

Os dados brutos são disponibilizados em arquivos .csv diários, com o registro de minuto a minuto de todas as variáveis, inclusive daquelas de controle, como medição de tensão, amperagem, velocidade dos ventiladores dos piranômetros, dentre outras. Cada coluna de dados possui uma denominação sem padronização exata. Não foi estabelecido pela empresa fornecedora da estação arquivo padronizado especificando as abreviações adotadas e nem as unidades de medidas apresentadas para cada variável. A data referente a cada dado é a primeira informação disponibilizada, estando no formato: Ano (AAAA) Mês (MM) Dia (DD)

- Hora (HH): Minuto (MM) Segundo (SS), considerando o fuso horário UTC-3 e desconsiderando o horário de verão.

Assim, definiu-se o download dos dados e disponibilização no servidor seeds.com para acesso dos pesquisadores do grupo. Os dados são renomeados conforme relatório de 
registro de dados, que também foi desenvolvido no âmbito desse estudo, com a participação dos demais pesquisadores do GEPEA. O relatório encontra-se no Apêndice 1.

Dada a limitação de tempo para desenvolvimento desse estudo, definiu-se, enquanto análise de qualidade, a realização de alguns procedimentos simples, que permitam a compreensão do estado geral da série que está sendo trabalhada. Deste modo, não foi estabelecido procedimento de retirada ou substituição de dados sinalizados como duvidosos, contudo foi definido procedimento também simplificado para composição de dados faltantes para fins de viabilização da aplicação das etapas de caracterização do recurso sistematizadas nesse estudo.

O período de dados utilizados foi do dia 20 de setembro de 2015 à 31 de maio de 2016, totalizando 8 meses e 10 dias de medições de minuto a minuto das variáveis: irradiância global horizontal (média de 60 registros por minuto), temperatura (média de 60 registros por minuto), precipitação (soma do registro por minuto), umidade relativa (média de 60 registros por minuto), pressão atmosférica (média de 60 registros por minuto). Os dados de irradiância difusa horizontal (média de 60 registros por minuto) e irradiância direta normal (média de 60 registros por minuto) estão disponíveis apenas apara o período restrito definido do dia 20 de setembro de 2015 a 13 de novembro de 2015, totalizando um mês e 23 dias completos de dados.

Os aspectos definidos para a análise de qualidade foram aplicados apenas para dados de irradiância de períodos cujo ângulo zenital fosse menor ou igual a $75^{\circ}$, evitando as medições mais incertas dos piranômetros e pireliômetros, e são definidos pelas etapas:

I. Verificação das linhas de registros faltantes

II. Verificação de linhas de registros repetidas

III. Verificação de dados faltantes

IV. Verificação de dados zerados

V. Verificação de dados negativos

VI. Verificação de dados maiores do que a irradiância no topo da atmosfera

VII. Análise de $k_{t c}$

Essas etapas foram realizadas por meio do software RStudio, os dados foram importados para o ambiente do RStudio e nele foram elaborados os algoritmos necessários para o tratamento na linguagem R. Os gráficos foram produzidos utilizando o pacote Ggplot2.

O Quadro 11 apresenta os principais resultados obtidos pela análise de tratamento. 
Quadro 11 - Análise de qualidade e tratamento de dados da ES UHE Porto Primavera

\begin{abstract}
Etapa Resultados
I Ao analisar a série histórica é possível verificar que alguns dos minutos ao longo da série não foram registrados. Essa foi a única etapa realizada para a série histórica completa, e não apenas para dados cujo ângulo zenital fosse menor ou igual a $75^{\circ}$. Do total de 367200 linhas de registro que deveriam existir foi identificada a falta de 62 linhas, compreendendo o período das 16:04 horas às 17:12 horas do dia 17/12/2015. Essas linhas foram adicionadas na série histórica e aos valores dos dados foram colocados como NA.

II Não foi encontrado nenhum horário com registro repetido.

III Os únicos dados definidos como NA foram aqueles introduzidos na série histórica pela Etapa I. Embora a sequência seja pouco representativa na série completa, optou-se por substituí-la por valores estimados para simplificar os cálculos posteriores em função da presença de células NA. Assim, a substituição foi realizada para os dados de IGH, por meio de valores coerentes com a ordem de grandeza das medições imediatamente anteriores e posteriores do período faltante (calculados por meio de média simples entre o valor imediatamente anterior e os valores sequenciais existentes após período de falha). Como nessa data o rastreador solar já não estava em funcionamento, as outras componentes de irradiância foram zeradas. Como as variáveis climáticas são utilizadas apenas para médias diárias, foram atribuídos a essas variáveis o último valor válido medido da série histórica, para que não haja comprometimento da ordem de grandeza da média diária.

IV Dentre dados de irradiância difusa e global (155.250 registros) foram encontrados 151 dados de IGH e IDH zerados. Esses dados foram encontrados no período da manhã do dia 22/01/2016 e na hora 17 do dia 25/9/2016 indicando certamente um conjunto de dados errados, que representa menos de $0,1 \%$ da amostra de dados com ângulo zenital inferior à $75^{\circ}$. Esses dados não foram substituídos ou retirados, pois entende-se que a sua representatividade nos cálculos realizados é ínfima e não influencia na definição final do comportamento do recurso.

V Não foi encontrado nenhum dado negativo.

VI Foi verificada a existência de valores de $I G H$ e $I D H$ superiores à $I G H_{0}$ e valores de $I D N$ superiores à $I D N_{0}$. A metodologia de cálculo de $I D N_{0}$ e $I G H_{0}$ foi construída conforme os elementos de cálculo apresentados na seção 4.1 com os dados do Quadro 9. A equação do tempo e a correção do ângulo horário em função da latitude também foram consideradas. $O$ memorial de cálculo encontra-se no Apêndice 2. Foram encontrados 1437 valores de $I G H$ superiores à $I G H_{0}$, sendo que 1259 encontram-se no mês de maio em horários que variam entre as 9 da manhã e 3 da tarde. Os demais dados foram verificados para os meses de setembro e abril. Em virtude dessa constatação, também foi aplicado o critério de dados fisicamente possíveis estabelecido pela BSRN, definido no item I. da seção 5.2.1 desse estudo. Todos os dados foram aprovados nesse critério.
\end{abstract}

(continua) 


\section{Etapa Resultados}

VII $k_{t c}$ é o nome atribuído, nesse estudo, ao coeficiente entre a medição de irradiância global aferida pelo sensor dividida pela irradiância global calculada a partir das medições de irradiância direta e difusa para o mesmo minuto, conforme equações apresentadas no Apêndice 2. Segundo o critério da BSRN, o coeficiente deve estar entre 0,92 e 1,08, enquanto que, segundo a rede Sonda, os valores admissíveis são aqueles entre 0,9 e 1,1. Esses critérios também são discutidos na seção 5.2.1. A Figura 52 apresenta o histograma de frequência relativa dos valores de $k_{t c}$ para o período restrito, já que este é o único intervalo de dados no qual essa verificação é viável.

Fonte: Elaboração própria

Figura 52 - Frequência dos valores de $K_{t c}$

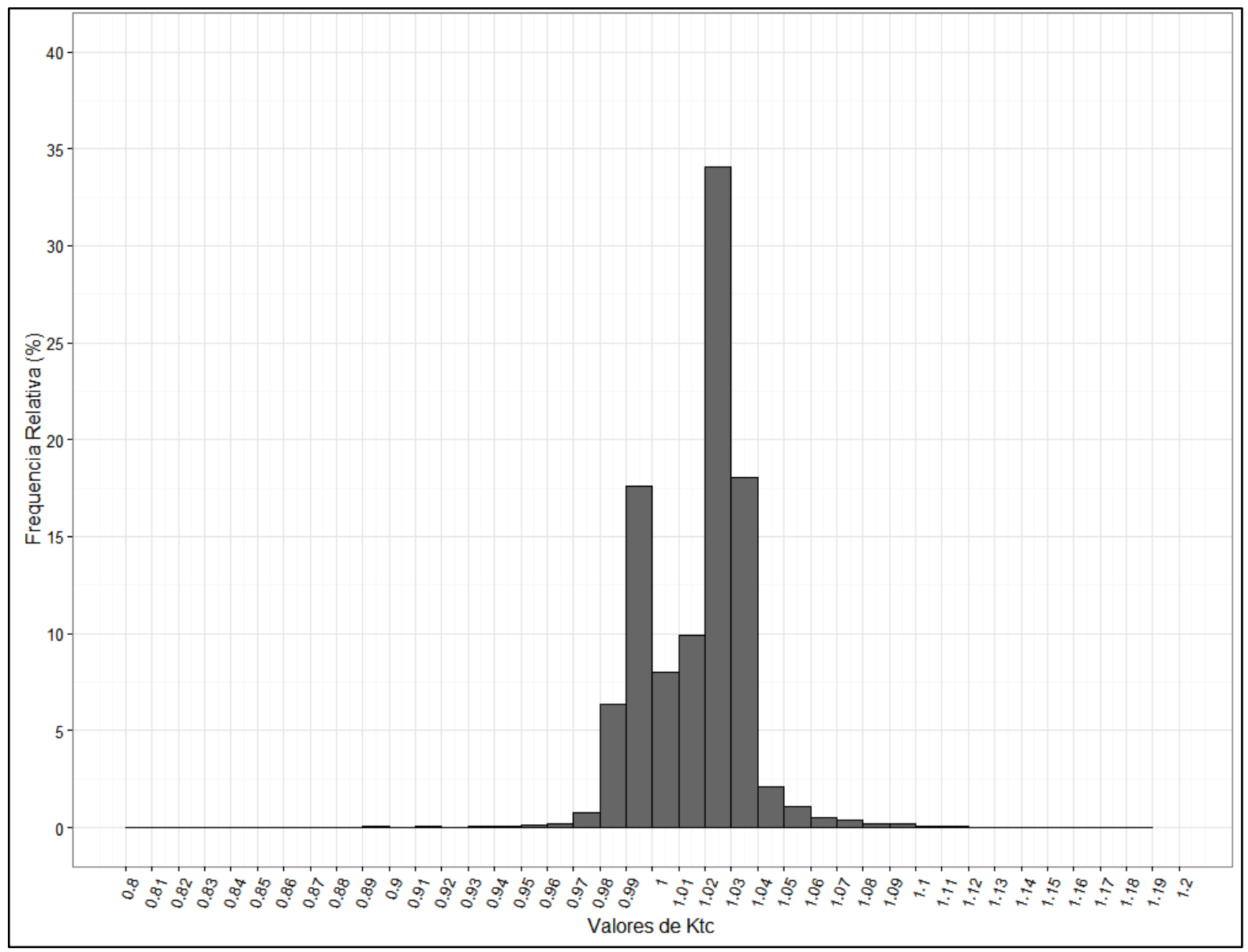

Fonte: Elaboração própria

A Figura 52 apresenta a distribuição relativa de valores de $k_{t c}$ entre 0,8 e 1,2. 31 valores de ktc foram encontrados fora deste intervalo representando cerca de $0,02 \%$ da amostra total do período restrito. 40 valores de $k_{t c}$ inferiores à 0,9 foram verificados enquanto que 168 superiores à 1,1 foram verificados. No total, esses valores, fora do intervalo considerado aceitável pela rede Sonda representam $0,6 \%$ da amostra total do período restrito. 
Em um processo ideal de tratamento de dados esses valores deveriam ser sinalizados como duvidosos e verificados um a um, considerando as medições imediatamente anteriores e posteriores, buscando a identificação de incoerências, contudo, devido à baixa representatividade dos valores na amostra completa e o tempo limitado para a realização desse estudo, esses dados não foram analisados individualmente e nem foram retirados da amostra.

A análise de qualidade de dados mostra, no geral, dados coerentes, com baixos índices de valores duvidosos. $\mathrm{O}$ armazenamento da série histórica foi estabelecido apenas enquanto variáveis globais do ambiente do RStudio dada a simplificação do processo de tratamento, de modo que se optou apenas pela disponibilização dos dados brutos para os demais pesquisadores do grupo.

\subsection{ASPECTOS TEMPORAIS (ESUPP)}

A análise de qualidade de dados representa o primeiro referencial para compreensão dos aspectos temporais do recurso, assim após a análise inicial e familiarização com a série histórica prossegue-se para a análise probabilística dos dados disponíveis.

\subsubsection{Construção das CDPs}

A análise temporal visa a formulação de dias característicos mensais probabilísticos, considerando a definição do comportamento característico da manhã, do meio do dia e da tarde e se possível, a caracterização de um dia por estação climática. Essa abordagem é inovadora, visto que, nos estudos encontrados na bibliografia, as caracterizações são feitas em função de diferentes intervalos de massa de ar. Esses intervalos definem a posição aparente do Sol em relação ao zênite, sem a diferenciação do período de manhã ou da tarde, englobando todos os dados de uma determinada faixa de ângulos zenitais no mesmo conjunto de dados. A Tabela 17 apresenta a diferença entre a abordagem tradicional de divisões de massa de ar e a abordagem proposta neste estudo.

Tabela 17 - Nova determinação dos intervalos de AM

\begin{tabular}{rrcc}
\hline Hora & $\begin{array}{c}\text { Massa } \\
\text { de Ar }\end{array}$ & $\begin{array}{l}\text { Massa de Ar Nominal- } \\
\text { Abordagem Tradicional }\end{array}$ & $\begin{array}{c}\text { Massa de Ar Nominal- } \\
\text { Abordagem Proposta }\end{array}$ \\
\hline $7: 30$ & 3,1 & 3,0 & $3,0 \mathrm{M}$ \\
\hline $8: 00$ & 2,3 & 2,5 & $2,5 \mathrm{M}$ \\
\hline $8: 37$ & 1,8 & 2,0 & $2,0 \mathrm{M}$ \\
\hline $9: 30$ & 1,4 & 1,5 & $1,5 \mathrm{M}$ \\
\hline
\end{tabular}




\begin{tabular}{cccc}
\hline Hora & $\begin{array}{c}\text { Massa } \\
\text { de Ar }\end{array}$ & $\begin{array}{c}\text { Massa de Ar Nominal- } \\
\text { Abordagem Tradicional }\end{array}$ & $\begin{array}{c}\text { Massa de Ar Nominal- } \\
\text { Abordagem Proposta }\end{array}$ \\
\hline $11: 26$ & 1,0 & 1,0 & 1,0 \\
\hline $15: 10$ & 1,2 & 1,0 & 1,0 \\
\hline $16: 15$ & 1,5 & 1,5 & $1,5 \mathrm{~T}$ \\
\hline $17: 15$ & 2,1 & 2,0 & $2,0 \mathrm{~T}$ \\
\hline $17: 38$ & 2,6 & 2,5 & $2,5 \mathrm{~T}$ \\
\hline $18: 03$ & 3,4 & 3,0 & $3,0 \mathrm{~T}$ \\
\hline
\end{tabular}

Fonte: Elaboração própria

Em função da dinâmica de movimentação Terra e Sol, as massas de ar não são as mesmas para todos os horários de todos os dias do ano. A Tabela 17 foi formulada com os da ESUPP do dia 8 de janeiro. Verifica-se que a abordagem tradicional compreende a formação de 5 intervalos de massas de ar, enquanto que a abordagem proposta compreende a divisão dos dados disponíveis em 9 conjuntos de massas de ar diferentes, isso implica em redução do espaço amostral respectivo a cada conjunto de massa de ar em função da maior divisão da quantidade total de dados disponíveis.

A análise de densidade de probabilidade ou de frequência relativa dos índices de transmitância $\left(k_{t}, k_{d}\right.$ e $k_{b}$ respectivamente) para $I G H, I D H$ e $I D N$, deve ser feita com uma quantidade significativa de dados. A análise de estudos efetuadas na seção 5.4 mostra que nenhum estudo analisado usou menos de um ano de histórico de medições. Como a disponibilidade de dados para a construção das curvas é inferior há um ano, foi aplicado um critério de divisão de massa de ar semelhante aos estudos analisados, de modo que se possam realizar algumas comparações com os resultados dos demais autores. As divisões de massa de ar utilizadas estão definidas na Tabela 18.

Tabela 18 - Determinação tradicional dos intervalos de AM

\begin{tabular}{cl}
\hline AM nominal & AM real \\
\hline $\mathbf{1 , 0}$ & $1,0<A M<1,2$ \\
\hline $\mathbf{1 , 5}$ & $1,4<A M<1,6$ \\
\hline $\mathbf{2 , 0}$ & $1,8<A M<2,2$ \\
\hline $\mathbf{2 , 5}$ & $2,3<A M<2,7$ \\
\hline $\mathbf{3 , 0}$ & $2,8<A M<3,5$ \\
\hline
\end{tabular}

Fonte: Elaboração própria 
O cálculo dos coeficientes foi realizado por meio das seguintes relações:

$$
\mathrm{k}_{\mathrm{d}}=\mathrm{IDH} / \mathrm{IGH}_{0}, \mathrm{k}_{\mathrm{t}}=\mathrm{IGH} / \mathrm{IGH}_{0}, \mathrm{k}_{\mathrm{n}}=\mathrm{IDN} / \mathrm{IDN}_{0}
$$

Os valores de $I G H_{0}, \cos \theta_{z}$ e $I D N_{0}$ foram calculados conforme as relações matemáticas apresentadas na seção 4.1 e o memorial de cálculo está apresentado no Apêndice 2. Os valores de $I D N_{0}$ calculados foram diários, enquanto que os valores de $I G H_{0}$ e $\cos \theta_{z}$ calculados foram de minuto a minuto. Para reduzir a incerteza da série e evitar dados errôneos, foram considerados, para essa análise, apenas dados cujo ângulo zenital correspondente fosse inferior ou igual à $75^{\circ}$.

É importante lembrar que, considerando a equação:

$$
I G H=I D H+I D N * \cos \theta_{Z}
$$

Se dividida por $I G H_{0}$ e considerando que $I G H_{0}=I D N_{0} * \cos \theta_{z}$ temos, conforme já discutido na seção 5.2.2, a equação (38):

$$
k_{t}=k_{n}+k_{d}
$$

A Figura 53 apresenta as CDPs para os valores de $k_{t}$ do período restrito para as respectivas massas de ar da Tabela 18. Os intervalos de $k_{t}$ foram definidos com amplitude de 0,02. As CDPs foram calculadas utilizando-se as funções geom_histogram e geom_density do pacote Ggplot2, utilizados no ambiente do RStudio. Verifica-se que, no geral, o caráter bimodal das curvas é mais evidente em massas de ar maiores, contudo, foi verificado para $\mathrm{AM}=2,0$ uma distribuição com três picos, perfil não encontrado nas CDPs apresentadas nos estudos da revisão bibliográfica. 
Figura 53 - Curvas de densidade de probabilidade de $k_{t}$ para o período restrito em função da massa de ar

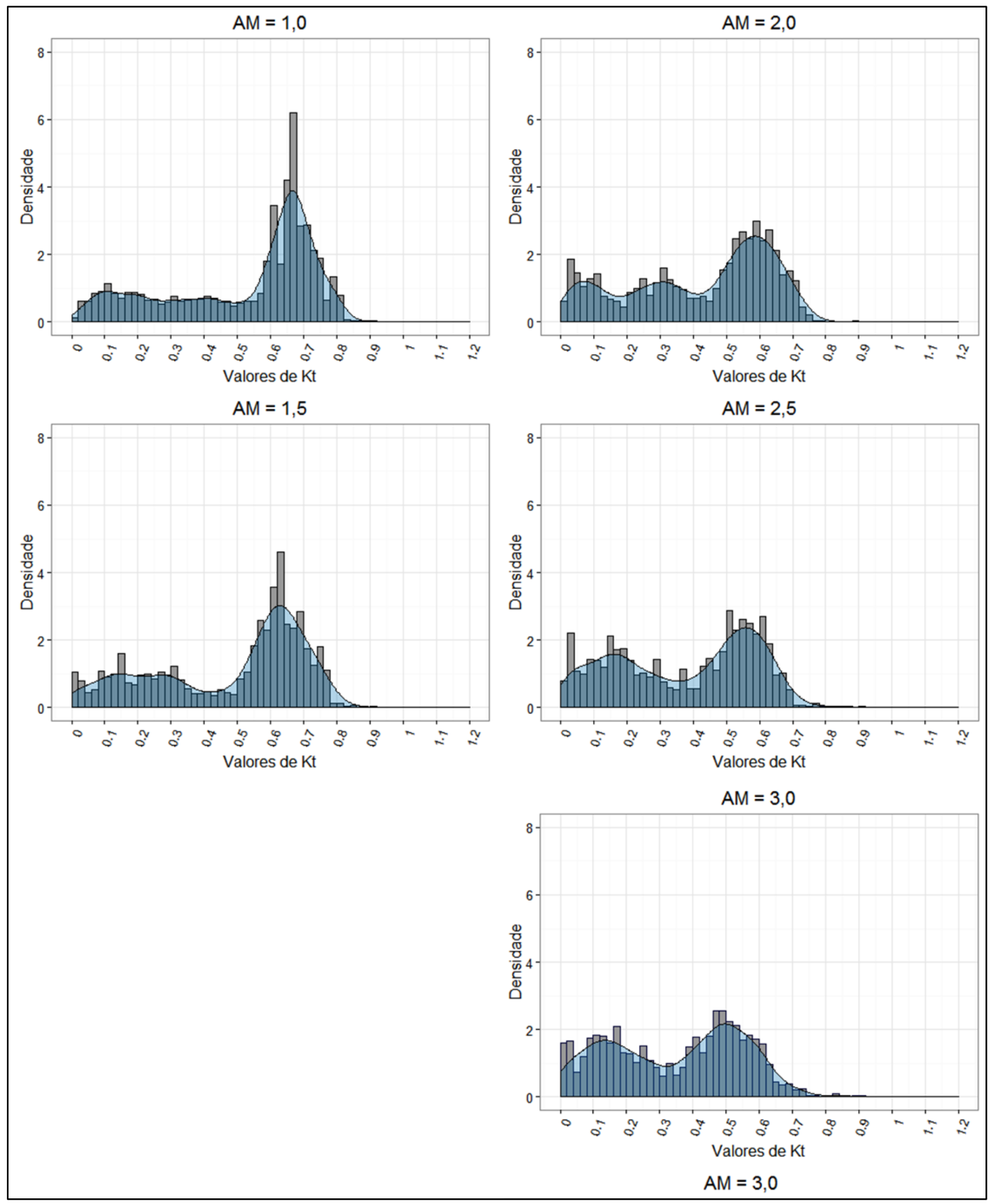

Fonte: Elaboração própria

As Figuras 54 e 55 apresentam as CDPs do período restrito para os valores de $k_{d} \mathrm{e}$ $k_{b}$ respectivamente, utilizando-se a divisão de massa de ar da Tabela 18. Os intervalos de $k_{d}$ e $k_{b}$ foram definidos com amplitude de 0,02 . 
Figura 54 - Curvas de densidade de probabilidade de $k_{d}$ para o período restrito em função da massa de ar

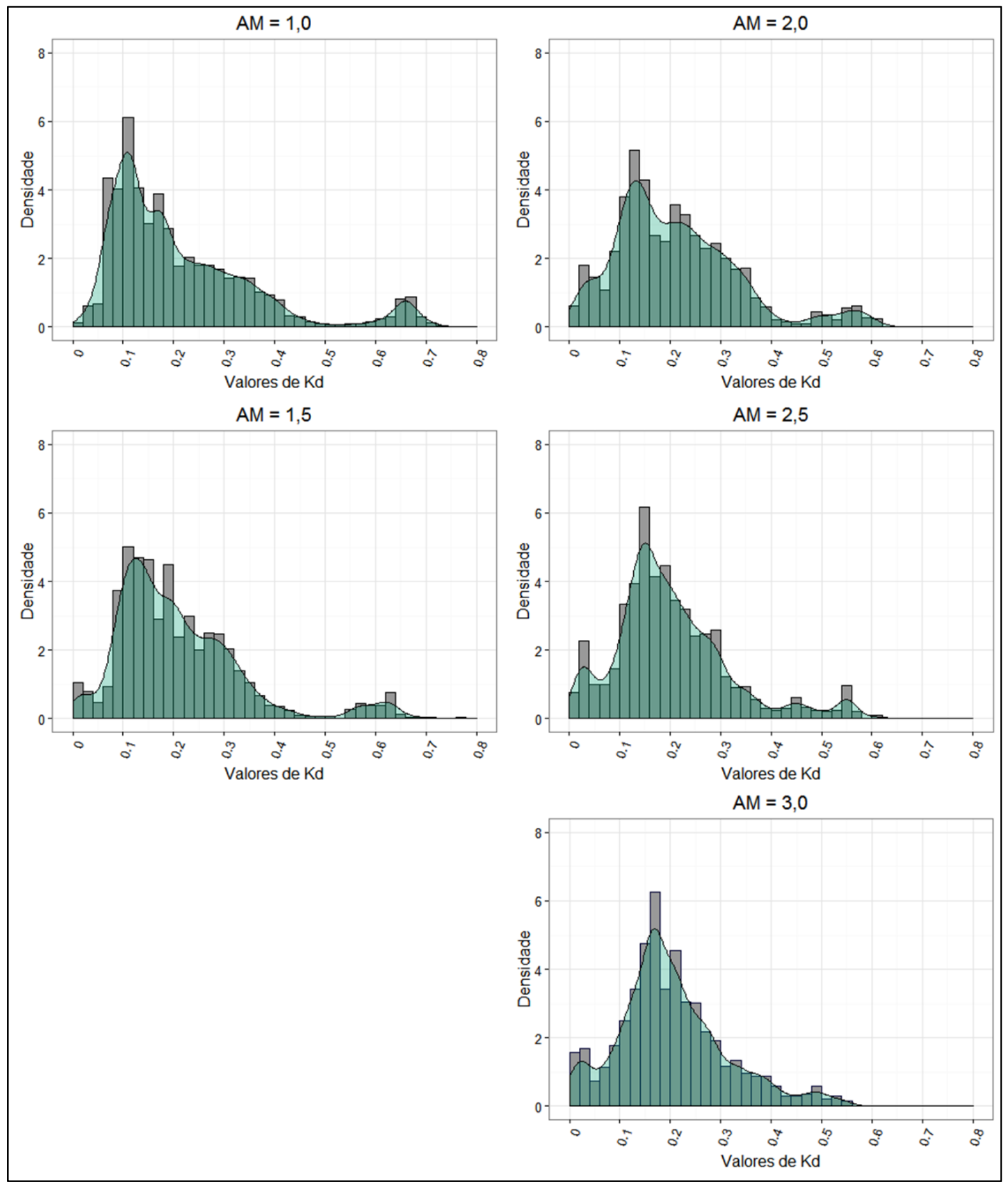

Fonte: Elaboração própria

As curvas de $k_{d}$ apresentam um comportamento semelhante ao encontrado por ASSUNÇÃO et al (2003), contudo o pico principal da curva se desloca levemente à direta conforme o aumento da massa de ar. No estudo de ASSUNÇÃO et al (2003) esse deslocamento é mais evidente. Além disso, as curvas da Figura 54 apresentam valores mais 
significativos de índices maiores do que nos estudos de TOVAR et al (1998) e ASSUNÇÃO et al (2003), formando um segundo pequeno pico na distribuição que se desloca a esquerda conforme a massa de ar aumenta. Contudo verifica-se que a alteração do perfil das curvas é menos sensível às alterações de massa de ar do que a alteração de perfil das curvas de $k_{t}$.

Figura 55 - Curvas de densidade de probabilidade de $k_{b}$ para o período restrito em função da massa de ar

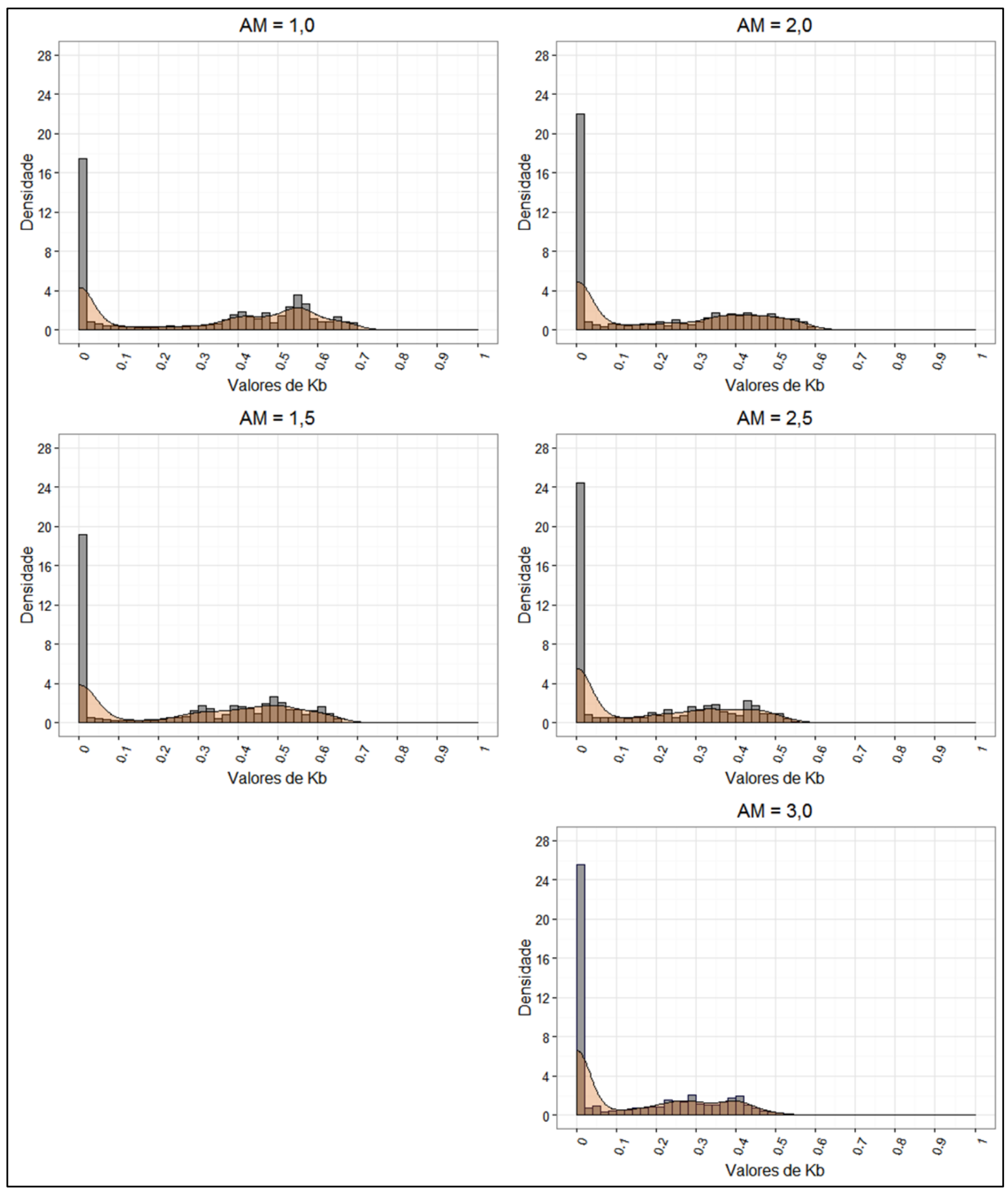

Fonte: Elaboração própria, 2016 
As curvas de $k_{b}$ apresentam um perfil semelhante ao encontrado por TOVAR et al (1999) e ASSUNÇÃO et al (2003), contudo verifica-se que o segundo pico da distribuição tem uma probabilidade bem menor de ocorrência quando comparado ao primeiro pico. Nos demais estudos analisados essa diferença entre os dois máximos da função é menor. Coerentemente, nesse caso, verifica-se a redução do segundo pico em função do aumento da massa de ar. Contudo, a densidade de ocorrência de medições nulas ou próximas à zero é bastante elevada em todo o período restrito. Isso pode ocorrer em função do pequeno espaço amostral de análise, que não representa a variação de um ano inteiro, mas sim de menos de dois meses do ano.

Considerando a maior série de dados disponível, ou seja, dados de $I G H$, foram elaboradas CDPs para cada mês do ano de $k_{t}$, com o intuito de verificar se há a possibilidade de formação de um padrão probabilístico para cada mês e estação do ano. Essas CDPs são apresentadas nos gráficos das Figuras 56 e 57.

Assim, é conveniente estabelecer as datas dos eventos vinculados a dinâmica TerraSol, de modo que não se percam de vista esses eventos para a análise do comportamento mensal de $k_{t}$ : os equinócios ocorrem em março e setembro, o solstício de inverno no hemisfério sul ocorre em junho e o de verão em dezembro e as estações climáticas para o hemisfério sul são definidas, aproximadamente conforme as datas do Quadro 12.

Quadro 12 - Estações climáticas

\begin{tabular}{|l|l|}
\hline Estação & Período \\
\hline Outono & 20 de março a 20 de junho \\
\hline Inverno & 21 de junho a 21 de setembro \\
\hline Primavera & 22 de setembro a 20 de dezembro \\
\hline Verão & 21 de dezembro a 19 de março \\
\hline
\end{tabular}

Fonte: Elaboração própria 
Figura 56 - Curvas de densidade de probabilidade de $k_{t}$ para os meses de Out/2015 a Jan/2016

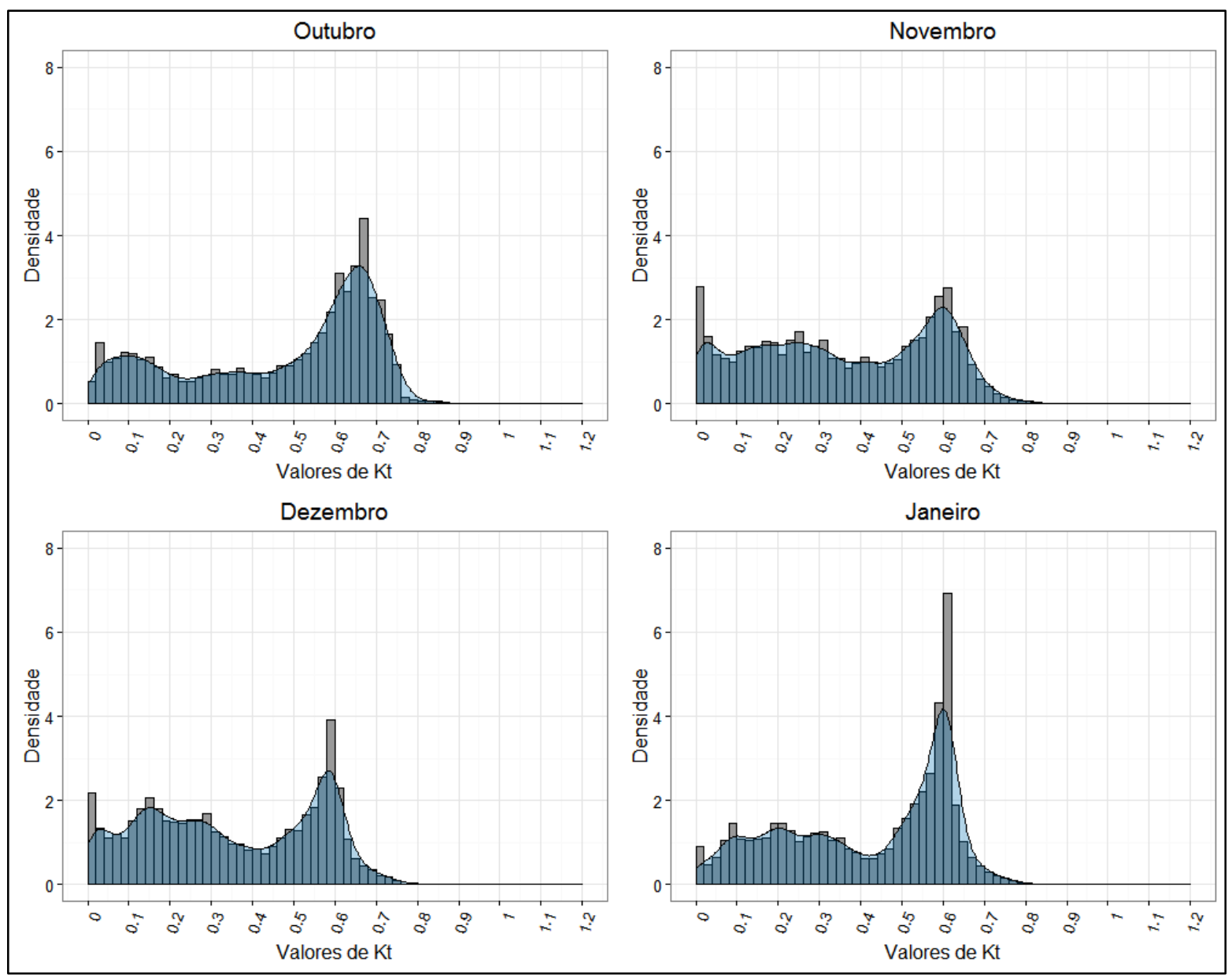

Fonte: Elaboração própria, 2016

Em outubro o pico de $k_{t}$ encontra-se no intervalo 0,66-0,68. Nos meses de novembro, dezembro e janeiro, o pico é deslocado à esquerda, permanecendo em torno de valores de $k_{t}$ de 0,58-0,62. Contudo, verifica-se um aumento significativo desse pico entre novembro e janeiro. Deste modo, pode-se concluir que, embora o pico de densidade corresponda a um valor menor de $k_{t}$ em janeiro, o recurso é mais estável nesse mês e menos estável em novembro.

Em fevereiro, em comparação com janeiro, o nível de estabilidade do recurso decai um pouco. Fevereiro apresenta um pico de densidade correspondente a valores de $k_{t}$ um pouco superiores aos encontrados em janeiro, contudo com densidade menor. A curva de fevereiro também apresenta relativa uniformidade de valores de densidade para $k_{t}$ entre 0,1 e 0,4 . 
Já abril e março apresentam os maiores valores de densidade para $k_{t}$ altos, sendo que em abril o pico se desloca ainda mais à esquerda em relação a março. Os dois meses apresentam altos valores de índices de irradiação, com grande estabilidade do recurso. Já em maio, o caráter bimodal é mais acentuado, de modo que o segundo pico apresente valores de $k_{t}$ em torno de 0,9 , e apresente inclusive densidades significativas para valores de irradiância superiores à irradiância extraterrestre. Contudo, dado o perfil mais distribuído da curva, conclui-se que, nesse mês, embora sejam alcançados altos valores da irradiação, o recurso se apresenta menos estável. Percebe-se, no geral, uma alteração, conforme o decorrer dos meses entre curvas com caráter bimodal acentuado, curvas de caráter unimodal acentuado e curvas sem definição de pico acentuadas. Esse perfil só poderia ser assegurado dispondo de alguns anos de série histórica de modo que as CDPs pudessem ser produzidas repetidas vezes para os mesmos meses de anos diferentes.

Figura 57 - Curvas de densidade de probabilidade de $k_{t}$ para os meses de Fev/2016 a Mai/2016

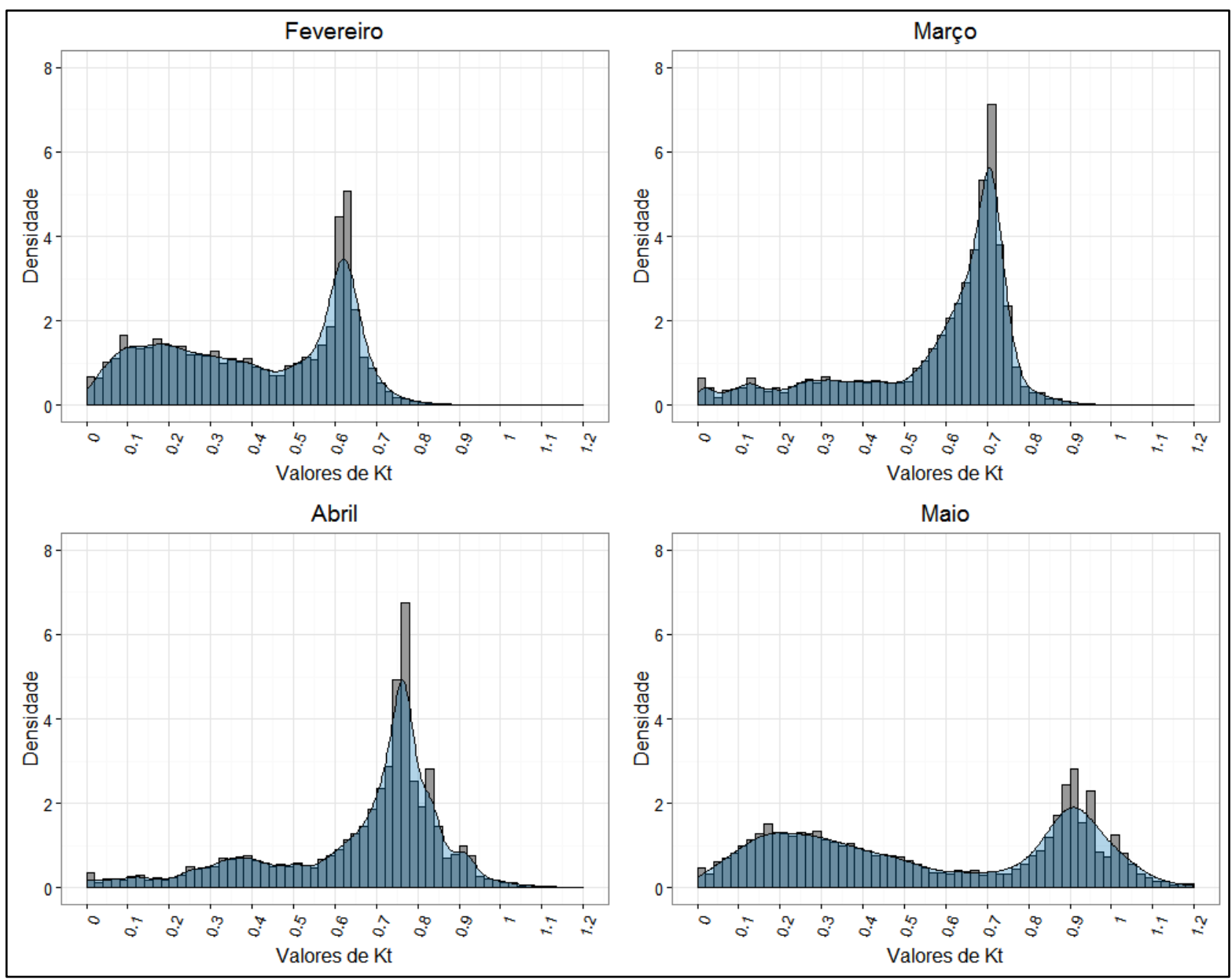

Fonte: Elaboração própria 
A caracterização das curvas é bastante variada de mês a mês, indicando a impossibilidade de construção de curvas características para cada estação climática. Em função da série histórica de período limitado, é possível a elaboração da CDP de duas estações climáticas. Os gráficos são apresentados nas Figuras 58 e 59.

A Figura 58 apresenta os gráficos dos três meses principais da Primavera e o gráfico referente a estação climática. O gráfico para a primavera foi elaborado utilizando-se os dados de 22 de setembro à 20 de dezembro.

A Figura 59 apresenta os gráficos dos três meses principais do Verão e o gráfico referente a estação climática. O gráfico para o verão contém os dados de 21 de dezembro à 19 de março.

Figura 58 - Curvas de densidade de probabilidade de $k_{t}$ para a Primavera

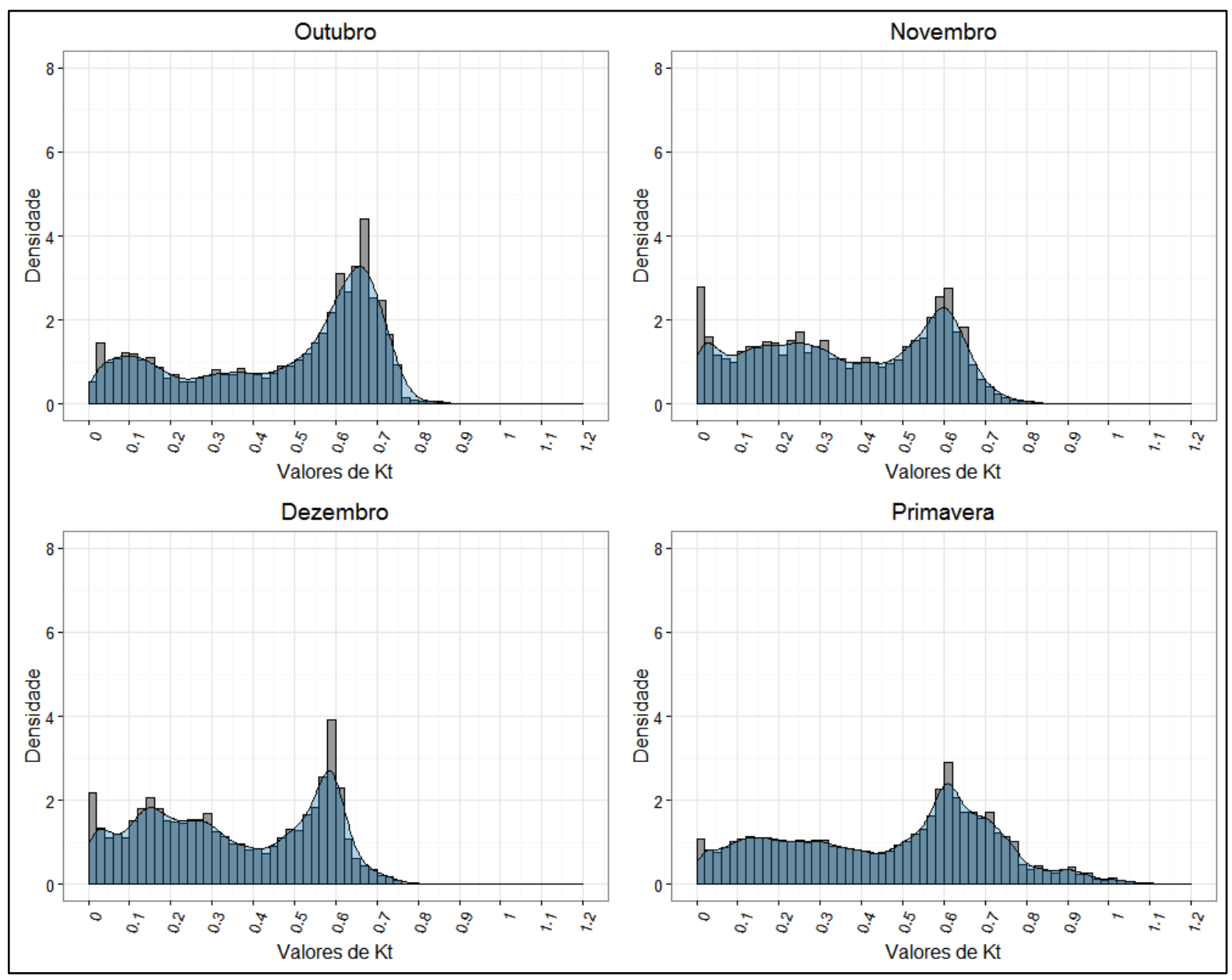

Fonte: Elaboração própria

Percebe-se que um gráfico único para cada estação do ano não caracteriza fielmente as probabilidades de cada mês que compõe a estação climática. Pela análise da Figura 58 
verifica-se que o caráter bimodal das curvas é mais acentuado em dezembro. Assim, a curva praticamente unimodal de $k_{t}$ em torno de 0,6 (primavera) não compreende o perfil principalmente de dezembro que também apresenta densidades relevantes de $k_{t}$ baixos.

Essa discrepância entre as curvas é ainda mais evidente para o verão. A curva referente à estação não evidencia o caráter unimodal definido em março e nem os altos valores de densidade de $k_{t}$ entre 0,6 e 07 .

Figura 59 - Curvas de densidade de probabilidade de $k_{t}$ para o Verão

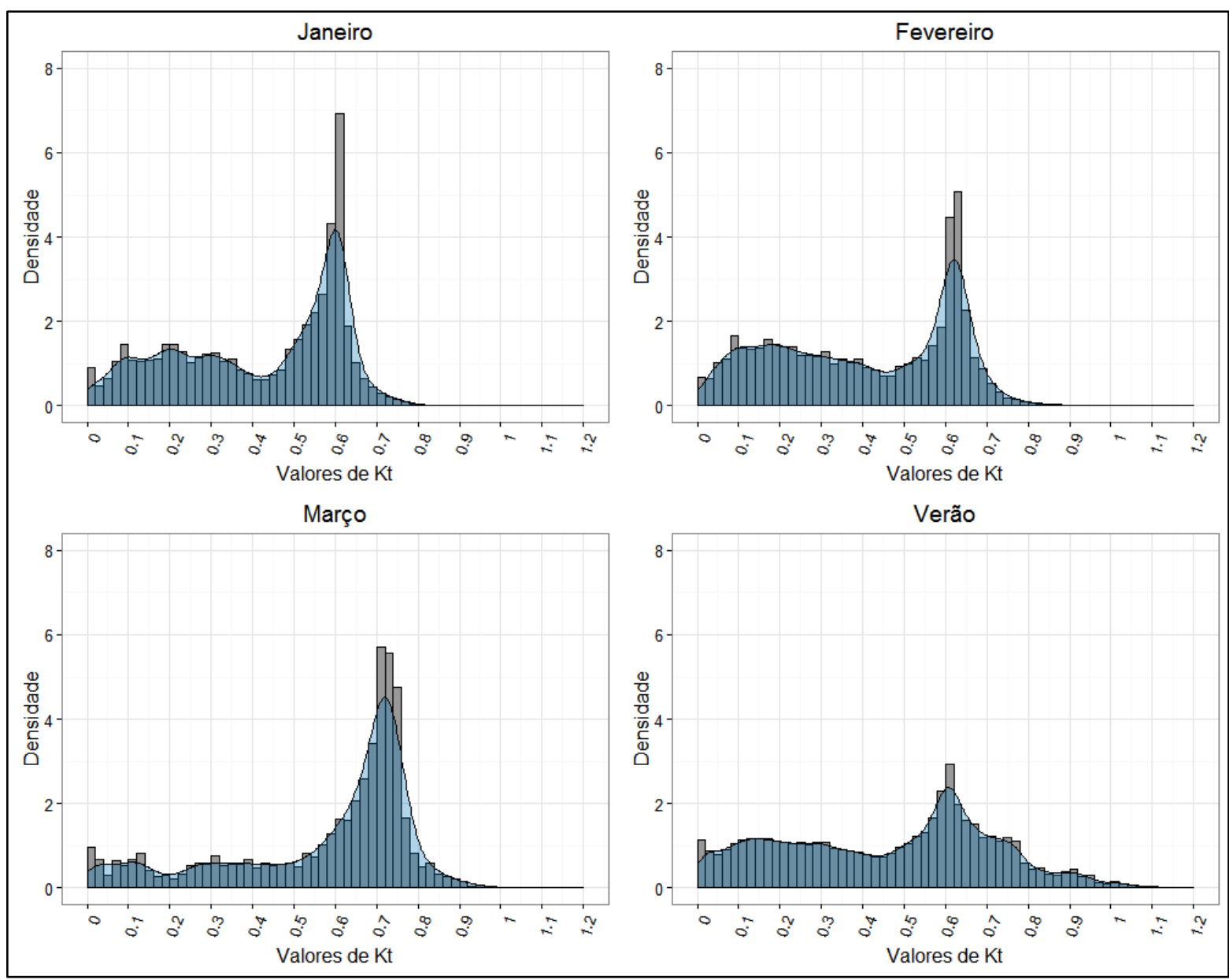

Fonte: Elaboração própria

Foram produzidas as CDPs para as diferentes massas de ar definidas na Tabela 18, para cada mês da amostra de dados. Os meses de novembro, março, abril não apresentaram um comportamento de alteração padrão do caráter bimodal em função das diferentes massas de ar. Os demais meses apresentaram, no geral, aumento do caráter bimodal conforme o aumento da massa de ar, contudo, o perfil das CDPs e das alterações conforme a massa de ar variam bastante de um mês para outro. Algumas curvas apresentaram caráter trimodal e outras 
unimodal, com grandes variações de densidade para intervalos subsequentes de $k_{t}$. Contudo, todas apresentaram redução da densidade de $k_{t}$ mais altos com o aumento da massa de ar. Com o intuito de apresentar a variação do comportamento das curvas mensais para diferentes massas de ar, o Apêndice 3 apresenta as CDPs de novembro, janeiro, abril e maio.

Essas curvas, se reproduzidas com dados de diversos anos de medição, poderiam apresentar um padrão de comportamento mais bem definido de modo que fosse possível a identificação de padrões probabilísticos.

\subsubsection{Método K-POP}

A aplicação do método K-POP foi realizada apenas para valores de $k_{t}$, devido à baixa quantidade de dados disponíveis de $k_{b}$ e $k_{d}$, ainda assim, a análise é comprometida, visto que os desenvolvedores da metodologia indicam que esta seja aplicada com no mínimo 1 ano de medições de médias de 1 minuto.

As etapas de cálculo foram:

A. Utilização de dados de minuto a minuto de $I G H$ cujo ângulo zenital correspondente fosse inferior à $75^{\circ}$.

B. Cálculo, para cada minuto, de cada dia, do índice $k_{t}$;

C. Arredondamento do valor de cada $k_{t}$ calculado para uma casa decimal.

D. Calculo da variação entre os $k_{t}$ subsequentes de cada dia.

E. Calculo da probabilidade da variação de $k_{t}$ subsequentes ser igual à zero para cada dia (denominada de probabilidade de persistência- $P O P_{D}$ ).

F. Calculo do $k_{t}$ médio de cada dia

Os valores de $k_{t}$ médio de cada dia a respectiva $P O P_{D}$ do dia foram plotados, conforme o gráfico da Figura 60. 
Figura 60 - Aplicação da metodologia K-POP

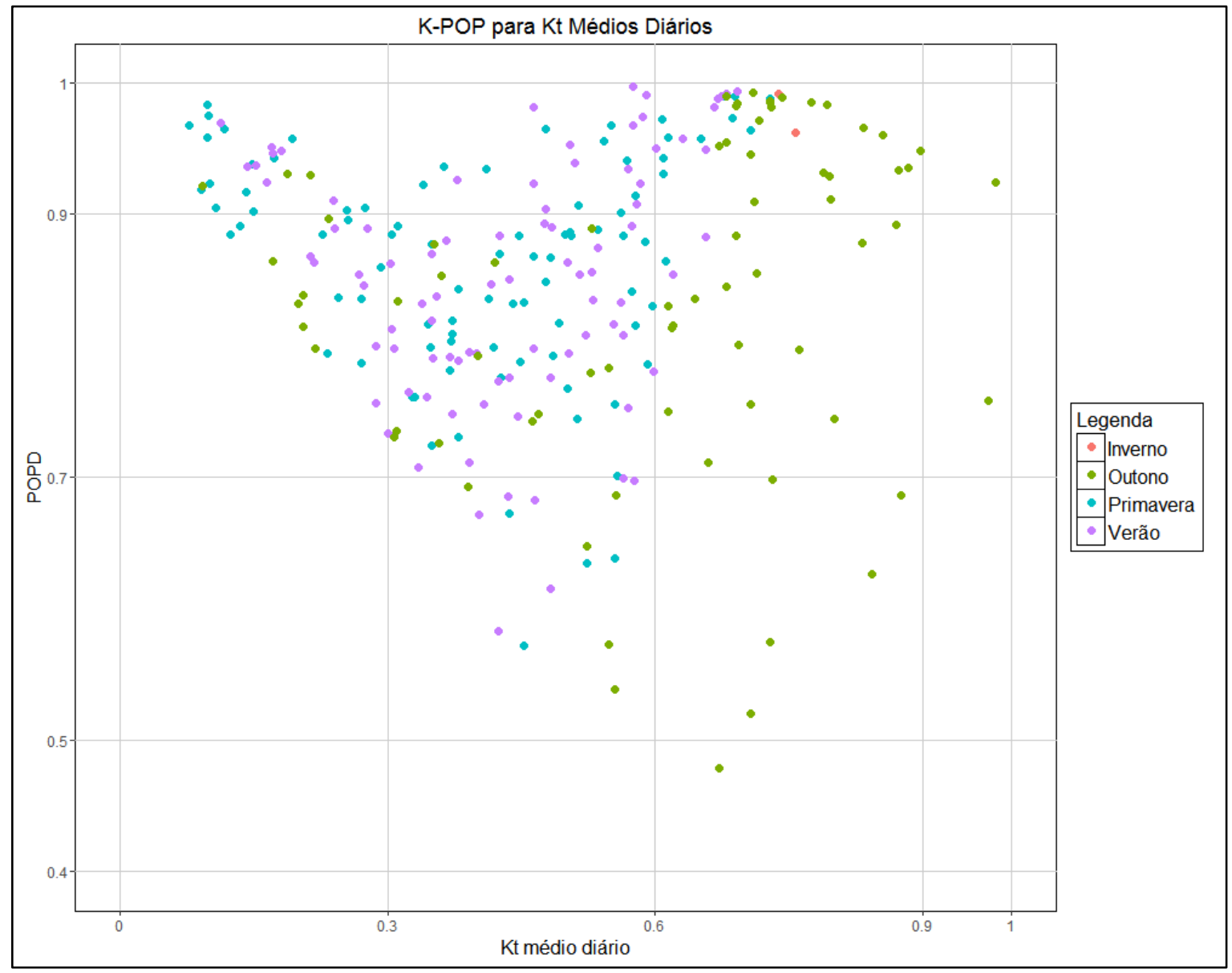

Fonte: Elaboração própria

Acrescentou-se no gráfico uma informação não prevista na metodologia inicial, que é a estação climática referente à cada ponto do plotado. Contudo, em virtude da falta de dados do período de inverno e do período de outono, tal análise fica prejudicada e incompleta.

Conforme a definição de classes apresentadas por KANG e TAM (2013), conclui-se que as classes que tiveram as maiores incidências de dados foram a 5 e a 1 , seguidas pelas classes 6, 3 e 2. O Quadro 13 apresenta a caracterização do ano para a radiação solar na região.

Quadro 13 - Resultado do métdo K-POP para ES Usina Porto Primavera

\begin{tabular}{|l|l|l|}
\hline Dias do ano & Classe & Descrição \\
\hline $30,1 \%$ & Indefinida & $\begin{array}{l}\text { Não foi possível realizar a caracterização desta parcela dos dias } \\
\text { do ano em função da inexistência de série histórica. }\end{array}$ \\
\hline $26,6 \%$ & 5 & $\begin{array}{l}\text { Média quantidade e média qualidade; parcialmente coberto por } \\
\text { nuvens, condição de céu variável ao longo do dia. }\end{array}$ \\
\hline
\end{tabular}




\begin{tabular}{|l|l|l|}
\hline Dias do ano & Classe & $\begin{array}{l}\text { Descrição } \\
\text { Grande quantidade e muita qualidade; condição de céu claro e } \\
\text { estável para quase o dia todo. }\end{array}$ \\
\hline $7,3 \%$ & 1 & $\begin{array}{l}\text { Pequena quantidade e muita qualidade; coberto por nuvens, } \\
\text { condição de céu relativamente estável para a maior parte do dia. }\end{array}$ \\
\hline $6,3 \%$ & 6 & $\begin{array}{l}\text { Pequena quantidade e média qualidade; nebulosidade e } \\
\text { condições do céu variando ao longo do dia. }\end{array}$ \\
\hline $6,3 \%$ & 2 & $\begin{array}{l}\text { Média quantidade e muita qualidade; parcialmente coberto por } \\
\text { nuvens, condição de céu relativamente estável para a maior } \\
\text { parte do dia. } \\
\text { Grande quantidade e média qualidade; condição de céu claro, } \\
\text { porém variável ao longo do dia. }\end{array}$ \\
\hline $4,2 \%$ & 4 & $\begin{array}{l}\text { Média quantidade e pouca qualidade; vários graus de } \\
\text { nebulosidade, com condições do céu variando } \\
\text { significativamente na maior parte do dia. }\end{array}$ \\
\hline $1,4 \%$ & 8 & $\begin{array}{l}\text { Grande quantidade e pouca qualidade; parcialmente ensolarado, } \\
\text { com condições do céu variando significativamente na maior } \\
\text { parte do dia. } \\
\text { Muita pouca qualidade, vários graus de nebulosidade e altos } \\
\text { níveis de flutuação ao longo do dia todo. }\end{array}$ \\
\hline $0,3 \%$ & 10 & \\
\hline
\end{tabular}

Fonte: Elaboração própria

No geral, o recurso na região pode ser considerado de média a grande qualidade, ou seja, com baixas flutuações ao longo de dia, e de média a grande quantidade. As variações de curtíssimo prazo (ao longo do dia) prejudicam o fator de eficiência de geração fotovoltaica, de modo que é mais importante a disponibilidade de um recurso estável, em quantidade média, do que um recurso de alta variabilidade em quantidade alta. A análise do restante do período de outono e do período de inverno podem alterar significantemente essa caracterização, portanto, essa análise não pode ser considerada definitiva.

A consistência dessa análise e o seu aprofundamento poderiam ser obtidos por meio da aplicação da metodologia aos índices $k_{b}$ se houvesse série histórica suficiente para tal.

\subsubsection{Variação de Medições Subsequentes}

Com o intuito de avaliar numericamente o grau de variabilidade da disponibilidade do recurso ao longo do dia, foi calculada, para cada dia da amostra de dados a variação em $\mathrm{W} / \mathrm{m}^{2}$ de minuto a minuto. O resultado é apresentado do gráfico de frequência relativa da Figura 61. 
Figura 61 - Variabilidade do recurso: taxas menores

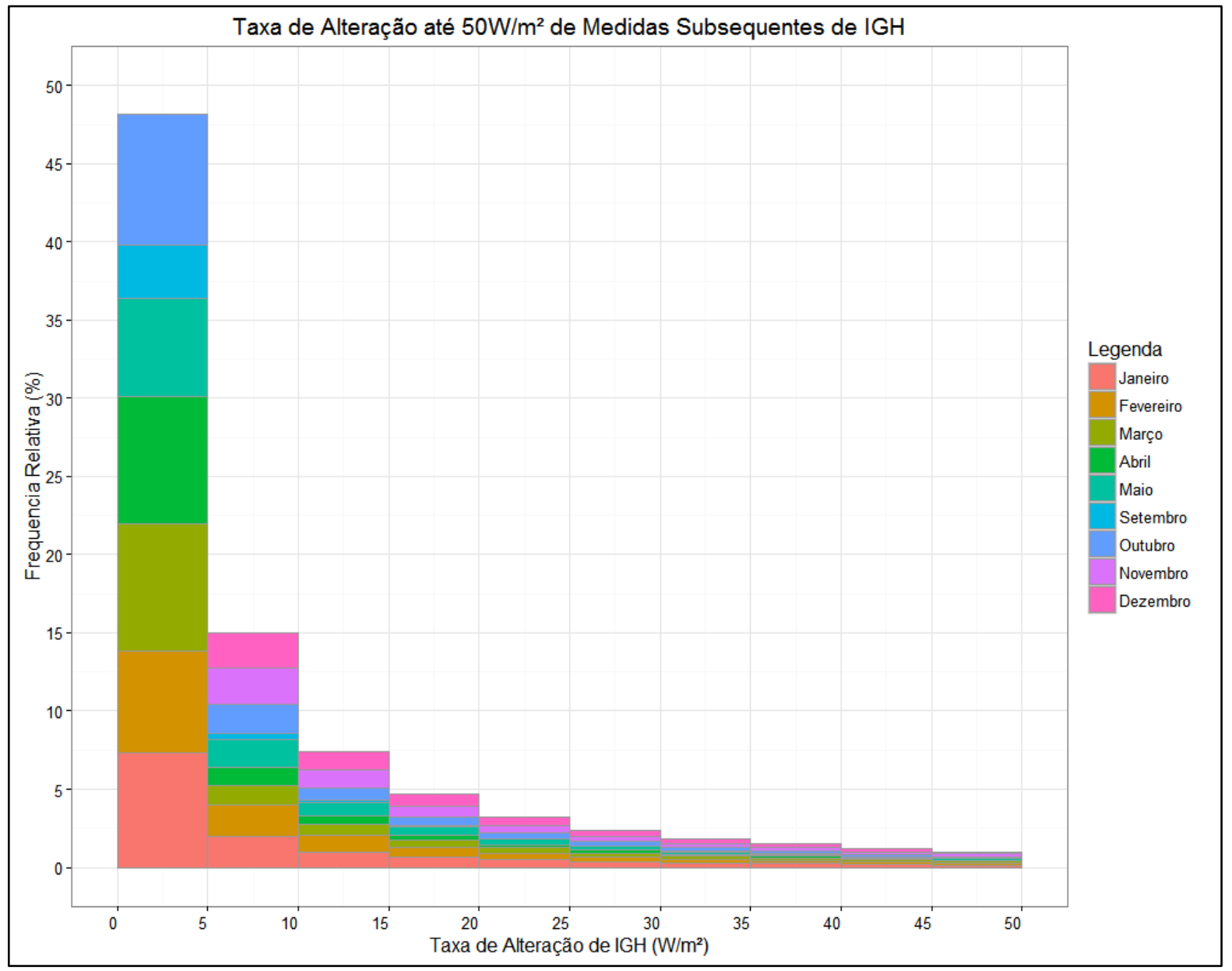

Fonte: Elaboração própria

Menos de $50 \%$ das variações são de até $5 \mathrm{~W} / \mathrm{m}^{2}$. Cerca de 30 variações configuram valores acima dos $700 \mathrm{~W} / \mathrm{m}^{2}$. Essas variações são bastante elevadas e deveriam ser analisadas em um procedimento de análise de qualidade dos dados. Nesses casos, considerando a existência de séries históricas de $I D H$ e IDN, seria possível verificar qual a variação nestes intervalos de minutos para essas componentes, identificando se há coerência ou não da variação nos três sensores. Ou, no caso de dois piranômetros medindo simultaneamente $I G H$, seria possível, por meio do procedimento de tratamento de dados averiguar se as mesmas alterações acontecem nos dois sensores.

O estudo realizado em KOUMPAROU et al. (2015) apresenta uma maior percentagem de dados variando entre 1 e $5 \mathrm{~W} / \mathrm{m}^{2}$ para a França e para Chipre, contudo, como a base de dados utilizada neste estudo não apresenta o período mínimo de 1 ano de medições, não é possível afirmar se o comportamento do recurso medido pela ESUPP é mais estável ou não do que aquele apresentado em Chipre ou na França. 
De modo a perceber as maiores variações em detalhes, foi produzido um segundo histograma (Figura 62), em diferente escala com as variações de medições subsequentes entre $50 \mathrm{~W} / \mathrm{m}^{2}$ e $900 \mathrm{~W} / \mathrm{m}^{2}$, o maior valor de alteração subsequente encontrado foi de $870 \mathrm{~W} / \mathrm{m}^{2}$.

Figura 62 - Variabilidade do recurso: taxas maiores

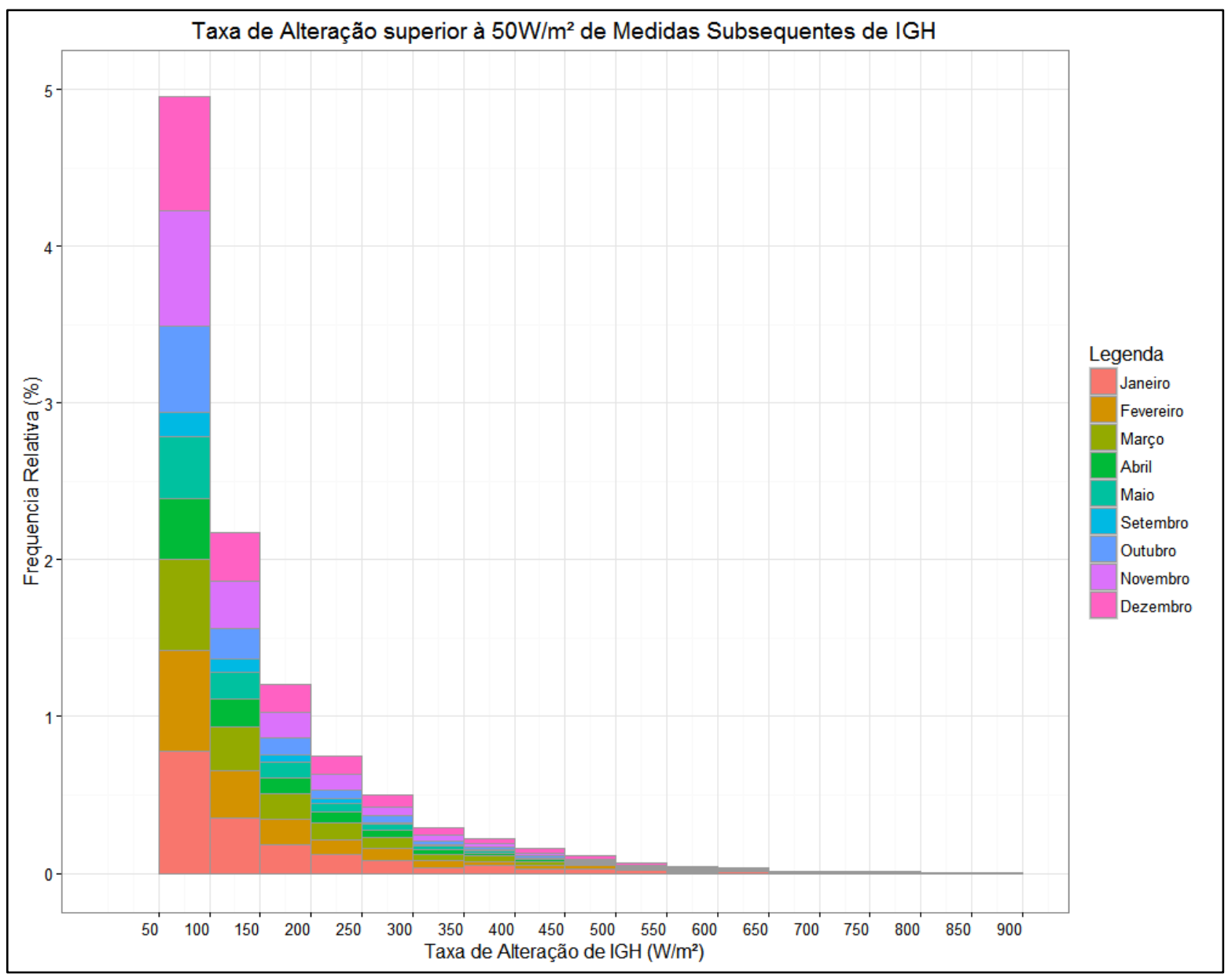

Fonte: Elaboração própria

As maiores taxas de alterações (Figura 62), assim como as menores (Figura 61) se distribuem de maneira relativamente homogênea entre os meses da série histórica. É importante relembrar que o mês de setembro possui apenas 10 dias de série histórica, por isso, a menor representatividade desse mês nas barras do histograma. Contudo, destaca-se que os meses de abril, março e outubro representam a quantidade mais significativa de baixas variações (de 0 à $5 \mathrm{~W} / \mathrm{m}^{2}$ ). Analisando as CDPs desses meses (Figuras 57 e 58) verifica-se que abril e março possuem alta densidade de valores de $k_{t}$, isso indica que o recurso nesses meses é de alta disponibilidade, bastante estável e com flutuações baixas. Já os meses de novembro, dezembro e janeiro são os mais representativos na verificação de variações entre 50 e 100 
$\mathrm{W} / \mathrm{m}^{2}$. Analisando as CDPs desses meses (Figura 56) verifica-se que novembro e dezembro possuem densidades de $k_{t}$ altos e baixos relativamente homogêneas, assim, conclui-se que, nesses meses, o recurso possui menor disponibilidade, sendo menos estável e com altas flutuações.

Essa análise permite indicar que a eficiência de geração, que não depende apenas da quantia de energia disponível, é maior na região para os meses de abril e março do que para os meses de novembro e dezembro.

\subsection{GEOANÁLISE DO RECURSO (ESUPP)}

A geoanálise configura o conhecimento do recurso característico daquela região para um ano completo, de modo a formar o ano característico de recurso em termos de quantidade e em termos de correlações com as demais variáveis climatológicas. Como a série histórica disponível é inferior a um ano de medições, não foi possível determinar o montante médio anual de energia disponível, contudo, buscou-se a caracterização do montante mensal de energia, uma caracterização da disponibilidade média ao longo do dia e a identificação de possíveis variáveis climáticas balizadoras na região.

\subsubsection{Variável Climática Balizadora e Modelos Empíricos}

Foram calculados os montantes diários de irradiância global horizontal, a temperatura média diária, a pressão atmosférica média diária, a umidade relativa média diária e o total de precipitação diário. Não foram considerados dados de nenhuma dessas variáveis para ângulos zenitais superiores a $75^{\circ}$. Essa premissa parte do princípio de que, como ao longo da noite não há valores positivos de radiação, a consideração das demais variáveis climáticas ao longo do período noturno poderia indicar uma falsa correlação entre as variáveis.

$\mathrm{Na}$ análise promovida na seção 4.5 foram utilizadas médias mensais dessas variáveis. Como a série histórica disponível possui um período bastante limitado, os cálculos foram realizados para médias e montantes diários de cada variável. Os gráficos das Figuras 63 e 64 apresentam as curvas lado a lado de cada variável com IGH e apresentam o coeficiente de Pearson calculado entre as duas curvas apresentadas em cada figura.

O cálculo do montante diário de irradiância global horizontal se deu somando todos os valores da série histórica referentes a ângulo zenital inferior $75^{\circ}$. Como cada medição por minuto representa a média de 60 registros, o montante da soma foi multiplicado por 60 e dividido por $10^{6}$. 
Figura 63 - Correlação IGH x Umidade Relativa e IGH x Temperatura

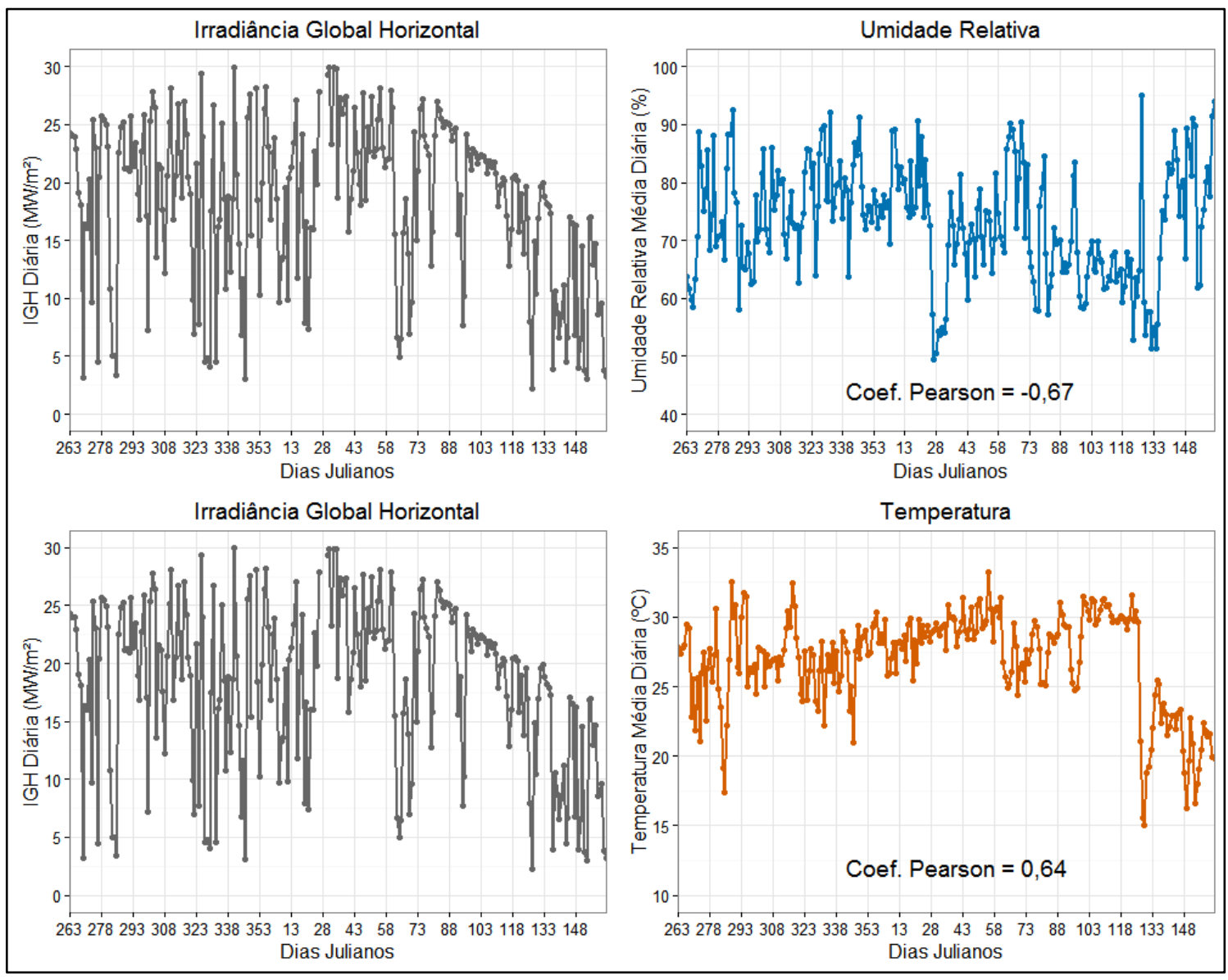

Fonte: Elaboração própria

Nenhuma das variáveis apresentou correlação forte com o comportamento da série de $I G H$. A série de umidade relativa e temperatura apresentaram coeficientes absolutos próximos e que configuram relação moderada negativa no caso da umidade relativa e moderada positiva no caso da série de temperatura. 
Figura 64 - Correlação IGH x Pressão Atmosférica e IGH x Precipitação

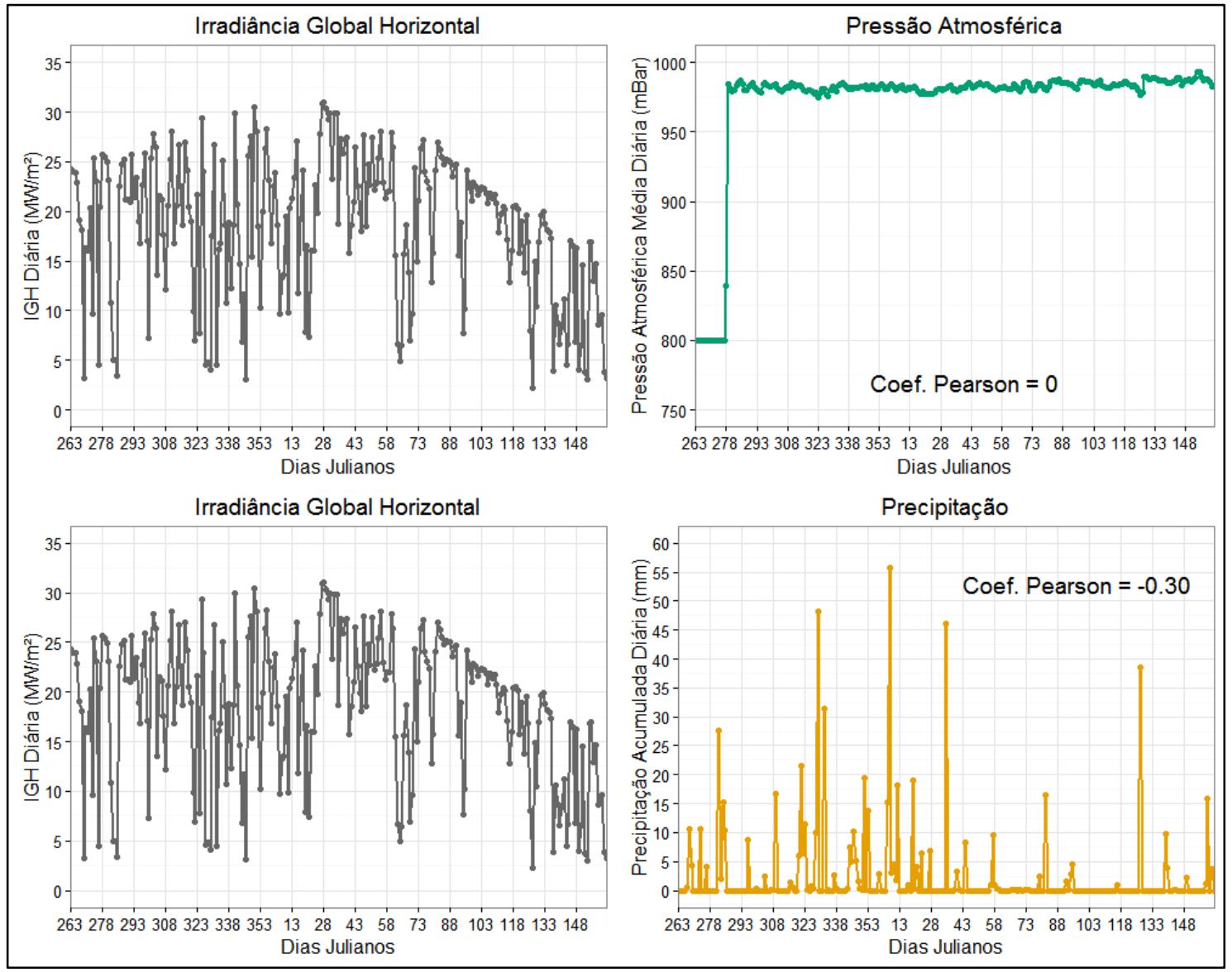

Fonte: Elaboração própria

A correlação entre as séries de $I G H$ e pressão atmosférica se apresentou como inexistente. Para verificação, foram desconsiderados os valores atípicos em relação à série encontrados entre os dias julianos 263 e 278 e o coeficiente foi recalculado, apresentando dessa vez uma relação muito fraca negativa (coef. Pearson $=-0,1$ ).

A análise de variáveis climáticas balizadoras produzida na seção 4.5 indicou relações entre insolação e outras variáveis climáticas em hidrelétricas existentes. Nessa análise as relações mais fortes encontradas foram entre insolação e evaporação, insolação e umidade relativa e insolação e nebulosidade.

A maior quantidade de modelos empíricos de estimativa de radiação apresentados na seção 4.3 indicam a utilização principalmente de dados de insolação e temperatura. Dada a inexistência de dados de isolação, nebulosidade e evaporação; os fracos coeficientes de correlação encontrados entre as curvas de $I G H$ e temperatura média; a baixa disponibilidade de dados (inferior a um ano) e a limitação de tempo para o desenvolvimento dessa pesquisa, não foram testados modelos empíricos de estimativa de irradiação diária média para a região. 
Em função da disponibilidade restrita de dados de $I D H$ e $I D N$ e a limitação de tempo para o desenvolvimento dessa pesquisa também não foram testados modelos de decomposição para estimativa diária média de irradiação difusa ou direta, contudo, o padrão de comportamento de ktc pode ser considerado uma boa variável de entrada para esses modelos.

\subsubsection{Energia Média Disponível}

Com o intuito de apresentar a quantidade média de energia disponível mensal, foram calculados os valores médios horários de irradiação para cada dia de cada mês e depois foi calculada a média mensal de cada hora, em $\mathrm{Wh} / \mathrm{m}^{2}$. Os resultados são apresentados nos gráficos da Figura 65.

Figura 65 - Quantidade média de energia disponível por mês- dia característico de cada mês

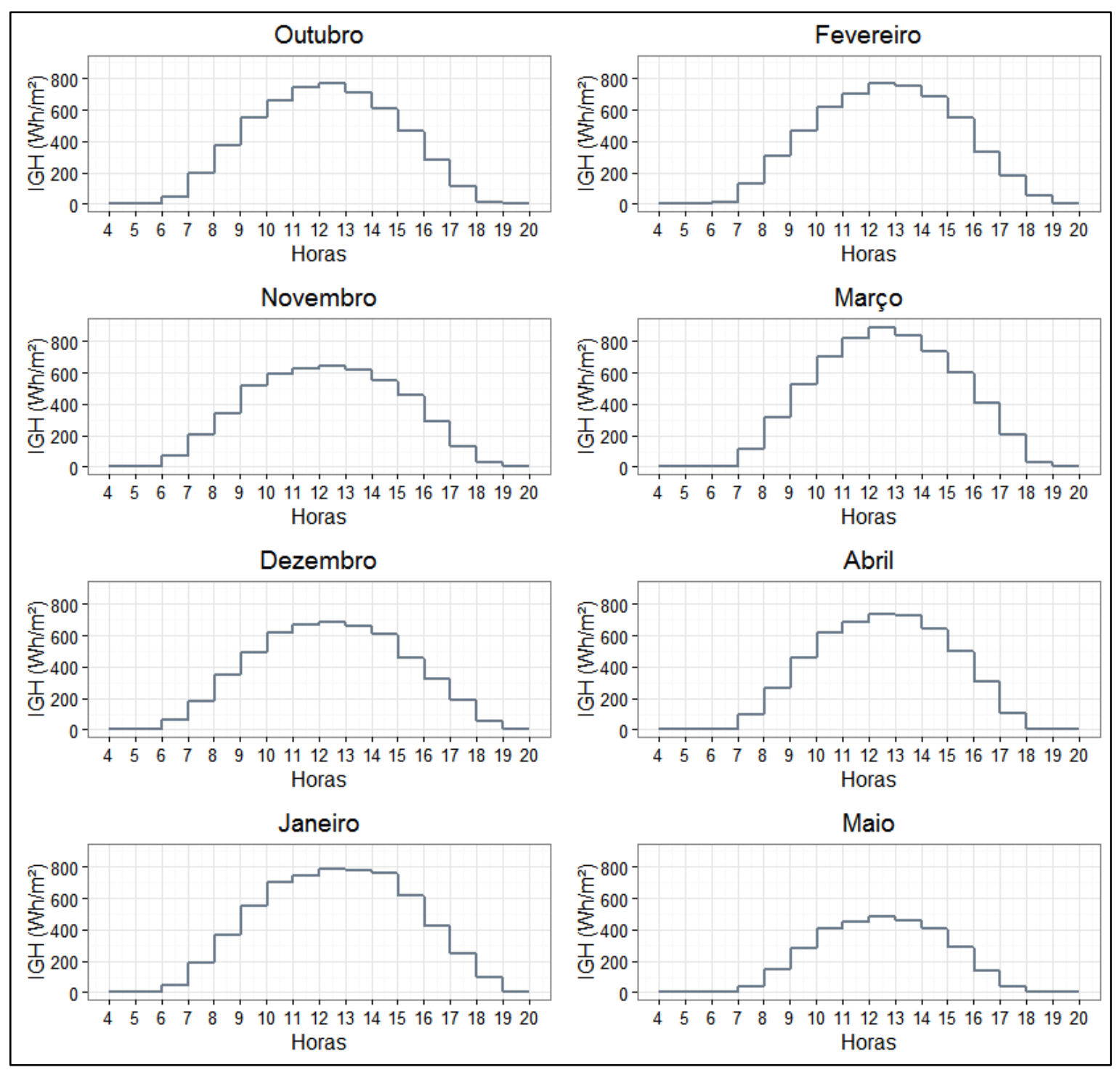

Fonte: Elaboração própria 
Foram produzidas curvas para os meses com série histórica completa, sendo estes: outubro, novembro, dezembro, janeiro, fevereiro, março, abril e maio. Para a composição desses gráficos foi utilizada toda a série histórica de dados de $I G H$ e não apenas aqueles que compreendem ângulo zenital inferior à $75^{\circ}$, de modo que seja possível a percepção das horas médias de nascer e pôr do sol de cada mês.

A Tabela 19 apresenta os valores os valores médios diários para cada mês, ou seja, a integral das curvas da Figura 65 e apresenta os valores do montante mensal de energia.

Tabela 19 - Consolidação do montante de energia disponível

\begin{tabular}{lcc}
\hline Mês & $\begin{array}{l}\text { Montante Mensal } \\
\left(\mathbf{k W h} / \mathbf{m}^{2}\right)\end{array}$ & $\begin{array}{l}\text { Montante Médio } \\
\text { Diário }\left(\mathbf{k W h} / \mathbf{m}^{\mathbf{2}}\right)\end{array}$ \\
\hline Janeiro & 195,45 & 6,30 \\
\hline Fevereiro & 161,10 & 5,55 \\
\hline Março & 192,15 & 6,20 \\
\hline Abril & 154,40 & 5,15 \\
\hline Maio & 97,18 & 3,14 \\
\hline Outubro & 171,66 & 5,54 \\
\hline Novembro & 152,42 & 5,08 \\
\hline Dezembro & 164,41 & 5,33 \\
\hline
\end{tabular}

Fonte: Elaboração própria

Comparando as curvas da Figura $65 \mathrm{com}$ as das Figuras 56 e 57 percebe-se que, por mais que maio apresente valores de densidade significativos para $k_{t}$ próximos ou superiores à 1, esse é o mês que apresenta a menor quantidade de energia total disponível. Verificando ainda a Tabela 19, conclui-se que o recurso se apresenta mais estável e em grande quantidade no mês de março, lembrando ainda que nesse mês, as variações de medidas subsequentes entre 1 e $5 \mathrm{~W} / \mathrm{m}^{2}$ é bastante significativa. Embora janeiro apresente uma disponibilidade de energia levemente superior a março é importante lembrar que nesse mês, as densidades para $k_{t}$ mais baixos é bastante distribuída e que a quantidade de variações de medições subsequentes superiores à $50 \mathrm{~W} / \mathrm{m}^{2}$ também é representativa. Logo, pela análise dos diferentes aspectos da caracterização fica claro que as análises devem ser realizadas tanto no aspecto temporal quanto geográfico, já que a análise de apenas uma vertente pode induzir resultados equivocados.

Diante da escassez de dados e da não completude de um ano de medições, buscou-se a validação dos cálculos produzidos por meio de dados de outra ES, dessa vez instalada na cidade de São Paulo, sob a influência de outro microclima e altos níveis de poluição. A 
escolha dessa estação se deu pela maior série histórica disponível e pela existência de uma rotina de manutenção, limpeza e verificação da calibração e bom funcionamento dos equipamentos.

Nas seções seguintes os mesmos cálculos realizados para a ESUPP serão reproduzidos para os dados dessa estação.

\subsection{CARACTERIZAÇÃO DA ES POLI ELÉTRICA}

\subsubsection{Localização}

A ES está localizada no Município de São Paulo- SP, Brasil, no prédio de Engenharia Elétrica da Escola Politécnica da USP. Conforme as especificações do Quadro 14

Quadro 14 - Localização da ES Poli Elétrica

\begin{tabular}{|c|c|c|c|c|}
\hline Nome & \multicolumn{4}{|c|}{ Estação Solarimétrica Poli Elétrica (ESPEL) } \\
\hline Município & \multicolumn{4}{|c|}{ São Paulo } \\
\hline Estado & \multicolumn{4}{|l|}{ São Paulo } \\
\hline Coordenadas Geográficas & Latitude & $-23,555^{\circ}$ & Longitude & $-46,731^{\circ}$ \\
\hline Altitude & \multicolumn{4}{|l|}{756 metros } \\
\hline Hora (UTC) & \multicolumn{4}{|l|}{-3} \\
\hline
\end{tabular}

Fonte: Elaboração própria

A ESPEL está localizada em uma área fechada sobre a laje que abriga uma das caixas d'água do prédio da Engenharia Elétrica da Escola Politécnica da USP, sob a influência: do albedo do concreto do chão do local, do albedo da superfície da grade de proteção e do albedo do horizonte preenchido por árvores presentes nos estacionamentos dos arredores.

\subsubsection{Sensores e Classificação}

Os equipamentos instalados são descritos no Quadro 15.

Quadro 15 - Caracterização dos equipamentos da ES Poli Elétrica

\begin{tabular}{|l|l|}
\hline \multicolumn{1}{|c|}{ Equipamento } & \multicolumn{1}{|c|}{ Marca/Modelo } \\
\hline Anemômetro & $\begin{array}{l}\text { Vector Instruments } \\
\text { A100LL-L34 }\end{array}$ \\
\hline Anemoscópio & $\begin{array}{l}\text { Vector Instruments } \\
\text { W200P-L34 }\end{array}$ \\
\hline
\end{tabular}

(continua) 


\begin{tabular}{|l|l|}
\hline \multicolumn{1}{|c|}{ Equipamento } & \multicolumn{1}{c|}{ Marca/Modelo } \\
\hline Termo - higrômetro & \multicolumn{1}{c|}{ Vaisala/ HMP155A-L12 } \\
\hline Barômetro & Young/61302V \\
\hline Pluviômetro & Dual Base \\
\hline Piranômetro -IGH & Kipp\&Zonen/CMP11 \\
\hline Piranômetro - IDH & Kipp\&Zonen/CMP11 \\
\hline Pireliômetro & Kipp\&Zonen/CHP1 \\
\hline
\end{tabular}

Fonte: Elaboração própria

A ES também conta com um datalogger, um conjunto de placas fotovoltaicas e conjunto de baterias para alimentação da estação. Os sensores piranômetros da estação obedecem a classificação secondary standard da ISO 9060, enquanto o pireliômetro obedece a classificação first class.

A ES começou a registrar dados no início do mês de novembro de 2014, contudo os dados só foram estabilizados no dia 23 de dezembro de 2014. No dia 30 de janeiro de 2015 os cabos de conexão dos piranômetros e pireliômetro se enrolaram em torno do rastreador solar causando o rompimento dos mesmos, de modo que a estação tenha permanecido sem registro de dados de irradiância até o dia 24 de março de 2015, quando o problema foi resolvido. Contudo, no processo de reinstalação dos equipamentos, o equipamento que ajusta o posicionamento do rastreador solar (sunsensor) foi instalado invertido em relação ao eixo horizontal. Esse sensor foi retirado no dia 27 de abril, de modo que o posicionamento do rastreador solar ficou, até o dia 20 de maio de 2015 a encargo apenas do sistema de GPS. Com isso, foram percebidos visualmente desalinhamentos da esfera de sombreamento e do pireliômetro para as primeiras horas da manhã e ultimas horas do dia durante o período de 24 de março à 27 de abril de 2015, conforme o registro fotográfico obtido às 6:50 da manhã do dia 26 de março de 2015 (Figura 66). 
Figura 66 - Registro fotográfico da esfera de sombreamento desalinhada

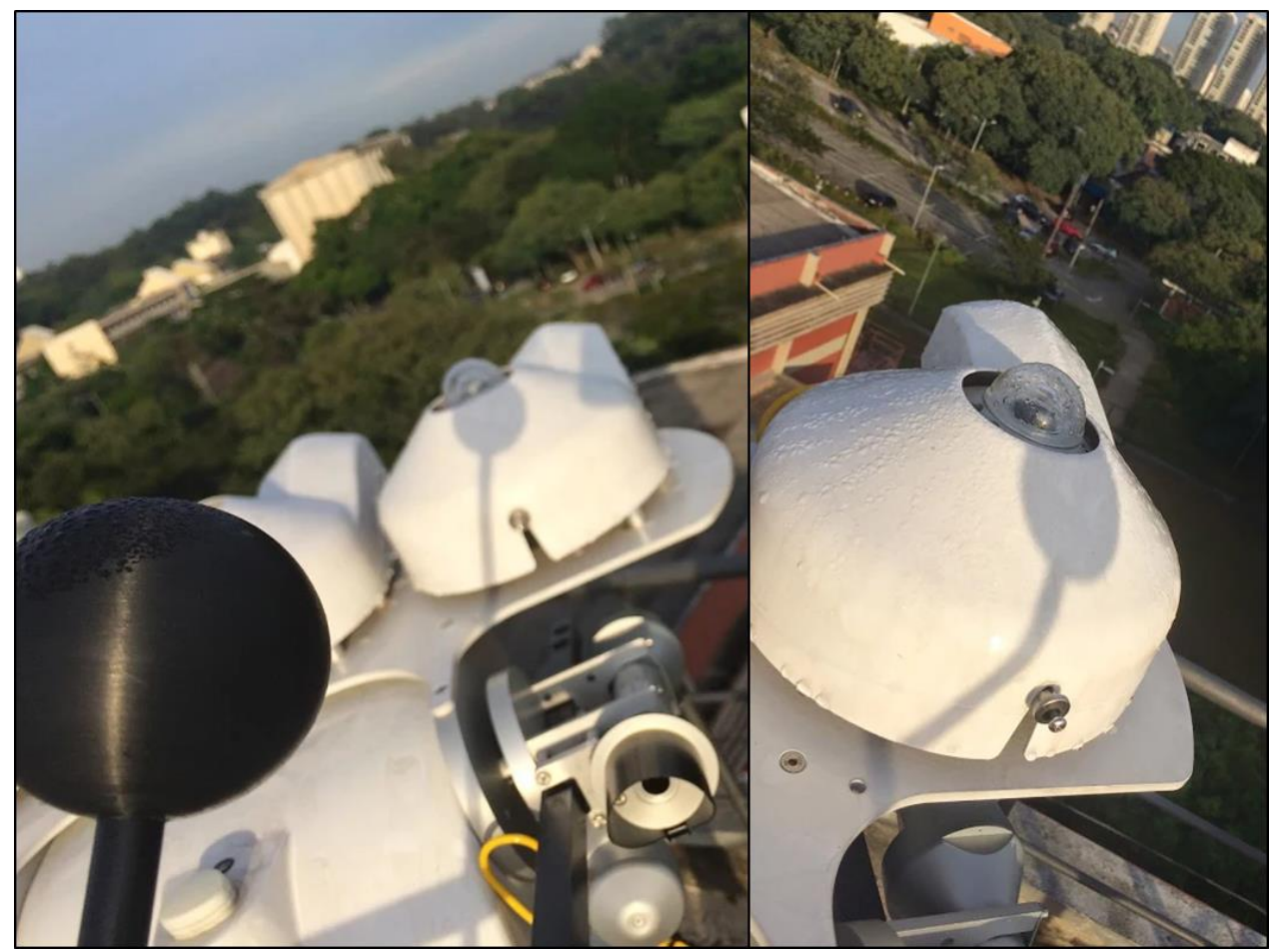

Fonte: Arquivo próprio

No dia 2 de outubro de 2015 houveram problemas com a conexão do datalogger resultando no armazenamento de dados no cartão de memória até o dia 17 de novembro de 2015, data na qual o cartão de memória parou de funcionar, ocasionando a falta do registro de dados até o dia 2 de janeiro de 2016, resultando no fechamento da série histórica trabalhada nesse estudo em 30 de junho de 2016.

\subsection{ANÁLISE E TRATAMENTO DOS DADOS DA ESPEL}

Os sensores da estação são limpos semanalmente e é durante o processo de limpeza que a verificação de alinhamento dos sensores é realizada. Os dados são disponibilizados online a partir do software da empresa responsável pela instalação da estação. Para acesso é necessário um cadastro e senha. Os dados disponíveis são brutos, sendo que não há nenhum procedimento de filtro ou composição/substituição de dados faltantes/errados.

Os dados brutos são disponibilizados em arquivos txt sem padronização de tempo (diário ou mensal) com o registro de minuto a minuto das variáveis climáticas e radiométricas. Os dados de controle também são disponibilizados de minuto a minuto, contudo em arquivo separado. A data referente a cada dado é a primeira informação disponibilizada, estando no 
formato: Ano (AAAA) Mês (MM) Dia (DD-) Hora (HH:) Minuto (MM:) Segundo (SS), considerando o fuso horário UTC-3 e desconsiderando o horário de verão.

Assim, definiu-se o download dos dados e disponibilização no servidor seeds.com para acesso dos pesquisadores do grupo. Os dados são renomeados conforme relatório de registro de dados do Apêndice 1.

Definiu-se, enquanto análise de qualidade, as mesmas etapas realizadas para os dados da ESUPP.

O principal objetivo em se utilizar os dados dessa estação é a aquisição de um mínimo completo de 1 ano de medições e alguns meses adicionais nos quais fosse possível replicar os cálculos mensais, validando ou não a padronização dos resultados para um mesmo mês, de anos diferentes. Contudo, ao analisar detalhadamente a série histórica, verificou-se que não há nenhum dezembro com dados disponíveis, apenas dados de 23 a 31 de dezembro de 2014. O mesmo é verificado para metade do mês de novembro. Assim definiu-se o uso dos dados de dezembro de 2014 em 2015 e os restante dos dados de dezembro e novembro foram estimados conforme detalhado no Quadro 16. Assim, o período total de dados considerados nesse estudo foi de abril de 2015 a março de 2016, adotando os meses de janeiro de 2015, abril de 2016, maio de 2016 e junho de 2016 como meses auxiliares, ou seja, meses completos utilizados para a validação dos cálculos mensais.

Os aspectos definidos para a análise de qualidade foram replicados, sendo estes:

I. Verificação de linhas de registros faltantes

II. Verificação de linhas de registros repetidas

III. Verificação de dados faltantes

IV. Verificação de dados zerados

V. Verificação de dados negativos

VI. Verificação de dados maiores do que a irradiância no topo da atmosfera (TOA)

VII. Análise de $k_{t c}$

O Quadro 16 apresenta os principais resultados obtidos pela análise de qualidade que foi realizada para os períodos de abril de 2015 a março de 2016, janeiro de 2015, e abril a junho de 2016. Com o intuito de simplificar o entendimento dos resultados apresentados, o período de abril de 2015 a março de 2016 fica então denominado como série anual, enquanto que o conjunto dos meses de janeiro de 2015, abril de 2016, maio de 2016 e junho de 2016 
fica denominado como série auxiliar, e o conjunto desses dois períodos fica denominada como série completa.

Quadro 16 - Análise de qualidade e tratamento de dados da ES Poli Elétrica

\begin{tabular}{|c|c|}
\hline Etapa & Resultados \\
\hline I & $\begin{array}{l}\text { lguns dos minutos ao longo da série histórica não foram registrados. Essa foi a } \\
\text { nica etapa realizada para a série histórica completa, e não apenas para dados cujo } \\
\text { ngulo zenital fosse menor ou igual a } 75^{\circ} \text {. Para essa etapa foi considerada a série } \\
\text { e dados completa, ou seja, de dezembro de } 2014 \text { a junho de } 2016 \text {. Do total de } \\
76960 \text { linhas de registro que deveriam existir foi identificada a falta de } 95.526 \\
\text { nhas, compreendendo o período de novembro e dezembros de dados faltantes e } \\
\text { utras falhas pontuais. Essas linhas foram adicionadas na série histórica. Os } \\
\text { alores dos dados foram colocados como NA. }\end{array}$ \\
\hline II & $\begin{array}{l}\text { oram encontradas } 11 \text { linhas com registros de dados repetidas, essas linhas foram } \\
\text { xcluídas da série histórica. }\end{array}$ \\
\hline III & $\begin{array}{l}\text { Foram encontradas } 98.852 \text { linhas com valores de IGH, IDN ou IDH como NA. } \\
\text { Todos eles foram preenchidos com valores estimados. O critério utilizado foi por } \\
\text { meio de média simples dos valores anteriores com os posteriores do período de } \\
\text { dados faltantes. Os maiores períodos sem dados foi o mês inteiro de dezembro de } \\
2015 \text {, os } 13 \text { últimos dias de novembro de } 2015 \text {, e os dois primeiros dias de janeiro } \\
\text { de } 2016 \text {, ou seja, um período contínuo de } 46 \text { dias sem registros. O procedimento de } \\
\text { preenchimento adotado foi: (i) utilizar os dados dos dois primeiros dias de janeiro } \\
\text { de } 2015 \text { em janeiro de } 2016 \text {, (ii) utilizar os dados dos dias } 23 \text { a } 31 \text { de dezembro de } \\
2014 \text { em dezembro de } 2015 \text {, (iii) preencher os } 16 \text { primeiros dias de dezembro com } \\
\text { a média simples entre os dados dos mesmos horários de novembro de } 2015 \text { e } \\
\text { janeiro de } 2016 \text {, (iv) preencher os dias } 17 \text { de dezembro a } 22 \text { de dezembro com a } \\
\text { média simples entre os dados dos mesmos horários de janeiro de } 2015 \text { e os dados } \\
\text { dos mesmos horários do dia } 23 \text { de dezembro à } 28 \text { de dezembro, (v) preencher os } 13 \\
\text { últimos dias de novembro com a média entre os dados dos mesmos horários dos } \\
\text { meses de outubro de } 2015 \text { e dezembro de } 2015 \text {. É importante ressaltar que esse } \\
\text { procedimento de preenchimento foi o mecanismo encontrado de preencher com } \\
\text { valores razoáveis e de ordem de grandeza coerentes para a série histórica, de modo } \\
\text { que fosse possível a continuidade dos estudos. Procedimentos física e } \\
\text { estatisticamente mais coerentes certamente já são existentes, contudo, a pesquisa } \\
\text { e/ou desenvolvimento dos mesmos requer um estudo que foge do escopo desse } \\
\text { trabalho e o qual não haveria tempo hábil para ser realizado. }\end{array}$ \\
\hline IV & $\begin{array}{l}\text { a série completa foram encontrados } 14 \text { dados de } I G H \text { e IDH zerados. Esses dados } \\
\text { ram encontrados no meio do dia, indicando certamente um conjunto de dados } \\
\text { rados, que representa menos de } 0,0006 \% \text { da amostra de dados com ângulo zenital } \\
\text { ferior à } 75^{\circ} \text {. Esses dados não foram substituídos ou retirados, pois entende-se que } \\
\text { sua representatividade nos cálculos realizados é ínfima e não influencia na } \\
\text { efinição final do comportamento do recurso. }\end{array}$ \\
\hline V & $\begin{array}{l}\text { ram encontradas quantidades significativas de dados negativos, todos de IDN, } \\
\text { ara os períodos iniciais da manhã e dos finais de tarde. A quantidade de dados } \\
\text { gativos de IDN para cada mês é apresentada na Tabela } 20 \text {. Todos esses dados } \\
\text { ram substituídos pelo valor zero. }\end{array}$ \\
\hline
\end{tabular}




\section{Etapa Resultados \\ VI Foram encontradas quantidades significativas de valores de $I G H$ superiores à $I G H_{0}$, conforme apresentado na Tabela 20. Em virtude dessa constatação, também foi aplicado o critério de dados fisicamente possíveis estabelecido pela BSRN, definido no item I. da seção 5.2.1 desse estudo. 50 dados de irradiância difusa horizontal do mês de abril de 2015 e 3 do mês de maio foram identificados como superiores aos valores estabelecidos pela BSRN; um valor do mês de junho e outro no mês de julho de 2016 de irradiância global horizontal foram identificados como superiores aos valores estabelecidos pela BSRN; contudo todos eles correspondem a valores muito próximos ao limite da BSRN e coerentes com os valores de medições anteriores e posteriores da série histórica. Nenhum dado foi excluído. \\ VII A figura 67 apresenta o histograma de frequência relativa dos valores de $k_{t c}$ da série anual e para a série completa.}

Fonte: Elaboração própria

Tabela 20 - Resultados da análise de qualidade de dados

\begin{tabular}{lll}
\hline Período & $\begin{array}{l}\text { Valores } \\
\text { negativos de IDN }\end{array}$ & $\begin{array}{l}\text { Dados superiores à } \\
\text { Irrad TOA }\end{array}$ \\
\hline Abril de 2015 & 2.280 & 394 \\
\hline Maio de 2015 & 4.790 & 1.682 \\
\hline Junho de 2015 & 5.000 & 5.983 \\
\hline Julho de 2015 & 5.000 & 4.320 \\
\hline Agosto de 2015 & 7.550 & 2.080 \\
\hline Setembro de 2015 & 5.400 & 66 \\
\hline Outubro de 2015 & 5.370 & 6 \\
\hline Novembro de 2015 & 3.120 & 0 \\
\hline Dezembro de 2015 & 2.560 & 0 \\
\hline Janeiro de 2016 & 4.000 & 0 \\
\hline Fevereiro de 2016 & 4.000 & 0 \\
\hline Março de 2016 & 6.000 & 9 \\
\hline Janeiro de 2015 & 3.700 & 0 \\
\hline Abril de 2016 & 5.000 & 119 \\
\hline Maio de 2016 & 6.000 & 1.771 \\
\hline Junho de 2016 & 5.000 & 5.944 \\
\hline
\end{tabular}

Fonte: Elaboração própria

Todos os valores negativos de IDN encontrados são da ordem de décimos ou milésimos e foram verificados no início do dia ou final da tarde. Já a verificação de $k_{t c}$ apresentada nos gráficos da Figura 67 apresentam um comportamento diferente do encontrado para os dados da ESUPP, cerca de $30 \%$ dos dados apresentaram medições de $I G H$ de $12 \%$ a $13 \%$ maiores do que os respectivos valores de $I D N * \cos z+I D H$, enquanto que $49 \%$ dos dados apresentaram valores de $k_{t c}$ entre 0.9 e 1.1 , ou seja, dentro do intervalo aceitável pela Rede Sonda. A parcela de dados com $k_{t c}$ entre 1,12 e 1,13 é bastante significativa. A primeira 
possível explicação para tal seria um possível desalinhamento do rastreador solar, de modo que as medições de $I D N$ não fossem registradas na sua totalidade, reduzindo o total dessa componente em relação ao real. Contudo, em função do processo constante de manutenção e monitoramento da estação e exclusão dos dados com ângulos zenitais superiores à $75^{\circ}$, essa possibilidade se apresenta pouco provável.

A segunda possível explicação e mais provável seria a interferência causada pela poluição no fluxo de radiação na região. Considerando a teoria de espalhamento de Mie, discutida na seção 4.2 indica-se que partículas com diâmetro maior do que o comprimento de onda da radiação, como o caso de material particulado, causam um processo significativo de espalhamento da radiação inclusive de espalhamento frontal, ou seja, aquele cujo ângulo da radiação espalhada é próximo à 0 em relação à radiação incidente, reduzindo a parcela de radiação direta e aumentando a parcela de radiação difusa, que pode incidir não uniformemente no sensor de radiação global e no sensor de radiação difusa, gerando uma descompensação da relação $I G H=I D N * \cos z+I D H$.

Figura 67 - Frequência dos valores de $k_{t c}$

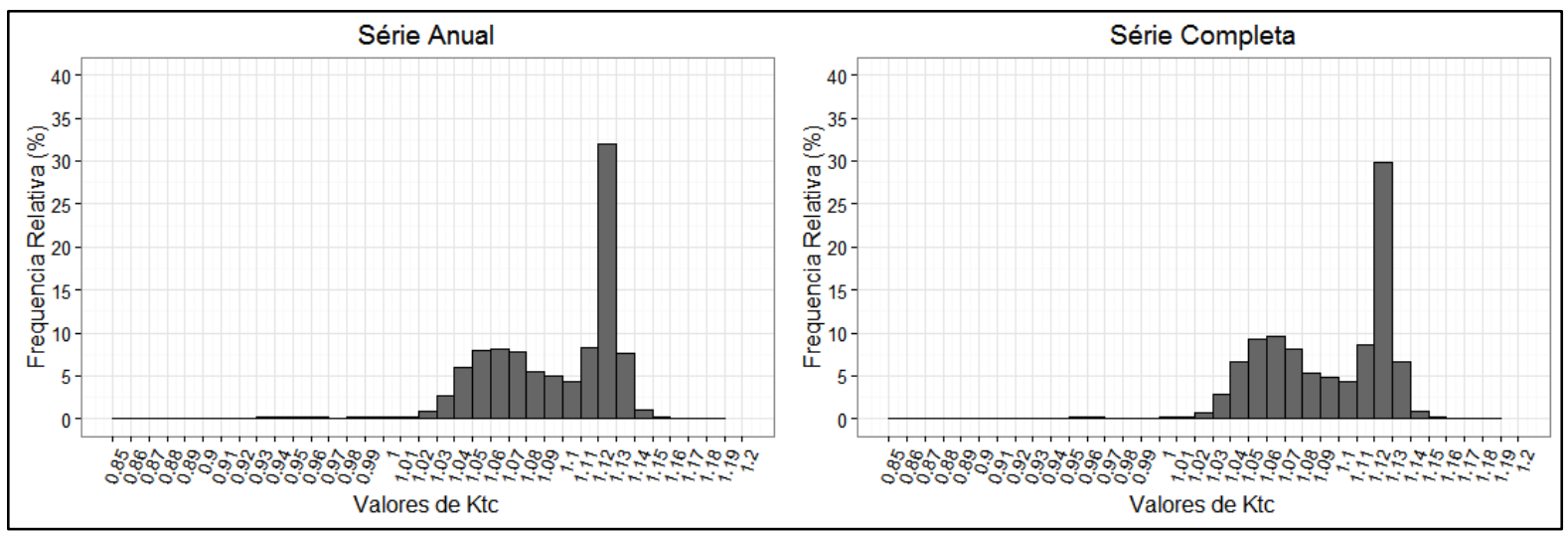

Fonte: Elaboração própria

A Figura 67 apresenta a distribuição relativa de valores de $k_{t c}$ entre 0,85 e 1,2. 705 valores de $k_{t c}$ foram encontrados fora deste intervalo para a série completa, representando cerca de $0,02 \%$ da amostra. Contudo, foi verificado que $51 \%$ da amostra da série completa (com ângulo zenital inferior a $75^{\circ}$ ) fica fora do intervalo de valores aceitáveis definido pela rede Sonda, que corresponde à $k_{t c}$ entre 0,9 e 1,1. Dada a alta representatividade da parcela fora dos limites aceitáveis, buscou-se analisar o comportamento geral do recurso, assim foram produzidos histogramas mensais dos valores de $k_{t c}$ nos quais verificou-se que esse comportamento é padronizado para todos os meses. 
A análise de qualidade de dados mostra, no geral, um comportamento diferenciado do encontrado nos dados da ESUHPP sem nenhuma justificativa clara ou direta para a não conformidade com os critérios de qualidade estipulados pela Rede Sonda. A discussão aprofundada desses aspectos foge do escopo desse trabalho, já que requer conhecimentos aprofundados de conceitos físicos e atmosféricos que por si só, representaria uma nova dissertação. Assim, define-se a não substituição desses valores e a realização dos cálculos admitindo a conformidade dos dados da série histórica.

\subsection{ASPECTOS TEMPORAIS (ESPEL)}

Após a análise inicial e familiarização com a série histórica prossegue-se para a análise probabilística dos dados disponíveis.

\subsubsection{Construção das CDPs}

Com o intuito de estabelecer comparações entre os demais estudos da revisão bibliográfica e com os resultados obtidos com os dados da ESUPP, foi aplicado à priori, o mesmo critério de divisões de massa de ar utilizadas na seção 7.3.

A Figura 68 apresenta as Curvas de Densidade de Probabilidade para os valores de $k_{t}$ da série anual para as respectivas massas de ar da Tabela 18. Os intervalos de $k_{t}$ foram definidos com amplitude de 0,02. As CDPs foram calculadas utilizando-se as funções geom_histogram e geom_density do pacote Ggplot2, utilizados no ambiente RStudio. Verifica-se que, o perfil das CDPs encontrado é bastante diferente daquele encontrado para os dados da ESUPP 
Figura 68 - Curvas de densidade de probabilidade de $k_{t}$ para a série anual em função da massa de ar

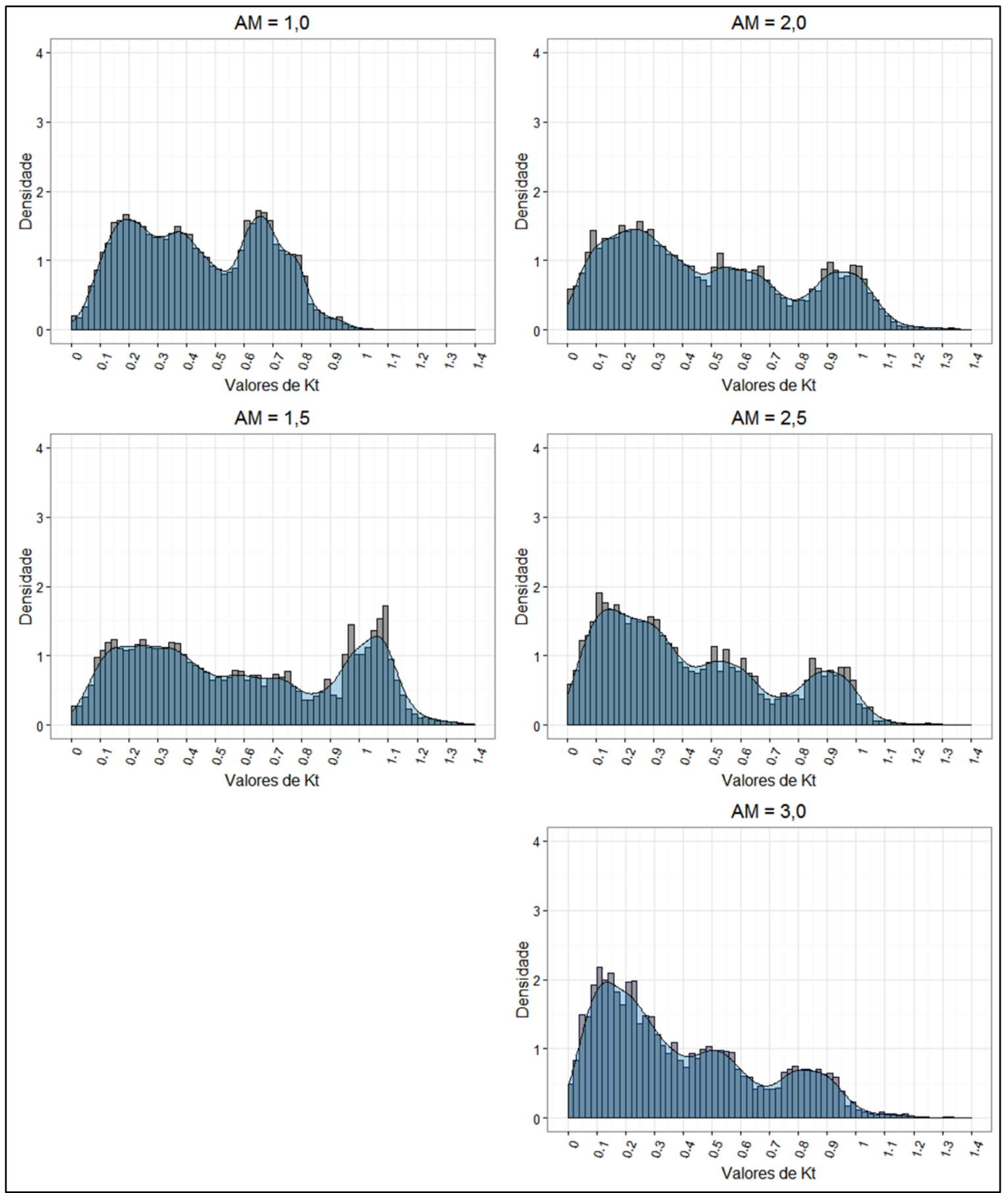

Fonte: Elaboração própria

As curvas apresentaram um caráter trimodal que não foi encontrado nas curvas verificadas na revisão bibliográfica, mas que foi verificada para $A M=2,0$ dos dados da ESUPP. Dado o caráter incomum das curvas, analisou-se a possibilidade de tal fato ser ocasionado pela inserção de 46 dias de dados obtidos por um método simplório de estimativa 
via média simples entre valores anteriores e posteriores aos dados faltantes, assim, esses 46 dias foram excluídos da série anual, originando a amostra de dados aqui denominada de série anual incompleta, que compreende o período de 01 abril de 2015 a 17 de novembro de 2015 e de 3 de janeiro de 2016 a 31 de março de 206. As curvas foram recalculadas, como apresentado na Figura 69.

Figura 69 - Curvas de densidade de probabilidade de $k_{t}$ para a série anual incompleta em função da massa de ar

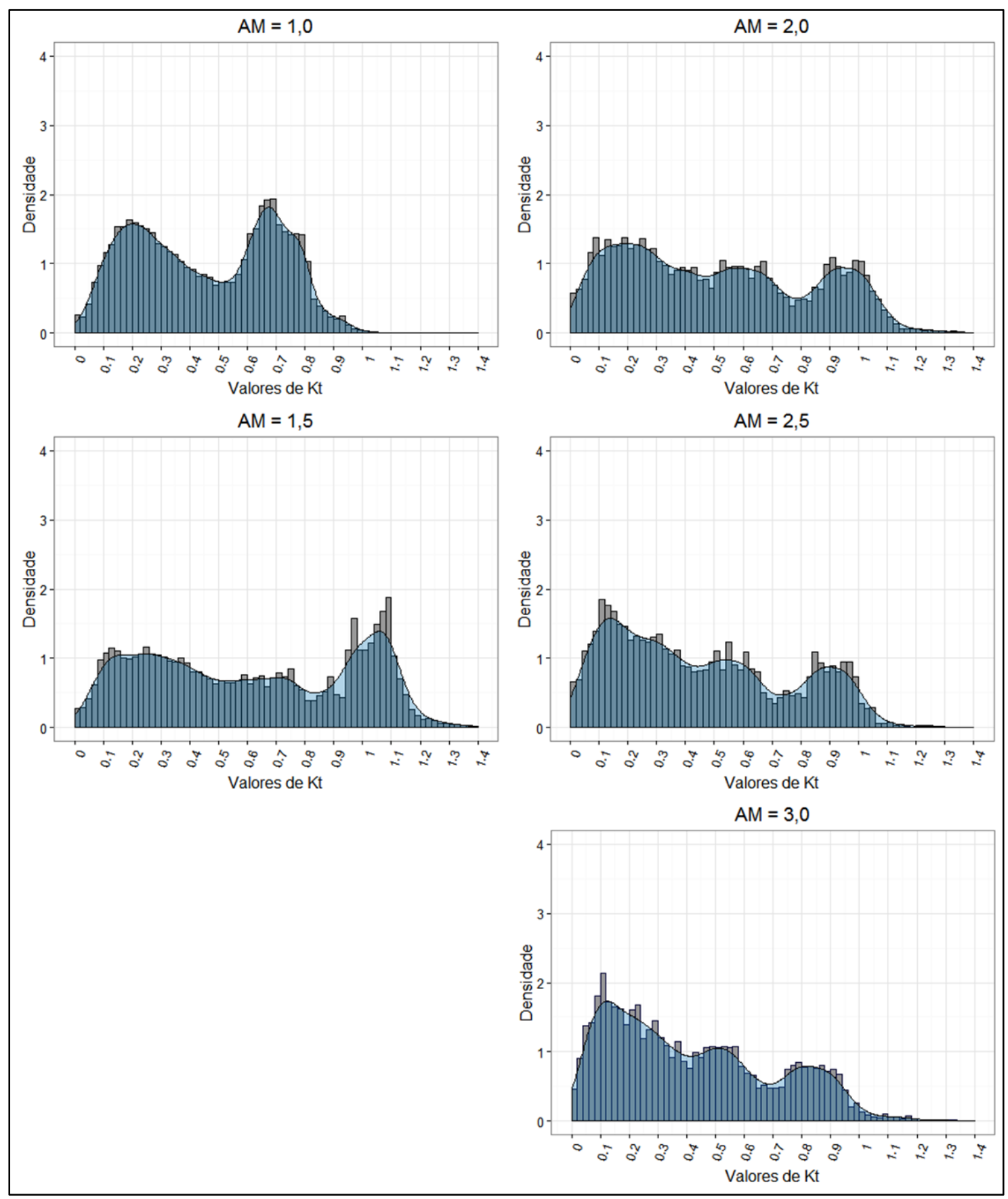

Fonte: Elaboração própria, 2016 
Com exceção da curva de $A M=1,0$, o caráter trimodal continua sendo verificado, de modo que o comportamento atípico não pode ser justificado pela inserção dos dados aproximados na série histórica. Verificou-se então se, a utilização de uma série de dados maior apresentaria o mesmo comportamento, assim, foram geradas as CDPs para a série completa, ou seja, a série anual acrescida dos 4 meses auxiliares. Os resultados obtidos foram bastante semelhantes às curvas obtidas para a série anual.

Assim, considerando a confiabilidade da série histórica, verifica-se um terceiro pico, recorrente em valores intermediários de $k_{t}$, esse pico se torna mais evidente conforme o aumento da massa de ar, essa verificação é totalmente coerente com a suposição realizada nas análises de $k_{t c}$, de que, o alto índice de poluição da região interfere significantemente no comportamento do recurso. Já que, quanto maior a massa de ar, maior o percurso percorrido pela radiação ao longo da atmosfera, espera-se que o nível de interferência seja maior, dada a concentração de material particulado. Assim, mesmo para dias de céu limpo e/ou parcialmente limpo, a interferência da poluição gera alta densidade de $k_{t}$ intermediários, gerando um comportamento trimodal que não é verificado quando o percurso da radiação pela atmosfera é mínimo, ou seja, $A M=1,0$.

É importante evidenciar que a geração de 46 dias de série por meio de valores médios, evidentemente contribui para o aumento da densidade de $k_{t}$ médios, porém, como o comportamento trimodal também é verificado quando se analisa a série sem a presença desses valores, é coerente que a maior interferência atmosférica na radiação seja o motivo dessa alteração de comportamento.

Com o intuito de fortalecer essa hipótese, foram construídas curvas de frequência relativa (CFR) de $k_{t c}$ também para diferentes massas de ar. Os resultados são apresentados nos gráficos da Figura 70. 
Figura 70 - Curvas de frequência relativa de $k_{t c}$ para a série completa para diferentes massas de ar

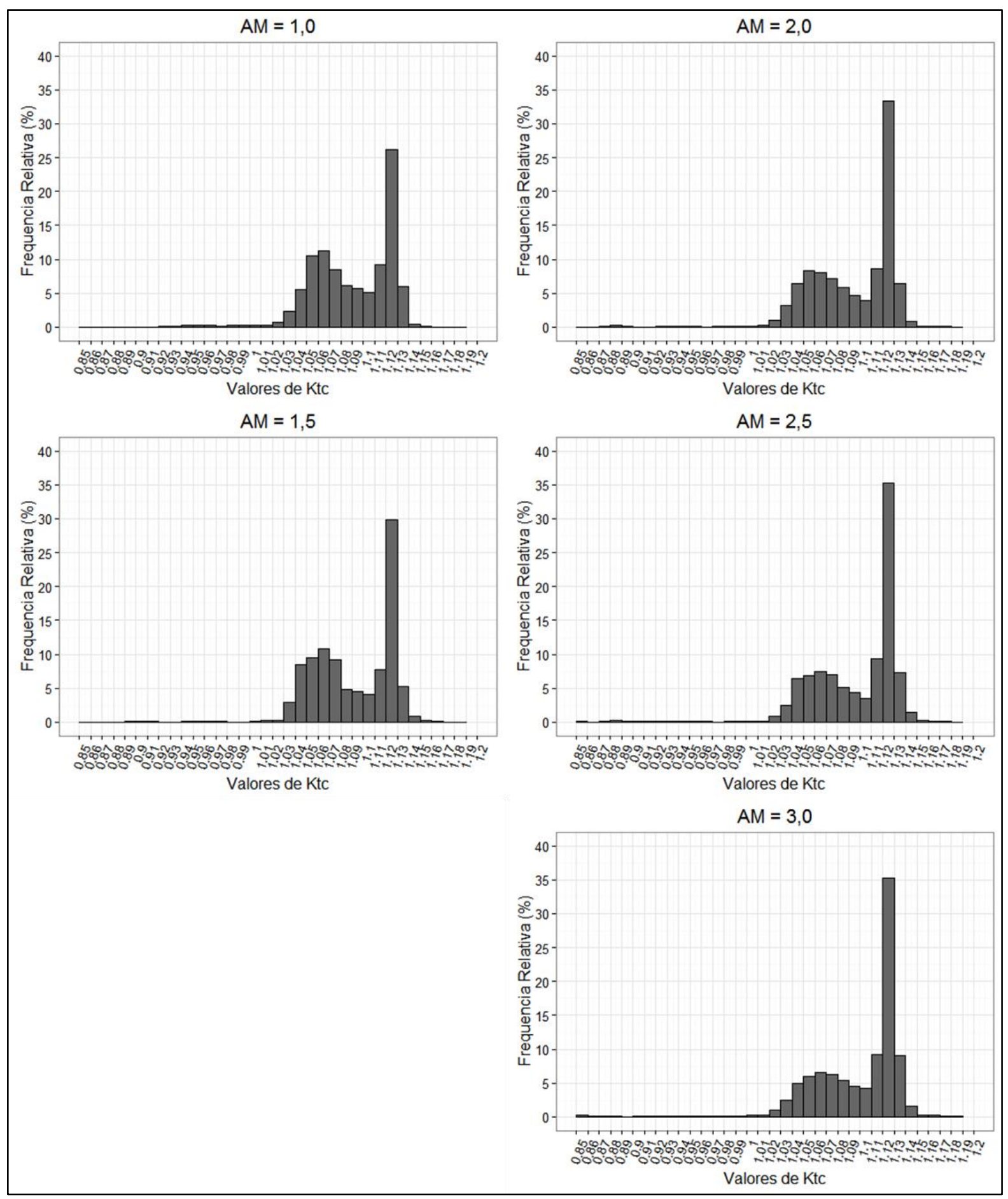

Fonte: Elaboração própria

A frequência de valores de $k_{t c}$ maiores que 1,1 aumenta conforme a massa de ar aumenta. Para $A M=1,0$, a quantidade de valores aceitáveis (entre 0,9 e 1,1) é de 52,8\%, já para $A M=1,5$ é de $51,6 \%$, para $A M=2,0$ é de $45,8 \%$, enquanto que para $A M=2,5$ é igual 
a $41,7 \%$ e para $A M=3,0$ é de $38,8 \%$. A frequência de valores de $k_{t c}$ superiores à 1,1 para $A M=1,0$ é de $47 \%$, enquanto para $A M=3,0$ é de $60,4 \%$. Embora a quantidade de valores altos de $k_{t c}$ aumente conforme o aumento de $\mathrm{AM}$, a quantidade em $A M=1,0$ ainda é bastante expressiva.

A mesma análise foi realizada para os dados da ESUPP. Nesse caso, para $A M=1,0$, a quantidade de valores aceitáveis (entre 0,9 e 1,1) é de 99,5\%, para $A M=1,5$ é de 99,4\%, para $A M=2,0$ é de $99,5 \%$, para $A M=2,5$ é igual a $98,9 \%$ e para $A M=3,0$ é de $98,3 \%$. A frequência de valores de $k_{t c}$ superiores à 1,1 para $A M=1,0$ é de $0,44 \%$, enquanto que para $A M=3,0$ é de $0,38 \%$. Ou seja, embora haja uma ligeira queda da parcela de valores aceitáveis conforme o aumento da massa de ar, não se verifica uma relação entre aumento da massa de ar e o aumento de altos valores de $k_{t c}$. Deste modo, essa análise corrobora com a hipótese de que a poluição e alta concentração de material particulado na atmosfera gera uma alteração significativa no comportamento do recurso.

Dando sequência a análise das CDPs para os dados da ESPEL, foram plotadas as curvas para os coeficientes $k_{b}$ e $k_{d}$. As curvas foram geradas tanto para a série anual, quanto para a série completa (série anual mais série auxiliar) e para a série anual incompleta (série anual menos os 46 dias de dados estimados). Os resultados obtidos foram bastante semelhantes, por isso, as Figuras 71 e 72 apresentam as CDPs para a série anual dos dois coeficientes. 
Figura 71 - Curvas de densidade de probabilidade de $k_{d}$ para a série anual em função da massa de ar

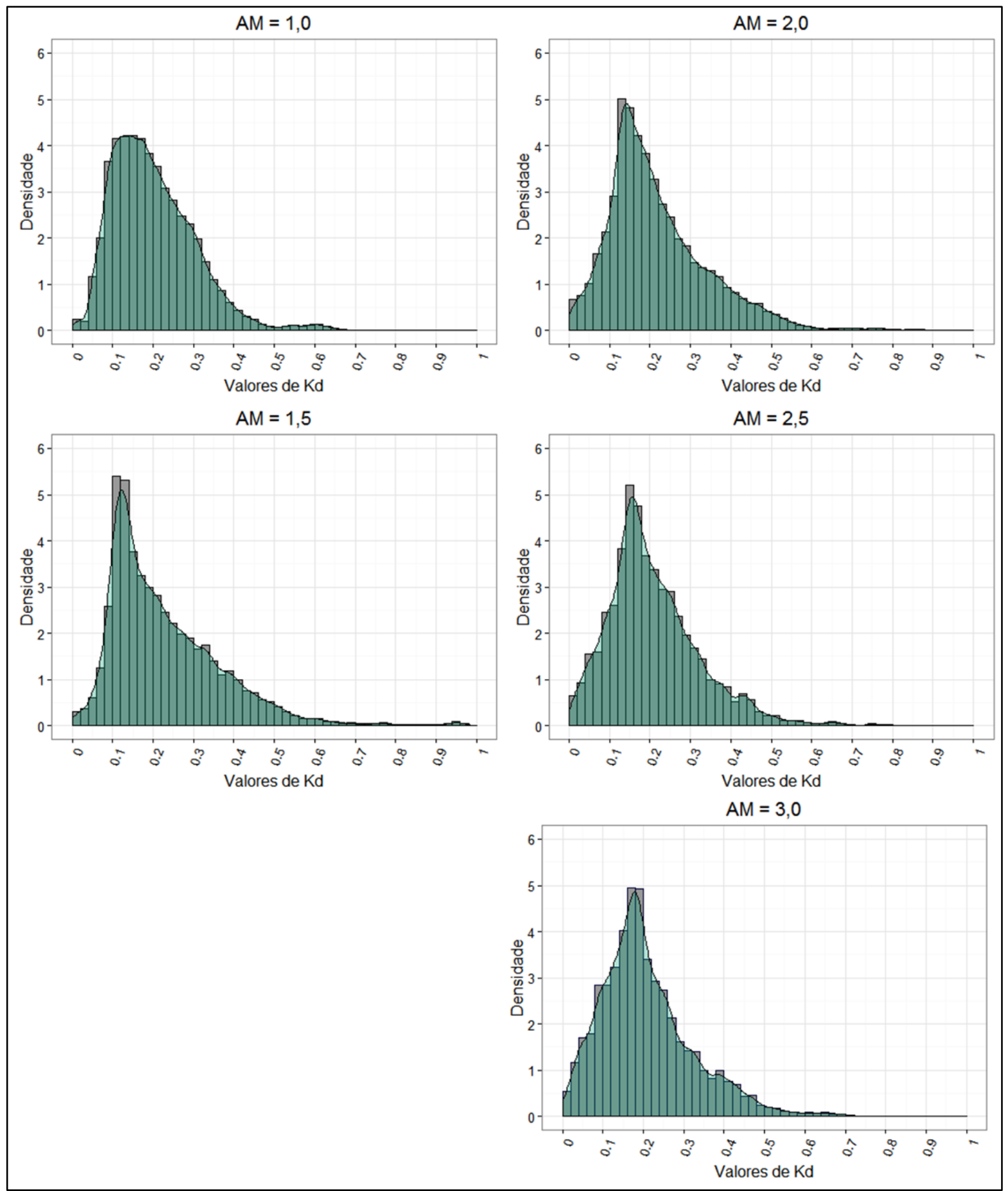

Fonte: Elaboração própria, 2016

Novamente verifica-se o deslocamento pequeno do pico de $k_{d}$ conforme o aumento da massa de ar, esse deslocamento se apresenta tão sutil quanto o encontrado para os dados da ESUPP, porém mais sutil do que o encontrado na revisão bibliográfica. Destaca-se a presença de valores altos de $k_{d}$ para $A M=1,0$. 
Figura 72 - Curvas de densidade de probabilidade de $k_{b}$ para a série anual em função da massa de ar

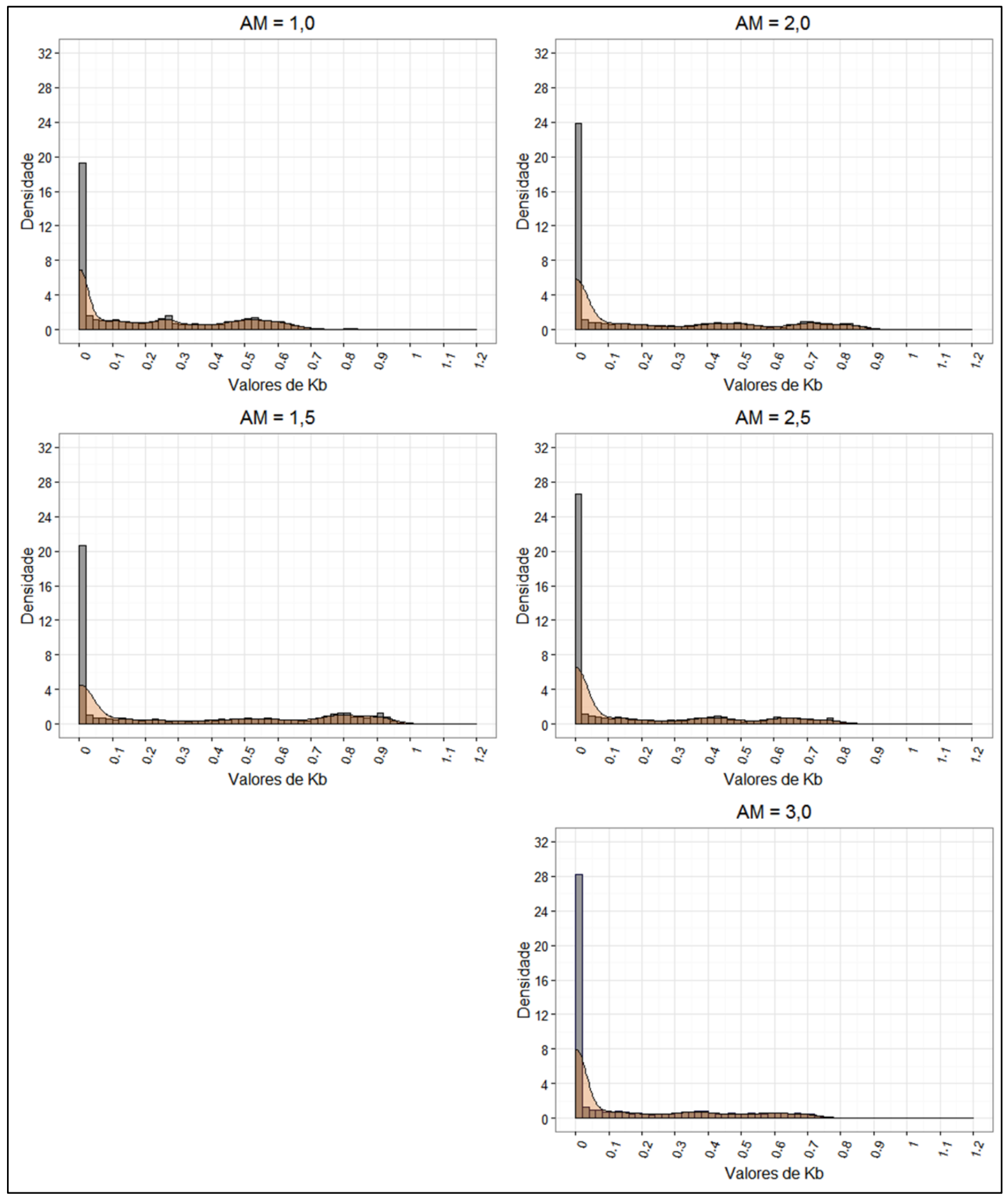

Fonte: Elaboração própria

As curvas de $k_{b}$ apresentam um perfil inicial semelhante ao encontrado por TOVAR et al (1999) e ASSUNÇÃO et al (2003) e para os dados da ESUPP. Coerentemente, a quantidade de dados zerados ou próximos a zero aumenta conforme a massa de ar aumenta. 
Porém, diferente dos estudos verificados na revisão bibliográfica, a curva não apresenta um caráter bimodal, mas sim unimodal de perfil exponencial no primeiro intervalo.

Com a finalização da análise do comportamento dos coeficientes de transmitância para a série anual e completa, procede-se à caracterização das CDPs mês a mês. Assim, os gráficos das Figuras 73, 74 e 75 apresentam as curvas mensais para a série anual.

Figura 73 - Curvas de densidade de probabilidade de $k_{t}$ para os meses de Abr/2015 a $\mathrm{Jul} / 2015$

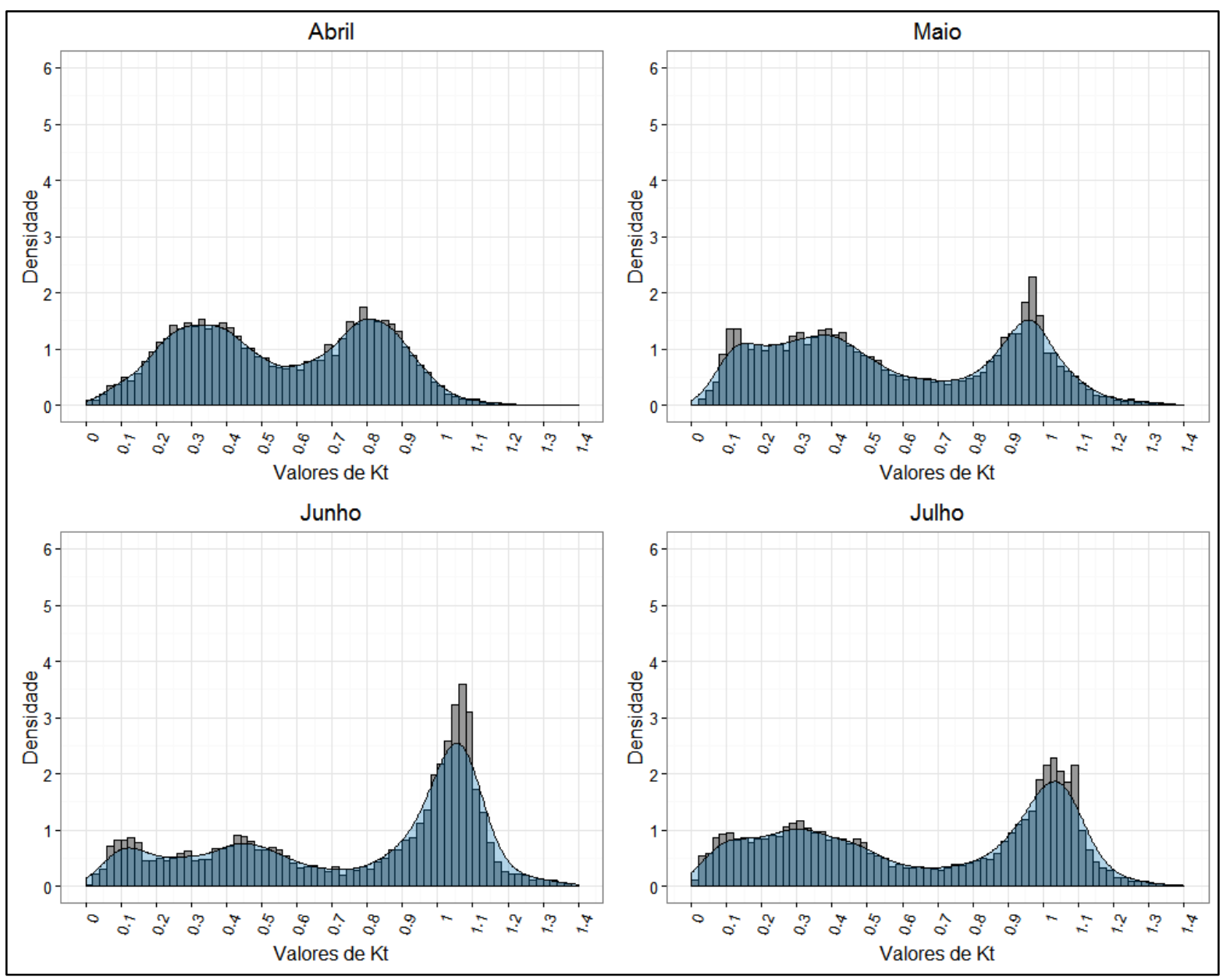

Fonte: Elaboração própria

Abril apresenta uma curva de caráter bimodal bem definido com picos em 0,35 e 0,8 e vale em 0,6. Já em maio, verifica-se o deslocamento do segundo pico para $k_{t}$ próximos à 1 , assim como verificado para os dados da ESUPP. Em julho e junho o segundo pico alcança valores superiores à 1 , com vale em $k_{t}$ da ordem de 0,6 a 0,7 . 
Figura 74 - Curvas de densidade de probabilidade de $k_{t}$ para os meses de Ago/2015 a Nov2015

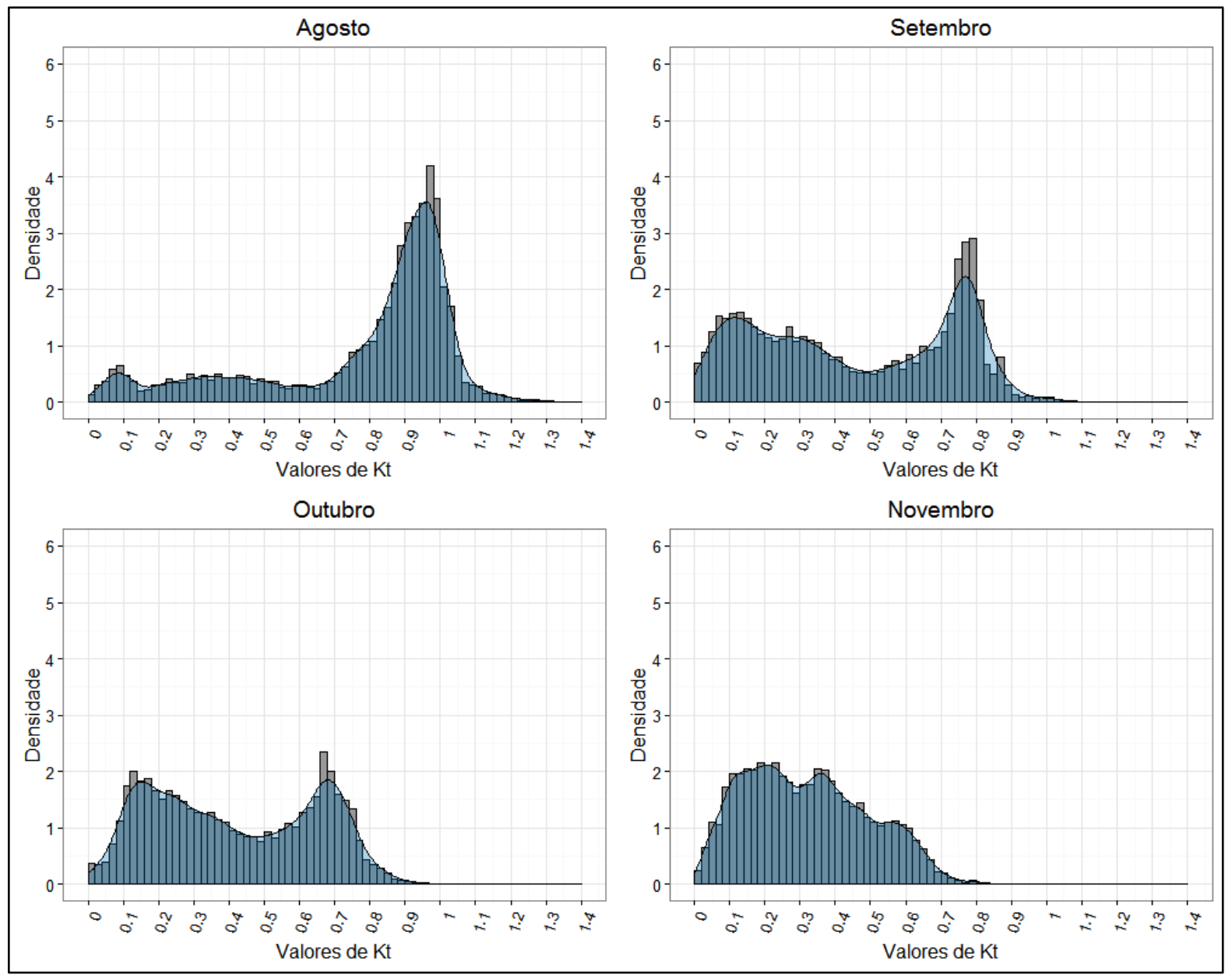

Fonte: Elaboração própria

Em agosto a curva alcança um caráter unimodal com pico entre 0,9 e 1, assim definese que de abril a julho à um movimento de deslocamento do segundo pico a direita, enquanto que de agosto a novembro o segundo pico se desloca à esquerda, período no qual os vales são encontrados principalmente na ordem de 0,5. A partir de dezembro, verifica-se o novo deslocamento do segundo pico para a direita, apresentando em janeiro, uma curva de caráter bimodal bem definida, com o segundo pico na ordem de 0,6 e vale em 0,4. Em março o pico alcança $k_{t}$ próximos a 0,7 e vale em 0,5 . 
Figura 75 - Curvas de densidade de probabilidade de $k_{t}$ para os meses de Dez/2015 a Mar/2016

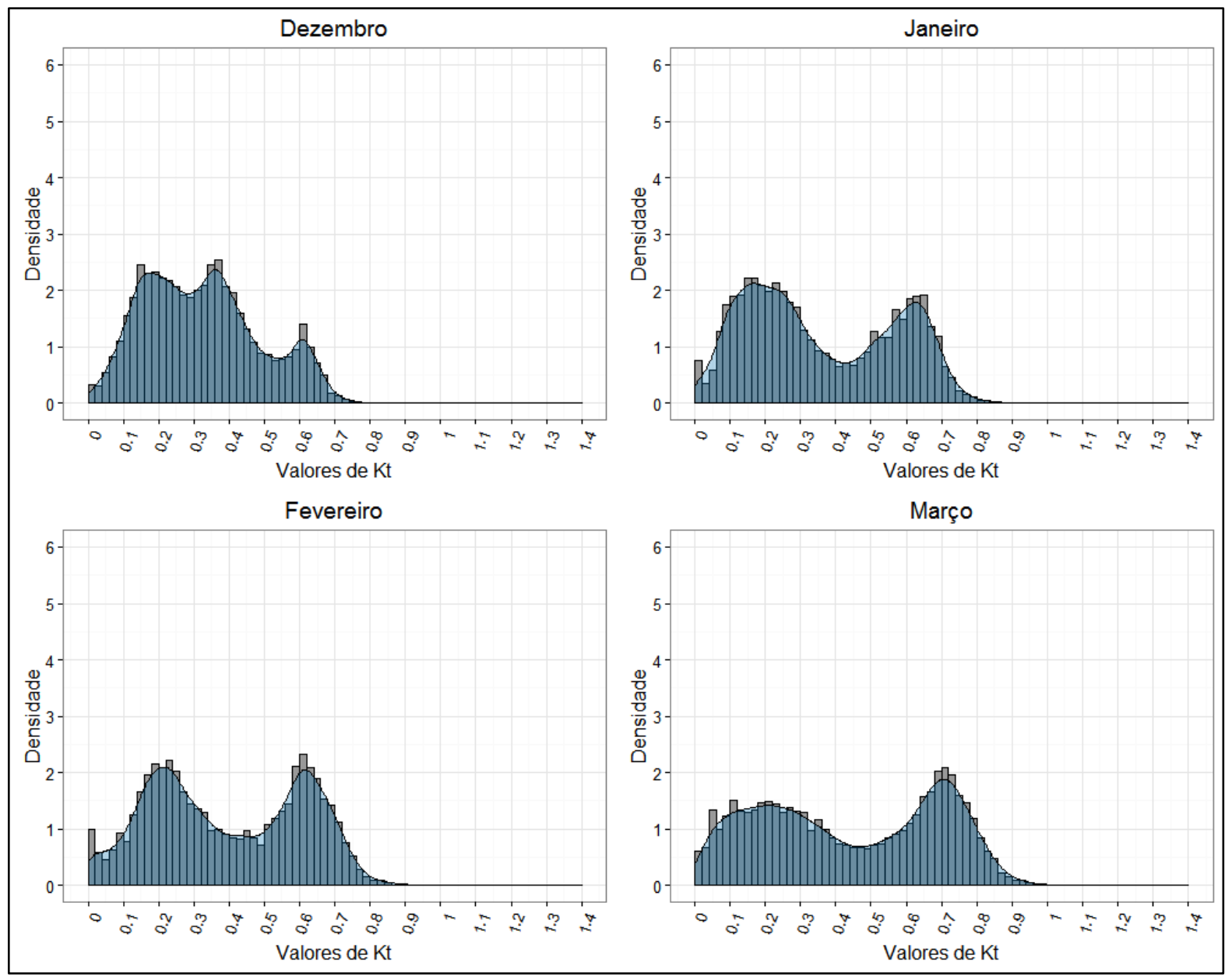

Fonte: Elaboração própria

Exceto as curvas de dezembro e novembro (produzidas parcialmente com dados aproximados), todas as demais apresentaram carácter bimodal. Enquanto que, a curva para a série anual incompleta apresenta a formação de três picos, como apresentado na Figura 76. 
Figura 76 - Curvas de densidade de probabilidade de $k_{t}$ para a série anual incompleta total

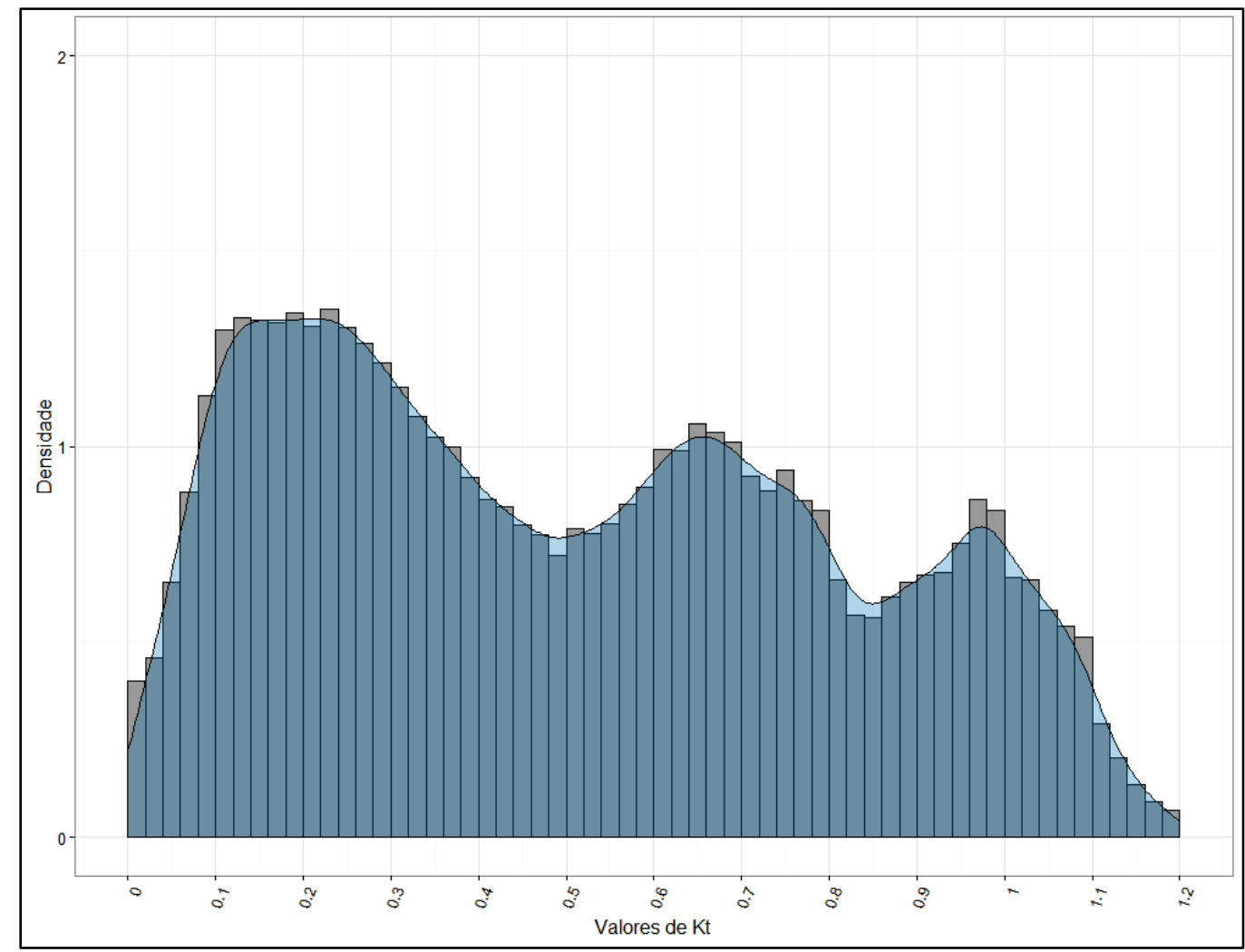

Fonte: Elaboração própria

No ciclo de deslocamento do vale e do segundo pico das CDPs mensais, os mesmos valores de $k_{t}$ (como 0,6 e 0,7 ) ora representam valores de picos e ora de vales, justificando o caráter trimodal da série anual, que é verificado mesmo quando desconsiderados os 46 dias de valores aproximados considerados na série.

Com o intuito de verificar a uniformidade das CDPs para o mesmo mês de anos diferentes, foram produzidas as curvas para os meses auxiliares, apresentadas na Figura 77. 
Figura 77 - Curvas de densidade de probabilidade de $k_{t}$ para a série auxiliar

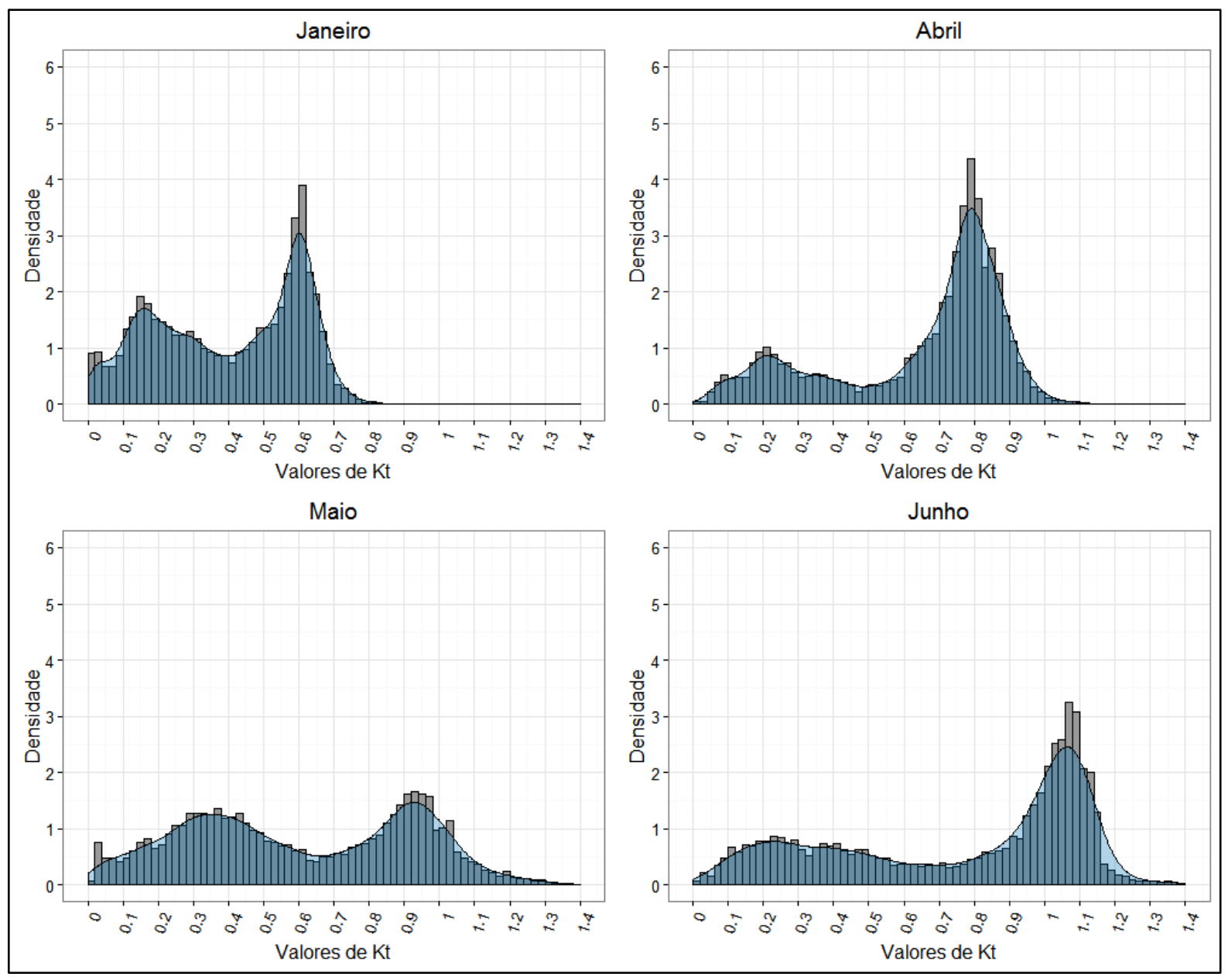

Fonte: Elaboração própria

As curvas do mesmo mês para anos diferentes não apresentam necessariamente o mesmo comportamento. As curvas de abril de 2015 e janeiro de 2016 apresentaram caráter bimodal homogêneo, já as curvas de abril de 2016 e janeiro de 2015 apresentaram uma densidade de segundo pico alta com relação a densidade do primeiro pico. Maio de 2015 e junho de 2015 apresentaram um grande intervalo de baixos $k_{t}$ para a definição do primeiro pico, enquanto maio de 2016 e junho de 2015 apresentaram um primeiro pico melhor definido, porém com perfil semelhante de diferença de densidades entre os dois picos. A principal semelhança encontrada em relação às curvas dos meses auxiliares e dos mesmos meses da série anual foi em relação aos valores de $k_{t}$ que determinam os momentos de inflexão das curvas. Os $k_{t}$ encontrados para o mesmo mês de anos diferentes que determinam os picos e vales são bastante semelhantes, assim define-se que é possível, pela análise de curvas de dois anos para o mesmo mês, determinar os intervalos de $k_{t}$ mais prováveis e 
menos prováveis, contudo, não é possível especificar a probabilidade dos eventos com acurácia.

Como verificado com os dados da ESUPP, a caracterização das curvas é bastante variada de mês a mês, indicando a impossibilidade de construção de curvas características para cada estação climática.

Também foram geradas as CDPs para cada massa de ar de cada mês da série completa. E novamente, assim como verificado com os dados da ESUPP, não houve identificação de uma relação padrão de comportamento das curvas de todos os meses em função das massas de ar. Alguns meses apresentaram comportamentos mais padronizados, mas nada que pudesse ser estendido a todos os meses da série anual. O Apêndice 4 apresenta as CDPs para as diferentes massas de ar definidas para os meses de janeiro de 2016, abril de 2015, maio de 2015 e junho de 2015. Em função da quantidade de meses e relações, buscou-se a reprodução dessas curvas com dados de dois anos diferentes do mesmo mês, utilizando-se os dados da série auxiliar. Essas curvas estão também no Apêndice 4.

A utilização de dois anos de série histórica resultou comportamentos mais padronizados em função das massas de ar do que os gráficos mensais produzidos com apenas um ano de série histórica. As curvas de janeiro, abril e junho apresentaram comportamento coerente conforme aumento da massa de ar: para os três meses, o aumento da massa de ar resultou na redução da diferença entre as densidades dos dois picos e no deslocamento do segundo pico à esquerda. Já as curvas de maio apresentaram menor dependência da massa de ar, embora também apresente um pequeno deslocamento do segundo pico à esquerda e aumento da densidade do primeiro pico conforme aumento da massa de ar.

Diante dessa constatação, buscou-se a aplicação da metodologia sugerida nesse estudo, de utilização de 9 intervalos de massas de ar diferentes, de modo que as massas de ar fossem diferenciadas entre os períodos da manhã e da tarde. Assim, os valores de massa de ar após às 12:00 de cada dia tiveram o seu sinal alterado, de modo que a definição dos intervalos ficasse conforme apresentado na Tabela 21.

Tabela 21 - Os nove intervalos para AM

\begin{tabular}{cc}
\hline AM nominal & AM real \\
\hline $\mathbf{3 , 0}$ & $2,8<A M<3,5$ \\
\hline $\mathbf{2 , 5}$ & $2,3<A M<2,7$ \\
\hline $\mathbf{2 , 0}$ & $1,8<A M<2,2$ \\
\hline $\mathbf{1 , 5}$ & $1,4<A M<1,6$ \\
\hline & (continua)
\end{tabular}




\begin{tabular}{ll}
\hline $\mathbf{1 , 0}$ & $-\mathbf{1 , 2}<\boldsymbol{A M}<\mathbf{1 , 2}$ \\
\hline $\mathbf{1 , 5}$ & $-1,6<A M<-1,4$ \\
\hline $\mathbf{2 , 0}$ & $-2,2<A M<-1,8$ \\
\hline $\mathbf{2 , 5}$ & $-2,7<A M<-2,3$ \\
\hline $\mathbf{3 , 0}$ & $-3,5<A M<-2,8$ \\
\hline
\end{tabular}

Fonte: Elaboração própria

Foram produzidos cinco conjuntos de nove ou oito curvas: um conjunto para cada mês presente em dois anos de série histórica e um conjunto para a série completa. As cinco figuras são apresentadas no Apêndice 5.

As nove curvas da série completa não apresentaram um comportamento bem padronizado conforme alteração de massa de ar. Contudo, verifica-se que para as massas de ar no período da manhã as densidades para os diferentes intervalos de $k_{t}$ são mais homogêneos indicando maior variabilidade das condições atmosféricas, enquanto que para o período da tarde verifica-se maior densidade de baixos valores de $k_{t}$. Para o mês de janeiro o perfil já é mais padronizado, verificam-se curvas de caráter bimodal, de modo que (com exceção de $\mathrm{AM}=3,0 \mathrm{M})$ as curvas do período da manhã e do meio dia apresentam o segundo pico da distribuição com densidades mais elevadas e deslocamento do $k_{t}$ desse pico para a direta conforme as massas de ar vão reduzindo, já no período da tarde verifica-se o oposto: o primeiro pico da distribuição com densidades mais elevadas e $k_{t}$ correspondente à esse pico em torno de 0,1 , indicando que, para o período da manhã a disponibilidade do recurso tende a ser muito maior do que para os períodos da tarde. Para o mês de abril pode-se verificar comportamento semelhante ao encontrado em janeiro com a diferença de que todas as curvas do período da tarde apresentam caráter bimodal que tendem à homogeneidade, ou seja, com baixa diferença entre a densidade dos dois picos, de modo que o deslocamento dos valores de $k_{t}$ do segundo pico apresentam um deslocamento maior à esquerda para o período da tarde do que à direita para o período da manhã, mostrando novamente que a disponibilidade do recurso tende a ser muito maior e estável de manhã do que de tarde.

Maio e junho, período no qual se verifica o solstício de inverno para o hemisfério sul, não apresenta horários com $\mathrm{AM}=1,0$. Por isso, para esses meses, foram produzidas oito curvas, quatro para o período da manhã e quatro para o período da tarde. Novamente verificase que, em maio ocorre menor dependência da massa de ar para a caracterização das CDPs, contudo, também se verifica um pequeno deslocamento do segundo pico à esquerda no período da manhã e à direita no período da tarde, porém sem alterações tão expressivas da densidade dos picos, de modo que, pode-se concluir que a formação das curvas na divisão 
tradicional de massas de ar não apresenta resultados muito diferentes do que quando se utilizam oito intervalos diferentes. Para junho, embora os resultados encontrados com cinco intervalos de AM não sejam tão diferentes dos encontrados com oito intervalos, é possível verificar que os segundos picos das CDPs apresentam densidades ligeiramente maiores para o período da tarde do que para o período da manhã, indicando que o recurso tende a estar mais disponível no período vespertino.

\subsubsection{Método K-POP}

A aplicação do método K-POP foi realizada para valores de $k_{t}$ e $k_{b}$ utilizando os dados da série anual. As etapas de cálculo foram idênticas às já apresentadas na seção 7.3.2. A Figura 78 apresenta os resultados para o método para os valores de $k_{t}$.

Figura 78 - Aplicação da metodologia K-POP para $k_{t}$

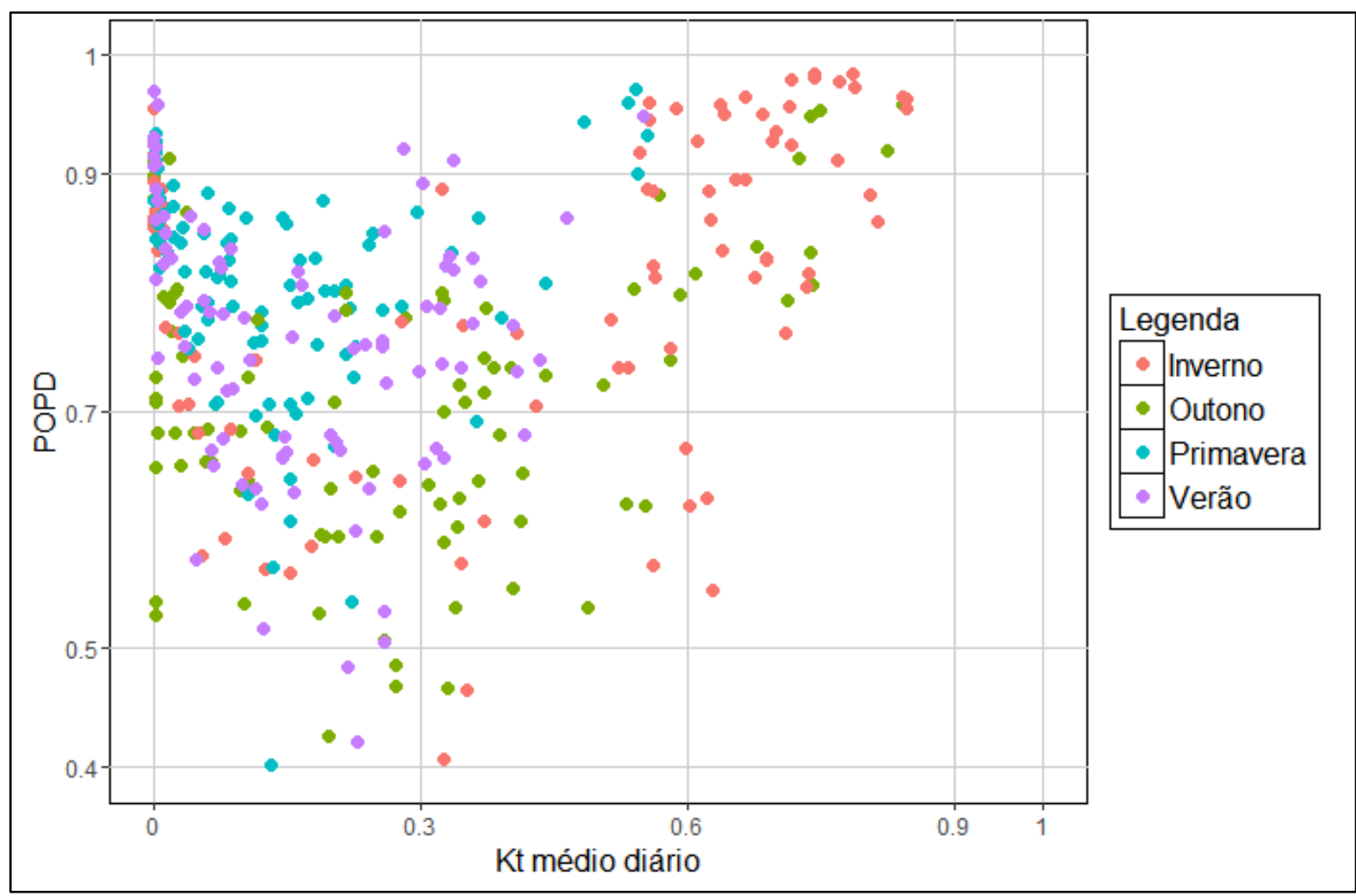

Fonte: Elaboração própria

As classes que tiveram as maiores incidências de dados foram a 6 e a 9 , seguidas pela classe 5. O Quadro 17 apresenta a caracterização do ano para a radiação solar na região. 
Quadro 17 - Resultado do métdo K-POP para ES Poli Elétrica

\begin{tabular}{|c|c|c|}
\hline Dias do ano & Classe & Descrição \\
\hline $39,3 \%$ & 6 & $\begin{array}{l}\text { Pequena quantidade e média qualidade; nebulosidade e condições } \\
\text { do céu variando ao longo do dia. }\end{array}$ \\
\hline $17,5 \%$ & 9 & $\begin{array}{l}\text { Pequena quantidade e pouca qualidade; céu coberto por nuvens com } \\
\text { vários graus de flutuação ao longo do dia todo. }\end{array}$ \\
\hline $12,6 \%$ & 5 & $\begin{array}{l}\text { Média quantidade e média qualidade; parcialmente coberto por } \\
\text { nuvens, condição de céu variável ao longo do dia. }\end{array}$ \\
\hline $6,6 \%$ & 8 & $\begin{array}{l}\text { Média quantidade e pouca qualidade; vários graus de nebulosidade, } \\
\text { com condições do céu variando significativamente na maior parte } \\
\text { do dia. }\end{array}$ \\
\hline $6,6 \%$ & 1 & $\begin{array}{l}\text { Grande quantidade e muita qualidade; condição de céu claro e } \\
\text { estável para quase o dia todo. }\end{array}$ \\
\hline $6,0 \%$ & 3 & $\begin{array}{l}\text { Pequena quantidade e muita qualidade; coberto por nuvens, } \\
\text { condição de céu relativamente estável para a maior parte do dia. }\end{array}$ \\
\hline $4,9 \%$ & 4 & $\begin{array}{l}\text { Grande quantidade e média qualidade; condição de céu claro, porém } \\
\text { variável ao longo do dia. }\end{array}$ \\
\hline $3,0 \%$ & 2 & $\begin{array}{l}\text { Média quantidade e muita qualidade; parcialmente coberto por } \\
\text { nuvens, condição de céu relativamente estável para a maior parte do } \\
\text { dia. }\end{array}$ \\
\hline $0,8 \%$ & 7 & $\begin{array}{l}\text { Grande quantidade e pouca qualidade; parcialmente ensolarado, } \\
\text { com condições do céu variando significativamente na maior parte } \\
\text { do dia. }\end{array}$ \\
\hline $2,7 \%$ & 10 & $\begin{array}{l}\text { Muita pouca qualidade, vários graus de nebulosidade e altos níveis } \\
\text { de flutuação ao longo do dia todo. }\end{array}$ \\
\hline
\end{tabular}

Fonte: Elaboração própria

No geral, o recurso na região pode ser considerado de baixa a média qualidade, ou seja, com vários graus de nebulosidade ao longo de dia, e de pequena quantidade. No inverno e outono o recurso se apresenta em maior quantidade e melhor qualidade do que nas demais estações. A classe 5, que determina média quantidade e média qualidade aparece como uma das dominantes tanto para a ESUPP quanto para os estudos aplicados na França, Chipre e EUA. As classes 6 e 8 não apareceram como dominantes em nenhum outro estudo, exceto a classe 6 para os dados da ESUPP. Mostrando que o recurso para a região de São Paulo não se apresenta tão atrativo quanto em outras regiões.

A Figura 79 apresenta a aplicação do método para os valores de $k_{b}$. A metodologia utilizada para a plotagem do gráfico foi a mesma utilizada para $k_{t}$. 
Figura 79 - Aplicação da metodologia K-POP para $k_{b}$

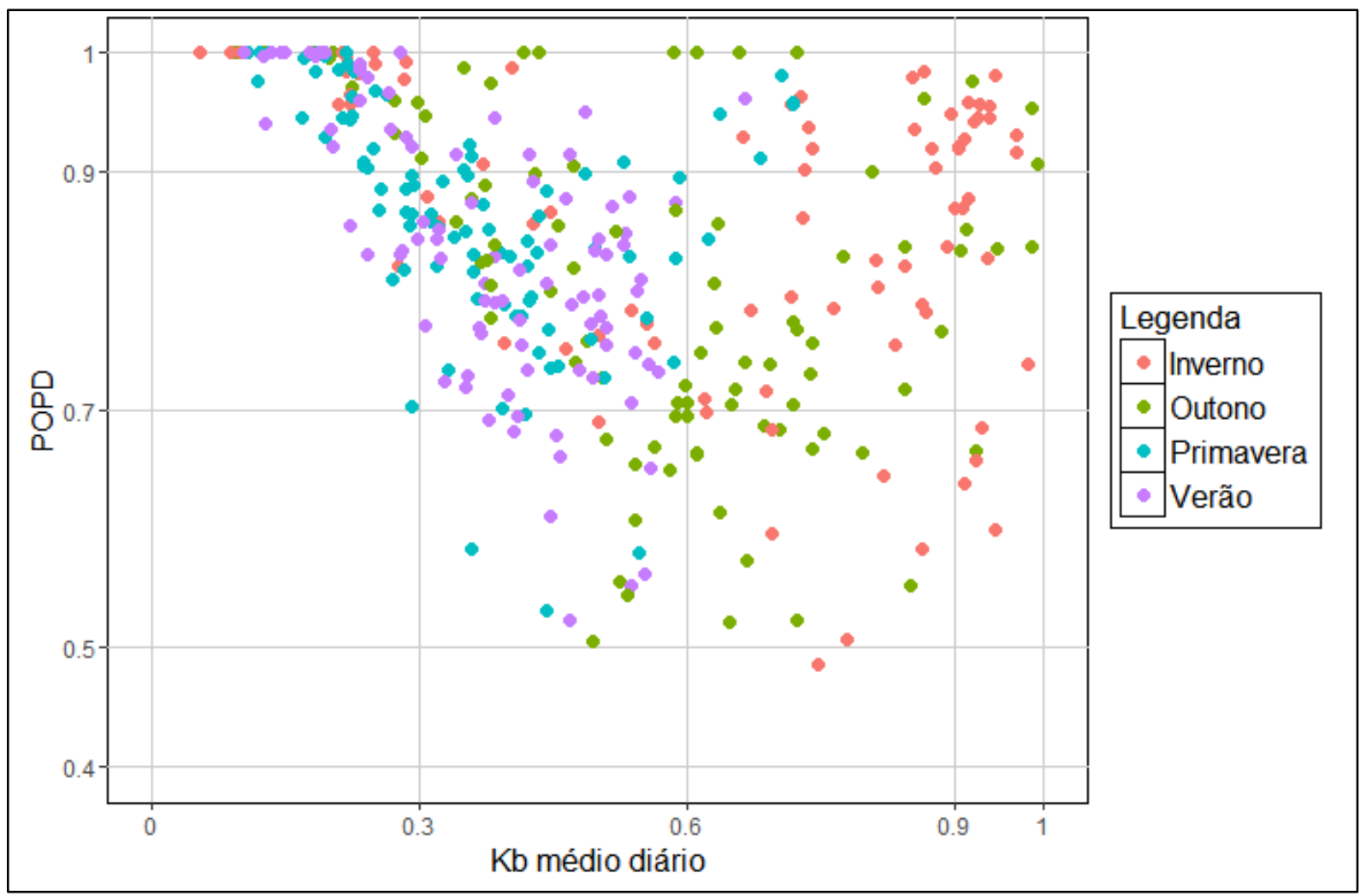

Fonte: Elaboração própria

Altos índices de $k_{b}$ são encontrados principalmente no inverno, enquanto muitos dias sem irradiância direta são verificados no verão e primavera. Os períodos de outono e inverno, por serem períodos secos, possuem menor formação nebulosa, favorecendo a incidência de irradiância direta. Na primavera verificam-se baixos valores de $k_{b}$, contudo, altas probabilidades de variações nulas. Assim, os resultados obtidos pela análise de $k_{b}$ estão em consonância com o verificado para $k_{t}$.

\subsubsection{Variação de Medições Subsequentes}

Foi calculada, para cada dia da amostra de dados, a variação em $\mathrm{W} / \mathrm{m}^{2}$ de minuto a minuto de $I D N$ e $I G H$. Novamente, menos de $50 \%$ das variações de $I G H$ são de até $5 \mathrm{~W} / \mathrm{m}^{2}$ e foram verificadas alterações superiores a $700 \mathrm{~W} / \mathrm{m}^{2}$, que em um processo ideal de tratamento de dados devem ser analisados. A distribuição de taxas de variações para cada mês se apresenta no geral homogênea. Os gráficos para $I G H$ são apresentados no Apêndice 6. Como os dados de IDN são mais sensíveis a formação de nuvens e alterações climáticas, optou-se 
por analisar esses resultados em mais detalhes. O resultado da frequência relativa de taxas de alterações de até $50 \mathrm{~W} / \mathrm{m}^{2}$ é apresentado no gráfico da Figura 80.

Figura 80 - Variabilidade do recurso: taxas menores

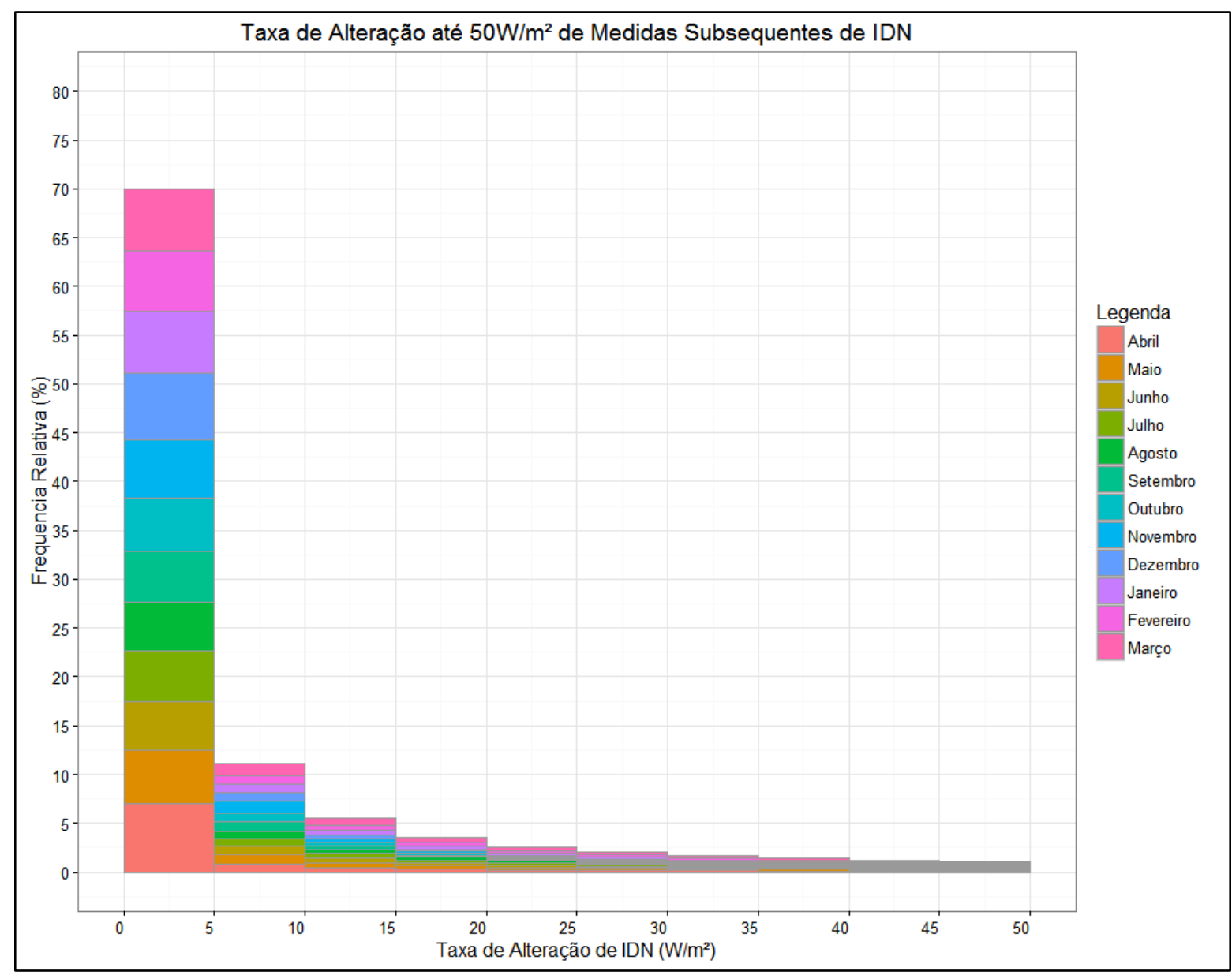

Fonte: Elaboração própria

As alterações em até $5 \mathrm{~W} / \mathrm{m}^{2}$ representam $70 \%$ das variações entre medidas subsequentes e estão distribuídas homogeneamente entre os meses da série anual. Assim, como o realizado para os dados de $I G H$ da ESUPP, foi produzido um segundo histograma (Figura 81), em diferente escala com as variações de medições subsequentes entre $50 \mathrm{~W} / \mathrm{m}^{2}$ e $950 \mathrm{~W} / \mathrm{m}^{2}$, o maior valor de alteração subsequente encontrado foi de $908 \mathrm{~W} / \mathrm{m}^{2}$. 
Figura 81 - Variabilidade do recurso: taxas maiores

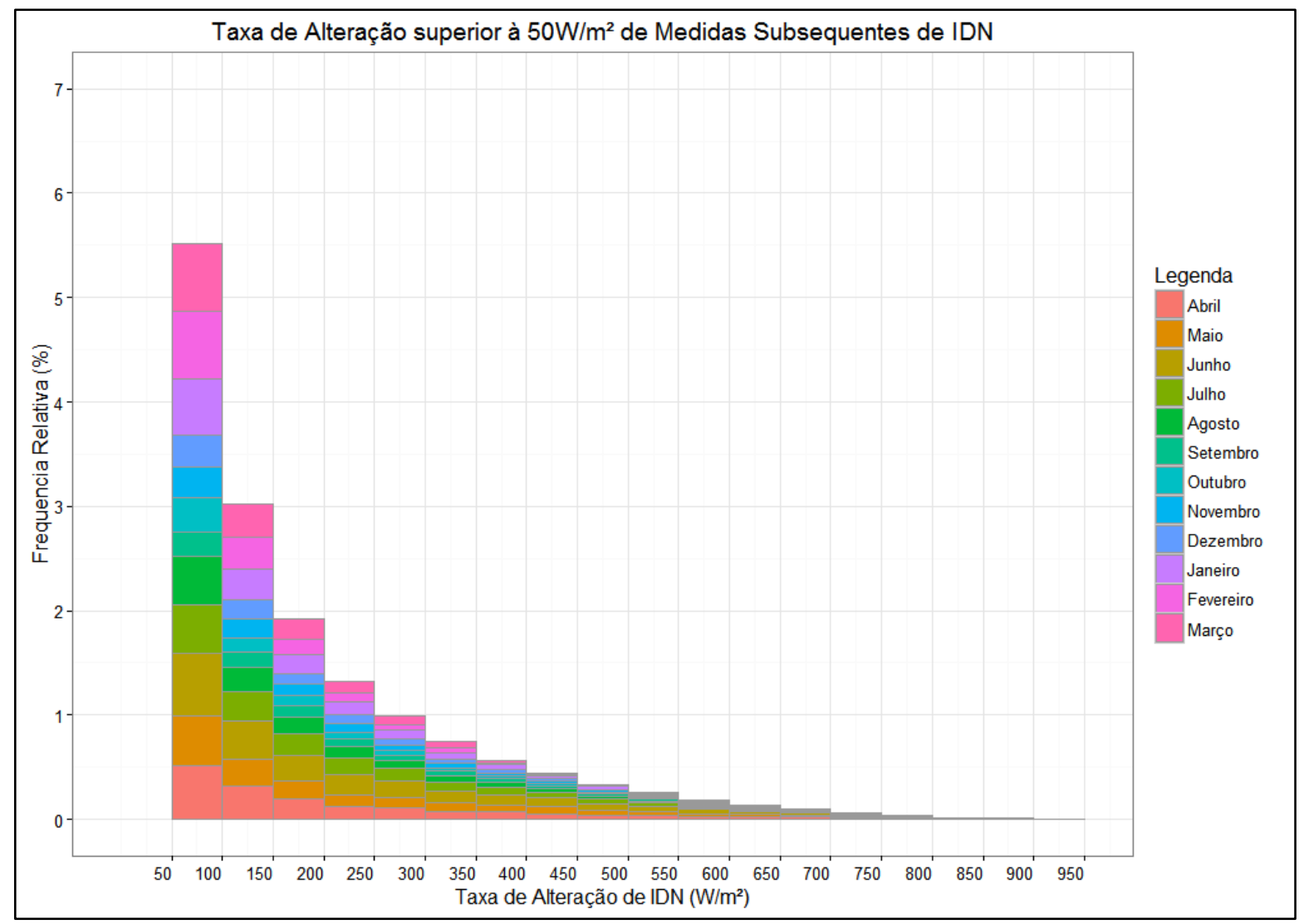

Fonte: Elaboração própria

Destaca-se que os meses de junho, fevereiro e março representam a quantidade mais significativa de altas variações. Os meses de fevereiro e março já haviam apresentado baixa estabilidade do recurso, conforme analisado para a estação do verão por meio da aplicação do método KPOP. Contudo, por meio do mesmo método, verificou-se que o inverno é a estação que apresenta um comportamento mais uniforme do recurso. Analisando as CDPs de junho (Figura 73 e Apêndice 5) verifica-se alta densidade de valores de $k_{t}$ altos, isso indica que o recurso nesse mês é de alta disponibilidade, estável, contudo, nos momentos de instabilidade, as variações são altas.

\subsection{GEOANÁLISE DO RECURSO (ESPEL)}

\subsubsection{Variável Climática Balizadora e Modelos Empíricos}

Foram calculados os montantes diários de irradiância global horizontal, a temperatura média diária, a pressão atmosférica média diária, a umidade relativa média diária e o total de precipitação diário. Com o intuito de buscar relações mais fortes entre as variáveis, não foram 
considerados dados de nenhuma dessas variáveis para ângulos zenitais superiores a $75^{\circ}$ e o período de 46 dias de dados aproximados da série anual foi excluído, assim, foi utilizado maior período com medições contínuas disponível: de 01 de abril de 2015 a 16 de novembro de 2015. Contudo, analisando os demais dados climatológicos, verificou-se que as medições do termo - higrômetro só estabilizaram em 19 de maio de 2015. Assim, a série utilizada para a análise de temperatura e umidade relativa compreende o período de 19 de maio a 16 de novembro, enquanto que a análise para pressão atmosférica e precipitação compreende o período de 01 de abril a 16 de novembro.

Os cálculos de coeficiente de Person foram realizados para médias e montantes diários de cada variável. Os gráficos das Figuras 82 e 83 apresentam as curvas lado a lado de cada variável com IGH e apresentam o coeficiente de Pearson calculado entre as duas curvas apresentadas em cada figura.

O cálculo do montante diário de irradiância global horizontal foi realizado com o mesmo procedimento utilizado para os dados da ESUPP.

Figura 82 - Correlação IGH x Umidade Relativa e IGH x Temperatura

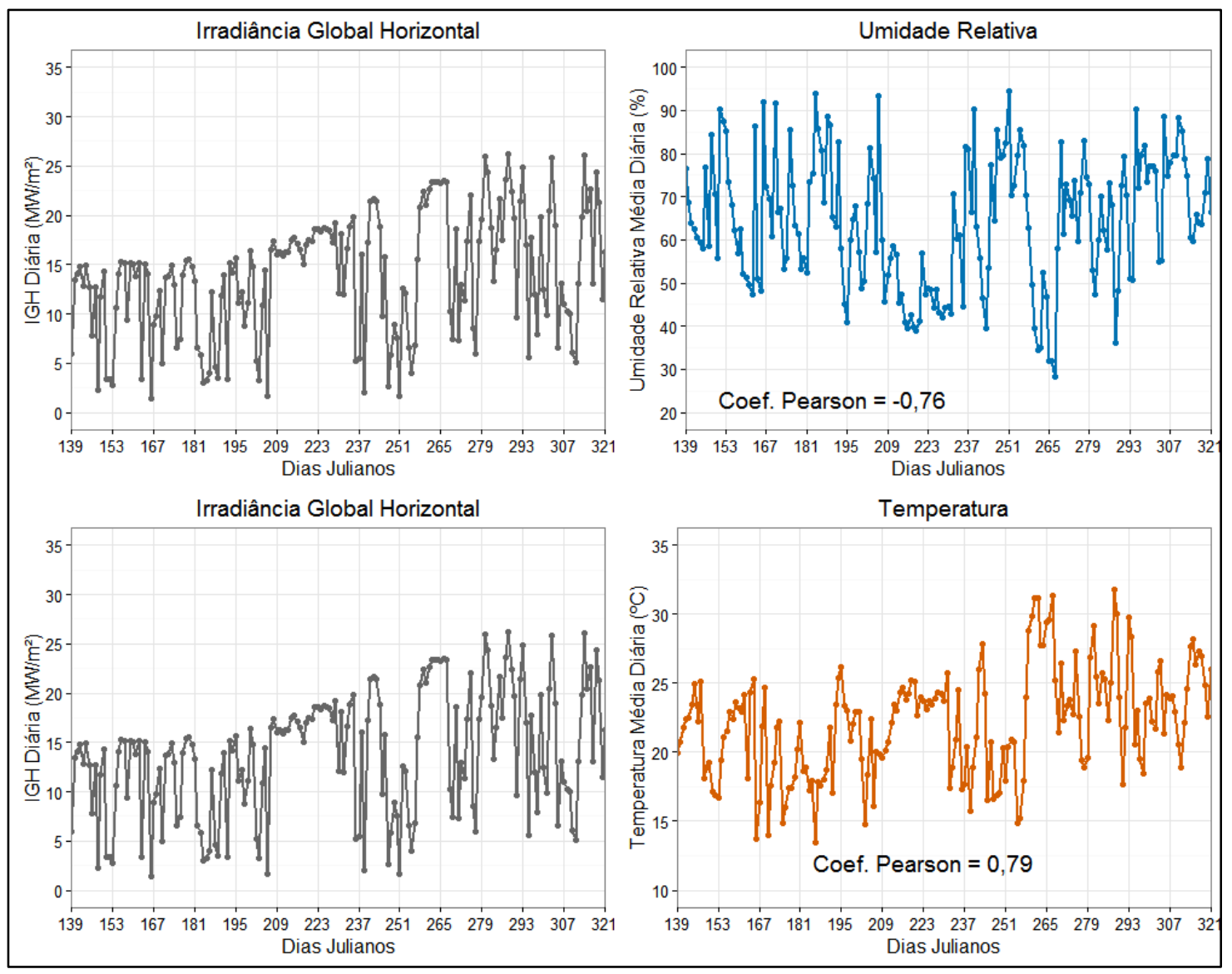

Fonte: Elaboração própria 
Nenhuma das variáveis apresentou correlação forte com o comportamento da série de IGH. Assim como na ESUPP, a série de umidade relativa e temperatura apresentaram coeficientes absolutos próximos que configuram relação moderada negativa no caso da umidade relativa e moderada, quase forte, positiva no caso da série de temperatura.

Figura 83 - Correlação IGH x Pressão Atmosférica e IGH x Precipitação

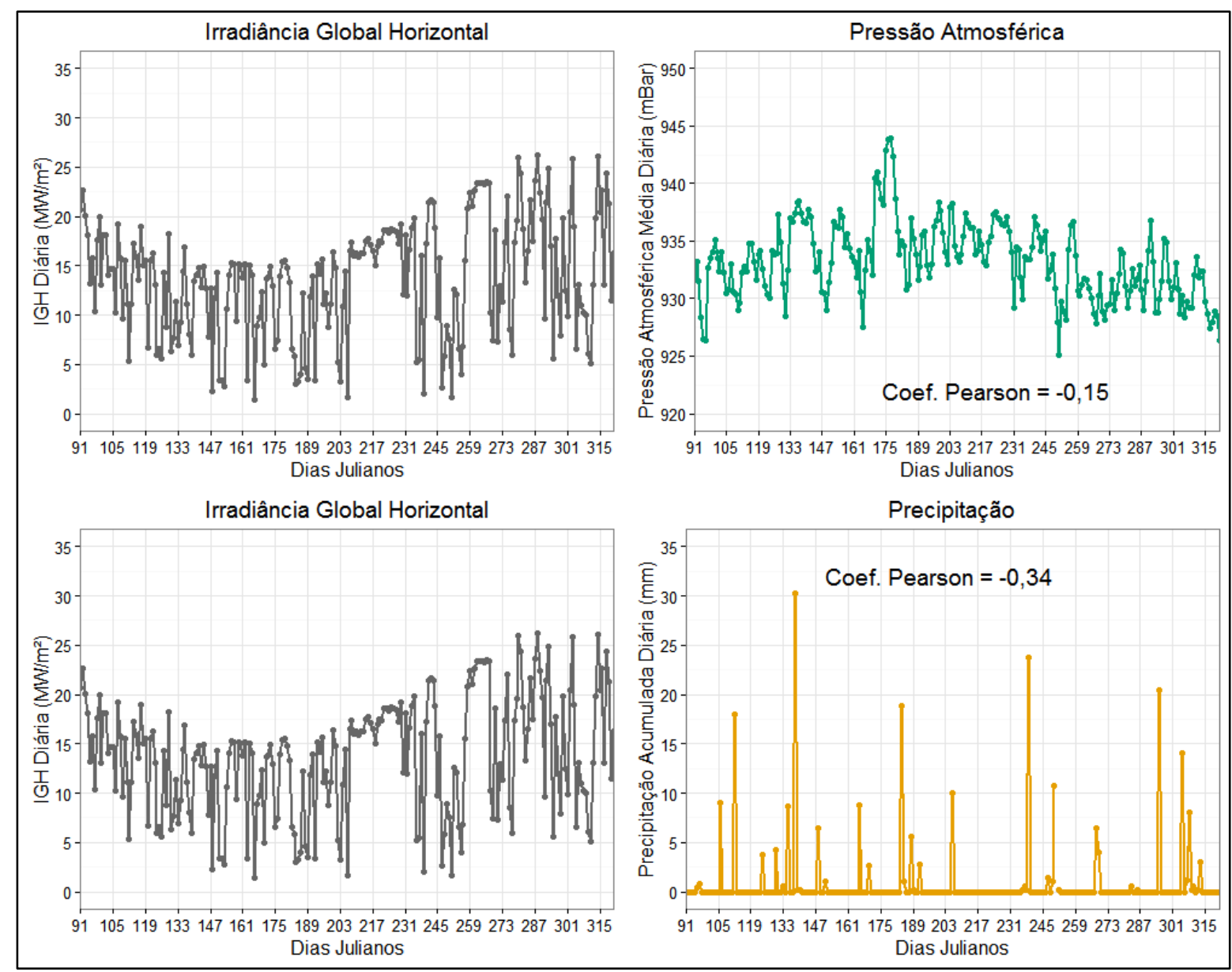

Fonte: Elaboração própria

As correlações entre as series de $I G H$ e pressão atmosférica e $I G H$ e precipitação são: muito fraca negativa e fraca negativa, respectivamente. $\mathrm{O}$ padrão apresentado foi bem próximo ao encontrado com os dados da ESUPP.

O coeficiente mínimo absoluto para estabelecer uma correlação forte é 0,8 , como a correlação com dados de temperatura verificada é bem próxima desse valor, define-se que modelos empíricos tomando como elemento principal a temperatura são promissores para a estimativa de irradiância da região, dada a baixa disponibilidade de série sequencial de medições (inferior a um ano) e a limitação de tempo para o desenvolvimento dessa pesquisa, não foram testados modelos empíricos de estimativa de irradiação diária média para a região, 
assim como não foram testados modelos de decomposição para estimativa diária média de irradiação difusa ou direta, sob a mesma justificativa e reflexão apresentada na seção 7.4.1.

É importante evidenciar que a análise do coeficiente de Pearson para diferentes hidrelétricas (seção 4.4) foi realizada para médias diárias mensais, enquanto que a análise com os dados da ESPEL e ESUPP foi realizada para médias diárias. Por meio do acesso a séries históricas maiores seria possível verificar se a análise por meio do coeficiente de Pearson gera resultados muito discrepantes considerando essas duas médias diferentes (diária ou mensal).

\subsubsection{Energia Média Disponível}

Foram calculados os valores médios horários de IGH para cada dia de cada mês e depois foi calculada a média mensal de cada hora, em $\mathrm{kWh} / \mathrm{m}^{2}$. Os resultados são apresentados nos gráficos no Apêndice 7. Para a composição desses gráficos foi utilizada toda a série histórica de dados de $I G H$ e não apenas aqueles que compreendem ângulo zenital inferior à $75^{\circ}$, de modo que seja possível a percepção das horas médias de nascer e pôr do sol de cada mês.

A Tabela 22 apresenta os valores médios diários para cada mês e apresenta os valores do montante mensal de energia.

Tabela 22 - Consolidação do montante de energia disponível

\begin{tabular}{|c|c|c|}
\hline Mês & $\begin{array}{r}\text { Montante } \\
\text { Mensal } \\
\left(\mathbf{k W h} / \mathbf{m}^{2}\right)\end{array}$ & $\begin{array}{r}\text { Montante } \\
\text { Médio Diário } \\
\left(\mathrm{kWh} / \mathrm{m}^{2}\right)\end{array}$ \\
\hline Abril 2015 & 129,50 & 4,32 \\
\hline Maio 2015 & 97,45 & 3,14 \\
\hline Junho 2015 & 99,67 & 3,32 \\
\hline Julho 2015 & 94,72 & 3,05 \\
\hline Agosto 2015 & 145,74 & 4,70 \\
\hline Setembro 2015 & 120,48 & 4,01 \\
\hline Outubro 2015 & 153,75 & 4,96 \\
\hline Novembro 2015 & 139,10 & 4,63 \\
\hline Dezembro 2015 & 157,20 & 5,07 \\
\hline Janeiro 2016 & 170,24 & 5,49 \\
\hline Fevereiro 2016 & 158,10 & 5,45 \\
\hline Março 2016 & 147,11 & 4,74 \\
\hline $\begin{array}{l}\text { Total/Média } \\
\text { Diária Anual }\end{array}$ & $1.613,06$ & 4,41 \\
\hline
\end{tabular}




\begin{tabular}{lrr}
\hline Mês & $\begin{array}{r}\text { Montante } \\
\text { Mensal } \\
\left(\mathbf{k W h} \mathbf{m}^{\mathbf{2}}\right)\end{array}$ & $\begin{array}{r}\text { Montante } \\
\text { Médio Diário } \\
\left(\mathbf{k W h} \mathbf{m}^{2}\right)\end{array}$ \\
\hline Abril 2016 & 150,60 & 5,02 \\
\hline Maio 2016 & 101,87 & 3,29 \\
\hline Junho 2016 & 99,20 & 3,31 \\
\hline Janeiro 2015 & 192,48 & 6,21 \\
\hline
\end{tabular}

Fonte: Elaboração própria

Os meses de abril e maio de 2016 apresentaram montantes de irradiação disponível $16,2 \%$ e $4,5 \%$ superiores aos mesmos meses de 2015, respectivamente. Junho apresentou basicamente o mesmo montante de irradiação disponível para os dois anos, enquanto que janeiro de 2016 apresentou um montante de irradiação disponível 11,5\% inferior ao montante do mesmo mês de 2015. Assim, pela análise da Tabela 22 e das CDPs verifica-se que ocorrem variações relevantes entre o mesmo mês de anos diferentes, embora alguns padrões de comportamento possam ser delineados, principalmente de posse de séries históricas maiores. Assim, com o intuito de unificar os aspectos discutidos, buscou-se a consolidação das informações para os 4 meses presentes tanto na série anual, quanto na série auxiliar, produzindo a caracterização do dia típico de cada mês.

Quadro 18 - Caracterização do recurso solar na região da ES Poli Elétrica

\begin{tabular}{|l|l|}
\hline Montante Médio de Energia & Dia Característico de Janeiro \\
\hline $\begin{array}{l}\text { Comportamento } \\
\text { Probabilístico }\end{array}$ & $\begin{array}{l}\text { Condições atmosféricas variáveis para o período da manhã. } \\
\text { Probabilidade de índice de transmitância atmosférica entre } \\
0,4 \text { e } 0,6 \text { em mais de } 40 \% \text { do tempo e entre } 0,1 \text { e } 0,3 \text { em } \\
30 \% \text { do tempo para o período da manhã e meio dia. } \\
\text { Condições de céu nebuloso para o período da tarde, com } \\
\text { probabilidade de índices de transmitância atmosférica entre } \\
0 \text { e } 0,2 \text { em } 60 \% \text { do tempo. }\end{array}$ \\
\hline Montante Médio de Energia & $\begin{array}{l}\text { Dia Característico de Abril } \\
\text { Comportamento }\end{array}$ \\
\hline Probabilístico & $\begin{array}{l}\text { Condições atmosféricas relativamente estáveis e sem } \\
\text { nebulosidade para o período da manhã. Probabilidade de } \\
\text { índice de transmitância atmosférica entre } 0,7 \text { e } 0,9 \text { em mais } \\
\text { de } 50 \% \text { do tempo para o período da manhã e meio dia. } \\
\text { Condições de céu nebuloso e instável para o período da } \\
\text { tarde, com probabilidade de índices de transmitância } \\
\text { atmosférica entre 0,6 e } 0,8 \text { em } 30 \% \text { do tempo e com } \\
\text { probabilidade de índices de transmitância atmosférica entre } \\
0,1 \text { e } 0,3 \text { em } 25 \% \text { do tempo. }\end{array}$ \\
\hline
\end{tabular}




\begin{tabular}{|c|c|}
\hline \multicolumn{2}{|r|}{ Dia Característico de Maio } \\
\hline Montante Médio de Energia & $3,21 \mathrm{kWh} / \mathrm{m}^{2}$ \\
\hline $\begin{array}{l}\text { Comportamento } \\
\text { Probabilístico }\end{array}$ & $\begin{array}{l}\text { Condições atmosféricas instáveis, com nebulosidade } \\
\text { variável para período da manhã. Probabilidade de índice de } \\
\text { transmitância atmosférica entre } 0,8 \text { e } 1,0 \text { em de } 35 \% \text { do } \\
\text { tempo e probabilidade de índice de transmitância } \\
\text { atmosférica entre } 0,3 \text { e } 0,5 \text { em mais de } 32 \% \text { do tempo. } \\
\text { Condições de céu nebuloso e bastante instável para o } \\
\text { período da tarde. Probabilidade de índices de transmitância } \\
\text { atmosférica entre } 0,1 \text { e } 0,3 \text { em } 23 \% \text { do tempo. Probabilidade } \\
\text { de índices de transmitância atmosférica entre } 0,8 \text { e } 0,1 \text { em } \\
28 \% \text { do tempo. Probabilidade de índices de transmitância } \\
\text { atmosférica entre } 0,3 \text { e } 0,5 \text { em } 30 \% \text { do tempo. Probabilidade } \\
\text { de índices de transmitância atmosférica superior a } 1 \text { em } \\
13 \% \text { do tempo. }\end{array}$ \\
\hline \multicolumn{2}{|r|}{ Dia Característico de Junho } \\
\hline Montante Médio de Energia & $3,31 \mathrm{kWh} / \mathrm{m}^{2}$ \\
\hline $\begin{array}{l}\text { Comportamento } \\
\text { Probabilístico }\end{array}$ & $\begin{array}{l}\text { Condições atmosféricas estáveis, e condições de céu limpo } \\
\text { para período da manhã. Probabilidade de índice de } \\
\text { transmitância atmosférica entre } 0,9 \text { e } 1,2 \text { em de } 55 \% \text { do } \\
\text { tempo e probabilidade de índice de transmitância } \\
\text { atmosférica entre } 0,3 \text { e } 0,5 \text { em } 20 \% \text { do tempo. } \\
\text { Condições atmosféricas estáveis, e condições de céu limpo } \\
\text { período da tarde. Probabilidade de índice de transmitância } \\
\text { atmosférica entre } 0,9 \text { e } 1,2 \text { em de } 55 \% \text { do tempo e } \\
\text { probabilidade de índice de transmitância atmosférica entre } \\
0,3 \text { e } 0,5 \text { em } 16 \% \text { do tempo. Apresentando estabilidade } \\
\text { ligeiramente maior que o período da manhã. }\end{array}$ \\
\hline
\end{tabular}

Fonte: Elaboração própria

\subsection{CONSOLIDAÇÃO DOS RESULTADOS E DISCUSSÕES}

Com base em todas as análises e cálculos realizados nesse capítulo pode-se consolidar e pontuar os seguintes resultados:

I. Existe uma dificuldade de obtenção de séries históricas completas e sequenciais, dada a verificação de uma série de problemas e manutenções nos equipamentos das duas estações solarimétricas analisadas.

II. Os procedimentos de tratamento de dados têm uma relação bastante forte com a análise dos aspectos temporais do recurso. Verifica-se isso por meio da análise de $k_{t c}$ e das variações de medições subsequentes. Ambos os processos são um referencial tanto para a análise de disponibilidade em curto prazo como para a análise de qualidade dos dados. 
III. A análise de $k_{t c}$ também se mostra como referencial para a determinação de modelos de decomposição para estabelecimento de valores faltantes da série histórica de IDN e $I D H$ já que, verificando os dados da ESPEL define-se que a relação $I G H=I D N *$ $\cos z+I D H$ não define valores das componentes condizentes com a série histórica.

IV. Série histórica de um ano não é suficiente para a determinação de padrão mensal de comportamento do recurso em função de divisões de massa de ar já que a quantidade de dados disponíveis é pequena, gerando CDPs muito heterogêneas e sem aparente padrão de comportamento.

V. A utilização de dois anos de série histórica resultou em curvas mensais com padrão melhor definido em relação à alteração de massas de ar.

VI. A relação entre curvas probabilísticas mensais para diferentes massas de ar, considerando a diferenciação entre massas de ar do período da manhã e do período da tarde, só pode ser considerada tendo à disposição, no mínimo três anos de medições. Define-se esse período já que dados de um único mês não foram suficientes nem para a divisão tradicional de massas de ar por mês. Como foram verificadas diferenças significativas entre as CDPs de um mesmo mês para anos diferentes é importante a construção das curvas para mais uma amostra mensal, de modo a verificar se as diferenças entre as curvas ao menos obedecem aos mesmos $k_{t}$ para os pontos de inflexão.

VII. Tradicionalmente, as CDPs de $k_{t}$ e $k_{b}$ verificadas obedecem caracter bimodal. Contudo, verificou-se que não necessariamente isso ocorre. As curvas anuais de $k_{t}$ para os dados da ESPEL apresentaram caráter trimodal, enquanto que as curvas de $k_{b}$ apresentaram caráter unimodal. Portanto, no caso de geração de modelos a partir dessa análise probabilística, é importante analisar se o recurso na dada localidade obedece ou não o perfil de curvas tradicionalmente adotado.

VIII. A análise das CDPs de $k_{b}$ mostrou que, coerentemente, a quantidade de medições iguais ou próximas à zero, aumentam conforme ocorre o aumento da massa de ar.

IX. A análise das CDPs de $k_{d}$ mostrou que, coerentemente, valores mais altos do coeficiente são encontrados à medida que os níveis de massa de ar aumentam, contudo, esse coeficiente mostrou baixa relação de comportamento conforme alteração de massa de ar.

X. Não é possível a utilização de um dia característico para cada estação do ano, já que as curvas mensais apresentaram comportamentos bastante diferentes. 
XI. O resultado da metodologia K-POP, definiu o recurso na região da ESUPP como de média à grande qualidade e de média a grande quantidade. Já para a região da ESPEL o recurso ficou definido como de baixa a média qualidade, ou seja, com vários graus de nebulosidade ao longo de dia, e de pequena quantidade.

XII. A geoanálise do recurso não apresentou fortes relações de comportamento. Uma análise das relações em intervalos de tempos diferentes poderia ter apresentado relações mais relevantes, de modo que as variáveis climáticas poderiam ser utilizadas para previsão da disponibilidade de recurso em curto prazo, e não para os montantes mensais ou anuais de energia. Dados de velocidade e direção do vento não são utilizados nos modelos e aparentemente não possuem influência na disponibilidade do recurso solar em solo, sendo necessária a validação de uma possível relação para intervalos de tempos diferentes.

XIII. O intuito da geoanálise é identificar variáveis climatológicas que apresentam correlação com o comportamento da irradiação, favorecendo a escolha de um modelo empírico de estimativa de irradiação. É importante observar que: uma correlação não necessariamente significa uma relação de causalidade. Assim, na possível identificação de variáveis climáticas balizadoras, não se pode afirmar que a variável em questão é de fato responsável pelo aumento ou diminuição da incidência de irradiação, mas sim, que a determinada variável pode ser um parâmetro facilitador no cálculo da estimativa dessa incidência e na escolha ou criação de um modelo empírico de estimativa. Já que, conforme discutido ao longo desse estudo, são inúmeras as variáveis que podem contribuir para a disponibilidade e variabilidade da energia primária solar em uma determinada região.

XIV. A média diária parcial anual de disponibilidade do recurso para a região da ESUPP é de $5,29 \mathrm{kWh} / \mathrm{m}^{2}$, enquanto a média diária anual de disponibilidade do recurso para a região da ESPEL é de $4,41 \mathrm{kWh} / \mathrm{m}^{2}$.

XV. A formação final ideal do dia característico de cada mês pode ser definida pela caracterização da disponibilidade média de energia por dia e por hora do dia, seguida da definição das maiores probabilidades correspondentes a valores de $k_{t}$ (e os seus respectivos valores em $\mathrm{W} / \mathrm{m}^{2}$ ) para as determinadas 9 massas de ar definidas e da probabilidade média de flutuação do recurso para a região. A principal dificuldade dessa formatação está na "tradução" dos intervalos de massa de ar para horários do dia. Tomando como exemplo $A M=1,0$ para abril, tem-se que, no primeiro dia do 
mês, essa massa de ar corresponde a um período de 2 horas e 50 minutos, já no dia 15 de abril, o período correspondente é de 50 minutos, a partir do dia 16 essa massa de ar não é verificada, voltando a ser recorrente apenas no mês de julho. A mesma massa de ar para janeiro dura cerca de 4 horas e 30 minutos com variações de poucos minutos entre o primeiro e último dia do ano, enquanto que, no mesmo mês, $A M=$ 3,0M dura em média 10 minutos, com variações da hora de início superiores a esse intervalo para o primeiro e o último dia do mês. Nesse sentido também é importante reconsiderar os intervalos utilizados para a formação de cada AM nominal já que determinados valores não estão compreendidos em nenhum intervalo e representam uma falta que pode ser superior a 1 hora na consideração das medições, dependendo do mês analisado. Portanto não é possível estimar horários médios mensais para cada AM nominal, sendo necessário a utilização da equação que define o ângulo zenital para a determinação diária dos horários que compreendem cada massa de ar equação (5) - e, a partir daí, determinar o coeficiente de transmitância mais provável para cada intervalo de tempo.

XVI. Tal análise de probabilidade dos índices de transmitância se torna completa se, a análise das taxas de alteração de medições subsequentes também fosse realizada para cada massa de ar. Deste modo, define-se para cada período do dia, o índice de transmitância provável, a taxa de variação provável e a quantidade média de energia disponível.

A partir dos resultados obtidos é realizada uma nova análise do fluxograma de processos de caracterização (Figura 51). Assim foi produzido o novo fluxograma apresentado na Figura 84.

A principal mudança produzida foi a alteração do critério de um ano de medições para três anos de medições para a construção das CDPs em função das massas de ar, já que essa metodologia considera a divisão do espaço amostral em 9 intervalos diferentes de massas de ar. Outra alteração foi a exclusão da possibilidade de formação de dias característicos por estação climática já que os perfis, tanto probabilísticos quanto de quantidade média de energia disponível variaram significantemente mês a mês.

No fluxograma também foram incluídas três novas etapas: "Caracterização do Dia Típico Probabilístico Mensal”, "Consideração das informações da caracterização do ano típico" e "Caracterização do Dia Típico Mensal”. 
Essa alteração foi feita com o intuito de evidenciar que a definição probabilística de $k_{t}, k_{d}$ e $k_{b}$ não configura um modelo final de estimativa de disponibilidade do recurso. É importante "traduzir" os horários referentes à cada intervalo de massa de ar, visto que essa informação não é constante e é essencial para que esses cálculos se transformem em uma ferramenta útil para a previsibilidade do recurso. Contudo, verifica-se que essa tradução não compreende intervalos mensais, mais sim diários, portanto, a definição desse processo pode configurar um modelo de previsão de curto prazo do recurso.

Além das modificações já explicitadas também foi acrescentada a etapa de definição de "Variável climática balizadora temporal". Essa etapa, que por questão de limitação de tempo não foi validada nesse estudo, configura a determinação de relações entre a irradiância e as variáveis climáticas em intervalos de tempo diferentes. Ou seja, a verificação de comportamentos climáticos que antecedem à uma determinada disponibilidade do recurso futuro. Nessa análise, pode-se verificar eventos tais como: o aumento de ventos em conjunto com queda de pressão atmosférica no momento $t$ sinaliza chuva no momento $t+1 \mathrm{e}$ consequentemente queda da disponibilidade do recurso solar no momento $t+1$. Assim a etapa definida como "Variável climática balizadora geográfica" define as análises discutidas nesse estudo sobre a formação de modelos empíricos de definição da disponibilidade do recurso a longo prazo. 
Figura 84 - Fluxograma validado das atividades visando à modelagem

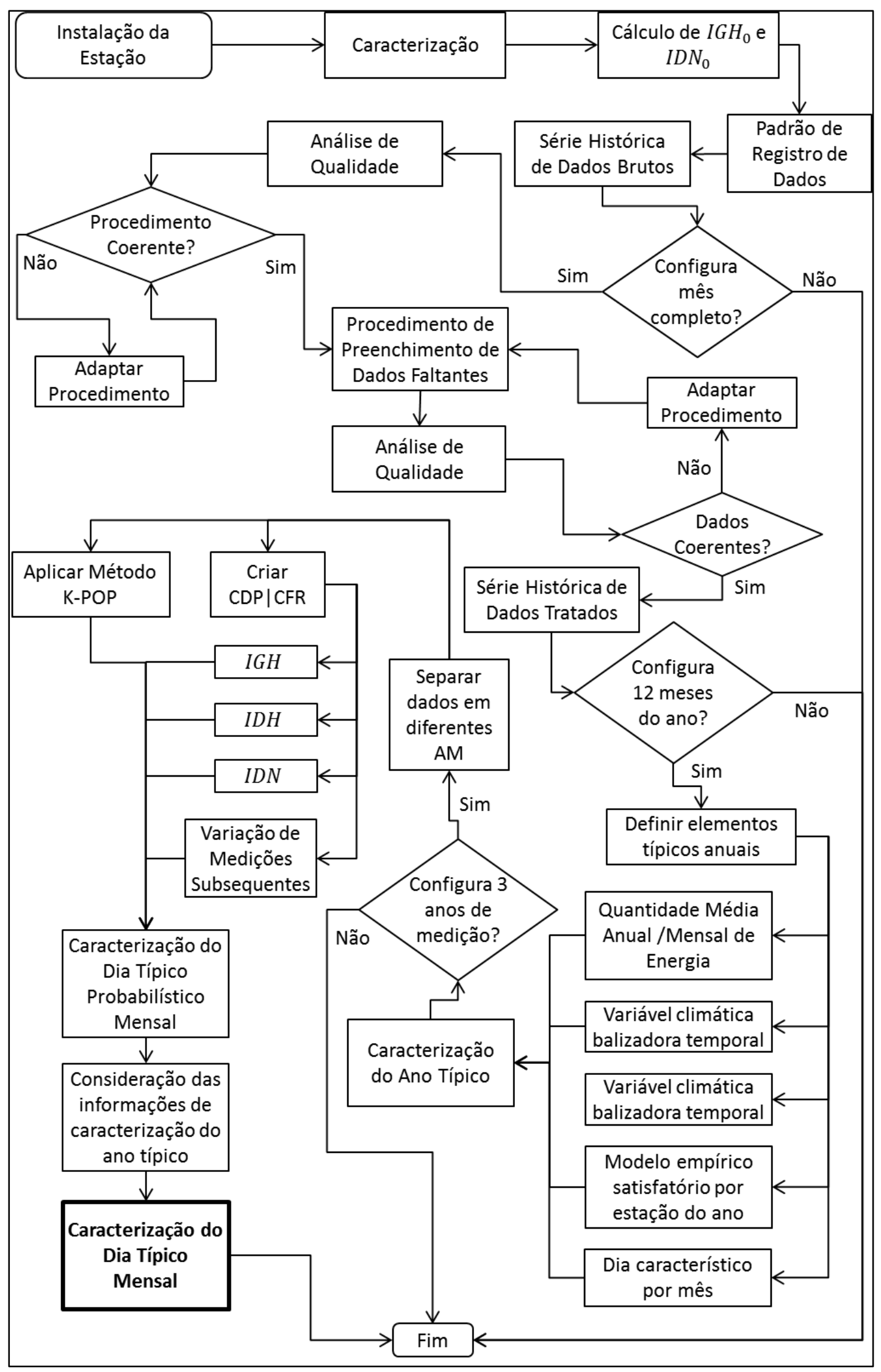

Fonte: Elaboração própria 


\section{CONCLUSÕES}

Esse estudo apresenta, analisa e sistematiza os elementos necessários à modelagem da energia primária solar para geração fotovoltaica em escala a partir de dados medidos em solo por uma estação solarimétrica. Assim esse estudo busca percorrer os principais aspectos acerca da fonte de energia solar primária para geração fotovoltaica e acerca da solarimetria visando a modelagem dessa energia por meio de medições em solo.

Nesse sentido, define-se a modelagem como o processo de construção de séries históricas somado ao conhecimento de eventos específicos do comportamento do recurso, visando a identificação da probabilidade de ocorrência futura desses eventos específicos, permitindo assim, a previsão da disponibilidade futura de energia.

Conclui-se, portanto, que a modelagem do recurso solar para geração fotovoltaica em escala se faz em dois momentos: (i) previsão da disponibilidade do recurso em longo prazo importante para a definição de potenciais de geração, cálculo de energia firme e viabilização econômica dos projetos e (ii) previsão da disponibilidade do recurso em curto e curtíssimo prazo - importante para a operação de usinas fotovoltaicas, principalmente daquelas de despacho centralizado.

As perspectivas de crescimento do uso da energia solar na matriz elétrica brasileira geram a necessidade de aprimorar o conhecimento nacional acerca da obtenção e tratamento dos dados de radiação. Nesse sentido, verificam-se, na bibliografia nacional, pouquíssimos estudos relacionados à solarimetria e construção de séries históricas de radiação. Os estudos acerca da solarimetria para geração de energia não possuem metodologias completamente consolidadas internacionalmente. No Brasil, se verificam poucos esforços no sentido de completar essas lacunas de conhecimento.

Esse estudo mostra que a modelagem da energia primária solar, embora possua ferramentas que possam ser amplamente utilizadas - como determinados parâmetros de qualidade de dados e modelos matemáticos - necessita de procedimentos específicos para cada região em estudo. A variabilidade do recurso está totalmente vinculada às especificidades climáticas de cada região, e carecem de um olhar atento e preciso das medições realizadas. Assim comprova-se que a melhor estimativa que se pode obter da radiação solar é por meio da formação de séries históricas oriundas de dados medidos por estações solarimétricas.

Essas estações possuem altos custos de aquisição, manutenção e operação. A instalação destas deve ocorrer em regiões de interesse e com perspectivas de aproveitamento 
do recurso solar, de modo a serem viabilizadas economicamente na atualidade, ainda nessas condições, o fornecimento desses equipamentos no Brasil ainda enfrenta obstáculos, principalmente no que diz respeito à instalação, manutenção e operação. Pela análise de dados de duas estações verifica-se uma série de entraves relacionados ao processo de instalação dos equipamentos (como a instalação incorreta de comprimento de cabos, favorecendo o enroscamento dos mesmos no rastreador solar e ocasionando o rompimento das instalações e a instalação do sunsensor e a instalação incorreta dos sensores de umidade relativa e temperatura). Outro entrave é o tempo necessário para correção das falhas apresentadas. Como os fornecedores dos equipamentos ainda não possuem instalações nacionais, a correção de problemas nos equipamentos muitas vezes exige o transporte dos mesmos para fora do país, acarretando em falhas de meses nas séries históricas. Assim, conclui-se que, dada a eminente exigência da EPE de necessidade de um ano de medições contínuas de $I G H$ para aceite de projetos no leilão de energia, os interessados devem se preocupar com o planejamento de instalação dessas estações para períodos superiores a um ano e incorporar o risco da não obtenção de um ano de medições contínuas em um ano de estação instalada na elaboração dos projetos.

A análise realizada com as normais climatológicas e a estimativa da quantidade de estações instaladas permite evidenciar a grande dificuldade em âmbito nacional na obtenção de séries históricas e na obtenção de informações acerca das estações de medição, tanto climatológicas, quanto solarimétricas, sendo este o principal desafio para o aprimoramento da construção de séries históricas e da caracterização do recurso. É importante observar que, o avanço tecnológico obtido na área da solarimetria (e não restrita a ela) permitiu o acesso à uma grande quantidade de dados em curtos períodos de tempos, o que acarreta na necessidade recente de desenvolvimento dos métodos de tratamento de grandes massas de dados, antes inexistentes.

A identificação de grupos e trabalhos acerca da solarimetria permite o acesso às suas produções bibliográficas que norteiam e embasam grande parte das informações contidas em todos os capítulos deste trabalho. Este mapeamento também permite a visualização da escassez de dados de qualidade em âmbito mundial e nacional. Programas voltados a esse fim, como a Rede SONDA e o BSRN possuem pouquíssimas estações vinculadas. O desenvolvimento e análise de mecanismos de qualidade de dados, que sejam coerentes à realidade brasileira, configuram uma oportunidade de desenvolvimento de pesquisa. São poucas as referências nacionais acerca desse tema de modo que não há uma averiguação se 
metodologias definidas por órgãos e instituições internacionais suprem a necessidade de entendimento e comprovação da qualidade das medições no Brasil. Outra oportunidade de desenvolvimento de pesquisa é a criação de ferramentas computacionais e algoritmos para a execução dos procedimentos de análise de qualidade de dados, visto a grande quantidade de informações a ser analisada.

Esse estudo assegura e evidencia o quão importante é o estabelecimento de um procedimento de tratamento e análise de qualidade da série histórica de modo que se produza, mês a mês, uma série de dados tratados com o respectivo registro da rotina de tratamento e das alterações produzidas na série de dados brutos, essas análises fazem parte da caracterização do recurso e através delas, parte dos aspectos necessários à modelagem começa a ser estruturado.

$\mathrm{O}$ efeito fotovoltaico possui uma forte relação de dependência com intervalos de comprimentos de onda. Por isso esse estudo busca não só a análise da irradiância global, mas também das parcelas difusa e direta. Uma caracterização mais detalhada do comportamento dessas parcelas favorece a definição dos fatores de eficiência dos painéis, já que a modelagem discriminada para as três componentes não só apresenta uma perspectiva da quantidade total do recurso disponível, mas também oferece elementos para uma possível caracterização dos comprimentos de onda incidentes em função da proporção da radiação direta e difusa incidente. $\mathrm{O}$ mesmo se aplica à análise da taxa de variação de medições subsequentes. A variabilidade do recurso afeta a eficiência de geração já que as tecnologias têm uma capacidade limitada em se adaptar às flutuações da irradiância incidente. Nesse sentido, conclui-se que a análise das taxas de variações subsequentes deve ser considerada tanto em modelos de previsibilidade do recurso de curto prazo, quanto nos modelos de longo prazo.

Tratando-se ainda da questão da variabilidade, o método K-POP se apresentou como um recurso de caracterização geral da fonte, já que ele apresenta a probabilidade da não ocorrência de flutuações significativas, mas não apresenta a probabilidade de altas flutuações e tão pouco a ordem de grandeza das alterações verificadas.

A análise realizada dos coeficientes de transmitância em função das massas de ar mostra que, para a formação de um dia característico mensal do recurso são necessários ao menos uma série histórica de três anos de duração. A análise com massas de ar diferenciadas para o período da manhã e da tarde mostra que esse insumo deve ser considerado para a formação de modelos de previsibilidade de curto e curtíssimo prazo do recurso já que foram verificadas alterações significativas no perfil dos índices de transmitância para os períodos da 
manhã e da tarde. Contudo, a identificação das probabilidades em função da massa de ar, carece da tradução das massas de ar em horários para cada dia do ano. Deste modo, essa constatação se define enquanto sugestão para estudos futuros.

As CDPs dos índices de transmitância não necessariamente obedecem o mesmo perfil de curvas para regiões diferentes, foram encontradas curvas trimodais e unimodais que até então não haviam sido verificadas nos estudos encontrados sobre o assunto. Nesse sentido supõe-se que a poluição exerce uma interferência significativa no comportamento do recurso, de modo que os índices de poluição e de concentração de material particulado na atmosfera possam ser considerados enquanto insumos para modelos de previsibilidade do recurso. $\mathrm{O}$ estudo aprofundado da relação entre a poluição e disponibilidade do recurso e da relação entre a poluição e a correlação entre as parcelas de irradiância global difusa e direta também são apontados como sugestões para estudos futuros.

Dada a limitação de tempo para elaboração desse estudo, a geoanálise do recurso não foi analisada em profundidade, de modo que novas relações entre as variáveis climáticas podem ser investigadas, principalmente aquelas que compreendem momentos temporais diferentes. Esse assunto também fica apontado nesse estudo como sugestão para estudos futuros, incluindo inclusive uma discussão aprofundada acerca da identificação de correlações e a sua relação com o efeito de causalidade.

Por meio da análise realizada a partir de normais meteorológicas, verifica-se que dados de insolação, nebulosidade e evaporação podem possuir relações interessantes com o comportamento da irradiação, portanto, poderiam fazer parte da composição de uma estação solarimétrica modelo.

Assim é possível constatar a necessidade de definição de um modelo universal de previsibilidade do recurso e verifica-se que os insumos mais relevantes para o modelo podem variar de região para região dada a caracterização geográfica e de microclima apresentadas.

Conclui-se, portanto, a indiscutível necessidade de dados radiométricos confiáveis medidos em solo para avanços científicos, tecnológicos e comerciais do aproveitamento do recurso solar como fonte energética, diante do atual contexto da busca por fontes alternativas de energia limpa e evidencia-se o grande caminho a ser percorrido para a consolidação de uma rede confiável, monitorada e amplificada de medições solarimétricas no Brasil e no mundo. 


\section{REFERÊNCIAS BIBLIOGRÁFICAS}

ABNT. [Associação Brasileira de Normas Técnicas]. NBR 10899:2013: Energia Fotovoltaica - Terminologia. 2013.

ALLEN R. Self-calibrating method for estimating solar radiation from air temperature. Journal of Hydrology, Utah, v. 2, n. 2, p. 56-67, 1997. 9

ASSUNÇÃO H.F. et al.. Modelling frequency distributions of 5 minute-averaged solar radiation indexes using Beta probability functions. Theoretical and Applied Climatology, vol. 75, pp. 213-224. 2003

AUSTRÁlIA. Bureau of Meteorology. Townsville Meteorological Office Photographs. Disponível em: <http://www.bom.gov.au/qld/townsville/photos.shtml>. Acesso em: 6 maio 2014

BENDT, P..The frequency distribuntion of daily insolation values. Solar Energy, v.27, pp. 119, 1981.

BRASIL. Centro de Previsão de Tempo e Estudos Climáticos. Desempenho do modelo GL versão 1.2 variável: radiação global diária. Época de análise: 2005. 2005. Disponível em: <http://satelite.cptec.inpe.br/radiacao/docs/GLAnalise2005janjun.pdf>. Acesso em 11 outubro 2014

BRASIL. Agência Nacional de Energia Elétrica. Superintendência de Pesquisa e Desenvolvimento e Eficiência Energética - SPE. Estação solarimétrica e equipamento de medição associados à Chamada de Projeto de P\&D Estratégico No 013/2011.Fl. 02 do Ofício Circular no 0004/2012-SPE/ANEEL, de 16/08/002, 2012.

BRASIL. Instituto de Pesquisas Especiais. Sistema de Organização Nacional de Dados Ambientais: Validação dos dados d disponível em: <http://sonda.ccst.inpe.br/infos/validação.html>. Acesso em: 05 março 2015.

BRASIL. Empresa de Pesquisa Energético. Plano Decenal de Expansão de Energia 2023. Ministério de Minas e Energia, Secretaria de Planejamento e Desenvolvimento EnergéticoEmpresa de Pesquisa Energética: Rio de Janeiro, 2014a. 
BRASIL. Instituto de Pesquisas Especiais. Sistema de Organização Nacional de Dados Ambientais. Disponível em: <http://sonda.ccst.inpe.br/infos/sobre_projeto.html>. Acesso em: 10 junho 2014. 2014b.

BRASIL. Instituto Nacional de Meteorologia. Normais Climatológicas do Brasil, 19611990. Disponível em: www.inmet.gov.br. Acesso em:16 julho 2014.2014c.

BRASIL. Operador Nacional do Sistema. Séries Históricas de Vazão. Disponível em: http://www.ons.org.br/operacao/vazoes_naturais.aspx. Acesso em: 5 julho 2014. 2014d

BRASIL. Empresa de Pesquisa Energética. Empresa de Pesquisa Energética: Destaque de leilões. Disponível em: <http://www.epe.gov.br/leiloes/Paginas/default.aspx>. Acesso em 30 março 2016

BORGES. V.P. et al. Avaliação de Modelos de Estimativa da Radiação Solar Incidente em Cruz das Almas, Bahia. Revista Brasileira de Engenharia Agrícola e Ambiental, Campina Grande, v.14, n.2, p.74-80. 2009

CARVALHO. F. J. et al. Avaliação de Modelos de Estimativa da Radiação Solar com Base na Temperatura do Ar para o Norte de Minas Gerais. Em CONGRESSO BRASILEIRO DE AGROMETEOROLOGIA, XVII, Guarapari. 2011. Anais... Guarapari: XVIICBA, 2011. s/p.

CAMPOS, F. S.. Estudo da variabilidade de precipitação. 56 p. 1990. Monografia (Graduação) Instituto Tecnológico da Aeronáutica. São José dos Campos, 1990.

CEBALlOS, J. C.. et al. Desempenho de Heliógrafos e Actinógrafos na Estimativa de Insolação e Fluxo Direcional. Revista Brasileira de Meteorologia, São José dos Campos, v.7, n. 2, p.563-581. 1992.

CIBA. Sensors installed in C.I.B.A: Atmosphere \& Energy Lab. Disponível em: <http://www3.uva.es/renova/eng/sensors.htm>. Acesso em: 4 abril 2014.

COULSON, K. L. Solar and Terrestrial Radiation: Methods and Measurements. New York: Academic Press Inc., 1975.

CROS, S.; WALD,L.. Survey of the Main Databases Providing Solar Radiation Data at Ground Level. In ANNUAL SYMPOSIUM REMOTE SENSING IN TRANSITION, 23 ${ }^{\text {rd }}$, 2003, Ghent, Belgium. Anais...Milpress; 2004. Pg. 491-497. 
DANTAS, S. F. de M.. Métodos de Estimativas da Irradiância Solar Global para os Extremos do Período Chuvoso (Abril) e Período Seco (Outubro) em Ambiente Semiárido no Rio Grande do Norte. 2013. 36f. Monografia (Graduação). Universidade Federal Rural do Semi- Árido. Angicos, 2013.

DE LA CASA, A. et al. Estimación de la radiación solar global en la provincia de Córdoba, Argentina, y su Empleo en un Modelo de Rendimiento Potencial de Papa. Revista de Investigaciones Agropecuarias. Buenos Aires, v. 32, n. 2, p. 45-61. 2003

DIAS, N. L.; DUARTE, H. F.. Obtenção de um Índice de Nebulosidade do Céu a partir da Análise de Dados de Radiação Solar. Em CONGRESSO BRASILEIRO DE METEOROLOGIA, XII, Foz do Iguaçú. 2002.Anais... XIICBM, 2002. Pg. 2700 - 27005.

DGS. Energia Fotovoltaica: manual sobre tecnologias, projecto e instalação. Lisboa: Greenpro, 2005.

ECHER, M. P. de Souza; et al.. A importância dos dados de cobertura de nuvens e de sua variabilidade metodologias para aquisição de dados. Revista Brasileira do Ensino de Física, São Paulo, v. 28, n. 3, p.341-352, 2006.

EPPLEY. The Eppley Laboratory Inc.. Disponível em: <http://www.eppleylab.com/>. Acesso em: 20 junho 2014

ETH. Swiss Federal Institute of Technology Zurich. Global Energy Balance Archive: Metadata. Disponível em: < http://www.geba.ethz.ch/retrieval/Metadata>. Acesso em 11 outubro 2014

EUA [Estados Unidos da América]. Central Intelligence Agency. The World Factbook. Disponível em: <https://www.cia.gov/library/publications/the-worldfactbook/rankorder/2147rank.html>. Acesso em: 28 junho 2014.

EUA [Estados Unidos da América]. National Oceanic and Atmospheric Administration. U.S. Department Of Commerce. Earth System Research Laboratory: Global Monitoring Division. Instruments mounted on the Albuquerque solar tracker include, from left to right, a total solar pyranometer, a diffuse pyranometer, and a UV-B Biometer. Disponível em: <http://esrl.noaa.gov/gmd/grad/isis/abq.html>. Acesso em: 23 novembro 2015 
EUA [Estados Unidos da América]. High Energy Astrophysics Science Archive Research Center. Astrophysics Science Division of National Aeronautics and Space Administration. Question: What is the solar cycle. Disponível em: < http://starchild.gsfc.nasa.gov/docs/StarChild/questions/question17.html >. Acesso em: 11 setembro 2016

FERNEDA, B. G. et al. Avaliação de Quatro Modelos Simplificados de Estimativa da Radiação Global Horária para a Região de Sinop, MT. Em CONGRESSO BRASILEIRO DE ENGENHARIA AGRÍCOLA, XLIII. Campo Grande, 2014. Anais...COMBEA, 2014. s/p.

FRISINA, V.A.. Estimativa da radiação fotossinteticamente ativa (PAR) em estufa de polietileno. Em ENCONTRO DE ENERGIA NO MEIO RURAL, 3. Campinas, 2000. Registros... 2003. s/p

FUJII, R. J. Modelo de Caracterização Sistêmica das Opções de Oferta Energética para o PIR. 2006. 180 p. Tese (Doutorado). Escola Politécnica. Universidade de São Paulo. São Paulo, 2006

GALLEGOS, H. G.; LOPARDO R. Spatial variability of the global solar radiation obtained by the Solarimetric Network in the argentine Pampa Húmeda. Solar Energy, v. 40, n. 5, p. 397-404, 1988.

GANA, N.N., AKPOOTU, D.O.. Estimation of Global Solar Radiation using four Based Models in Kebbi, North-Western, Nigeria. Pelagia Research Library: Advances in Applied Science Research, v. 4, n. 5, p. 409-421. 2013

GILGEN, H.; OHUMURA, A.. The Global Energy Balance Archive. Bulletin of the American Meteorological Society, Boston, v. 80, n. 5, p.831-850, 1999.

GTES [Grupo de Trabalho de Energia Solar]. Centro de Referência Para Energia Solar e Eólica Sérgio de Salvo Brito. Manual de engenharia para sistemas fotovoltaicos. Rio de Janeiro: Cresesb, 2004

GUEDES M. et al. Correlações entre Umidade Relativa, Nebulosidade e Irradiância Solar no Observatório Espacial do Sul. 2005. Disponível em: <http://sonda.ccst.inpe.br/publicacoes/periodicos/CienciaNatura_MarcusGuedes_etal.pdf >. Acesso em: 20 abril 2014 
GUIDON, M. A. A. de O.. Estudo das variações climáticas na área do lago de Tucuruí. 1991. 2 v. Dissertação (Mestrado). Faculdade de Filosofia, Letras e Ciências Humanas. Universidade de São Paulo. São Paulo, 1991.

HARGREAVES, G. H.; SAMANI, Z. A. Estimating potential evapotranspiration. Journal of Irrigation and Drainage Engeneering, v. 108, p. 225-230, 1982.

INÁCIO, C. O. Geração de Séries Sintéticas de Irradiância e Caracterização do Recurso Solar Brasileiro para a Geração Fotovoltaica. 2015. 127p. Dissertação (Mestrado). Programa de Engenharia Elétrica. Universidade Federal do Rio de Janeiro. Rio de Janeiro, 2015.

IRSOLAV. Tecnical Report: Solar Resource Assessment. Madri: IRsolav, 2010.

ISO [International Organization for Standardization]. ISO 9060: Solar Energy - Specification and Classification of Instruments for Measuring hemispherical solar and direct solar radiation. Genebra: International Organization For Standardization, 1990

JOURNÉE, M., BERTRAND, C., Quality control of solar radiation data within the RMIB solar measurements network. Solar Energy v. 85, p.72-86. 2011.

JURADO, M. et al. Statistical distribution of the clearness index with radiation data integrated over five minutes intervals. Solar Energy, v.40, n. 6, pp. 469-473, 1995.

KANG, B. O., TAM, K.. A New characterization and classification method for daily sky conditions based on ground-based solar irradiance measurement data. Solar Energy, 94, pp. 102-118. 2013

KIPP \& ZONEN. Solar Instruments Disponível em: <http://www.kippzonen.com/ProductGroup/1/Solar-Instruments>. Acesso em: 20 junho 2014 KOUMPAROU, I. et al., Characterization and classification of daily sky conditions on Cyprus and France based on ground measurements of solar irradiance and exhibition. EUROPEAN PV SOLAR ENERGY CONFERENCE AND EXHIBITION. 31. 2015. Proceddings... Eupvsec, 2015. p. 1698 - 1703.

LI-COR. Pyranometer Laght Sensors. Disponível em: <http://www.licor.com/env/products/light/pyranometers/>. Acesso em: 20 junho 2014 
LIU, H.Y.B, JORDAN, C.R..The interrelationship and characteristic distribuntion of direct, diffuse and total solar radiation. Solar Energy, v.4, pp. 1-19, 1960.

LONG, C.N., DUTTON, E. G. BSRN Global Network recommended QC tests, V2.0. 2002. Disponível

em:

<http://bsrn.awi.de/fileadmin/user_upload/redakteur/Publications/BSRN_recommended_QC_ tests_V2.pdf>. Acesso em: 20 março 2015.

MARTINS, F. R. et al.. Levantamento dos Recursos de Energia Solar no Brasil com o Emprego de Satélite Geoestacionário: O Projeto Swera. Revista Brasileira do Ensino de Física, São Paulo, v. 26, n. 2, p.145-159, 2004.

MAXWELL, E., et al. User's manual for SERI QC software, assessing the quality of solar radiation data. Report No. NREL-TP-463-5608. 1617 Cole Boulevard, Golden, Colorado: National Renewable Energy Laboratory, 1993.

MCARTHUR, L. J. B. Baseline Surface Radiation Network (BSRN): operations manual, version 2.1. Geneva: WCRP-121; WMO/TD-No. 1274, 2005.

MILLS, A., et al., Understanding variability and uncertainty of photovoltaics for integration with the electric power system. Report no. LBNL-2855E, Ernest Orlando Lawrence Berkeley National Laboratory, 2009.

NIKOLAIDIS, A. I. et al., Reliable integration of a concentrating solar power plant in a small isolated system through an appropriately sized battery energy storage system. IET Renewable Power Generation. DOI: 10.1049/iet-rpg.2015.0337, pp. 1-8. 2016

OUALI, K., ALKAMA, R. A New Model of Global Solar Radiation based on Meteorological Data in Bajaia City (Algeria). Energy Procedia. v.50, p. 670-676. 2014

PANGEA. Data Publisher for Earth \& Environmental Science. Disponível em: < http://www.pangaea.de/ddi?request=bsrn/BSRNParameterInUse \&format=html\&title=BSRN+ Parameter+in+use >. Acesso em: 12 dezembro 2014

PAULESCU, M. et al., Weather Modeling and Forecasting of PV Systems Operation: green energy and technology. London: Springer-Verlag, 2013. 
RAICHIJK, C., TADDEI, F.. Estudio Comparativo de Modelos Empíricos de Estimación de la Radiación Solar Directa Horaria. Avances en Energias Renovables y Medio Ambiente. v. 16 n.11, p. 23-28. 2012

ROSA, D. J. de M.. Caracterização da Radiação Solar: O caso da Cidade Universitária/USP e da Ilha do Cardoso/Cananéia. 2003. 168p. Dissertação (Mestrado). Programa Interunidades de Pós-Graduação em Energia da Universidade de São PauloPIPGE-USP. São Paulo, 2003.

SCIENCE MUSEUM GROUP. Collection Online: Objects. Disponível em: $<$ http://collectionsonline.nmsi.ac.uk/detail.php?type=related $\& \mathrm{kv}=55091 \& \mathrm{t}=$ objects $>$. Acesso em: 6 maio 2014.

SENTELHAS, P.C., ANGELOCCI, L.R. Radiação Solar Balanço de Energia. Material de Aula Expositiva da Disciplina LEB306-Meteorologia Agrícola da ESALQ/USP. Disponível em: www.leb.esalq.usp.br/aulas/Ice306/Aula5_2012.pdf. Acesso em: 2 fevereiro 2015

SHAYANI, R. A.. Medição do Rendimento Global de um Sistema Fotovoltaico Isolado Utilizando Módulos de 32 Células. 2006. 205p. Dissertação (Mestrado) - Universidade de Brasília, Brasília, 2006.

SILVA. V.J. et al. Método para Estimar Radiação Solar na Região Noroeste de Minas Gerais. Revista Ciência Rural. Santa Maria, v.42, n. 2, p. 276-282. 2012

SKARTVEIT, A., OLSETH J.A.. The probability density and autocorrelation of short-term global and beam irradiance. Solar Energy, vol. 49, n. 6, pp. 477-487. 1992

SOUZA, M. B.. Influência da Formação de Reservatórios no Microclima e no Clima Urbano: estudo de caso em Presidente Epitácio (SP). 2010. 203 f. Tese (Doutorado). Faculdade de Filosofia, Letras e Ciências Humanas. Universidade de São Paulo. São Paulo 2010.

SUEHRCKE, H., MCCORMICK, P. G. The frequency distribution of instantaneous insolation values. Solar Energy, v.40, n. 5, pp. 413-422, 1988.

TIBA, C. et al (Comp.). Atlas Solarimétrico do Brasil: banco de dados solarimétrico. Recife: Ed. Universitária da UFPE, 2000. 
TOLMASQUIM, Maurício Tiommo (Cood.). Energia Renovável: Hidráulica, Biomassa, Eólica, Solar, Oceânica. Rio de Janeiro: EPE, 2016

TORRES, R. et al. Modelos para Estimación de la Radiación Solar Para el Altiplano Central de Bolivia. Revista Boliviana de Física. La Paz, v. 23, p. 1-7. 2013

TOVAR, M. et al. One minute global irradiance probability density distributions conditioned to the optical air mass. Solar Energy, v.62, n. 6, pp. 387-393, 1998.

TOVAR, M. et al. One minute $\mathrm{kb}$ and kd probability density distributions conditioned to the optical air mass. Solar Energy, v.65, n. 5, pp. 297-304, 1999.

UDAETA, M. E. M.. Novos Instrumentos de Planejamento Integrado de Recursos energéticos na USP: Pesquisa Científica Realizada e Ferramentas Metodológicas Consolidadas do PIRnaUSP Aplicadas à RAA. 2012. 125 p. Tese (Livre Docência). Escola Politécnica. Universidade de São Paulo. São Paulo, 2012.

VIANELLO, R. L.; ALVES, A. R. Meteorologia básica e aplicações. Viçosa: Editora UFV, 2002.

VIGNOLA, F. et. al.. Solar and Infrared Radiation Meassurements. Boca Raton: Taylor \& Fracis Group, 2012.

VILELA, W. A.. Estudo, Desenvolvimento e Caracterização de Radiômetros para Medidas da Radiação Solar. 2010. 178p. Tese (Doutorado). Instituto Nacional de Pesquisas Espaciais. São José dos Campos, 2010.

VOLKER-QUASCHNING. Photo Gallery: Solar and Wind Measurements. Disponível em: <http://www.volker-quaschning.de/fotos/messung/index_e.php>. Acesso em: 5 maio 2014

WEBER, E. J.. Estimativa e Mapeamento da Radiação Solar Incidente em Superfícies com Topografia Heterogênea na Zona de Produção Vitivinícola Serra Gaúcha. 2011. 145f. Tese (Doutorado). Faculdade de Agronomia. Universidade Federal do Rio Grande do Sul. Porto Alegra, 2011.

WMO [World Meteorological Organization]. Guide to Meteorological Instruments and Methods of Observation, Ed. de 2008, atualizada em 2010. Geneva: Chairperson, Publications Board, 2012 
WMO [World Meteorological Organization]. World Climate Research Program Report: Baseline Surface Radiation Network (BSRN), update of the technical plan for BSRN Data Management. Geneva: Chairperson, Publications Board, 2013.

WRDC [World Radiation Data Center]. World Radiation Data Center. Disponível em: $<$ http://wrdc.mgo.rssi.ru/>. Acesso em: 15 agosto 2014

Younes, S. et al.. Quality control of solar radiation data: present status and proposed new approaches. Energy, v.30, 1533-1549. 2005. 


\section{APÊNDICES}

APÊNDICE 1- MANUAL DE ARMAZENAMENTO DE DADOS BRUTOS 


\section{LOGÍSTICA FUNDAMENTAL DE APOIO A P\&DS PARA MANUSEIO DE GRANDES QUANTIDADES DE INFORMAÇÕES}

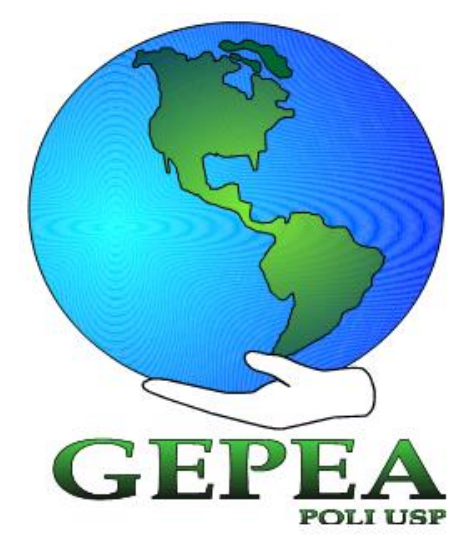

Definição do Procedimento de Armazenamento de Dados Brutos de Estações Meteorológicas, Solarimétricas e Anemométricas

Coordenador: Miguel Edgar Morales Udaeta

$\begin{array}{ll}\text { Equipe: } & \text { Ananda Nascimento } \\ & \text { André Luiz Veiga Gimenes } \\ & \text { Angélica Luana Linhares } \\ & \text { Henrique Fernandes Camilo } \\ & \text { Jonathas Luiz de Oliveira Bernal } \\ & \text { Juliana de Oliveira Martins } \\ & \text { Luiz Claudio Ribeiro Galvão } \\ & \text { Martim Debs Galvão } \\ & \text { Miguel Edgar Morales Udaeta } \\ & \text { Paulo Helio Kanayama } \\ & \text { Raul Vaz de Paula } \\ & \text { Renan Walsechi Santana de Moura } \\ & \text { Stefania Relva Gomes } \\ & \text { Vinicius Oliveira da Silva }\end{array}$

Responsável: $\quad$ Stefania Gomes Relva $\quad$ stefania.relva@gmail.com 


\section{RESUMO}

Este relatório tem por objetivo apresentar os elementos definidos para registro de dados meteorológicos, anemométricos e solarimétricos obtidos pelas estações das quais o GEPEA possui acesso. A padronização do registro de dados possibilita que a disponibilização das informações se torne mais eficiente e clara, viabilizando que qualquer pessoa possa compreender com facilidade os dados apresentados. Deste modo, cria-se uma base sólida para a construção de históricos de medição, facilitando o desenvolvimento das pesquisas do grupo. Para a definição dos padrões foi realizada uma série de reuniões entre os pesquisadores do grupo, considerando os responsáveis pela manutenção dos dados e os que se utilizam atualmente dos dados medidos. Define-se, portanto, o procedimento de nomenclatura, tanto dos arquivos de dados, quanto das variáveis, os períodos de coleta e a definição dos dados contidos em cada arquivo. 


\section{INTRODUÇÃO}

Dados anemométricos, climatológicos e solarimétricos podem ser registrados com periodicidade baixa resultando em uma grande quantidade de informações diárias. Esses registros são obtidos por meio dos dataloggers sem uma padronização ou critério do período registrado. Para que a leitura desses dados se torne amigável é importante que haja um processo de padronização da disponibilização dessas informações.

Esse relatório tem como objetivo geral apresentar as definições e procedimentos para o armazenamento dos dados anemométricos, climatológicos e solarimétricos obtidos por estações meteorológicas, solarimétricas e anemométricas das quais o GEPEA possui acesso. Assim, os objetivos específicos deste relatório são definidos em: (i) registrar, para usos futuros, o procedimento de registro de dados, de modo que o padrão seja mantido ao longo do tempo, independente das pessoas que estão tratando do assunto e (ii) auxiliar e tirar possíveis dúvidas acerca das informações dispostas em cada arquivo de dados àqueles que estiverem utilizando esses arquivos já prontos.

A padronização do registro de dados possibilita que a disponibilização das informações se torne mais eficiente e clara, viabilizando que qualquer pessoa possa compreender com facilidade os dados apresentados. Deste modo, cria-se uma base sólida para a construção de históricos de medição, facilitando o desenvolvimento das pesquisas do grupo. Para a definição dos padrões foi realizada uma série de reuniões entre os pesquisadores do grupo, considerando os responsáveis pela manutenção dos dados e os que se utilizam atualmente dos dados medidos.

Assim, esse relatório define: (i) o formato dos arquivos de armazenamento de dados (ii) as informações que devem estar presentes em cada arquivo, (iii) os critérios de nomeação de cada arquivo, (iv) a definição da ordem de disposição das informações, (v) os critérios de nomeação de cada variável e (vi) elementos de suporte ao acesso dos dados, como o meio de disponibilização dos mesmos e das demais informações que caracterizam cada estação de medição e disposição de diretórios.

\section{FORMATO DOS ARQUIVOS DE ARMAZENAMENTO DE DADOS}

Os arquivos devem ser em formato .txt já que a extensão é adaptável à utilização em diversos softwares. 


\section{INFORMAÇÕES PRESENTES EM CADA ARQUIVO}

Cada estação de medição é constituída de um conjunto de sensores que medem diferentes variáveis. Portanto fica definido que, os dados serão disponibilizados em arquivos separados para cada sensor de cada estação. Ao final de um mês completo de medições devese também fornecer um arquivo .txt completo das variáveis: do mês inteiro de medições com todas as variáveis de medição de cada estação. As medições a serem registradas devem prioritariamente ser fornecidas de minuto a minuto. Caso o sensor registre medições de segundo em segundo, a tabela deve registrar a média de cada minuto, seguido do desvio

padrão deste período e dos respectivos máximo e mínimo. Caso o datalogger promova também o registro de contador, ou seja, apresente o valor de quantas medidas foram registradas naquele minuto, essa informação também deve ser fornecida no arquivo .txt daquele sensor. Além disso, o arquivo deve conter a data completa de cada medição: ano, mês, dia, hora, minuto, segundo e dia juliano, além do formato padrão de datas fornecido pelo datalogger.

Tanto para arquivos de dados diários quanto para o arquivo do conjunto mensal de dados é importante que haja apenas uma linha de cabeçalho, na qual deve conter apenas o nome das variáveis apresentadas. Cada momento de medição, com os respectivos valores medidos naquele momento devem constar em linhas subsequentes ao cabeçalho.

\section{CRITÉRIOS DE NOMEAÇÃO DE ARQUIVOS}

Define-se que os arquivos diários devem possuir as seguintes informações no nome do arquivo, na ordem apresentada a seguir:

1. Nome da estação

2. Latitude da estação

3. Longitude da estação

4. Altitude da estação

5. Nome do sensor

6. Nome da variável de medição

7. Data (ano, mês, dia)

8. Período de integração dos dados

Define-se que os arquivos mensais devem possuir as seguintes informações no nome do arquivo, na ordem apresentada a seguir: 
1. Nome da estação

2. Latitude da estação

3. Longitude da estação

4. Altitude da estação

5. Data (ano, mês)

Cada informação do nome deve ser diferenciada da próxima informação por meio da utilização do caractere underscore (_). O padrão de declaração de cada informação supracitada é apresentado a seguir.

\subsection{Nome da Estação}

O nome da estação deve ser definido em 5 letras em caixa alta, de modo que as duas primeiras definam o tipo da estação conforme o seguinte padrão:

- ES: Estação Solarimétrica

- EA: Estação Anemométrica

- EM: Estação Meteorológica

As três letras seguintes devem significar o nome que o GEPEA definiu para referenciar a estação em questão, como o seguinte exemplo:

- ESPEL: Estação Solarimétrica Poli Elétrica

\subsection{Latitude da Estação}

A latitude deve ser definida com uma letra em caixa alta ( $\mathrm{L}$ ou $\mathrm{O})$, dois números inteiros e três casas decimais. A separação entre inteiros e decimais deve ser feita por hífen (), já que pontos (.) podem causar erros de leituras em alguns softwares e sistemas computacionais. Assim, a Estação Solarimétrica presente na Faculdade de Engenharia Elétrica da POLI-USP (ESPEL) cuja latitude é $23,538^{\circ}$ Leste, deve ter os seus arquivos com os nomes iniciados da seguinte maneira:

- ESPEL_L23-538

\subsection{Longitude da Estação}

Assim como a latitude, a longitude deve ser definida com uma letra em caixa alta ( $\mathrm{N}$ ou S), dois números inteiros e três casas decimais. A separação entre inteiros e decimais deve ser feita por hífen (-). Assim, a ESPEL cuja longitude é 46,365 no Hemisfério Sul, deve ter os seus arquivos com os nomes iniciados da seguinte maneira:

- ESPEL_L23-538_S46-365 


\subsection{Altitude da Estação}

A altitude deve ser definida com quatro números inteiros. Assim, a ESPEL cuja altitude é 720 metros, deve ter os seus arquivos com os nomes iniciados da seguinte maneira:

- ESPEL_L23-538_S46-365_0720

\subsection{Nome do Sensor}

O nome do sensor deve ser definido em duas letras com a primeira em caixa alta. Caso seja necessária a definição da altura de um sensor para diferenciação de sensores iguais em uma mesma estação (como no caso de anemômetros que comumente são instalados em diversas alturas em uma mesma estação de medição), o valor da altura do equipamento deve ser colocado imediatamente após a sigla do nome do equipamento sem a utilização do caractere underscore (_). O valor da altura deve ser sempre registrado com três números inteiros. Portanto, supondo que a Estação Solarimétrica Poli Elétrica tivesse mais de um anemômetro instalado e considerando que um deles foi instalado à 30 metros de altura, o nome do arquivo de dados diários desse equipamento deve prosseguir da seguinte maneira:

- ESPEL_L23-538_S46-365_0720_Am030

A informação de altura do equipamento deve ser colocada no nome do arquivo apenas em caso de mais de um equipamento instalado na mesma estação em alturas diferentes, com o propósito de medir uma variável em função da altura de instalação, como acontece principalmente com anemômetros e anemoscópios.

\subsection{Nome da variável de medição}

O nome da variável de medição deve ser definido em duas letras com a primeira em caixa alta. Essa definição no nome da tabela é necessária visto que alguns sensores podem medir mais do que uma variável, assim como algumas variáveis podem ser obtidas por sensores diferentes. Portanto, considerando um anemômetro instalado à 30 metros de altura, utilizado para a medição da velocidade do vento, o nome do arquivo de dados diários desse equipamento para a ESPEL deve prosseguir da seguinte maneira:

- ESPEL_L23-538_S46-365_0720_Am030_Vv

\subsection{Data das medições}

A data informada no nome dos arquivos de dados diários deve seguir o formato AAAAMMDD, enquanto que a data informada no nome dos arquivos de dados mensais deve seguir o formato AAAAMM. Assim, seguindo o exemplo utilizado até então, o nome do 
arquivo de dados do dia 02 de março de 2016 para o suposto anemômetro, instalado à 30 metros de altura, deve prosseguir da seguinte maneira:

- ESPEL_L23-538_S46-365_0720_Am030_Vv_20160302

Enquanto que o nome do arquivo de dados completos mensais dessa estação para março de 2016 deve desconsiderar o dia, o nome do equipamento e o nome da variável (já que todas as variáveis devem estar inclusas no mesmo arquivo), resultando no seguinte formato:

- ESPEL_L23-538_S46-365_0720_201603

\subsection{Período de integração dos dados}

O período de integração de dados corresponde à unidade de tempo na qual os dados são apresentados. No caso ideal, consideram-se arquivos com dados brutos de minuto a minuto. Contudo, é possível a obtenção de registros de segundo em segundo, dentre outros períodos. Para o armazenamento dos dados das estações das quais o GEPEA possui acesso, fica determinado que o registro deve ser prioritariamente de minuto a minuto. Assim, a última informação que deve ser inserida no nome dos arquivos é uma letra em caixa alta, sendo: "M" para dados integrados ou registrados de minuto a minuto e "S" para dados registrados de segundo a segundo. Deste modo, considerando o exemplo tratado até então, o nome dos arquivos de dados diários registrados de minuto a minuto e o nome dos arquivos de dados mensais registrados de minuto a minuto é concluído da seguinte maneira, respectivamente:

- ESPEL_L23-538_S46-365_0720_Am030_Vv_20160302_M

- ESPEL_L23-538_S46-365_0720_201603_M

\subsection{Padronização das siglas de nomes de equipamentos e variáveis medidas}

O Quadro 1 apresenta o padrão de siglas que devem ser utilizadas para os equipamentos e variáveis das quais o GEPEA já possui acesso aos registros de medições.

Quadro 1 - Padrão de Siglas de Variáveis e Equipamentos

\begin{tabular}{|l|l|l|l|}
\hline Equipamento & Sigla & Variável & Sigla \\
\hline Anemômetro & $\mathrm{Am}$ & Velocidade do Vento & $\mathrm{Vv}$ \\
\hline Anemoscópio & $\mathrm{Ac}$ & Direção do Vento & $\mathrm{Dv}$ \\
\hline Barômetro & $\mathrm{Br}$ & Pressão Atmosférica & $\mathrm{Pr}$ \\
\hline \multirow{2}{*}{ Piranômetro } & $\mathrm{Pi}$ & Irradiancia Global Horizontal (IGH) & $\mathrm{Gl}$ \\
\cline { 3 - 4 } & & Irradiancia Difusa Horizontal (IDH) & $\mathrm{Df}$ \\
\hline Pireliômetro & $\mathrm{Pr}$ & Irradiancia Direta Normal (IDN) & $\mathrm{Dr}$ \\
\hline Pluviômetro & $\mathrm{Pl}$ & Precipitação & $\mathrm{Pp}$ \\
\hline \multirow{2}{*}{ Termo-Higrômetro } & \multirow{2}{*}{$\mathrm{Th}$} & Temperatura & $\mathrm{Tp}$ \\
\cline { 3 - 4 } & & Umidade Relativa & $\mathrm{Ur}$ \\
\hline
\end{tabular}


No caso do surgimento de novos equipamentos ou variáveis, este relatório deve ser atualizado, contudo deve-se manter o padrão de utilização de apenas duas letras, sendo a primeira delas em caixa alta, as siglas já existentes não devem ser alteradas já que isso acarretaria em prejuízo à padronização de dados existentes e futuros.

\section{CRITÉRIOS DE NOMEAÇÃO E DISPOSIÇÃO DAS INFORMAÇÕES DENTRO DOS ARQUIVOS DE DADOS}

\subsection{Disposição das informações e nomeação das datas}

Para que a compreensão das informações apresentadas seja facilitada, os arquivos .txt devem possuir todos a mesma estrutura interna. Dados registrados de um em um minuto podem geralmente ser originados (i) da média da integração de 60 medições (por segundo), (ii) de apenas um registro por minuto ou (iii) da integração de 60 medições (por segundo). Em qualquer um dos casos, a estrutura de dados deve conter, antes dos registros de medições, as informações de datas e horários.

O datalogger normalmente registra a data em um único vetor, no formato: AAAAMMDD-HH:MM:SS. Essa estrutura deve ser padronizada dividindo as informações em vetores diferentes, com nomes padronizados, conforme o cabeçalho apresentado na Figura 1.

Figura 1 - Cabeçalho da disposição de datas

\begin{tabular}{|l|l|l|l|l|l|l|l|}
\hline Ano & Mes & Dia & Hora & Minuto & Segundo & Dia_J & Data \\
\hline
\end{tabular}

$\mathrm{O}$ ano deve ser registrado com 4 números, o mês e o dia com dois números. A informação mês deve ser registrada no arquivo .txt sem acento, como na Figura 1. Todos os nomes devem ser inicializados com uma letra em caixa alta.

As horas devem variar entre 00 e 23 e os minutos devem variar entre 00 e 59, assim como os segundos. De modo que o primeiro horário do dia seja 00:00:00 e o último seja 23:59:59 no caso de arquivos com dados registrados por segundo e 23:59:00 no caso de arquivos com dados registrados por minuto. Ou seja, nas tabelas com dados por minuto os segundos devem estar sempre zerados.

A variável Dia_J representa o dia juliano e varia de 1 a 365 e em caso de ano bissexto varia de 1 a 366 . 
A variável Data representa o formato original de data fornecido pelo datalogger, que não deve ser apagado ou editado.

Após a definição dessas informações, nessa ordem, procede-se às informações dos dados medidos. Em caso de dados que são coletados por minuto originados da média da integração de 60 medições (por segundo), o datalogger fornece a média do minuto (Avg), os valores máximo (Max) e mínimo (Min) das medições ao longo desse minuto e o desvio padrão (Std). Nesse caso, o registro da variável deve iniciar com a sigla da variável, como já definido na Tabela 1, seguido do caractere underscore (_) e da sigla do tipo de medida. Tomando como exemplo a Irradiância Global (Gl), o registro das informações dentro do arquivo .txt procede-se necessariamente na ordem e com a nomenclatura apresentada no cabeçalho da Figura 2.

Figura 2 - Cabeçalho da disposição dos valores para variáveis obtidas pela média da integração ao longo do minuto

\begin{tabular}{|l|l|l|l|l|l|l|l|l|l|l|l|}
\hline Ano & Mes & Dia & Hora & Minuto & Segundo & Dia_J & Data & Gl_Avg & G1_Max & Gl_Min & Gl_Std \\
\hline
\end{tabular}

No caso de variáveis como a precipitação, por exemplo, que se costuma apresentar o total acumulado (Sum) em um minuto, a notação a ser utilizada deve ser a apresentada no cabeçalho da Figura 3.

Figura 3 - Cabeçalho da disposição dos valores para variáveis obtidas pela integração ao longo do minuto

\begin{tabular}{|l|l|l|l|l|l|l|l|l|}
\hline Ano & Mes & Dia & Hora & Minuto & Segundo & Dia_J & Data & Pp_Sum \\
\hline
\end{tabular}

Para variáveis cujo o registro é feito pontualmente (Int) uma vez por minuto, sem que aquela medição represente a média do acúmulo ou o próprio acúmulo ao longo do minuto, como, por exemplo, pode ocorrer com a temperatura, a notação a ser utilizada deve ser a apresentada no cabeçalho da Figura 4.

Figura 4 - Cabeçalho da disposição dos valores para variáveis obtidas pelo registro unitário

\begin{tabular}{|l|l|l|l|l|l|l|l|l|}
\hline Ano & Mes & Dia & Hora & Minuto & Segundo & Dia_J & Data & Tp_Int \\
\hline
\end{tabular}

A definição apresentada na Figura 4 também deve ser utilizada para as tabelas cujo perído de medição é de 1 segundo. Algumas estações de medição também fornecem um dado 
extra, definido como Contador. O Contador indica quantos registros foram realizados para que se alcançasse o valor de medição apresentado. Tomando como exemplo a Irradiância Global: esse tipo de variável pode ser obtido por segundo, portanto 60 medições devem ser utilizadas para o cálculo dos valores de média, máximo, mínimo e desvio padrão por minuto. Nesse caso o contador de cada minuto deve ser igual à 60. Assumindo o exemplo da temperatura, que pode ter medições pontuais por minuto: nesse caso o contador deve assumir o valor igual à 1 para cada minuto. Em caso do datalogger disponibilizar essa informação, ela deve ser a última a ser apresentada no conjunto de informações daquele sensor/variável.

\subsection{Nomeação dos tipos de valores}

Assim, o Quadro 2 apresenta sistematicamente a sigla para cada tipo de valor apresentado. Caso algum novo tipo de valor ocorra, uma nova sigla precisa ser criada e esse relatório precisa ser atualizado. Qualquer nova sigla deve obedecer ao padrão de possuir 3 letras com a primeira em caixa alta. As siglas já existentes não devem ser alteradas já que isso acarretaria em prejuízo à padronização de dados existentes e futuros.

Quadro 2 - Padrão de sigla para cada tipo de valor de variáveis medidas

\begin{tabular}{|l|l|}
\hline Tipo de Valor & Sigla \\
\hline Média de 60 medições realizadas em 1 minuto & Avg \\
\hline Valor máximo de 60 medições realizadas em 1 minuto & Max \\
\hline Valor mínimo de 60 medições realizadas em 1 minuto & Min \\
\hline Desvio padrão de 60 medições realizadas em 1 minuto & Std \\
\hline Integral dos valores obtidos em 1 minuto & Sum \\
\hline Registro pontual da medição realizada 1 vez por minuto & Int \\
\hline Contador & Cnt \\
\hline
\end{tabular}

Os vetores de informações devem estar dispostos no arquivo .txt necessariamente na ordem apresentada nessa seção. Cada vetor deve ser separado por “,”. Valores inexistentes de medições devem estar registrados como "NA".

No caso do arquivo de dados mensais, é importante que a sequência de apresentação das diferentes variáveis medidas (com os seus respectivos tipos de valor) seja a mesma em todos os arquivos de todas as estações. Assim define-se a ordem de disposição das variáveis, de modo que a primeira variável a ser apresentada é aquela alocada logo após aos vetores de data apresentados na Figura 1.

\section{Estação Meteorológica}

a. Velocidade do Vento 

b. Direção do Vento
c. Temperatura
d. Pressão atmosférica
e. Precipitação
f. Umidade Relativa

2. Estação Anemométrica
a. Velocidade do Vento da menor altura de instalação do medidor
b. Direção do Vento da menor altura de instalação do medidor
c. Velocidade do Vento da altura intermediária de instalação do medidor
d. Direção do Vento da altura intermediária de instalação do medidor
e. Velocidade do Vento da maior altura de instalação do medidor
f. Direção do Vento da maior altura de instalação do medidor
g. Temperatura
h. Pressão atmosférica
i. Precipitação
j. Umidade Relativa

No caso de a estação possuir mais de 3 conjuntos de Anemômetro/Anemoscópio, procedese com a mesma lógica. Essa lógica também deve ser aplicada para estações solarimétricas e meteorológicas que eventualmente tenham mais do que um conjunto de anemômetro/anemoscópio

3. Estação Solarimétrica
a. Irradiância Global Horizontal
b. Irradiância Difusa Horizontal
c. Irradiância Direta Normal
d. Velocidade do Vento
e. Direção do Vento
f. Temperatura
g. Pressão atmosférica
h. Precipitação
i. Umidade Relativa

No caso de a estação possuir outros medidores de radiação, esses devem ser apresentados logo após os dados de Irradiância Direta Normal e antes dos dados de Velocidade do Vento. 
Tratando-se de estação solarimétrica é importante que os dados de irradiância ou aqueles vinculados ao brilho solar sejam os primeiros apresentados, a mesma lógica se aplica à estação anemométrica no caso de dados de ventos. As demais variáveis meteorológicas tiveram a ordem padronizada para todas as estações, evitando diferenças entre arquivos de estações diferentes. Portanto, no caso do acréscimo de novas variáveis, a lógica estabelecida é: encaixar na ordem conforme a relevância do dado, levando em consideração qual o principal fim da estação. Contudo, a ordem definida para a apresentação dos dados de velocidade e direção de vento, bem como de irradiâncias global, direta e difusa não devem deixar de serem apresentadas prioritariamente para estações anemométricas e solarimétricas respectivamente.

\section{DISPONIBILIZAÇÃO DOS DADOS, INFORMAÇÕES DAS ESTAÇÕES E ESTRUTURA DE DIRETÓRIOS}

\subsection{Disponibilização dos dados e estruturas de diretórios}

Os dados devem ser disponibilizados no SEEDS com a criação de link para acesso externo. Cada estação deve possuir um diretório próprio, e dentro deste, outros diretórios que devem armazenar os dados sistematizados por data e por variável, além das informações características da estação, tais como: listagem dos equipamentos instalados, incluindo marca e modelo; caracterização da localização da estação; arquivo com as unidades de medida de cada variável apresentada, bem como a definição das siglas dos equipamentos e variáveis e arquivo com dados de controle.

Os dados de controle são aqueles que apresentam o monitoramento do funcionamento geral da estação, tais como: amperagem e voltagem de cada sensor, níveis das baterias, velocidades dos ventiladores dos piranômetros, dentre outros. Esses dados devem ser salvos em arquivo .txt mensais, sem nenhum critério de padronização. Portanto, devem ser salvos da mesma maneira que são obtidos através do datalogger.

Assim, a sistematização dos diretórios deve obedecer a seguinte estrutura:

1. Diretório de Estações de Medição

\subsection{Arquivo.doc-Relatório}

\subsection{Diretório de cada estação}

1.2.1. Diretório de Dados

1.2.1.1. Arquivo .txt- Unidades de Medida e Siglas 
1.2.1.2. Diretórios de dados de cada ano

1.2.1.2.1. Diretórios de dados de cada mês do ano

1.2.1.2.1. Diretórios de dados de cada dia do mês

1.2.1.2.1.1.1.1.Arquivos .txt de dados de cada variável do dia.

1.2.1.2.2. Arquivo .txt dos dados do mês

\subsubsection{Diretório de arquivos auxiliares}

1.2.2.1. Diretório de arquivos de dados de controle

1.2.2.1.1. Arquivos .txt dos dados de controle de cada mês

1.2.2.2. Arquivo.txt de Especificação de equipamentos e da localização da estação

Toda a estrutura de diretórios e arquivos auxiliares também deve ser nomeada de maneira padronizada, essa padronização bem como a disposição das demais informações da estação são apresentadas na próxima seção.

\subsection{Disponibilização das informações e nomeação dos diretórios}

1. Diretório de Estações de Medição

Esse é diretório inicial que deve concentrar as informações de todas as estações de medição das quais o GEPEA possui acesso. Esse diretório deve ser nomeado como: "Estações de Medição".

\subsection{Arquivo.doc-Relatório}

Arquivo deste relatório. Esse arquivo deve ser nomeado como: "Procedimento de Armazenamento de Dados v2016". A cada atualização deve ser salva uma nova versão, indicando, no nome do arquivo, o ano da atualização. Em caso de mais de uma atualização no mesmo ano, deve-se acrescentar, no nome do arquivo, uma letra minúscula do alfabeto latino, iniciando-se em “b”, para a segunda versão do ano.

1.2. Diretório de cada estação

Cada estação da qual o GEPEA possui acesso aos dados deve ter o seu próprio diretório dentro do diretório "Estações de Medição". Nele deverão ser incluídas de maneira sistemática (conforme itens a seguir) todas as informações referentes à estação. Esse diretório deve ser nomeado seguindo o padrão: “'Nome da estação' ('Sigla da estação')”. O nome da estação deve ser definido pelo GEPEA, a sigla deve ser definida conforme o padrão apresentado na seção 4.1 deste relatório.

1.2.1. Diretório de Dados 
Nesse diretório deve haver todas as informações referentes ao histórico de medições da estação. Ele deve ser nomeado como: "Dados"

\subsubsection{Arquivo .txt- Unidades de Medida e Siglas}

Deve ser gerado um arquivo .txt com vetores separados por “,”. O primeiro vetor deve conter a lista de variáveis de medição da estação, o segundo vetor deve conter as respectivas siglas de cada variável conforme definido nas seções 4.9, 4.6 e 5.2 deste relatório. O terceiro vetor deve conter as respectivas unidades de medição nas quais as medições estão sendo disponibilizadas. Caso a estação forneça o valor "Contador" (conforme Capítulo 5 deste relatório) é importante que esse arquivo .txt também indique que a unidade de medição desse valor é unitária adimensional. Esse arquivo deve ser nomeado como “'Sigla da Estação’_Unidades_de_Medida e Siglas”. Esse arquivo deve conter 1 linha de cabeçalho, os 3 vetores devem ser nomeados respectivamente como: "Variavel", "Sigla", "Unidade_de_Medicao".

\subsubsection{Diretórios de dados de cada ano}

Dentro do diretório de dados da estação deve haver um diretório para cada ano de medição da estação. A nomeação desse diretório deve seguir o padrão: "'Sigla da estação'_'AAAA"”.

\subsection{Diretórios de dados de cada mês do ano}

Dentro do diretório do ano deve haver uma quantidade de diretórios igual à quantidade de meses do ano que a estação registrou medições. A nomeação desses diretórios mensais deve seguir o padrão: “'Sigla da estação'_'AAAAMM"'.

\subsection{Diretórios de dados de cada dia do mês}

Dentro do diretório mensal deve haver uma quantidade de diretórios igual à quantidade de dias do mês que a estação registrou medições. A nomeação desses diretórios mensais deve seguir o padrão: “'Sigla da estação'_,AAAAMMDD”".

1.2.1.2.1.1.1.1.1. Arquivos .txt de dados de cada variável do dia.

Esses arquivos devem ser produzidos e nomeados conforme Capítulos 3 e 4 deste relatório.

1.2.1.2.2. Arquivo .txt dos dados do mês 
Esse arquivo deve ser produzido e nomeado conforme Capítulos 3 e 4 deste relatório.

\subsubsection{Diretório de arquivos auxiliares}

Este diretório deve conter as especificações técnicas e os dados de controle da estação de medição. Ele deve ser nomeado como: "Especificações da Estação".

\subsubsection{Diretório de arquivos de dados de controle}

Este diretório deve conter o conjunto de arquivos de dados de controle da estação e deve ser nomeado como: "Dados de Controle".

\subsection{Arquivos .txt dos dados de controle de cada mês}

Os dados de controle não devem ser editados. Deve ser criado um arquivo .txt para cada mês de funcionamento da estação. Esses arquivos devem ser nomeados conforme o padrão: "Sigla da estação_AAAAMM'_Controle".

1.2.2.2. Arquivo.txt de Especificação de equipamentos e da localização da estação

Deve ser produzido um arquivo .txt, sem padronização de vetores, com as informações: (i) localização da estação-latitude, longitude, altitude, (ii) lista de equipamentos instalados e seus respectivos modelos, marcas e siglas utilizadas nos arquivos de dados e (iii) se possível, breve descrição dos elementos ao redor do local aonde a estação está instalada (ex. presença de árvores, prédios, altos níveis de poluição e etc).

Caso o GEPEA possua acesso aos manuais dos equipamentos e demais documentos dessa ordem, deverá ser criado um novo diretório dentro do diretório "Especificações da Estação", para o armazenamento desses documentos. A Figura 5 representa um exemplo dessa estrutura definida, para facilitar a compreensão dos padrões de nomeação definidos. 
Figura 5 - Exemplificação do esquema de nomeação de arquivos e diretórios

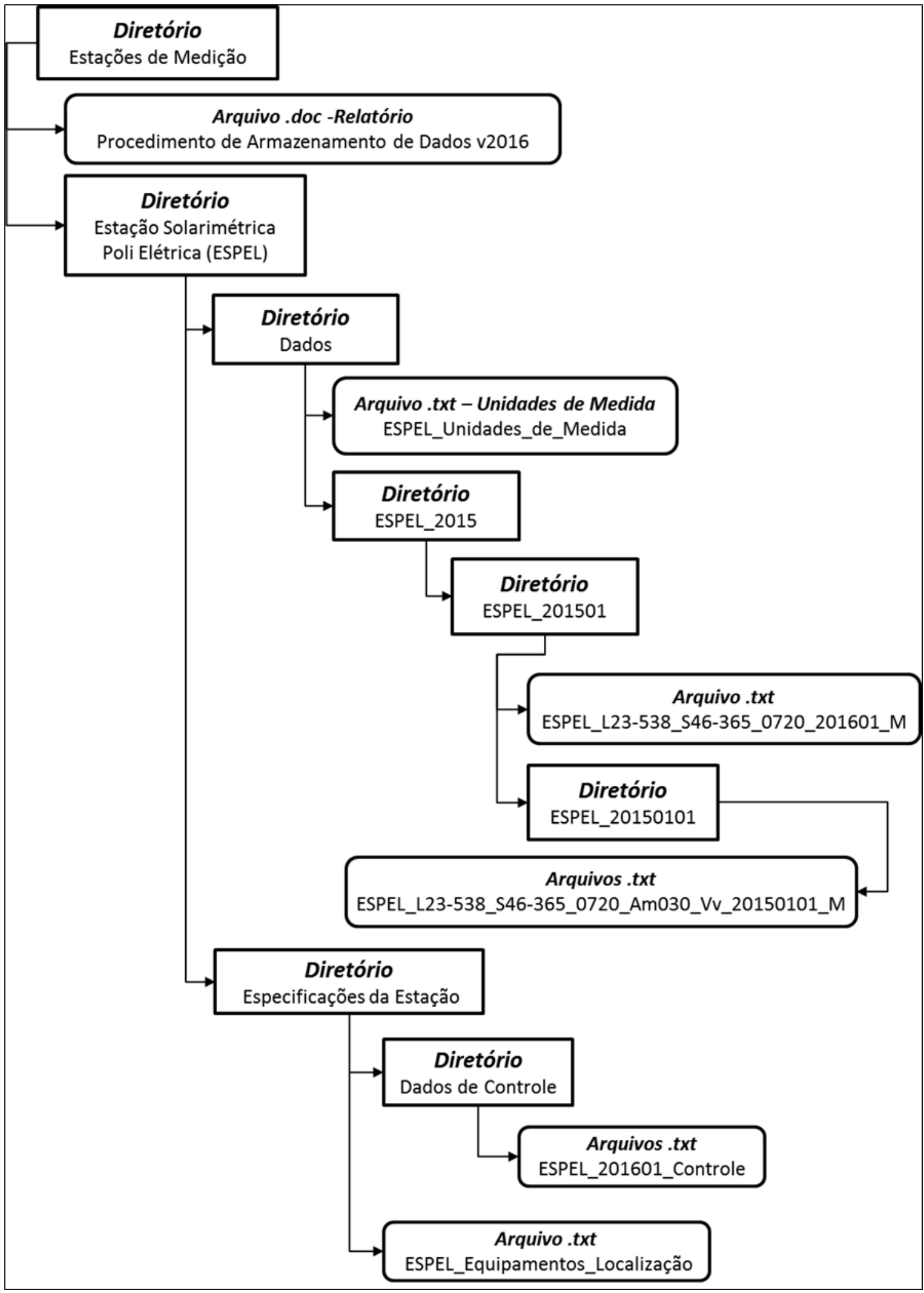

Na Figura 5 cada bloco contém: (i) o nome do diretório ou arquivo, ou (ii) um exemplo de nomeação, seguindo os exemplos apresentados no Capítulo 4 e neste capítulo. 


\section{CONSIDERAÇÕES FINAIS}

Esse relatório buscou sistematizar a apresentação e nomeação tanto dos dados, quanto da disponibilização dos dados de medição dos quais o GEPEA possui acesso. Deste modo, busca-se a implementação desse processo para que o fluxo de informações seja perene e eficaz.

Quaisquer alterações nesses processos devem ser documentadas, apresentando o novo padrão e indicando qual era o padrão anterior, para que também não haja perdas do fluxo de informação a cerca desse processo. É importante ressaltar que, para qualquer novo padrão de nomeação de arquivos e variáveis, deve-se sempre evitar a utilização de caracteres como: ponto (.), acentos e quaisquer outros diacríticos. 


\section{APÊNDICE 2- MEMORIAL DE CÁLCULO DE IGHo, IDNo E KTC}

- Cálculo de $I D N_{0}$ para ESUPP:

$\left(\frac{\mathrm{R}_{\mathrm{m}}}{\mathrm{R}}\right)^{2}=1+0,033 \cos (360 \mathrm{NDA} / 365)$ - para cada NDA (dia juliano) da série histórica disponível.

$I_{0}=1367$

$I D N_{0}=I_{0}\left(\frac{R_{m}}{R}\right)^{2}$ - para cada dia da série histórica disponível.

\section{- Cálculo de $\cos \theta_{z}$ para ESUPP:}

$\delta=23,45 \sin [(360 / 365)(N D A-80)]$ - para cada NDA da série histórica disponível. $\phi=22,486^{\circ}-$ latitude da ESUPP

○ Cálculo da correção de $h$ em função da equação do tempo

$B=360^{\circ}(N D A-81) / 364$ - para cada NDA da série histórica disponível.

$E=9,87 \sin (2 B)-7,53 \cos (B)-1,5 \sin (B)$ (equação do tempo) - para cada dia da série histórica disponível.

$l=52,955^{\circ}$ longitude da ESUPP

\section{Correção do fuso-horário (CFH):}

$C F H=\left(l-45^{\circ}\right) 4$

$45^{\circ}$ é o meridiano de referência do fuso-horário local

O movimento de rotação da Terra é de 1 grau a cada 4 minutos.

Correção total em minutos (CT):

$C T=E+C H F$

Definição do minuto real (MR):

$M R=M C+C T-$ para cada minuto da série histórica

$M C$ corresponde ao minuto aferido pelo datalogger, apresentado na série histórica, transformado em minuto corrido, ou seja, que varia de 0 a 1339 ao longo do dia.

Definição do ângulo horário (em graus) solar:

$h=(M R-720) / 4$ 
Com $(12$ horas $* 60)=720$ minutos - já que $h$ assume valores negativos para o período da manhã, nulo ao meio dia e positivo para o período da tarde, conforme a Tabela 6.

$\cos \theta_{z}=\sin \phi \sin \delta+\cos \phi \cos \delta \cos h$ - para cada minuto da série histórica

- Cálculo de $I_{G H}$ para ESUPP:

$I G H_{0}=I D N_{0} \cos \theta_{z}$ - para cada minuto da série histórica

- Cálculo de $\boldsymbol{k}_{t c}$ para ESUPP:

$k_{t c}=\frac{I G H}{I D H+I D N * \cos \theta_{z}}-\operatorname{com} I G H, I D H$ e IDN correspondendo as medições aferidas pelos sensores para cada minuto da série histórica e $\cos \theta_{z}$ calculado para cada minuto da série histórica conforme a sequência de cálculos supracitada.

- Cálculo de $I D N_{0}, I G H_{0}$ e $\cos \theta_{z}$ para ESPEL:

Os cálculos dessas variáveis para ESPEL obedeceu a mesma sequência lógica e foi realizada para os dias julianos e minutos corridos da série completa analisada, considerando os seguintes valores de longitude e latitude:

$\phi=23,555^{\circ}$ - latitude da ESPEL

$l=46,731^{\circ}$ - longitude da ESPEL 
Figura 3.1 - CDP de $k_{t}$ para novembro

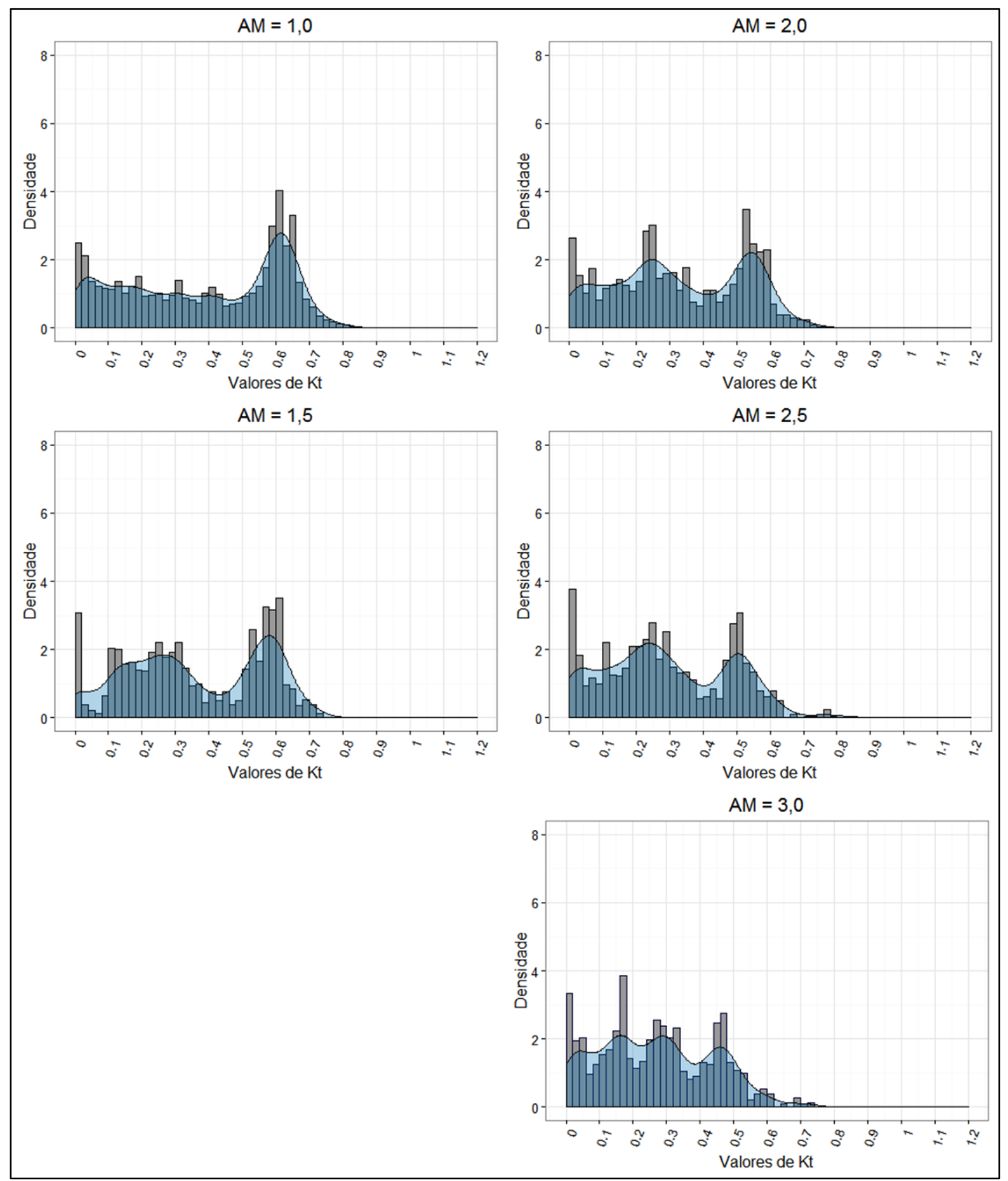

Fonte: Elaboração própria 
Figura 3.2 - CDP de $k_{t}$ para janeiro

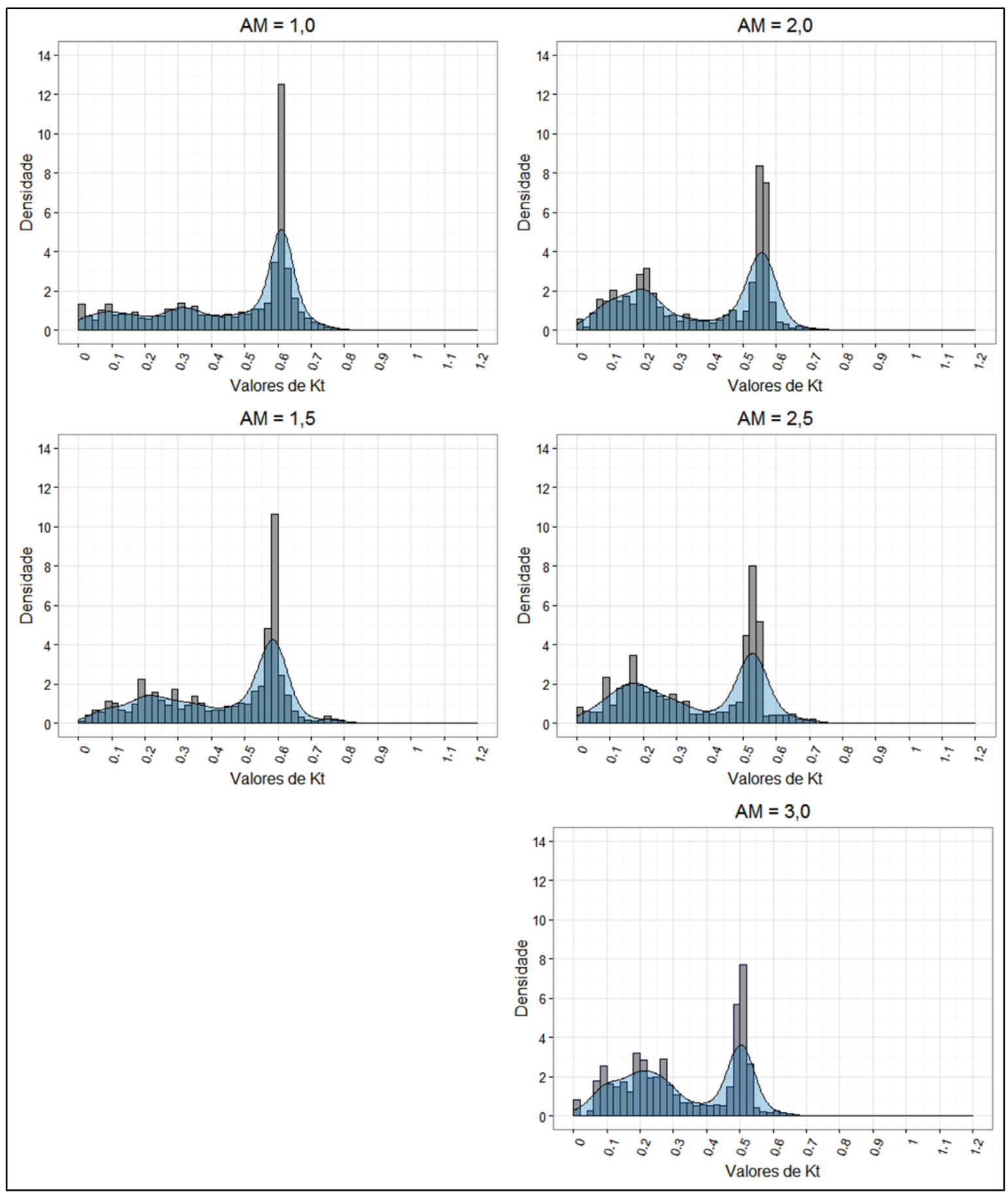

Fonte: Elaboração própria 
Figura 3.3 - CDP de $k_{t}$ para abril
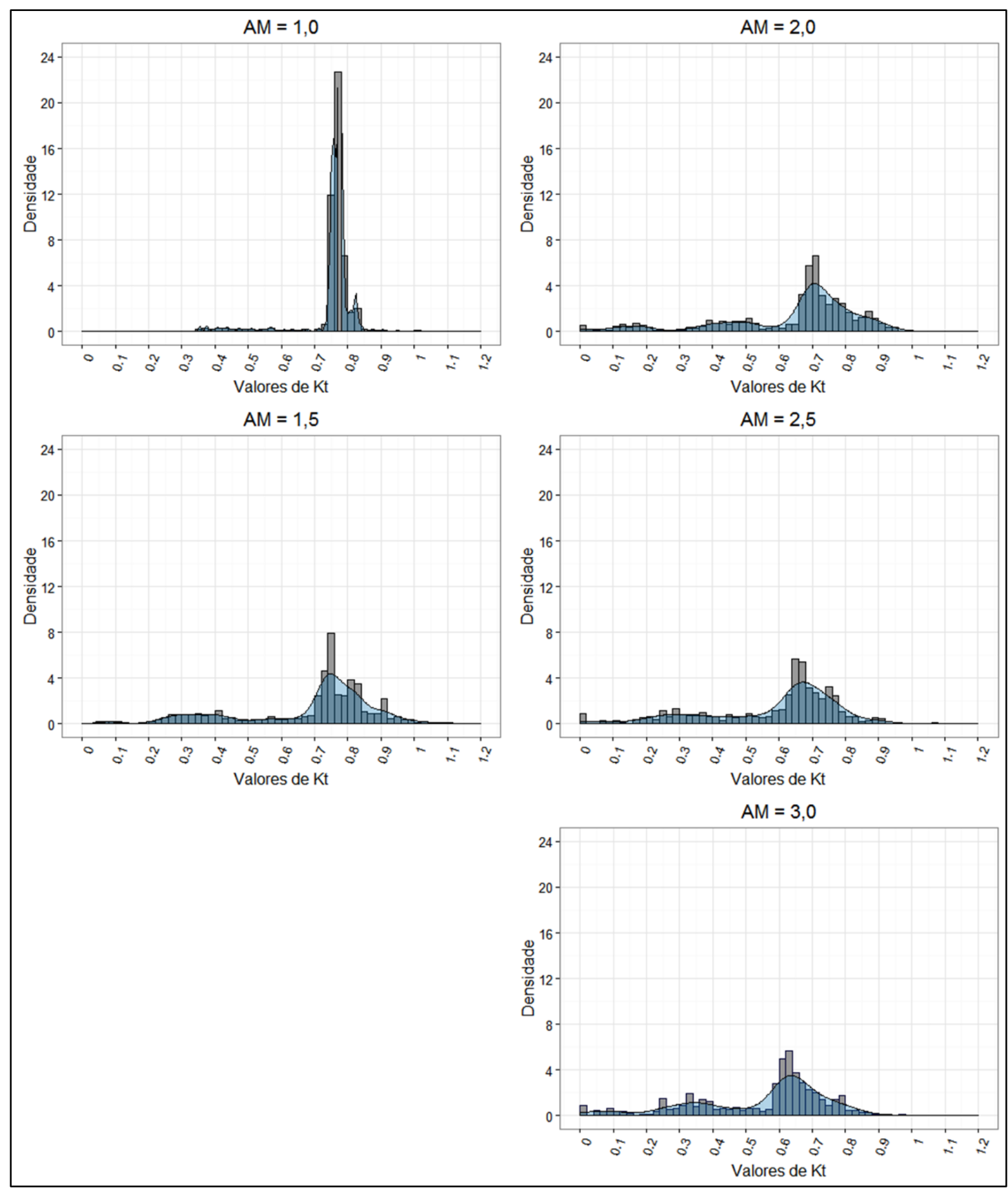

Fonte: Elaboração própria 
Figura 3.4 - CDP de $k_{t}$ para maio

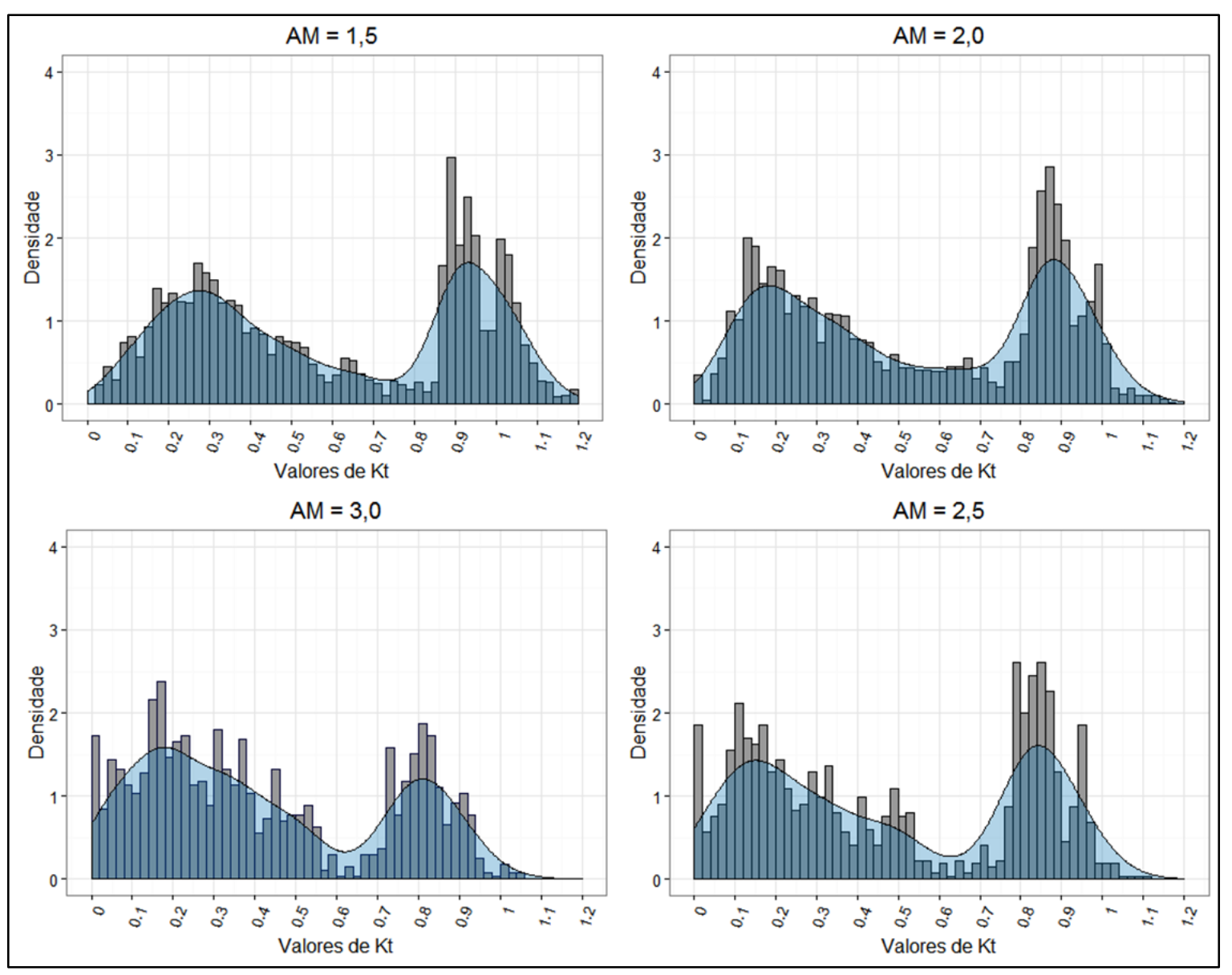

Fonte: Elaboração própria 
APÊNDICE 4 - CDPs MENSAIS COM DADOS DE 1 E 2 ANOS DE KT PARA 5 INTERVALOS DE AM- ESPEL

Figura 4.1 - CDP de $k_{t}$ para abril de 2015

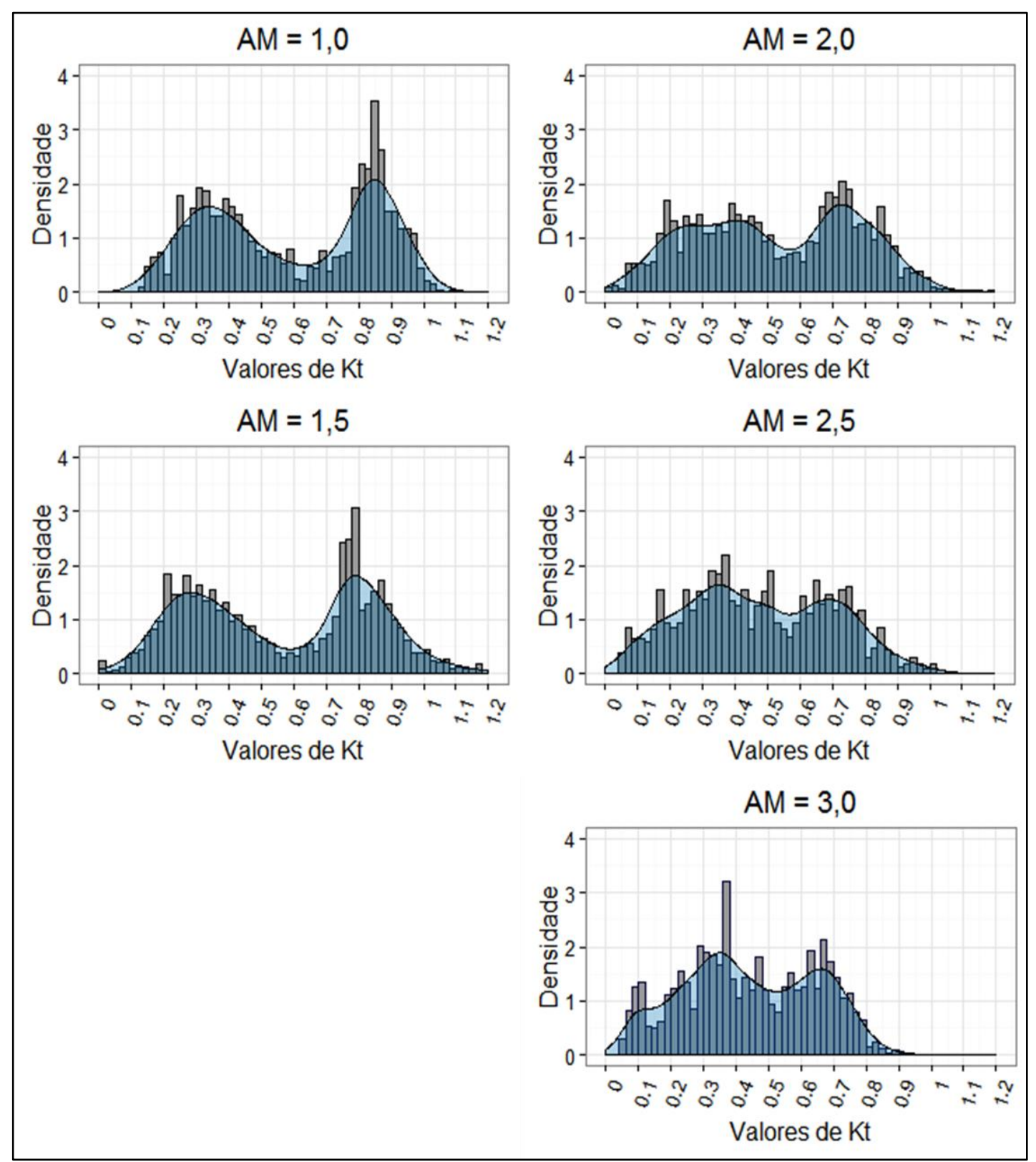

Fonte: Elaboração própria 
Figura 4.2 - CDP de $k_{t}$ para abril $(2015+2016)$
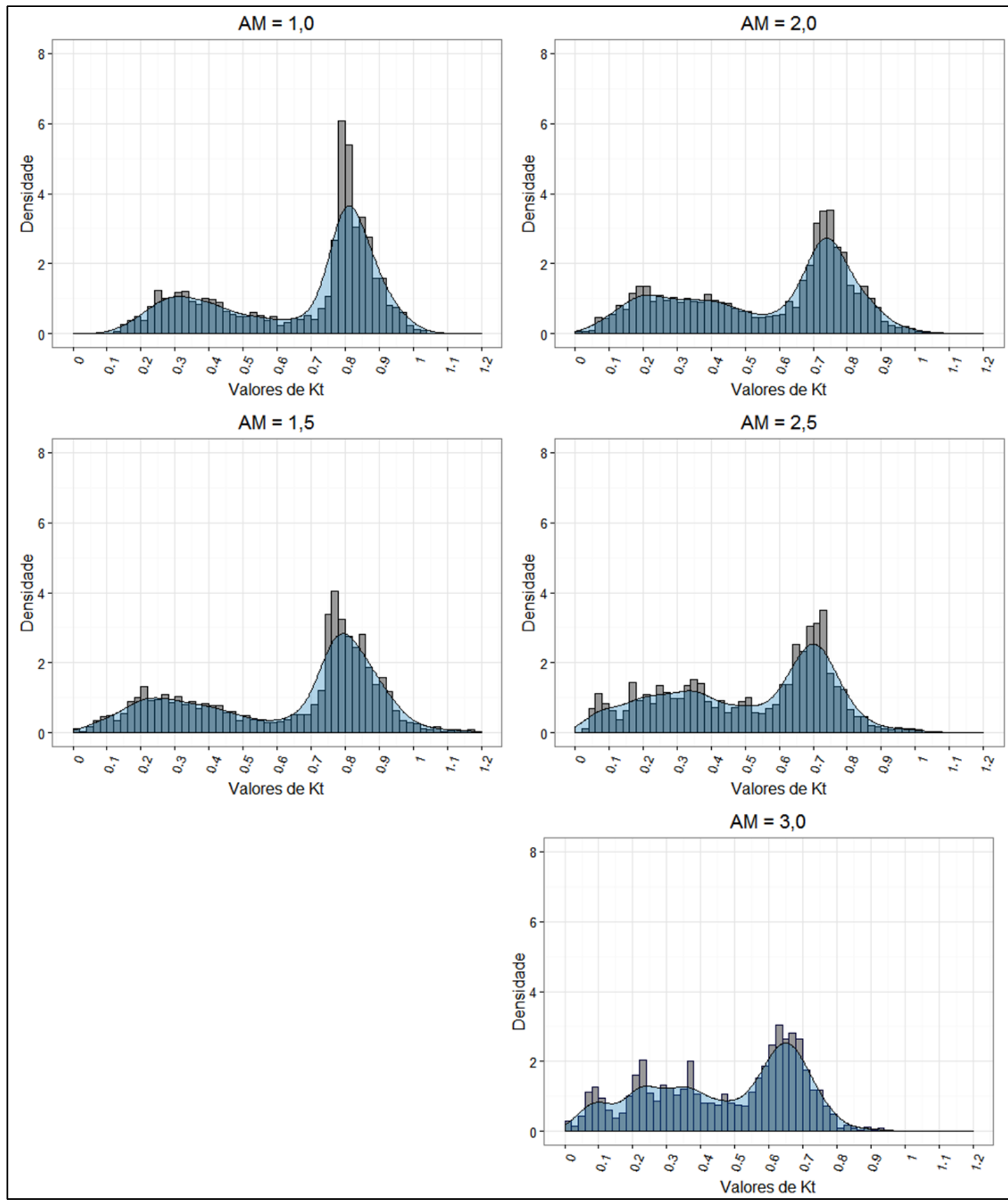

Fonte: Elaboração própria 
Figura 4.3 - CDP de $k_{t}$ para maio de 2015
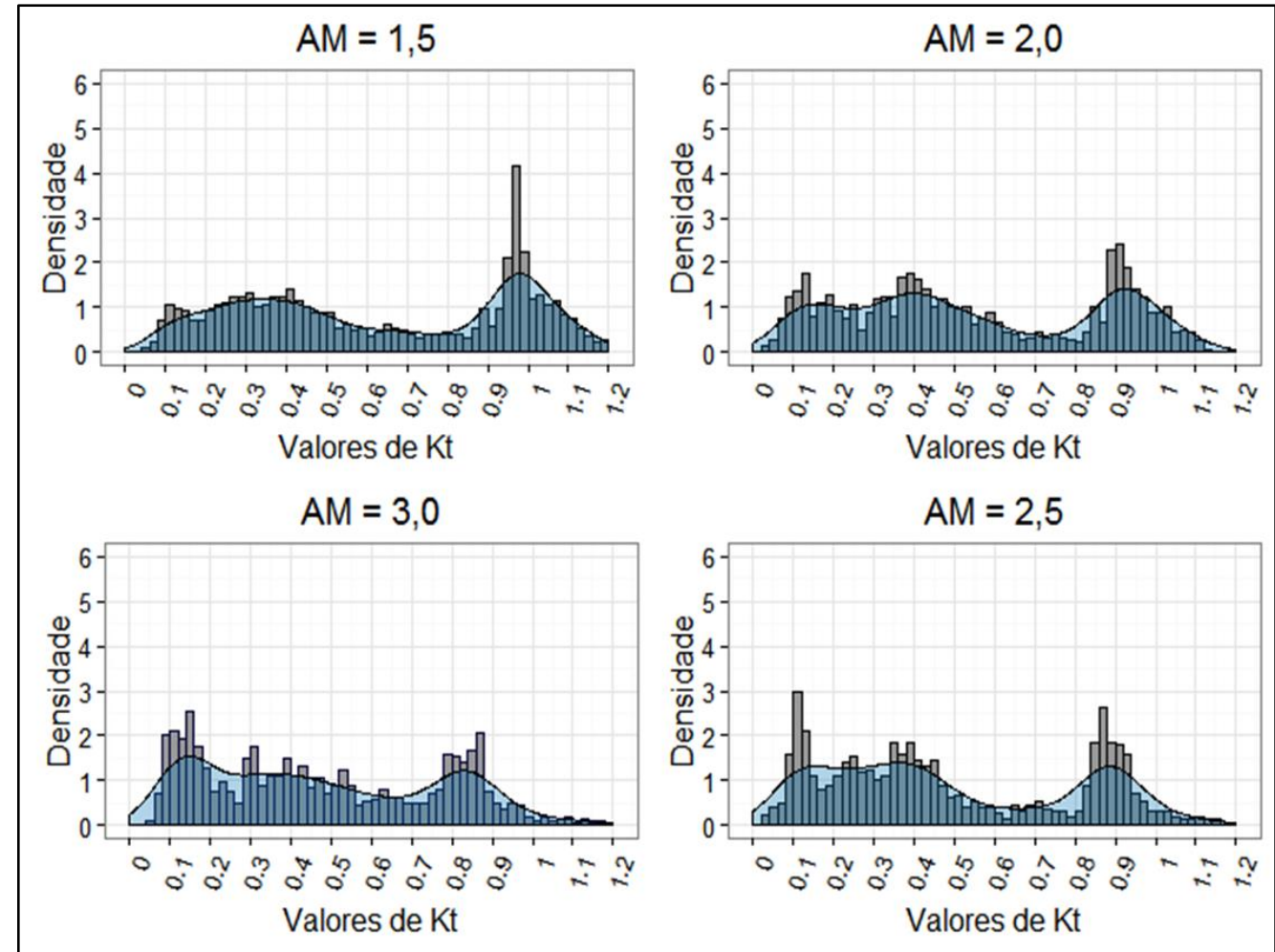

Fonte: Elaboração própria

Figura 4.4 - CDP de $k_{t}$ para maio $(2015+2016)$
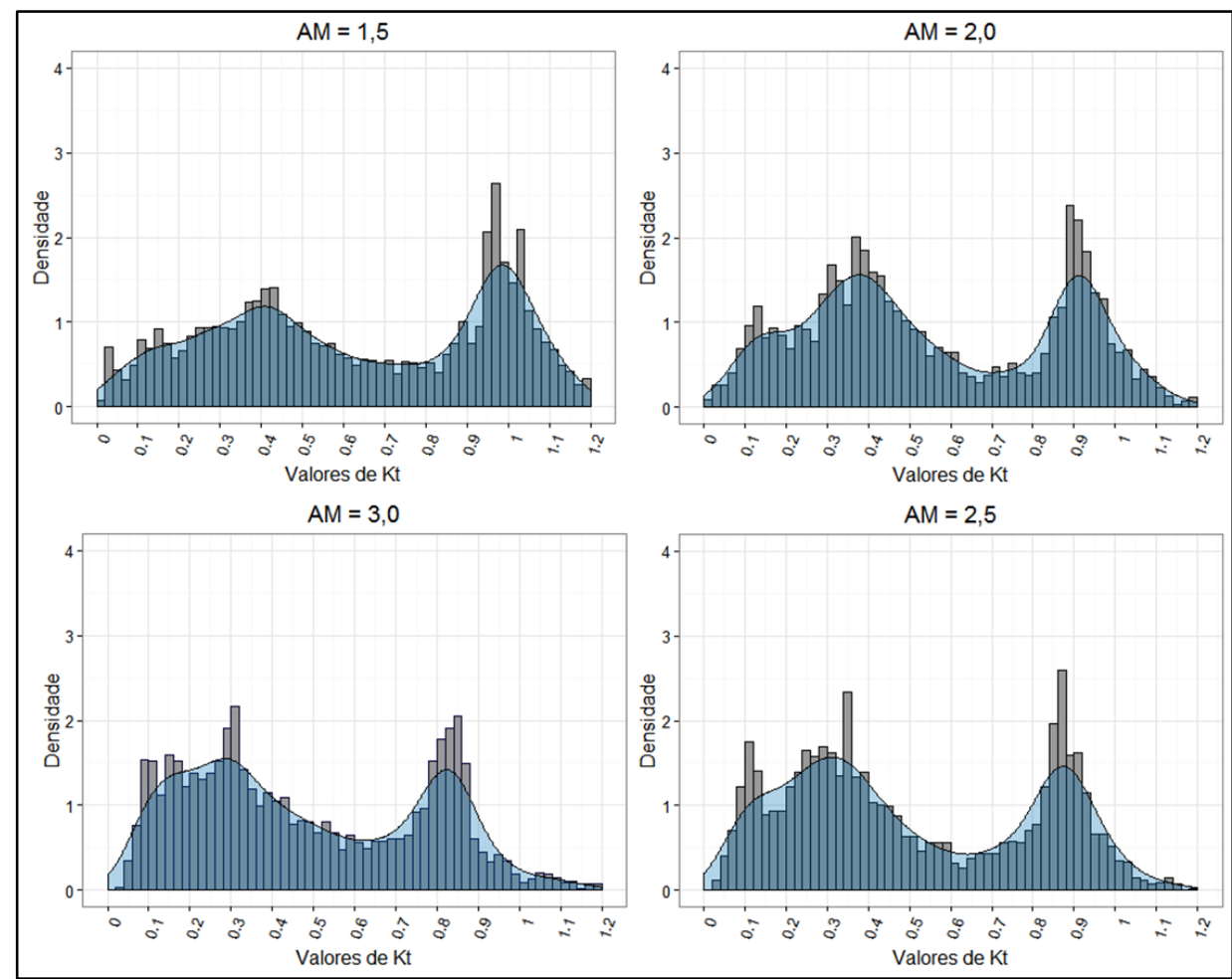

Fonte: Elaboração própria 
Figura 4.5 - CDP de $k_{t}$ para junho de 2015

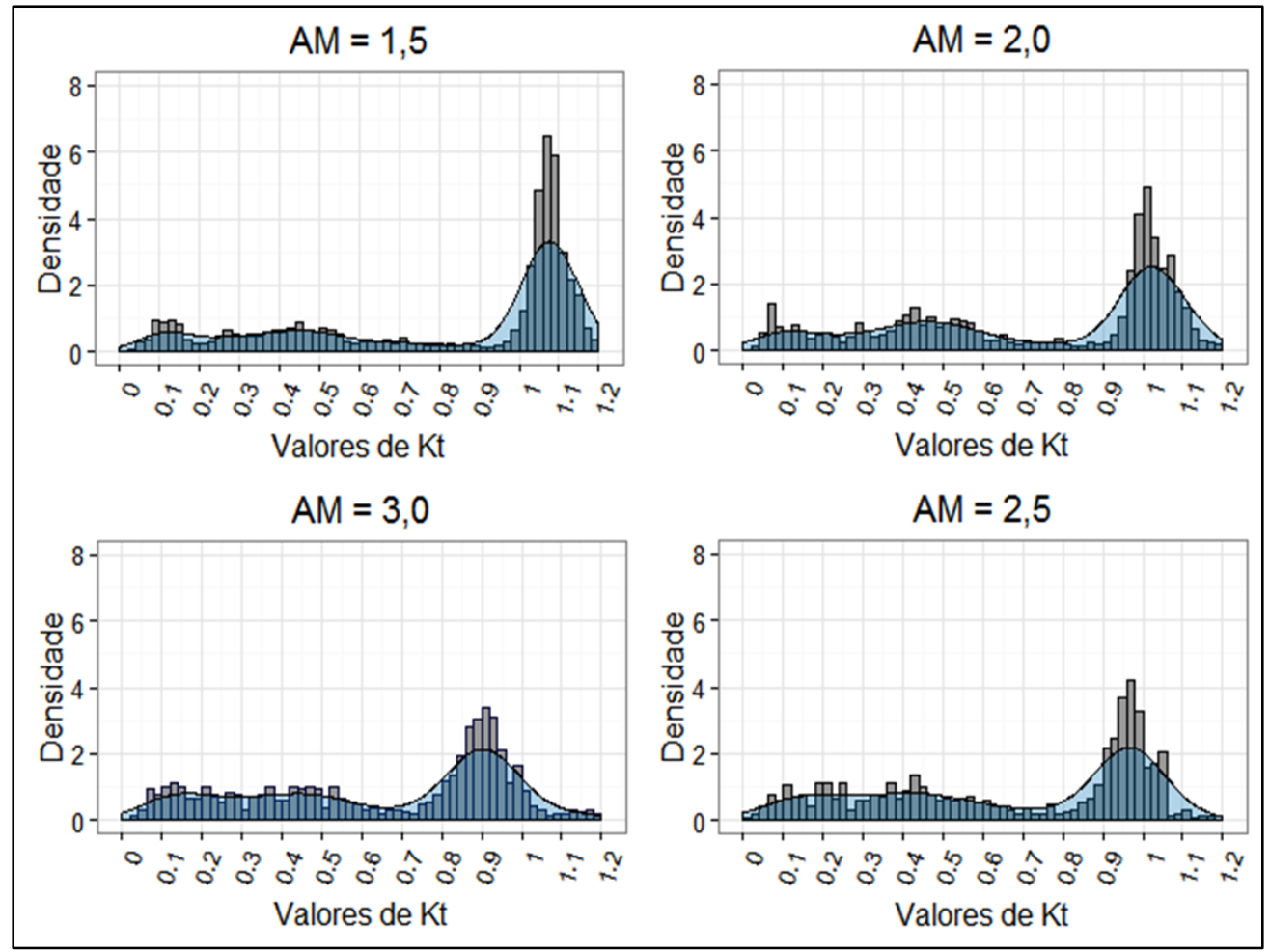

Fonte: Elaboração própria

Figura 4.6 - CDP de $k_{t}$ para junho $(2015+2016)$

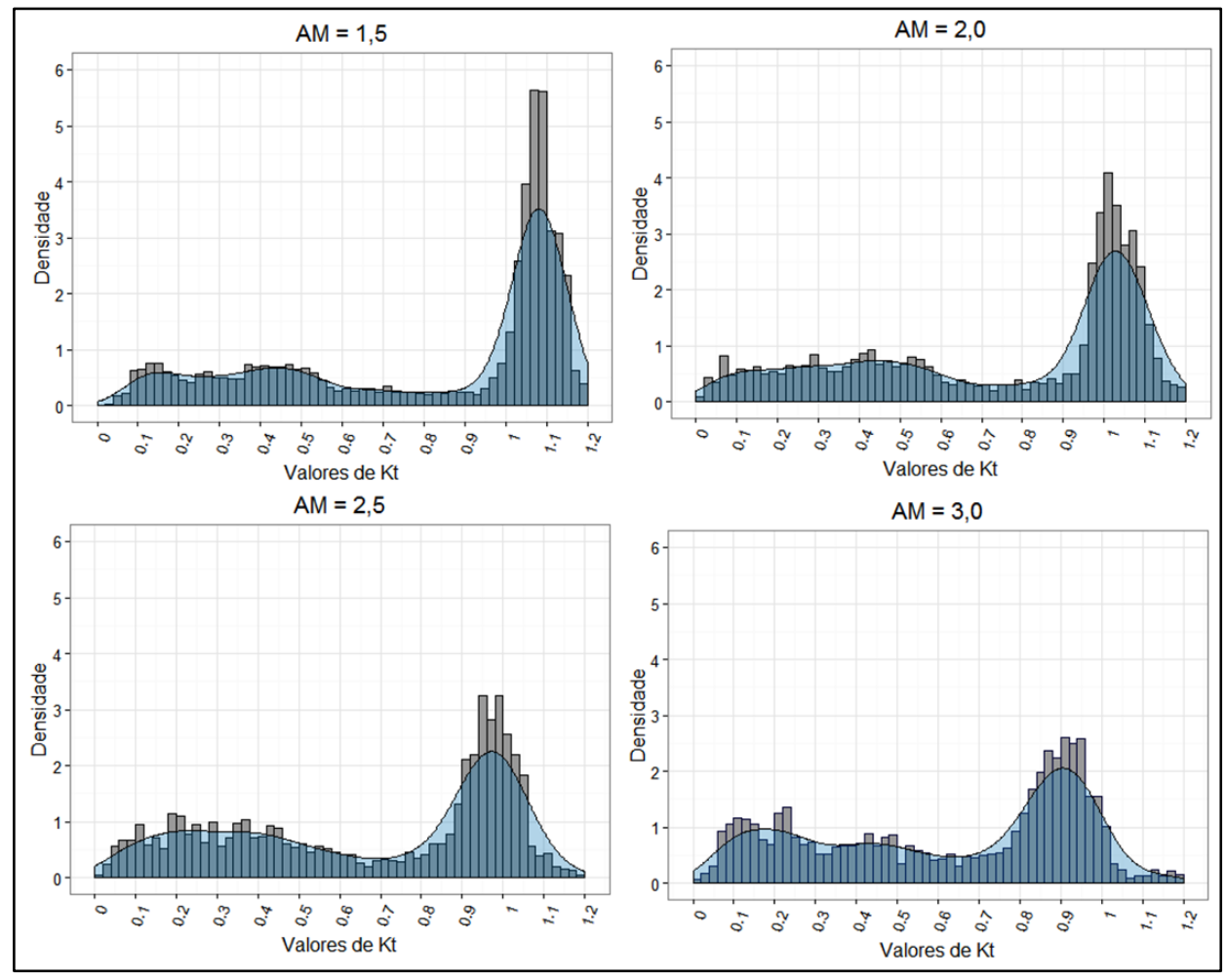

Fonte: Elaboração própria 
Figura 4.7 - CDP de $k_{t}$ para janeiro de 2016

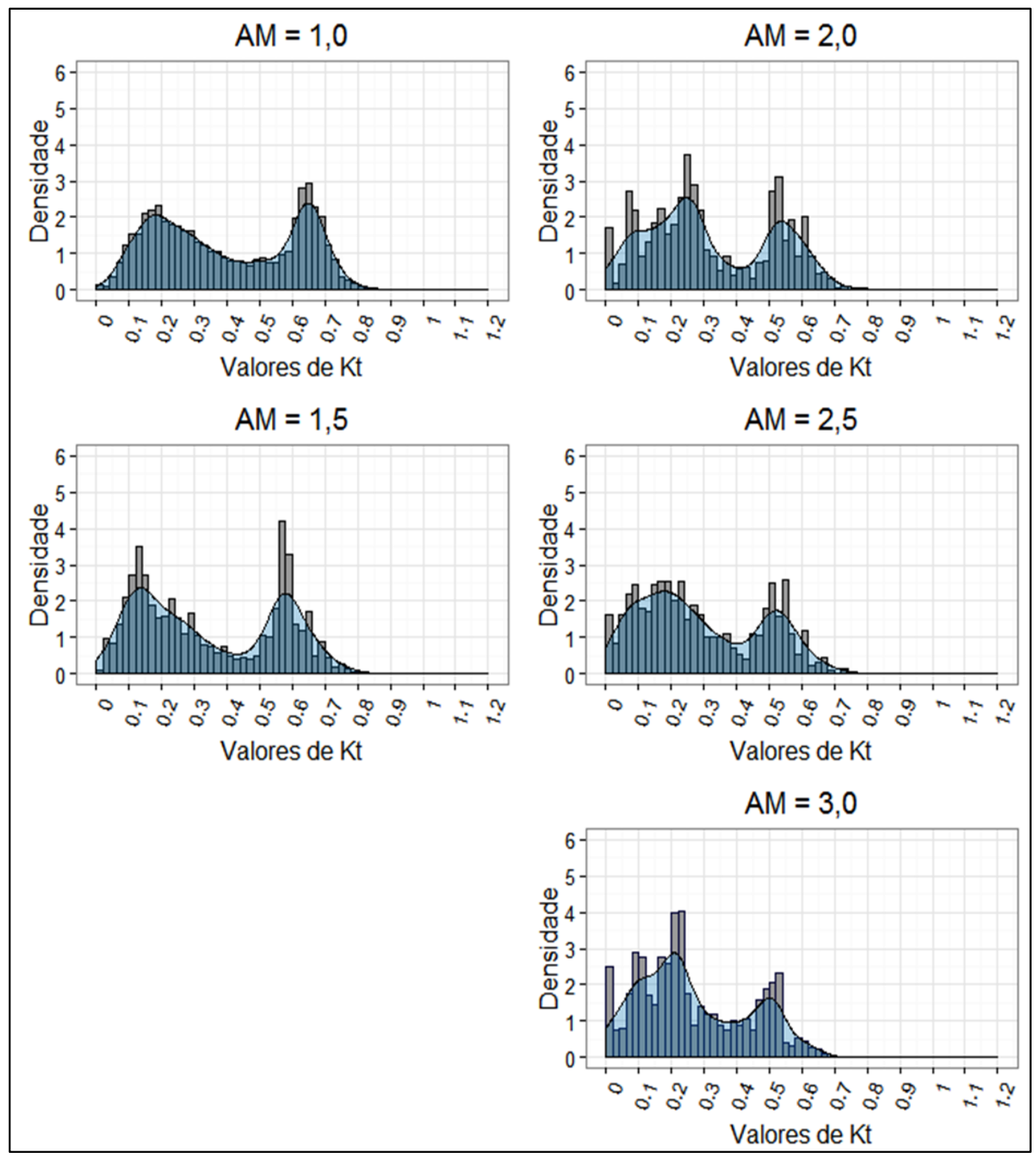

Fonte: Elaboração própria 
Figura 4.8 - CDP de $k_{t}$ para janeiro $(2016+2015)$

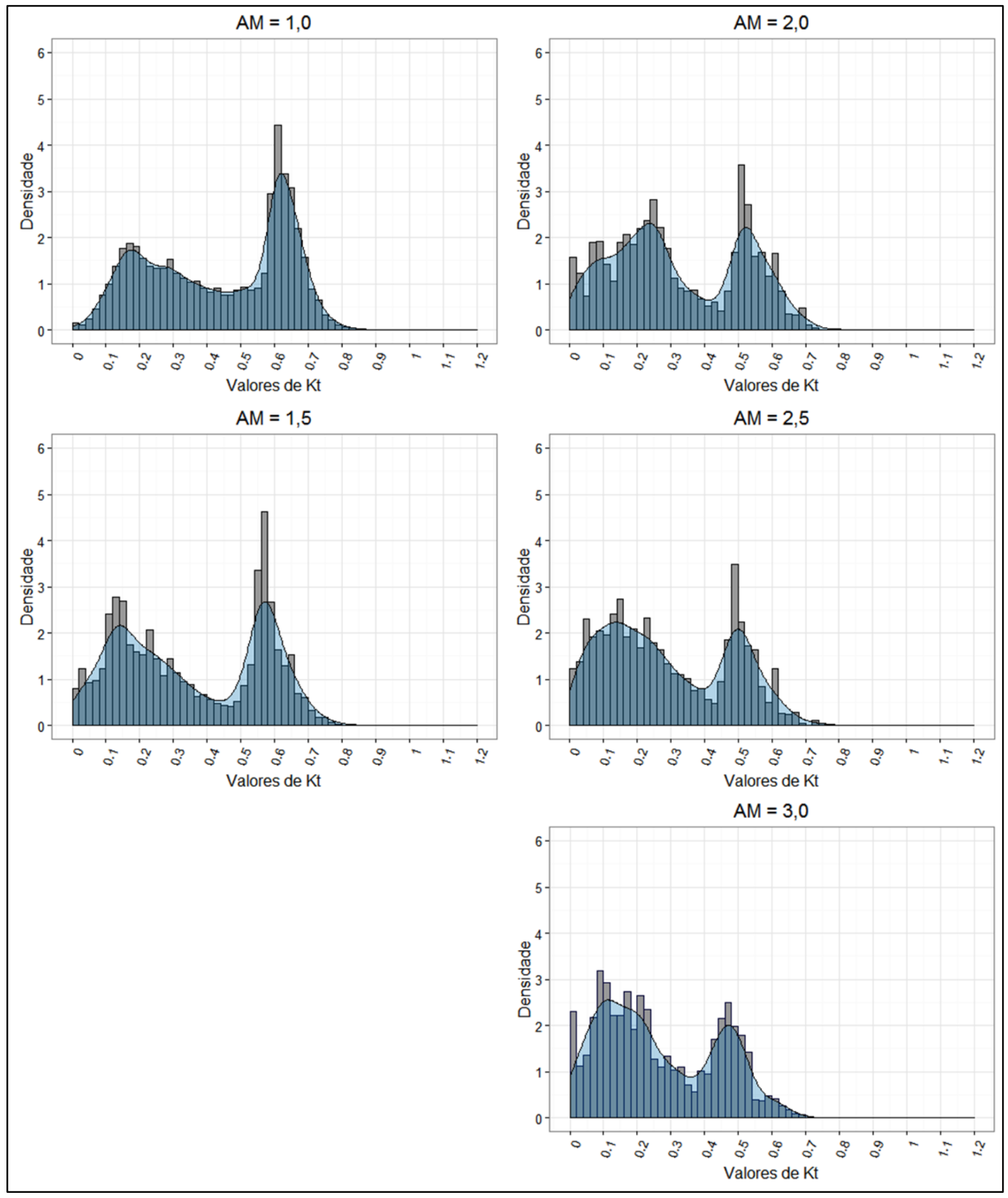

Fonte: Elaboração própria 
APÊNDICE 5 - CDPs MENSAIS COM DADOS DE 2 ANOS DE KT PARA 9 INTERVALOS DE AM- ESPEL

Figura 5.1 - CDP de $k_{t}$ para maio $(2015+2016)$

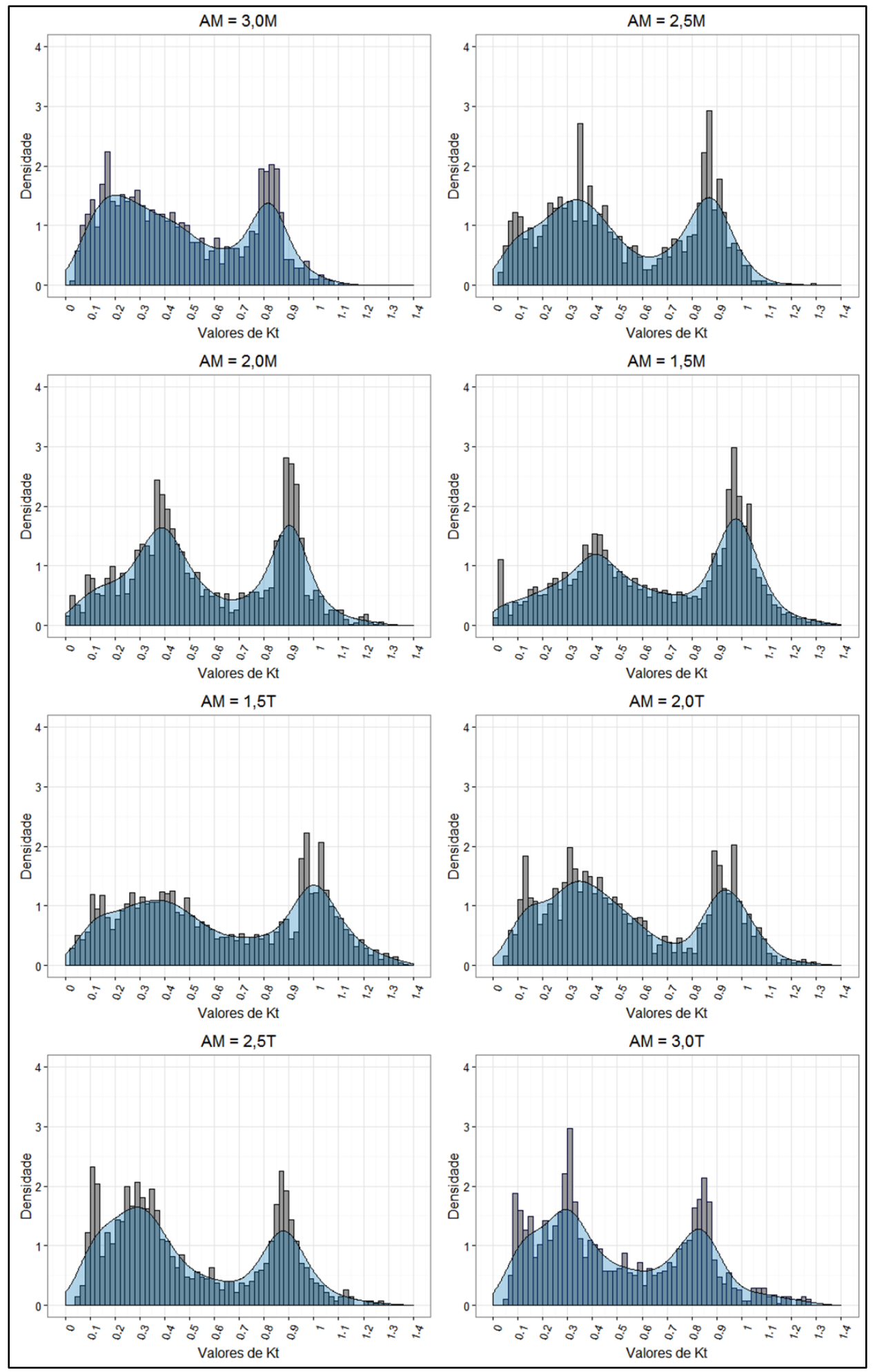

Fonte: Elaboração própria 
Figura 5.2 - CDP de $k_{t}$ para abril $(2015+2016)$

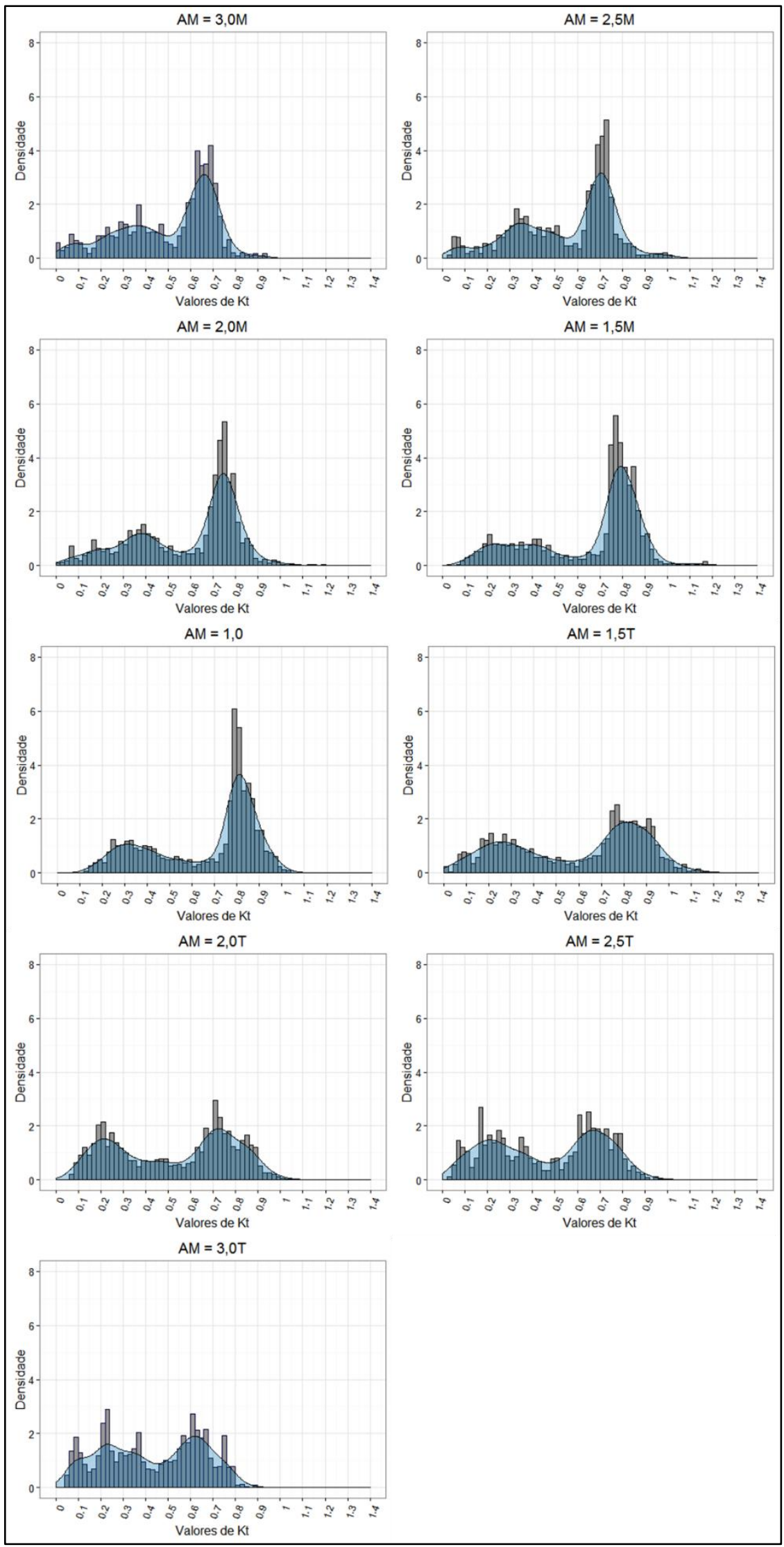

Fonte: Elaboração própria 
Figura 5.3 - CDP de $k_{t}$ para junho $(2015+2016)$

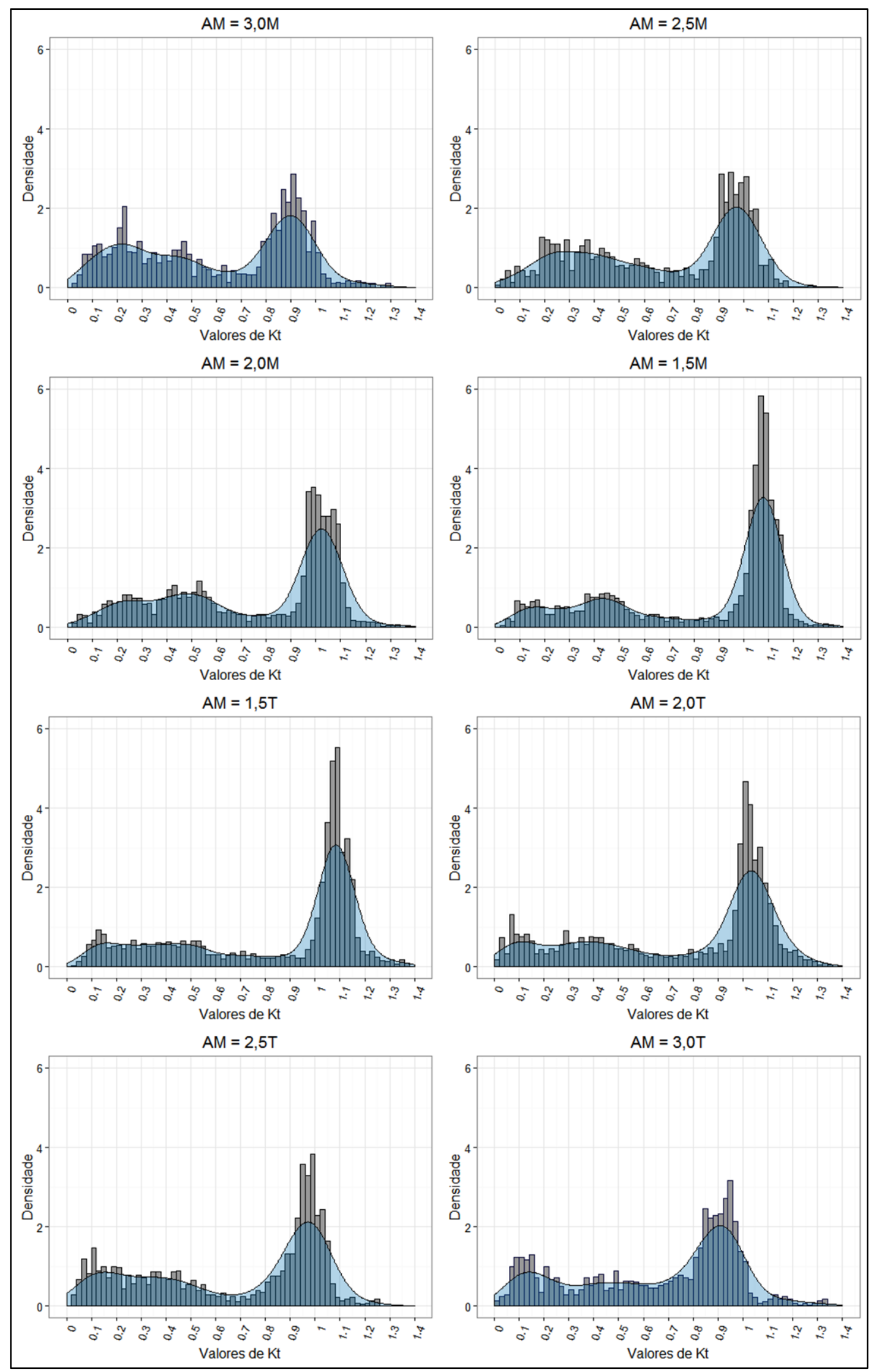

Fonte: Elaboração própria 
Figura 5.4 - CDP de $k_{t}$ para janeiro $(2015+2016)$

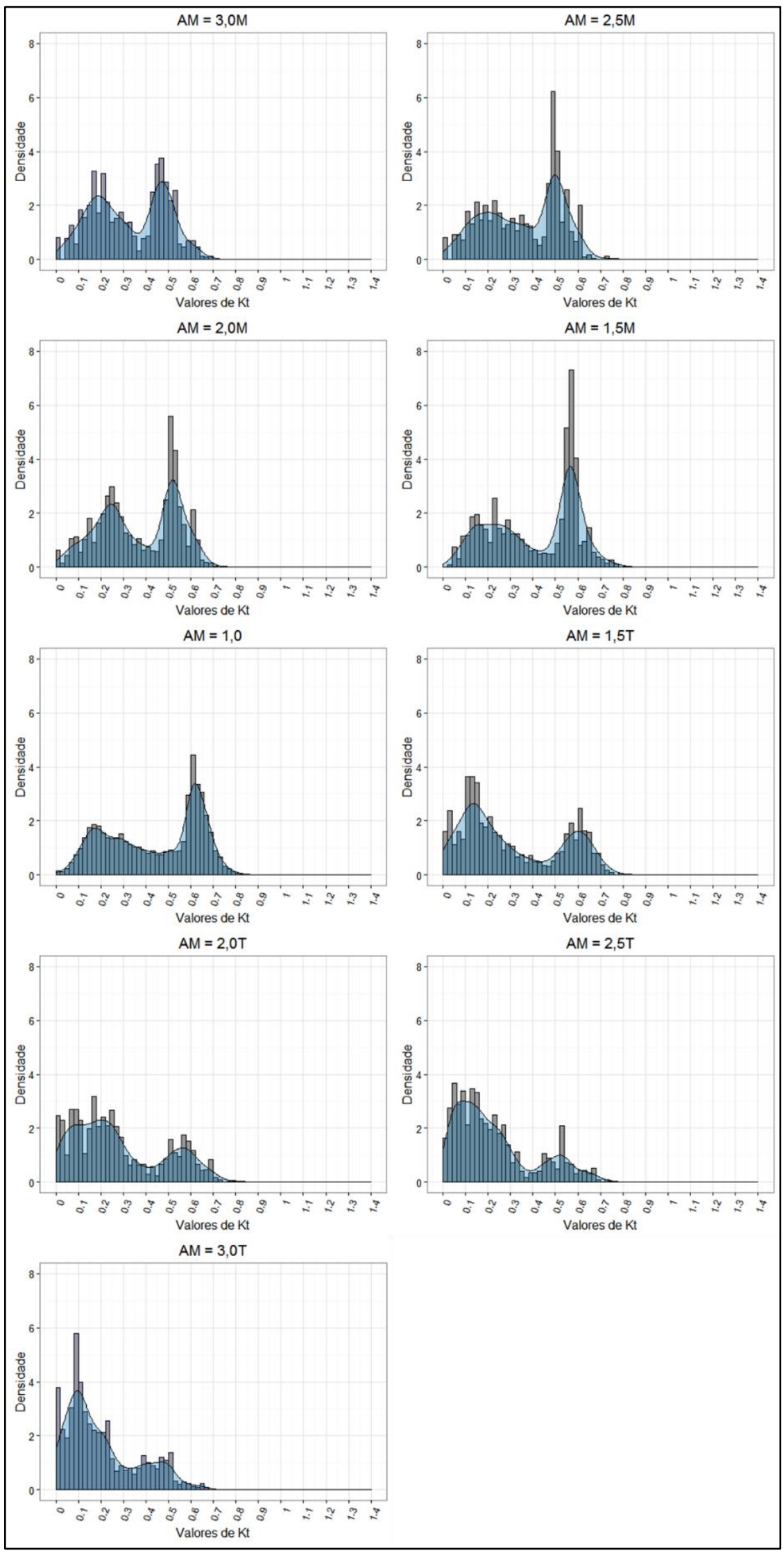

Fonte: Elaboração própria 
Figura 5.5 - CDP de $k_{t}$ para a série completa

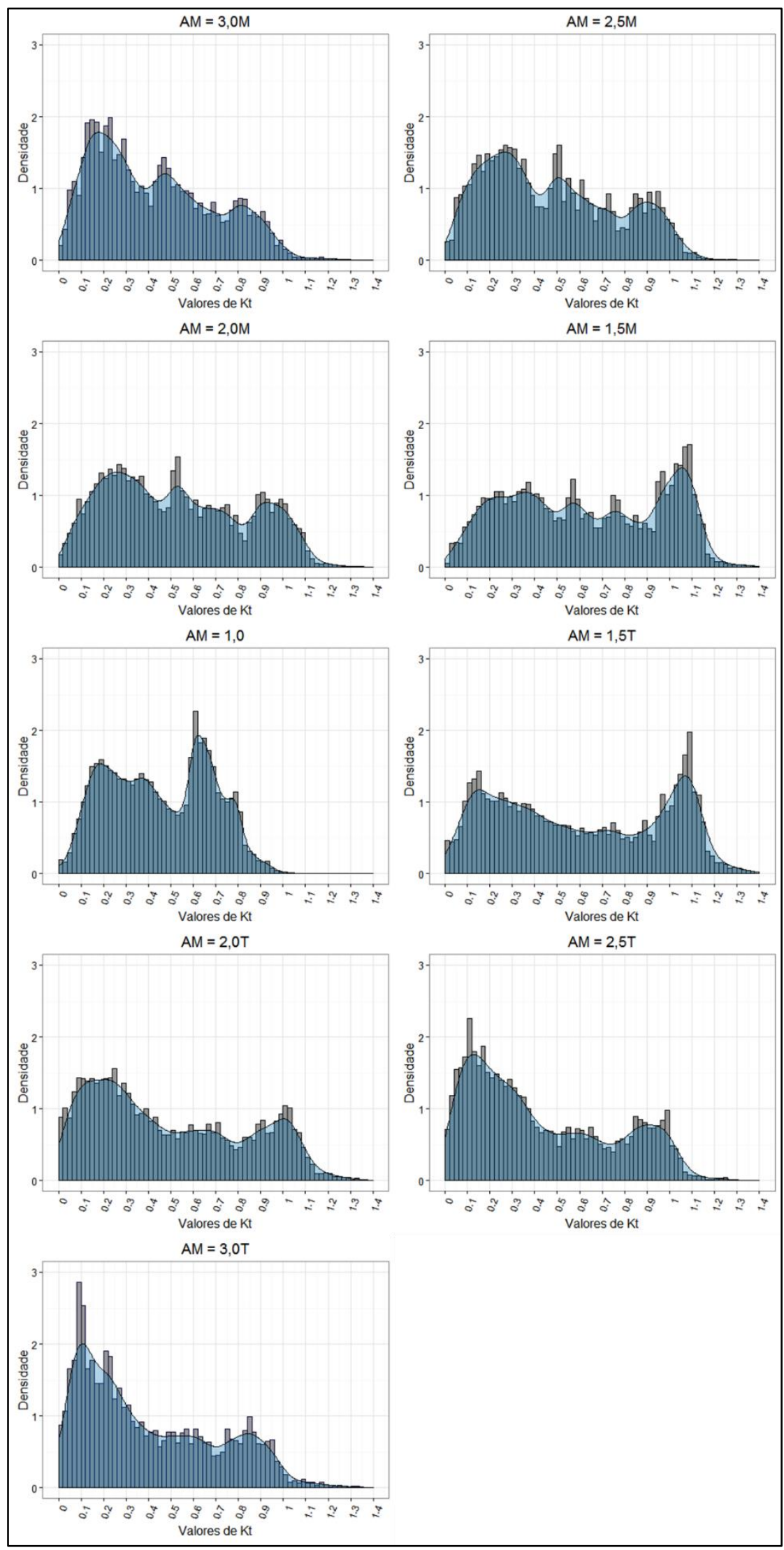

Fonte: Elaboração própria 


\section{APÊNDICE 6 - VARIAÇÃO DE TAXAS DE MEDIÇÕES SUBSEQUENTES DE IGH - ESPEL}

Figura 6.1 - Taxa de alteração de até $50 \mathrm{~W} / \mathrm{m}^{2}$ de medidas subsequentes de IGH.

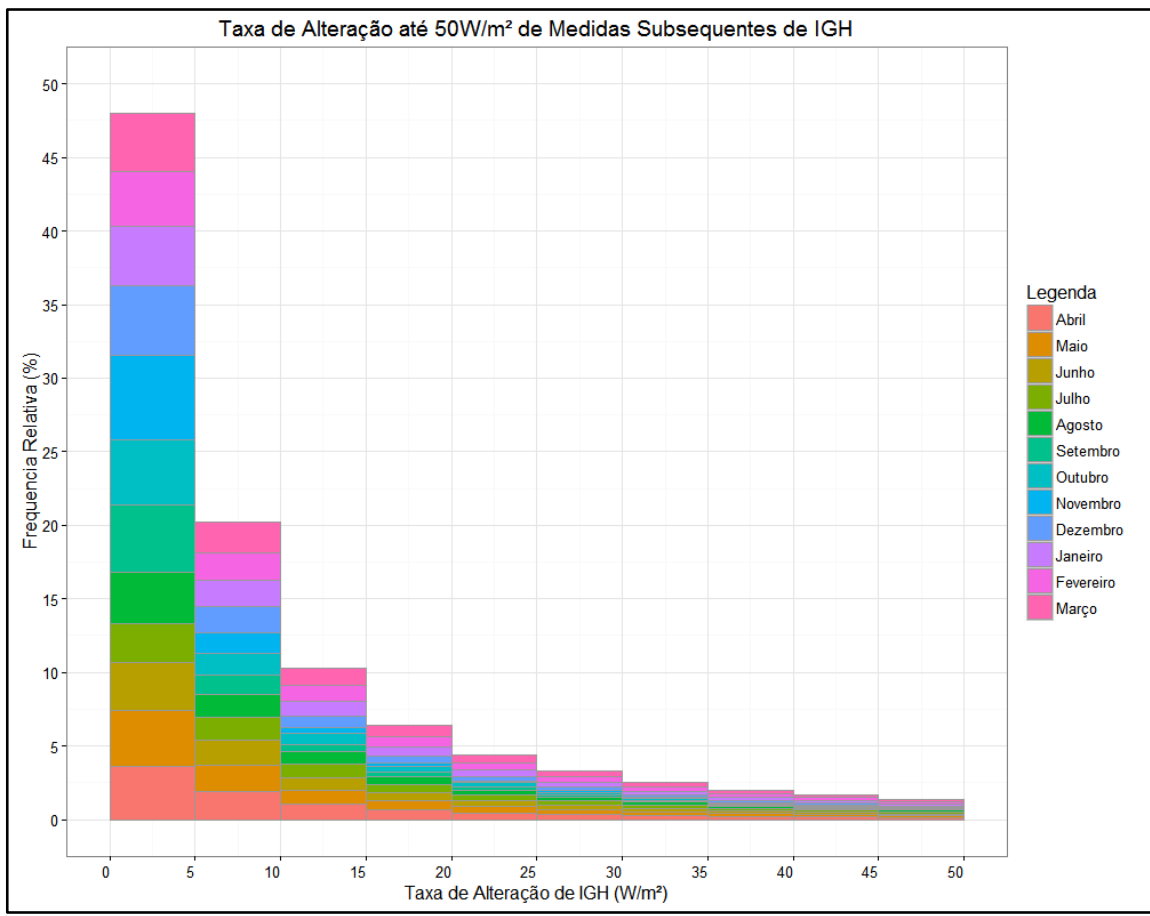

Fonte: Elaboração própria

Figura 6.1 - Taxa de alteração de até $50 \mathrm{~W} / \mathrm{m}^{2}$ de medidas subsequentes de IGH.

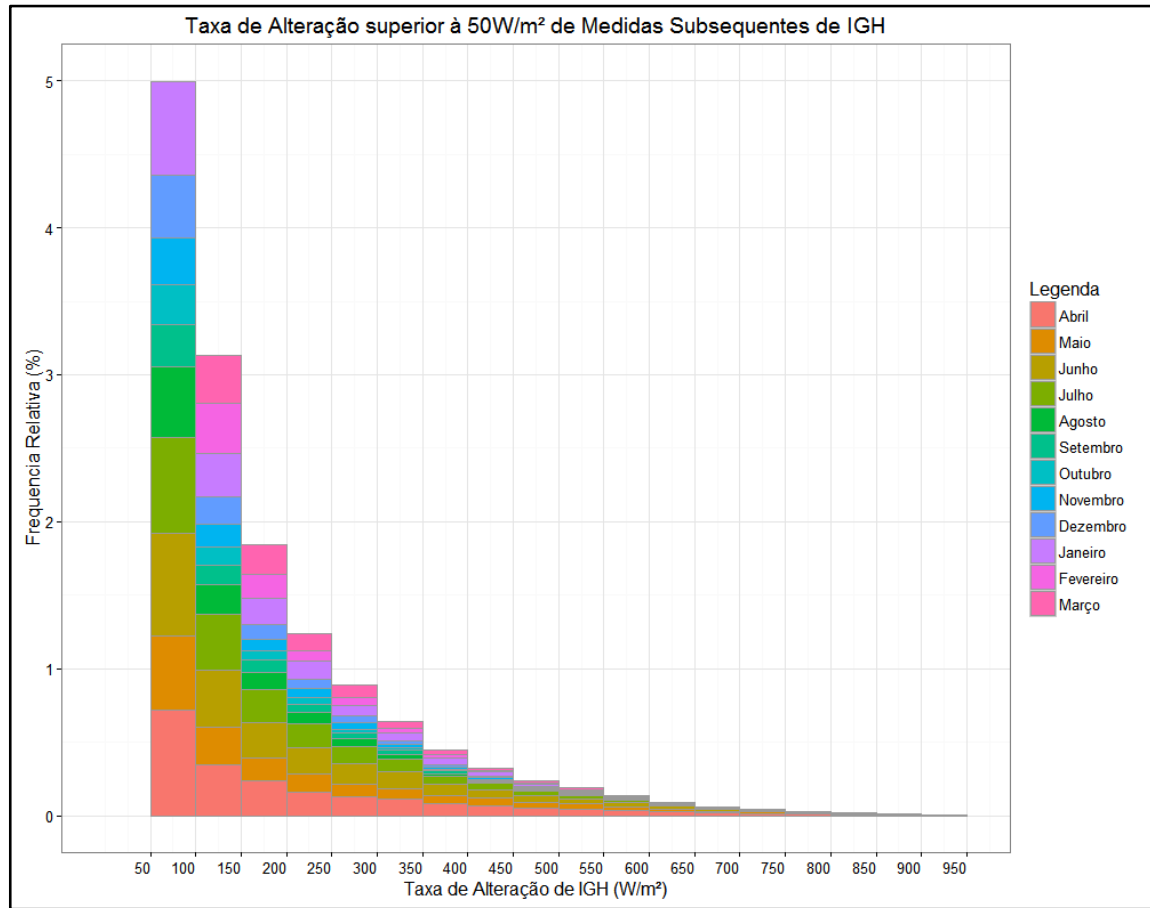

Fonte: Elaboração própria 


\section{APÊNDICE 7 - DIAS CARACTERÍSTICOS MENSAIS}

Figura 7.1 - Quantidade média mensal de energia disponível por dia - parte 1
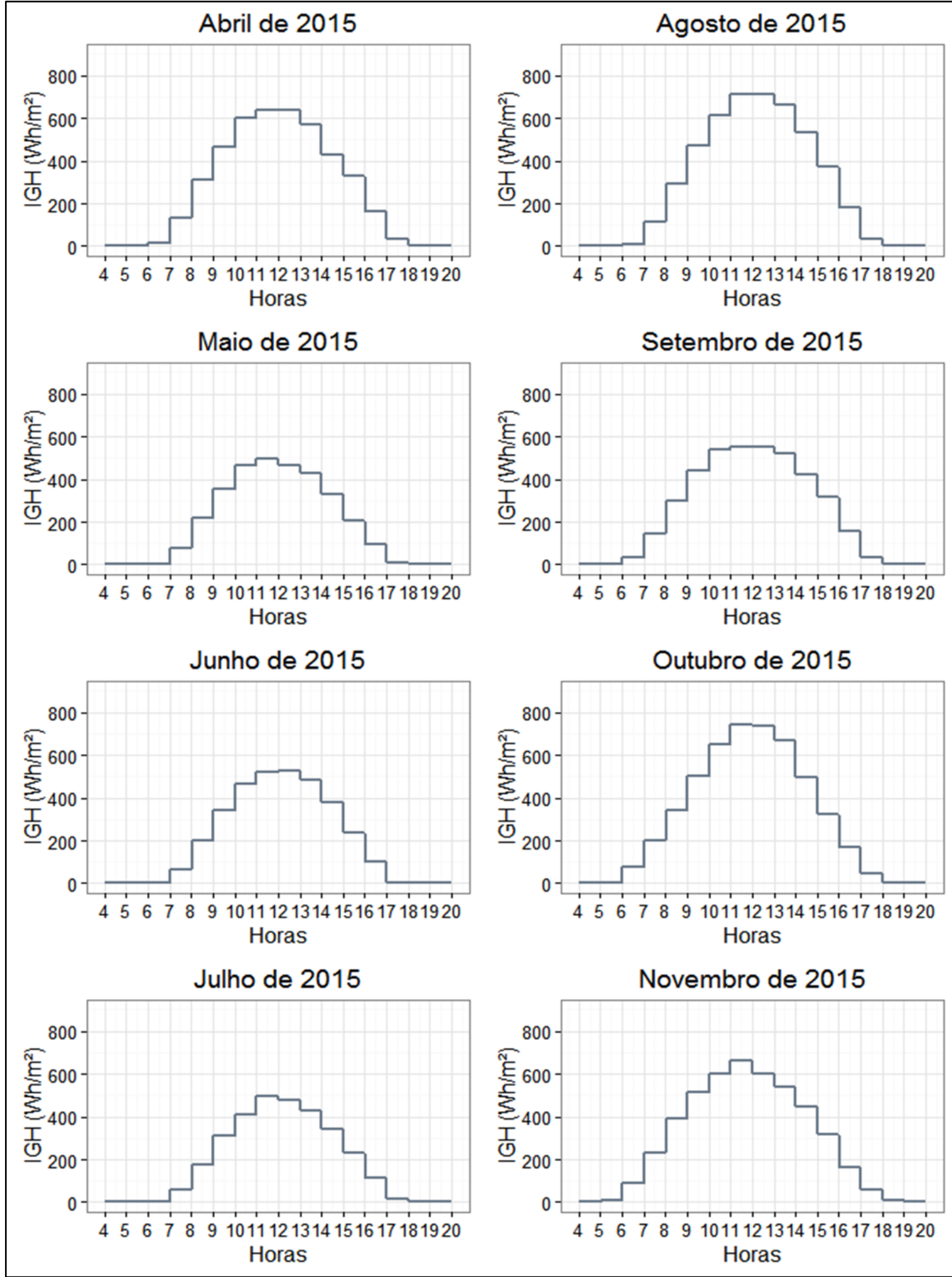

Fonte: Elaboração própria 
Figura 7.2 - Quantidade média mensal de energia disponível por dia - parte 2

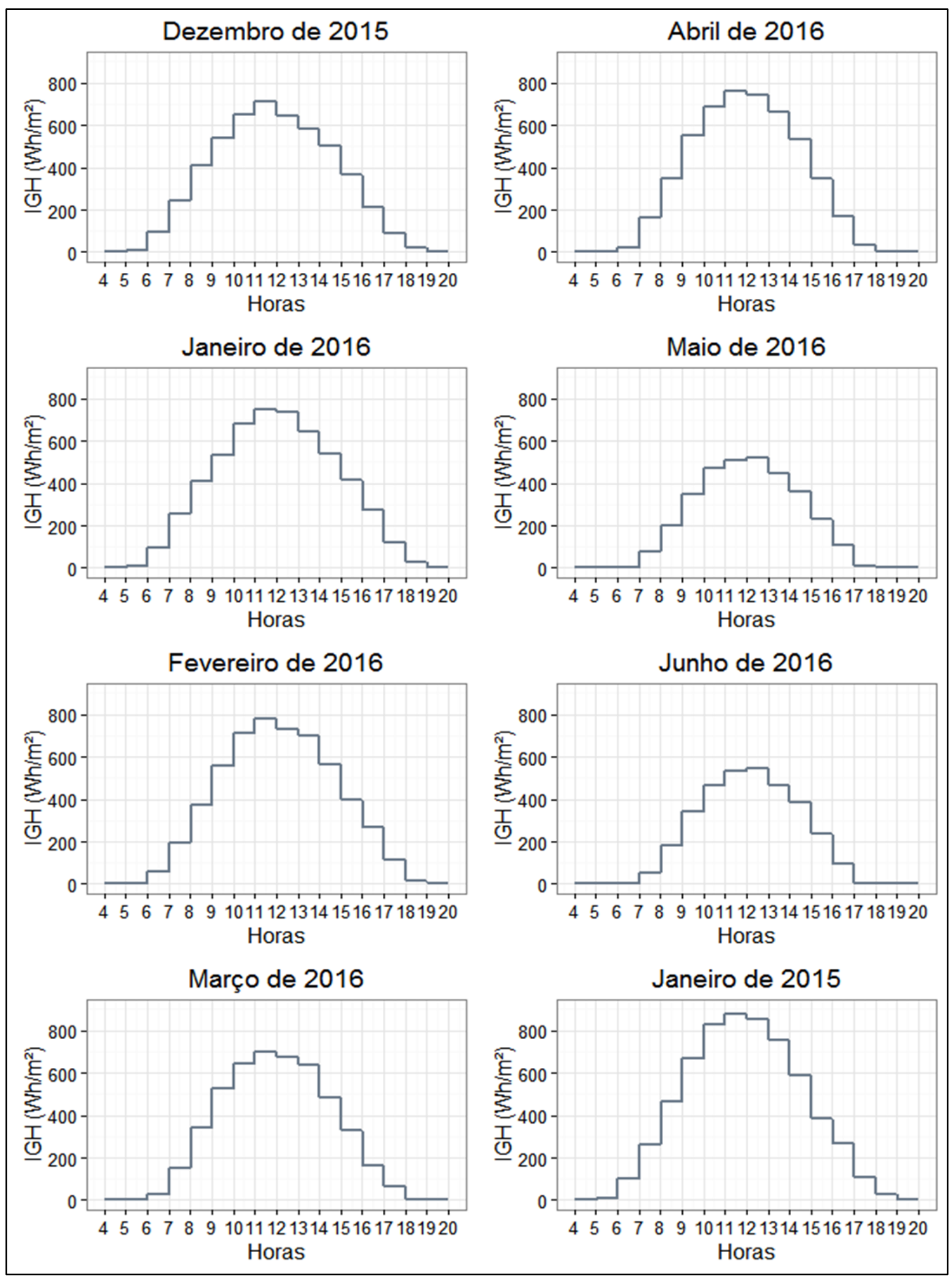

Fonte: Elaboração própria 